Genre in Archaic and Classical Greek Poetry: Theories and Models 


\section{Mnemosyne Supplements}

MONOGRAPHS ON GREEK AND

LATIN LANGUAGE AND LITERATURE

Executive Editor

C. Pieper (Leiden University)

Editorial Board

A. Chaniotis (Institute for Advanced Study, Princeton)

K.M. Coleman (Harvard University)

I.J.F. de Jong (University of Amsterdam)

T. Reinhardt (Oxford University)

VOLUME 428

The titles published in this series are listed at brill.com/mns 


\title{
Genre in Archaic and Classical Greek Poetry: Theories and Models
}

Studies in Archaic and Classical Greek Song, Vol. 4

\author{
Edited by \\ Margaret Foster \\ Leslie Kurke \\ Naomi Weiss
}

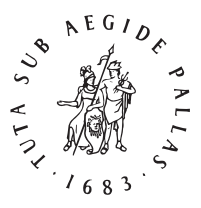

B R I L L 
\begin{tabular}{|l|}
\hline B R I L L \\
\hline P E N
\end{tabular}

This is an open access title distributed under the terms of the CC-BY-NC-ND 4.O License, which permits any non-commercial use, distribution, and reproduction in any medium, provided no alterations are made and the original author(s) and source are credited.

Library of Congress Cataloging-in-Publication Data

Names: Foster, Margaret, 1977- editor. | Kurke, Leslie, editor. | Weiss, Naomi A., 1982- editor.

Title: Genre in archaic and classical Greek poetry : theories and models / edited by Margaret Foster, Leslie Kurke, Naomi Weiss.

Other titles: Studies in archaic and classical Greek song ; v. 4.

Description: Boston : Brill, 2019. | Series: Mnemosyne supplements, o169-8958 ; volume 428 | Includes bibliographical references and index.

Identifiers: LCCN 2019032900 (print) | LCCN 2019032901 (ebook) | ISBN 9789004411425 (hardback) | ISBN 978900441259o (ebook)

Subjects: LCSH: Greek poetry-History and criticism. | Literary form-History-To 1500 .

Classification: LCC PA3095 .G46 2019 (print) | LCC PA3O95 (ebook) | DDC 881/.0109-dc23

LC record available at https://lccn.loc.gov/201903290o

LC ebook record available at https://lccn.loc.gov/20190329o1

Typeface for the Latin, Greek, and Cyrillic scripts: "Brill". See and download: brill.com/brill-typeface.

\section{ISSN 0169-8958}

ISBN 978-90-04-41142-5 (hardback)

ISBN 978-90-04-41259-0 (e-book)

Copyright 2020 by the Authors. Published by Koninklijke Brill NV, Leiden, The Netherlands. Koninklijke Brill Nv incorporates the imprints Brill, Brill Hes \& De Graaf, Brill Nijhoff, Brill Rodopi, Brill Sense, Hotei Publishing, mentis Verlag, Verlag Ferdinand Schöningh and Wilhelm Fink Verlag. Koninklijke Brill NV reserves the right to protect the publication against unauthorized use and to authorize dissemination by means of offprints, legitimate photocopies, microform editions, reprints, translations, and secondary information sources, such as abstracting and indexing services including databases. Requests for commercial re-use, use of parts of the publication, and/or translations must be addressed to Koninklijke Brill NV.

This book is printed on acid-free paper and produced in a sustainable manner. 


\section{Contents}

Preface and Acknowledgments VII

Note on Abbreviations, Texts, and Translations IX

List of Figures and Tables $\mathrm{X}$

Notes on Contributors XI

Introduction 1

Margaret Foster, Leslie Kurke, and Naomi Weiss

\section{PART 1 \\ Keynote Address}

1 Genre, Occasion, and Choral Mimesis Revisited, with Special Reference to the "Newest Sappho" 31

Gregory Nagy

\section{PART 2}

Genre, Generification, and Performance

$2 \quad$ Linus: The Rise and Fall of Lyric Genres $\quad 57$

Andrew Ford

3 Sappho's Parachoral Monody 82

Timothy Power

4 The Speaking Persona: Ancient Commentators on Choral

Performance 109

Francesca Schironi

\section{PART 3}

Genre Mixing

5 Chorus Lines: Catalogues and Choruses in Archaic and Early Classical Hexameter Poetry and Choral Lyric 135

Deborah Steiner 
6 Generic Hybridity in Athenian Tragedy $\quad 167$

Naomi Weiss

$7 \quad$ Athens and Apolline Polyphony in Bacchylides' Ode $16 \quad 191$ Margaret Foster

\section{PART 4}

Affect, Materiality, and the Body: The Somatics of Genre

8 Is Korybantic Performance a (Lyric) Genre? 231

Mark Griffith

9 Iambic Horror: Shivers and Brokenness in Archilochus and Hipponax 271

Mario Telò

10 Experiencing Elegy: Materiality and Visuality in the Ambracian Polyandrion 298

Seth Estrin

11 Pindar, Paean 6: Genre as Embodied Cultural Knowledge 325 Sarah Olsen

Bibliography 347

Index Locorum 384

General Index 395 


\section{Preface and Acknowledgments}

This is the fourth volume in a series within Brill's Mnemosyne Supplements that records the proceedings of the Network for the Study of Archaic and Classical Greek Song (http://greeksong.ruhosting.nl/). Three volumes in this series have already been published: The Look of Lyric: Greek Song and the Visual, eds. V. Cazzato and A. Lardinois; The Newest Sappho, eds. A. Bierl and A. Lardinois; and Authorship and Greek Song, ed. E.J. Bakker. Two more volumes are in preparation: one on the reception and transmission of Greek lyric poetry from 6 оо вСE to $400 \mathrm{CE}$, and another on Greek lyric and the sacred. The Network was founded in 2007 as a means of facilitating interaction among scholars interested in the study of archaic and classical lyric, elegiac, and iambic poetry.

Most of the papers included in this volume were originally presented at a conference entitled "The Genres of Archaic and Classical Greek Poetry: Theories and Models," held at the University of California, Berkeley in September 2015. For financial support for the conference, we are grateful to the Network for the Study of Archaic and Classical Greek Song, and to the UC Berkeley Dean of Arts \& Humanities, Doreen B. Townsend Center for the Humanities, Departments of Classics and Comparative Literature, and the Gladys Rehard Wood Chair. For advanced conference planning and organization, thanks to Egbert Bakker, André Lardinois, Richard P. Martin, Melissa Mueller, Nelly Oliensis, and Natasha Peponi; for designing the poster, thanks to Richard Neer; and for essential help during the conference, thanks to Marissa Henry, Chris Waldo, and Andrew Wein. The CASMA staff, especially Gary Spears and Sarah Calderon, provided essential logistical support. We want to thank all the speakers and core members of the Network in attendance for making the conference such a lively and stimulating event; in addition to the contributors to the volume, we are grateful for the participation of Lucia Athanassaki, Anton Bierl, Ewen Bowie, Michel Briand, Deborah Boedeker, Vanessa Cazzato, Kate Gilhuly, Athena Kirk, André Lardinois, David Larsen, Dirk Obbink, Enrico Prodi, Ralph Rosen, Ian Rutherford, Renate Schlesier, Alan Sheppard, and Eva Stehle. We are particularly grateful to Virginia Jackson, Chris Nealon, and Yopie Prins for providing a non-Greek, comparative lyric perspective. Thanks finally to Marissa Henry for translating the paper of Claude Calame, although in the end Professor Calame was not able to attend.

In the transition from conference to volume, all papers underwent a process of peer reviewing at the hands of the editors, as well as two anonymous reviewers for the Press. We thank the two anonymous reviewers for their comments, queries, and provocations, which made the volume stronger and more 
coherent. In addition, the contributors had the opportunity to read each other's papers and revise them in dialogue with each other. For editorial assistance in the preparation of the volume, we are grateful to Joshua Benjamins, Massimo Cè, Alexander Forte, and Michael Konieczny; for administrative support, thanks to Gary Spears and Teresa Wu. We also wish to thank Donald Mastronarde for his papyrological assistance in reading Pindar fr. 128c SM. Above all, we are indebted to André Lardinois, who has provided support and guidance at every stage, right up to the volume's publication. Thanks to the whole Brill editorial team, and especially to Christoph Pieper for his sage editorial involvement and attention to the volume. Finally, we would like to thank the Anne and Jim Rothenberg Fund for Humanities Research at Harvard University and the Gladys Rehard Wood Chair at UC Berkeley for providing the funds to make this book permanently available through Open Access. 


\section{Note on Abbreviations, Texts, and Translations}

Names of ancient authors and titles of texts are abbreviated in accordance with the list in The Oxford Classical Dictionary, third edition (2003) xxix-liv; names of journals follow the abbreviations of L'Année Philologique. Unless otherwise specified, Greek and Latin authors are quoted from the Oxford Classical Texts, except for early Greek poetry, which is cited from the following editions: (1) Greek lyric poetry from Campbell 1982-1993; (2) Greek iambic and elegy from West 1989-1992; (3) Sappho and Alcaeus from Voigt 1971, except Sappho fragments 58 and pre- 58 Cologne from Gronewald and Daniel 2007; Sappho fragments 5, 9, 15, 16, 16a, 17, 18, 18a, the Brothers Song, and the Kypris Song from Obbink 2016a; (4) Pindar from Snell and Maehler 1987 (the Epinicia), or Maehler 2001 (the Fragments). Unless otherwise noted, translations are by the contributors themselves. 


\section{Figures and Tables}

\section{Figures}

4.1 P.Mich. inv. 2810 (second century CE), fr. A, with Il. 1.308-375 (col. X-XI) 120

4.2 P.Strasb. gr. inv. 31-32 verso (early third century CE), v, ll. 1-20 (Il. 1.317-336) 122

5.1 Attic black-figure volute krater (François Vase), са. 570 вC E. Florence, Museo Archeologico $4209 \quad 154$

5.2 Attic red-figure psykter attributed to Oltos, ca. 520-510 B CE. New York, Metropolitan Museum of Art 1989.281.69 155

5.3 Attic black-figure Little Master lip kylix, ca. 55 в С E. Tarquinia, Museo Nazionale Tarquinese RC $4194 \quad 156$

5.4 Attic black-figure kylix from Argos, ca. 6оo-55 в в. Berlin, Antikensammlung Staatliche Museum F $3993 \quad 158$

5.5 Middle Corinthian black-figure aryballos, ca. 56о в Се. Corinth, Archaeological Museum, C-1954-1 160

5.6 Late Geometric oinochoe (probably Etrurian), ca. 700-68о вСE. London, British Museum 1849,0518.18 161

5.7 Protoattic black-figure loutrophoros attributed to the Analatos Painter, ca. 7Oо BCE. Paris, Musée du Louvre CA $2985 \quad 163$

5.8 Attic black-figure lekythos attributed to Amasis, ca. 550-53 вС B. New York, Metropolitan Museum of Art 31.11.10 164

10.1 The Ambracian polyandrion. Second half of sixth century BCE. Ephorate of Antiquities of Arta. 300

10.2 The Ambracian polyandrion. Second half of sixth century BCE. Ephorate of Antiquities of Arta. 301

10.3 Inscribed stele base of Smikuthos. Late sixth century вСE. Ephorate of Antiquities of Athens. Kerameikos Museum I 327. 306

10.4 Inscribed stele base of Kleoitos. Third quarter of the sixth century BCE. Athens, Epigraphical Museum 10641. 308

10.5 Detail of inscription of Ambracian polyandrion. Ephorate of Antiquities of Arta. 316

\section{Table}

8.1 The Logic of Ancient Greek Musical Practice $\quad 237$ 


\title{
Notes on Contributors
}

\author{
Seth Estrin
}

is Assistant Professor in Art History at the University of Chicago. He has published on Minoan wall painting and grave monuments of the Archaic and Classical periods. His current research focuses on funerary sculpture as a medium of recognition in Classical Athens.

\section{Andrew Ford}

is the Ewing Professor of Greek Language and Literature at Princeton University. His current work seeks to bring out the interactions between the Greek critical tradition and the poets who read that tradition even as they were being read by it.

\section{Margaret Foster}

is Associate Professor of Classical Studies at Indiana University. Her work leverages the interpretative strengths of Cultural Poetics' theoretical framework and the analytical practices of literary formalism. Bringing together these two approaches, she has published on a range of authors, from Homer to Horace, and genres, including epic, tragedy, lyric, and historiography. She is the author of The Seer and the City: Religion, Politics, and Colonial Ideology in Ancient Greece (University of California Press 2018). She is currently working on a book about the politics and polemics of fifth-century epichoric poetry and its generic dialogue with Attic tragedy.

\section{Mark Griffith}

is Professor of Classics and of Theater, Dance, and Performance Studies at the University of California, Berkeley. His work has focused mostly on Greek drama, literature, and music.

\section{Leslie Kurke}

is Gladys Rehard Wood Professor of Classics and Comparative Literature at the University of California, Berkeley. Her primary interests are in ancient Greek literature and cultural history-focusing especially on archaic Greek poetry, Herodotus, the ideology of form, and various interactions of word and world, literature and its "others" (the economics of literature, text and popular culture, the dialectic of performed song and place/monuments). Her most recent book, co-authored with Richard Neer, is Pindar, Song, and Space:Towards a Lyric Archaeology. 


\section{Gregory Nagy}

is Francis Jones Professor of Classical Greek Literature and Professor of Comparative Literature, Harvard University. He is also Director at Harvard's Center for Hellenic Studies in Washington, DC. His publications include Homer the Preclassic (University of California Press 2010, paperback 2017)

\section{Sarah Olsen}

is Assistant Professor of Classics at Williams College. She has written articles on Homer, the ancient novel, Greek vase painting, and choral spectatorship in early Greek thought. She is the author of Solo Dance in Archaic and Classical Greek Literature: Representing the Unruly Body (forthcoming from Cambridge University Press).

\section{Timothy Power}

is Associate Professor of Classics at Rutgers University, New Brunswick. He has published on topics in archaic and classical Greek lyric poetry, performance, and music. He is currently writing a book on sound and listening in early Greek religion.

\section{Francesca Schironi}

is Professor of Classical Studies at the University of Michigan. She has published extensively on Hellenistic scholarship in scholia and in papyri, and especially on Aristarchus of Samothrace. She is the author of The Best of the Grammarians: Aristarchus of Samothrace on the Iliad (University of Michigan Press 2018).

\section{Deborah Steiner}

is the John Jay Professor of Greek at Columbia University. Her publications focus chiefly on archaic Greek poetry and explore interactions between the literary and visual sources of the period. A forthcoming manuscript treats notions of chorality in a variety of media in archaic and early classical Greece.

\section{Mario Telò}

is Professor of Classics at the University of California, Berkeley. His interests are situated at the intersection of materiality, aesthetics, and psychoanalysis. Among his recent publications, The Materialities of Greek Tragedy (co-edited with Melissa Mueller [Bloomsbury 2018]) places Greek tragedy in critical dialogue with the New Materialism. His new book, Archive Feelings: A Theory of Greek Tragedy, is forthcoming in the series "Classical Memories/Modern Identities," published by Ohio State University Press. 


\section{Naomi Weiss}

is the Gardner Cowles Associate Professor of the Humanities in the Department of the Classics at Harvard University. She has published widely on representations of musical culture and performance in archaic and classical Greece, especially in fifth-century tragedy. She is the author of The Music of Tragedy: Performance and Imagination in Euripidean Theater (University of California Press 2018) and is currently working on a book about the aesthetics of theatrical spectatorship in classical Athens. 
978-90-04-41259- $\odot$

Downloaded from Brill.come4/26/2023 $09: 51: 26 \mathrm{AM}$ via free access 


\section{Introduction}

Margaret Foster, Leslie Kurke, and Naomi Weiss

Our music in those days was divided according to its own forms and postures. There was a form of song comprising prayers sung to the gods, called "hymns"; opposite to this was another form of song which someone might well call "dirges." "Paeans" were another. Then there was yet another called the "dithyramb," which was about the birth of Dionysus, I believe. They gave the name "laws" [nomoi] to another form of song-this sort was for the kithara, they used also to say. Once these, and certain others, had been arranged, it was not allowed to misuse one form of song for another .... But later, with the passage of time, the poets became rulers and held sway over unmusical lawlessness. Although by nature poetic, the poets were ignorant about what is just and lawful for the Muse. In a sort of Bacchic frenzy, more overwhelmed by pleasure than they should have been, they jumbled together dirges with hymns and paeans with dithyrambs; they used kithara sounds to imitate the sounds of the aulos - they confounded everything.

PLATO, Laws 7ooa9-e1, tr. PANGLE

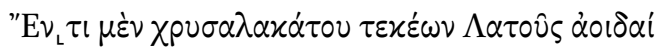

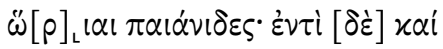

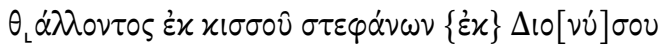

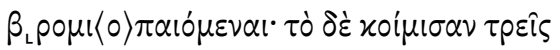

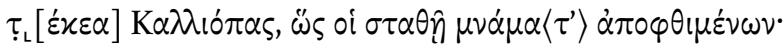

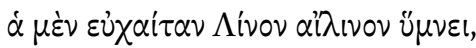

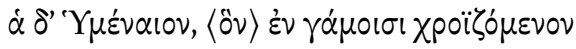

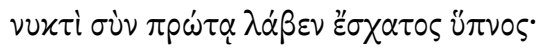

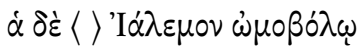

10

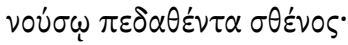

viòv Oiárpou $\langle\delta \dot{\varepsilon}\rangle$

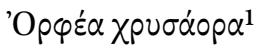

1 The text of this fragment is quoted in the scholia to Eur. Rhes. 895, preserved in only one thirteenth-century ms which seems to have been copied from an already damaged or corrupted text, so the text of the fragment is very troubled. We mainly follow the texts of Maehler 2001 and Race 1997, which are very similar (Race simply includes a few more supplements in 
There are songs for the children of gold-spindled Leto, paean [songs] in due season, and there are also [songs] for Dionysus' crowns of flourishing ivy, [songs] smitten with wine/drunkeness. But, [in contrast to those], [other songs] put to sleep three sons of Calliope, in order that memorials of the dead be set up for her: one [song] sang ailinon for Linus with beautiful hair; another [sang] of Hymenaeus, whom the last sleep took when his skin was touched in marriage together with the first night. And another sang Ialemus, shackled in strength by flesh-rending disease. But the son of Oeagrus, Orpheus with his golden lyre ...

PINDAR, fr. 128c SM

The conference on which this volume was based was organized originally to revisit and interrogate the question of genre, what it means, and how to think about it for archaic and classical Greek poetry. Coming together almost fifty years after the performance model of lyric genre first developed, our speakers were encouraged to engage with a wide array of scholarship, theory, and comparative material in the hope that a more holistic understanding of the concept and its relevance to the study of ancient texts might emerge. ${ }^{2}$ In this same spirit we do not begin this introduction to the volume with one particular definition of genre, since we want to foreground and allow for the different approaches of our contributors, which together push beyond current dominant trends within the field.

We begin instead with a famous passage of Plato's Laws, juxtaposed to a much less familiar fragment of Pindar, because both seem to offer us tantalizing views of an illud tempus of perfect, pure emic genre. These texts seem to speak of a world of clear, recognizable, and distinct generic forms based on addressee or figure celebrated/commemorated; context or occasion of performance; and singers and audience. ${ }^{3}$ The two together point to a system of specific song types in which the umbrella term "lyric" (including poetry composed in melic, iambic, and elegiac meters) is too broad to be meaningful, while

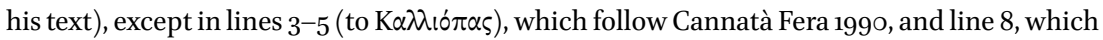
includes in the text the suggested emendations of Henry 1999. Thanks to Donald Mastronarde for sharing with us his new transcription of the scholion and Pindar fragment, examined under UV light, and for extensive discussion of the textual difficulties and merits of different proposed emendations.

2 On literary genre in general: Dubrow 1982; Fowler 1982; Frow 2015. On genre in anthropology/ sociolinguistics: Briggs and Bauman 1992; Bauman 200o. On genre within Classics: Conte 1994; Depew and Obbink 20ooa; Barchiesi 20o1; Bakola, Prauscello, and Telò 2013; Maslov 2015: 40-97, 246-317.

3 Calame 1974 also juxtaposes these two texts, in the service of a somewhat different argument. 
Plato here in the Laws and Pindar also limn a generic system that precedes and seems to operate at a skew line to the much later tripartite division of epic, drama, and lyric as the three "natural kinds" of mimetic poetry. ${ }^{4}$ The latter system itself ultimately depends on and goes back to models developed by Plato in the Republic and Aristotle in the Poetics, which make mimesis- "imitation" or "representation" - the defining feature of verbal art. ${ }^{5}$ Thus our two quoted passages suggest a rift or gap between an emic poetic genre system and the theories of poetry later developed within the culture ${ }^{6}$ while they also seem to open up a window onto a precious archaic system of song in performance that preceded and was innocent of the Classicizing systems and definitions ("the three natural kinds") later imposed upon it.

And yet, slight discrepancies between these two texts already suggest cracks in the surface of our pure genre world, or perhaps better-multiple sedimented layers within a centuries-long stratigraphy of genre. ${ }^{7}$ Thus the Laws passage uses the Greek term humnos narrowly as a technical term for a song comprising prayer to a god (akin to our "hymn"), while the same term functions as a much more general term for choral song in Pindar and throughout archaic Greek poetry. ${ }^{8}$ A.E. Harvey, in a foundational article in 1955 , "The Classification of Greek Lyric Poetry," called attention to the fact that all that we have of archaic and classical Greek lyric poetry comes to us mediated through the editorial work of Hellenistic Greek scholars, who of necessity had to sort and classify a great mass of heterogeneous material into books (papyrus rolls of 1,00o-2,ooo lines) organized by kind. Where we can discern the terms of that classification system best (in the cases of Pindar and Bacchylides), it is clear that there is some divergence or misfit between the original performance occasions of many of these preserved texts and the broader generic labels that the Hellenistic scholars developed to organize them into books (e.g., "epinician" was not a functional category in the archaic and classical period; Pindar himself desig-

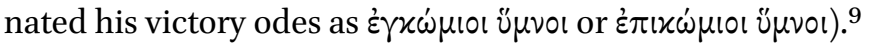

4 For these three as the "natural kinds," see Genette 1992.

5 Although, as Genette 1992 notes, Plato and Aristotle themselves do not develop the threefold model of "natural kinds," since they basically omit lyric from their systems as not obviously mimetic in the way that epic and drama are.

6 Cf. Ford 2002, Farrell 2003.

7 For the terms "sedimentation" and "stratigraphy," cf. Maslov 2015: 22-33, following Veselovsky and Jameson 1981.

8 On this discrepancy, cf. Harvey 1955: 165-168. Calame 1974: 119-12o helpfully reframes this as an issue of signifier vs. signified - the signifier humnos (or paean, or dithyramb) endures, but what it signifies shifts over time. For the meaning of humnos in early Greek poetry, see also Maslov 2015: 294-307.

9 Harvey 1955: 158-164; cf. Agócs 2012: 194-197, Maslov 2015: 279-28o. 
Harvey therefore advocated cautious skepticism about the generic labels we have inherited for various earlier Greek poetic texts: is a "paean" always a "paean"? Does it have to have a refrain? Is a dithyramb always a dithyramb? Can we accept one Hellenistic definition that a dithyramb is always a narrative poem? Harvey himself did not advocate the complete rejection of the generic terms that have come down to us, citing this very passage of Plato's Laws to stabilize the system and argue that many of its terms preexisted the work of the Hellenistic scholars (mainly in the domain of choral lyric)..$^{10}$

All of this means that in the domain of early Greek poetic forms, we inherit phenomena of kaleidoscopic complexity: an abundance of material (most of it preserved in fragmentary form) in different meters (iambic, elegiac, and melic), much of it quoted and embedded in other Greek texts which frame, contextualize, and sometimes label these poetic scraps by genre (possibly anachronistically). Given the wild heterogeneity and fragmentation of what has come down to us and the uneven stratigraphy of generic labels, how do we make sense of all this material?

Harvey himself pointed one way forward, by contrasting Hellenistic taxonomies with the original purpose and occasion of a given ancient song. ${ }^{11}$ Such an approach to genre in archaic and classical Greek poetry was given additional impetus and support by the development of models for the oral composition of Homeric poetry - the argument that the highly formulaic nature of Homeric epic gave evidence that this poetry was orally composed in performance by skilled bards in a centuries-long tradition. Oral formulaic theory, developed in relation to Homer by Milman Parry and Albert Lord, prompted much more expansive interest in orality within Greek studies, as constituting forms of culture, poetic composition, and performance radically different from those of the modern literate world. The extension of the model of orality beyond Homer to all of archaic and classical Greek poetry down to the end of the fifth century в Се had a profound impact on the modeling of poetic performance and poetic kinds for this period. ${ }^{12}$ Bruno Gentili, inspired by the work of Parry, Lord, and especially Eric Havelock, insisted on the sheer difference or strangeness of Greek poetic production compared to modern poetry. For Gentili, Greek poetry

10 Harvey 1955: 164-174. Although Harvey does not note the connection with choral lyric, because he does not accept choral vs. monody as a real distinction (159 n. 3), and because he wants to argue for the connection of threnos with elegy, Calame 1974 notes the predominance of choral lyric forms here.

11 Harvey 1955: 159-16o.

12 See Lord 1960 [2000]; Parry 1971. The oral model was significantly extended beyond Homer by Havelock 1963, 1982 . 
was "an essentially practical art," "closely linked to the realities of social and political life," always composed for performance before a specific audience and on a specific occasion..$^{13}$ Performance, audience, memory, and practical function became the key terms, and Gentili drew on comparative oral theory and anthropology to help him imagine how archaic and classical Greek poems functioned within their original contexts of performance.

Within this turn to orality and performance, Claude Calame and Gregory Nagy developed innovative models of genre, and these models still represent an influential paradigm within the field. ${ }^{14}$ Claude Calame, a student of Gentili, in 1974 offered "Réflexions sur les genres littéraires en Grèce archaïque." Here he identified genre not just with a set of immanent formal features to be discerned through structuralist/semiotic analysis of the poetic system, but also with occasion and the "horizons of expectation" of audiences à la H.R. Jauss. ${ }^{15}$ Gregory Nagy, a student of Albert Lord, extended Calame's analysis in the mid-199os with an important article entitled "Genre and Occasion" (on which he elaborates with reference to Sappho in this volume).${ }^{16}$ Here Nagy simultaneously correlated genre with occasion and performance with the Austinian "performative," allowing him to define (Greek) genre as "the set of rules that produce a speech act." ${ }^{17}$ Nagy, however, dissociated the "speech act" from Austin's philosophical context of individual agency and judgment, identifying it instead as "myth" (a narrative significant for a community) performed as "ritual." Within these terms, "the occasion is the genre," but Nagy also added that "if the occasion is destabilized or even lost, the genre can compensate for it, even re-create it."18

Nagy combined the latter idea (genre as a compensation for or recreation of occasion) with a bold and thoroughgoing reconceptualization of mimesis in early Greek poetry. For Nagy, the primary meaning of mimesis in the early

13 Quotations from Gentili 1988: 3; see also A.T. Cole's Translator's Introduction to that volume.

14 We will not attempt to summarize here all the relevant work of Calame and Nagy, since both are incredibly prolific scholars who have over decades (and hundreds of publications) developed, elaborated, and nuanced their thinking on genre. We will instead focus on a couple of their earliest and most influential articles on the topic. For a fuller bibliography of Nagy's work, see his Keynote in this volume; for a representative selection of Calame's work, see the volume bibliography.

15 Calame 1974.

16 Nagy 1994-1995. This article represents a concise summary of the much more expansive presentation of these arguments in Nagy 1990 and Nagy 1996.

17 Nagy 1994-1995:13. Nagy draws the term "speech act" from Austin 1975; in thinking of genre in terms of the principles producing a speech act, he draws on Todorov 1990.

18 Nagy 1994-1995:13 (emphasis in original). 
Greek context was "ritual reenactment," whereby the choral performers of a song for the duration of the performance actually became and embodied the mythical figures whose stories they sang. This model of mimesis endured into Attic tragedy, but when the myth-ritual-performance system came to be destabilized or eroded, the primary meaning of mimesis was lost and a secondary meaning, "imitation," came to the fore. ${ }^{19}$ Hence, Plato's critique of poetry in the Republic as "mere" mimesis ("imitation") is simply a misunderstanding of the older system. By this reorientation, Nagy reconciled the older Greek system of genre based on occasion and performance with the Platonic/Aristotelian model of verbal art defined as mimesis - two systems that otherwise seem to operate at skew lines to each other.

The revolutionary oralist/performance/occasion paradigm of Gentili, Calame, and Nagy can be seen, in turn, as a reaction to older approaches to Greek poetry. It was first a rejection of an idealist Hegelian, teleological reading of the slow unfolding or "discovery" of the Greek Geist through the progressive stages of epic, lyric, and tragedy. This approach, mainly associated with Bruno Snell and Hermann Fränkel, celebrated Greek lyric as the earliest revelation of the subjective "I" in moments of high emotional intensity, in contrast to the serene third-person narration and objective distance of epic. ${ }^{20}$ At the same time, the emphasis on song in performance also represented a rejection of New Criticism and other kinds of formalism, with their turn away from history and context. New Criticism, a powerful movement outside of Classics in the 195os, remained the dominant paradigm for the close reading of poetry within Classics even into the 196os and 7os, while the work of Elroy Bundy in the early 196os, pursuing rigorous rhetorical, topological analysis of Pindaric epinician, spawned another strain of formalism native to the field of Greek poetry. ${ }^{21}$ Although Bundy insisted that everything in epinician served the purpose of praising the victor, both "victor" and "praise" became completely bland generic categories, and Bundy and his followers ranged freely over all of Greek literature and across all its genres to find comparanda for different motifs and motif sequences in the odes. $^{22}$

In response to all this, the approaches of Gentili, Calame, and Nagy represented a return to a different kind of history and context, combined (especially

19 Nagy 1994-1995; cf. Nagy 1996 chs. 1-4. For similar arguments, see Jones 1962 on tragedy as masked drama, and Vernant 1991 chs. 9-10 on the image in Greek culture ("from the presentification of the invisible to the imitation of appearance").

$20 \quad$ See (e.g.) Snell 1946; Fränkel 1975.

21 Bundy 1986 [1962].

22 For this characterization of Bundyist formalism, cf. Cole 1988: xvi. 
in the case of Calame and Nagy) with structuralist/semiotic methodologies. Their ideas of history — all different from the older Hegelian, teleological model of Snell and Fränkel - were also different from each other. And along with different versions of history, we find different models of the lyric "I." For Gentili, the historical context for melic, iambic, and elegiac poems is local and specific, their speakers engaged in quotidian political and social struggles that their verses perform before different interested audiences. ${ }^{23}$ Calame draws more heavily on the history of religion, invoking anthropological models of initiation and rites of passage to situate and make sense of the poetic remains of Alcman and Sappho. In this anthropological modeling, the focus shifts from the historical and biographical ego to the essential communal functions of poetry in performance, with the ego filling the social/structural role of chorus leader or chorodidaskalos. ${ }^{24}$ For Nagy, the influence of oral formulaic theory, the study of Homer, and structuralist and Indo-European linguistics are paramount, so that history is itself embedded in the language and meters of Greek poetry and its traditional formulae. Thus Nagy effectively mines the deep history in texts, reconstructing elements and motifs all the way back to Indo-European, through the reading of all of Greek poetry together as one continuous "macrotext" or signifying system..$^{25}$ Consonant with these reading strategies, the "I" for Nagy becomes a "generic I," a traditional speaking position thrown up or generated by each separate genre over hundreds of years of performance. We should therefore think of "Homer" as the arch-poet of heroic epic; "Hesiod" as the equivalent for theogonic poetry; "Theognis" as the alibi or placeholder for disaffected aristocrats in sympotic elegy throughout the Greek world; and "Sappho" as the lyric "sister" speaking for a long traditon of women's song on archaic Lesbos. ${ }^{26}$

The oralist/performance/occasion paradigm has been an exceptionally productive model within Greek literary studies, stimulating a wide array of significant scholarship over the last forty-five years or more. As we have noted, it remains an influential paradigm in approaches to genre for archaic and classical Greek poetry, especially in north American and continental scholarship. The conference upon which this volume is based opened with this paradigm, with a Keynote Address by Gregory Nagy, and several of the papers here take their cue from the fundamental work of Nagy and Calame.

23 Gentili 1988; for a similar modeling of the "historical I," cf. Rösler 1980, 1985.

24 See esp. Calame 1977, 1983, 1997a.

25 See esp. Nagy 1974, 1979/1999.

26 For the "generic I," see Nagy 1994-1995: 20; for Homer and Hesiod, see Nagy 1982; for Theognis, Nagy 1985; for Sappho, Nagy 2016 and in this volume. 
And yet, like any paradigm, it has its limits-inevitably, in complementary distribution to the things the model fits better are the things it occludes or ignores. ${ }^{27}$ Thus one might say that this paradigm represents an overweighting of the anthropological, the ritual, and the communal over against the literary, the fictional or fictive, and the tussle or dialectic of individual instantiation and tradition. This overweighting inevitably produces two different effects or tendencies - occlusions or blindspots on different scales - both of which have unnecessarily isolated the study of archaic and classical Greek poetry from important trends in the literary humanities. First of all (as Andrew Ford notes in his contribution to the volume), the structuralist method of Calame and Nagy does not deal well with the individual poem - with the texture of the literary in all its specificity and complexity. ${ }^{28}$ This isolates us from a broader movement within the humanities, where there has been a significant return to formalism and theoretically-informed formalist analysis. ${ }^{29}$ At the same time, the insistence of this anthropological/performance paradigm that archaic and classical Greek poetry is radically strange and different from all that came after it has succeeded only too well. For it has cut us off from significant conversations about the longue durée of literary history current throughout the broader humanities. Here one might think of the heated debates around the transhistorical existence of "the lyric" and lyric history represented by Jonathan Culler's 2015 Theory of the Lyric and the New Lyric Studies advocated by Virginia Jackson and Yopie Prins. ${ }^{30}$

Indeed, a similar discontent with the influential anthropological occasion/ performance model animates another recent volume (also based on a conference in 2015), Textual Events: Performance and the Lyric in Early Greece, edited by Felix Budelmann and Tom Phillips. ${ }^{31}$ The editors and contributors to this volume push back against the sociopolitical or ideological reading of archaic Greek lyric, aiming instead to recuperate all the formal, sensuous, and imaginative powers and effects of these texts that they contend such readings elide. Instead, they offer the concepts of archaic Greek poetry read as "literature" and as "textual events," where by "event" they mean the power of highly-wrought

27 See de Man 1983 on the necessary inter-implication of "blindness" and "insight" in any theoretical approach.

28 Cf. Culler 1975: vii-viii, 113-130, 258-259, explicitly acknowledging that his "structuralist poetics" has no interest in offering new readings of individual poems.

29 See, e.g., Best and Marcus 20o9; Felski 2015; Levine 2015.

$30 \quad$ For the debate, see Jackson 2005; Yaeger 2008; Jackson and Prins 2014; Culler 2015. Another relevant trend is the Russian-influenced "Historical Poetics" of Boris Maslov and Ilya Krieger; see Maslov 2015; Krieger and Maslov 2016.

Budelmann and Phillips 2018, based on an Oxford conference in March 2015. 
literary texts to conjure other worlds and new possibilities of feeling, perception, and thought. ${ }^{32}$ We are very much in sympathy with the "New Formalist" turn that the Textual Events volume offers. At the same time, our volume can be read as complementary to that of Budelmann and Phillips, zeroing in on related issues that they do not tackle explicitly, through engagement with a wider range of texts and theoretical approaches. Thus, for example, as Budelmann and Phillips note in their introduction, they do not "attempt to address ... head-on" "the challenges posed by genre in Greek lyric and by Greek lyric as a genre," even while "genre is a thread that runs through" the essays in the volume. ${ }^{33}$

In contrast, the purpose of this volume is explicitly to revisit the concept of genre in archaic and classical Greek poetry nearly fifty years after the significant interventions of Gentili and Calame, and nearly thirty years after Nagy's influential work of the 1990s. The essays in the volume illustrate the different ways in which we can expand upon the advances we have made within this paradigm, while also moving beyond the anthropological occasion/performance model. In many cases, the essays build on theories, models, and lines of argument already current in the field-some of which have themselves developed out of the older paradigm; others derive from the interaction or creative borrowing of Greek studies from other disciplines (including Latin literary studies, art history, dance theory, and affect theory, among others).

We begin with the Keynote Address of Gregory Nagy. ${ }^{34}$ In a return to his study on genre and occasion, Nagy refines his formulation of the paradigmatic term "occasion" by identifying it as an instance of mimesis in the sense of "ritual reenactment." Turning to Sappho, Nagy understands the experiences and emotions that constitute Sappho's songs as belonging above all to the personae who inhabit her song world. An event expressed by a given song, such as a familial crisis or a bout of unrequited love, does not itself prompt the occasion of its own choral performance. Rather, for Nagy, it is the mimesis of such events, performed by a singing and dancing chorus, that comprises the occasion.

32 See Budelmann and Phillips 2018a: for "literature" or the "literary," see pp. 9-15; for "textual events," see pp. 6-10, 23-26. For this concept of "event," they follow the philosopher Alain Badiou; see Badiou 2013 and Payne 2018.

33 Budelmann and Phillips 2018a: 19-22; all quotations from p. 19. Likewise, they note that they will not explicitly tackle the "much discussed issue of lyric mimesis" (p. 9, n. 12), which this introduction and many of our contributors consider from different angles.

34 Appropriately enough, given his focus on oral performance and occasion, Nagy has opted to preserve the oral, lecture quality of his talk at the original conference. We have therefore labeled Nagy's contribution as a "Keynote," and tried, as much as possible, to preserve its performative qualities in the text. 
Nagy's Keynote is followed by three contributions that engage with and/or critique the anthropological/performance paradigm from different perspectives. Andrew Ford challenges an illud tempus or "pre-lapsarian" model of a perfect fit between text and performance occasion in archaic Greece. He argues that we need to move beyond both the idea of poetry as mimesis and that of lyric mimesis as ritual reenactment, proposing instead that we think of genre in terms of "generification" - the ongoing process of its production. Timothy Power rethinks the "choral hypothesis" for Sappho's lyrics, which has long been a crucial component of the anthropological/performance paradigm of Calame and Nagy, arguing instead for a model of "parachorality" that would allow for a more substantial fictive component in the setting of Sapphic song. Finally, Francesca Schironi's paper reconsiders the centrality of performance by turning to an entirely different body of material - the scholia, especially those on Pindar - and investigating how the issue of mimesis (or "speaking personae") was conceptualized in Alexandrian scholarship. As Schironi discovers, references to performance (in our sense) are largely absent from the scholia; they view the chorus instead simply as one more speaking persona. Thus for these ancient readers at least, all early Greek poetry (including Homer) is read mimetically as if it were drama.

We then proceed to two clusters of papers whose approaches in many cases develop out of the anthropological paradigm, but also offer ways beyond it, in dialogue with a variety of other disciplines, theories, and methods. The papers in the first cluster-those of Steiner, Weiss, and Foster-all complicate the notion of "pure" genre from different perspectives. The remaining papers of Griffith, Telò, Estrin, and Olsen all engage with ideas of affect, materiality, and embodied experience to reconsider in different ways current approaches to genre in the study of Greek poetry.

Rather than summarize each essay here, we will lay out programmatically three themes or methodological trends that figure prominently in the rest of the volume. These three themes are not mutually exclusive; often individual essays instantiate two or even three of them at once, and in doing so together herald a new, integrated approach to genre in archaic and classical Greek poetry.

\section{Genre Mixing}

As far back as we can go, there is no "before" of pure or pristine genre that we can locate in our texts. Traditionally, scholars have recognized that, in the Hellenistic and Roman periods, there was constant complex genre mixing, 
generic self-consciousness, and dynamic play with genre within texts, but the current oralist/performance model has tended to exempt archaic Greece as an illud tempus of pure genre in performance. ${ }^{35}$ And yet, Homer and tragedy have always presented significant exceptions to this model. Thus, as Richard Martin has argued, Homeric epic is better defined as a "super-genre" that subsumes within it a multiplicity of "genres of discourse," emic speech genres like flyting, advising, remembering, and mourning as well as lyric forms more narrowly defined, like paean, threnos, and Linus song. ${ }^{36}$ In her essay in this volume, Naomi Weiss proposes that we extend the term "super-genre" to Attic tragedy as well, since (as has become more and more apparent in recent years) tragedy is the ultimate appropriative cultural system, folding into itself all the multifarious resources of the Greek "song culture" for its complex multimedia art. ${ }^{37}$

But genre mixing, complexity, and dynamic play are also evident in our preserved examples of archaic elegiac, iambic, and melic poetry (even if not, in most cases, on the same scale as in Homer and tragedy). Nor can all of these effects be put down to the fragmentary state of our remains, or to the underspecification or "indeterminacy" of genre. ${ }^{38}$ This is patently true for the epinicia of Pindar and Bacchylides, as well as their other choral songs. ${ }^{39}$ So, for example, scholars still debate whether Bacchylides 17 is a paean or a dithyramb, or an amalgam of both, while Margaret Foster explores the complex, "polyphonic" genre mixing of Bacchylides $16 .{ }^{40}$ But for a much earlier example, we might consider the Cologne Epode of Archilochus. In the influential reading of Gregory Nagy, the Cologne Epode is blame poetry—but blame poetry mas-

35 Examples of the earlier consensus: Kroll 1924; Rossi 1971; Zetzel 1983; Barchiesi 2000; Farrell 2003; etc. This is also the framework of Nagy 1994-1995, who quotes Williams 1968 for this point.

$36 \quad$ Martin 1989, 2005.

37 On the incorporation of different genres within tragedy, see esp. Herington 1985, from whom we draw the phrase "song culture" (although Herington focuses mainly on epic in tragedy); Nagy 199o: 382-413; Rutherford 1994-1995; Swift 2010; Kurke 2013b; Weiss 2018. For a more political approach to the appropriative nature of Attic tragedy, see Kowalzig 2006, 2007a; Foster 2017.

38 For "generic indeterminacy," see Carey 1995: 97 and n. 21; Rutherford 2001: 3-10, 90-91; Currie 2005: 21-24; Lowe 2007.

39 For genre mixing in different Pindaric epinicia, see Kurke 1988, 199o, 2013b; Carey 1995; Maslov 2015; for genre mixture in Bacchylides, Fearn 2007: 87-16o. See also Barchiesi 2001: 153 on the prevalence of genre mixture or "transgeneric texts" in the fifth and fourth centuries BCE, as well as Phillips 2018 and Thomas 2018, considering genre mixture within Pindar's ninth paean and the Homeric Hymn to Hermes, respectively.

40 On the genre(s) of Bacchylides 17, see Schmidt 1990; Zimmermann 1992: 91-93; Van Oeveren 1999; Kowalzig 2007b: 88-94; Calame 2009; Tsagalis 20o9; D’Alessio 2013. 
querading as erotic idyll. This tale of man and maid dallying in a meadow works all the more effectively as blame because of its seductive narrative surface; in the course of the poem, the speaking ego manages to destroy the reputations of both the older sister, Neoboule (by what he says about her) and the unnamed younger sister (by what he does to her in the course of the poem). ${ }^{41}$

We see such generic play in this poetry because, as Boris Maslov has convincingly argued, by the time we encounter the whole Greek system, it is already a literary system, subject to the mediation of multiple levels of dynamic genre production and proliferation. ${ }^{42}$ Another way of formulating this might be to say, in Bakhtin's terms, that the texts as we encounter them are always already participants in "secondary genres," literary forms that have absorbed "primary genres" of spontaneous verbal interaction like greeting, prayer, victory announcement, or the "Ie Paian" cry. ${ }^{43}$ Such a model of primary and secondary genres can help elucidate Nagy's double definition of genre as both occasion and compensation for a lost occasion. ${ }^{44}$ In Bakhtin's terms, Nagy's first definition applies to primary speech genres, the second to secondary or derived speech genres once they have developed into literary forms. In these terms, the illud tempus of pure, unmediated genre as performance and occasion is not directly available to us; it can only be a scholarly mirage.

Importantly, as Maslov also notes, there need be no necessary or strict correlation between the crystallization of a complex second-order literary system and a broader cultural shift from orality to literacy. ${ }^{45}$ The too-rigid dichotomy between these two terms (orality and literacy) dominated past scholarship, and with it an unexamined equation of "oral" (oral composition, oral performance, oral transmission) with the immediacy of pure, performative emic genres of song. And yet, there has been a seismic shift in thinking about orality and literacy beyond Classics and within it from the days of Eric Havelock

\footnotetext{
$41 \quad$ Nagy 1976.

42 Maslov 2015: 9-22, 36-116. For the idea that literary discourse is more highly "genred," Maslov follows Silverstein 1993.

43 On "primary" and "secondary genres," see Bakhtin 1986, esp. 6o-67 and the lucid summary of Maslov 2015: 42-47. This distinction is already acknowledged in Harvey 1955: 172-174, who notes the difference between the spontaneous, ritual paean — which may be simply the "Ie Paian" refrain—and the "literary" paeans of Pindar and Simonides.

44 Nagy 1994-1995: 13, discussed above, p. 5.

45 Bakhtin, in his general formulation of the categories "primary" and "secondary genre," had mainly aligned secondary genres with the written (vs. the oral), but, as Maslov 2015: 43 notes, secondary genres like epic or aetiological myth may develop independently of writing.
} 
and Walter J. Ong. ${ }^{46}$ There is now a recognition that the two forms interact unevenly, coexisting and cooperating for long periods of time, and that there are significant continuities as well as differences between oral and literate cultures. ${ }^{47}$ But this broader shift in the cultural and sociological modeling of the orality-literacy interface has rarely penetrated the discourse on the genres of archaic Greek poetry. Indeed, even within a pure oralist model, the extraordinary generic mixture and generic self-consciousness of Homeric epic should itself call into question the alignment of orality with pure performance genre.

So, for example, Andrew Ford's essay in this volume argues that, as far back as we can go, we find our poets always already engaged in self-conscious play with genre. Ford suggests that the poets are themselves "ethnographers of genre," citing Pindar fr. $128 \mathrm{c}$ SM (to which we will return) and Homer's elaborate, punning allusion to two different accounts of the generic origins of Linus song embedded in Iliad 18. Ford is thus extending backward in time the model of generic play and generic complexity much more commonly associated by scholars with Hellenistic and Roman poetry. ${ }^{48}$ Ford usefully introduces the term "generification" to suggest that, from the point of view of production, genre is a dynamic process, always in flux, which is only crystallized retrospectively through reception. ${ }^{49}$

We might combine Ford's concept of dynamic, ongoing "generification" with two important points made by Joseph Farrell in his article "Classical Genre in Theory and Practice."50 First, Farrell notes a significant gap between ancient literary theory and ancient poetic practice when it comes to genre. The ancient theory of genre was essentializing and moralizing, assuming unproblematic, clear boundaries between genres and a hierarchy of genres or literary kinds neatly correlated with the social status and moral character of the poets who worked within them. In contrast, ancient poetic practice was consistently more sophisticated and more complex than ancient theory—and even the explicit statements of ancient poets-allowed..$^{51}$ Second, as one element of such com-

46 For the traditional model of orality vs. literacy, see Havelock 1963, 1982; Ong 1982; cf. Goody and Watt 1968; Miller 1994.

$47 \quad$ Harris 1989; Thomas 1989, 1992; Kirk forthcoming.

48 See esp. the discussions of Barchiesi 2000, 2001 and Farrell 2003; both Barchiesi and Farrell acknowledge that the same kind of generic play and generic complexity can be found in archaic and classical Greek poetry, although both focus more on Roman material.

49 Cf. Todorov 1990: 13-21; this is, in a sense, already the point of Harvey 1955.

5 Farrell 2003.

$5^{1} \quad$ Farrell 2003: 386-396; note esp. Farrell's discussion of the weird misfit between Horace's 
plex generic play or self-consciousness within poetic texts, Farrell notes that genre is often articulated within a dyadic structure of contrast or difference. Thus, for example, in Pindar's second Pythian ode, the speaking "I" elaborately contrasts himself with the noxious Archilochus, "fattening himself on heavyworded hatreds" (Pyth. 2.55-56). The name "Archilochus" here stands for blame poetry, which Pindar, the consummate praise poet, eschews or disavows. ${ }^{52}$ In one sense, Farrell's point is a structuralist one: we might say that genre is a system of differences with no positive terms. ${ }^{53}$ That is to say, genres can only be defined and articulated in a contrastive system with other adjacent or opposed genre categories. And yet, in deconstructive terms, as Farrell points out, each genre then seems inevitably to subsume or include its "other," in a necessary inter-implication of discourses. ${ }^{54}$

With the conceptual apparatus provided by Maslov, Ford, and Farrell, we might return to the passages from Plato's Laws and Pindar quoted at the start. These passages have generally been read, together or separately, to stabilize and substantiate the existence of an unproblematic system of pure, unmixed emic genres. ${ }^{55}$ But we should perhaps pry these two passages apart and recognize how profoundly different they are in their goals and models of genre. To consider the passage from Plato's Laws first: given the misfit convincingly demonstrated by Farrell between ancient theory and ancient practice, why should we believe Plato at all? Why accept that there was ever a time of pure, unmixed or "uncontaminated" genres? ${ }^{56}$ Plato's goal here is obviously political,

explicit injunctions against genre-mixing and his own (deeply mixed and hybridized) form in the Ars Poetica (pp. 393-395).

52 Farrell 2003: 387-388, following Nagy 1979: 222-228. Cf. Barchiesi 2001: 156 on how Roman poets "tend to stage programmatic respect to a traditional genre, precisely to be able to dramatize their work as deviation or genre-bending; the whole process is part of the semiotics of poetry, not a disinterested confession or the disclosure of a true laboratory. To this end, they need genres to be perceived as strong, pure, and sufficiently unmixed; they practice a reconstructive approach to genre, not a capricious reshuffling."

53 This is famously Saussure's definition of language as a structuralist system (Saussure 1972 [1916]).

54 Farrell 2003: 387-389: "Our Pindaric illustration indicates a persistent tendency on the part of Greek and Roman poets to declare their generic allegiances (or to comment on the generic constraints that they faced) in dyadic terms. Such declarations frequently take the form, 'I am doing X, which is to say, the opposite of Y.' This habit discloses a keen awareness on the poets' part that the different genres in question are more than casually linked. Indeed, each necessarily includes the other within its conceptual framework, as an opposite to be sure, but one that is very like a twin." (quote from pp. $388-389$ ). For a broader deconstruction of genre along similar lines, see Derrida 1980.

55 So, e.g., Harvey 1955; Calame 1974; Rutherford 1994-1995.

$5^{6}$ Cf. Barchiesi 2001: 153: "Are we encouraged to construct an age of generic purity as a foil 
as he extends the essentializing modeling of genre from poets to audiences, and from moral/ethical capacities to political forms and their degeneration. ${ }^{57}$ The period of distinct musical genres is presented as emblematic of a reverence for "ancient laws" more broadly, which the Athenian Stranger aims to replicate in the new colony of Magnesia; the dissolution of such laws marks the beginning of "excessive freedom" in the wake of the Persian Wars. Despite the loose historical framing, this is a nostalgic myth about the Athenian past rather than an historical (let alone Panhellenic) reality. Plato here adopts the sort of dyadic approach to genre discussed by Farrell, constructing a Golden Age of pristine genres in order to stage its subsequent breakdown.

Pindar's threnos fragment is up to something else entirely. First, against the taxonomic, genre-stabilizing reading of this fragment, we should note that our text is not a treatise offering objective evidence for the ancient Greek genre system, but a poem-in fact, a threnos or mourning song composed on commission for the family of a deceased individual. ${ }^{58}$ Papyrus fragments of Pindar's threnoi confirm that this is the beginning of the poem, which offers an elaborate priamel of different occasions/genres of song: paeans for Apollo and Artemis, dithyrambs for Dionysus, then three different mourning songs named for and originally sung over three mortal sons of Calliope who died prematurelyLinus, Hymenaeus, and Ialemus. Finally, the poet mentions Orpheus as "son of Oeagrus," just at the point where our fragment breaks off.

This moment is, as Ford notes in his essay in the volume, an instance of Pindar's own poetic anthropology or meta-narrative about the aetiology of genre in particular occasions. ${ }^{59}$ But what has not been emphasized enough is how extraordinary it is for Pindar to construct a priamel from different kinds or genres of lyric song. There are several parallels in Pindar for an opening priamel that serves to focus in on the poet's theme or topic, but what is unique here is the use of different occasions/genres of song for that opening focus-

precisely because we work too hard on the Kreuzung model in Alexandrian literature? Is respect for genre always a 'good old days' feature, as Plato wants us to believe when his agenda is indicting generic anarchy in the Laws?"

57 For a strong political reading of this passage of Plato, see Rancière 2004, with discussion and explication by Hallward 2006, Halpern 2011. See also Folch 2015: 121: "[this] eclectic generic history ... is not about genres per se, but a theory of moral and political psychology worked out in generic terms."

58 That it is a threnos is confirmed by POxy 2447 , fr. $4 \mathrm{~b}$, which preserves the first few letters of the first lines of fr. 128c SM in what is clearly a book of threnoi. See Cannatà Fera 199o: 137 .

Cf. Ford 2002: 15-16. 
ing device. ${ }^{60}$ As such, the priamel bespeaks a remarkable level of poetic selfconsciousness, and offers an excellent example of Farrell's point that ancient poets often articulate genre through explicit contrast and differentiation from neighboring or opposed genres. Here, however, it is not a simple "dyadic structure," but something much more complicated, as we shall see in a moment. In addition, since the terms of the priamel are also the very medium of song and we have no explicit introductory statement like, "What kind of song should I sing?" ${ }^{61}$ we might read the opening lines as a deliberate misdirection that is potentially also transgressive. For when the song begins, we may think we are hearing a paean. If so, this would seem to be a violation of a religious taboo, not to invoke Apollo or sing his characteristic song-type in the context of death and mourning. ${ }^{62}$ On this reading, Pindar is not simply cataloguing, but also promiscuously mixing "hymns with dirges, paeans with dithyrambs" - precisely the decadent miscegenation of genres the Athenian Stranger of Plato's Laws so deplores. The opening is thus, at the very least, unsettling - a weird and intense generic mise-en-abîme.

But, given what we know of Pindar's practice in priamels elsewhere, this may be an even more complicated example of genre mixture or genre hybridization. As Maria Cannatà Fera notes in discussing this fragment and its priamel opening, Pindar's priamels tend to pivot or shift topic or domain on their third term. ${ }^{63}$ As she analyzes this priamel, the structure is (A) songs to gods (subtypes paean and dithyramb); (B) mourning songs for mortal men (subtypes Linus song, Hymenaeus, Ialemus song); and (C) Orpheus. Although we have lost the context, this progression makes it very likely that the mention of Orpheus here has some other function; he is not simply an example of yet another dead mortal for whom songs mourn. ${ }^{64}$

6o Contrast the parallel opening priamels cited by Cannatà Fera 1990: 138: Ol.11.1-4, Ol.1.1-4; the former specifies different times when rain and winds are useful, the latter names and contrasts water, gold, and the sun.

61 For parallels for this kind of set-up, see Pind. Ol.13.11-23, Nem.10.1-18, Isthm.7.1-15. For a similar conceit, cf. Homeric Hymn to Apollo (III), lines 19-50, 207-216.

62 For the taboo on mixing Apollo/paean with death and mourning, see Aesch. Ag. 10721079, fr. 161 TrGF. For such transgressive, "chthonic paeans" in tragedy, see (e.g.) Aesch. Cho. 149-151; Soph. Trach. 205-224; Eur. Hel. 174-178, IA 1475-1531, with discussion by Rutherford 1994-1995 and Weiss 2014.

63 Cannatà Fera 1990: 139-144; for this characteristic pivot in Pindaric (and Bacchylidean) priamels, see also Carson 1984: 116-119.

64 Cannatà Fera 1990: 143-144; as Cannatà Fera notes, unlike the other three, Orpheus' name does not correspond to the name of a particular song-type. Ford 2002: 16 in a somewhat different way from Cannatà Fera recognizes the mention of Orpheus as a moment of thematic shift or mediation: on Ford's reading, Orpheus, in his attempt to rescue Eurydice 
Cannatà Fera's intuition gains support from the imagery and epithets of these opening lines. Leto, mother of Apollo and Artemis, is "gold-spindled" in line 1; as often in Pindar, the divine is associated with the incorruptible glitter of gold. ${ }^{65}$ At the same time, songs in honor of the gods are aligned with seasonal renewal and repetition: paean songs are $̈$ pı $\alpha$ ( "in due season," line 2), while the dithyramb of Dionysus is associated with the flourishing vegetation of his crown(s) (line 3). ${ }^{66}$ In contrast, with the three dead sons of Calliope, the epithets and imagery focus on their mortal bodies and progressively emphasize

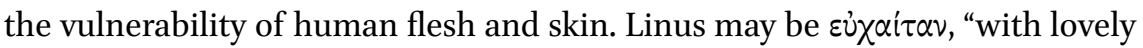
hair" (line 6), underscoring his youthful beauty, ${ }^{67}$ while Hymenaeus dies or dis-

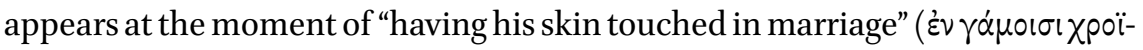

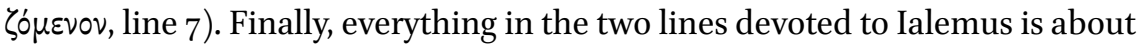
the vulnerability of mortal body and mortal flesh — he is "shackled in strength" ( $\pi \varepsilon \delta \alpha \theta \dot{\varepsilon} v \tau \alpha \sigma \theta \varepsilon^{\prime} \nu \circ \varsigma$, line 10) by a disease that "strikes raw flesh" ( $\left.\omega \mu \circ \beta \dot{\lambda} \lambda \omega\right)$, or per-

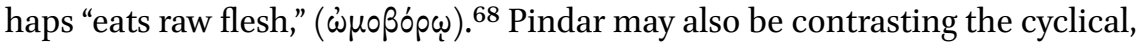

from the underworld, crosses the mortal-immortal divide constructed by the earlier terms of the priamel.

65 For the classic study of gold in Pindar, see Duchemin 1970. Leto is likewise "gold-spindled" at Nem. 6.36; for other goddesses to whom the same epithet is applied, see $\mathrm{Ol} .6 .104$ (Amphitrite); Nem. 5.36 (Nereids); fr. 29.1 SM (Melia).

66 Indeed, we even find a contrast within the different types of divine songs, since paeans are seasonal, sung in the spring ( $\omega_{p}(\alpha)$ ), while the "flourishing ivy" of Dionysus' crowns is evergreen.

67 We say "may" because there are three different plausible readings here: (1) We follow

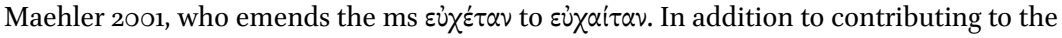

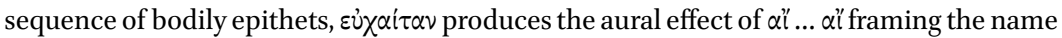
of Linus in the line, thus miming the mourning exclamation over the dead son. (2) Cannatà Fera (1987: 19-20, 1990: 150-152) defends the ms reading عن̉ ₹́์ $\tau \alpha v$. Although this adjective is otherwise attested only in late Greek, Cannatà Fera contends that it is characteristically

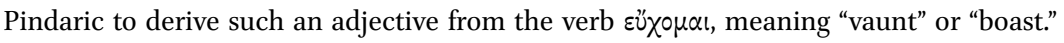
Thus, she argues, the derived adjective means "vaunting" or "boastful," and she connects it with the tradition that Linus was killed by Apollo for "likening himself to him in song" (Paus. 9.29.6; cf. Carm. Pop. fr. 88o PMG and the report of Philochorus preserved in the scholia to Iliad 18.570). With this epithet, as Cannatà Fera 1987: 20 points out, the poet alludes to the cause of Linus' death, just as he does more explicitly with Hymenaeus and

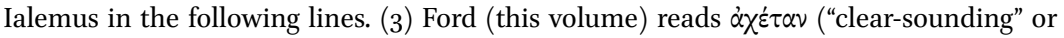
"resounding"), which had been taken to be the ms reading before Cannatà Fera's careful reinspection of the text, and notes that "the epithet underscores [the] sonic power" of Linus' name as a refrain. As Donald Mastronarde points out to us, the ms reading عù $\chi^{\varepsilon-}$ $\tau \alpha \nu$ would represent a very easy corruption phonetically and paleographically from either

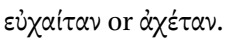

68 These are both emendations for the text's nonce-word $\delta \mu \circ \beta \dot{0} \lambda \omega ; \omega \mu \circ \beta \dot{\omega} \lambda \omega$ is Hermann's

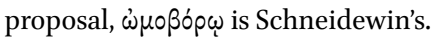


seasonal temporality of songs to the gods with brief, circumscribed mortal time and its sudden foreclosure. Reading voxтi at the beginning of line 8, Hymenaeus disappears suddenly "one night"; Pindar may emphasize the abruptness of his disappearance by the juxtaposition of "first" and "last" in the same line. ${ }^{69}$

But with Orpheus, everything changes. We seem to shift again from mortal, vulnerable bodies to immortal, golden attributes. Orpheus is $\chi p \cup \sigma \alpha \dot{\alpha} 0 p \alpha$, which in this context presumably means "with golden lyre."70 The "gold" sends us back to Leto's epithet in the opening line, while the possession of a golden lyre strongly identifies Orpheus with Apollo himself.71 It seems likely that the mention of Orpheus (the third term of the priamel) leads into or introduces Pindar's own song. The play of epithets suggests that Orpheus stands here for the transcendence of mortality through the immortal power of song, in what would simultaneously be the conjuncture or synthesis of the two different generic types in a new form of lyric.

Thus Plato's Laws represents pure ideology, lamenting a lost Golden Age of pristine, unmixed genre, while Pindar's fragment boldly enacts a dazzling genre mixture to transubstantiate a dead body into immortal song. Within the complex literary and cultural space of genre, ancient theory and ancient practice go their separate ways and pursue their different ends.

Several of the papers in the volume offer readings of such generic selfconsciousness and dynamic generification or genre hybridity in archaic and classical Greek poetry. In addition to Ford's analysis of Homer as playful ethnographer of the Linus song, Timothy Power argues for a complex dialectic of the broad categories of choral and monodic song within the poems of Sappho, while Mario Telò tracks the intermittent engagement of rough, abrasive iambic with the soft, luxurious phonics, thematics, and affect of Sapphic monody in his contribution. Naomi Weiss, as already mentioned, explores tragedy

69 Donald Mastronarde, based on his own inspection of the ms under UV light, confirms the reading vuxti for the beginning of the line. The rest of line 8 is problematic (there is no subject to govern $\lambda \alpha \dot{\beta} \beta v)$, so it is difficult to tell what "first" and "last" refer to here.

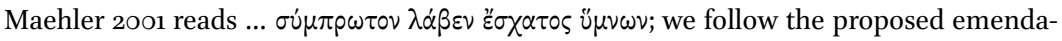
tions of Henry 1999: 14 ("whom his last sleep took together with his first night").

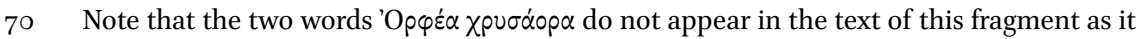
is transcribed by the scholiast to Euripides' Rhesus; the phrase is preserved by a scholion to Iliad ${ }_{15.25} 6$ (4.67.16 Erbse), and was added to the text of fr. 128c SM by Bergk, who is followed in this by all subsequent editors. Snell then suggested on the basis of the meter and the exact responsion of $\chi p v \sigma-$, that these words may form the beginning of the antistrophe.

The other traditional meaning of the epithet $\chi p v \sigma \alpha \dot{\alpha} \rho \alpha \alpha$, "with golden sword," may

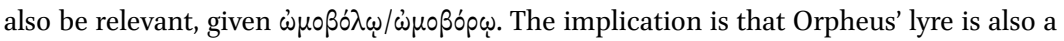
weapon or defense against the ravages of mortality. 
as a "super-genre," while Margaret Foster offers a detailed reading of a particular instance where different genres seem to cohabit within a single composition of Bacchylides without losing a sense of their own generic autonomy. Finally, Deborah Steiner describes what she calls the "genre contamination" of early hexameter and choral song through choruses as catalogues and catalogues as dancing choreuts.

\section{The Ritual and the Fictional}

Our second point is very closely connected with our first. If the texts we have are always already literary and instantiations of secondary genres not entirely subsumable to a single original performance occasion, we need to allow more scope in our interpretations for elements of the fictive or fictional as a complement to ritual elements within archaic and classical Greek poetry. Here scholars in different areas and periods of literary studies provide potentially powerful models to think with. Thus, for example, Roland Greene proposes that "lyric discourse is defined by the dialectical play of ritual and fictional phenomena, or correlative modes of apprehension that are nearly always available in every lyric, though particular specimens, collections, and schools may try to protect one at the expense of the other."72 $\mathrm{He}$ acknowledges that his is a phenomenological approach, concerned with the "modes of apprehension" of lyric by its audience(s). By "ritual element," Greene means "the poem's office as directions for a performance" —all those qualities of sound, prosody, rhetoric, semantics, and symbolism that enable it to take over any speaker, making it compulsory, communal, and eminently repeatable. ${ }^{73}$ In contrast, Greene defines lyric's fictional mode or capacity as:

the poem's other identity for apprehension, not as potentially immediate but as represented speech. ... A lyric's fictional capacities are enlisted in various ways: where the reader is able to construe the poem as a 'speaking, addressing, expressing, [or] alluding' within a hypothetical context that articulates and holds the boundaries between self and things, subject and object, and so on; where the history evoked by the work is not merely

\footnotetext{
72 Greene 1991: 5 .

73 Greene 1991: 5-10; quotation from p. 5. Note that for Greene, "ritual" is actually a metaphorical category, whereas for us dealing with archaic and classical Greek poetry, it is literal. Culler 2015 depends heavily on Greene's "ritual element" for his model of lyric while disavowing Greene's “fictional mode” as its complement.
} 
coextensive with its performance; where the poem's voice is posited not as the reader-auditor but as a character; where temporality has been addressed through some formal strategy equivalent to a plot; and where the fortunes of tone, rhetoric, and meter are susceptible to analysis within that plot. ${ }^{74}$

Greene formulates his model of lyric discourse as an interaction or dialectic of ritual and fictional modes in the context of reading lyric sequences, starting with Petrarch's Canzoniere and tracing out what he defines as a long tradition of "Post-Petrarchism." Because he is reading lyric sequences, Greene is particularly interested in counterposing the fictional, narrative capacity of lyric to its ritual dimension, but nonetheless, he insists that both modes of apprehension are available in the reading of individual lyrics as well. ${ }^{75}$ As we shall see, the concept of lyric sequence may in fact be relevant for iambic and for lyric monody, but even on the level of the individual poem, Greene's notion of ritual and fictional elements "interrogating" each other, or helping to establish each other's primacy, promises to be useful in the reading of archaic Greek poetry.

Another way of getting at certain kinds of complexity that the oralist/performance/occasion paradigm has perhaps discouraged us from exploring (and one entirely consonant with Greene's model) is Eve Sedgwick's concept of the "periperformative." Writing mainly about the nineteenth-/twentieth-century novel, Sedgwick is interested in narrative moments that seem to pullulate around actual performative utterances, where the latter are defined as the public, official, efficacious speech constituted by the first-person singular, present indicative active verb. ${ }^{76}$ Sedgwick's prime example of the performative is the matrimonial, "I now pronounce you man and wife," or "I do," but her model applies to other performatives embedded in poetry and narrative as well. ${ }^{77} \mathrm{In}$ relation to these, she is fascinated by the unofficial, private statements referring to performatives that seem to spring up in spatial proximity to them. These periperformatives are unauthorized, often negated and katachrestic; they can be expressions of affect and subjectivity in relation to the performative. They also borrow from or mobilize many different speech genres simultaneously,

\footnotetext{
74 Greene 1991: 10; the quotation within his quotation is from Smith 1978: 28.

75 Greene 1991 passim; see esp. 11-17.

76 Sedgwick 2003, following and elaborating the definition of the "performative utterance" by the philosopher Austin (1975). For further discussion of periperformatives applied to the poetry of Cavafy, see Sedgwick 2011: 53-67.

77 Matrimonial performatives are more relevant for the nineteenth-century novel, whereas for Cavafy's lyric, Sedgwick is much more attuned to the ritual performative of prayer and its periperformative deformations.
} 
whereas (as she notes) the performative utterance derives its efficacy from being just one thing (a valid marriage ceremony cannot also be an oath-taking or a christening). ${ }^{78}$ And as the performative clearly aligns with ritual, so Sedgwick's periperformative roughly overlaps with Greene's "fictional mode."

In fact, something like Greene's axis or model has already emerged within the field of archaic Greek poetry from the current intense interest in reperformance. Already in his 1994-1995 article "Genre and Occasion," Gregory Nagy had proposed that individual Pindaric epinicia were characterized by an overloading of cues for different occasions and performance contexts, such that each epinician incorporated its own past performance history and anticipated its posterity in reperformance via deictics and other signals. Subsequent scholarly focus on deictics and reperformance in Greek poetry has fully borne out Nagy's contention, leading to a recognition that some of the deictics and performance cues within any particular setting have to be fictive. ${ }^{79}$ This has led in turn to an acknowledgment among Pindarists that within any given poem, Deixis ad oculos and Deixis am Phantasma are formally indistinguishable, and are meant to be, in order to facilitate multiple performances in multiple venues. ${ }^{80}$ In addition, other studies have recognized that it is not just place or occasion that can shimmer in and out of fictionality within the Pindaric ode, but also its temporality, shifting between the moment of composition and that of performance, and the speaking ego, which can oscillate between a member of the communal komos and the professional poet who stands apart from it. ${ }^{81}$

Nagy's own approach to such overloading or oscillation has been to subsume the fictional within the ritual, insisting that all such shifting references are to different ritual occasions, so that the poem itself "absolutize(s) occasion." 82 Thus for Nagy (as for Calame), it is ritual all the way down. ${ }^{83}$ Such an

78 Sedgwick 2003: 67-80.

79 On deixis, see especially Felson 1999; essays collected in Felson, ed. 2004; Edmunds 2008; Athanassaki 2011.

80 See esp. Bonifazi 2004, Ferrari 2012; cf. Morrison 2007, 2012 on reperformance. For a different articulation of the complex fictive settings of Pindaric epinicia, see Agócs 2012, and for a different approach to reperformance, see the essays of Hunter and Uhlig 2017, which develop theories from modern performance studies to emphasize that there is always a gap or mediation in "performance"; that all performance is reperformance.

81 For temporality, see especially D'Alessio 2004, followed by Morrison 2007. For somewhat different approaches to epinician temporality, cf. Budelmann 2017, Spelman 2018. For the shifting positionality of the Pindaric ego, see Morgan 1993; Kurke 2005; Currie 2013; Maslov 2015: 97-116.

82 Nagy 1994-1995: 19; see also his Keynote in this volume.

83 This is also perhaps the motivation behind the insistence of scholars of the anthropologi$\mathrm{cal} /$ oral/ritual school that Sappho too must be choral: thus Calame 1977, 2009c; Lardinois 
approach tends to gloss over complexities we might better grasp with something like Greene's model: "even to privilege one [ritual or fictional element] is usually a matter not of ignoring the other, but of subsuming it so that it helps rather than hinders the establishment of the other's primacy." ${ }^{84}$ Thus we might rather say that Pindaric poetics mobilizes the fictional to buttress and assert the ritual authority of epinician as a latecomer genre of choral poetry.

Following Greene's model of lyric discourse as a dialectic of ritual and fictional elements would also allow us to keep both meanings of mimesis in play for archaic Greek poetry-that is, both the ritual meaning ("reenactment") and its sense as fictional "imitation," which for Nagy represents an abrupt diachronic shift. Following Greene's model, we might say that it is precisely the shimmering oscillation of ritual "reenactment" and fictional "imitation" that characterizes this poetry and leads inevitably to full-scale drama that is also still ritual. ${ }^{85}$ Alternatively, in Sedgwick's terms, we might think about choral lyric as the domain of the performative par excellence-as scripts for ritual or for ritualization. ${ }^{86}$ In these terms, we might see Pindar's generically overstuffed epinicia as urgently soliciting the special authority of choral poetry by posing as multiple performatives simultaneously.

In contrast to choral lyric, Greek monodic or sympotic forms seem to have encouraged or accommodated more extreme forms of fictionalization, and this may have much to do with the temporary license and ludic space provided by the ancient symposium as a context secluded from the public sphere. ${ }^{87}$ Within iambic, such fictionalization has often been recognized, though usually under

1996; Nagy 2007, 2016, etc. For critiques of ritualist/choralist readings of Sappho, see Yatromanolakis 2004, D'Alessio 2018, and the essay by Power in this volume.

84 Greene 1991: 12. Note that Greene is talking here about the practices and priorities of both poets and critics. So we might say that this style of deploying the fictional to help promote the primacy of the ritual mode characterizes both Greek choral poetry and the Nagy/Calame reading thereof.

85 This is also perhaps a useful conceptual framework to apply to Henrichs' concept of "choral projection," which strikingly occurs in both non-dramatic and dramatic choral poetry (Henrichs 1994-1995, 1996a, 1996b). On the continuity of this phenomenon between archaic lyric and classical drama see Power 2000; Weiss 2018; also Kowalzig 2007b: 13-55 on the fusion of past and present, myth and ritual, through the "hinge" of choral performance.

86 For "ritualization," see Bell 1992; for application of the concept to Greek choral poetry, see Kurke 2005, 2007; Kowalzig 2007b: 40-43. This is perhaps what ultimately motivates Nagy's identification of performance and the Austinian performative (as noted above, p. 5) - and why his model in fact works best for choral poetry.

87 For this, see esp. the essays collected in Murray, ed. 199o; Kurke 1996; Morris 1996, 200o: 178-184; Neer 2002: 9-26; Collins 2004. 
the rubric of poetic "persona." 88 Thus one compelling reading of the fragments of Archilochus and Hipponax sees the iambist as a generically low figure, a scapegoat with the power to scapegoat others, often cast in the role of a burlesque or picaresque Odysseus traversing a nightmare world of filth, violence, and sex. ${ }^{89}$ And here, the concept of lyric sequence may be important, as scholars have noted implied narratives that arc across many individual fragments. ${ }^{90}$

In a very different register, monodic lyric too seems to open up a space for fiction or fictionalization. For this, we need look no further than Sappho fr. $1 \mathrm{~V}$. We are accustomed to refer to this poem as the "Hymn to Aphrodite," but in fact, the quicksilver movement of this song effortlessly eludes any straightforward ritual reading. Although it begins as a word-perfect cletic hymn, it rapidly morphs into narrative of a past epiphany of Aphrodite (which cannot be assumed to be a normal part of a real ritual hymn). ${ }^{91}$ As scholars have long recognized, the speaker "Sappho" here thus assumes the role of an epic hero-an amatory Diomedes or Odysseus, enjoying a close, intimate relation to a patron goddess. ${ }^{92}$ And, as in the case of iambic, it is suggestive that Sapphic monody seems interested in exploring the fictive and narrative capacities of the lyric sequence - whether this be through multiple poems of love and separation, or (as the newest papyrus finds make abundantly clear) through multiple snapshots of an ongoing family drama. ${ }^{93}$ Nor is this kind of fictionalized lyric sequence restricted to Sapphic monody. Such a model would well accommodate the narrative thrust of Alcaeus' $\sigma \tau \alpha \sigma i \omega \tau i x \dot{\alpha}$, which, as far as we can tell, were organized already in the Hellenistic edition in a chronological and thematic sequence (first exile; betrayal of Pittacus; second exile, etc.). ${ }^{94}$

Sedgwick's periperformative provides a complementary way of thinking about iambic and monody in relation to public ritual performative utterances (including choral lyric). Thus we might take iambic $\beta \omega \mu$ $\omega \lambda$ oxi $\alpha$ (literally, "skulking around the altar") as emblematic of this-on the disreputable fringes of

88 See already Dover 1964; West 1974: 26-33; Nagy 1976, 1979: 243-252.

89 Miralles and Portulas 1983, 1988. See also Seidenstücker 1978; Rosen 1988; Miller 1994: 9-36.

$90 \quad$ Miralles and Portulas 1983, 1988.

91 On lyric, narrative, and anti-narrative in this poem, see Purves 2014.

92 This fictive or narrative element is implicit in the readings of Rissman 1983; Winkler 199o; Hutchinson 2001: 149-160.

93 On Sappho's Brothers Song as part of an extended song cycle on (fictional) brothers and family relations, see Lardinois 2016; Peponi 2016.

94 On the organizational principles of the Hellenistic edition of Alcaeus, see Acosta-Hughes 2010: 134-140; cf. Hutchinson 2001: 192-194, discussing a particular sequence of "exile poems" in a sanctuary. 
ritual, but not the ritual itself. ${ }^{95}$ Likewise for Sappho and Alcaeus: Timothy Power, in his essay in the volume, argues forcefully for what he calls Sappho's "parachorality"-her frequent conjuring within monodic song of choral forms and choral value. This, as he notes, seems to be a particular feature of Sapphic song, which frequently mentions choruses and choral song, although it is never clear that the chorus mentioned is actually performing the composition. In addition to offering a clear instance of the fictional element in Sappho, Power's concept of parachorality neatly aligns with Sedgwick's periperformative. ${ }^{96}$

Given this alignment and Power's reading of Sappho fr. $17 \mathrm{~V}$ as extended parachorality unmarked by any frame, we are tempted to suggest that $\pi \lambda \dot{\alpha} \sigma 10 \mathrm{~V}$, the mysterious first word of this poem, is the "nearby" of the periperformative. That is, not in the temenos of Hera, where choruses sing, but nearby. ${ }^{97}$ At the same time, Sedgwick's subtle analysis gives us a different vocabulary to characterize those non-speech acts that crowd around the performative and refer to it. For Sedgwick, these moments are often peculiarly imbued with affect, and they may ironize or negate the pure force of the performative, as much as simply invoke its power. Such a model might usefully be applied to a reading of Alcaeus fr. $130 \mathrm{~B}$ V, with which Power ends his discussion (as a striking instance of Alcaean parachorality). Here the speaking ego portrays himself as a miserable exile out in the wilds, longing to hear one performative utterance that is distinctly male and civic (the summoning of the assembly and the boule) while almost inadvertently stumbling into a very different performative, the ritual "uncanny echo of the sacred, yearly ululation of the women" (fr. 13oB, lines 1920). It is difficult to gauge the tone and mood of our speaker, fictively isolated and suspended in a no-man's land between two gendered ritual cries. Power opts for a more optimistic community-building reading of Alcaeus's closural parachoral gesture, but we might follow the interpretations of Anne Pippin Burnett and Anne Carson, to parse the ego's alienated periperformative in the middle of the song as more self-ironizing and bitterly negative. ${ }^{98}$

95 Note Hipponax's periperformative play with prayers in frr. $34,35,36$, and $38 \mathrm{~W}$.

96 Cf. Yatromanolakis 2004 for analogous arguments about Sappho's poetry framed in terms of a distinction between performative and descriptive contexts. See also the important discussion of D'Alessio 2018; D'Alessio notes that Sapphic lyric seems to favor a position of "marginality" in relation to communal, ritual performances (discussing esp. Sappho frr. 17, 22, 27, and the Brothers Song).

97 Cf. D’Alessio 2018: 45 for a similar reading of the mysterious opening word of Sappho fr. 17.

98 Thus Burnett 1983: 176-181; Carson 1995: 119-126; such a reading of Alcaeus might productively engage with Sedgwick's (2011) reading of periperformatives in Cavafy. 
In addition to Power's essay, several other contributions to the volume also engage the issue of the interplay of ritual and fictive elements within archaic and classical Greek poetry. Olsen approaches this issue through the performance and reperformance of Pindaric paean, while Weiss considers how enactments and evocations of different ritual performances track and drive the dramatic narrative of a tragedy.

\section{Materiality, Affect, and the Body}

Finally, several of our contributors bring to bear on the issue of genre in archaic and classical Greek poetry new theoretical approaches concerned with materiality, affect, and the body and bodiliness. All these critical movements (closely connected with each other) comprise the "material turn," itself a reaction to the abstraction and logocentrism of the "linguistic turn" represented by structuralism, semiotics, deconstruction and other versions of poststructuralism. At the same time, these versions of the material turn aim to further poststructuralism's critique and decentering of the unquestioned hegemony of the individual autonomous subject. Thus the "New Materialisms" reject the hierarchy of subject and object, positing a more equal, horizontal relation between them; the agency of objects; and even the objecthood of human bodies as "walking minerals." ${ }^{99}$ In like manner, affect theory aims both to materialize and to depersonalize "emotion," substituting for the model of internal, private feelings "affects" that circulate freely and contagiously among bodies, and between subjects and objects. ${ }^{100}$ While materiality, affect, and bodies are all hot topics throughout the humanities at large, attention to them also represents an organic and logical development of the oralist/ performance/ occasion paradigm. So, for example, Claude Calame's emphasis throughout his work on the initiatory function of ritual song and dance already points us to the importance of the body, embodied practices, and embodied knowledge. In a sense, his model of the functioning of "choruses of young women" is analogous to Bourdieu's habitus, the slow, sedimented bodily inculcation of all that "goes without saying because it comes without saying," or to Catherine Bell's notion that the goal of repeated ritual acts is the formation of "ritualized bodies." 101

99 See (e.g.) Gell 1998; Latour 2005; Bennett 2010.

100 See (e.g.) Deleuze and Guattari 1987; Sedgwick 2003; Ahmed 2004; Altieri 2007; Seigworth and Gregg 2010.

101 For the connections among habitus, bodily practices, and the experience of doxa, see 
In these terms, the focus on materiality, affect, and the bodily gives us new ways of grounding and specifying what exactly performance does and how it does it. To consider affect first: Mario Telò provides this concise definition in his essay in the volume:

Affect theory views emotion as a boundless exchange of feeling, circulating beyond bodily boundaries, blurring the distinction between subject and object, the source or producer and the target or receiver. Feeling, in this perspective, becomes a dispossessed, impersonal, contagious force.

This model of affect helps us think in new ways about the sensory crossover or intimate bodily identification of performers and audiences that several scholars have argued for as a distinctive feature of Greek poetry in performance. ${ }^{102}$ At the same time, because theorists of affect are interested in tracking at the micro-level the psychic and bodily effects of form, they offer us finer instruments to analyze the interaction of elements of performance and literary/formal features within Greek poetry. ${ }^{103}$ Telò puts all these aspects of affect theory to work in his contribution to the volume, capturing a distinctive iambic affect of horror - the rough, sado-masochistic thrills of pleasurable pain generated in performer and audience alike by the materiality of iambic language (specifically, the rough rho and broken rhythms of Archilochus, Hipponax, and their later imitators).

Similarly, Seth Estrin in his essay in the volume focuses on the materiality and bodily effects produced by the distinctive structure of funerary elegy, read in intimate connection with its material support in the context of a particular monument (the Ambracian polyandrion). For Estrin, both the formal structure of the elegiac couplet and the materiality of the stone cenotaph enact a disjunctive logic of presence and absence that elicits in the reader/viewer of the inscribed monument the same experience of loss and mourning felt by the philoi and fellow citizens of the dead. The speaking, mourning monument thus takes over its reader, controlling his movements, and thereby interpellates him as mourner and citizen. Olsen's paper also focuses on embodied practices and embodied experience, to reconstruct how the specifics of "embodied cultural knowledge" contribute to the distinctive "feel" of paean even in individual, sympotic reperformance. Her paper also moves beyond something like Bourdieu's

Bourdieu 1977: 78-95, 164-171, 1990: 52-79 (quotation taken from Bourdieu 1977: 167). For the formation of "ritualized bodies" as the goal of ritualization, see Bell 1992: 94-117.

102 See Peponi 2009, 2012; Kurke 2012, 2013a; Olsen 2017.

103 See (e.g.) Ablow, ed. 2010; Brinkema 2014. 
model of habitus or Bell's of the formation of ritualized bodies, since Olsen borrows from dance theory the theoretical tools to track not just the proper social formation of bodies but also their potential resistance.

All three essays offer us new definitions of genre attentive to bodies and affect - what we might call the somatics and atmospherics of genre. Thus Telò boldly proposes that we think of genre as "the material environment created by the unlimited circulation of lyric affect, inside and outside the poetic frame." For Estrin, the funerary elegy and the mourning monument configure a particular "structure of feeling," a generic form that also structures the viewer's experience. And Olsen adapts the concept of "embodied cultural knowledge" from dance theory to propose that we think of a genre like paean as a distinctive structure of somatic memory.

In light of the theoretical work done by these papers, we can see the importance of the themes of materiality, affect, and the bodily also in other contributions to the volume. Sarah Olsen's notion of genre as an archive or repertory of "embodied cultural knowledge" that conjures up particular memories and affects in (re)performance is suggestive for Deborah Steiner's essay. For the latter, too, is very much about the bodiliness - the somatics - of catalogues, which may perhaps have evoked strong associations of choral performance in their ancient audiences. Likewise, Olsen's model of genre is very relevant for Mark Griffith's contribution on Korybantic (and other ecstatic) performances as a lyric genre. For, as Griffith compellingly demonstrates, these ubiquitous "subliterary" performances do indeed constitute a genre-a genre most of all defined by a particular configuration of the bodily and affective states they elicit in their participants. In addition, Griffith's close reading of Aristotle's Politics Book 8 reinforces an important point made by Schironi's paper: modern scholars tend to think that ancient theorists of literature almost entirely ignore the domain of performance, so that their essentializing, moralizing taxonomies of genre have little to contribute to modern analysis, but we have perhaps been looking in the wrong places. Just as Schironi briefly considers ancient treatises on dance that are much more engaged with the performative and bodily aspects of Greek song than, for example, the scholia to Pindar, Griffith showcases Aristotle as an astute theorist of the bodily and affective powers of music in performance. That is to say, if we look beyond the Poetics, Aristotle seems to anticipate in striking ways many of our current critical and theoretical concerns. Finally, that the bodily and affective may also, to some extent, lurk behind the familiar categories of the Poetics is suggested in turn by Naomi Weiss' essay in the volume. For, as she notes, the play within tragedy of different embedded lyric genres that anticipate or stage the turns of the plot were likely to have cued the embodied memory of many audience members, thus 
grounding (for example) Aristotle's characteristic tragic emotions of pity and fear in the audience's kinesthetic bodily reactions.

The multiple points of intersection among these different approaches demonstrate the breadth and inclusivity of the volume as a whole, which aims neither to promote nor foreclose any one definition of genre. We hope that the papers here, read individually and especially together, will open up new ways of thinking about genre in archaic and classical Greek poetry. 
PART 1

Keynote Address 
978-90-04-41259- $\odot$

Downloaded from Brill.come4/26/2023 $09: 51: 26 \mathrm{AM}$ via free access 


\title{
Genre, Occasion, and Choral Mimesis Revisited, with Special Reference to the "Newest Sappho"*
}

\author{
Gregory Nagy
}

\section{Introduction}

This essay is the third part of a tripartite project. The first part, "Genre and Occasion," was published in Mètis (1994-1995), and the second part, "Transmission of Archaic Greek Sympotic Songs: From Lesbos to Alexandria," was published ten years later in Critical Inquiry (2004). Eleven years still later, I delivered the present essay, "Genre, Occasion, and Choral Mimesis Revisited," as a keynote lecture at the University of California, Berkeley, on the occasion of the conference on which this volume is based.

The subtitle of my essay refers to the "newest Sappho," by which I mean the new fragments of Sappho as published in a 2016 book edited by Anton Bierl and André Lardinois, The Newest Sappho (P. Obbink and P. GC Inv. 105, frs. 15 ). This book contains not only the new fragments of Sappho as edited by Dirk Obbink but also a set of chapters that comment extensively on those fragments. I focus here on two of those chapters in that book: (1) chapter 11 by Leslie Kurke, "Gendered Spheres and Mythic Models in Sappho's Brothers Poem," and (2) chapter 21 by myself, "A Poetics of Sisterly Affect in the Brothers Song and in Other Songs of Sappho."

My essay here, just like my keynote lecture as indicated above, is dedicated to two people named Leslie/Lesley. I start with the first of the two, my friend Leslie Kurke. I focus on her interpretation of a song that is part of the new set of Sappho fragments that I already mentioned. In this Sappho fragment, containing a large part of a text now known as the Brothers Song, we read near the beginning that a female speaker, evidently the character of Sappho, is in the process of speaking to someone. In chapter 11 of the book that I also already mentioned, The Newest Sappho, Kurke argues that this someone to whom Sappho is speaking is Sappho's mother. This reading meshes with that of Dirk Obbink in

* This essay was preliminarily published online in Classical Inquiries (October 1, 2015), http:// classical-inquiries.chs.harvard.edu/genre-occasion-and-choral-mimesis-revisited-with-

special-reference-to-the-newest-sappho/. 
chapter 2 of the same book. ${ }^{1}$ I am quite persuaded by Kurke's argument, though my own argument here will be slightly different from hers.

Let me draw attention to a detail. I started speaking above about the character of Sappho. One reason for my referring to Sappho this way is that, as I argue in chapter 21 of the book The Newest Sappho, the name of Sappho actually means "sister." Linguists call this kind of name a nomen loquens or "speaking name," which is a form of identification where a given person is named after a primary characteristic of that person. In various regions of the United States, for example, women are given the name Sissy or even Sister. But there is also a deeper reason for my speaking about the character of Sappho, not simply about Sappho. It is because the speaking persona of Sappho is a mimetic speaker.

The word mimetic comes from the ancient Greek concept of mimesis, which I define as meaning primarily "reenactment" and secondarily "imitation." We may also translate this word as "representation," in the sense that any imitation of an original something or someone can be seen as a representation of that something or someone. I argue, then, that the speaking done by Sappho in her songs is achieved by way of a process that I call mimesis in the title of this chapter. In terms of my argument - and I cannot emphasize this enough — the name of Sappho meant "sister" not necessarily because (1) she was a historical person who was simply named that way or because (2) she was a fictitious sister-a character of "fiction" who was created by her own songs. Rather, Sappho meant "sister" primarily because her identity was reenacted and kept on being reenacted by way of the singing and the dancing performed on festive occasions by the girls and the women of the island of Lesbos.

I just said girls and women, not just girls, and we will see later on why I said it this way. These girls and these women, as we will also see, are bonded together on festive occasions by way of a system of social grouping that is known in ancient Greek as the choros. This word is usually translated as "chorus," but such a translation can be misleading, since the modern word "chorus" is ordinarily understood to mean simply a group that sings. By contrast, the Greek term refers to a group that dances as well as sings. That is why, when I say choral mimesis in the title of this chapter, I mean a reenactment by way of a group that sings and dances. In the case of Sappho, as I have been arguing since 199o, her songs reveal her to be a choral personality, that is, someone who performs in a dancing as well as singing group known as a choros "chorus." ${ }^{3}$

1 See also Obbink 2014: 41.

2 See also $\S \S 156-162$ of the online version, available at https://chs.harvard.edu/CHS/article/ display/5983.

3 Nagy 2016: 456. I first used this expression choral personality in Nagy 1990: 370, with reference 
In another work on choral mimesis, centering on the Delian Maidens in the Homeric Hymn to Apollo, I emphasized the mimetic power of the chorus in performance. ${ }^{4}$ And, as I also emphasized in that work, there is an astounding variety to be found in this power of the chorus to reenact, to imitate, to represent different kinds of persons or places or things. ${ }^{5}$ In my present work, however, I limit my scope of interest to the choral character of Sappho herself in the songs that are attributed to her. Even in this limited sphere, as we will see, there is a remarkable variety of roles that are played out in the words spoken by Sappho as a prima donna who leads the choral singing and dancing.

\section{Genre and Occasion}

Now that I have contextualized the term choralmimesis in the title of this essay, I need to elaborate on my relevant use of the terms genre and occasion. In an essay I mentioned at the beginning, "Genre and Occasion" (1994-1995), I outlined the essentials of what I will now summarize here.

Of the two terms genre and occasion, the first is more problematic than the second. It would be more useful, I argued, to confront a more fundamental challenge, which is, to arrive at a definition of poetry itself in an archaic social context where the technology of writing was involved in neither the composition nor the performance of any given poem or song. Within such a context, definitions of genre have to be correlated with questions of occasion. ${ }^{6}$ And the occasion is captured, longterm, in a process that I have already described as mimesis. ${ }^{7}$

What I just said applies to both poetry and song. I should add that, as in my earlier work, I treat poetry here as a subcategory of song and of songmaking in general. That is why, for example, I prefer to say "the Brothers Song" instead of

to Calame 1977: 367-377 (also 126-127). See also Lardinois 1996 and the remarks of Calame 2009c: 5; also Ferrari 2014: 17.

4 Nagy 2013 b.

5 In Nagy 2013b: 245-246, I give examples from the songmaking of Pindar.

6 In Nagy 1994-1995: 12, I draw attention to the perceptive use of the term occasion in Calame 1974: 116, 120, 121. In the same article, he provides a particularly useful critique of various concepts of genre in both the pre-Alexandrian and the Alexandrian eras. Important also is his assessment of Rossi 1971. To my mind, any argumentation that cites Rossi 1971 without citing Calame 1974 is incomplete.

7 Nagy 1996: 59-103. 
"the Brothers Poem" in referring to what I am about to quote and to translate. And I should also add that, as I argued already in a book published in 199o, Pindar's Homer, the term "lyric" is too broad a category to qualify as a "genre" in ancient Greek verbal art; as for "epic," this term is too imprecise and can likewise be disqualified as a "genre" - at least, with reference to the earliest attested phases of Greek songmaking. ${ }^{8}$

\section{Correlating Genre and Occasion with Composition and Performance}

In order to achieve a more accurate taxonomy of Greek songmaking in its earliest phases, two factors must be consistently kept in mind: composition and performance. Only in this way, I think, can we arrive at a basis for considering the utility of a concept such as genre - and of the related concept, occasion. ${ }^{9}$

For the moment, I define occasion as the context of performing something that is composed or precomposed. And I define genre as a set of rules that generate such a performance. ${ }^{10}$

A genre, as a set of rules that generate a given performance of a given composition, can equate itself with the occasion of performance." To this extent, the occasion is the genre. ${ }^{12}$ For example, a song of lament - that is, a song that follows the generic rules for composing and performing a lament-can equate itself with the occasion of ritually grieving for the dead. ${ }^{13}$ Moreover, if the occasion is destabilized or even lost, the genre can compensate for it, even recreate it. $^{14}$

I referred above to the act of lamentation for the dead as a ritual. I justify my use of this term here because, as is most evident in the earliest attestations of

8 Nagy 1990: 17-115.

9 Nagy 1994-1995: 12.

10 This formulation is a compressed version of what I said in Nagy 1994-1995: 13, where I also introduced the notion of performance as a speech act, as analyzed in Nagy 1990: 31. In my compressed presentation here, I force myself to make do without using the term speech act.

11 Nagy 1994-1995: 13. There but not here, I consider the factor of performance in the context of a speech act.

12 Nagy 1994-1995: 13, following Nagy 1990: 362.

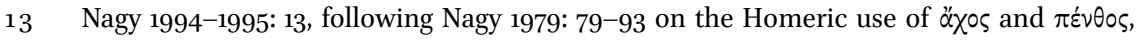
both meaning "grief," as programmatic indicators of ritual songs of lament.

14 Nagy 199o: 9, 362 n. 127. 
ancient Greek songmaking, the occasions for the performances of songs such as laments are in fact occasions of ritual. And here I understand ritual in the broadest possible sense of the term. I now offer a working definition: ritual in any given traditional society is doing things and saying things in a way that fits the cosmic order as viewed by that society. Correspondingly, I must add, myth in any given traditional society is saying things that ultimately connect with the ritual world of that society. In terms of these general working definitions of ritual and myth, ritual frames myth in traditional societies: myth is performed, and the performance is ritual. To put it another way, performance frames the composition of myth, and we cannot fully grasp the essence of such composition without knowing about its performative frame..$^{15}$

These broad definitions are meant to address the worries of experts in literature who are unfamiliar with anthropological approaches to customary events in traditional societies. Such unfamiliarity leads to a narrow understanding of ritual. It is as if ritual were confined to events that involve making direct contact with something that is overtly sacred, as in the case of sacrificing to superhuman powers. But ritual can in fact include a wide variety of events that are framed by such acts as sacrifice. The trouble is, many of these events would no longer seem to have anything to do with ritual in the narrow sense of the word as understood by the modern mind.

One such event would be the singing of a song about unrequited love in the traditional world of songmaking. To the modern mind, the act of singing such a song may seem nothing more than a form of artistic self-expression. In a traditional society, on the other hand, the singing may be framed in the context of, say, a celebration that is inaugurated by a sacrifice. Such celebrations, as we will see in the case of songs attributed to Sappho, include events like the singing of songs about unrequited love.

But what happens if the frame is lost? That is, what happens if the occasion for performing a given genre of song - like a love song — becomes obsolete? Such obsolescence seems in fact inevitable when we consider the eventual breakdown of older conventions in the history of ancient Greek song culture. So, if we face up to the historical realities, the question is most justifiable: to repeat, what happens if the occasion for performing a given genre of song becomes obsolete? My answer, as I work it out in this essay, is that there are two possible outcomes:

1. If the occasion becomes obsolete, then the corresponding genre may become obsolete as well.

15 Nagy 1994-1995: 14, following Nagy 1990: 8-9, 31-33. 
2. Even if the occasion becomes obsolete, the corresponding genre may remain current by way of compensating for the obsolescence of the occasion. And the compensation may take place by way of some alternative occasion of performance. ${ }^{16}$

In this essay, I concentrate on a historical example where both outcomes are attested, and this example involves the songmaking of Sappho.

\section{Genre and Occasion in the Songmaking of Sappho}

On the island of Lesbos around 6оовсе, which is the historical situation that leads ultimately to the texts recording the songs attributed to Sappho, the primary genre that mediated the relevant songmaking can be described as choral lyric song, and the kind of occasion that called for such song can best be described as festive performances by groups of girls and, as we will soon see, of women as well. At this point, I must emphasize again that the original Greek

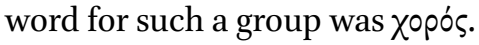

But there is more to it. In the case of Sappho, we can detect alternative kinds of occasion for performing her songs. Here I summarize briefly my relevant findings as presented in two lengthy pieces of research, published in 2007 and 2016. The 2007 piece is entitled "Did Sappho and Alcaeus ever meet?"17 As for the 2016 piece, which is chapter 21 in the Newest Sappho book, I have already referred to it at the beginning and will now refer to its title only in an abbreviated form: "A Poetics of Sisterly Affect."18

Besides the primary kind of occasion for the performing of Sappho's songs, which was the singing and dancing of female choroi "choruses," there were also secondary kinds of occasion. Already in the same era, around 6оовсЕ on Lesbos, the songs of Sappho could also be sung and danced by male performers in a kind of informal singing and dancing group known as the komos, which can be translated roughly as "a gathering of revelers." Further, these songs could even be sung monodically — that is, solo-by male performers at occasions that could be either public or private. In the case of public occasions, the monodic performers would be professional singers who competed with each other at festivals. ${ }^{19}$ Timothy Power has done important research on this kind of

\footnotetext{
16 Nagy 1994-1995: 13-14, following Nagy 199o: 9, 362.

$17 \quad$ Nagy 2007.

18 Nagy 2016.

19 I make the argument in both Nagy 2007 and Nagy 2016.
} 
public occasion. ${ }^{20}$ As for private occasions, the word for this kind of venue was sumposion or "symposium": here I single out the arguments of Ewen Bowie in chapter 6 of the 2016 Newest Sappho book, "How did Sappho's Songs get into the Male Sympotic Repertoire?"21 So we see here a variety of different occasions for performing the songs of Sappho, and all these occasions could have coexisted with each other at the same time and in the same place, that is, around 6оо BCE on the island of Lesbos. ${ }^{22}$

Of all the possible occasions for singing the songs of Sappho, however, I think only two survived beyond the original setting as dated at around 6оо вСЕ. These two kinds of occasion were the public concert and the private symposium, since the songs of Sappho kept on being performed for centuries beyond 6оо вСЕ in places like Samos and Athens by professional solo singers at public festivals and by amateur solo singers at private symposia. ${ }^{23}$ And the textual recording of Sappho's songs seems to derive from this ongoing phase of performing the songs. But the actual wording of the songs themselves, as I argue, goes back all the way to the choral lyric phase of the tradition, dating back roughly to 6оовСЕ.

\section{Diachronic Sappho}

I used the term "original setting" above in referring to the performances of female choruses on the island of Lesbos at around 6оо BCE. But this term is for me inadequate, since my own reconstruction of such performances depends on a diachronic perspective, which I combine with a synchronic perspective in analyzing the texts reflecting the songmaking attributed to Sappho. The terms synchronic and diachronic, as I use them here, come from linguistics. ${ }^{24}$ When linguists use the word synchronic, they are thinking of a given system or structure as it exists in a given time and space; when they use diachronic, they are thinking of that system as it evolves through time. I must add that a historical perspective is not the same thing as a diachronic perspective:

\footnotetext{
20 On singing to the accompaniment of the kithara in monodically performing the songs of Sappho, see Power 2010: 258-263, followed by Nagy 2011c: $155^{-1} 5^{8}$.

21 In chapter 17 of the same book, Renate Schlesier argues that the performers of Sappho's songs at symposia could be courtesans (Schlesier 2016).

22 Again, Nagy 2007, 2015.

23 Nagy 2007.

24 See Nagy 2011b §11, with reference to Saussure 1972: 117.
} 
Both synchronic and diachronic perspectives are a matter of model building. We can build synchronic models to describe and explain the workings of a structure as we see it attested in a given historical context. We can likewise build diachronic models to describe and explain how that given structure may have evolved from one of its phases into other phases. What we have built, however, is a set of models to be tested on historical realities. The models are not the same thing as the realities themselves. And the realities of history as a process are not dependent on such models. History may either confirm or upset any or all aspects of our models, since the contingencies of history do not need to follow the rules of existing structures. ${ }^{25}$

From a diachronic perspective, the system that we know as Sappho's poetics can be viewed, I argue, as an evolving medium. So, when I say "diachronic Sappho" in the title of this section, I am referring to a model of a poetic system as I reconstruct it through time. By contrast, when we speak of a "historical Sappho," we are imagining the existence of a person who lived in a historically identifiable era. I say "imagining" because for me the existence of such a historical person is not at all proven to be a fact if we rely simply on the words that are attributed to Sappho in the texts ascribed to her. What she says about herself and about anyone and anything else in her songs is a function of her songmaking: it is not some kind of reportage about her historical circumstances. In terms of my argument, the words of Sappho can be used as evidence for understanding the history of the songmaking attributed to her, but I insist that whatever the persona of Sappho says about herself cannot be used as factual evidence about the life and times of Sappho.

\section{A Diachronic View of Sappho's Occasions}

From a diachronic point of view, the earliest transmission of Sappho's songmaking depended on an ongoing tradition of performing her songs in a setting that corresponded to a primary occasion, which was the choral lyric singing and dancing of girls and even of women at festive events. In the two lengthy pieces of mine that I mentioned above, "Did Sappho and Alcaeus ever meet" and "A Poetics of Sisterly Affect," I explored in some detail the historical evidence for identifying a location for such a primary occasion, which was a sacred precinct

$25 \quad$ Nagy $2011 b$ § 16. 
located in the middle of the island of Lesbos. The ancient Greek name for this precinct was Messon, meaning "middle place," and this name survives in Modern Greek as Mesa, referring to the very same place that had once been a venue, as I see it, for the songs of Sappho-and even of Alcaeus.

Festive choral lyric performance, as the primary genre for Sappho's songs, was also the primary occasion for these songs. Further, this occasion is captured, longterm, in the process of mimesis.

\section{An Occasion for a Song of Sappho}

Here I return to the work of Leslie Kurke on the Brothers Song of Sappho in chapter 11 of the 2016 Newest Sappho book. As I noted from the start, Kurke thinks that the woman who is being addressed by the speaking persona of Sappho in this song is the mother of Sappho. She points to the fact that Martin West, in his reconstruction of Song 9 of Sappho by way of a new papyrus fragment, thinks that this other song, which features the speaker addressing someone as "mother," immediately preceded the Brothers Song in the textual tradition of Sappho's collected songs. ${ }^{26}$ I quote here only the relevant wording of the new Sappho fragment: ${ }^{27}$

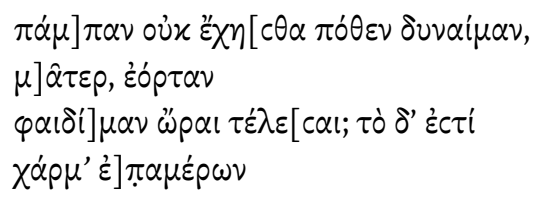

... Don't you have the resources for me to be able, Mother, to celebrate [telein] at the right season [ōrā] the festival [eortā], which is a delight [charma] for [us] mortals, creatures of the day that we are?

SAPPHO fr. 9. $2-5$

In terms of Kurke's argument, Sappho here is speaking to her mother on the occasion of a festival that she desires to celebrate. As I infer from the wording of this fragment, the occasion for any given song of Sappho may at times be a festival, and the genre of such a festive song is normally choral singing and dancing. In what follows, I will try to link the terms choral and mimesis as featured in the title of my essay.

26 West 2014: 7 .

27 I follow here the text as restored by West 2014. But the translation is my own. 
Kurke thinks that Sappho is speaking to her mother not only here in Song 9 but also in the Brothers Song. Let me now quote for you the surviving part of the Brothers Song:

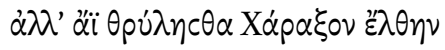

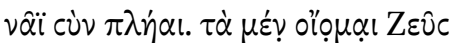

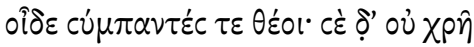
$\tau \alpha \hat{\tau} \tau$ vónc $\theta \alpha \mathrm{l}$,

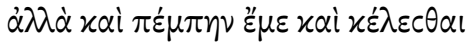

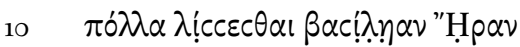

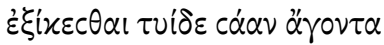
$\nu \hat{\alpha} \alpha \mathrm{X} \alpha \dot{p} \alpha \xi o v$

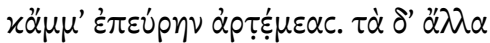

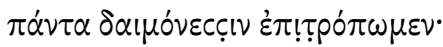

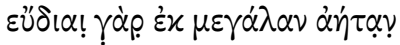

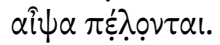

$\tau \omega \hat{\nu} x \varepsilon \beta \dot{o} \lambda \lambda \eta \tau \alpha l \beta \alpha c^{\prime} \lambda \varepsilon u c^{\prime} \mathrm{O} \lambda \dot{\nu} \mu \pi \omega$

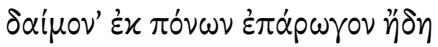

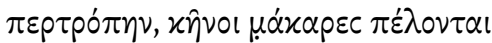

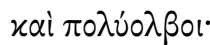

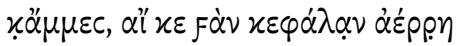

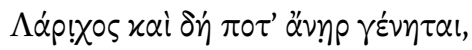

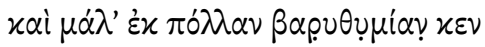
$\alpha i \psi \alpha \lambda \dot{\theta} \theta \varepsilon \iota \mu \varepsilon v$.

But you are always saying, in a chattering way [thrulein], that Charaxos will come in a ship full of goods. These things I think Zeus knows, and so also do all the gods. But you shouldn't have these things on your mind.

Instead, send [pempein] me off and instruct [kelesthai] me to implore [lissesthai] Queen Hera over and over again [polla] that he should come back here [tuide] bringing back [agein] safely his ship, I mean Charaxos, 
and that he should find us unharmed. As for everything else, let us leave it to the superhuman powers [daimones], since bright skies after great storms can happen quickly.

Those mortals, whoever they are, whom the king of Olympus wishes to rescue from their pains [ponoi] by sending as a long-awaited helper a superhuman force [daimōn]

to steer them away from such pains - those mortals are blessed [makares] and have great bliss [olbos].

We too, if he ever gets to lift his head up high, I mean, Larichos, and finally mans up, will get past the many cares that weigh heavily on our heart, breaking free from them just as quickly. SAPPHO, Brothers Song

In this song, as in the fragment from the other song I quoted, Sappho Song 9, we read about a festival. As we saw also in Sappho Song 9, the word for such a festival is eorta. As for the Brothers Song, there is a corresponding reference to a festival, expressed by way of the word pempein "send," which is a terminus technicus, as Kurke calls it, for the idea of organizing a sacred procession that culminates in a festival that is celebrated at the precinct of a divinity. In this case, the festival is sacred to Hera, and Sappho is pictured as readying herself to lead a procession that will be heading off for the festival. Kurke refers to my chapter in the same volume, where I make the argument about the word pempein as such a terminus technicus. ${ }^{28}$ Comparing a passage from the Electra of Euripides with reference to the festival of Hera at Argos (vv. 167-174), I argue that the Brothers Song features the speaking persona of Sappho as a choral leader who wishes to be sent in a procession to the sacred precinct at Messon, where a festival of the goddess Hera will be celebrated, just as the same speaking persona of Sappho in Song 9 had wished that her mother should find the means for her to celebrate this festival. ${ }^{29}$ We see here a validation of a formula proposed by Anton Bierl concerning processions as represented in Greek theater: he argues that any procession that leads into a choral performance will thereby become part of the choral performance. ${ }^{30}$

\footnotetext{
28 Nagy 2016: 459 .

29 Nagy 2016: 460-461.

30 Bierl 2009: 57 n. 152, 107, 272-273, 284, 294-295, 318-319. See also Bierl 2011.
} 
The choral essence of the performance that is represented in the Brothers Song is likewise evident in another song of Sappho that has now been supplemented by the newly-found fragments:

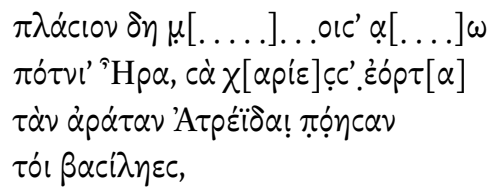

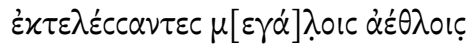
$\pi \rho \hat{\omega} \tau \alpha \mu \dot{\varepsilon} \nu \pi \dot{\varepsilon} \rho \mathrm{E}^{\prime}\left[\lambda \lambda_{10 \nu}\right] \cdot \ddot{\alpha} \psi \varepsilon \rho \rho \nu \delta \xi$

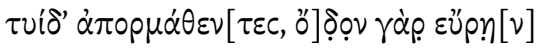

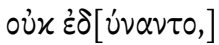

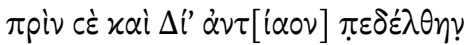

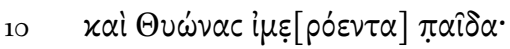
vôv $\delta \dot{\varepsilon} x[\alpha i ́ \ldots . . . . .].] \ldots \pi o ́ \eta \mu \varepsilon v$ $x \dot{\alpha} \tau \tau \dot{\partial} \pi \dot{\alpha} \lambda[\alpha ı v$

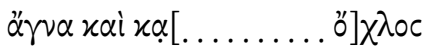
$\pi \alpha p \theta \varepsilon \dot{\varepsilon}[\nu \omega \nu \ldots . . . \ldots . \gamma] u v \alpha i x \omega \nu$

Close by, ....,

O Queen [ potnia] Hera, ... your ... festival [eortā], which, vowed-in-prayer [arâsthai], the Sons of Atreus did arrange [poiein ] for $y o u,{ }^{32}$ kings that they were,

5 after first having completed [ektelein] great labors [aethloi], around Troy, and, next [apseron], after having set forth to come here [tuide], since finding the way was not possible for them

31 On the restoration of this line, I follow Ferrari 2014: 18. Otherwise I mostly follow Obbink 2016a.

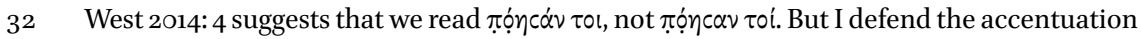

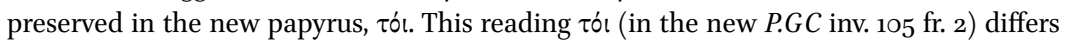
from the reading $\tau$ ol (PSI 123 and POxy. 1231). As I argue, we see here an emphatic use of the pronoun, "for you," not an enclitic use. 
until they would approach you (Hera) and Zeus lord of suppliants

[antiaos]

and (Dionysus) the lovely son of Thyone.

And now [nun de] we are arranging [poiein] [the festival],

in accordance with the ancient way ...

holy $[$ agna $]$ and ... a throng [okhlos]

of girls [parthenoi] ... and women [gunaikes]

15

on either side ...

the measured sound of ululation [ololūgā] .

SAPPHO fr. 17.1-16

Here it is made explicit that the festival in progress, while the speaker is represented as speaking, is in honor of the goddess Hera. Here is the way I describe it in chapter 21 of the Newest Sappho book, "A Poetics of Sisterly Affect":

Although the first line of Song 17 here is too fragmentary to be understood for sure, the next line makes it clear that the persona of Sappho is praying to Hera herself, speaking to her about the eortā "festival" (2: Éóp $\tau[\alpha])$ that is being arranged in honor of the goddess. The speaking Sappho goes on to say that the festival that "we" in the present are arranging (11: $\pi \dot{\eta} \eta \mu \varepsilon v)$, as "we" offer supplications to Hera, is being arranged

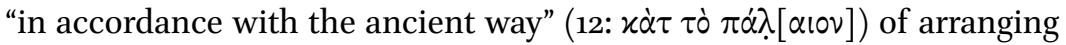
the festival, just as the heroes of the past had arranged it (3: $\pi$ óncav). In these contexts, I am translating the word poiein "make" in the specific sense of "arrange," with reference to the observance of a ritual. I find in Thucydides (2.15.2) a striking parallel in wording: "and the Athenians, continuing what he [= Theseus] started, even now arrange [poieîn] for the goddess [= Athena], at public expense, the festival [heortē] named the

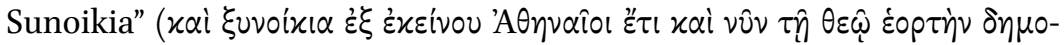
$\tau \varepsilon \lambda \hat{\eta} \pi 010 \hat{c}(\mathrm{v})$.

Comparing these three songs, I now highlight the significance of the word ora (hora) in Sappho Song 9. As I have argued in another project, hora in the sense of "season, seasonal recurrence" is linguistically and even thematically related to Hera, which is the name for the goddess of seasons. ${ }^{33}$ So, the use of the word ora (hora) in Song 9 points to Hera as the honorand of the eorta (heorte). 
Now I return to the relevant wording in the Brothers Song (5-7): $\pi \dot{\varepsilon} \mu \pi \eta \nu$

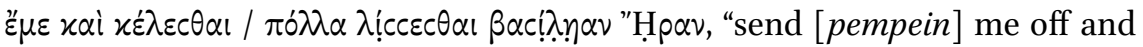
instruct [kelesthai] me / to implore [lissesthai] Queen Hera over and over again [polla]." I understand such an act of instructing someone to do something as a choral act, and I interpret the relation between the instructor and the instructee as a choral relationship between the mother as a woman and the daughter as a girl. The woman chorally authorizes the girl. And such a choral relationship is formalized in the distinction between gunaikes "women" and parthenoi "girls" at the end of Song 17 of Sappho. This song refers explicitly to a choral performance at the sacred precinct of the goddess Hera on the occasion of her festival, which is called an eorta. As I argued in "A Poetics of Sisterly Affect," the occasion of Song 17 marks the performance of Sappho herself as the prima donna who leads the choral singing and dancing at the festival of Hera. As the prima donna, she is the main celebrant, as marked by the programmatic use of the verb poiein at line 11 of this song in the sense of "celebrate a festival."

In the Brothers Song, then, if Kurke is right, there is a mother involved. And then there are the brothers. In this Brothers Song, the brother called Charaxos is mentioned by name, and so too is another brother called Larichos. And then there is also another song where one of the two brothers is mentioned without being named, and it must be Charaxos. Here is the relevant part of the song:

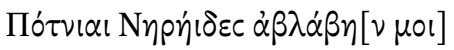

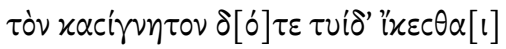

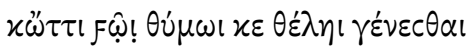

$$
\begin{aligned}
& x \eta \hat{\nu} \sim \tau \varepsilon \lambda \varepsilon \dot{c} c \theta \eta \text {, }
\end{aligned}
$$

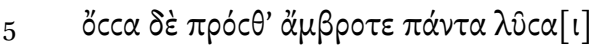

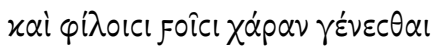

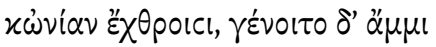

$$
\begin{aligned}
& \mu \eta \delta \alpha^{\prime} \mu \alpha \mu \eta \delta^{\prime} \text { हic. }
\end{aligned}
$$

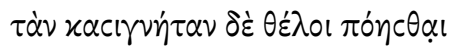

O Queen Nereids, unharmed [ablabēs] may my brother, please grant it, arrive to me here [tuide], and whatever thing he wants in his heart [thümos] to happen, let that thing be fulfilled [telesthēn]. 
5 And however many mistakes he made in the past, undo them all. Let him become a joy $[k h a r a \bar{a}]$ to those who are near-and-dear [philoi] to him, and let him be a pain [oniā] to those who are enemies [ekhthroi]. As for us, may we have no enemies, not a single one.

But may he wish to make his sister [kasignètā] 10 worthy of more honor [timmā]. The catastrophic [lugrā ] pain $[$ oniā $]$ ... in the past, he was feeling sorrow [akheuōn $]$... SAPPHO fr. $5 \cdot 1-11^{34}$

Here I recapitulate what I said in chapter 21 of the Newest Sappho book..$^{35}$ I start with the fact that the loving sister in Song 5 is expressing a wish that her errant brother should become a $\chi \alpha$ ' $\alpha \alpha$ or "joy" to her loved ones (6), not an ovía or "pain" (7) - a pain that is then described as $\lambda u \gamma p \alpha$ "catastrophic" (10). ${ }^{36}$ It should be the other way around, she is saying, so that the family will have the joy-while the enemies will have the pain.

Later on in Song 5 , the speaking persona of Sappho turns to Aphrodite, addressing her as Kupris and describing her with the epithet c乏́ $\mu \nu \alpha$ "holy" (ci

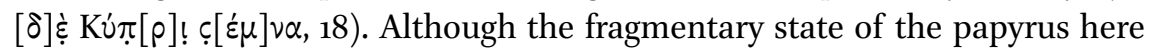
prevents us from seeing the full context, it is clear that the sister is praying to the goddess to prevent further misfortune from happening to her brother, who "in the past was feeling sorrow" ( $\pi[\dot{\alpha}] \rho \circ \theta \theta$ ' $\alpha \chi \varepsilon \dot{\omega} \omega \nu, 11)$.

But the pain that torments the family because of the brother's misfortunes is not the only kind of torment we find in the poetics of Sappho. The same word ovia "pain" that refers to the torment experienced by the family of Sappho refers also to the torment of erotic love experienced by Sappho herself. In Song 1 of Sappho, her speaking persona prays to Aphrodite to release her from such torment:

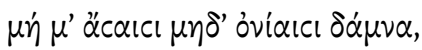
$\pi \dot{\tau} \tau \nu 1 \alpha, \theta \hat{\nu} \mu \circ$

34 For the text here, I generally follow what is printed in Obbink 2016a, though I occasionally commit to one of two possible readings considered by the editor, as at line 11 .

35 Nagy 2016: $45^{\circ}-45^{2}$.

36 It is possible, of course, that [ov] $\alpha \alpha v$... $\lambda v^{\prime} \gamma p \alpha \nu$ is a genitive plural, not an accusative singular. 
Do not dominate with hurts [asai] and pains [oniai],

O Queen [potnia], my heart [thümos].

SAPPHO fr. 1.3-4

Similarly in the first six lines of the Kupris Song the speaking persona of Sappho once again turns to Aphrodite, that is, to Kupris, and she prays yet again that the goddess may release her from the torment of an erotic love that is quite unrequited:

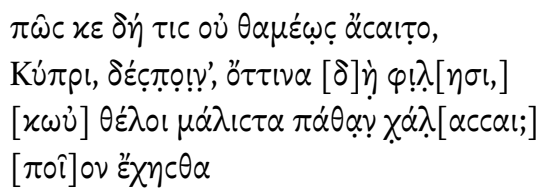

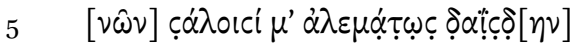

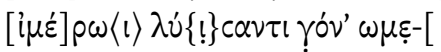

How can someone not be hurt [asasthai, verb of the noun asa "hurt"] over and over again,

O Queen Kupris [Aphrodite], whenever one loves [philein] whatever person

and wishes very much not to let go of the passion?

[What kind of purpose] do you have

5 [in mind], uncaringly rending me apart

in my [desire] as my knees buckle?

SAPPHO, Kupris Song 1-6

The ending of this song was already known before the discovery of the new supplements for the beginning as I just quoted it. At this ending, we find the persona of Sappho declaring the poetics of her own self-awareness:

...है $\gamma \omega \delta^{\prime}$ ' है $\mu^{\prime} \alpha{ }^{\prime} \tau \alpha l$

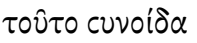

And I-aware of my own self-

I know this.

SAPPHO fr. 26.11-12

We have just seen, then, some powerful examples of singing about unrequited love. To the modern mind, as I said at the beginning of this essay, the act 
of singing such songs may seem nothing more than a form of artistic selfexpression. But we can see from comparing these texts with each other that the medium for expressing the emotions in such songs is in fact choral.

\section{Rethinking Mimesis}

As I have already argued, mimesis involved primarily reenactment and secondarily imitation. ${ }^{37}$ But now I rethink the formulation:

If you re-enact an archetypal action in ritual, it only stands to reason that you have to imitate those who re-enacted before you and who served as your immediate models. But the ultimate model is still the archetypal action or figure that you are re-enacting in ritual, which is coextensive with the whole line of imitators who re-enact the way in which their ultimate model acted, each imitating each one's predecessor. ${ }^{38}$

When it is your turn, your moment to reenact something in this forward movement of mimesis, you become the ultimate model in that very moment. As a way of understanding occasion, then, I propose to equate it with the moment of mimesis. ${ }^{39}$

Things started changing, however, by the middle of the fifth century вСЕ. Ву now the primary meaning of mimesis as "reenactment" was becoming lost or at least destabilized, and the secondary meaning was encroaching on the primary meaning. ${ }^{40}$

My interpretation of mimesis as an authoritative "reenactment, impersonation" is supported by the celebrated description of mimesis in the Poetics of Aristotle as the mental process of identifying the representing "this," as in the ritual of acting a drama, with the represented "that," as in the myth that is being acted out by a drama: in Greek this mental process can be expressed by way

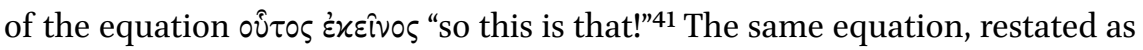

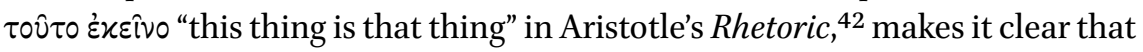
the media of representation that Aristotle has in mind are not just the visual

37 See further Nagy 1994-1995: 14; also already 1990: 42-44, 373-375, especially 42 n. 125 .

38 Nagy 1996: 56.

39 Nagy 1994-1995: 15 .

40 Nagy 1990: 339-381, taking into account the acute observations of Nehamas 1982.

41 Arist. Poet. 1448b17. Nagy 199o: 44.

42 Arist. Rh. 1371b9. 
arts but also the verbal arts, primarily the art of songmaking and poetry as performed in drama. ${ }^{43}$ So long as the represented "that" remains absolute - that is, absolutized by the myth - the representing "this" remains a reenacting "this." 4 So long as "this" imitates an absolute "that," it reenacts as it imitates; the reenactment remains primary, and the imitation remains secondary. ${ }^{45}$ Once you start imitating something that is no longer absolute, however, you can no longer reenact the absolute: then you can only make a copy, and your model may be also just a copy. I have just described here the general mentality induced by the destabilization of the conceptual world of mimesis. ${ }^{46}$

Earlier, I made the claim that genre can compensate for the occasion. But now, applying the semantics of mimesis, I extend the argument by claiming that genre can even absolutize the occasion. A striking example is the "epinician moment" as dramatized in the epinician songs ("victory odes") of Pindar. ${ }^{47}$ Seth Schein has analyzed Pindar's Pythian 6 as an illustration of that moment, ${ }^{48}$ and he quotes in this context the remarks of Hans-Georg Gadamer, who has this to say about the element of the occasional in the epinician songs of Pindar:

The occasional in such works has acquired so permanent a form that, even without being realised or understood, it is still part of the total meaning. Someone might explain to us the particular historical context, but this would be only secondary for the poem as a whole. He would only be filling out the meaning that exists in the poem itself.49

With this formulation in mind, I tried to rethink the essentials of Pindaric songmaking in my 1994 essay "Genre and Occasion." I argued that any given Pindaric composition defies the realization of all the signs of occasionality that it gives out about itself. This defiance is not the result of any failure to adhere to the given occasion of real performance. Rather, it is a mark of success in retaining aspects of occasionality that extend through time. If we think of occasion as a performative frame, even a ritual frame, then what we see in a Pindaric composition is an absolutized occasion. Moreover, this occasion is absolutized by deriving from the diachrony of countless previous occasions. In other words,

\footnotetext{
43 Nagy 1994-1995: 15-16.

44 Nagy 1990: 42-44.

45 Nagy 1994-1995: 16, following Nagy 1990: 42-44. See also Nagy 1996: $55^{-56}$.

46 Cf. Nehamas 1982.

47 Nagy 1990: 381.

48 Schein 1987: 246-247.

49 Gadamer 1975: 129.
} 
a Pindaric composition refers to itself as an absolute occasion that cannot be duplicated by any single actual occasion. Only an open-ended series of actual occasions, occurring in a continuum of time, could provide all the features of an absolutized occasion. ${ }^{50}$

\section{Occasions for the Songs of Sappho}

I now turn from the occasions for the songmaking of Pindar, as sketched in my essay "Genre and Occasion," to occasions for the songmaking of Sappho. As the title for my current essay indicates, where I speak of choral mimesis, I am concentrating here on choral occasions for Sappho's songmaking, not on monodic occasions, which would be appropriate for concerts featuring professional male singers or for symposia featuring amateur male singers. And the primary occasion for a choral performance would be a festival, the word for

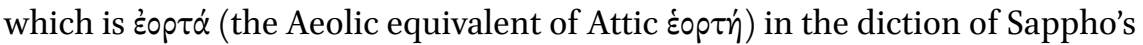
songmaking. We see the word in line 3 of Song 9 and in line 2 of Song 17 .

In the discursive framework of a chorus, what Sappho says when she speaks by way of choral song is not simply some kind of reportage about her historical life and times. What she says, rather, is a mimesis of situations as sung and danced by a chorus led by a prima donna. Such situations are exemplified, as we have seen, by choral songs about unrequited love. And the choral mimesis is not only the act of talking about persons in the third person, thus representing those persons, such as the two brothers named Charaxos and Larichos in the Brothers Song. Nor is it only the act of addressing persons in the second person, thus also representing those persons, such as the mother in Song 9. It is also the act of representing a person even in the first person, and this represented person does not have to be the same person as the representing performers who say "I" or "we" when they perform in the chorus.

Choral performance at a festival is not some ad hoc event. It is a seasonally recurring event, celebrated in honor of the god or goddess whose sacred precinct is the venue for the celebration. But this is not to say that the chorus sings and dances only about the festival. True, the chorus can sing and dance about its own context by referring to the festival, as we see in Song 17 , for example, but it can also sing about anything and everything that can happen to any persons in the third person or to the addressees in the second person or even to the self, who can be pictured as the main speaker, that is, as the prima donna

50 Nagy 1994-1995: 18-19. 
of the singing and the dancing of the chorus. The things that happen, however, do not have to be things that are being experienced then and there in the context of the performance. The things that happen do not even have to be things experienced in the past by the choral persons who are speaking in the first person as they sing and dance their song. The experiences may belong primarily to the persons who figure in the mimetic world of the song that is being sung and danced and only secondarily to the persons who perform the song in the here and now of the festival.

This formulation, I argue, can apply to choral performance not only on the occasion of seasonally recurring festivals but also on the occasion of ad hoc events like laments performed at funerals or love songs performed at weddings. On such occasions as well, choral mimesis can allow for the modeling of identities on preexisting identities. In this essay, however, I concentrated on the seasonally recurring event of a festival held at the sacred precinct of Messon, as described by the words of Sappho in Song 17 .

In terms of my overall argument, moreover, the Brothers Song likewise has as its occasion the sacred precinct of Messon. Here we see the persona of a sister who is singing about her experiencing $\pi$ óvor "pains" (line 18) caused by two brothers named Charaxos and Larichos. In the case of the second brother to be mentioned, Larichos (line 22), the sister is upset that the brother cannot seem to achieve adulthood: he fails to "man up" (line 22). That is the pain. In the case of the first brother to be mentioned, Charaxos (lines 5, 12), the pain that he causes can be reconstructed by combining the references here in the Brothers Song with references in other songs of Sappho, and I am convinced that these references add up to a story about a disastrous love affair that depletes the wealth of the whole family. As we reconstruct the story, Charaxos has fallen in love with a courtesan from Naucratis whose name in the songs of Sappho is Doricha.

These three names, Doricha and Larichos and Charaxos, can all be explained in terms of generic namings, much as the name of Sappho herself can be explained as generically meaning "sister." In chapter 4 of the Newest Sappho book, "Sappho, Iambist: Abusing the Brother," Richard P. Martin argues persuasively that Doricha means something like "tiny little gift," derived from doron "gift." Such a meaning, combined with a diminutive suffix like -icha, would produce a fitting name for a courtesan or prostitute. Similarly, I would argue that Larichos is a diminutive name derived from the adjective laros, which in Odyssey 2.35 is associated with the delicious taste of wine. ${ }^{51}$ It is as if the name

$5^{1} \quad$ I think that the long $a$ of laros in Homeric diction results from a kind of innovative poetic lengthening: see Nagy 2008: 34-35. 
of this brother meant something like "tiny little delicacy."52 Such an interpretation can supplement, I think, the argumentation of André Lardinois in chapter 7 of the Newest Sappho book. He highlights the testimony of Athenaeus, who

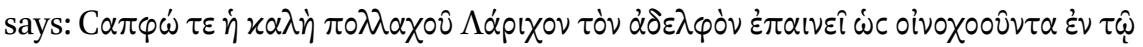

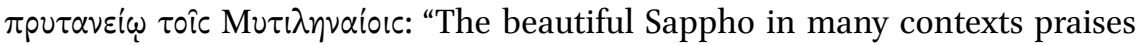
her brother Larichos, because he poured the wine for the Mytilenaeans in their

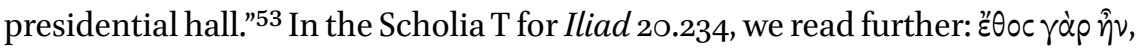

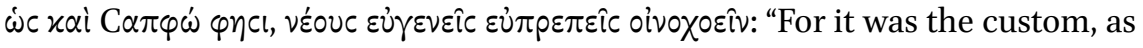
even Sappho says, for good-looking young aristocrats to serve as wine-pourers." And then there is Charaxos, which I think is a diminutive name derived from the noun $\chi \alpha \rho \alpha$ "delight, joy." We have seen this word $\chi \alpha$ pó in line 6 of Song 5 , where the voice of Sappho wishes that Charaxos become a "joy" to her and to the whole family. It is as if the name of Charaxos were a wish-fulfillment for the sister who has experienced so much pain in worrying about her errant brother. And here we may consider also the festive context of $\chi \alpha \rho \dot{\alpha}$ "delight" in Song 9 . So, Charaxos is the would-be "tiny little joy" or "tiny little delight" for the family. This theme seems to be picked up by the poet Posidippus when he describes

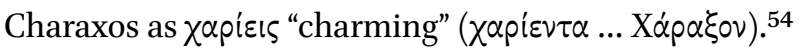

To talk this way about your brothers is a sisterly thing to do. And the intimacy of such talk, replete with diminutives, can be imitated in choral song. Such talk can sound like baby talk, and I think that the verb $\theta p u \lambda \varepsilon i v$, which is conventionally translated as "chatter," can refer to such baby talk. As I argued in "A Poetics of Sisterly Affect," even the name of Sappho conveys the impression of such baby-talk as imitated in the mimetic performances of female choruses. ${ }^{55}$ I find it significant that Electra in the Euripidean drama that is named after her uses this word $\theta p u \lambda \varepsilon i v$ at line 910 when she tells her brother Orestes about her strong desire to "chatter" on and on to him about all the things she has experienced since the separation of these two siblings. And such talk is not just sisterly talk: it can also be motherly talk, as imitated in choral song. That is the sense of

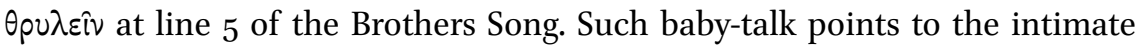
conversations that can take place between mothers and daughters, between women and girls, in choral performance.

52 In chapter 14 of the 2016 New Sappho book, "'All you Need is Love': Some Thoughts on the Structure, Texture, and Meaning of the Brothers Song as well as on Its Relation to the Kypris Song (P. Sapph. Obbink)," Anton Bierl has already drawn attention to the association of Larichos with the adjective laros.

53 Ath. 10.425a.

54 Posidippus $122 \mathrm{AB}$, line 2, quoted in Ath. 13.596c. On this association of Charaxos and $\chi \alpha \mathrm{pi}^{-}$ हıৎ "charming," see also Burris, Fish, and Obbink 2014: 24.

55 Nagy 2016: 489-491. 
Such relationships-between mother and daughter, between sister and brothers-are not "fictional" in the songs of Sappho. But they are not "historical," either. Rather, such relationships are simply mimetic. To speak of a "fictional" or a "biographical" relationship, either way, is to set up a false dichotomy. And the same goes for the idea of a "fictional" or a "biographical" Sappho. All these personae are primarily mimetic, and their occasion is what happens by way of choral performance. The crisis of worrying over an errant brother-or of suffering from an unrequited love-is not the occasion for choral performance. The occasion is the mimesis of such emotional crises. And such occasions can happen at festivals, even if such festivals take place only once every year.

\section{A Second Lesley}

Here I finally arrive at a point where I can introduce the second Lesley to whom I dedicate this essay. She is Lesley Gore, who recorded in 1963 a song that became wildly popular and stayed that way for a long time. The title of the song is "It's My Party." Gore is pictured on the album cover, a girl wearing a mischievous half-smile. Her looks in this picture do not match the feelings that she is singing about in her song, which is all about crying — crying about unrequited love.

It's my party and I'll cry if I want to

Cry if I want to

Cry if I want to

You would cry too, if it happened to you

Nobody knows where my Johnny has gone

But Judy left the same time

Why was he holding her hand

When he's supposed to be mine?

It's my party and I'll cry if I want to

Cry if I want to

Cry if I want to

You would cry too, if it happened to you

Play all my records, keep dancing all night

But leave me alone for awhile 
Till Johnny's dancing with me

I've got no reason to smile

It's my party and I'll cry if I want to

Cry if I want to

Cry if I want to

You would cry too, if it happened to you

Judy and Johnny just walked through the door

Like a queen with her king

$\mathrm{Oh}$, what a birthday surprise

Judy's wearing his ring

It's my party and I'll cry if I want to

Cry if I want to

Cry if I want to

You would cry too, if it happened to you

Oh, it's my party and I'll cry if I want to

I like to compare this song about an emotional crisis with some songs attributed to Sappho, who dates all the way back to 6оо вСE or thereabouts. My favorite part of the song sung by Lesley Gore is where the singer tells her listeners that she doesn't mind if they play all her records all night, dancing all the while to the music of the song, but she wants to be left alone for a while, because she has no reason to smile. Back then in 1963 , records would be played at occasions like birthday parties, and young people could indeed dance all night long to the songs that were sung on the records. But the occasion for the singing recorded on records is not the sadness of a lonely speaker who sings about unrequited love. Rather, the occasion is the performance of her song as a recorded double-track for a vinyl disk that makes 45 revolutions per minute every time the song is played on the record-player. And, as the record gets played and replayed over and over again, the sadness of the girl who is pictured in the song recurs over and over again. So also the singer in the songs of Sappho implores Aphrodite over and over again to free her from the sadness of unrequited love, or she prays to Hera over and over again to make things all better for her family and thus ease her anxieties. Each time a chorus sings and dances her songs, the sadness and the worries recur. And the occasion is the mimesis of these emotions by way of song and dance. The emotions themselves are not the occasion. 
For all we know, the occasion for such singing could be a yearly festival, where the song could get performed and reperformed every year, over and over again, just as the sadness of the girl who is pictured in the song recurs over and over again. But that will not stop the singer from wearing a mischievous halfsmile.

As the blues singer Rubin Lacy once said, you don't have to have the blues to sing the blues:

I've sung 'em on many a day and never thought I had 'em. What did I want to have the blues for, when I had everything I wanted, all the liquor, all the money I needed, and more gals than I needed? What did I need with the blues? I was playin' 'em because everybody loved to hear me play 'em and I loved to play 'em. I could play 'em, yeah. ${ }^{56}$

$5^{6}$ Quoted in Evans 1982: 112. Thanks to Adam Holland. See also Nagy 2004: 48. 
PART 2

Genre, Generification, and Performance 
978-90-04-41259- $\odot$

Downloaded from Brill.come4/26/2023 $09: 51: 26 \mathrm{AM}$ via free access 


\title{
Linus: The Rise and Fall of Lyric Genres
}

\author{
Andrew Ford*
}

Schemes for classifying works of art according to genre flourish outside the academy_in bookstores, on music-streaming services, on Netflix; yet in literary studies genre criticism has been facing increasing resistance since the 1980 os when Frederic Jameson pronounced it "thoroughly discredited by modern literary theory and practice." Suspicion hangs over the word in academic criticism, where it often seems that no sooner is a genre mentioned than its integrity as a concept is undermined and any normative authority it might have had is dismissed. One senses at times a Nietzschean disdain for genres as cobwebs spun out by desiccated pedants which supermen-poets brush through without a thought. Such attitudes have, to be sure, some grounds: it would be naïve now to regard genres as pure and timeless essences rather than hybrid, politically conditioned and contingent groupings of works that are always evolving and always changing their "laws." Demystifications of genre can, however, overshadow its other, productive side, the possibilities it offers to sharpen and enrich a message and to provide orientation for an audience hearing a song for the first time. The fact that the authority and perpetuation of genres depend on poets and audiences at least as much as on scholars is not always acknowledged, nor is the reality that genres are omnipresent and inescapable: we greet no song without a frame.

The status of genre is no less suspect in the study of those Greeks who laid out many of the basic lines and much of the terminology used in Europeanderived criticism. In the article on "genre" for the current Oxford Classical Dictionary, for example, Glenn Most and Gian-Biagio Conte aim for a balanced presentation but find little positive to say about ancient genres. They note that genre can be useful for poets and critics if it be regarded as "a system of literary projection inscribed within the texts, serving to communicate certain expectations to readers and to guide their understanding." Yet they find ancient

* Thanks to the participants and organizers of the conference at Berkeley for stimulating the thoughts in this essay, which I had the opportunity to present to the Classics Department of New York University in December 2015. Particular thanks are also due to Stephen Menn and to the editors of this volume for searching and productive criticism.

1 Jameson 1981: 91, a much-cited tag. 
discussions of specific genres "for the most part unsatisfactory": these are characterized as "one-sidedly formal" and "more interested in classifying existing works than in understanding the mechanisms of literary production and reception." The systems the ancients built up, they write, are more relevant to "the needs of the school and the library" than to the interpreter, for they not only ignore some important genres such as the novel but "bungle" others-and here they name lyric poetry.

Indeed, out of all classical genres, lyric seems to be the most suspect, both as a coherent general category and for its endlessly enumerable subvarieties. To take the latter problem first, consider a text from late in the process, the "Manual of Literature" compiled by an Imperial-era grammarian called Proclus. Proclus' discussion of lyric summarizes much from Didymus' On the Lyric Poets, which in turn drew on Alexandrian monographs on individual poets, themselves carrying forward studies of many of these same figures among the Peripatetics. By the early first century вСЕ a canon of nine (or ten) lyric poets had

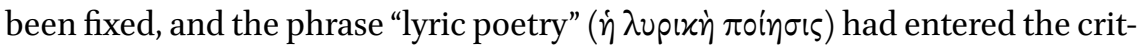
ical lexicon. ${ }^{2}$ The harvest of all this for Proclus was a complete system of poetic genres that identified lyric as a class of poems that, for all their variety, were distinct from epic, elegy, and iambus. Only after surveying these latter forms does Proclus take up "melic" poetry (the reason for his choice of term will emerge below) and remark: "Melic is the genre with the most subdivisions and distinct

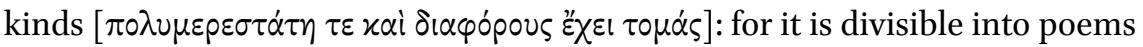
to gods, poems to men, poems to gods and men, and those for occasional events in life." ${ }^{3}$ Under these four subdivisions he compiles 28 lyric genres, though even these are not enough to capture the full variety of ancient lyric: Proclus leaves out a number of song names that are found in earlier authors, and other lists exist. ${ }^{4}$ The inadequacies of this scheme might suggest that lyric/melic is a catch-all category for "leftover" forms and so ancient lyric genres can safely be disregarded as unreal; but, as we will see, this vocabulary and its notional authority were a resource for poets as early as Homer, and some of these labels guided the production and reception of Greek poetry for a millennium.

For all its problems of definition, the question of genre imposes itself at a time when studies of Greek lyric are flourishing. To document this in the present volume would be superfluous, but it is worth highlighting how important notions of genre have been to the present revival. Beginning in the late

2 Färber 1936: 1-7. On Proclus: Severyns 1938; West 2013: 7-11.

3 Procl. ap. Phot. Bibl. 319b32-35 Bekker.

4 E.g. 24 lyric genres in the (mostly overlapping) Scholia Londinensia in Dionysii Thracis Artem Grammaticam 3.450.10-451.27 Hilgard. 
1970s, Claude Calame, Wolfgang Rösler, and Bruno Gentili moved beyond older notions of genre based solely on form and content and stressed the importance of the context of performance for defining kinds of poetry. ${ }^{5}$ This broader conception of genre tied to occasions of Greek social, political, and religious life remains central in many areas of research, such as Pindaric victory songs or the interactions between lyric and tragedy. ${ }^{6}$ It is also important, I will argue, to the current exploration of "chorality" as a modality that may migrate among several traditionally distinct lyric forms. As we investigate these aspects of lyric, it is crucial to avoid a one-dimensional attitude to genre lest, as often happens when we think in terms of "lyric," we fall into replicating memes from an outmoded Romantic theory and adopt its unhelpful dialectic between liberty and restraint, with genres playing the role of tyrannical impositions upon the spontaneous freedom of artists. ${ }^{7}$ This essay accordingly suggests some benefits for readers of Greek poetry in attending to ancient ways of classifying lyric song.

In what follows I will first put the problems of defining lyric genres in context by comparing recent debates in modern literary studies, where lyric has also been undergoing a contentious revival. While classicists have been concerned with relating specific lyric texts to performance situations, moderns have been looking at the problem from the other end and questioning whether these varied song practices constitute a coherent category of literature. In modern European literatures it is only late that an idea of "the lyric" comes onto the critical scene, and the grounds on which it does so are so dubious as to raise questions about whether it makes sense to speak of "the lyric" at all. These debates suggest that one promising way forward is to pay more attention to the historical processes by which ideas of lyric and its genres were constructed, moving the focus away from substantive definitions to the processes by which distinct kinds of nondramatic and nonnarrative song were identified and named. On this basis, I will then turn to the Greeks and outline their methods for lyric "generification" in the archaic and classical periods; generification is as old as song, or at least as old as the second song, and I will stress how it was the work of poets, audiences, and critics all together as they pursued not only taxonomic but ritual, pedagogic, communicative, and aesthetic aims. ${ }^{8}$

5 Calame 1977; Rösler 1980; Gentili 1984.

6 On Pindar, see most recently Morgan 2015: $1 \mathrm{ff}$. (on allegedly “impure" epinicia) and Maslov 2015: ch. 1, esp. 62-76. On tragedy and lyric, see Swift 2010; Gagné and Hopman 2013b; Andújar et al. 2018, as well as Foster's and Weiss' essays (this volume).

7 As in Croce's 1902 influential repudiation of genre. See Duff 2009 for a valuably complex picture of genre in Romantic theory.

8 As Leslie Kurke points out to me, Bell 1992 made a comparable move in replacing the term 
Surveying the parameters governing early lyric generification will show that the norms that prevailed in the period between Homer and Pindar were radically changed when Plato and Aristotle devised new literary systems based on what each called mimesis. The shift was momentous for, whether one translates mimesis as "imitating" or "representing," lyric poetry was marginalized in the new systems and as a result was never adequately incorporated into a synoptic scheme of literary forms with a special task of its own. At this point the ancient story joins up with the modern one, for the conception of poetry as mimesis developed in the classical period persisted through the eighteenth century and continued to determine the (non-)status of lyric. Here classicists have proposed a new way forward by defining a new notion of mimesis as neither "imitation" nor "representation" but "ritual reenactment." I will examine the merits and limitations of this suggestion and, in a final section, will take up one very old lyric form - the Linus-song - to argue that, despite the problems attaching to traditional Greek notions of genre, a sensitivity to lyric generification provides readers with valuable perspectives that neither mimetic nor ritual approaches afford.

\section{The Rise of Modern Lyric}

The arrival of the modern conception of lyric can be placed around 1800 when lyric was elevated into a full-fledged genre that could be set beside epic and drama as one of the three "natural forms," in Goethe's words, of serious literary production. ${ }^{9}$ Adumbrations of the idea can be found in eighteenth-century texts and earlier, but what most held lyric back from being recognized as a general class of literature was the orientation of classical theory toward mimesis, the "imitation" or "representation" of life and action. Mimesis in this sense had been, since Aristotle, the obvious function of epic or drama; some other kinds of poetry, such as satire or idyll, could also be said to "imitate" life as well, but a great deal of nonepic and nondramatic verse (e.g. sonnets, elegies, "Pindaric" and other odes) had very little in the way of plot or characters, making it unclear what such poetry "imitated." The 1800 turning point (whose arrival and causes are variously pinpointed by historians of criticism) was made possible by the

"ritual" with "ritualization" in order to grasp ritual as a form of social activity and so better to understand how such acts are differentiated from others and imbued with social value.

9 The account here draws especially on Abrams 1953; Guillén 1971; and Genette 1986; insightful shorter synopses: Patey 1993; Calame 1998a; Jackson and Prins 2014: 11-16; and the contributions of Goldhill and Güthenke in Billings et al. 2013. 
development in Romantic thought of a more robust conception of the inward, individual subject; this made it possible for lyric to be seen as mimetic, for it could be said to express the inner life of the poet, what Hegel called Erlebnis, "lived experience." Once lyric was endowed with mimetic content, it became eligible to be integrated among the classical genres and inscribed in a great dialectical history: an age of epic objectivity gave way to lyrical subjectivity in the seventh century вСЕ, followed by their synthesis in classical drama.

When lyric was elevated to the noble ranks of literature, it was assigned the expression of inward thought and feeling as its particular province, and this conception has proved hard to eradicate even as it has been steadily dismantled over the last half century. The New Critical pedagogy of the 196os was committed to an ideal of the autonomous work of art that reduced the lyric "I" to a persona, at best a fictional representation of any individual's real-life speech. René Wellek in a classic article of 1967 exposed the roots of lyric ideology in German Romanticism and challenged its overvaluation of expressiveness, which he thought threatened to engulf all other art in a single aesthetic project. Because any genre must be constantly transformed as it interacts with other genres, Wellek advised abandoning attempts to define "the lyric" and urged instead a focus on the variety of its narrower forms. ${ }^{10}$ Finally, scholars like Ralph Cohen and Jameson rejected essentialist approaches to literary form altogether and presented genres rather as social institutions, negotiable and self-interested. ${ }^{11}$ As a result, substantive definitions of lyric genres lost their normativity and were seen as open-ended processes, groupings of texts that were subject to repeated modification as new ends arose that needed to be fulfilled.

Still, one could argue for the utility of some general, if evolving, notion of lyric until Virginia Jackson led a "new lyric studies" movement in the past decade. ${ }^{12}$ These critics deplore what Jackson calls the "supersizing" of lyric in the nineteenth century as a distorting homogenization of diverse writing, performance, and publishing practices and one that now tyrannizes literary study. A specialist in Emily Dickinson attentive to the materiality of every scrap she jotted, Jackson protested against the editors and pedagogues who would hide the particularity of her work behind a screen of idealized "lyric." Quite apart from the injustice this perspective does to Dickinson, Jackson claimed, the collapsing of heterogeneous practices into a single reductive idea has had wider pernicious effects, leading to a current tendency among critics to "lyricize" their

\footnotetext{
$10 \quad$ Wellek 1967.

11 Cohen and White 2003; Jameson 1981.

12 Jackson 2005; cf. Yeager 2008 and the excellent anthology of lyric criticism by Jackson and Prins 2014.
} 
objects of study, in a term taken from Mary Poovey; this generalizing of lyric ideology to all literary expression, predicted by Wellek, can be seen in the common tendency now to equate "poetry" with lyric, a nearly complete reversal of the classical relegation of lyric to leftover status.

Most recently, Jonathan Culler has entered the fray with a book that in some respects pushes back against this trend. It is entitled Theory of the Lyric and its thesis is epitomized in the definite article: Culler argues that it is not enough to dissolve the category of lyric into an unassimilable variety of nonepic, nondramatic poetic practices, for to do so precludes any appreciation of how lyric poets create for themselves a larger tradition of their own. Acknowledging the need for critical attention to the historical processes that brought an idea of "the lyric" to the fore, he aims to revive the idea of lyric as a "set of norms and structural possibilities" that has "persisted since the days of Sappho, despite lyric's different social functions and manifestations." ${ }^{13}$ I think that current Greek lyric studies can profitably attend to both Jackson and Culler, accepting a process-theory of genre while also looking out for continuities that are maintained or reasserted in the transformations of lyric through history. As Culler argues, an overarching history of lyric need not blur the specificity of each poet and era but may in fact counteract the tendency of lyricization to reduce all poetic production to a single formula.

\section{The Rise of Archaic Lyric Genres}

The prevailing account of Greek lyric genres, again shrewdly epitomized by Most and Conte, is that in archaic Greece poetic kinds were defined and named partly in view of their form and content but primarily by "communally recognized, often ritually sanctioned situations of performance." But at a time that is usually located in the later fifth century and associated with the bookish Euripides, a fall occurred as such songs passed beyond their generative performative contexts and became the object of a more purely formal and aesthetic attention. Although this was a happy fall to the extent that it "facilitated artistic experimentation with genres," a vital link with social life was broken, and the subsequent rigidification and formalization of genres in Alexandria was a way of compensating for this lost significance. Heirs to Hellenistic poetics, we moderns misread early lyric texts if we ignore how their words related to the world and content ourselves with connecting words to words about words. Among

13 Culler 2015: 83-85. 
classicists' versions of this story is W.R. Johnson's nostalgic The Idea of Lyric, which holds up the ancients as a model of engaged, communitarian song that we have lost since Whitman. ${ }^{14}$

Such stories imply that a richer appreciation of genre in the archaic period may provide a path back to the bright, pre-fallen songworld, but the journey is not easy: to seek out some presumed essence of "the lyric" behind these texts would be to fall back into Romantic modernism, but neither can we take shelter in the historically attested, emic subgenres, for Harvey showed in a landmark article that their definitions usually go no further back than Hellenistic scholarship. ${ }^{15}$ Some light, however, may come from considering what I am calling lyric "generification" in the archaic and classical periods, observing both how certain forms of Greek song became recognized as distinct and nameable genres and how far this repertoire of nonepic, nondramatic songs was thought of as a coherent class.

A good enough place to begin is the representation of lyric in Homer. As expected, when he names kinds of nonepic song these are closely tied to specific sociopolitical occasions. Soldiers sing the paean when distressed or triumphant; matching male and female choruses sing the humenaios at weddings and the Linus-song at harvest; at funerals, female kin of the deceased dominate the dirge, threnos. These genres are socially defined not only by the occasions they accompany but by the way performing roles are assigned according to gender, status, and kinship. All this fits well with the idea of the social origins of Greek lyric genres, but it is crucial in using such evidence to keep in mind that Homer's agenda was something other than supplying us with raw ethnographic data. To see this it suffices to consider his description of the paean that the Greek soldiers perform in Iliad 1 to beg Apollo to stop the plague. After the delegation led by Odysseus has returned Chryseis to her father, the old man prays and sacrifices, there is a meal, and then kouroi serve wine to inaugurate a paean (1.469-474 West):

But when they had put aside the desire for food and drink, the youths crowned the wine-jars with drink and served out to all, first pouring drops for libation into the cups. All day they supplicated the god with song and dance, the young men of Achaea, finely singing the paean-song, singing and dancing for Hekaergos, and the god rejoiced as he listened.

14 Johnson 1982.

15 Harvey 1955. 


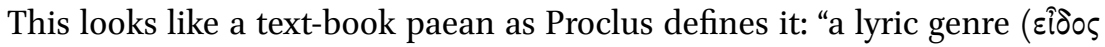
ఏंगेऽ) now addressed to all the gods but in ancient times addressed to Apollo and Artemis in order to stop plague and disease."16 The song name "paean," taken from its refrain, epitomizes its original function to invoke Apollo Paian as healer. Does Homer's scenario, then, prove that under the fussy Hellenistic classifications may lie real, ancient lyric forms that emerged from highly charged occasions of communal life? This may be, but a second look at the scene brings out elements that belong to paeans in a quite different spirit: this all-male group singing goes on for hours and comes after a meal as a separate service, marked off with libations; all this is more suggestive of the paeans that inaugurated archaic symposia, and indeed Homer's metaphor in saying the

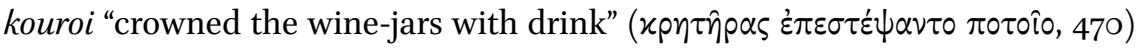
can evoke the garlands worn on such occasions. There is no doubt that occasion counted for much in early Greek conceptions of lyric, but already in Homer's time a single song-kind could be used on different occasions; moreover, if a poet's description of paeanic performance could take the liberty of mixing distinct uses of the form, we may suspect that actual musical arrangements could be flexible as well. ${ }^{17}$ The methodological upshot is that, in investigating early generification, we must not expect poets to be transparent reporters nor that we will be presented with the original, uncontaminated essence of songs.

If occasion was often the dominant factor in defining archaic lyric kinds, formal and thematic features were indispensable as well. The most basic and long-lasting formal distinction that Greeks made within what we call "poetry"

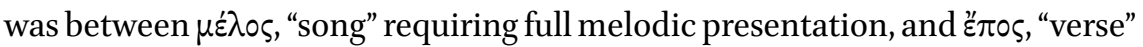
that may have been chanted but was not sung; as recitable verse, epos included hexameters, elegiacs, and iambo-trochaic stichoi, whereas Alcman's strophes or Sapphic stanzas counted as melos. Although general verbs meaning "to sing," such as i $\mu \nu \varepsilon i v$ and $\dot{\alpha} \varepsilon i \delta \varepsilon i v$, may be used equally of the performance of melos and epos, the key point is that melos is never used of songs composed in stichic form. (This is why Proclus uses "melic poetry" when he takes up lyric after treating epic, elegy, and iambus.) This formal distinction, rather than some assumed "expressive" function, is the strongest justification we have for continuing to speak of Greek lyric poetry, and it is the reason that Page's Poetae Melici Graeci and Lobel's collection of what he called the $\mu \dot{\varepsilon} \lambda \eta$ of Sappho and Alcaeus are in separate volumes from West's Iambi et Elegi Graeci. It should

16 Procl. ap. Phot. Bibl. 320a2O-24 Bekker.

17 Further on the paean in Il. 1: Ford 2006: 289-291; Wecowski 2014: 208-209. 
be noted, however, that the distinction between sung melos and recited epe was not purely formal for the Greeks, for each kind carried with it social implications, connoting, for example, certain skills, education, and experience required of potential performers and a range of roles available to audiences. Singable form was fundamental to lyric generification, but not as form for its own sake.

After occasion and form, the third and final parameter in defining archaic lyric kinds was "content," the range of topics conventionally thought appropriate to song in a given context and performative mode. Again, content was implicated in values beyond the literary, for the most basic and enduring distinction operating in this area was a religious hierarchy that segregated songs to gods from those for mortals. A well-known passage from the Homeric Hymn to Apollo can illustrate this (156-164):

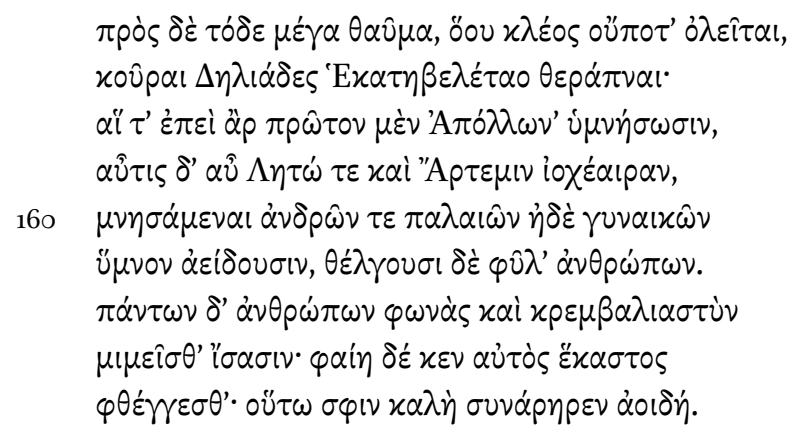

And there is this great wonder besides-and its renown shall never perish — the girls of Delos, handmaidens of the Far-shooter; for when they have first sung Apollo, and then Leto and Artemis who delights in arrows, they sing a song of men and women of the past, and enchant the tribes of men. And they know how to imitate the voices of all men and their clattering sounds: each would say that he himself were singing, so finely is their song fitted together.

This group of unmarried females favors certain themes that are clearly articulated and organized. First to be mentioned are their songs ${ }^{18}$ in honor of the island's patron Apollo: quite context-appropriate. Distinct from these ( $\alpha \hat{\tau} \tau\left\llcorner\varsigma \delta^{\prime}\right.$ $\alpha \hat{\imath}, 159)$ are songs for his virgin sister and mother: quite appropriate to the performers' gender and status. Only after these songs for the gods do we come to 
songs of early mortals in $160 .{ }^{19}$ The basic underlying distinction between songs for gods and songs of mortals underlies Proclus' primary division of lyric kinds quoted above and structures Plato's history of song in the Laws (70oa-e). Plato's speaker imagines that clear-cut generic distinctions prevailed in the musical

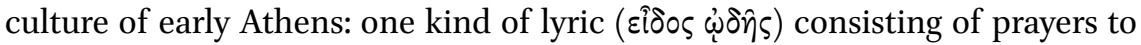
the gods was termed "hymns" and included paeans, dithyrambs, and kitharo-

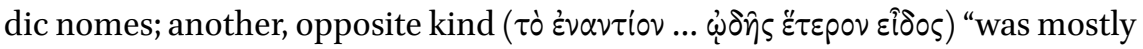
termed dirges." Plato's history goes on to include a fall in which poets began to mix these pristine forms, "blending dirges with hymns and paeans with dithyra-

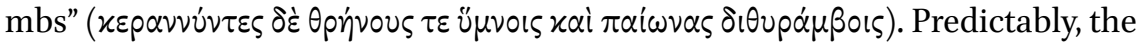
result of this neglect of "what is right and proper in the realm of the Muses"

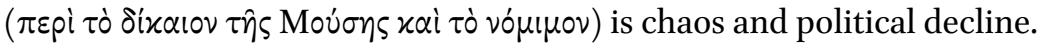

All three parameters are at work in a very rich story Pindar tells of lyric generification, a difficult fragment beginning a dirge: ${ }^{20}$

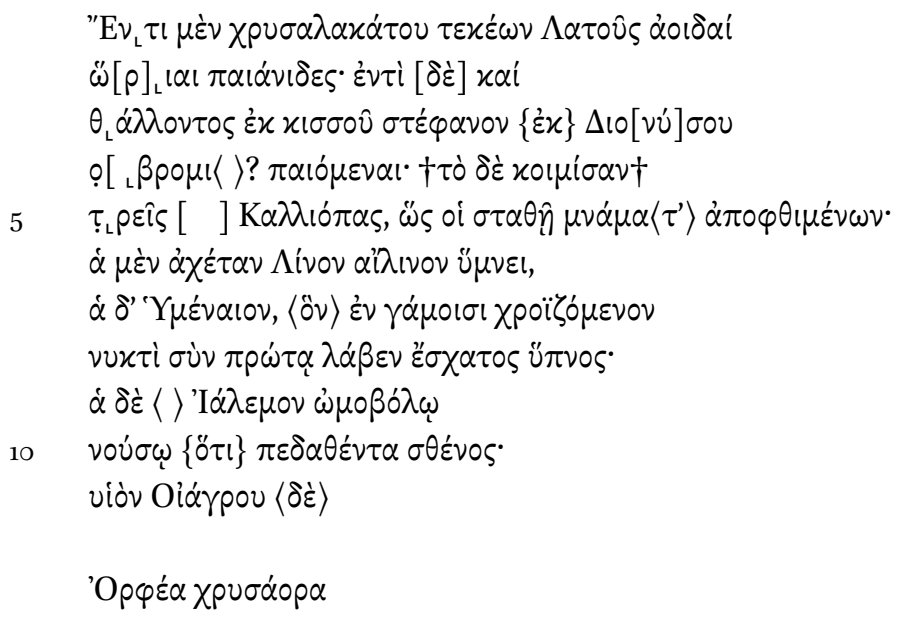

There are songs for children of Leto of the golden distaff, paeans in due season. There are other songs ... from flourishing ivy ... a garland of Dionysus

$\cdots$

three ... of Calliope so there might be set up for her memorials of the dead:

19 Cf. Hes. Theog. 10o-101 where heroic song ( $\chi \lambda \varepsilon \hat{\imath} \alpha \pi \rho \circ \tau \varepsilon \rho \omega \nu \alpha \dot{\alpha} \theta \rho \omega \dot{\omega} \pi \omega \nu)$ is distinguished, hus-

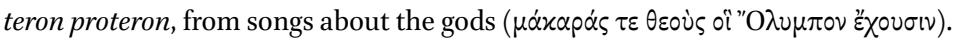

20 Pi. fr. $128 \mathrm{c} \mathrm{SM}(=56$ Cannatà Fera $)$ with the text of Henry 1999 at vv. $6-8$. Cf. Calame 1998a: 101 for a different interpretation. 
one sang for clear-sounding Linus, ailinon; another for Hymenaeus, whom the last sleep took on that first night when his skin was touched in marriage; another for Ialemus when his strength was strapped by wasting disease; but the son of Oeagrus,

Orpheus of the golden sword ...

The opening four verses appear to distinguish paeans to Apollo and Artemis from Dionysus' dithyramb and then to set against these songs lamenting death in $5^{-10}$. Under the latter head Pindar collects three subvarieties which, as expected, show a similarity of form (refrain), theme, and occasion. Like Homer, Pindar is more than a simple reporter; he is actively synthesizing myths to provide an aetiology for each variety of threnos: Pindar makes Linus, Hymenaeus, and Ialemus children of the Muse Calliope, and suggests that upon each one's untimely demise his name was ceaselessly repeated in grief until the specific instance of mourning was transmogrified into a genre, a song-type that bore the name of its original object. (The importance of the refrain is doubly encoded

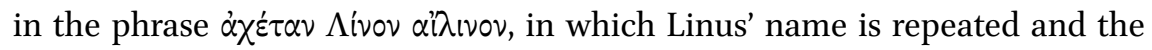
epithet underscores its sonic power.) The mention of Orpheus as the fragment breaks off is suggestive, since he was a singer who tried to cross the god-mortal divide, but the structure of the opening relies on the basic distinction made by Plato and Proclus between seasonally recurring songs to the gods and dirges, the quintessential expression of mortality.

Pindar's text bespeaks an age of anthropological interest in the varieties of song-types and singing practices before Herodotus and Plato. His testimony reveals that, well before Euripides came on the scene, the process of lyric generification itself might be a topic for a poet's conscious reflection and reimagination. The history implied by Pindar's syncrisis has a double message for classicists: on the one hand we are reassured to see that he uses the same three parameters to identify lyric genres as we do, but on the other it is worrying that his mythological scenario of how threnodic genres arose is the same as our "historical" model that traces lyric genres to the generalization of early cultic acts.

\section{The Rise of Classical Greek Lyric}

A fundamental change between archaic and classical taxonomy came when Plato and Aristotle, the granddaddies of the Greek genre system, downplayed 
the importance of social occasion in defining genres and replaced it with something each called mimesis. Mimesis, conventionally translated as "imitation," was given a different meaning by each author, but in both it denoted an enunciative mode of discourse, an immanent linguistic property. They thus removed the social determinants from archaic lyric genres and left the genre as a whole with only a formal definition. These well-known passages have momentous implications for the philosophers' views of poetry, but we will confine ourselves to observing how well lyric poetry fits into each one's system.

In the third book of the Republic (392c-394c), Socrates proposes that all of what we call literature ${ }^{21}$ falls into one of three basic kinds. This novel scheme (which may be Plato's invention) neglects performative context altogether and gives little importance to the formal melos/epos opposition; Plato's overriding consideration is the discourse's mode of enunciation. As Socrates explains $(394 \mathrm{~b}-\mathrm{c})$, there is one kind of poetry and tale-telling that consists entirely of "imitation" ( $\delta \dot{\alpha} \mu \mu \eta \dot{\eta} \sigma \varepsilon \omega \varsigma$ "ö $\lambda \eta)$, which he uses in Book 3 in the sense of impersonation; this is found in drama where everything is spoken in the persona of a character who is not the author. A second kind of literature works purely through narration ( $\left.\dot{\alpha} \pi \alpha \gamma \varepsilon \lambda \dot{ }{ }^{\prime} \alpha\right)$, with everything being delivered in the persona of the author/performer; this is exemplified by the dithyramb, a genre of lyric. Finally, there is the mode that mixes narration with the impersonation of characters, exemplified in Homeric epic.

Since the nineteenth century, this passage has been claimed as support for the tripartition of literature into drama, lyric, and epic. The importance of Gérard Genette's Architext is to have overthrown that claim, arguing that Plato's second class, pure narrative with no admixture of impersonation, hardly corresponds to our idea of lyric. He points out that, at the start of Plato's discussion

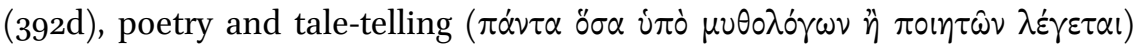

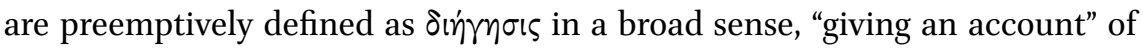
something. Thereby Plato leaves out of account all nonrepresentational poetry, including prayers, expressions of desire, enmity, or despondency —in short, he leaves out a good deal of what we would call lyric. To be sure, Socrates cites the dithyramb as an example of unmixed poetic narrative (394b-c), but his phrasing is curiously non-committal — the mode is "best exemplified, I sup-

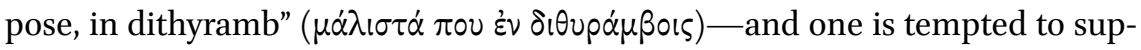
pose that this is because classical dithyramb neither always eschewed mimetic speech—Bacchylides' dithyrambs are a counterexample—nor seems always to

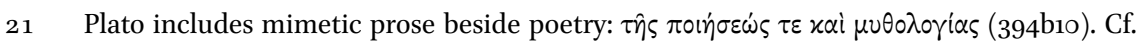
392d, quoted in the text below. 
have been bent on telling a story, to judge from Pindar's dithyrambs. However we work out that problem, ${ }^{22}$ the significant point is that Plato's definition of poetry as mimesis limits his recognition of lyric to those forms that were ostensibly narrative.

Aristotle's single most important difference from Republic 3 is to redefine mimesis as "representation" rather than "impersonation," but lyric will be as ill served in his scheme. ${ }^{23}$ The first three chapters of the Poetics set out a comprehensive grid on which one can locate all the major genres of poetry recognized in Aristotle's day (with a place for mimetic prose as well). Like Plato, Aristotle replaces occasion with mimetic mode, but he gives equal weight to form and content. Chapter 1 identifies literary forms according to how they combine three "media of representation": speech, rhythm, and melody; this entails a definition of lyric in formal terms as mimesis that uses all three media throughout (1447b24-26). (Epic, by contrast, never uses melos, and drama uses it only in the parts we call odes or arias.) The content or "objects of representation" discussed in chapter 2 are social/ethical rather than theological: people better, worse, or like us. It is in chapter 3 that Plato's modes are revised (1448a19-24):

The third difference in these arts has to do with the manner in which any one of these objects may be represented; for it is possible to represent the same objects in the same medium but in different modes. Thus they may be represented either in narration (whether the narrator speaks at times in an assumed role, which is Homer's way, or always in his own person without change) or in a mode in which the characters are presented as functioning and in action.

As the Hutton translation here reprinted makes clear, Aristotle turns Plato's tripartite classification of literature into a bipartite one: pure narrative and mixed narrative are lumped together into a single modal class that he opposes to dramatic mimesis/impersonation. The pure narrative class, the ostensible home for lyric in Plato's scheme, is folded in with epic and other mixed forms with the result that any distinctness lyric discourse may have is swallowed up.

Aristotle does not, as some charge, neglect lyric entirely, for we have seen it defined formally in chapter 1 where dithyramb and the kitharodic nome are its exemplars. Still, it is true that the Poetics as we have it pays scant attention to lyric forms except as an element in drama. To the extent that Aristotle's

22 Cf. Käppel 2000 for the view here, vs. D'Alessio 2013.

23 On mimesis in Plato and Aristotle see Halliwell 2002: 37-97. 
neglect of Pindar \& Co. needs an explanation, the most important cause lies in his commitment to mimesis. Different as their notions of mimesis are, Plato and Aristotle agree in defining poetry as mimesis in one enunciative mode or another; as a consequence, both have trouble taking account of the many kinds of lyric poetry that present no proper narratives but are rather rhetorical presentations of ethical points of view or expressions of conventional attitudes or emotive responses to situations; neither Plato nor Aristotle would think they "imitated" or "represented" anything much at all. ${ }^{24}$ It was this lack of an identifiable object of lyric mimesis that would keep the genre on the sidelines until 1800.

To sum up: in Greek literary history the musical form of lyric always singled it out as an empirically distinct class of poetry, but the various forms of song were not synthesized into anything like a super-genre in the classical age: Plato barely notices lyric in Republic 3, and Aristotle recognizes it mainly as a formal possibility in Poetics 1, while epic representation and dramatic impersonation claim his attention. There is force to Genette's argument that when modern critics found their tripartite scheme anticipated in Aristotle and Plato, this was merely a "retrospective fiction," an appeal to authority in hopes of naturalizing their own approach and thereby disguising, even from themselves, their innovative conception of lyric. What debarred Plato and Aristotle from bringing all lyrics together into a single substantive category, and what hid lyric so long from modern theory, was their assumption that poetry is mimesis, and so lyric theory must come to terms with that concept.

\section{New Notions of Mimesis}

The focus in Plato and Aristotle on poetry as mimesis, as verbal representations of characters in action, marginalized lyric in both classical and later European poetics, a marginalization that was only undone at the cost of reducing all lyric to self-expression. As we still stand in the shadow of that theory, it is good to be reminded by Earl Miner, the great scholar of comparative poetics, that Western criticism is an outlier in this regard: "Lyric," he says, "is the foundational genre for the poetics or systematic literary assumptions of cultures throughout the world" and the poetics it inspires are affective/expressive, not mimetic. ${ }^{25}$ Recent work on Greek lyric, however, has found a way to bypass the limitations

24 Menn (n.d.) is the best discussion I know of why Aristotle gives no extended account of lyric.

25 Miner 2000: 3-4, quoted by Culler 2015: 1. 
of the classical literary system by positing a new account of mimesis that does not depend on making expressiveness the essence of lyric and that reduces lyric taxonomy to a subsidiary problem.

The most influential theorist of the new model has been Gregory Nagy, who in a series of works has profoundly redescribed the turn from archaic to classical genre by redefining archaic mimesis. Nagy agrees with the usual account that occasion provided a necessary frame for early poetic speech acts, and he agrees that, when the performative occasion for a given kind of song was lost or felt to be lost, a sense of genre could compensate for that loss, even substitute for it in a way. But for Nagy a more important force shaping archaic poetry was mimesis, which originally meant neither Plato's mimicking of another nor Aristotle's representation of action in speech; Nagy's archaic mimesis was a ritual process by which a mythical origin was recaptured through the performer's impersonation in the sense of reenactment. A convenient illustration of Nagy's complex argument is the Hymn to Apollo above. Nagy points out that this portrayal of the Delian Maidens appears in a rhapsode's hexametric hymn, so that we have an intergeneric exchange: a rhapsode "imitates" a choir whom he will subsequently (166-173) bid to "imitate" his discourse in turn; for Nagy, the statement that the girls "know how to imitate" the voices of all people ( $\mu \mu \varepsilon i \sigma \theta$ ' " $\sigma \alpha \sigma \omega, 163)$ means more than copying local dialects or language: mimesis refers to the power of any chorus to reenact the founding performers of their song and to communicate that power to others who will reenact them in turn: as he puts it, "These Maidens are models of mimesis by practicing mimesis." ${ }^{26}$ So mimesis is a magico-ritual process in which "mimetors" are not belated "copiers" of earlier models, but reenactors of earlier reenactors on the same level. Pindar's threnodic fragment may be taken as an instance of mimesis in this sense, for he draws his new song into the genre of threnos by briefly reenacting the aboriginal divine refrains.

Nagy's focus on reenactment puts the putative origin of any lyric genre in brackets and indeed undercuts the usual account of how genres arise. On the usual account, genres arise out of real-life occasions that become generalized when repeated in other situations; a ritual-generated song, by dint of repetition in other, nonritual contexts, turns into art. But Nagy reverses this: ritual mimesis was never an imitation of "real-life" song events but itself generated the "original" event by conferring "absolute" status upon the putative model. The founding event is not to be sought in prehistory but stands before us as nothing more than the whole line of ritual reenactments of "absolute" models viewed

26 Nagy 1994-1995: 16; cf. id. 2013b and Peponi 2009 on the Hymn to Apollo. 
diachronically. Genre is thus a byproduct of ritual utterance; in fact it is a mirage created by a magical speech act that claims both to reproduce the speech act of a mythic model and to serve as a model for later occurrences of the song. ${ }^{27}$

Nagy's powerful account avoids the naiveté of seeking the essence of any genre in its putative original form; in addition, he warns that the determinative role accorded to "occasion" in the usual account may be a fantasy, a founding myth for the idea of genre. One must agree with Nagy to the extent that, whatever may have transpired in prehistory, we only have access to song genres as retrospective projections from later presents. One may still question, however, the historical shift posited in this model, for Nagy's history depends, like Pindar's, Plato's, and the "modern" theory of lyric, on a fall that has rendered a vital aspect of song in its original settings opaque to us. For Nagy, the great change was "caused by a gradual weakening of ritual practices" around the middle of the fifth century and is reflected in a contemporaneous shift in the semantics of the mimesis-words: ${ }^{28}$ when an originally secondary sense of "imitate" prevailed over an original primary sense of "ritually reenact," the work of poets as "reenacting" archetypal originals was forgotten and came to be replaced by the classical idea that poets "imitated" poets who had sung similar songs before. Ritual fell into art, poetry into technique, opening the path to Plato and Aristotle and their formal redescription of magico-ritual song as melos, whose power their belated mentalities could not properly appreciate.

This and allied conceptions of ritual mimesis influence many current studies of Greek lyric. In the shorter, "monodic" songs of Sappho and Alcaeus, for example, the speaking voice is increasingly seen not simply as a persona (far less as an historical personage) but as a traditional role, generic in the full sense of the term. Similarly, the overt occasionality of Pindaric epinician need not point to performance contexts but can be reabsorbed into the texts as a generic function of the praise-poet's role. ${ }^{29}$ So influential is this approach that ritual mimesis has become supersized itself and is now seen as the motor driving a wide range of archaic poetry. Much current work on Greek chorality endows that performative mode with a power that Albert Henrichs named "choral projection": a dramatic chorus can toggle back and forth between their occasion-defined role as performers in an Athenian Dionysiac festival and their mimetic role as

27 Cf. Barchiesi 2000: 174: "If one can assume that the original performance and its social context made genre superfluous, then genre, as Nagy has suggested, is a postmortem of performance."

28 Nagy 2013b: 228; cf. id. 1994: 15 .

29 See, e.g. Obbink 2014 on Sappho's recently found "Brothers" poems and Nagy 1994-1995 on Pindar. 
singers/actors in a heroic-age drama. ${ }^{30}$ More generally, something of the ritual idea of mimesis is invoked in Barbara Kowalzig's anthropological and sociological studies of chorality; for her, choral singing is not one performative mode among others but a "socially effective mechanism" for putting religious tradition to use. She is close to Nagy when she writes, "In choral performance ritual and art dissolve into each other: the difference between past and present is collapsed, as is the difference between the performing chorus and their mythical analogues." ${ }^{31}$

This line of approach to Greek lyric derives from structural anthropology and linguistics and regards poetry in the first instance as a species of human behavior and thence as a sublimated form of political and social activity. As such, it can bring out important operations of these works that a literary approach to genre would miss; but the reverse is also true, and I am not prepared to consign so much Greek lyric poetry to ritual: supersizing the idea of ritual mimesis and putting reenactment at the core of archaic lyric risks, in Genette's terms, stressing fiction over diction, gliding over what made each song unique and distinct, even from others composed for the same addressee on the same occasion. In addition, downplaying specific genres in favor of a generalized mimesis pervading all archaic song will overlook the ways that poets exploited traditional conceptions of lyric kinds to enrich their creations and invest them with authority. To illustrate, I conclude by tracing how one tiny archaic genre, the Linus-song, was generified from the pre-Hellenic Near East to Hellenistic Alexandria. It will be a story that does not rely on a fall, or at least one that puts the fall back before the story begins.

\section{Linus Generified}

The first remarkable feature of the Greek Linus-song is that its very name-and this epitomizes a key point I have argued - shows that it was already remade before it appears on our screens in ostensibly pristine form. In myth, Linus was an early-slain musical hero, the child of a Muse whose lamentation for her son gave rise, as Pindar suggests, to the Linus-song, a prototypical dirge. Philology takes the opposite view, interpreting the figure Linus as the personification of a

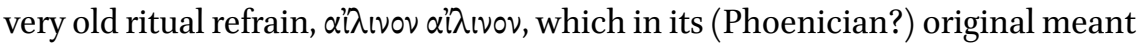
something like "Woe, woe is us." 32 A partially demythicized account is given by

30 See Gagné and Hopman 2013b.

$31 \quad$ Kowalzig 2007b: 67.

32 Chantraine 2009 s.v. $\lambda$ ivos, $L f r g E$ s.v. $\lambda$ ivov. On the Linus song: Färber 1936: 1.44, 71, 2.61ff.; 
Herodotus (2.79) who tells us that the song for Linus is performed in Phoenicia, Cyprus, and elsewhere under various names; he traces its origin to Egypt where the original name/refrain was Maneros. Egyptian informants persuaded Herodotus that Maneros was the son of their first king and that the lamentation that arose upon his early death was for a long time the only song in this ancient kingdom. ${ }^{33}$ Herodotus' generification begins (like Pindar's) by setting the Greek Linus-song beside other songs with comparable refrains in presumably similar tones. Like modern scholars (and unlike Pindar), he realizes that the Linus-song has an historical and not divine origin; for him, in fact, the name Linus is already a translation ( and his song is but a Greek derivative of a type to be found in other cultures.

Bearing in mind that the oldest kinds of Greek song we hear of have a backstory, let us turn to the earliest mentions of the Linus-song, first a fragment of Hesiod (fr. $305 \mathrm{M}-\mathrm{W}$ ):

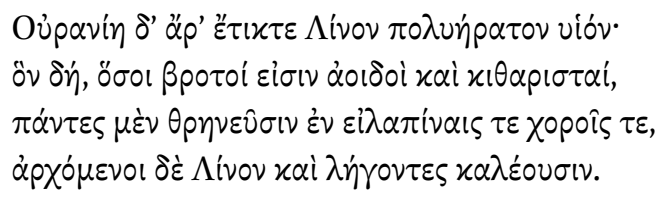

Urania then gave birth to Linus, her exceedingly lovely son, he whom all mortal singers and kithara players lament at their festive choruses, calling "Linus" as they begin and end.

The song is a variety of dirge invoking Linus, a Muse's offspring celebrated by those who play and sing to the kithara; all of them, Hesiod says, are wont to call on Linus "as they begin and end." Taking Hesiod as a reporter would suggest that such performances in his day regularly featured the refrain $\alpha^{i} \lambda$ ivov $\alpha^{i} \lambda$ ivov; the mention of choruses suggests a call-and-response performative mode. We thus picture the Linus-song as an antiphonal lament for a figure that kitharasingers portrayed as the patron of their art.

We hear more about the song in Homer: when Hephaestus represents a city at peace on Achilles' shield in Iliad 18, he decorates it with two songs, a wedding song (491-497) and the Linus-song. The latter accompanies a grape harvest $(565-572)$ :

Häussler 1974; Calame 1977: 1.154-155 with bibliography at n. 217; on Linus: West 1983: 5667; Stephens 2002-2003; Power 2010: 208-210 (with nn. 55, 58), 212. 


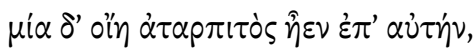

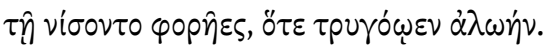

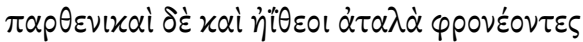

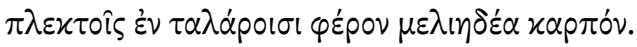

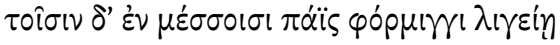

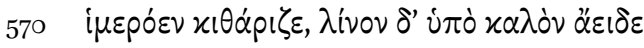

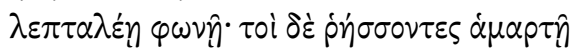
$\mu \circ \lambda \pi \hat{\eta} \tau^{\prime}$ i

And one single path led thereto [the vineyard], which the vintagers took whenever they gathered the vintage. And maidens and youths in childish glee were bearing the honey-sweet fruit in wicker baskets. And in their midst a boy played the kithara delightfully on a clear-toned lyre, and sang beautifully in accompaniment the Linus-song with his delicate voice; and his fellows beating the earth in unison followed on with bounding feet dancing and shouting.

Formally, this looks like a rustic version of Hesiod's Linus-song: paired choruses of unmarried boys and girls carry fruit in baskets and frisk about a boy who plays a lyre; as he sings, the choristers dance and "shout out," very probably its ritual refrain ( $i v \gamma \mu \hat{\omega}, 572$, is an onomatopoeic word).

If we press further and ask what the boy sings, grammar leaves room for interpretation: my translation follows most modern commentators in taking it that the boy "sang in accompaniment to ... his clear sounding lyre" ( $\varphi$ ópuir/

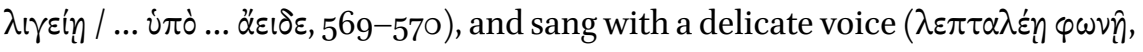
571). ${ }^{34}$ As for what he sings, reading a proper name in 570 and translating $\Lambda$ ivov

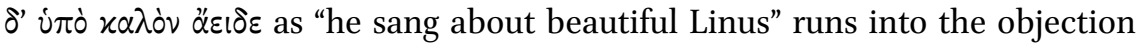
that the verb $\alpha \dot{\alpha} \delta \delta \varepsilon i v$ in epic does not normally take a personal object: when $\alpha \dot{\varepsilon}-$ $\delta \varepsilon \imath \nu$ governs an accusative this will be the name of a song-type (such as paean, Il. 1.174) or an abstract statement of theme (such as "Achilles' wrath," Il. 1.1). ${ }^{35}$ Hence most read $\lambda$ ivov as the name of a lyric genre: "he sang the Linus-song beautifully."36 This reading is entirely plausible, for we have already seen in the case of the paean that by Homer's day proper names of patron figures had been generalized into names of the songs honoring them.

On this reading, Homer testifies to the importance of occasionality in the archaic genre system by embedding the Linus-song in a context. Mark Edwards,

34 So Leaf 1902 ad 18.570; Edwards 1991 ad 18.569-570.

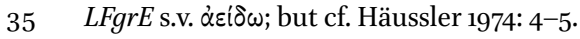

36 With $x \alpha \lambda$ óv adverbial: Diehl 1940: 106; Häussler 1974: 3 n. 9. 
however, comments: "The [Linus] song is always referred to as a dirge, and it seems odd to sing it here on what is obviously a cheerful occasion" (1991: 225). An explanation is not far to seek: a dirge to accompany vintaging makes perfect sense ethnologically, for Linus belongs, like the early-dying Adonis, to Easternstyle fertility cults featuring songs of lamentation at harvest. ${ }^{37} \mathrm{Hence}$, presumably, Hesiod is untroubled by the idea of a festive song lamenting Linus ( $\theta p \eta$ -

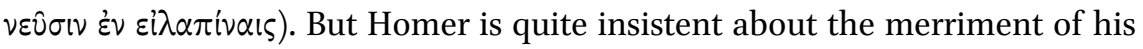

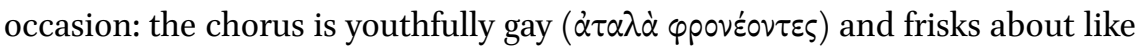

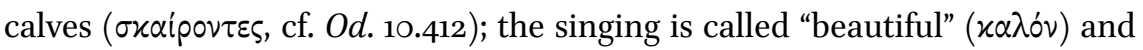

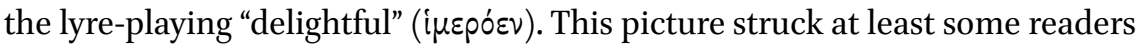
as anomalous and may be the reason that Zenodotus suggested a different construal of the text. A scholiast informs us that Zenodotus proposed to read not $\lambda i v o v$ or $\Lambda$ ivov in the accusative, but $\lambda$ ivos, which he apparently took as an alternate nominative form of the word $\lambda$ ivov, -ov, "flax-string": "the boy played the lyre delightfully, and the flax-string sang beautifully in accompaniment to his delicate voice" (570-571). The scholiast filters Zenodotus to us through his critic Aristarchus, so we cannot be sure of his intentions, but other ancient commentators raise the possibility that he meant to restore consistency of occasion to the Linus-song by emending away this incongruously cheerful example: on his reading, Homer says nothing about a Linus-song but only mentions a singing string. Zenodotus could have pointed to a good Homeric parallel for the syntax: when Odysseus strings his bow in the Odyssey and tests it by plucking the

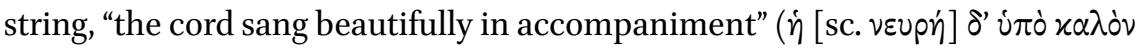

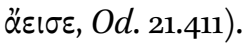

But the great Aristarchus would have none of this, as the same scholiast informs us: he took $\lambda$ ivov as the accusative of $\lambda$ ivos, which he explained was the name of a song genre ( $\gamma \varepsilon \dot{\varepsilon} v \varsigma \tau \iota$ ü $\mu \nu 0 v)$; Homer's phrase "is the equivalent of saying 'the boy sang a paean' or some such genre."38 As I said, modern commentators side with Aristarchus, but Zenodotus' "string theory" had earlier supporters. One was the cultural historian Philochorus of Athens in the third century ВСЕ. He related a myth in which Linus was killed by Apollo because he replaced his kithara's flax-string ( $\lambda$ ivov $x \alpha \tau \alpha \lambda \nu$ v $\sigma \alpha \varsigma$ ) with gut-strings $(\chi 0 p \delta \alpha i \varsigma){ }^{39}$ Thus an old story of pastoral-agricultural antagonism provided an alternative aetiology for the Linus-song, deriving its name not from the slain hero but from

37 Shaw 2013: 184-191. Sappho 214 Voigt (= 140b LP) associated Linus (under the name Oitolinus) with Adonis.

38 Schol.(A) ad 18.570a. Zenodotus' suggestion is called "not indefensible" by Leaf 19o2: 2.311312 ( $a d$ 18.570) and is defended by Van der Valk 1963: 1.153-154 and Barris 2016.

Philoch. FGrHist 328 fr. 207 (= Schol. Il. 18.570c3 ff.). 
the instrument of his devotees (in its imagined earliest form). Earlier still, Heraclides of Pontus noticed this passage and commented that, though Homer was aware of gut-strung lyres, he kept the word $\lambda$ ivov. ${ }^{40}$ I suggest, then, that for some exegetes the Linus scene raised worries about the consistency of occasion in an old lyric genre, and this worry is explicit in the Attic Glossary of Aristophanes of Byzantium. Listing a series of folk genres, Aristophanes says the himaios was a miller's song, the humenaios went with weddings, and ialemos with occasions of mourning; "but linos and ailinos are sung not merely on occasions of mourning but also 'upon a happy song,' as Euripides has it [in Heracles 348]."41 Aristophanes seems to have agreed with Aristarchus and modern commentators in recognizing a Linus-song in Iliad 18, but, like Edwards, he realized he was admitting a usage that fit ill with other data about the genre.

On the usual account of archaic generification, the name of the Linus-song preserves its organic connection to a social occasion of pre-Homeric antiquity; and as that connection faded, some later scholars explained the song's name from the instrument still used in such celebrations. Nagy rightly cautions that the alleged origin may be a mythic projection from the present, though the persistence of $\lambda$ ivov, a non-Indo-European word, as a name for vegetable fabrics today inclines me to keep the historical scenario alive as a possibility. I would, however, add a complicating suggestion: the string-etymology need not be regarded as the fruit of a post-archaic, "fallen" phase in the generification of the Linus-song, for it is animadverted to in Homer's text itself. Like Pindar, Homer may have been less concerned to document archaic song customs than to enter into ongoing negotiations about the contexts and history of a form. The Linus-song was, after all, already old and exotic for Homer and may have been more talked about than actually heard, since not enough examples survived to find their way into Proclus' handbook. Homer seems aware of the antiquity of the song, inscribing it, along with the humenaios, on a divine artifact made while the Trojan War was still in progress; he also seems aware of the type's ethnographic affinities in placing it at a harvest festival. But with the phrase $\lambda \varepsilon \pi \tau \alpha \lambda \varepsilon_{n} \varphi \omega \nu \eta \hat{~ i n ~ 18.571 ~ H o m e r ' s ~ t e x t ~ a l s o ~ g e s t u r e s ~ t o w a r d ~ t h e ~ a l t e r n a t e ~ r e a d i n g ~}$ that would silence the Linus-song while making the lyre-string sing. The epithet, an extended form of $\lambda \varepsilon \pi \tau o ́ s$, is a hapax in Homer and slightly oddly used, as Edwards also notes (on 18.571-572): "The meaning here is not obvious, but presumably complimentary."42 Literally "peeled" or "husked" (Il. 20.497), $\lambda \varepsilon \pi \tau o ́ \varsigma$

\footnotetext{
$40 \quad$ Heraclid. Pont. 16o Wehrli (= Phot. Lex. s.v. $\lambda$ ivov).

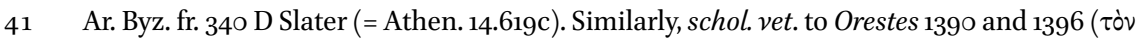

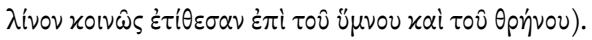


could be extended to mean "thin" in connection with voice, but a thin voice seems hardly wanted for an outdoor festive song, so the word is usually further extended to mean "fine" or "delicate" with the implication of "pleasing," as the

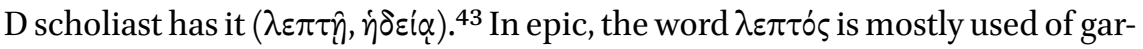
ments and other woven fabrics. Indeed, the Iliad applies $\lambda \varepsilon \pi \tau$ ós to $\lambda$ ivov in 9.661

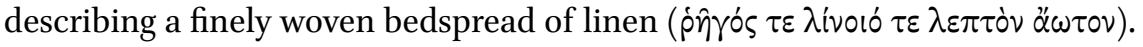
So the boy in Iliad 18 may well be, as Aristarchus held, singing the Linus-song, but with a voice that is fine-spun as a linen thread. ${ }^{44}$ Supported by the syntactic parallel from Odyssey 21, $\lambda \varepsilon \pi \tau \alpha \lambda \varepsilon \dot{n} \eta \omega \omega \eta \hat{\eta}$ leaves us uncertain whether the lovely Linus-song derives from a kithara string or from a dying god. ${ }^{45}$ Homer's epithet $\lambda \varepsilon \pi \tau \alpha \lambda \varepsilon_{n}$, then, suggests an aetiology to explain why, as Hesiod attests, Linus was a patron of kithara players; but at the same time, by occluding Linus, it could transport us to a pre-Iliadic songworld in which the proper name had yet to be generated.

This look at the archaic Linus-song suggests that the histories we tell about the generification of lyric can go back well beyond our earliest texts and so may not be fully captured in a "before and after" scenario. We are accustomed to think that a devotion to poetry that was $\lambda \varepsilon \pi \tau$ ó in the sense of "subtle" marked the new aesthetic of Callimachus and his Roman heirs (whose tenuis glosses $\lambda \varepsilon \pi \tau \dot{s} \varsigma$ ), though we must also allow that antecedents for this use of the word are already found in Attic comedy. ${ }^{46}$ But the $\lambda \varepsilon \pi \tau \alpha \lambda \varepsilon \dot{\eta} \eta$ voice of the Linus-song encourages us at least to lengthen this history and perhaps too not to seek a turning point at which early communal genres "fell" to become belated abstractions. It was already impossible for Homer to speak about any kind of song without being also an ethnographer of song, for the choice to represent a harvest- or a wedding-song required a name under which to locate it, an address in the social imaginaire where old, nonepic song was to be found. For reasons we can only guess at, the Iliad poet declined to take the opportunity his ecphrasis afforded to depict an early epic poet singing epic, though the Odyssey frequently indulges in such self-regarding ironies. On Hephaestus' shield, Homer apparently wanted to represent song sub specie aeternitatis, and in casting about for an old song the activity of harvesting, like marrying, was a

\footnotetext{
43 Cf. Chantraine 2009 s.v. $\lambda \dot{\varepsilon} \pi \omega$.

44 Diehl 1940: 89 would go further and connect $\lambda$ ivo $s$ with metaphors for singing as "weaving"

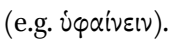

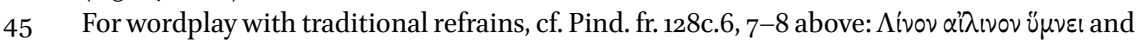

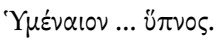

46 E.g., Ar. Ran. 828, 876, 956, Nub. 153, 320, 1496 with O'Sullivan 1992: 137-138, 142. On Linus as a figure of leptotes in Alexandrian poetics, see Stephens 2002-2003.
} 
good place to look. It is not at all surprising, then, to find Homer not only evoking lyric genres but participating in their ongoing redefinition. We do not have to wait for the iconoclastic Euripides to find the productive power of poetic genres reflecting on genre. Indeed, it seems that precisely because these were Homer's issues, Euripides was provoked to step in and reexamine Linus' genre in his Heracles.

In arguing that the Linus-song was not confined to occasions of lament, Aristophanes of Byzantium cited as an example the extraordinary first stasimon of that play, which begins by declaring itself a generic hybrid ( $H F$ 348358):

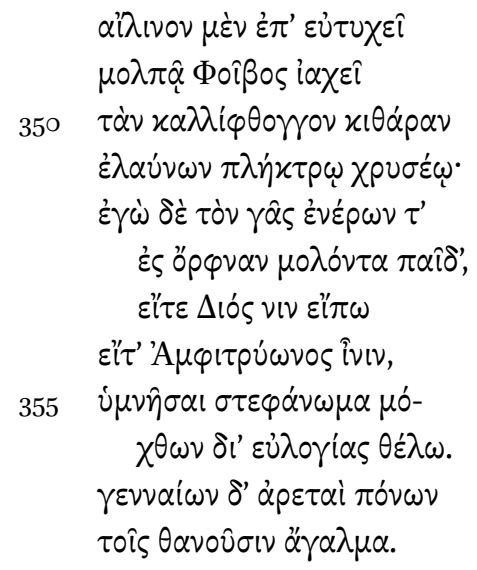

Ailinon cries out Phoebus upon a happy song, striking his fair-sounding lyre with a plectrum of gold; but for that one who has entered the darkness of the earth and of the dead - whether I am to call him child of Zeus or of Amphitryon-I wish to sing a song of praise as a crown on his labors: the noble struggles of the good are their delight when they die.

Although they have heard that Heracles is dead, the old men of Thebes announce that they will sing a congratulatory song, "crowning his labors with praise" (355-356), and the long decorative ode that follows celebrates his triumphs when one would have expected a dirge. ${ }^{47}$ An excuse for this mismatch of song to occasion is the fact that one may doubt, as the singer does, whether the deceased is to be praised as a mortal or as semidivine (352-355); the age-old

47 On epinician elements in this ostensible dirge, see Swift 2010: 121-129. Weiss' essay (this volume) brings out the "polyphony" and generic "malleability" of the other lyrics in this play. 
shibboleth expressed in Proclus, Plato, and earlier does not work here. But like a good mimetic choir, the chorus can take Phoebus as their model, who mixes messages when he "cries out ailinon upon a happy song" (348-349).

As a matter of literary history, it is not clear what Euripides might be referring to here: Fränkel assumed certain Apolline songs must have used the ailinon refrain; but it may simply be, as Bond suggested, that Phoebus stands metonymically for the kithara music he inspires and that ailinon was relatively common as an ephumnion in that repertoire (or was thought to have been so once, with Hesiod fr. $305 \mathrm{M}-\mathrm{W}$ in mind). ${ }^{48}$ Whatever practices the chorus is claiming as precedent, it would be too simple to sum up the Heracles stasimon as a characteristically "modern" mixing of pure genres. Euripides does indeed produce a lyric not quite like any that has come before, but his crossing dirge with epinician is not arbitrary defiance of generic convention but a desperate engagement with the limits of those conventions: facing the unprecedented challenge of singing a god-man, he reaches back to the roots of lyric to claim as precedent the Linus-song's notorious instability between mourning and celebration.

My aim has been to defend the relevance of genre-aware criticism to Greek lyric not simply by pointing out that even travesties of genre depend on genre, nor by reiterating what everyone allows in theory-that generic "constraints" can be productive and are in any case always at work. I began by acknowledging that classical and classically derived conceptualizations of lyric genre are not directly useful in exploring how lyric poets worked with genre because of their attachment to notions of poetry as mimesis. I then argued that we can compensate for these limitations to an extent by turning away from genres as literary essences and attending instead to generification, to representations in Greek lyric of how song genres arise, claim authority, and are modified. But I also submit that we need not go further and construct from such representations a history of lyric generification as a story of fall from an original fullness of meaning, a story that in itself must incur suspicion as a Romantic trope. As Nagy's analysis suggests, the usual fall story is less valuable as history than as a poetic move in the texts themselves, hinting to audiences that, amid the endless variety and confusion of speech, the primordial form of this song is about to reappear and to exert its ritual power. But by the same token Nagy's own fall story from ritual to romance must also be regarded as an effect of the text. A look at the Linus-song suggests that poets early learned to revise and exploit 
lyric history not because they had fallen out of touch with an organic song community but as a way of complicating the response of an audience who wanted the new song to work like the old: the tactic of invoking an unspoiled version of the present song in the past is a risky one that may seem to concede that the dream of unfallen speech has already been confounded by history and that no lyric now can be quite perfect nor completely efficacious. But this gambit can also be a way of suggesting that, in the messy congeries of the present, that same old song may be rising once again on this occasion in this season.

Lyric genres do rise and fall in history-Who sings the Linus-song now?but they are not mere phantoms from the past. If we attend to the work done by traditional genres in our texts, pausing to grant them some power before dissolving them into other genres or rushing past them as of no consequence to true poets, we will be able to notice how lyrics may reenact both the original state and its fall concurrently. Generification arises as a topic of song in many Greek lyrics because any occasion that calls for song calls for the (re)establishment of a form in which to sing with authority. Thus to pause any history of lyric on the fall is to give an incomplete account. To read ancient lyrics in ancient terms is to be open to the possibility that old genres can come to life again, like Linus, and to recognize that even in their late, revised, and reconstituted forms they are not cut off from the wellsprings of lyric. 


\title{
Sappho's Parachoral Monody
}

\author{
Timothy Power*
}

\section{Choral Sappho}

Scholars have long been open to the possibility that Sappho composed some of her songs, above all certain epithalamia, for female (or in some cases mixed) choruses to sing on more or less public occasions, though the tendency has been to view any such songs as the exception to the primarily monodic output of this "supreme artist of the individual song to the lyre." It is only over the past two decades or so that a more expansive "choralist" assessment of Sappho's poetry has emerged. It has now become increasingly accepted among contemporary students of archaic Greek poetry that the composition and performance of choral melic were integral to Sappho's musico-poetic activity, just as much, if not more so than her production of monody, and that a respectable number of the extant fragments, perhaps considerably more than previously thought, may derive from originally choral rather than solo songs. ${ }^{2}$ The once-canonical image of Sappho as a solo performer in a private setting has not been entirely discarded, but it has been fundamentally complicated. ${ }^{3}$

The choral reassessment of Sappho owes much to Malcolm Davies' 1988 article "Monody, Choral Lyric, and the Tyranny of the Handbook," in which he assails the misleading division between those poets deemed exclusively choral and those deemed exclusively monodic that has since the nineteenth century been a persistent feature of histories of Greek literature. As Davies

* My thanks go to the editors for their invaluable comments and corrections. I am grateful also to the participants in the Network conference at Berkeley and to audiences at Bard College and UCLA for their responses to earlier versions of this paper.

1 Lesky 1966: 141-142; cf. Page 1955: 119. An early, proto-choralist exception to the "exceptionalist" view of Sappho's choral activity is Latte 1953 .

2 See e.g. Lardinois 1994, 1996 (discussed below), and 2001; Aloni 1997; Nagy 2007, 2016; Calame 2009c; Ferrari 2010; Caciagli 2011; Bierl 2016a, 2016c; Ladianou 2016. The solo reperformance of Sappho's songs is generally agreed to have been the rule, at least in the archaic and classical periods. Gell. NA 19.9.4 attests to choral reperformances of Sappho (and Anacreon) at dinner parties in the second century CE. See Ladianou 2016: 359 .

3 Schlesier 2013 and Bowie 2016, however, in presenting arguments for a "sympotic Sappho" have revived the view of a dedicatedly monodic Sappho. 
shows, our identification of the performance genre of fragments of archaic lyric has been unfairly prejudiced by our too-rigid categorizations of their poets as either choral or monodic, when in fact most worked in both media, and by the not-always-definitive criteria of form and content that have long been used to differentiate monody from choral lyric: length of poems and strophes; meter and dialect; first-person statements; intimate and personal versus "communal" expression.

Davies was primarily concerned to show that many extant fragments of Stesichorus and Ibycus that have usually been deemed choral may rather derive from monodic songs. Although he cites in passing K.O. Müller's observation that "it is probable that the Aeolic poets sometimes composed poems for choral exhibition, for choruses were undoubtedly performed in Lesbos, as well as in other parts of Greece," Davies does not make the case for a choral Sappho; in fact, he seems content to keep her securely in the monodic camp with Alcaeus and Anacreon. ${ }^{4}$

Eight years after Davies, however, André Lardinois took up this case with vigor in his "Who Sang Sappho's Songs," which remains the most sustained and detailed argument for Sappho's activity as a choral poet. ${ }^{5}$ Taking his cue from Davies' critique of the totalizing segregation of "monodic" from "choral" poets and building on Claude Calame's study of the pervasive role of choreia in the lives of women and girls in early Greece, Lardinois fundamentally challenged the monodic construction of Sappho- the solo singer performing for her exclusive group - on philological, historical, and anthropological grounds. ${ }^{6}$ He demonstrated that many of the elements of form and content in Sapphic texts that scholars had long reflexively taken to be generic markers of monody are hardly definitive indices of solo performance, and find clear parallels in choral texts (or texts generally believed to be choral). Brief strophes? Choral songs (if such they are) of Alcman had those, too (e.g. 14a), as they did the seemingly "personal" expressions of erotic desire that would seem to mark so many of Sappho's songs as monodic. While not denying that Sappho did compose monody - fragment 1, with its persistent assertions of Sappho's own "I," is difficult for all but the most extreme "choralist" to read as anything but monody, for instance (though, as Lardinois argues, we cannot rule out the pos-

4 Müller 1840: 165 (quoted by Davies 1988: 59). For Davies' monodic bias, see Cingano 2003: 3233 .

5 Lardinois 1996, anticipated by Lardinois 1994.

6 Calame had already made strong arguments for Sappho's role as chorus leader in his Les Choeurs de jeunes filles en Grèce archaïque (1977a: 1.127, 369-370 [cf. 1997a: 65, 212]). 
sibility that a mute chorus danced as Sappho sang this or other apparently solo songs) - Lardinois shows that much of what has been assumed to be monodic may well have been choral, and may in fact more likely have been choral than solo, at least in initial performance.

Furthermore, Lardinois argues compellingly from a comparative angle that, given what we know about the prominence of female choruses in the societies of early Sparta and elsewhere in Greece, it would be hard to believe that choral melic did not in some significant way inform Sappho's activity as composer and performer. While it is true that in the earliest stage of reception that we can observe, Attic iconography of the sixth and fifth centuries BCE, Sappho is depicted as a monodic lyre-singer, that depiction is as likely to be a reflection of the mode in which her songs were reperformed in the Athenian contexts of the male symposium and perhaps too the aristocratic gynaeceum as any authentic indication of how they were first delivered on Lesbos. ${ }^{7}$ Learned Hellenistic and Imperial readers of Sappho, who knew her corpus far better than we do, certainly had no problem imagining her as a chorus leader with a public profile. A prime example is an anonymous epigram that depicts Sappho leading a female chorus on her lyre at Hera's "shining temenos," presumably the same sanctuary precinct that appears to be the setting for Sappho's fragment 17, which I shall discuss below. ${ }^{8}$

Whether or not we are sold on the specifics of their arguments, we must recognize the importance of the essential contribution made by Davies and Lardinois, which is to disrupt the largely unexamined orthodoxies and inherited assumptions about archaic lyric poets and poetic genres that often determine our assessments of original performance modality and occasion. The crucial takeaway from reading both is the recognition, now itself something of an orthodoxy, that we-those of us who believe in the interpretive value of attempting to reconstruct as best we can the reality of a given fragment's initial performance, even when such attempts necessarily remain fraught with uncertainty—should deal with each archaic lyric text on its own basis, regardless of the "baggage" its author or (when known) its poetic genre brings along, trying to remain simultaneously as skeptical and open-minded as possible in

7 Something similar would hold for what may be a still earlier point of reception: Anacr. fr. 358. Chamaeleon fr. 10 Koepke (ap. Ath. 13.599c) claimed that the Lesbian woman who is Anacreon's elusive object of desire in this song is meant to be Sappho. But this sympotic, monodic reception of Sappho, if that is what fr. 358 represents, tells us nothing definite about the original performance of Sappho's own songs.

8 Anth. Pal. 9.189. Cf. Lardinois 1994: 75; Ladianou 2016: 359-361. 
our use of both text-internal and external factors to form hypotheses about its original conditions of performance. ${ }^{9}$

This, of course, is easier said than done. Methodological purity is impossible. Assumptions will persist, both inherited and personal. Arguments will tend inevitably toward circularity as testimonia about performance, when rhetorically advantageous, are brandished as evidence to support reconstructions or, when inconvenient, written off as late, unreliable, or both. And what will seem to one reader an indubitable sign of monodic or choral execution will seem eminently ambiguous to another. Thus Davies' own critique of received assumptions about monodic and choral performance itself begins with and builds on a counter-assumption-a "growing perception," as Davies puts itabout the performance of Stesichorus, that "in the light of his epic-style and immensely long narrative poems he is unlikely to have been a choral lyric [poet]." ${ }^{10}$ Others, however, will perceive (and have perceived) these criteria to be hardly decisive for monody, and indeed quite consistent with choral song. Others too will question the selective treatment by Davies, and Stesichorean "monodists" more generally, of the testimonia: notices that associate Stesichorus with Homer and the kithara are enlisted to confirm the belief that his triadic songs must have been monodic (or specifically solo kitharodic), while those that reasonably enough associate triadic structure with choral execution are dismissed as irrelevant. ${ }^{11}$

Lardinois' opposite tack of choralizing a monodic Sappho also builds on the sort of received assumptions against which he cogently warns. First and foremost is that long-held belief that Sappho did compose some choral songs, which for Lardinois forms a sort of given baseline for his more expansive choralist arguments. Yet it must be emphasized that we can hardly be sure she did. ${ }^{12}$ A case in point is fragment 140 , which Lardinois, following Page, who is gen-

While I agree that we should not necessarily want to privilege "one 'primary' performance over all the others" (Agócs: 2012: 192), I think we should also not want to pretend that a fragment's original performance medium bears no essential relationship to its textual identity and "literary" distinctiveness.

10 Davies 1988: 53. The perception's initial growth spurt dates to West 1971, which presented the theretofore most concerted arguments for a monodic Stesichorus. See now also West 2015. Willi 2008: 76-82 remains a convenient summary of the debate over Stesichorean performance.

11 See West 1971: 312-313 and Lefkowitz 1991: 193-194, in the context of a monodist argument for the solo performance of Pindar's epinicia.

12 See Stehle 1997: 274, and now D'Alessio 2018, whose critique of choralist assumptions, though differently oriented—and more radically skeptical—complements the one offered in this chapter. 
erally a staunch monodist, adduces as a near-unassailable example of "genuine choral song." In his view, the fragment, which presents us with two verses of a dialogic lament sung by a group of korai and Aphrodite, is likely to come from a cultic Adonis song performed by "a person (or group) impersonating the goddess Aphrodite" and a chorus of girls impersonating the mythical korai: ${ }^{13}$

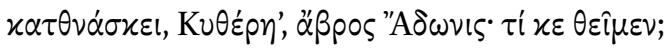

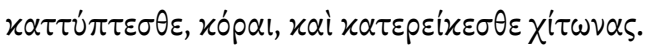

Delicate Adonis is dying, Cythera. What should we do?

Beat your breasts, girls, and rend your garments.

But pieces of Sappho's (very probably) monodic poetry could involve dramatic mimesis, simulated voices, and imaginary situations, such as we see in fragments 1 (Aphrodite makes an epiphany and converses with Sappho), 65 (Sappho addressed, probably by Aphrodite), 94 (stylized dialogue between Sappho and friend), 95 (apparently another epiphanic situation, with Sappho addressing a divinity, probably Hermes), 133 (Sappho addressed, perhaps by Aphrodite), and 137 (dramatic dialogue). It is just as likely, then, that fragment 140 derives from a monodic song, in which a solo singer voiced both sides of the exchange. ${ }^{14}$ Or we could even imagine a solo singer "quoting" the exchange in a mythical narrative such as we see in fragment 44.

Lardinois also accepts the consensus that certain of the epithalamia grouped together in the Alexandrian edition of Sappho (in the ninth book, or, more probably, the eighth ${ }^{15}$ were chorally performed. Since there can be no doubt that both the literary and iconographical evidence proves choruses routinely sang at weddings, the inference that the Sapphic epithalamia were mostly choral is reasonable and probably correct in the main. But other scenarios consistent with monodic performance are imaginable, and the "clear indications of choral performance" Lardinois finds in the textual remains of these wedding

13 Lardinois 1996: 152. Cf. Page 1955: 119 n. 1; Lardinois 2001: 77.

14 See Lidov 2016: 100-109 on the mimetic adaptability of the singing ego in Sapphic poetry and Yatromanolakis 2004: 59 on Sappho's "polyphony" and "diverse poetic personae." Dramatic mimesis and imaginary situations are recurring features of archaic lyric monody in general. Alc. fr. 10 and Anacr. 385 and 432, for example, present female speaking characters. Fictive encounters are of course stock in trade for composers of iambic poetry, e.g. Archil. fr. 122 (a father speaking to his daughter) or the Cologne Epode. See Albert 1988: 51-54; Slings 199o; D'Alessio 2009: 115-117 and 2018: 62.

15 See Dale 2011: 55-67, building on Yatromanolakis 1999: 193-194. 
songs may not be so clear to others. ${ }^{16}$ For instance, while the "dialogue-form" of fragment 114, an exchange between a bride and her personified (lost) virginity, may well support a choral reading, its decontextualized two lines may, as with fragment 140a, equally well represent a monodic dramatization or quotation. ${ }^{17}$ Lardinois himself acknowledges that Sappho may have composed (very probably) solo songs such as fragment 44 for performance at the wedding banquet. Fragment 114 could conceivably have been part of such a song. Or perhaps the song was not at all a "functional" epithalamium meant to be performed during the course of a wedding event, but merely treated matrimonial matters for some other narrative or rhetorical purpose, on some other occasion.

This last suspicion could of course be aroused by any of Sappho's (apparent) epithalamia, but especially by the two songs (fragments 27 and 30 ) with nuptial imagery and references that are included, apart from the epithalamia, in Book 1 of the Alexandrian edition. As Dale observes of fragment 30, "The language and imagery here are not incompatible with wedding songs, but it does not follow that the fragment must then be from an epithalamium."18 For Lardinois, however, these were pragmatic wedding songs, separated from the other epithalamia only because of their meter (Sapphic stanzas, which they share with other songs in Book 1), not their function, and, as such, are very likely to have been chorally executed. This line of argumentation has important "choralizing" ramifications for the rest of the Sapphic corpus: if accepted, it proves that "there can be no question of any clear, metrical division between Sappho's choral and monodic poetry, since we possess wedding songs (fragments 27, 30) as well as supposedly monodic songs (fragment 1 ), in the same Sapphic stanza."19

Lardinois finds in the two fragments features that are "very hard to explain" as anything other than signs of choral performance: the first-person plurals at fragments 27.8 and 30.9, which would seem to indicate choral performers,

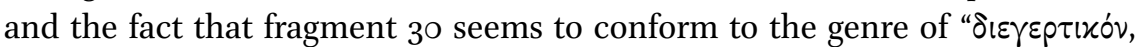
a song traditionally sung the morning after the wedding night by friends of the bride and groom." ${ }^{20}$ But it must be noted that in neither fragment do we

16 Lardinois 1996: 151 n. 4.

17 Cf. West 1970: 327.

18 Dale 2011: 57. Cf. Lasserre 1989: 36-38.

19 Lardinois 1996: 157; cf. Tognazzi 2009: 55 n. 1. A similar argumentative logic dissociating performance mode and metrical/structural form is at work in the monodists' reduction of triadic structure to a "purely musical principle of composition" (West 2015: 79, restating West 1971: 313), indiscriminate of performance mode (so already Crusius 1888: 9-14; cf. Cingano 2003: 23-24).

Lardinois 1996: 158 n. 39. Ferrari 2010: 113-114 imagines a different scenario: fr. 30 is not a 
find a first-person plural performative statement that outright clinches the choral performance of the song itself. Choruses seem to be present in both, but in neither-and this is true of all the Sapphic fragments in which indices of chorality are present - can a choral group be confidently identified as the actual performer. ${ }^{21}$ Fragment 3 o runs as follows (with the supplement of Lobel in line 6): \\ night ... maidens ... celebrating through the night ... they sing your love \\ and your violet-robed bride's.
}

But wake up and go (get?) the young men who are your age, so that we may see (as little) sleep as the bright-voiced (bird).

The speaker who in the second stanza calls upon (probably) the groom to fetch his peers, presumably in order to form a mixed chorus with the maidens (parthenoi) who are mentioned in the first stanza, is difficult to identify with those maidens. The maidens are singing at a pannuchis, as parthenaic wedding choruses were indeed wont to do, but their choral singing is described by the

"waking song," but meant to be performed after the wedding banquet; the groom is to be roused ( $\left.\varepsilon_{\gamma} \varepsilon \dot{\rho} \theta \varepsilon ! ! \zeta\right)$ from the party to join his friends in the wedding procession. Cf. Aloni 1997: 61.

21 Cf. Ladianou 2016: 343; D’Alessio 2018: 57, "Sappho's poems very rarely use indexical markers to embed themselves pragmatically within their own contexts of performance." But of course such vagueness is not inconsistent with choral lyric. Pindar's choral epinicia, for example, demonstrate ambiguity in their performative self-presentation, for a range of possible reasons, including the prospect of their own monodic reperformance. See Morrison 2012; Currie 2017. 


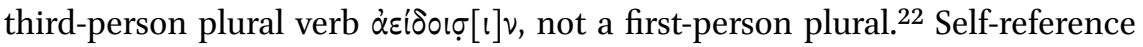
is thus unlikely. It seems preferable to postulate scenarios made possible by monodic performance. One is that the persona loquens throughout is the song's solo singer, who both describes the scene and plays the role of a master of ceremonies or chorus leader within it, arranging the performance of the $\delta \varepsilon \gamma \varepsilon p \tau i x o$, whether in actuality (if we think this a functional hymeneal song), or, as I think more probable, merely in the song's imaginary. ${ }^{23}$ The first-person plural ' $\delta \delta \omega \varepsilon v$ in line 9 would accordingly represent not the parthenaic chorus alone, but the

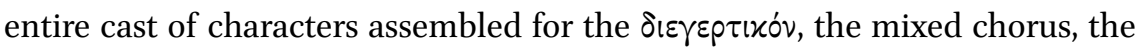
married couple, and the speaker. ${ }^{24}$

Another possibility is that in the first preserved stanza we hear the voice of the solo singer qua narrator, while in the second we hear a simulated choral voice. That is, the second stanza might represent a quotation, embedded within the monodic song, of the choral song performed by the parthenoi who are evoked in the first stanza. ${ }^{25}$ It would thus be the "singing" maiden chorus, given voice by the soloist, that commands the groom to rise and muster his own choral contingent. Such stylized injunctions to perform, delivered in the course of a musical performance itself, are not uncommon in choral lyric (see e.g. the female chorus' song at Ar. Thesm. 953-958). To the monodic simulation would accordingly have been added a touch of choral verisimilitude. ${ }^{26}$

Fragment 27 is slightly better preserved than fragment 3o, but the implied setting and speech situation are still frustratingly hazy:

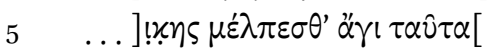

$$
\begin{aligned}
& \text {.. ] } \zeta \dot{\alpha} \lambda \varepsilon \xi \alpha l, x \dot{\alpha} \mu \mu^{\prime} \dot{\alpha} \pi \dot{v} \tau \omega \delta \varepsilon \varepsilon[
\end{aligned}
$$

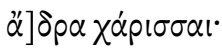

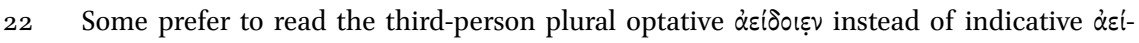

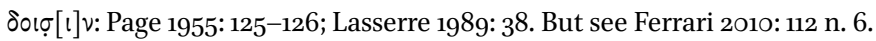

23 Dale 2011: 57 suggests a related possibility: the fragment belongs to "a mythological narrative with direct speech," in which the speaker would be an embedded character impersonated by, but not identical to, the narrating performer. Lasserre 1989: 38 believes Sappho herself sang fr. 30 on an actual wedding occasion.

24 Ferrari 2010: 114 offers a similar reading.

25 As fr. 1.18-24 indicates, Sappho did not always feel the need to put introductory (and closing) formulae around quoted speech. See also frs. 114, 137, and 140, with Führer 1967: 2-3. But conceivably the verb $\dot{\alpha} \varepsilon \dot{\delta} \delta \circ \iota \sigma$ [ı] $\nu$ might serve to introduce the quoted song.

26 For choral song's textualized projection of its present performance into the future, see D'Alessio 2004. 


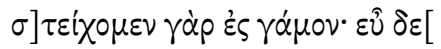

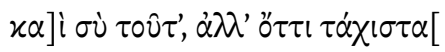

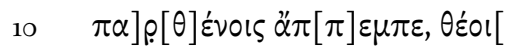

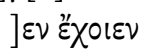

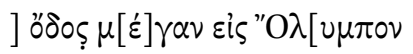

$$
\begin{aligned}
& \dot{\alpha}] \nu \theta \rho \omega[\pi \quad] \alpha i x .[
\end{aligned}
$$

for you too were once a child ... to sing and dance, come, these things ... converse ... and grant us from ... (generous?) favors.

For we are going to a wedding; and you also (know?) this well; but as quickly as possible send off (the) maidens, gods ... may they have ...

... road to great Olympus ... mortals ...

As with fragment 30, much depends on whether we can identify the voice utter-

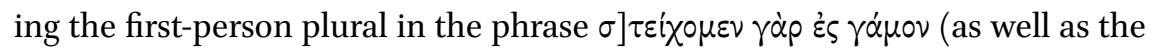
first-person-plural dative pronoun $\alpha \mu \mu \mu$ in line 6) with the parthenoi mentioned in line 10. On one reading, there is no identification: the speaker is an individual voiced in performance by a solo singer, and the "we" encompasses both her and the parthenoi to whom she refers. But self-reference does seem less problematic than in fragment 30 , and it must remain a distinct possibility that the "we" belongs to the maidens themselves, and that it is they who command the addressee to send them on their way $(\alpha \ddot{\pi}[\pi] \varepsilon \mu \pi \varepsilon, 10)$, emphatically specifying their own maiden status as they do so (i.e. [us] parthenoi). The addressee may well be the bride, who in her younger days "sang and danced" ( $\mu \varepsilon \lambda \tau \varepsilon \sigma \theta$ ', 5 ) in a chorus, but has now aged out of the group. ${ }^{27}$ Choral song and dance is exactly what we imagine the parthenoi intend to perform when they arrive at the wedding ceremony ( $\gamma \alpha \dot{\mu} \% \mathrm{v})$, and what indeed they are currently performing on some ritual occasion immediately prior to it, perhaps during the wedding procession itself. Fragment 27, then, would be the choral song Sappho composed for performance on such an occasion. ${ }^{28}$

But again, keeping in mind the mimetic and imaginary capacities of monody, we must remain open to the possibility that the choral voice need not be

\footnotetext{
27 Aloni 1997: 57. Tognazzi 2009 argues that the bride's mother is the addressee; Ferrari 2010: 32 proposes one of Sappho's rivals.

28 Cf. Aloni 1997:56-57; Tognazzi 2009:54-55. Caciagli 2009 admits the possibility of a choral speaker, but remains agnostic.
} 
"real," but rather simulated by a monodic singer, and the performance occasion entirely imagined. Such a simulation may have been part of a stand-alone narrative situation related in the song. (We are missing the first stanza, which could have provided the set up.) But we might entertain a further possibility, that the monodically represented choral song may have been an episode in a larger narrative cycle of songs concerning a girl's marriage, in which the chorus itself was a "character." ${ }^{29}$ Page thought that fragment 27 was likely placed immediately before fragment 30 at the end of the first book of the Alexandrian collection. ${ }^{30}$ Might we be tempted to see in this (possible) late editorial ordering some recognition of Sappho's own narrative sequencing of these two songs, one involving a parthenaic chorus singing for the bride before the wedding ceremony, the other, the night and the morning after?

At any rate, we should want to let go of the certainty that fragments 27 and 30 are transcripts of songs that were actually performed, whether by a chorus or a soloist, on a specific wedding occasion. Yes, they might represent generic templates that Sappho designed to be performed and reperformed at any wedding celebration. But the real possibility that these were monodic songs about weddings rather than "wedding songs" proper, and were performed probably in some connection to a wedding event-as preparation or commemorationbut not actually as an occasional and functional part of one, offers, I think, a compelling alternative scenario. ${ }^{31}$

\section{Parachoral Sappho}

Despite the impression the previous pages may have given (and the following pages may give), I am not interested in mounting a monodist counter-critique of the choralist critique of monodist complacency. In subjecting certain appar-

29 That Sappho composed sets of thematically and narratively related songs seems now more probable after the discovery of the Brothers Song and the fragments from the Green Collection, which together point to a cycle of songs, all in Sapphic stanzas, devoted to matters relating to Charaxos' (mis)adventures. See Lardinois 2014: 192, 194 and 2016; Neri 2015: 6768; Obbink 2016c: 211; Peponi 2016: 234; Boedeker 2016b: 194. Archilochus' cycle of iambic poems concerning the Lycambids has been discussed as a parallel: Lardinois 2016: 184 .

30 Page 1955: 126. See now too Obbink 2016a: $44-45$ for the placement of these songs (probably out of alphabetical order) at the end of Book 1.

31 Lasserre 1989: 134 comes to a similar conclusion in respect to fr. 27; cf. too Caciagli 2009 for 27's intermediary status between public and private. D'Alessio 2018: 46-50 discusses "the way in which pragmatic self-referentiality" in frs. 27 and 30 is "far from straightforward" (47). 
ently choral fragments to a monodist rereading, my intentions are much in the spirit of the choralist project: to explore viable (if inevitably conjectural) alternatives to established interpretive assumptions. ${ }^{32}$ In fact, I find myself in sympathy with both Lardinois' general outlook — not only his rejection of truisms, but his recognition of the liberating potential inherent in our very lack of certainty about Sapphic performance, which allows, or rather compels us to read the poetry with a view to alternative performance modes and representational possibilities - as well as his specific arguments for the choral execution of certain Sapphic compositions.

Even for those who remain immune to some or all of those arguments, they are nonetheless a salutary reminder of how thoroughly steeped in choral culture Sappho and her audience must have been, and how much of her poetry that choral skeptics would still consider monody engages with that culture. For if Sappho's poetry was not in fact as choral as Lardinois and other choralists would have it, it is still the case that much of it is marked by discursive and conceptual tendencies we might call "parachoral." By this I mean that Sappho's (probable) monodies routinely position themselves in meaningful relation to choreia, integrating, through allusion, descriptive reference, and mnemonic evocation, or indeed through outright simulation, the language, imagery, tropes, and postures of choral performance and occasion, and, by extension, their broader cultural contexts and connotations. ${ }^{33}$ The debate over a choral versus monodic Sappho remains important to our understanding of the poetry. It can, however, have the undesirable side effect of overshadowing the emotional, symbolic, and rhetorical work choral song-and-dance does as an expressive and ideational resource, a discourse, within Sappho's poetics.

32 In this respect, I would agree with Caciagli 2016:446 that "the point is not actually to divine the one correct context for a poem, but simply to raise the question about the context." Cf. Yatromanolakis 2009a: 218; Budelmann and Phillips 2018: 14.

33 See Bierl's remarks on what he calls the "virtual chorus" in Sappho: "Sappho thus assumes a living choral culture for the reception of her poetry, even when the songs are performed by an individual singer. I designate this phenomenon as the 'virtual chorus': although her songs may not have been sung by a chorus, Sappho nonetheless notionally employs the girls' chorus of her circle as a cultural and visual reference point" (2016a: 311; cf. Bierl 2008). Relevant too are the remarks on Sappho's choral themes and imagery in Nagy 1990: 370-371 and Ladianou 2016, and, more generally, Yatromanolakis' characterization of her poetry as a "communicative, performative event that could absorb elements of diverse ritual discourses" (2004: 63). See also the approach taken by D'Alessio, who emphasizes the occasional "marginality" of Sappho's texts, which rarely "present themselves as straightforward scripts of ritual performances, to be staged. They rather evoke such performances, or look at them sideways" (2018: 61). 
In fragments 27 and 30, we saw, representations of choral performance play an important structural and atmospheric role in the hymeneal mise-en-scène while not reflecting the performance of the songs themselves, which was probably monodic. There are notable parachoral moments too in fragments 16 (reminiscence of Anactoria's "lovely step and the brilliant sparkle of her face," 17-18), 94 (shared memories of participating in a choros, 27-28, perhaps in a sacred grove), and 96 (recollections of delight taken in Atthis' song and dance in the chorus [molpa, 5]; cf. the reference to bygone melpesthai in fragment 27.5). These are songs in which choral performance serves as a flashpoint of memory and desire, and an enduring testament to the bonds that continue to tie now-distant friends. ${ }^{34}$

The recently restored fragment $5^{8}$ presents a still more vivid case of parachorality: the singer addresses her younger companions, paides, in the persona of an Alcman-like kitharistes or chorus leader addressing a parthenaic chorus, both lamenting that she is now too old to dance along with her friends and accepting that transition as an inevitability. ${ }^{35}$ Sappho may well have taken on the role of kitharistes in actual choral performances on Lesbos, as we see her doing in the epigram mentioned earlier, but in the monodic fragment 58 choreia is treated as a figure of thought, a situational metaphor for the social and affective dynamics of Sappho's group (or any analogous group), not to mention for the human condition itself.

\section{Fragment 17: A Parachoral Monody}

I would like to propose that in another song, fragment 17, Sappho offers us a particularly rich example of "parachoral monody." This reading admittedly goes against the grain. Fragment 17 is a text that even decided monodists have long taken to be a contender for choral performance on a public ceremonial occasion. ${ }^{36}$ With the expanded reconstruction of the fragment afforded by

34 The parachoral reading of fr. 94.27-28 depends on Lobel's supplement $\chi$ ]ọpos, which gains support from $\psi$ ó $\varphi$ os 'sound' in the next line. One would like to have a better sense of the context in which $\chi$ ópos appears, alongside the musical terms $\alpha$ p $\mu \circ v^{\prime} \alpha \varsigma$ and $\lambda i \gamma \eta \alpha$, at fr. 70.911. On Ferrari's reconstruction, an exiled Sappho envisions an idealized scene of choral music-making such as she and her companions used to enjoy (2010: 19-22). Music and memory are more certainly entwined in fr. $71.5^{-6}$, but choral language, if it was there, leaves no traces in this lacunose fragment.

35 Cf. Alcm. fr. 26, with Lardinois 1996: 169 and Bierl 2016a: 323-324. On the representation of performance in fr. 58 , see also Boehringer 2013 .

36 E.g. West 1970: 327; Fränkel 1975: 181; Williamson 1995: 136; Stehle 1997: 275. 
the recently published papyrus from the Green Collection, the case for performance by a chorus on a festival occasion seems even stronger. Here is the latest version of the text as edited by Dirk Obbink (along with Obbink's translation, which includes some minor supplements not presented in the Greek text; I have left out those in the first and second-to-last stanza): ${ }^{37}$

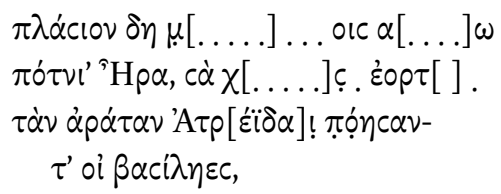

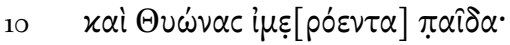

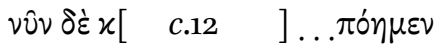

$x \dot{\alpha} \tau \tau \dot{\partial} \pi \dot{\lambda} \lambda[\alpha 10 \nu$,

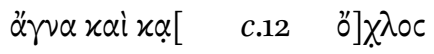

$\pi \alpha \rho \theta \varepsilon ́\left[\begin{array}{lll}\nu \omega \nu & c .12 & \gamma\end{array}\right] v \nu \alpha i x \omega \nu$

$15 \alpha \dot{\alpha \mu \varphi ा c . ~[~}$

$$
\mu \varepsilon \dot{\varepsilon} \rho^{\prime} \dot{\partial} \lambda[
$$

$\pi \alpha c[$

.[.] . $\nu 1 \lambda[$

$\varepsilon^{\prime \prime} \mu \mu \varepsilon v \alpha[\mathrm{l}$

20

$$
\left[{ }^{\wedge} \mathrm{H}\right] \rho^{\prime} \dot{\alpha} \pi i x \varepsilon[c \theta \alpha \mathrm{l} .]
$$

Near here, indeed, [

your [ ] festival, revered Hera,

which the Kings, the Atreidai, established

on a vow, 
$5 \quad$ since they had accomplished heroic exploits

in the beginning at Troy, but later on

putting in just here: for they could not

find their way

before they had approached you, and Suppliant

10 Zeus and Thyone's soothing child.

Now we, too, [continue] to perform [these things]

just like of o[ld]

that are pure and $\left[\begin{array}{l}\text { ] throng } \\ \text { of unmarried women [ ] wives } \\ \text { around [ } \\ \text { measures[ }\end{array} \quad\right.$.]

Each $[\ldots$

$[\cdots$

to be $[\ldots$

$20 \quad[\mathrm{He}] \mathrm{ra}$, to come back.

We now have explicit mention of a festival (źóp $[$ [ ], 2), one presumably devoted to Hera, who is also invoked in line 2, and celebrated at a shared sanctuary of Hera, Zeus, and Dionysus (cf. 9-10) that would appear to be the one located at Messon. ${ }^{38}$ We have too the first-person plural $\pi$ ón $\mu \varepsilon \nu$ (11), which may be appealingly interpreted as a performative verb linking a singing chorus' present ( $\nu \hat{v} \nu \delta \dot{\varepsilon} \chi\left[\alpha{ }^{\prime}, 11\right)$ ritual-cultic performance with performance in the foundational mythical past ( $\chi \dot{\alpha} \tau \tau \dot{o} \pi \dot{\alpha} \lambda \underline{[}[\alpha\llcorner o v, 12)$, when the Atreid kings made sacrifice at the sanctuary. ${ }^{39}$ Such aetiological grounding in myth of here-and-now cult and ritual, including choral song itself, is a recurring feature of archaic choral poetry. ${ }^{40}$

Furthermore, we can now read ó] $\chi \lambda \lambda_{0 c} \mid \pi \alpha \rho \theta \varepsilon[\nu \omega \nu . . . \gamma] \cup \nu \alpha i x \omega \nu$ in lines 1314 , as well as $\mu \varepsilon \dot{\tau} \rho \alpha$ in line 16 , a word with musical and orchestic connotations, and perhaps also another such word, the infinitive $\operatorname{co}_{\lambda}\left[0 \lambda u^{\prime} c \delta \eta \nu\right.$ "to raise

38 Full discussion in Caciagli 2016. For the pan-Lesbian sanctuary at Messon, see also Caciagli 2010 and Boedeker 2016b.

39 Calame 2009c: 4-5 already argued for the choral execution of fr. 17 along these lines, working with a far more exiguous text.

40 E.g. Bacchyl. 20.1-6, with D'Alessio 2013: 124-125. On the aetiological habit in early choral lyric, see Kowalzig 2007b. Calame 2009c: 5 comments on the "cultic effectiveness" of the mythical episode in fr. 17. 
the ololuge cry," immediately after it. ${ }^{41}$ All this is tempting to take as a performing chorus' self-descriptions, whether explicitly hic et nunc, or perhaps, if the text again looked back in time, via the indirect self-reference afforded by "choral projection" into the past. ${ }^{42}$ In the latter case, Sappho's chorus would be aligning its own performance with, and suggesting its ritualized reenactment of, the mythically paradigmatic female choruses that danced and sang on the originary occasion of the Atreids' visit, much like the "throng" of Tro-

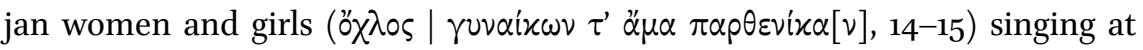
the wedding of Hector and Andromache in fragment 44, who are conceivably meant to represent a glorious prototype for wedding choruses on Sappho's Lesbos. ${ }^{43}$

Obviously, we are still missing critical parts of the first and last stanza, which might point us toward or further away from the idea that the song was intended for actual choral execution. Scholars have offered various reconstructions of the song's first two lines that would push our understanding of the text in a more choral direction; these are ingenious, yet entirely speculative, and so best left out of this discussion. ${ }^{44}$ As they stand, it is impossible to know what to make of the adverb $\pi \lambda \dot{\alpha} \sigma \iota_{0}$ "nearby," but, if it does refer deictically to the spatial relation of persona cantans to festival site, then we might be looking at the text of a prosodion: the chorus sings either as it approaches the sanctuary of Hera, anticipating the festivities to come, or as it moves in a procession toward the altar within the sanctuary itself.

The final stanza demands even greater feats of speculation, but the presence of $\dot{\alpha} \pi i x \varepsilon[\sigma \theta \alpha \mathrm{l}$ in line 20 could indicate that it included a prayer to Hera to secure a homecoming for Sappho's brother Charaxos, echoing the prayer for nostos offered up by the Atreids. But even such a personal touch in an other-

41 The presence of $\mu \varepsilon \dot{\varepsilon} \tau \alpha$ will be of interest to students of ancient music, if indeed it does have its musico-poetic meaning of "meters, measures," which is otherwise securely attested only in the fifth century. Cf. Ford 2002: 18. (If גppovi $\alpha \varsigma$ at fr. 70.9 has a technical musical sense, it would likewise be the earliest attestation of that musical term; see Franklin 2003: 302 n. 11.)

42 See Henrichs 1996a for "choral projection."

43 This performance resembles in other details too the one adumbrated in fr. 17. The Trojan

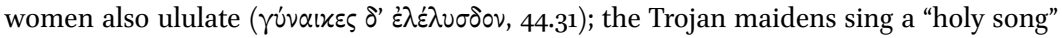

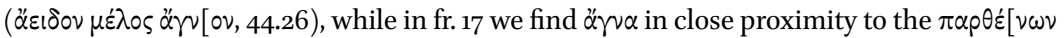
(13-14). Both frs. 17 and 44 in turn recall the evocation of women's choral performance at Messon in Alc. fr. 13ob.17-20 (discussed below). Intertextual engagement between two or more of these texts is possible, but all three might draw independently upon a common mythopoetic language of choreia, reflective of epichoric choral practice on Lesbos. Cf. Gentili 1988: 219-220.

44 See the apparatus criticus at Obbink 2016a: 20. 
wise publically oriented song would not drastically compromise a hypothesis of choral delivery before a festival audience.

In their commentary on the augmented text of fragment 17 , Burris, Fish, and Obbink conclude that 17 "is (or at least is presented as) a choral song intended for cultic performance." They propose that the most likely performance site would be Messon, perhaps during the Kallisteia festival for Hera. ${ }^{45}$ While there is indeed much to recommend reading fragment 17 as the choral "real thing," I would like to expand upon that parenthetical note of caution, "(or at least is presented as)." As Burris, Fish, and Obbink realize, just as nothing in fragment 17 seems to dictate against a choral reading, so nothing guarantees it. ${ }^{46} \mathrm{We}$ should remain receptive to the possibility that the song is a monodic simulation of choral performance, and that its cultic-festive setting and choral indices are purely imaginary textual effects, fictions conjured up by the solo singer in collusion with her audience, presumably a more private than communal and festive one. ${ }^{47}$ On this reading, fragment 17 would represent an extreme example of parachorality, a complete paroidia, so to speak, of a cultic choral song, in the performance of which Sappho, or indeed any singer of fragment 17, fully assumed the role of a chorus.

A monodic "choral fiction" of this extent—and there would seem to be no nonmimetic frame around the fiction, as far as we can tell —is not, to my knowledge, elsewhere attested. ${ }^{48}$ But, as we have seen, relevant instances of situational mimeticism and dramatic impersonation are well attested for archaic monody, including Sappho's own poetry, so it is far from being out of the question. Solon, performing his "Salamis Elegy" at the symposium—as he very likely

45 Burris, Fish, and Obbink 2014: 5. But a variety of festivals must have been held in Hera's sanctuary at Messon; see Caciagli 2016: 428-429.

46 On this last point, see Neri 2014: 21. D'Alessio 2018: 45 presses it further: on his cautious reading, nothing in 17 even implies its choral performance.

47 I hesitate to speculate any further about the nature of that audience, or the site where such a monodic performance would have taken place. At home in Mytilene? At a festivalrelated gathering at or near Messon itself? Bowie 2016: 153, 156 thinks of a solo performance of fr. 17 by Sappho at a Mytilenean symposium. Caciagli 2016: 447-448 thinks of a semi-public first performance at Messon (though it is unclear to me whether he believes the song was performed by a chorus). Obbink $2016 \mathrm{c}: 212$ proposes a recurring ritual performance occasion for the Charaxos songs. For D'Alessio 2018: 45, the most that can be said regarding context is that 17 "look[s] at cultic performance from the margin."

48 As D'Alessio 2009: 116 notes, we have fragments of songs that seem to have been "entirely constructed as speeches by fictional or typical characters," and so lack (as far as we can tell) introductory and/or closing formulae. In Alc. fr. 1ob, a woman's voice commences the poem, as perhaps too in Anacr. 385. Theognidean elegy offers further instances: 257-26o; 579-582; 861-864. On this last elegiac poem, see Martin 2001. 
did, despite the anecdotal traditions that have him singing the poem in the agora ${ }^{49}$ - could play from the very beginning of his song the role of a herald, just arrived from Salamis to impart an urgent message to his audience (fr. 1.12). A solo singer giving voice to an imaginary chorus might require more of her audience's phantasia, but the impersonation would surely not create undue confusion. If we look beyond archaic lyric to Attic drama, we find a comparable text in Aristophanes' Thesmophoriazusae: Agathon's bravura monodic rendition of an antiphonal choral hymn, in which he sings the parts of both chorus leader and female chorus (101-129). Indeed, fragment 140a, if it was monodic rather than choral, would seem to give us already in Sappho an analogous example of a chorus in dialogue with a chorus leader, with both parts played by the solo singer. As I argued in the previous section, fragments 27 and 30 may have involved monodic quotations of choral song.

But, if this scenario passes the probability test, the next question we must ask is: what motivates this parachoral posturing? If we believe fragment 17 to be monodic and we do not try to answer this question, then we default to a tacit assumption about its composition that essentially resembles Page's assessment of the non-political hymns of Alcaeus (fragments 307, 308, and 34), according to which they were mere "literary exercises, designed for the entertainment of an audience ... [rather] than devotional cult-songs. ${ }^{50}$ On a monodic reading, fragment 17 would conform in part to Page's characterization of the Alcaean hymns, in that it only pretends to be a public cult song. (It should be noted, however, that none of these hymns includes indications of chorality, real or imagined; their model seems rather to be solo citharodic or rhapsodic hymns.) It seems unlikely, however, that Sappho intended fragment 17 to be a freestanding literary exercise or divertissement. Such categories seem hardly applicable to archaic poetry, which, though pleasurable, typically served as a pragmatic medium of communication responsive to specific social occasions, situations, and concerns. Page in fact concluded that fragment 17 did address a particular issue that was a concern to Sappho: "The theme of this poem ... was probably some personal matter, to which the allusion to the Atreidae was subsidiary. Sappho needs the help of Hera, as the Atreidae needed it in the famous story .... The last two stanzas explained the cause of Sappho's anxiety."51 "Last two stanzas" aside - we now know that the second-to-last stanza of fragment 17 probably did not refer to any personal matters-Page's conclusion remains compelling.

49 Bowie 1986: 18-19.

50 Page 1955: 244 .

51 Page 1955: 61-62. 
Any number of "personal matters" could have motivated Sappho's hymn to Hera. ${ }^{2}$ But there is reason to believe that the final stanza of fragment 17 included a prayer to Hera for her brother's arrival on Lesbos, or, even if Charaxos was not named, that the song was nevertheless intended to be an implicit expression of Sappho's hopes for her brother's safety. ${ }^{53}$ Although fragment 17 was apparently not placed alongside the other poems concerning Charaxos beginning with the letter $\Pi$ in the first book of the Alexandrian Sappho edition, it nevertheless seems reasonable to read the song, which tells a myth concerned with homecoming from sea, in the context of prayers for his safe return that are expressed in other songs: the Brothers Song ( $\dot{\alpha} \pi \dot{i} \kappa \varepsilon[\sigma \theta \alpha$ l at 17.20 recalls $\dot{\xi} \xi i x \varepsilon \sigma \theta \alpha$ l

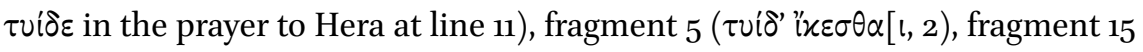
(prayer to Aphrodite that Charaxos reach harbor), and perhaps fragment 9 as well. ${ }^{4}$ In fragment 9, Sappho possibly evokes Hera as "Mother" in line 3 - a cult

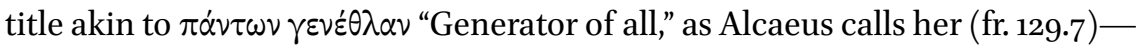
in the context of a prayer for Charaxos. ${ }^{55}$

If Charaxos was in fact a real person, and fragment 17 represents a genuine attempt to win for him divine protection, then perhaps what Sappho was doing with this parachoral monody was to lay claim for her solo song to what Leslie Kurke calls "choral value," that privileged ideology of religious and social efficacy attributed to choruses in early Greek culture, and thus to lend the impression of such religious efficacy and social moment to her solo prayer to Hera. ${ }^{56}$ (A.E. Peponi has suggested to me the apt metaphor of "amplification" to describe the intended effect.) The imagined site and occasion of performance, a potently sacred and storied festival at the geographical and sociopolitical centerpoint of Lesbos, Messon, would complement this virtual transfer of genre and value.

Much the same interpretation applies, I would argue, if Charaxos is a construct of Sappho's poetic imagination, a character in a fictive family drama that played out over a cycle of interlinked poems and that had some paradigmatic

$5^{2} \quad$ See the review of proposals in Neri 2014: 13.

53 So already Caciagli 2011: 155-157. See now Caciagli 2016; cf. Boedeker 2016b; Bierl 2016a: 324. As Lidov 2016: 67 notes, "It is improbable that this [final stanza] is a cletic prayer, asking for Hera's arrival, because final prayers are usually imperative."

54 For the separation of fr. 17 from the other Charaxos songs beginning with $\Pi$, see Lardinois 2016: 173. It may have been kept apart for reasons we cannot grasp; see Neri 2014: 22 n. 76.

55 See Lardinois 2016: 172-173, who notes too that $\dot{\alpha} \beta \lambda \alpha[\beta$ at fr. 9.9 is "reminiscent of $\dot{\alpha} \beta \lambda \dot{\alpha} \beta \eta \nu$ ('unharmed') in the opening line of fragment 5." Cf. Dale 2015: 20. West 2014: 7-8, however, reconstructs a domestic scenario for fr. 9, in which Sappho addresses her own mother. See now D'Alessio 2018: 55-56.

$5^{6} \quad$ Kurke 2012. 
value for her Mytilenean audience. ${ }^{57}$ In this case, of course, fragment 17 's choral fiction is not a response to real events, but rather a "naturalistic" response to demands in Sappho's imaginary world. In other words, since the social value and cultural significance of chorality and the Messon sanctuary would be as self-evident on a fictionalized Lesbos as the real one, the mobilization of a (fictional) chorus to beseech Hera for a brother's safe return would be a logical development in the story. ${ }^{58}$

It is unclear how the Charaxos story, whatever its relation to reality, was articulated across the various poems concerned with it. An appealing argument has been made for its presentation in vignettes that were "meant to operate as distinct and self-standing facets of a narrative that was never explicitly organized as such. ${ }^{59}$ If we do assume a place for Charaxos in fragment 17 , however, we will not want to discount a close narrative connection between fragment 17 and the Brothers Song. The parachoral orientation of the latter is arguably clear enough: its opening exchange, in which the persona loquens tells the addressee to "send me and bid me to beseech Queen Hera over and over again that Charaxos

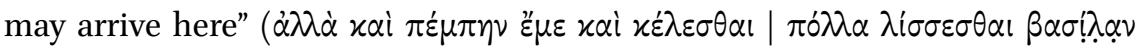

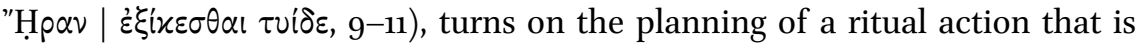
implicitly choral. ${ }^{60}$ As Gregory Nagy has shown, $\pi \dot{\varepsilon} \mu \pi \eta \nu$ "send" is ritually and performatively marked: the speaker refers to a pompe, a formal procession to Hera's sanctuary, presumably at Messon, where the prayer for Charaxos will be delivered with a kind of concentrated intensity $(\pi \dot{0} \lambda \lambda \alpha) .{ }^{61}$ We can assume that this heightened supplication of the goddess, at a site known for its choruses, is intended to take the form of choral song; pempein is in fact used precisely for the ritual dispatch of choruses (Xen. Mem. 3.3.12; Eur. El. 432-434). ${ }^{62}$ Might this

57 For Charaxos as fictional and the Charaxos songs as socially relevant fictions, see Lardinois 2016; Lidov 2016; Obbink 2016c: 213. On the "cycle," see n. 29 above.

$5^{8}$ I should add that, even if Charaxos (whether real or imaginary) played no role at all in fr. 17, but some other "personal matter" motivated the song—for instance, Sappho's own imminent departure into exile (thus Tsomis 2001:45) - the rhetoric of parachorality would have the same purpose, the enrichment of a monodic prayer.

59 Peponi 2016: 234 .

6o Kurke 2016: 249 observes how the Brothers Song itself takes on a choral guise, its solo persona loquens blending into a collective persona cantans as the song proceeds from the first-person singular in line 9 to consistent first-person plurals in and after the prayer at 1113: "[I]f we read the quoted prayer as extending through the whole poem, we must imagine its words doubled and voiced simultaneously by ego and $s u$, the two voices fusing as a kind of chorus."

61 Nagy 2016: 459-46o; cf. Kurke 2016: 242. For Messon as the probable destination, see Boedeker 2016b; Obbink 2016c. For $\pi \dot{\lambda} \lambda \alpha$, see Bierl 2016a: 366 .

62 See Nagy 2016: 460: "the procession is in fact already a chorus in the making." I would also 
projected choral prayer find its realization, as it were, in the cult hymn to Hera evoked in fragment 17 ? The texts permit no certain answer, but a parachoral "sequencing" between these two Sapphic monodies remains an intriguing possibility. ${ }^{63}$

\section{Parachoral Alcaeus?}

It is instructive to compare Sappho fragment 17 with Alcaeus fragment 129, which, through vivid deixis, locates its performer (and, by extension, its audience) at a cult site most scholars now agree is Messon: ${ }^{64}$

$$
\begin{aligned}
& \text { ] . . } \rho \dot{\alpha} . \alpha \tau o ́ \delta \varepsilon \Lambda \dot{\varepsilon} \sigma \beta 101
\end{aligned}
$$

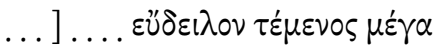

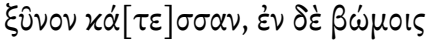

$$
\begin{aligned}
& \dot{\alpha} \theta \alpha \nu \alpha \dot{\tau} \tau \omega \nu \mu \alpha x \alpha \dot{\alpha} \omega \omega \nu \text { हैं } \eta x \alpha \nu
\end{aligned}
$$

$5 \quad x \dot{\alpha} \pi \omega \nu \dot{j} \mu \alpha \sigma \sigma \alpha \nu \dot{\alpha} \nu \tau i \alpha \circ \nu \Delta \dot{\alpha} \alpha$

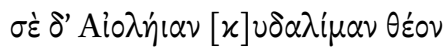
$\pi \alpha \dot{v} \tau \omega \nu \gamma \varepsilon v \varepsilon \dot{\varepsilon} \theta \lambda \alpha \nu, \tau \dot{\nu} \nu \delta \dot{\varepsilon} \tau \dot{\varepsilon} \rho \tau o \nu$

$\tau o ́ v \delta \varepsilon x \varepsilon \mu \eta \dot{\eta} \lambda 10 \nu \dot{\omega} v \dot{v} \mu \alpha \sigma \sigma[\alpha] \nu$

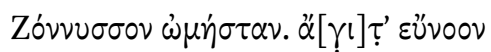

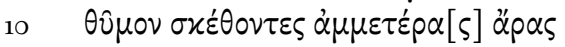

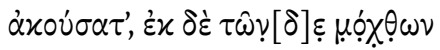

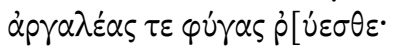

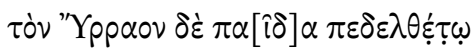

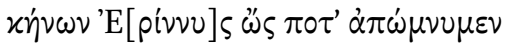

$15 \tau \tau^{\prime} \mu о \nu \tau \varepsilon \varsigma \ddot{\alpha} . .[\quad \ldots] \nu .$.

$\mu \eta \delta \dot{\alpha} \mu \alpha \mu \eta \delta^{\prime}$ हैं $\alpha \tau \dot{\alpha} \nu$ ह่ं $\tau \alpha i \rho \omega \nu$

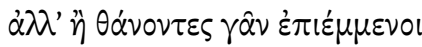

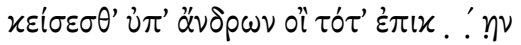

draw attention to Sappho fr. 27, in which apopempein (10) probably does not mean "dismiss" the girls, but rather "send them off" by way of a wedding procession. Cf. D'Alessio 2018: 49 n. 43 .

63 Cf. Neri 2015: 56; Caciagli 2016: 435 .

64 See Robert 1960: 300; Nagy 1993. 


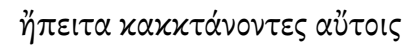

20

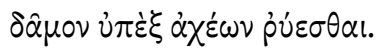

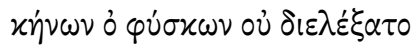

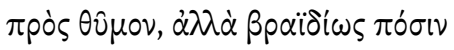

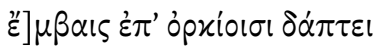

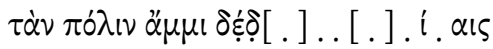

25 ov่ xàv vónov [.]ov. . [ ] ]. [ ]

$\gamma \lambda \alpha \dot{x} \alpha \varsigma \dot{\alpha}[.] . . .[.] . .[$

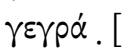

Múpotị[0

... the Lesbians established this great and conspicuous sanctuary precinct as a common one and in it they put altars of the blessed immortals,

and they gave Zeus the title God of Suppliants and you [Hera], the Aeolian, Glorious Goddess, Generator of all, and the third, this one, they named Kemelios,

Dionysus, Eater of Raw Flesh. Come, having a favorable spirit hear our prayer, and from these troubles and from difficult exile rescue us.

The son of Hyrrhas [Pittacus] let their Erinys pursue, since once we swore an oath, cutting ... at no point any one of our companions (to abandon?),

but either to lie clothed in earth, killed by men who at that time ... or else having killed them to rescue the people from their woes.

Pot Belly did not speak to the heart of those men, but casually stepping upon the oaths he devours our city ...

not according to law ... gray ... written (?) ... Myrsilus ...

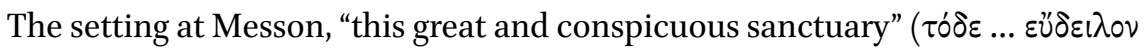

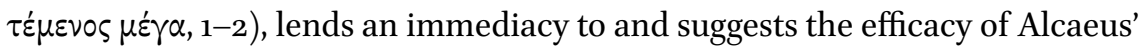
prayer to Hera (and by association Zeus and Dionysus) for the political salvation of his faction and the punishment of his enemy Pittacus. This setting was, 
in my view, purely imaginary even on first performance, as I am inclined to believe about Sappho fragment 17 as well. ${ }^{65}$

Others take the descriptive setting as the actual performance context, arguing that the song was composed for a gathering of Alcaeus and his companions in the sanctuary precinct itself, where they sought asylum. ${ }^{66}$ This is certainly possible; as often in archaic lyric, there is no way for us to distinguish with certainty deixis am Phantasma from ad oculos. Yet the thickly laid-on deixis in

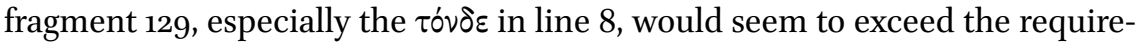
ments of a pragmatic communicative situation within the sanctuary itself. We are, I think, dealing with "imaginary deictic over-determination," which aims to produce a reality effect rather than to delineate a visible reality. ${ }^{67}$ The intention behind this was arguably to ensure that whenever and wherever fragment 129 was reperformed, Alcaeus' Messon would be vividly conjured up. But Alcaeus could just as well have been intent on creating the illusion of a "real" Messon in the song's primary performance, in Mytilene or wherever else. Of course, even on a first performance at Messon, the emphatic deictic gestures of fragment 129 would conceivably have rendered the visible shrine already hyper-real, a fiction in the making.

The deictic $\dot{\varepsilon} v \delta \varepsilon^{\prime}$ "and in it" at line 3 also contributes to the fictivization of the shrine. This phrase belongs to the ecphrastic register of archaic poetry, appearing in vivid descriptions of imaginary artifacts, places, or scenes. ${ }^{68}$ It recurs

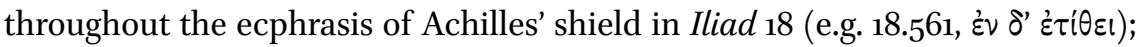
in Pindar fragment 7ob.10, 12, and 15, it draws the mind's eye to elements of the divine choral dance imagined by the poet. Sappho's description of the sacred grove that is the setting for the hymnic fragment 2 recalls fragment 129 in its

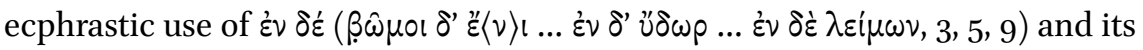
emphatic deixis $(1,13)$. Sappho sets a scene that is, if not outright imaginaryand the dreamlike tenor of the song as a whole does suggest fantasy rather than reality - then at least heavily aestheticized and mediated. ${ }^{69}$

65 Cf. Burnett 1983: 159-161 and Gagné 2013: 219. On gaps between performative and descriptive setting in the Lesbian poets, see Yatromanolakis 2004 and D'Alessio 2018.

66 Rösler 1980: 195-196 and Vetta 1981: 495; see too Caciagli 2016: 444.

67 "Deictic over-determination": Edmunds 2012 (who applies the phrase to deictic elements in fr. 13ob); "reality effect": Barthes 1989: 141-148. On the "superfluous" tóvos, see Hutchinson 2001: 198. D’Alessio 2009: 115-118 discusses imaginary deixis.

68 See Furley and Bremer 2001b: 145.

69 See Bowie 2016: 154-155, who notes how the final stanza of fr. 2, in which Aphrodite is requested to serve wine to the celebrants in the grove, "undermines any literalist interpretation" of the performance context described in the song. Cf. Burnett 1983: 264; D'Alessio 2018: $36-38$. 
Whatever the original performance setting of fragment 129, Messon's status as a rhetorical and symbolic resource within the song stands apart; that status indeed transcends any performance occasion, even one at Messon itself. The same could be said for Sappho fragment 17. Both songs capitalize on the religious potency of Messon to enhance their appeal to the gods (whether real or virtual). In both songs, too, episodes from the illustrious myth-history of the site provide a backdrop against which their messages resonate, taking on a mythically enriched dimension. In fragment 17 , the Atreids' prayer for nostos may be the model for a choral prayer at Messon for Charaxos. Alcaeus looks even further back, imbricating the deictic evocation of the present-day shrine at Messon with an account of its foundation by a distant generation of Lesbian ancestors (fr. 129.1-9). The history lesson is pointed: the political cooperation and piety symbolized by the establishment of this commonly held ( $\xi \hat{v} v o v, 3$ ) precinct, where now the song is notionally performed, stand in sharp contrast to the transgressions of Alcaeus' enemies. ${ }^{70}$

There may be another parallel between the two songs: parachorality. Alcaeus has not invited the same choralist scrutiny Sappho has. Choral language and imagery are all but absent from the fragments, while a number of them clearly point to sympotic contexts of performance. Two exceptional cases are fragment 13ob.17-20 (discussed below) and fragment 249.2, which mentions a $\chi\left[0\right.$ ] pov, $^{2}$ in an obscure context. There is accordingly little cause to challenge the consensus view that fragment 129 was a sympotic monody; the fragment lacks the festive, musical, and performative references that in Sappho fragment 17 suggest "actual" choral performance. Fragment 129 might nevertheless send more muted parachoral signals. While its consistent use of first-person plural forms is not unparalleled in Alcaeus (see fragment 6), in the context of a monody that integrates formal and generic elements of cult hymn - in the archaic period a choral genre above all —and that situates its performance at a traditional site of choral performance, these forms arguably create the subtle impression of a choral song. ${ }^{71}$ Such notional "amplification" of the monodic voice would, as in fragment 17 , have added heft to the prayer delivered in the song, while also

70 Cf. Edmunds 2012 on "the irony that [Alcaeus] and his comrades find themselves outcasts in a temenos that ... stands for the Lesbians as a people." Could Messon's mythic associations with homecoming, foregrounded in Sappho fr. 17, also have influenced Alcaeus' choice to situate this and other exile songs there? The remarks in Lidov 2016: 62 are germane.

71 On the choral norm of archaic cult songs, see Furley and Bremer 20o1a: 25-26. If Hera was directly invoked in the first or second line of fr. 129 (see Rösler 1980: 196-197; Hutchinson 2001: 195), its hymnic character would have been communicated from the start, and listeners might thereby have been made more sensitive to parachoral cues as the song pro- 
affirming the ties that bind Alcaeus' sympotic group. It would be as if its members, through the representative voice of the solo performer, sing together as a chorus. (One could imagine a scenario in which Alcaeus' companions actually sang fragment 129 in unison at a sympotic gathering, rendering it a de facto choral song. But the "choralized" reperformance at symposia of lengthier lyric monodies such as fragment 129 does not seem to have been common practice. $)^{72}$ In a song that ostensibly aims to reverse the political violence and marginalization endured by Alcaeus' hetaireia, the implicit casting of the hetaireia in the role of a chorus, a perennial symbol of collective harmony, singing at the "common" shrine at Messon would be especially appropriate.

Parachorality plays a more explicit part in the companion piece to fragment 129 , fragment $13 \mathrm{Ob}$. This song is a monody probably intended for sympotic performance first in Mytilene: it is addressed to one Agesilaïdas (4), presumably a member of Alcaeus' hetaireia, and it refers to the citizens of Mytilene with a proximal deictic $(\tau \omega \nu \delta \varepsilon \dot{\varepsilon} \omega \nu, 6){ }^{73}$ It is set, however, in a sacred precinct ( $\mu \alpha x \alpha \dot{\alpha} \rho \omega \nu$ $\tau \varepsilon \dot{\mu} \mu \varepsilon v \circ \theta_{\varepsilon} \varepsilon^{\prime} \omega \nu, 13$; cf. fragment 129.2) that appears to be the one at Messon. ${ }^{74}$ Like fragment 129, fragment 130b treats the theme of exile, but in the case of this song it seems even harder to defend the view that it emerged during an actual period of exile at Messon; it reads rather as a dramatized representation of the experience of exile, its scenario imaginary. The monodic singer takes the part of a "wretched ego" (1) lamenting his absence from Mytilene. He depicts his life in the environs of the temenos, where he has taken up residence $(1,10,16)$, as one of loneliness and desolation (9-10). Yet he is a witness to "gatherings" (бuvó $\delta \circ \sigma l, 15)$ at the sanctuary; the second to last stanza describes one. "I dwell," he says, "keeping my feet away from troubles" (16),

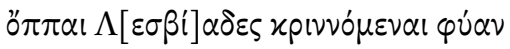

$\pi \dot{\omega} \lambda \varepsilon v \tau^{\prime} \dot{\varepsilon} \lambda \varkappa \varepsilon \sigma i \pi \varepsilon \pi \lambda \circ \mathrm{l}, \pi \varepsilon \rho \grave{~} \delta \dot{\varepsilon} \beta \rho \varepsilon \dot{\varepsilon} \mu \varepsilon l$

gressed. Nagy 1993: 223 comments on the choral ambience of fr. 129's dramatic setting at Messon.

72 The unison singing of a paean to mark the commencement of the symposium is attested (e.g. Plut. Quaest. conv. 615b), but such pieces were surely simple and short.

73 D'Alessio 2018: 44 takes a different view of this deictic, arguing that it implies a situation in which the citizens are present at the same festival as the speaker. This view is not necessarily inconsistent, however, with the reading of fr. $13 \mathrm{ob}$ offered here.

74 Frs. 129-131, preserved on the same papyrus (POxy. 2165), all seem to deal with exile from Mytilene; frs. 129 and 13ob, and probably the lacunose fr. 13oa, at least, are set at Messon. An Alexandrian editor presumably grouped together the songs because of their shared theme and setting (Hutchinson 2001: 193); before that they may already have been performed in sequence by symposiasts (Edmunds 2012). 


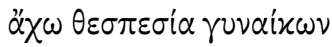

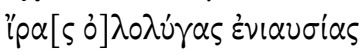

where the Lesbian women, judged for their beauty, go about in their trailing robes, and around resonates the marvelous sound of women's sacred yearly cry (ololuga).

Alc. 13ob.17-20

This "beauty contest" may well be the festival for Hera called the Kallisteia, which has been thought a possible context for Sappho fragment 17. Regardless of whether we want to make a specific connection between the two fragments, however, it is important to stress that the women's ritual performance described by Alcaeus in all likelihood took the form, like that in fragment 17, of choreia. "The marvelous sound of women's sacred yearly cry" may refer specifically to some extraordinary ululation that was characteristic of the festival. But it can also be understood as a metonymy for annually recurring songs performed at the festival by female choruses. In Sappho fragment 44.25-31, similar language appears in a scene that is clearly choral: at the arrival of Hector and Andromache, Trojan maidens "sang a holy song, and the marvelous sound

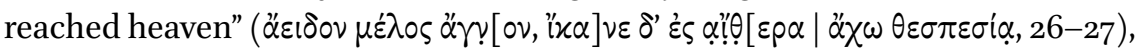

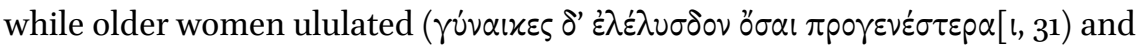
men sang a choral paean. ${ }^{75}$

We have, then, in fragment $13 \mathrm{ob}$ choral performance embedded in monodic song. The text in fact presents us with a situation that is parachoral in an almost literal sense: the speaker stands by as the women conduct their festival. This situation is often read as emblematic of the speaker's alienation from Mytilenean political life and from human society more generally. Anne Carson, for instance, detects a contrast between the men's soundscape of the city recalled at the beginning of the song - the speaker "longs to hear the assembly called by the herald, and the council" (3-5) - and the "otherworldly echo of women shrieking" described in the penultimate stanza. The speaker's "exposure" to the ololuga - a ritual cry uttered only by women —is a "condition of his political nakedness" as an exile. ${ }^{76}$

Carson's interpretation, though insightful, risks overestimating Alcaeus' "othering" of the women's song. Hutchinson by contrast emphasizes the "attrac-

75 For the similarities between the performances described in fr. 13ob and Sappho frs. 17 and 44, see n. 43 above. For choruses at the Kallisteia, see Nagy 1993, 2007, 2016. 
tiveness" of the festival described by Alcaeus: the speaker delights in the spectacle before him, even as its very beauty underscores the misery of his exile. What is more, the festival represents a poignant "image of the community" that is denied to him. ${ }^{77}$ Edmunds notes how the specifically choral dimension of the festival highlights the speaker's social exclusion: "The picture of the annual women's festival, with the 'sacred ululation,' which is choral and communal, contrasts with the self-representation of Alcaeus, who is isolated, a vox clamantis in deserto."78 Edmunds' remark suggests a possible "meta-performative" aspect to the parachoral scene, a tension that emerges between the monodic song's own solo performance-isomorphic with the speaker's vox clamantisand the collective voice of the women's chorus it evokes.

Might the very evocation of that choral voice, however, also offer a resolution to this formal tension, and point toward a closing of the gap between isolation and community even as it dramatizes it? In other words, while it is natural to interpret the parachoral situation in fragment $13 \mathrm{ob}$ as reinforcing a sense of alienation, it is also possible to read it as marking an optimistic turn. On this reading, the festive choreia performed in concert by all the Lesbian women at Messon - with its "sacred yearly cry," indicative of order, piety, and institutional stability—prompts hope for the speaker's reintegration into Mytilenean society, and indeed offers to Mytilene itself, now consumed by stasiotic violence (6-9), a vision of a more harmonious politics in which such reintegration would be stable and lasting. ${ }^{79}$ It is as if the women's constitutive exclusion from civic life grants their choral ritual a transcendence of the political that is in turn exemplary for men's inclusion in civic life.

The final stanza is largely lost, but it clearly began with a prayer to the gods for deliverance "from the many" present woes $(21-22) .80$ The prayer is voiced against the backdrop of the just-described women's festival, with its cry that fills the entire sanctuary. Rather than assuming that Alcaeus meant only to contrast the two vocalizations, we might better hear them as blended or continuous: the solo prayer emerges from the resonance of the choral cry, drawing upon its sublime and sacred energy. Once again, it is a matter of a monodic song, within its textual imaginary, availing itself of choral value.

\footnotetext{
77 Hutchinson 2001: 213.

78 Edmunds 2012; see also Nagy 1993: 222-223.

79 Cf. Power 2018: 28-29.

8o Cf. Hutchinson 2oo1: 213: "an abrupt call for delivery."
} 


\section{Conclusion}

There can be no question that choralist readings of Sappho have productively upended quaint and complacent images of Sappho singing "feminine monody for a feminine audience" in the gynaeceum or the schoolroom, and have opened up new avenues for reconstructing Sappho's performance contexts and the interpretation of her songs. ${ }^{81}$ Yet we should nevertheless be willing to take a page from the choralists' own challenge to reflexive assumptions about Sapphic performance and regard anew, from a post-choralist vantage point, as it were, Sappho the monodist, considering the possibility of whether apparently choral songs of hers were not chorally performed, but rather represent sophisticated products of her monodic artistry.

In the first section of this paper, I proposed that some of the "wedding songs" commonly regarded as choral may in fact have been monodic, involving choruses as "characters" represented or quoted within a solo song rather than as actual performers. In the second, I introduced the concept of parachorality to describe such representations, and Sappho's more general tendency to engage with choreia, a musical performance practice charged with profound social and cultural meaning and value, to create emotional, thematic, rhetorical, and narrative effects within her monodic poetry. In section three, I explored the possibility that fragment 17 , a song generally regarded as an authentic choral cult hymn to Hera delivered at the goddess' sanctuary at Messon, was actually a parachoral production, a monodic simulation of public choral performance. The goal of this simulation, I argued, would have been to add rhetorical and religious bolster to Sappho's solo, probably private prayer for the return of her brother Charaxos. In the final section, I turned to Alcaeus fragments 129 and 13ob, which also represent themselves as being performed at Messon. As in Sappho fragment 17 , that performance setting is likely to be imaginary, a fiction intended to serve the communicative agenda of the songs. Furthermore, I proposed that fragment 129 wears the mask of a choral song, though in a less mimetically committed fashion than fragment 17 . Parachorality informs fragment $130 \mathrm{ob}$ in a more obvious way: its evocation of women's choreia at Messon-an outside take on the sort of performance Sappho represents from the inside-involves a complex semiotics, at once emblematizing the speaker's social alienation and offering a model of political accord.

$81 \quad$ Vetta 1992: 208. 


\title{
The Speaking Persona: Ancient Commentators on Choral Performance
}

\author{
Francesca Schironi*
}

One influential modern approach to genre in Greek lyric poetry is to focus on performance. ${ }^{1}$ On the other hand, while distinguishing lyric poetry either by meter or by eide (i.e., content, purpose, and occasion), ${ }^{2}$ ancient commentators seem to have had much less interest in purely performative questions. ${ }^{3}$ For them, genre mostly was an issue of "speaking persona," as most clearly outlined by Proclus in his Prolegomena to Hesiod:

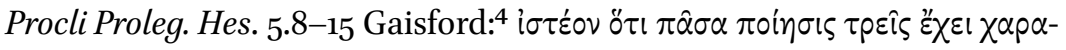

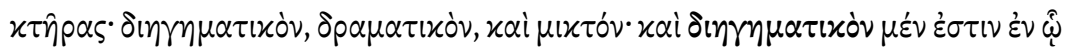

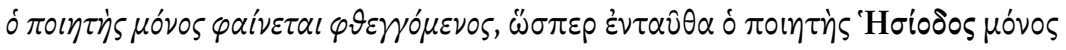

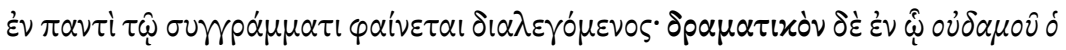

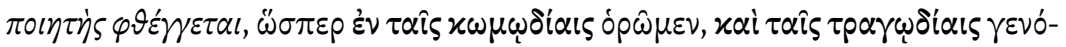

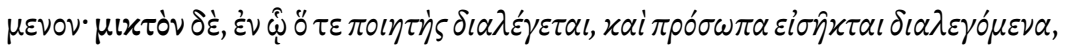

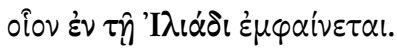

It is important to note that poetry as a whole is of three types: narrative, dramatic, and mixed. Narrative is [the type] in which only the poet appears to be speaking, as here the poet Hesiod alone appears to be speaking throughout the entire poem. Dramatic [is the type] in which the poet

* I would like to thank Giambattista D'Alessio, Meg Foster, Leslie Kurke, Monica Negri, and Naomi Weiss for their help and suggestions.

1 See, for example, Calame 1974, 1977 [1997a/20o1, in English]; Gentili 1984 [1988, in English]; Lardinois 1994, 1996; Nagy 1990, 1994-1995, 1996.

2 See Färber 1936 (which is still the most complete collection of ancient sources on lyric poetry); Irigoin 1952: 31-75; Harvey 1955; Negri 2004.

3 As Rutherford 2001: 107 rightly observes, "most cases of eidographic indeterminacy arose because Hellenistic classifiers tended to neglect the performance scenario of songs in favour of formal features, and to the extent that they were concerned with performance, they may sometimes have misinterpreted it."

4 Gaisford 1823: 5 . 
never speaks, as we see to be the case in comedies and tragedies; mixed [is the type] in which the poet speaks and introduces characters speaking, as is clear in the Iliad. $^{5}$

The division among narrative, dramatic, and mixed genres is fairly common in antiquity and derives from Plato, who famously in the Republic (392d-394d) distinguishes between dramatic imitation (tragedy and comedy), narrative (dithyrambs), and a mix between dramatic and narrative (epic poetry). ${ }^{6}$ Aristotle, too, seems to have the same definition in mind when (Poet. 1448a2O-24) he says that it is possible to present things by narrating and becoming another person, as Homer does (i.e., Plato's mixed type) or by remaining the same (i.e., Plato's narrative), or by representing people who act (i.e., Plato's dramatic). ${ }^{7}$ Aside from tragedy and comedy, which are easy to label as "dramatic" ( $\delta \rho \alpha \mu \alpha-$ $\tau(x o ́ v)$, this conceptualization of literary genres gives unexpected results when compared to our theory of genres. Whereas we label dithyramb and epinician poetry as "choral lyric" and consider Homer and Hesiod as belonging to "epic" because we look at the performative aspects of each genre, ancient exegetes saw these texts mostly from the point of view of the speaking personaand this changed everything. In this perspective, Hesiod is now coupled with dithyramb as examples of "narrative" poetry ( $\delta \eta \eta \eta \mu \alpha \tau i x o ́ v)$ because the poet is the only speaking voice. Homer, on the other hand, belongs to the "mixed" genre ( $\left.\mu \varkappa \tau \tau^{\prime}\right)$ because he alternates narrative parts, where he is the speaking persona, with dramatic ones, where he introduces his characters, who speak directly within the text.

Starting from these premises, in what follows I will examine the attitudes towards choral performance in exegetical literature, and especially in the scholia to Pindar, to see whether these sources can give us a clue as to which genre Pindar's poems belonged and why. This analysis will also show that while Hel-

5 All translations are mine.

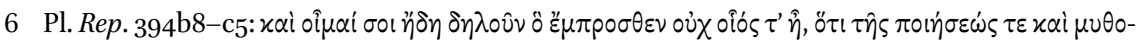

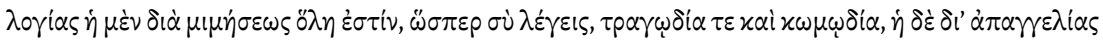

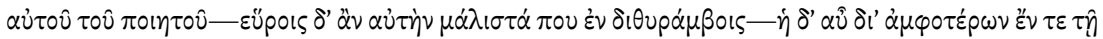

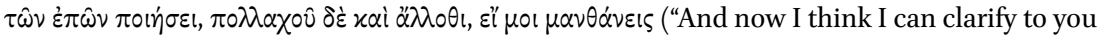
what I was unable to before, that one type of poetry and story-telling is completely through imitation — as you say, tragedy and comedy; another happens through the narrative of the poet himself-you may find it especially in dithyrambs; and one happens through both [i.e., narrative and imitation], and [this happens] in epic poetry and in many other genres, if you understand me").

7 On this classification, see Färber 1936: 3-7; Haslam 1972: 20-24; Nünlist 2009: 94-99 (with further bibliography). 
lenistic and later scholars might not have read lyric poetry with a specific interest in performance per se (rather their focus was indeed on explanations of words, myths, and characters referred to in the lyric texts), they did take an interest in the chorus. Yet their attitude towards choral performance was very different from ours and was determined by a different conceptualization of poetic genres, in which the "speaking persona" was more important than the performative aspects of each type of text.

\section{The Chorus Speaks to and Is Addressed by the Poet}

Dances and choral performances were common in the Hellenistic period and many contemporary inscriptions testify to their popularity. ${ }^{8}$ Thus, at least from their own experience, the Alexandrian scholars were well acquainted with the fact that lyric poetry was sung and danced. ${ }^{9}$ The question is whether they bothered to discuss performative aspects beyond questions of prosody or meter, which were important simply for editing lyric poems. ${ }^{10}$ Music and dancing are a different matter because, even if related to the rhythm of the text, they are external to it from an editorial or exegetical point of view.

The scholia to Pindar offer some interesting evidence when it comes to the chorus' actions and performative acts. In what follows I will focus on this corpus $^{11}$ and other evidence from the fourth century вСЕ to the Byzantine period to examine how ancient commentators looked at the choral performance of lyric poetry. ${ }^{12}$

8 As shown by Chaniotis 2009 in his survey of the evidence available (inscriptions, papyri, and ancient authors); cf. also Prauscello 2006: 104-116.

9 See Pretagostini 2009, who surveys the evidence for musical and choral performances in Callimachus and Theocritus. On the idea of the "chorus" in Greek authors from Plato to Dionysius of Halicarnassus, see Peponi 2013c.

10 On Aristophanes' editorial criteria for Pindar's and Bacchylides' poems, see Irigoin 1952: 35-48 and Negri 2004: 152-176.

11 I will not consider fragments of commentaries on papyrus. In preparing this article, however, I surveyed all the marginalia to lyric poetry collected by McNamee 2007 as well as several fragments of papyrus hypomnemata on the main lyric poets, and did not find any specific notes on performance (with the exception of minor notations which I quote below in nn. 16 and 51 ). As for the Pindar scholia, I have disregarded notes discussing prosody and meter as well as those discussing the "external" realities of the Pindaric odes, such as the specific festival or occasion, because the former have more to do with the editorial activity and the latter with the historical context of the ode rather than with its performance. Some scholia discussing cultic contexts connected with Pindaric odes have been recently studied by Ferrari 2012.

I follow the edition and line numeration of Snell-Maehler for Pindar's text. However, the 
Most often the scholia mention the chorus when they need to explain who is speaking in an ode-which suggests that ancient scholars included the chorus among the "speaking personae" in a lyric poem. Thus a $\lambda$ óyos can be attributed

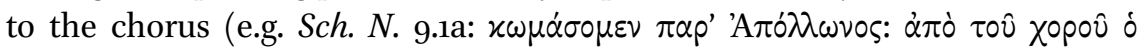
$\lambda$ óros). ${ }^{13}$ Aside from other cases of first-person statements, ${ }^{14}$ addresses or sentences within the poem are also attributed to the chorus. ${ }^{15}$

Yet the chorus is not the only speaker in Pindar's odes. So, for example, commentators are sometimes in doubt whether to attribute the words to the poet or to the chorus. ${ }^{16}$ In other instances, they note exchanges between the chorus and some other speaking persona, most often the poet. This especially occurs when an imperative is used. When this occurs, scholiasts usually understand it as addressed by the poet to himself or to the chorus, as happens, for instance, in a series of scholia to Olympian 9 all discussing second-person singular impera-

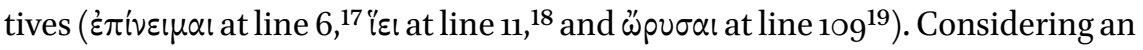
imperative singular as addressed to the multitude of the chorus members was not a problem. Indeed, according to Aristarchus, this was typical of Pindar: ${ }^{20}$

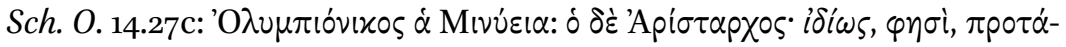

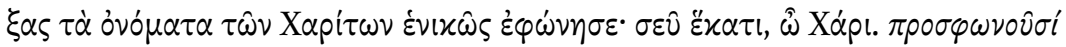

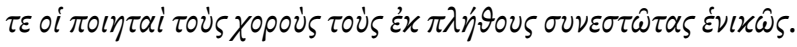

scholia edited by Drachmann 1903-1927 follow the previous numeration (which supposedly goes back to Aristophanes of Byzantium), so there is a discrepancy between the line references in the scholia and the lines of Pindar.

$13 x \hat{\omega} \mu \circ \varsigma$, "revel," and derivatives are often "translated" in the scholia with "chorus" and

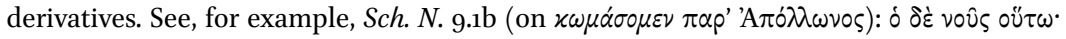

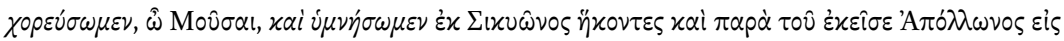

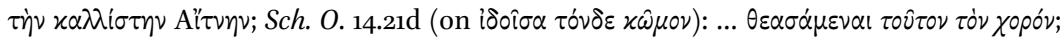

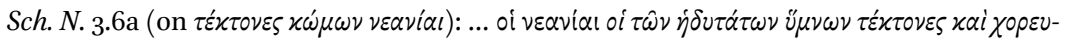
$\tau \alpha i$. There are, however, exceptions: see below, n. 23 .

14 E.g., Sch. P. 9.172 (where the commentator takes عîंov as first person singular rather than third person plural, as correct); Sch. I. 7.51a.

15 E.g., Sch. O. 4.7h; Sch. O. 8.66; Sch. P. 8.140c (briefly discussed below).

16 E.g., Sch. P. 5.96a; Sch. P. 6.1a (but see Sch. P. 6.1e). In Pae. 8 in POxy. 5.841, two scholia discuss whether it is the poet or the chorus speaking in the incipit; cf. D'Alessio 1991: 101; Rutherford 2001: 212, 216; McNamee 2007: 321.

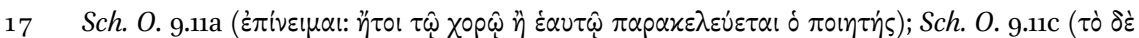

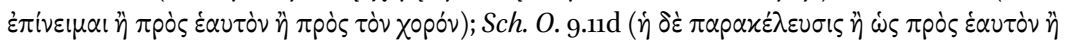

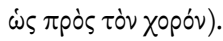

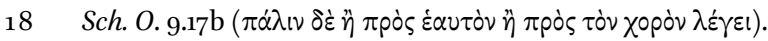

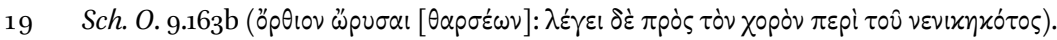

On Aristarchus' Pindaric studies, see Horn 1883 and Irigoin 1952: 51-56. 
"[For I have come singing of Asopichus in Lydian mode with my art, because] the Minyan land is victorious at Olympia [thanks to you ( $\sigma \varepsilon \hat{v}$

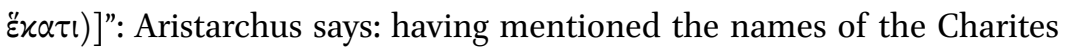
[above] (i.e., at lines 13-15) in his typical manner [Pindar] has [now] addressed them in the singular: "thanks to you, Charis." And the poets address the choruses, which consist of a multitude of people, using the singular..$^{21}$

When, however, the imperative is followed by a vocative singular and also a reference to "companions," then the guess is that Pindar addresses the chorodidaskalos. This, for example, is the case with Olympian 6, where after a long passage with a speaking I (82-87), we read "Now, Aeneas, exhort your companions first to sing Hera the Maiden" (87-88). The scholiast concludes that Aeneas was the chorodidaskalos "whom he [i.e., Pindar] used because he himself had a thin voice and was not able to speak at length to the chorus by himself in public" (Sch. O. 6.148a). ${ }^{22}$

Finally, another speaking persona appears in the scholia: the laudandus, who can sometimes speak directly in the poem. For example, when in Pythian 9 we read (88-89): "I will celebrate them (i.e., Heracles and Iphicles) with a revel, as I have experienced a good thing, in accomplishment of my prayer," the ancient commentator concludes that "the words are addressed to Heracles and Iphi-

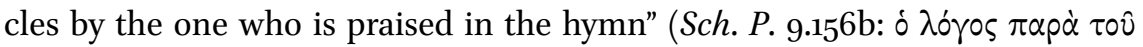

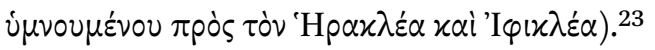

As is clear, most of these attributions are deduced from the text itself on the basis of common sense or using factual information connected with details concerning the poet, the chorus, or the laudandus.

This attitude of deducing speakers on the basis of textual clues emerges most clearly when we look at Pythian 8, whose scholia have been studied by many

21 Yet, even when the plural imperative is used, ancient commentators suggest that Pindar is giving commands to the chorus or deities in the plural, as for example in Sch. O. 10.1a

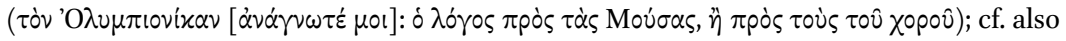
Sch. O. 10.1d, h, i.

22 Cf. also Sch. O. 6.149a. But when later on (92-93) the singular imperative is not followed by

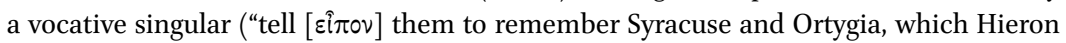
rules with a pure scepter"), Aristarchus concluded that the poet is now addressing the chorus as a whole (Sch. O. 6.158b).

23 Even if the first-person verb here is $\varkappa \omega \mu \alpha \dot{\sigma} \sigma \mu \alpha$, "I will celebrate with a revel," the commentator concludes that the speaking persona is not the chorus, as is usual (see n. 13 above). This is so presumably because the reference to a recent success clearly points to the victor. 
scholars. ${ }^{24}$ According to the scholia, the first part of the ode up to line 55 is considered to be sung by Pindar (with some direct words by Amphiaraus at lines 44-55). ${ }^{25}$ Then (55-66) the chorus speaks (perhaps in the victor's persona), then Pindar again (67-69), and finally the chorus in its own persona (70-100). Edwin Floyd, who studied this case, thought that the ancients were correct in this reconstruction and suggested that they had a score to look at. ${ }^{26} \mathrm{I}$ do not think that we necessarily need to assume that they had a score to come up with this line attribution. On closer analysis, we see that all the scholia indicating a speaker do so because there is a reference in the text that suggests that speaker. References to a "lyre," the "gentle voice" (31), or the "art" (34) suggest that Pindar is the speaker (Sch. P. 8.40a, Sch. P. 8.4ob, Sch. P. 8.43a on line 31; and Sch. P. 8.46b on line 34). The claim that the hero Alcmeon is a neighbor (57-58) excludes, in these commentators' minds, Pindar as the speaking voice. Two possibilities are thus suggested: either the chorus speaks impersonating the victor, who lived next to a heroon of Alcmeon (Sch.P. 8.78a), or the chorus is simply speaking in its own persona because the chorus members, just like Aristomenes, are from Aegina (Sch. P. 8.83a) — so Alcmeon can be both neighbor and guardian of either Aristomenes or the chorus members. ${ }^{27}$ Then, the "harmony" at line 68 suggests Pindar again (Sch. P. 8.95a). Finally, the mention of a komos (70) and the fact that Aegina is called "mother" (98) suggest that this is the chorus speaking (Sch. P. 8.99a on line 70 and Sch.P. 8.140c on line 98), since Pindar is not from Aegina and (presumably) does not revel. ${ }^{28}$ All the exchanges are thus deduced from the text and some special keywords connected with each one of the three characters "onstage": the poet, the chorus, and the victor.

24 Floyd 1965; Lefkowitz 1975: 179-184; and Meijering 1987: 121-122 (who reads them in a slightly different way).

25 Cf. Sch. P. 8.1b and Sch. P. 8.10a.

26 In particular Floyd (194) suggested the following division: $1-55$ sung by the coryphaeus; $55^{-}$ 66 sung by the chorus (in persona victoris); 67-69 sung by the coryphaeus; 70-100 sung by the chorus (in propria persona). In other words, the coryphaeus would sing alone when impersonating Pindar.

27 Unless, as Sch. P. 8.78b suggests, the neighbor is Amphiaraus, who died at Thebes, and thus can be considered as Pindar's neighbor - in this case, Pindar would be speaking; cf. Lefkowitz 1975: 180; Hubbard 1993; Pfeijffer 1999b: 540-545.

28 In fact, Aristomenes could also utter these words, since he is from Aegina too. This is probably why Sch.P. 8.140c suggests the chorus as a hypothesis ( 


\section{The Chorus, Pindar, and Other Characters}

As our survey has shown, ancient scholars seem above all to see the chorus as mainly a speaking persona in an ode, alternating lines with the poet and sometimes with the victor himself. This idea was used to explain many first-person statements, personal references, and imperatives in the text. The ambiguous first-person statements in Pindar are still hotly debated among modern scholars, ${ }^{29}$ so it is not surprising that the ancients, too, found it problematic to deal with the Pindaric speaking voice. Yet their way of approaching the "speaking I" in lyric poetry seems to be profoundly different from ours. In this regard, a scholium to Nemean 7 gives some interesting clues. The explanation here is again triggered by a reference in the text, when Aegina is defined as "my [illustrious] native land" (85: $\dot{\varepsilon} \mu \hat{\alpha} \ldots \pi \dot{\alpha} \tau \rho \alpha)$ :

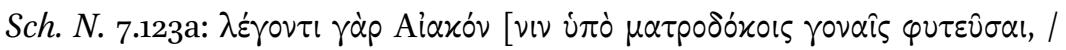

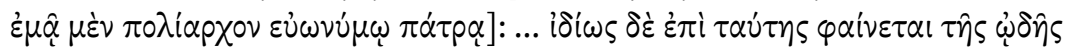

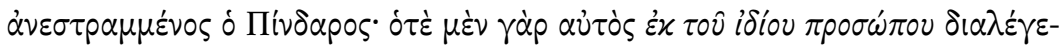

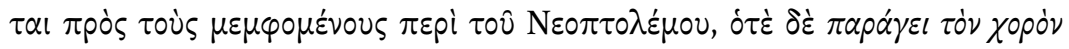

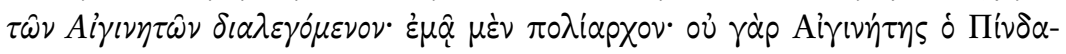
pos.

"For they say that by the seeds received by the mother, he generated Aeacus, prince in my illustrious land": ... Pindar seems to have used an alternation [of speakers] in this song, as is typical of him. For sometimes in his own persona he himself addresses those who censure Neoptolemus, sometimes, on the other hand, he introduces the chorus of the Aeginetans talking [as happens here]: "prince in my [illustrious land]." For Pindar is not from Aegina.

Since Pindar is not from Aegina, the commentator deduces that this is the chorus speaking, while elsewhere in the poem Pindar has spoken in his own persona. While this is the usual problem involving a "speaking I," what is interesting in this note is the use of a specific formula of ancient scholarship on

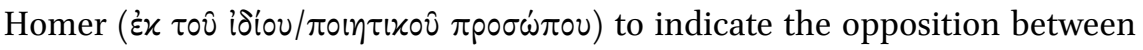
Homer and his characters. For example, a very close parallel to this phrasing can be found in the following scholium in which Aristarchus discusses the use of trumpets in a Homeric simile: 


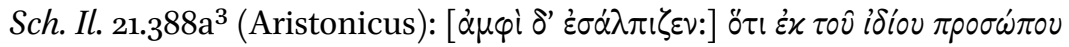

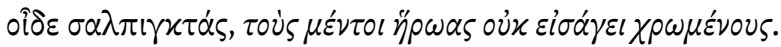

["And [great heaven] trumpeted around":] because speaking in his own persona he knows trumpets, but he does not introduce heroes as using them.

Aristarchus correctly notes that the trumpet is unknown to the Homeric heroes, and so Homer never introduces characters using it; however, a metaphorical use of the derived verb $\sigma \alpha \lambda \pi i \zeta \varepsilon i v$ in the narrative shows that Homer knew this instrument. ${ }^{30}$ While this is not a question of deciding who is speaking, the theoretical background is the same: Aristarchus, just like the anonymous commentator in $S c h . N .7 .123$ a, sees the poet either speaking in his own

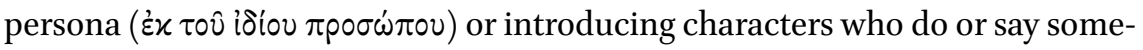

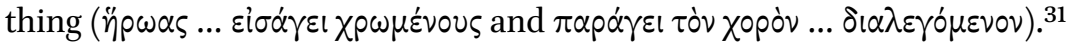

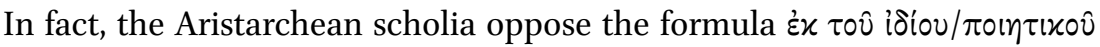
$\pi \rho \circ \sigma \dot{\omega} \pi \circ v$ (when the poet speaks in in own persona) to $\dot{\xi} \xi \dot{\eta} \rho \omega \ddot{x}$. (when his characters, i.e., the Homeric heroes, are speaking). For instance, Aristarchus explains that Ephyra is a byname for Corinth and is the name used by the characters. On the other hand, when Homer speaks in his own persona (i.e., in the narrative), he calls it Corinth:

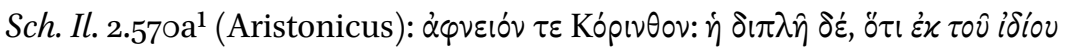

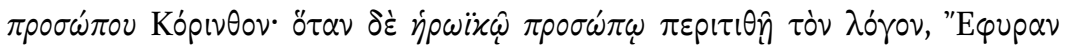

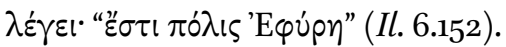

"And wealthy Corinth": the diple 32 [is placed here] because [he says] "Corinth" speaking in his own persona; when he makes his heroic characters speak, he says "Ephyra": "there is a city called Ephyra" (Il.6.152). ${ }^{33}$

30 See Schironi 2018: 334 .

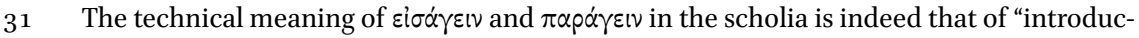
ing a character" in the sense of "putting him/her onstage." See Meijering 1987: 127, who rightly notes that "Greek literary theory does not draw a very sharp line between presenting a scene literally on the stage and presenting a narrative scene to the mind's eye." In this article I offer a possible answer for why this is so.

32 On the diple, a critical sign used by Aristarchus, see Schironi 2018: 49-52.

33 See also Sch. Il. 6.152b (Aristonicus) and Sch. Il. 13.301b (Aristonicus); cf. Schironi 2018: 298 and 511 . 
Since in victory odes "real" heroes normally do not speak, in the Pindar scholia we find a variant of these formulas, $\pi \alpha p \alpha \dot{\alpha} \tau o \hat{v} v i x \eta \varphi o ́ p o v$, to indicate that the laudandus is the speaking persona. This happens in the scholia discussing $I .7 \cdot 39-42$, lines which contain two first-person statements. The first one (39: "I will sing [a $\dot{\varepsilon} i_{\sigma o \mu \alpha l]}$ adorning the hair with a wreath; may the envy of the immortals not disturb us") obviously pointed to the poet, who "sings," as the speaking voice (Sch. I. 7.53a). The question, on the other hand, was how to interpret the following statement (40-42): "by pursuing the pleasure that

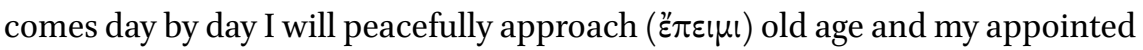
time." For Aristarchus, these words, too, were spoken by the poet (Sch. I. 7.55a), but another anonymous commentator suggested adding a period at the end of line 39 , so as to consider lines $40-42$ as spoken by the victor:

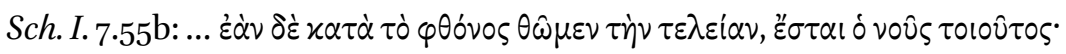

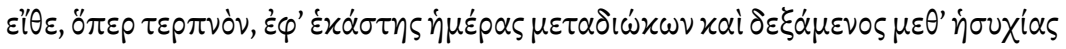

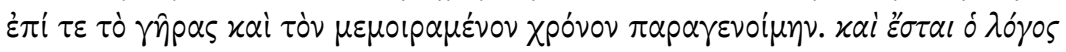

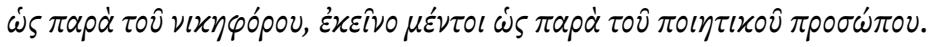

... However, if we put the full stop after "envy," this will be the meaning: "I wish that pursuing what is pleasurable every single day and receiving it in peace, I would reach old age and my appointed time." And the words will be as spoken by the victor; on the other hand, that solution [i.e., Aristarchus' solution] is [that the words are] as spoken by the persona of the poet. ${ }^{34}$

Needless to say, just as in the cases analyzed above, both solutions are derived from the text; in fact, while the first action ("I will sing") clearly points to the poet, the second one ("I will approach old age, etc.") could fit both the poet (as Aristarchus suggests) and the laudandus (as the anonymous commentator prefers). Yet this scholium is interesting because it uses labels common in Homeric criticism, here adapting them to Pindar's specific context (where the victor is also a speaker). In addition, it proves that Aristarchus, who conceptualized Homer's speaking voices in that way, also took an interest in the question of who was speaking in Pindar, so here the connection between Homeric and Pindaric exegesis becomes clear.

Indeed the same formulas are used in the scholia to Pindar even in the absence of a first-person statement, as in the Homeric examples just discussed:

34 For other cases of the formula (or variations of it) to indicate the victor as the speaking

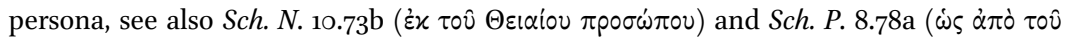

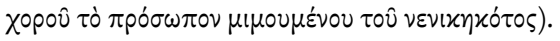




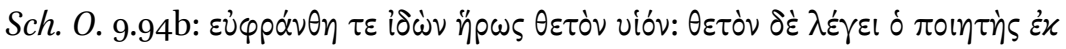

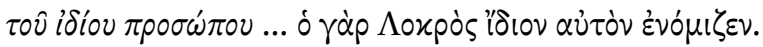

"And the hero rejoiced at seeing his adopted son": the poet says "adopted" speaking in his own persona ... for Locrus considered the baby as his own.

The hero mentioned here is Locrus; Zeus impregnated the daughter of Opous of Elis and gave her as a bride to Locrus. Hence the baby is an "adopted" son for Locrus. Yet this is valid only from the point of view of an omniscient narrator, that is, Pindar, and not for Locrus, who considered the baby to be his own son; so in this line - the commentator concludes-it is Pindar speaking. ${ }^{35}$

The use of these formulas typical of Homeric scholarship with reference to Pindar's poems suggests that the exchanges between the poet, the chorus, and the laudandus are not seen so much from a performative point of view, but instead are viewed like the exchanges in speaking-personae in the Homeric poems. This is especially clear because, just as with the Homeric lines, in Pindar, too, these "line attributions" are not limited to first-person statements but even concern what we would consider "impersonal" statements within the narrative parts. In commenting on both Homer and Pindar, scholars considered certain words or expressions (e.g. "trumpets," "Ephyra," or "adopted") suitable only to a certain category of speakers, and this is how they attributed the lines. If this is true, that is, if the question of who was speaking in the lyric text was conceived by the ancient grammarians as a question of "characters," we can look at all these notes discussing changes of speakers from a different perspective.

\section{Change of Speakers and Ancient Editions}

Normally (and not surprisingly) ancient discussions about changes of speakers are frequent in dramatic texts. ${ }^{36}$ Similarly, papyri of dramatic texts often signal changes of speakers either by paragraphoi or by characters' names, as in a papyrus of Euripides' Hypsipyle (POxy. 6.852, second-third centuries CE). In the case of actors' texts there are letters denoting actors' roles. POxy. 27.2458 (third century $\mathrm{CE}$ ), for example, contains a fragment from Euripides' Cresphontes with the stage indications $A$ and $\Gamma$ for the two actors. ${ }^{37}$

35 For other cases of the formula घंx/àं O. 6.88c; Sch. O. 13.10oc; Sch. P. 4.67b.

36 Cf. Nünlist 2009: 338-343.

37 Cf. Gammacurta 2006: 95-110. See also POxy. 3.413; P.Hibeh 2.180; PSI 10.1176; P.Ryl. 3.484; 
As for lyric poetry, I have analyzed elsewhere cases in which ancient editors and commentators indicated the change of speakers. ${ }^{38}$ The most interesting example among those I discussed was the Louvre papyrus of Alcman (first century CE), which has three marginal notes as well as paragraphoi at lines $35^{-}$ 63 of the Partheneion that signal a semi-choral exchange between the girls on

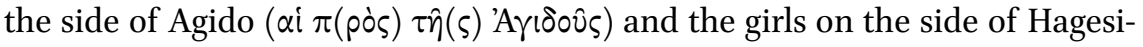

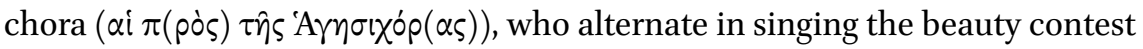
between Agido and Hagesichora. ${ }^{39}$ The commentator does not speak of "semichorus A" and "semi-chorus B," which would suggest a "performance" text, as in the papyri with actor's notes. Rather, the Alcman papyrus uses the names of the "characters" in the poem, Agido and Hagesichora, and this seems to point more to a "reader's text," just as in dramatic papyri where the characters' names, and not the actors' sigla, are marked. The scribe of the Alcman papyrus comments upon a written text, even if he probably knew that it was originally performed.

In fact, the interest in speakers is not limited to performative texts. Speaker indications appear also in some Homeric papyri. ${ }^{40}$ These can signal changes of speakers simply with paragraphoi. For example, P.Berol. inv. 7807 (second-third centuries CE) has a paragraphos to mark the beginning of Achilles' famous speech in Iliad 9 (308). P.Mich. inv. 2810 (second century CE), on the other hand, marks every change of speaker in Iliad 1 with slanting paragraphoi. In particular, here also changes of addressees within a speech are marked, as at line 334, Achilles first addresses the heralds and at line 337 he then speaks to Patroclus, both marked in the manuscript (fig. 4.1).

In some Homeric papyri, the scribes even added the names of the speakers in the margin. For example, P.Strasb. gr. inv. 31-32 verso, a fragment of a roll dating to the early third century $\mathrm{CE}$, has the names of the speakers and the addressees throughout Iliad $1{ }^{41}$ Most interestingly, here the scribe has also marked when Homer, "the poet," is speaking. For example in column v, lines 1-20, covering Iliad 1.317-336, we read (see also fig. 4.2):42

P.Berol. inv. 13876; P.Berol. inv. 21119; P.Varsov. 2; P.Lit.Lond. 97, studied by Gammacurta 2006: 7-94.

$38 \quad$ Schironi 2016.

39 See discussion in Schironi 2016: 33-38. For an image of the papyrus, see Römer 2013, tab. I-VII.

40 They have been recently studied by Azzarello 2008.

41 Edited by Schwartz 1954: 45-62.

42 I reproduce the text of the papyrus as edited by Schwartz 1954: 49, but have added diacritics and readings aids; I have also eliminated the many itacistic errors present in the papyrus. On the other hand, I have added the three paragraphoi which the scribe used 


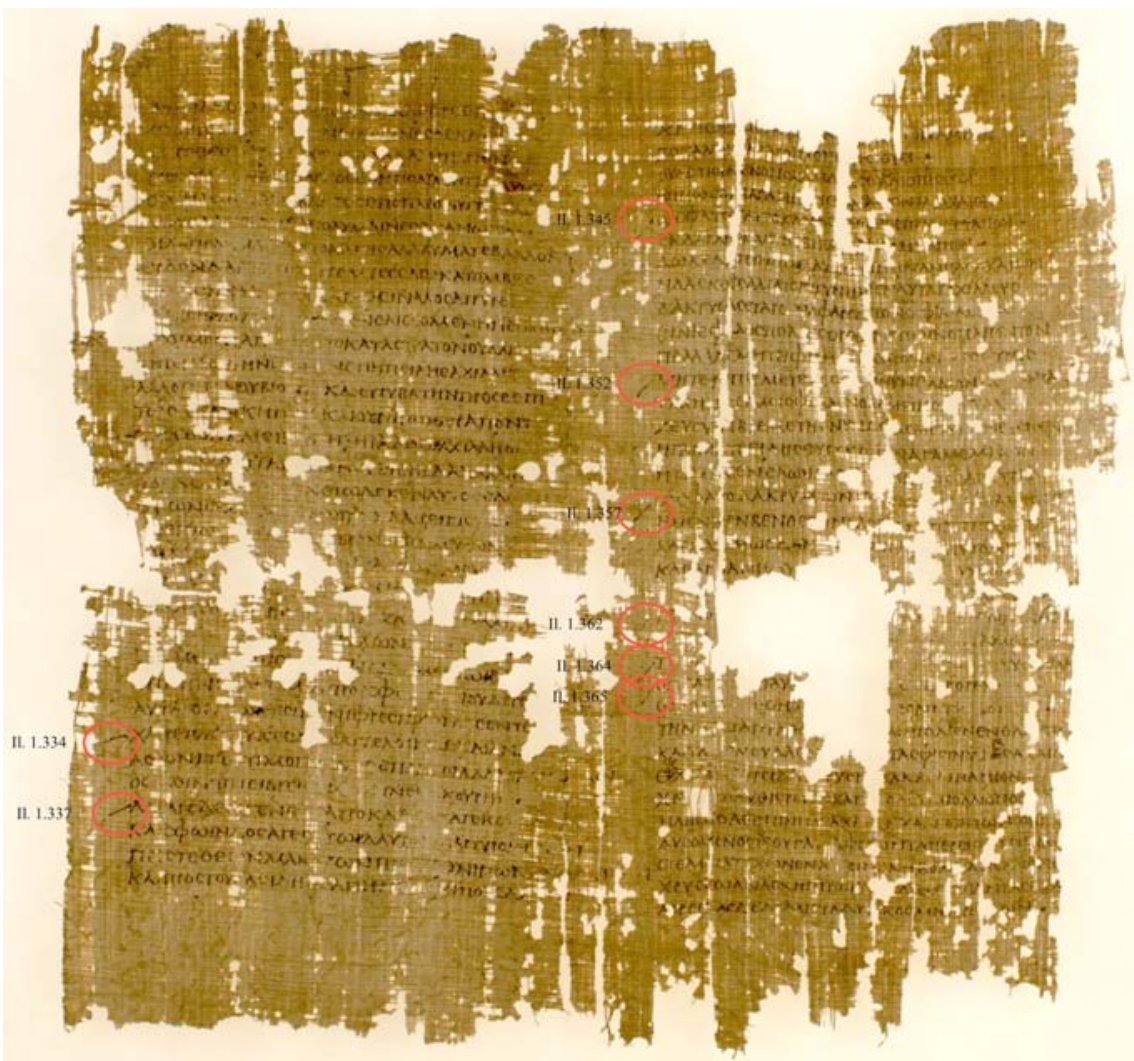

FIGURE 4.1 P.Mich. inv. 2810 (second century CE), fr. A, with Il. 1.308-375 (cols. X-XI) IMAGE COURTESY OF THE UNIVERSITY OF MICHIGAN PAPYROLOGY COLLECTION

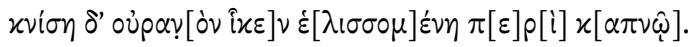

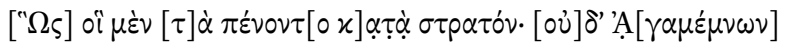

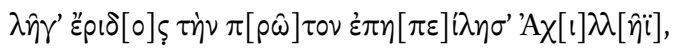

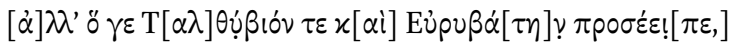

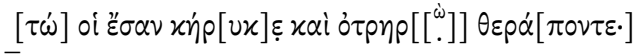

to mark the change of speakers (in addition to the names in the margin); Schwartz transcribed only one of them (the one between lines 325 and 326), but the digital image of the papyrus clearly shows that paragraphoi are also present between lines 321 and 322 and lines 333 and 334. 
325

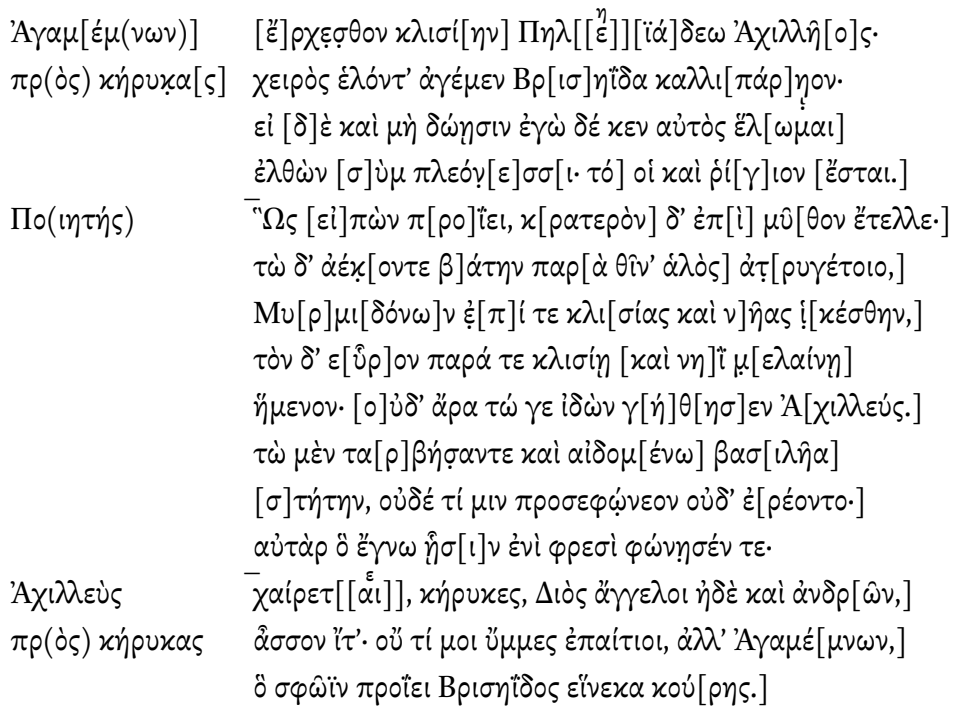

And the smell reached the heaven, rolling with the smoke.

In this way they were busy in the camp. But Agamemnon

did not stop from the strife he started when he first threatened Achilles, but he spoke to Talthybius and Eurybates who were his two heralds and quick servants:

Agamemnon "Go to the hut of Achilles, son of Peleus.

to the heralds Taking fair-cheeked Briseis by the hand, lead her away.

If he does not give her, I myself will take her, coming with more men. This will be even worse for him."

Poet After he said so, he sent them away and gave them a stern order. The two men unwillingly went along the shore of the barren sea and arrived to the huts and ships of the Myrmidons.

They found him sitting near his hut and black ship; and Achilles did not rejoice upon seeing them.

They, feeling fear and respect for the lord, stood still and did not address him nor did they ask anything. But he realized this in his heart and spoke to them:

Achilles "Greetings, heralds, messengers of Zeus and of men, to the heralds Come closer. You are not guilty towards me, but Agamemnon, Who sent you two for the girl, Briseis."

In this ancient edition of the Iliad, Homer is equated with his characters, which is exactly what we have seen for Pindar and the chorus. The type of phrasing

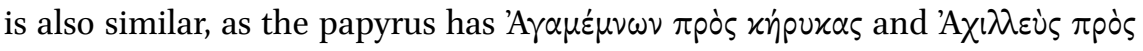




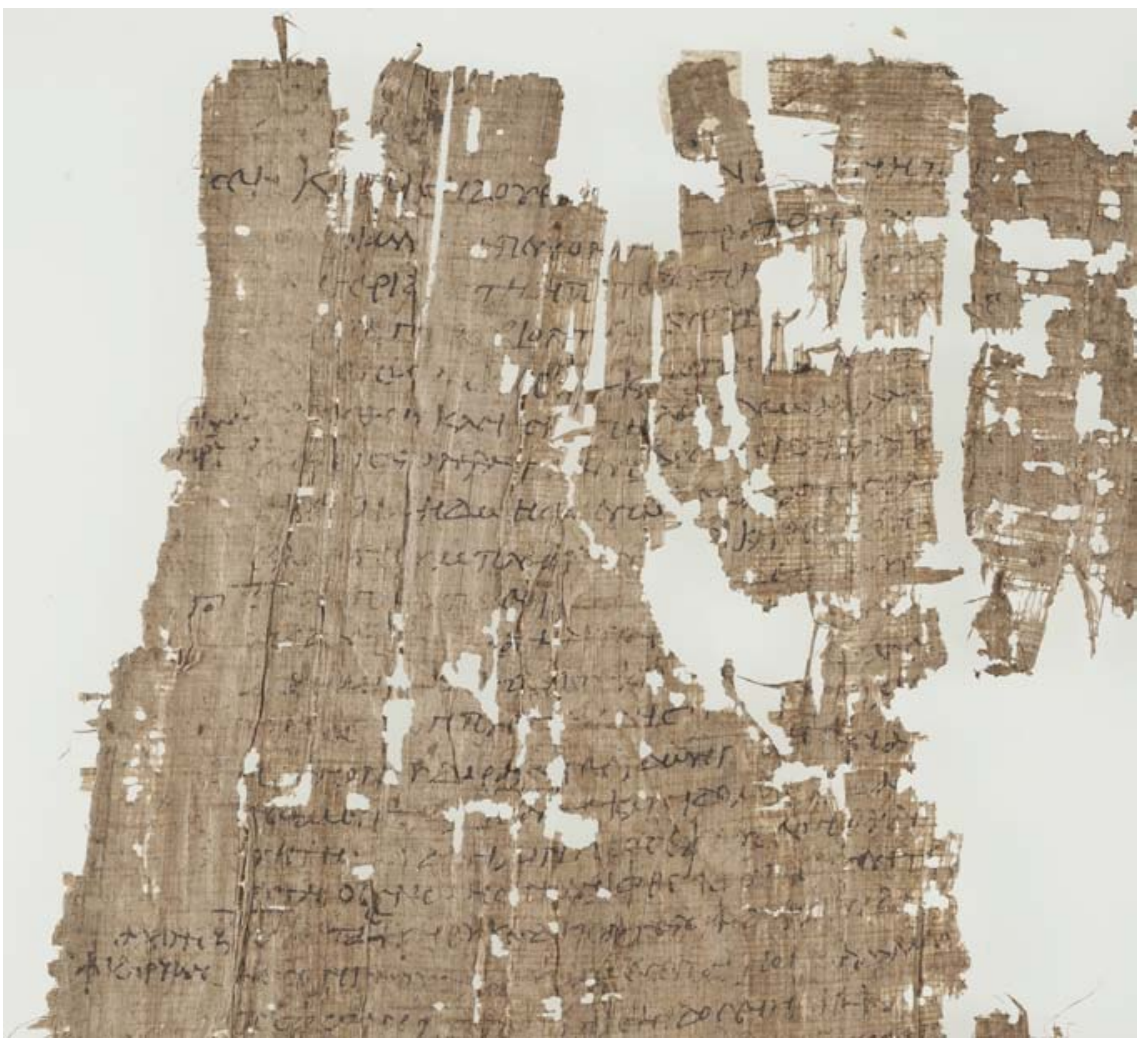

FIGURE 4.2 P.Strasb. gr. inv. 31-32 verso (early third century CE), v, lines 1-20 (Il. 1.317-336).

IMAGE COURTESY OF BNU STRASBOURG

xท́puxas, phrases which parallel what we read in the Pindar scholia when they

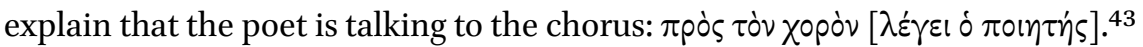
The famous Bankes Homer (P.Lit.Lond. 28, second century CE), a luxury edition of Iliad 24, works in almost the same way but has only the name of the speakers, not that of the addressees. Here, too, different speakers are named: Cassandra, Priam, Andromache, Hecuba, and again the poet. ${ }^{44}$

With Homer it is quite easy to find out who is speaking because the omniscient narrator introduces speakers. So in theory there is no need to indicate changes of speakers in an edition, unless the text itself is conceived as an

43 See above nn. 17, 18 and 19.

44 In POxy. 2.223 (third century CE), containing Iliad 5, at cols. ix-xiii (Il. 5.204-290) the "poet" is listed together with other speaking characters: "Pandarus," "Aeneas," "Sthenelus to Diomedes," "Diomedes." The rest of the papyrus often has the left margin missing, so other indications might have been lost. 
exchange of speaking roles from the start, where the poet intervenes among characters. At the level of exegesis, on the other hand, since with Homer usually there is no problem in identifying characters, this is not an urgent problem and so there are not many scholia discussing who is speaking. ${ }^{45}$ In the case of drama and lyric poetry, on the other hand, the identification of speakers is a problem because there is no external narrator to introduce them, and so sometimes the exact attribution of lines among characters may be unclear (a problem which modern editors of tragedy and comedy still face). The ancients tried to solve these uncertainties by using clues from the text itself. For instance, the ancient scholar of the Alcman papyrus could certainly have derived the notion of the two semi-choruses from just reading the poem, especially for the lines containing the "beauty contest" - even though Pollux's Onomasticon (4.107, p. 233.4-9 Bethe) confirms the presence of semi-choruses in Sparta, and Sosibius, the Hellenistic authority for ancient Sparta, says that gymnopaidiai were performed by triple choruses, one of boys, one of men, and one of old men, and that they also sang odes by Alcman (Ath. 15.678b-c).$^{46}$ Similarly, our analysis of the Pindar scholia has shown that all notes discussing the chorus' words are derived from the text itself. This, of course, does not mean that ancient scholars did not know how lyric poetry was performed originally, that is, with a chorus that danced and spoke all the words of the poem. They were also aware that Pindar was most likely absent from the scene and that the victor, even when present, was simply sitting and enjoying the performance, without uttering a word. Yet they conceived of both Pindar and the victor as active speaking personae, as "characters," who did not actually need to perform the ode to be part of its text, just like the chorus. The notes in the Alcman papyrus as well as those on Pindar do not betray any interest in performance, but rather an interest in clarifying the text seen as an exchange among speaking personae; the aim is to give each line to the proper character using the text itself as evidence.

\section{Beyond Speaking, What Does the Chorus Do?}

As we have seen, in the Pindar scholia the chorus is an important speaking persona. Yet, from a performative point of view, a chorus should be also

45 Those scholia discussing who is speaking often do so when direct speeches are not introduced by a verb of saying; see Aristarchus in Sch. Il. 4.303a; 16.203a; 23.855a. On the other hand, the Homeric scholia very often consider whether Homeric speeches fit the characters who say them; cf. Schironi 2018: 429-433, 435-437, 456-461.

See Schironi 2016: 46-49. 
(or mostly?) dancing. The way ancient scholiasts discuss choral dancing or physical movements is, however, quite disappointing if we are looking for insights into ancient choral performance. Where scholia talk about movements of the chorus it is because some word for movement occurs in the text. ${ }^{47}$ Verbs of movement suggest to the ancient scholars' mind that someone is engaged in physical movement, whether or not connected with dancing. This is not an interest in performance, but rather in explaining each word in the text.

When it comes to "real" dancing and dance steps, the results are even more disappointing. A search for words linked with the root $\chi 0 \rho$ - for the noun "chorus" and its derivatives yields nothing aside from the scholia discussing the chorus as a speaking (or moving) character which I have just surveyed. If we look for more technical words connected with dancing, we are plunged into purely antiquarian notes. A typical case occurs at Pythian 2, when at line 69 Pindar mentions the "Castoreion." This odd reference prompts a long explanation to clarify that the Castoreion is an armed dance; the commentator discusses its origin and its difference from the pyrrhic dance, quoting many learned sources:

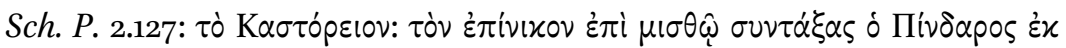

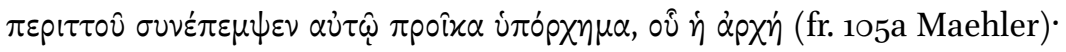

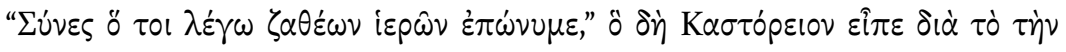

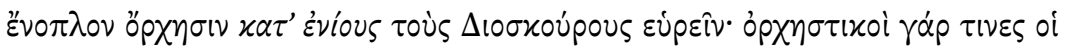

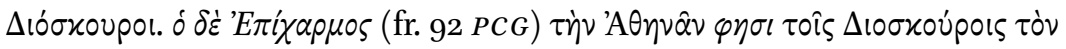

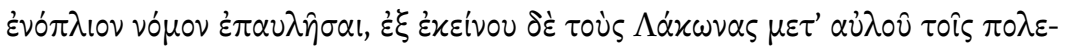

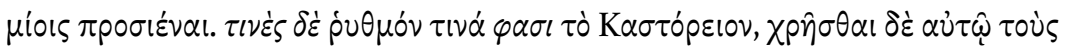

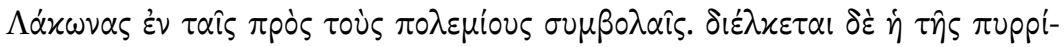

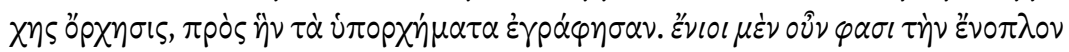

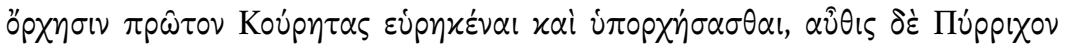

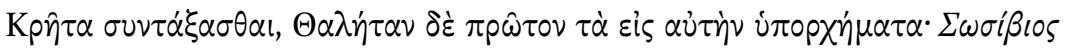

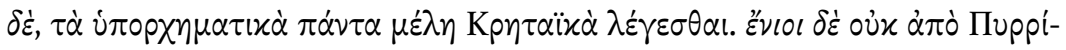

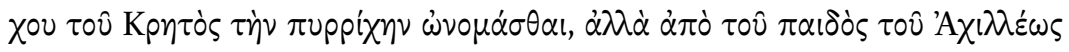

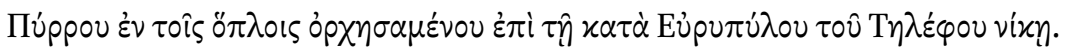

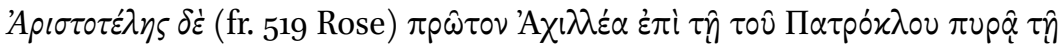

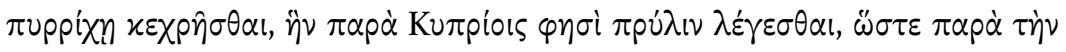

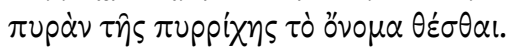


The Castoreion: having composed the epinician for money, in addition Pindar sent him a hyporchema as a gift, whose incipit was: "Understand what I tell you, you whose name means holy temples."48 He called it Castoreion because according to some the Dioscuroi invented the armed dance; for the Dioscuroi were dancers of a sort. And Epicharmus says that Athena played the martial melody on the pipe as an accompaniment for the Dioscuri, and that because of this the Laconians approach the enemies with the accompaniment of the pipe. Some say that the Castoreion is some sort of rhythm and that the Laconians use it when they engage with their enemies. The pyrrhic dance is different [from the Castoreion] and for it [i.e., for the pyrrhic dance] [poets] wrote hyporchemata. Some say that the Curetes first invented the armed dance and danced it, and then the Cretan Pyrrhichus organized it and Thales was the first to compose hyporchemata for it; Sosibius, however, says that all the hyporchematic songs are called Cretan. But some say that the pyrrhic dance is not named after Pyrrhichus the Cretan, but after the son of Achilles, Pyrrhus, who danced in his armor upon his victory over Eurypylus, son of Telephus. Aristotle, on the other hand, says that Achilles first danced the pyrrhic dance on the pyre of Patroclus, which, he says, the Cyprians call "prylis," so that the name "pyrrhic" derives from "pyre."

Again, the learned scholium derives from the necessity of explaining an obscure reference in the text. This is mostly an antiquarian note focusing on the mythical origin of the dance and quoting a lot of learned authorities, but without any description of the steps or what this dance looks like. The interest is broadly historical, not performance-oriented. Otherwise, the explanations are text-derived. For example, there are several scholia discussing the "Archilochus song," which Pindar mentions in the opening of Olympian 9, saying that the hymn is sung at Olympia, has a refrain sung three times, and is celebrated by the

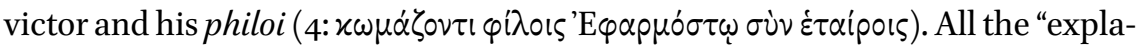
nations" in the preserved scholia simply rephrase what Pindar has already said in these opening lines (Sch. O. 9.1a-k). Or they contain an "educated guess," for

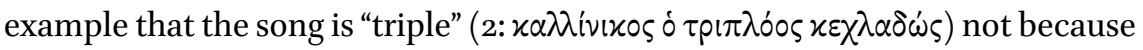
it has three refrains but because it is performed once at the time of the victory, then in the gymnasium, and then at home, or because (Aristarchus' opinion) it had three strophes (Sch. O. 9.3a-l). The few other examples discussing choral 
dancing in the scholia are all along these same lines: they try to explain the words used in the text, and never go beyond them. ${ }^{49}$

This result on the chorus' movements in the Pindar scholia parallels the situation concerning the musical element. As noted by Lucia Prauscello, ${ }^{50}$ scholia seem to guess references to musical modes based on ethnic qualifiers. ${ }^{51} \mathrm{In}$ addition, just as with the scholia commenting on choral dance, none of these scholia actually explains what these harmonies are from a musical point of view. ${ }^{52}$

\section{The Chorus Dances ... in Theory}

The conclusions reached on the basis of the Pindar scholia do not, however, mean that in their work ancient critics took no interest at all in choral dancing, music, and more generally the performative aspects of lyric poetry. We simply do not find annotations on these elements in their exegetical and editorial practice, but elsewhere. Didymus, the famous Alexandrian scholar, seems to have taken both music and choral performance into account when discussing the different genres of choral lyric in his lost work on Lyric Poets. We have only some fragments, ${ }^{53}$ and one of them is particularly interesting:

49 See also, e.g., Sch. N. 3.1c. All occurrences of the root $\sigma \tau \rho$ - (which covers $\sigma \tau \rho \dot{\varepsilon} \varphi \varepsilon \varepsilon v, \sigma \tau p \circ \varphi \eta$, $\sigma \tau p \circ \varphi$ ós, etc.) refer to metrical division, so they are not relevant here. The only exception

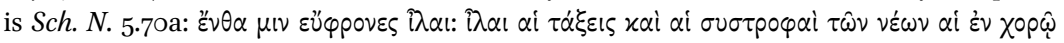

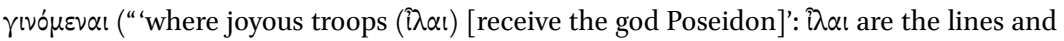
the turns of the youths, those happening in the chorus"). Here too the reference to the movements and turns of the chorus is suggested by the text itself (i $i \alpha \mathrm{\alpha l}$, "troops," often of soldiers). I suspect that the military meaning of $i \lambda \alpha$ ı suggested to the mind of the scholiast the marching movements and the twists of the chorus dancers.

50 Prauscello 2012: 77-82 (esp. 79).

51 Dorian mode (Sch. O. 1.26a, c, g; Sch. O. 3.9a, c, d); Aeolian mode (Sch. O. 1.164b; Sch. P. 2.125c and 128a; Sch. N. 3.136a); Lydian mode (Sch. O. 5.44a, c, g, i; Sch. O. 14.23c; Sch. N. 4.71; Sch. N. 8.24a, b); Locrian mode (Sch. O. 10.17k and 10.18b). Among papyri, POxy. 26.2449 has

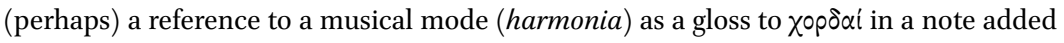
in the lower margin; cf. McNamee 2007:348.

$5^{2}$ My survey also confirms the conclusions reached by Prauscello 2006 about Greek music and Alexandrian commentators. Reacting especially against Thomas Fleming and E. Christian Kopff but also against the Gentili school that claimed that Alexandrian grammarians systematically used musical scores in order to edit lyric poetry, Prauscello has shown that the evidence does not support this claim. See especially Prauscello 2006: 7121. The connection between music and scholarly practice is also very thin in the papyri surveyed by Martinelli 2009 .

They are collected and discussed by Grandolini 1999 . 


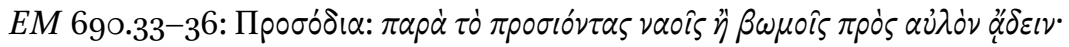

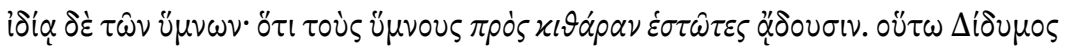
$\dot{\varepsilon} \nu \tau \hat{\omega} \pi \varepsilon p i \lambda \nu \rho i x \hat{\omega} \nu \pi \circ i \eta \tau \hat{\omega} \nu .54$

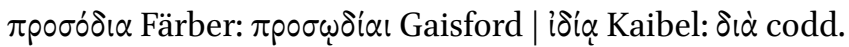

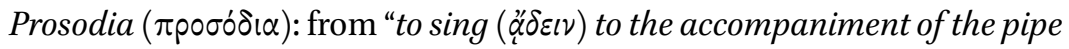

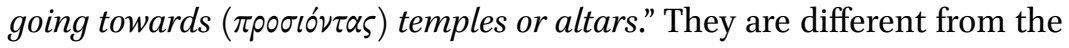
hymns. Because they sing hymns standing in place and to the accompaniment of the kithara. Thus Didymus in On Lyric Poets.

The etymology of the prosodion is connected with the movements of the chorus, which goes towards temples and altars. And prosodia are opposed to hymns exactly because the chorus behaves differently and the musical accompaniment is different. A related passage is found in the so-called Byzantine Capitula:

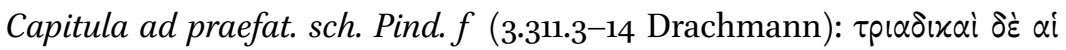

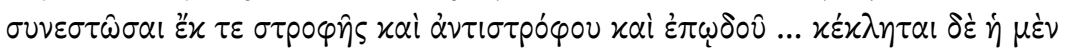

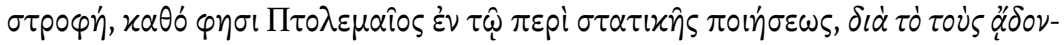

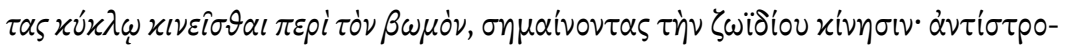

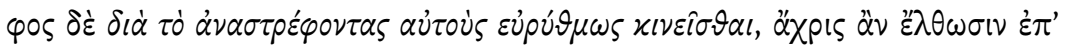

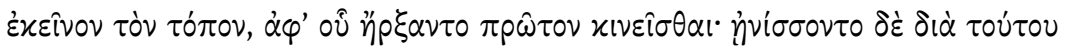

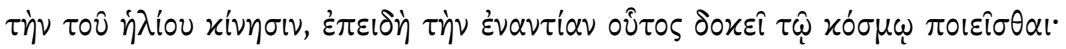

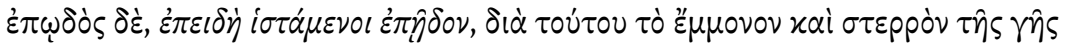
$\pi \alpha \rho เ \tau \tau \hat{\omega} \tau \tau \varsigma$.

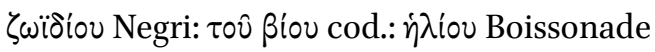

The odes organized in strophe, antistrophe, and epode are triadic ... It is called strophe, as Ptolemaeus says in his On Stationary Poetry, because those who sing move around the altar in a circle, signifying the movement of the zodiac. The antistrophe [is so called] because they move in the opposite direction according to the rhythm until they reach the spot from which they first started moving. With this movement they hinted at the movement of the sun, because this seems to move in the opposite direction 
from the cosmos. The epode [is so called] because they sang it standing still, representing in this way the firm stillness of the earth.

Monica Negri has proven conclusively that this Ptolemy is not Claudius Ptolemaeus but Ptolemy Epithetes, a grammarian contemporary with Aristarchus. ${ }^{55}$ In his treatise entitled On Stationary Poetry he explained the terms strophe, antistrophe, and epode on the basis of choral movements, not very differently from Didymus. The analogy between celestial and choral movements is very well attested in antiquity, both in tragedy ${ }^{56}$ and in other sources which give a cosmological interpretation of the chorus, as in the passage above. ${ }^{57}$ This doctrine, probably derived from Pythagorean sources, ${ }^{58}$ is beyond the scope of this analysis. The note in the Capitula, however, is interesting for our inquiry because it proves that Alexandrian grammarians did take into consideration the chorus' movements and music when defining and framing choral lyric as a genre. As for Ptolemy, the very title of his monograph, On Stationary Poetry

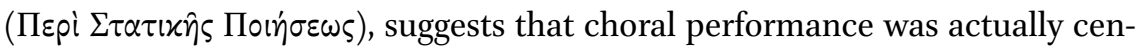
tral when discussing lyric poetry from a theoretical perspective, so that it was at the basis of its technical terminology. Some dramatic scholia also explain the word stasimon with reference to choral movement (or, rather, lack thereof), for example the following: ${ }^{59}$

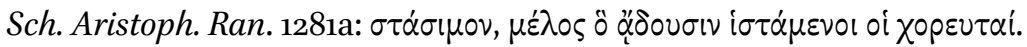

Stasimon, a song which the choreutai sing standing still.

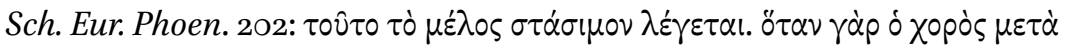

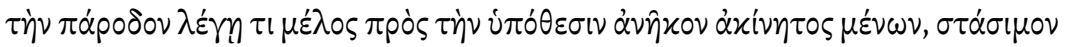

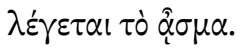

This song is called stasimon. For when after the parodos, the chorus, standing without moving, delivers a song connected to the content of the play, the song is called stasimon.

55 Negri 2001, against Montanari 1988: 107-109.

56 E.g., Eur. El. 464-469, Soph. Ant. 1146-1152. For a survey and discussion of star imagery in tragedy, see Csapo 2008.

57 Cf. Färber 1936: 20-22 (who still believed that the theory came from Claudius Ptolemaeus). Many of the scholia discussing the triadic structure of choral dancing are analyzed by Briand 2009.

58 Cf. Negri 2001: 126-127.

59 All these examples are discussed by Negri 2001:135-136; my analysis is very much indebted to hers. 
Interestingly enough, Aristotle gives a different definition of stasimon when he says that it is the part of the chorus' song without anapaests and trochees

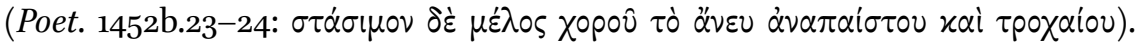
Here Aristotle does not take the movements of the chorus into consideration but only the metrical patterns of the lines. Of course, meter and dancing steps were connected, but this connection is absent in Aristotle's definition. This suggests that the same phenomenon (the choral performance) could be looked at in two very different ways by Greek scholars: it could be considered as a dancing body which physically moved on a floor (so Didymus and Ptolemy Epithetes) or it could be seen in more abstract terms, as a portion of a text, characterized by a specific metrical pattern (so Aristotle). The latter characteristic was of course originally an aural phenomenon connected with performance and with the dancing steps. Yet a metrical pattern was also something which (unlike the dancing) could be reproduced and "seen" in a written text, at least since the time when the Greek alphabet, as well as new writing conventions, allowed scribes to signal long and short syllables more accurately. ${ }^{60}$ Metrical patterns, unlike dancing steps, were the focus of Aristotle when describing the chorus. But this is the point of view of a "reader" rather than a "spectator" of lyric poetry.

\section{Conclusions}

In this article I have tried to show that the question to ask is not if ancient scholars had an interest in performance but rather when and how this interest emerges.

Ancient commentators did take an interest in music and choral dancing at a theoretical level to distinguish between different types of lyric poetry, as Didymus and Ptolemy Epithetes do. In the exegetical practice on specific authors and odes, however, they do not seem to have been interested in the most purely performative aspects of lyric poetry, such as the music and the choral performance. The performance-related references in the scholia originate from the text. These textual references then lead the commentator to guess the chorus' activities or the musical element. Yet these explanations are mostly antiquar-

6o This happened with the adoption of the Ionic alphabet, which differentiated between $\varepsilon$ vs. $\eta$ and 0 vs. $\omega$ and which was introduced in Athens at the end of the fifth century. In fact, such an alphabet may have been widely used even earlier than 403/4O2 BCE and beyond Attica; see D'Angour 1999: 120-123. In addition, Aristotle (Soph. el. 177b4-7) seems to know reading signs $(\pi \alpha \rho \dot{\sigma} \sigma \eta \mu \alpha)$ which made it possible to disambiguate words also in terms of vowel length. 
ian (origin of a dance or of a musical mode) or deduced from clues in the text itself. Nevertheless, even if most often the explanations are text-derived, we cannot exclude the possibility that sometimes grammarians could have used additional evidence to support their analyses. The idea of semi-choruses, for example, suggested by the text of Alcman's partheneion, could have been supported by the historical research of Sosibius, who is in fact also quoted in the scholium on the Castoreion (above, pp. 124-125). Yet the exegetes' interest in the extratextual realities of a lyric passage, sometimes backed up by antiquarian sources, started only from the text itself, when it required some explanation beyond the linguistic one.

These data seem to match what Nünlist has found in his study of performance-related notes in dramatic scholia. ${ }^{61}$ If his analysis gives the impression that there are quite a few notes discussing stage action in dramatic scholia, this is simply because to understand a dramatic plot a reader must visualize what is happening onstage. ${ }^{62}$ In addition, most notes discussing stage action in scholia to Greek drama can be deduced from the text itself, just as with Pindar.

In my view, this "textual" attitude towards performance arose from two different and coexisting factors. On the one hand, the lack of interest in performance is inherited from Aristotle. Just as he defined a stasimon in terms of meter and not of dance, so he famously excluded spectacle, that is, performance, from the technical parts of tragedy:

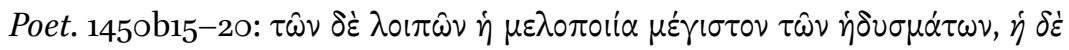

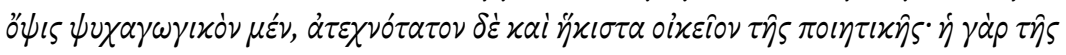

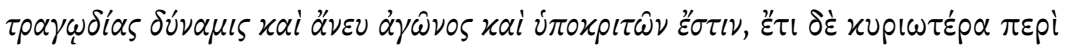

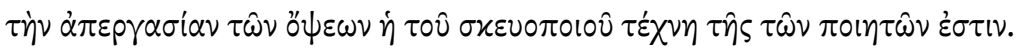

Of the other [parts], song is the greatest element to spice up poetry. Spectacle is something that appeals to our imagination but lacks any technical expertise and is the least peculiar to poetic art. For the potential of tragedy exists even without performance and actors; moreover, to produce spectacles the technical expertise of the one who makes stage equipment is more important than the technical expertise of the poets.

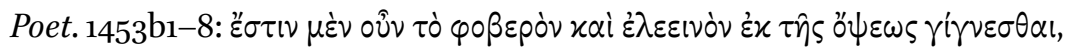

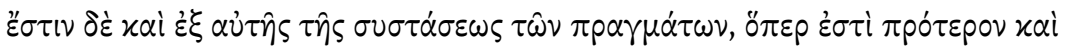

$61 \quad$ Nünlist 2009: $33^{8-365}$.

62 As Nünlist 2009: 365 , himself recognizes: "most of the relevant notes primarily serve the needs of a reading audience." 


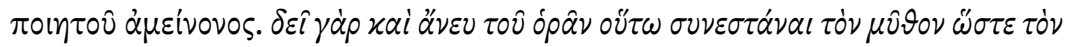

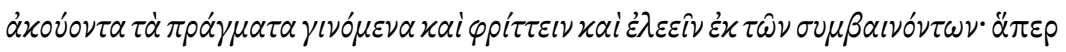

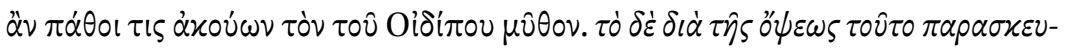

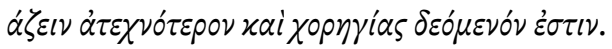

What causes fear and pity can happen through spectacle, but also from the structure of the incidents itself, which is superior and [the mark] of a better poet. For the plot should be put together in a way that, even without watching, one who hears the events that unfold in it will shiver with fear and feel pity at what happens; this is what someone listening to the plot of Oedipus would feel. To obtain this effect through spectacle requires less technical skill and needs abundant means for the production. ${ }^{63}$

If, following Aristotle, performance was not considered really part of dramatic poetry, at least from a technical point of view, then later "literary critics" might have concluded that the performative aspects of archaic and classical poetry did not belong to the exegetical practice. This attitude explains what we read in the lyric and dramatic scholia. Scholars knew that these genres, especially lyric poetry, had music and dancing. They therefore had to deal with these elements, but took them into account only in theoretical discussions, when "framing" the different types of lyric poetry. However, music and choral performance did not impact their exegetical and editorial practice. What really mattered to them was the text, and the text itself gave all the answers they needed.

In addition, there was the lesson of the Alexandrians and in particular of Aristarchus, who inaugurated the practice of clarifying an author from the author himself. ${ }^{64}$ Even if we might not like the many text-derived explanations in the Pindar scholia, for the ancients this was sound methodology because it meant to "clarify Pindar from Pindar," following the teaching of the most renowned of the grammarians, Aristarchus.

63 On the problematic status of the chorus and choral performance in the Poetics, see Halliwell 1986: 238-252; cf. also Peponi 2013c: 23-26; Weiss 2018: 3-6.

64 The maxim "to clarify Homer from Homer," often ascribed to Aristarchus, is not by him but rather is used by Porphyry to define his own methodology in the Homeric Questions (QH

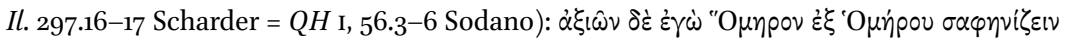

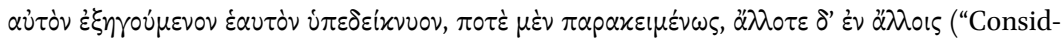
ering it right to explain Homer from Homer, I have shown that Homer interprets himself sometimes in passages which are nearby, sometimes in other [more remote] passages"). Cf. Pfeiffer 1968: 226-227, and Porter 1992: 73-80. Aristarchus did, however, consistently apply the principle of clarifying Homer from Homer in his philological activity; see Schironi 2018. 
Finally, the ancients looked at genres according to the speakers. The distinction among dramatic, narrative, and "mixed" genres is familiar to modern readers above all from Plato and Aristotle; yet, as we have seen, it is also reflected in some ancient editions attested in papyrus fragments, which signal the speakers within the poem: they are the Homeric heroes as well as "the poet," i.e., Homer. The previous analysis suggests that Pindar's epinicians, too, belonged to the "mixed" genre, because the poet behaves like Homer, intruding in the text with his own voice as well as introducing characters who speak in their own personae: the chorus and the victor. Alcman's partheneion, in contrast, might have been considered "dramatic," with the girls of Agido and those of Hagesichora as the only speakers, as $P$. Louvre suggests. ${ }^{65}$

In the Homeric poems and Pindar's victory odes, both belonging to the "mixed" type, the poets were speakers just like their characters or, in the case of Pindar's odes, the "real" performers in the chorus. Yet this dialogue among characters (whether it was purely dramatic or mixed) was firmly set on the page. And one could simply explain these texts with the text itself. Clarifying an author from the author himself was a very good principle when applied by Aristarchus to Homer, as it avoided allegorical readings extraneous to the text. However, because of the influence of Aristotle and Aristarchus and because both Homer and choral poetry were considered "dialogues among speakers," this principle was unfortunately applied to Pindar and Alcman, who might instead have benefited from a look beyond the text.

65 A similar reconstruction was suggested by Rutherford 2001: 101, for some lyric genres, when he hypothesized that while the dithyramb belonged to the diegetic (or narrative) genre, the hyporchema belonged to the mimetic (or dramatic) genre, and the paean to the mixed genre. 
PART 3

Genre Mixing 
978-90-04-41259- $\odot$

Downloaded from Brill.come4/26/2023 $09: 51: 26 \mathrm{AM}$ via free access 


\title{
Chorus Lines: Catalogues and Choruses in Archaic and Early Classical Hexameter Poetry and Choral Lyric
}

\author{
Deborah Steiner
}

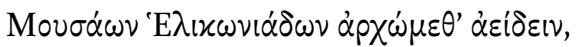

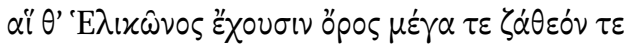

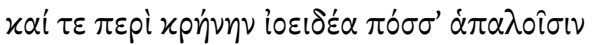

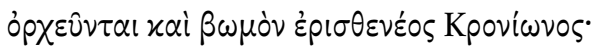

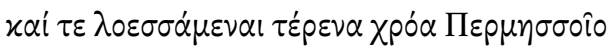

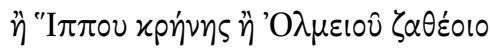

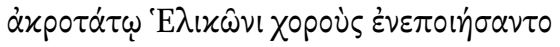

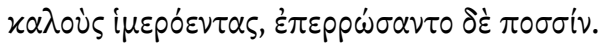

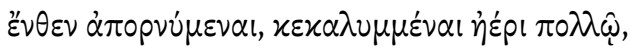

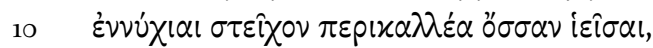

Let us begin to sing from the Heliconian Muses, who possess the great and holy mountain of Helicon and dance with supple feet about the violetdark spring and the altar of Cronus' broad-strengthed son. And having washed their tender skin in Permessus or the spring of Hippocrene or holy Olmeius, they perform fair, desire-instigating choral dances and ply their feet. Setting out from there, enshrouded in much mist, they process by night, emitting their very beautiful voice.

HES. Theog. 1-10

Hesiod's Theogony opens in a manner that sharply differentiates it from its Homeric counterparts: in place of the singular "goddess" or "Muse" whom the Iliad and Odyssey proems invoke, Hesiod's divinities form a plurality. More than this, the opening vignette depicts the Muses engaged in a particularized activity, performing a ring dance around a body of water and altar with the "tender feet" distinctive of choral maidens in archaic epic and lyric poetry. ${ }^{1}$

1 Cf. Alcm. fr. 3.10. 
The divinities' presentation as an archetypal chorus continues through this opening visualization: a few lines on, we meet them "making dances," plying their feet in the manner of Iliadic and other choral dancers, ${ }^{2}$ and like the prototypical chorus on the shield of Achilles, and those that follow in the lyric corpus, the Muses' ensemble is both beautiful and desire-instigating. ${ }^{3}$ Even as the performers sing - thereby satisfying the later Platonic definition of choreia as "song-dance" (Leg. 654a) — their motion changes: now, marching ( $\sigma \tau \varepsilon i ́ \chi \omega$ regularly denotes orderly, ranked movement) down from the Heliconian heights, the deities process. Here poetic content and choral formation coincide. Just as the Muses perform a reverse Theogony, beginning at the succession struggle's end as they move from the mountain to lower land, so they invert the regular sequence that determines the movements of a chorus: first the linear procession to the sacred site, and then the ring dance, typically performed around an altar or other center point, on reaching its destination. The Heliconian Muses, by contrast, quit the "altar of Cronus' son" and the divinely-inhabited bodies of water (so often the site of choral dancing, particularly by nymphs) so as to descend into the mortal, secular realm. The song sung by the goddesses as they journey downwards - a last-to-first inventory of the Olympians and those preceding them-already supplies the template for the mode of discourse that Hesiod will adopt in the poem that follows: the catalogue or list.

The Theogony's opening scene succinctly exemplifies the larger phenomenon explored in this chapter, the copresence of choruses and catalogues in archaic and early classical poetry. For all that the catalogue is regularly viewed as an element integral to hexameter poetry and among the hallmarks of that genre, both in Hesiod's proem and elsewhere, choruses regularly appear when such lists occur, whether as performers of the itemized accounts and/or as the subjects of a poet or internal speaker's "catalogic" presentation. In the twofold argument made here, the coincidence between troupes of singer-dancers and a catalogue depends in no small part on the "incipient chorality" that the enumerative device possessed in the archaic Greek imaginary, and calls into question the assumption that several of the catalogues in choral poetry necessarily derive from prior hexameter sources; rather, I propose, both Homeric and Hesiodic lists may take their cue from, or be informed by, choral performances staged before a civic audience on ritual occasions. More broadly, in

2 E.g. Il. 24.616, Hymn. Hom. Ven. 261.

3 Il. 18.49o-561; Alcm. fr. 3. For representations of maiden choruses in the lyric and dramatic corpus recapitulating the terms used here, see Swift $2016 \mathrm{~b}$.

4 I borrow the expression from Power 2011: 75 . 
the bilateral exchanges my discussion suggests, the introduction of a catalogue within hexameter and choral poems offers an instance of what might be styled "generic contamination" or boundary crossing, whereby a composer in one genre embeds within his or her piece a mode of discourse drawn from a very different performance tradition. On these occasions, I argue, the list's generic underpinnings remain discernible in its diction, design, speaker/singer, and/or the manner or context of its presentation.

The discussion that follows falls into two sections, the first given over to close readings of three passages, one from hexameter epic, two from fifthcentury choral compositions, that variously illustrate the generic exchanges between lyric and hexameter song and feature indicators of the stylistic hybridity that results from these poetic interactions. Part two goes on to propose some underlying reasons for the phenomenon just observed. Drawing attention to continuities between the morphologies of catalogues and chorusesthe designs and formations both adopt, the relations between the individuals or items in a list and the singer-dancers making up the choral ensemble, the hierarchies structuring the two assemblages - in both the poetic and visual repertoires, it suggests that these features may explain the reasons why, as my opening example from Hesiod and the passages treated in section one demonstrate, hexameter epic looks regularly to a chorus to perform a list and choral lyric to the monodic genre when incorporating a catalogue into its song and dance.

\section{"Generic Contamination" in Homer, Bacchylides, and Corinna}

A single overarching question informs my close readings of three passages from archaic and classical poetry: if my claim for generic commingling is correct, then how might we discern in these lines their authors' acts of appropriation and what structural, stylistic, dictional and other generic "fingerprints" reveal their borrowings? Or, more specifically, what in the epic passage points to its choral derivation or, as argued here, coexistence in the form of a composition performed by a chorus before a civic audience; and, conversely, where do the choral poets acknowledge the hexameter tradition's use of the catalogue and their debts to that genre? Through a detailed examination of each passage, I hope also to suggest some of the reasons fueling a poet's choice to import elements from a different generic and performance tradition and to observe the dividends that the practice pays.

For the chorality informing the most "purple" of all Homeric catalogues, my reading takes its cue from a treatment of the passage by Bruce Heiden and 
builds on his discussion. ${ }^{5}$ As part of a larger argument that aims to demonstrate the curiously populist orientation of the Catalogue of Ships, its privileging of the common soldiers and communities they have left behind over the aristocratic heroes who dominate the remainder of the poem, Heiden suggests that the Catalogue does indeed conform to its characterization in Cedric Whitman, who styles it a "hymn to the army." 6 For Heiden, the designation is more than merely rhetorical. Rather, the list exhibits its "hymnal" and collective dimensions by its inclusion of features more typical of lyric than hexameter poetry and most closely parallels a lyric lament, a threnody such as would be performed by a civic chorus at a funerary ritual on behalf of those who had lost their lives fighting abroad. Among the chief lyric giveaways identified by Heiden are: the introduction of the refrains so characteristic of choral laments and which invest the movements described with a "rhythmic performance dimension comparable to dance"; the ways in which the poet invites us to view the vessels not just as soldiers advancing in their ranks but as members of choral

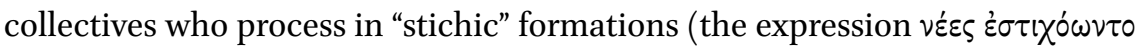
closes four of the entries); and the use of diction suggesting parallels between the structure of the crews and those of choral ensembles and identifying those who assemble the contingents as choregoi-like leaders to the troops that "follow". 8 While Heiden focuses all but exclusively on the appeal to the Muses and the subsequent inventory, I want first to look at the events immediately preceding the invocation before noting some additional elements in the list consistent with a lyric composition.

The preliminaries to the Catalogue prepare the ground for what follows, alerting us to the way in which the poet prefaces his enumeration by ordering its multiple items and by suggesting the presence of a chorus leader. Following Nestor's proposal that the heterogeneous mass of assembled troops be divided by tribe and phratry (362) and the army's sacrifice and meal, the leaders carry

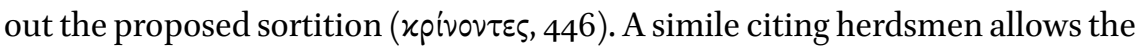
audience to visualize the action, with the addition of a fresh term evocative of a decking out that introduces an aesthetic dimension to the arrangement (474$476)$ :

5 Heiden 2008, esp. 145-152.

6 Whitman 1958: 262, cited by Heiden 2008: 129 .

7 Heiden 2008: 149 .

8 Heiden 2008: 149 . 


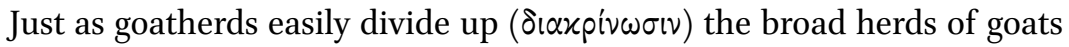
when they mingle on the plain, even so the leaders divided and marshaled

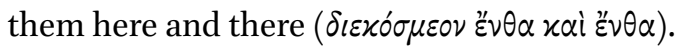

Thucydides uses $\delta เ \varepsilon x o ́ \sigma \mu \varepsilon เ$ of the organization-cum-arraying of the Panathenaic procession (6.57.1), while Xenophon of Ephesus' description of the pompe celebrating the Ephesia selects the verb in its uncompounded form for the simultaneous ornamentation and orderly positioning of the chorus in the line (Ephesiaca 1.2.4). The Athenian Xenophon, speaking of how the good housekeeper groups her different pots and pans according to their kind prior to their inventorying, spells out, albeit half fancifully, connections between the act of division, orderliness, and the aesthetic and expressly rhythmic harmony (so eüpu$\theta \mu o v$, a term regularly used in the context of mousike and groups of performers moving in time) that results, and a choral arrangement (Oec. 8.19-20):

No serious man will smile when I claim that there is beauty in the order

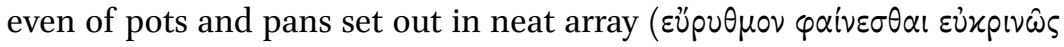
$\chi \varepsilon \mu \varepsilon^{\prime} \nu \alpha \varsigma$ ). There is nothing, in short, that does not gain in beauty when

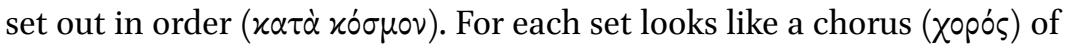
utensils, and the space between the sets is beautiful to see, when each set

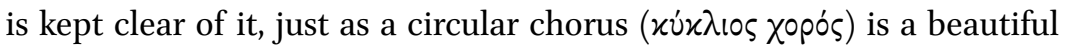
spectacle in itself.

Indeed, kosmos belongs among the defining features of a chorus, the quality succinctly foregrounded in the account given by the messenger in Euripides' Bacchae, where he remarks of the maenadic troupe responding to Agave's choregic summons: "they started up, upright, wondrous to behold in their

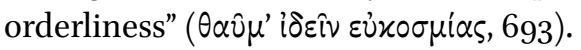

Choral ordering frequently depends on the choregos, and so the troops' disposition in Iliad 2 ends by spotlighting this figure standing among the soldiery (477-481):

Lord Agamemnon there among them, like to Zeus delighting in thunder with regard to his eyes and head, and to Ares in his waist and Poseidon in his chest, just as a bull is preeminent among the herds. For he is conspic-

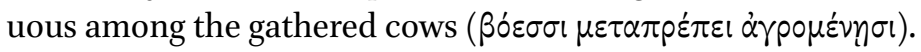

The term used of Agamemnon, $\mu \varepsilon \tau \alpha \pi \rho \varepsilon \varepsilon \pi \varepsilon$, regularly signals the choregos, distinguishing Nausikaa as she leads her attendants in their dance (Od. 6.109). With a very similar expression, Agido is styled $\dot{x} x \pi \rho \varepsilon \pi \eta \dot{\zeta}$ in Alcman's Parthe- 
neion (fr. 1.46), and even as the Homeric hero-bull is conspicuous among the cows, so this chorus-leader "appears outstanding as if one placed among a grazing herd a perfect horse, a prize-winner" (45-48). ${ }^{9}$ It is the fourth-century Xenophon again who explicitly compares a company of soldiers, where each man occupies his appointed place within the larger group, and the well-functioning choral ensemble. Approving his son's proposal to arrange competitions in the warlike exercises required of soldiers in battle, Cambyses remarks that, by virtue of this regimen, "you might see military companies that are just like

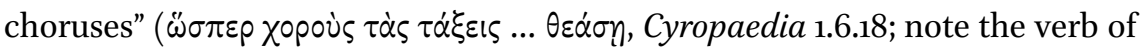
spectatorship appropriate to chorus viewers). Still more apposite is the return to the analogy in Cyropaedia 3.3.70: in disarray following the failure of a first assault, the troops "halted in their regular position, knowing much more accurately than a chorus each one the spot in which he should stand" ( $\pi \circ \lambda \dot{\nu} \mu \alpha \hat{\lambda} \lambda \circ \mathrm{v}$

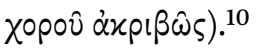

The Iliadic scene of the troops' arrangement closes just before the invocation to the choral Muses, the transition point between the narrative and the start of the Catalogue. In the divinely channeled list that follows, the chorality latent in the preceding episode becomes more marked. Not only, as Heiden well observes, do the naval contingents resemble members of choral collectives processing in their ranked formations, but we witness the stationing of these assemblages when they reach their destination, where they stand waiting to perform anew. In his account of the Boeotian contingent at 525, the poet notes how the ships' leaders "placed the ranks" ( $\sigma \tau i \chi \alpha \varsigma^{\prime}$ i $\left.\sigma \tau \alpha \sigma \alpha \nu\right)$, an action that has a second sounding when Ajax similarly positions his twelve ships alongside another group: "and he, leading [twelve ships], positioned them where the

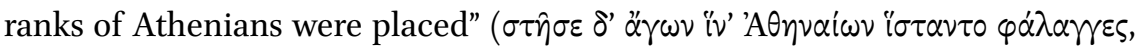
558). The verb used in both phrases has a choral dimension of its own, supplying the vox propria for the setting up, deploying, or instituting of a chorus in the

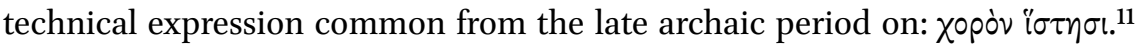
The kosmesis that occurred in the troops' sorting-cum-decking-out now determines Menestheus' conduct; the Athenian hero receives special mention for his skill in arranging/adorning (

9 For the suggestion that it is the poet-choregos who positions Agido here, see Peponi 2004: $313-315$.

$10 \quad$ Cf. Xen. Mem. 3.4.4.

11 See Nagy 1990: 361-362; Calame 1997a: 45; and particularly Myers 2007; note too Peponi 2004: 315; Kavoulaki 2011: 371-373. The first extant usage of the term appears in Pind. fr. $5^{2 b}$.99.

12 Cf. Pind. Pyth. 9.118 for a choregos who similarly adorns ( $(\circ \sigma \mu \eta \dot{\sigma} \sigma \alpha \varsigma)$ his lead dancer in an agonistic event. 
an agonistic context - only Nestor can "vie" ( bination of terms positions the heroes as rival choregoi seeking to outdo one another with the brilliance of their choruses and their aesthetically pleasing deployment. Indeed, later poets and prose-writers would respond to and realize the choral dimension discernible in the Homeric enumeration: both the parodos of Euripides' Iphigenia at Aulis and Thucydides' account of the Sicilian armada gathered at the Piraeus (6.30-32) acknowledge their Homeric "catalogic" template while casting their respective fleets, crews, and expedition leaders as so many rivalrous participants in a choral performance. ${ }^{13}$

If Heiden's larger claim is correct - that together the accumulation of choral terminology and the Catalogue's generically heterogeneous stylistic features turn the list into something approximating a collective song-and-dance that celebrates those whose death at Troy their townsmen in their homelands mourn in choral performances ${ }^{14}$ — then the possibility of a further convergence between a choral performance and a distinctly different poetic tradition opens up. As Joseph Day reminds us, these laments might be transcribed in monumental form, now assuming the shape of inscribed epitaphs - this a genre with conventions of its own which may incorporate a roll call of the dead-where individuals would encounter and vocalize them anew. ${ }^{15}$ It is no happenstance that the inscription on the Ambracian cenotaph analyzed by Seth Estrin in this volume and that, in Day's suggestion, would originally have taken the form of a choral performance, lists the names of the four citizens who died abroad while engaged on a mission for their polis.

As for the impetus behind the Homeric poet's incorporation of a choral threnos, the embedding of this different genre not only suits the nature of those whom the aoidos begins by invoking as overseers of the catalogue to come, the collective Muses who regularly perform laments on the occasion of funerary rites (e.g. Odyssey 24.6o-61). More than this, the act of transference allows the monodic singer to meet the challenge rehearsed in that invocation, effectively granting him the multiplicity of tongues and mouths ( $\delta \dot{\varepsilon} x \alpha \mu \dot{\varepsilon} \nu \gamma \lambda \hat{\omega} \sigma \sigma \alpha l, \delta \dot{\varepsilon} x \alpha \delta \dot{\varepsilon}$ $\sigma \tau{ }^{\prime} \mu \alpha \tau$, 489) that he cites as prerequisites for the performance of so outsized a catalogue, thereby appropriating for his single person the vocal capacities that belong to a choral ensemble.

The amalgamation of the two distinct genres and performance traditions is no less evident in my examples from choral poetry, both featuring a single

13 See Steiner 2018 for these and other examples and, on the Iphigenia at Aulis, Weiss 2018: 193-205.

14 Heiden 2008: 150-151.

15 Day 2007. 
parthenaic group, the nine daughters of the river god Asopos. As I detail elsewhere, in compositions by fifth-century choral poets as well as in a Euripidean stasimon ( $H F$ 781-789), these maidens repeatedly serve as objects of "choral projection," supplying one among the archetypal troupes of singer-dancers whom latter-day ensembles select as models. ${ }^{16}$ But a paradigmatic choralityalso visible in contemporary artistic representations where her sister Asopids dance in choruses during the abduction of Aegina ${ }^{17}$ —is not the only characteristic assigned to this sorority. Instead, as the passages from works by Bacchylides and Corinna treated here illustrate, poets may also choose to frame them within a catalogue, introducing Asopos' daughters and their histories in the form of a list. In the standard view, this mode of presentation results from both composers' debt to a preexisting hexameter source, the Pseudo-Hesiodic Catalogue of Women, where, following Martin West's broadly accepted reconstruction, ${ }^{18}$ the Asopids were a central presence in the poem's fourth book. In place of this straightforward act of appropriation, I suggest that Bacchylides and Corinna are no mere followers: maintaining the sorority's signature chorality, they also draw on the hexameter tradition to which the maidens simultaneously belong, thereby engaging in that "transgenericity" (in Michel Briand's phrase $)^{19}$ already practiced in the Catalogue of Ships.

Bacchylides' ninth ode, composed on behalf of the Nemean victory of Automedes from Phleious, exploits the multiplicity of rivers, or water sources, all bearing the name Asopos: one formed the southern limit of Boeotia, the second, a spring, was located on Aegina, ${ }^{20}$ and the third, featured in the song for the Phleian victor, traced its course through Phleious and originally formed the border between Thebes and Plataea. ${ }^{21}$ This is the Asopos who, along with his progeny, receives explicit praise in lines $40-52$, where the singers rehearse how the river-god's renown has traveled to the far points of the earth, further stoked by the fame of his daughters. Invoking the deity, the singers hail their addressee before beginning their celebration (47-65):

16 Steiner forthcoming. Among the examples I cite, note particularly Bacchyl. 13.77-95 SM and Pind. Nem. 3.1-16.

17 E.g. a red-figure stamnos of ca. 475-425 (Bochum, Ruhr Universistät, Kunstsammlungen S1172), or a column-krater of ca. 46o attributed to the Boreas Painter (New York, Metropoli$\tan$ Museum 96.19.1).

18 West 1985: 100-103. See too Larson 2002: 139-140.

19 Briand used this phrase in his paper at the conference on which this volume is based.

$20 \quad$ See Fearn 2007: 102-105, building on Privitera 1988.

21 Hdt. 7.199-200 also mentions the existence of a Thessalian Asopos that flowed into the Gulf of Malis. For discussion see Kowalzig 2007b: 195-201 and Nagy 2011a: 52-54 (drawing on West 1985: 162-163). 


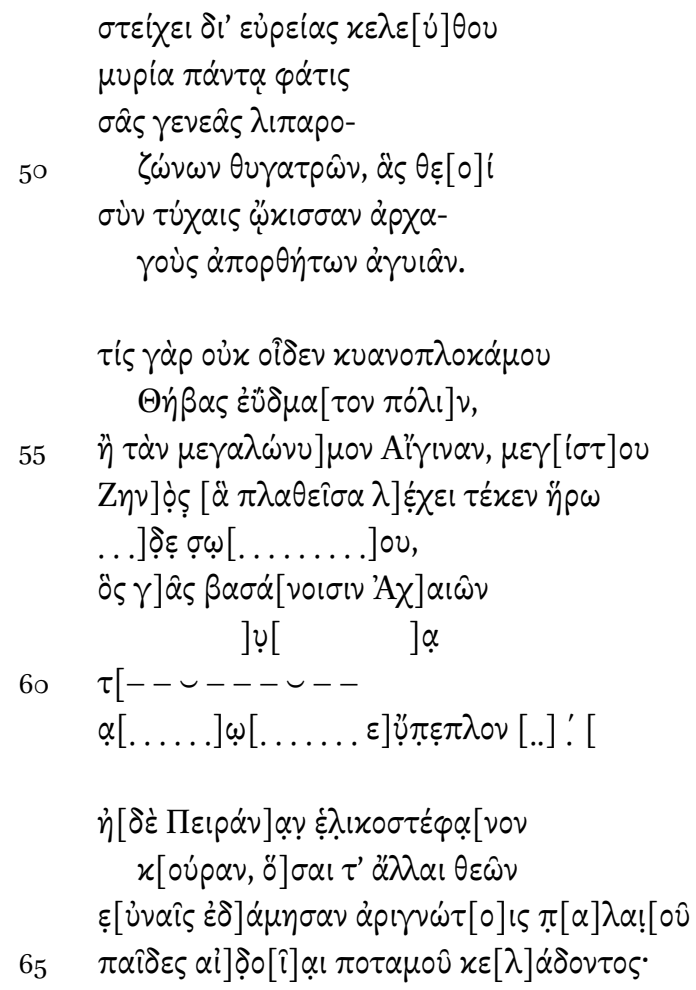

On a wide path travel in all directions the countless reports of your progeny, the shining-girdled daughters whom the gods with good fortune have settled as rulers of unsacked streets. For who does not know of the well-built town of dark-haired Thebe or of the renowned Aegina, who (came to) the bed of great Zeus and bore the hero ... whom the land of the Achaeans by the tests ...? ... fair-robed ... and (Peirene the maiden) of the twining garland, and all those who were mastered in far-conspicuous beds of the gods, venerable daughters of the ancient sounding river.

While the personified river serves, as so often, as the perfect means of establishing a "natural" connection and two-way vector between the victor's home and the site of his win, Asopos' multiple daughters occupy the chief portion of the celebration. As G.B. D'Alessio observes of the lines, ${ }^{22}$ this is the "passage which comes closest to a Hesiodic catalogue in the preserved songs of Pindar and Bacchylides," and he further notes that the $\ddot{\eta}$, retained by some editors at the start 
of line 62 in place of the $\ddot{\eta}[\delta \varepsilon$ printed by Jebb and used here, suggests "that the list may have been coordinated through the disjunctive particle, recalling the $\ddot{\eta}$ oin formula" of the Catalogue of Women that gave the work its alternate name, the Ehoiai.

A catalogue structure continues to inform the passage. Despite the lines' lacunose condition, we can assume that the singers would have listed at least some of the river's progeny: with Thebe heading the enumeration and Aegina next in line, two or even three other daughters would have been named, each accompanied by an epithet. ${ }^{23}$ David Fearn suggests the inclusion of Cleona in line 61, and Peirene, the Corinthian spring, seems a likely candidate for $62 .{ }^{24}$ The catalogue ends in the fashion typical of hexameter lists, with a summary reference to "all those other venerable daughters of the ancient sounding river."

But alongside the choice of a (Pseudo-Hesiodic) catalogue format for the Asopids' presentation, with all the authority and aggrandizement that the hexameter and now canonical Panhellenic source would lend the home-based ensemble in the current composition, the maidens' choral character is no less prominent. Bracketing the geographical-mythical excursus are references to Automedes' victory and its celebration in song and dance on his arrival home. In lines $27-36$ (fully cited below), the singers recall the laudandus' winning cast with the discus before pivoting to the moment of his return to Phleious and

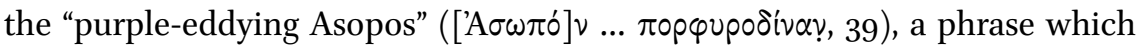
acts as lead-in for the account of Asopos and his daughters. A second matching mention of the river ( $\pi \circ \tau \alpha \mu \circ \hat{v} \chi \varepsilon[\lambda] \alpha \dot{\delta} 0 \nu \tau \circ \varsigma, 65)$ concludes the description of the Asopids, signposting this embedded section's end and a return to where the song left off as the singers resume praising Automedes. With the river and its epithet in final position in the line, the lacunose phrase that follows moves directly back to the present occasion where the "shouts of pipes" ( $\alpha \dot{\nu}] \lambda \hat{\omega} \nu$

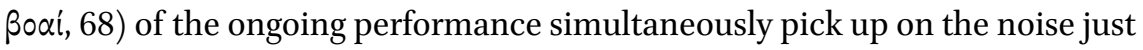
emitted by the water. The bookending of the section introducing the Asopids between two celebrations of the victor not only alerts us to the connections that the poem suggests between the objects of praise, the Asopos, its offspring, and the local boy made good; it also draws attention to choreia as the critical mechanism for the propagation of renown, a counterpart to the extensive (epic) river/genealogical network that Bacchylides has traced out and that, like the water course with its self-multiplication in its progeny, is both synchronic and diachronic in scope.

23 Maehler 1982: 1.186 makes various proposals concerning the other names.

24 Fearn 2003: 361. 
The interfaces between the present-day festivities and the nine Asopids are also visible in the diction of the framed passage, which depicts the maidens in terms that align them with Bacchylides' choreuts and their ongoing performance, and positions the mythical sorority as the originary chorus on whom Automedes' celebrants now model themselves. Styled "shining-girdled"

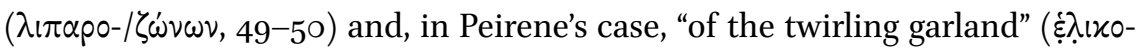
$\sigma \tau \varepsilon \dot{\varepsilon} \varphi\left[\right.$ [vov, 62), ${ }^{25}$ the Asopids' accessories correspond not just to the radiance of the current singer-dancers (the sine qua non of any chorus worth watching), ${ }^{26}$ but perhaps to their circular choreography too. Fresh rotations belong to the maidens' watery progenitor, who, in a striking hapax, has displayed its "purple eddies." Sound as well as movement and sparkle links the different sections: the noise emitted by the river, then echoed by the clamorous pipes, supplies an audible and musical counterpart to the $\varphi \dot{\alpha} \tau \iota$ featured in the description of the river and his daughters' renown.

Nor is this choral "mapping" confined to the Phleian chorus members; while Automodes resembles the parthenoi and their father insofar as he, like them, supplies the object of choral encomium, the visualization of the athlete (his hair similarly garlanded, $\sigma \tau \varepsilon \varphi \alpha \dot{v} \omega, 23)$ at the moment of his triumph in the lines immediately preceding the Asopids' introduction positions him as leaddancer/choregos of the celebratory band $(27-36)$ :

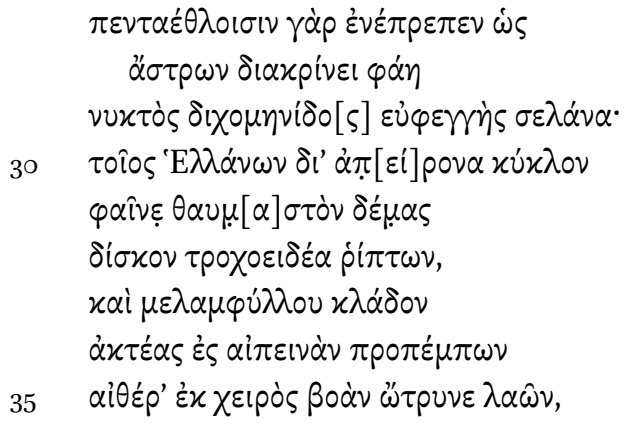

For among the pentathletes he was conspicuous, as the fair-shining moon stands distinguished from (i.e. outshines) the light of the stars in the midmonth night, even so in the boundless circle of the Greeks did he display his awesome form as he cast the wheel-shaped discus, and send-

25 For the choral association of $\dot{\lambda} \lambda \dot{\sigma} \sigma \omega$ and its cognates, see Csapo 1999-200o.

26 See Kurke 2012: 228-229. 
ing forth from his hand the shoot of the dark-leaved elder into the sheer heavens he stirred up the acclamation of the crowd, or when he completed the flashings of the wrestling.

Each and every phrase suits a choregos as portrayed in the earlier lyric (and hexameter) tradition. No less pertinent to choreia than the "conspicuousness" already treated above that sets Automedes apart from the other contestants are the associations of the nighttime sky illuminated by the moon and attendant stars; ${ }^{27}$ whether on the first band of the Iliadic shield or in Alcman's first Partheneion, these constellations are paradigmatic choral dancers, the less brilliant celestial bodies following the lead of, or circling about, their stellar choregos. As commentators note, here Bacchylides also echoes the conceit in Sappho fragment $96.6-10 \mathrm{~V}$, a choral song in which the performers praise a now departed chorus member, ${ }^{28}$ the former première of their troupe; it was in her song-and-dance $(\mu \dot{\partial} \lambda \pi \alpha, 5)$ that the sorrowing Atthis left on Lesbos chiefly took delight. Just as Automedes stands out in his dazzle, so this parthenos-turnedbride maintains her choral preeminence in her new home: "she is conspicuous ( $\dot{\mu} \mu \pi \rho \varepsilon \dot{\pi} \pi \tau \tau \alpha l)$ among the Lydian wives like the rosy-fingered moon ... outshining all the stars" ( $\left.\pi \dot{\alpha} \nu \tau \alpha \pi \varepsilon \rho\langle\rho\rangle \dot{\varepsilon} \chi 01 \sigma^{\prime} \ddot{\alpha} \sigma \tau \rho \alpha\right)$.

Automedes' likeness to the (literally) star performer in a choral band extends to the delineation of the events - a virtual victory catalogue - in which he triumphed. First off is his discus throw $(30-32)$, the moment that supplies the tenor for the lunar simile. The description privileges circularity: the athlete in the midst of his fellow contestants stands equivalent to the moon with its circlet of subordinate astral bodies as he throws the rounded discus (a move which requires the body to describe an arch and then turn about its axis) while positioned in the center of the crowd sounding its acclaim. The scene recalls not just Odyssey 8.370-380, where the chorus encircling the troupe's star performers staging their acrobatic pas de deux likewise raises an approbatory sound; if the Homeric account of the chorus on Achilles' shield (cited in section two) reflects traditional notions of choral dancing, then the spin of the potter's wheel ( $\tau$ poxóv, Il. 18.60o) supplies a canonical comparandum for the gyrating chorus, this reflected in the Asopids and their "purple-eddying" ( $\pi \circ p \varphi v p o \delta i v \alpha y$ ) father. ${ }^{29}$

Two further details in the visualization draw on choral terminology, practices, and audience response. Even as Automedes' bodily form is "wondrous"

\footnotetext{
$27 \quad$ For discussion and examples, see Ferrari 2008 and Csapo 2008.

28 For the fragment as chorally performed, see Lardinois 1996: 161-162.

29 For $\delta เ v \varepsilon \dot{\omega} \omega$ as an indicator of circular (and, in his view, dithyrambic) dancing, see Csapo 1999-2000: 418-424 and 2008: 273-274.
} 
$\left(\theta \alpha \nu \mu[\alpha] \sigma \tau \sigma^{\prime}, 31\right)$ in the eyes of the spectators, so thauma is Odysseus' sensation as he watches the Phaeacian youths dance ( $\theta \alpha \dot{v} \mu \alpha \zeta \varepsilon \delta \dot{\varepsilon} \theta \nu \mu \hat{\omega}, O d .8 .265)$, a response shared by the Ionians gathered on Delos who witness the extraordinary and paradigmatic song-dance of the Deliades, styled a "great thauma" in and of itself (Hymn. Hom. Ap. 156). ${ }^{30}$ Most striking of all is the unprecedented noun that Bacchylides selects for Automedes' wrestling moves, $\dot{\alpha} \mu \dot{\alpha} \rho \gamma \gamma \mu \alpha(36)$. Here, I suggest, the poet nods to a second Sapphic intertext, the evocation of Anactoria at the close of fragment $16 \mathrm{~V}:{ }^{31}$ recalling the departed maiden, the persona loquens describes her longing to see "the desire-causing step and

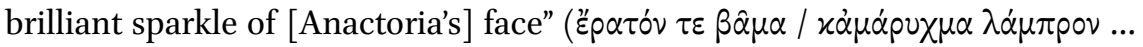
$\pi p \circ \sigma \omega \dot{ } \pi \omega, 17-18)$. The snapshot recalls the girl as she once performed as the leader of the ensemble, endowed, again, with the sparkle distinct to choral dancers; ${ }^{32}$ already in Homeric song and the hymnic repertoire, the cognate noun $\mu \alpha \rho \mu \alpha \rho \gamma \eta \dot{n}$ appears in the formulaic phrase $\mu \alpha p \mu \alpha \rho \gamma \gamma \alpha i$... $\pi \circ \delta \hat{\omega} \nu$, where it evokes the twinkle emanating from a dancer's feet as he/she performs as chorus member or choregos (e.g. Od. 8.265, Hymn. Hom. Ap. 203). Bacchylides may also anticipate the soon to be echoed Ehoiai in his diction here: $\dot{\alpha} \mu \dot{\alpha} p u \gamma \mu \alpha$ finds a still closer match in the formulaic phrase so frequent in the Catalogue of Women, Xapi $\tau \omega \nu ~ \alpha \mu \alpha p u ́ \gamma \mu \alpha \tau \alpha$, an expression repeatedly applied to heroines celebrated for their beauty. As Fearn comments, Automedes is "thus attracted into the language register associated with the kinds of feminine mythological archetypes who appear in Bacchylides' central myth, the Asopids,"33 and, I would add, more expressly to their Pseudo-Hesiodic representation. If Fearn's further suggestion that we might imagine Automedes as a member of a group of youths charged with celebrating the local heroines in choral performances is correct, ${ }^{34}$ then the mythical and real-world choruses become still more closely affiliated; just as such epichoric groups danced and sang on behalf of Aegina and her sisters on that island, ${ }^{35}$ so the Phleians may have done the same for the Asopids.

30 For thauma as a prime response to choral performances, see Neer 2010: 62-63 citing Bacchyl. 17.117-139 SM and Kurke 2012: 223, 227.

31 Also cited by Fearn 2003: 364 in passing; see too Cairns 2010: 256.

32 Typically Sappho reworks the hexameter formula, attributing the sparkle to the face while replacing the expected "feet" with the reference to the dancer's step.

33 Fearn 2003: 364. Very relevant is Fearn's further point that the "objectification" of Automedes positions him, like the Asopids, as a focus of erotic longing; that role is also suited to my reading of the laudandus as chorus leader insofar as choristers regularly express desire for their choregos.

34 Fearn 2003: 364.

35 See Steiner forthcoming for the Aeginetan choral celebrations. 
Commentators regularly observe that the Hesiodic Catalogue still more fully informs the final work considered here, this one composed by a poet who, like the Catalogue's supposed author, was native to Boeotia. Of course any mention of Corinna comes surrounded by debates concerning her date, the manner in which her songs were performed, and their intended audience, and I make two assumptions, closely argued for by other scholars, ${ }^{36}$ in the reading that follows: first, that Corinna belongs to the fifth century, and second, that her poems were most likely composed for choruses of parthenoi in Tanagra and perhaps elsewhere in Boeotia. Among the more extensive fragments is the socalled "Daughters of Asopos," a work whose extant portion occupies columns two to four of fragment 654. The Asopids are introduced in the early portion of the text, presented as a list narrating the abductions and marriages of at least some of the nine that the lines then number. The term $\hat{\omega} \nu$, "of these," suggests the start of the inventory, with Aegina in first position, then followed, in rapid succession, by Corcyra, Salamis, "lovely Euboea," Sinope and Thespia:

\begin{tabular}{|c|c|}
\hline$\omega \omega^{\prime \prime} \mathrm{H} \gamma[\iota \nu \alpha \nu$ & $\gamma \varepsilon] \nu \varepsilon^{\prime} \theta \lambda \alpha \nu$ \\
\hline$\Delta$ घùऽ[ & $\dot{\alpha}] \gamma \alpha \theta \omega \hat{\omega} \nu$ \\
\hline$\pi \alpha \tau p o[$ & $\dot{\varepsilon}] \varsigma$, \\
\hline Kopxov́ [pav & $\left.\dot{\varepsilon} x x^{\prime} \Sigma \alpha \lambda \alpha \mu \hat{\imath}-\right]$ \\
\hline 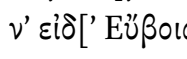 & 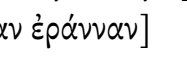 \\
\hline$\Pi \circ \tau \iota[\delta \alpha \omega \nu x)$ & $\left.\ell^{\prime} \psi \varepsilon \pi \alpha\right] \tau \varepsilon i ́ \rho$, \\
\hline$\Sigma \iota \nu[\dot{\omega} \pi \alpha \nu \delta \dot{\varepsilon}$ & $\left.\Lambda \alpha \tau 0^{\prime \prime} \delta \alpha\right] \varsigma$ \\
\hline$\Theta \varepsilon \dot{\varepsilon} \sigma\left[\pi \iota \alpha \nu \tau^{\prime}\right.$ & है $\chi \omega \nu^{\circ}$ \\
\hline
\end{tabular}

Of these (daughters) Zeus, giver of good things, (took) his child Aegina ... from her father's ... while Corcyra (and Salamis) and (lovely Euboea) (were stolen) by father Poseidon, and (Leto's son) is in possession of Sinope and Thespia ...

36 Here I follow, among others, Stehle 1997: esp. 101-104; Larson 2002; Collins 2006: 19-20 (with an overview of the argument); Lardinois 2011: 165-168. The case for the choral character of Corinna's poetry rests on admittedly slender grounds. Fr. 655.1-16, which opens with an invocation to Terpsichora ("she who delights in choruses") and is spoken in the voice of a poet or that of the collective chorus, which announces that it proclaims the legends of its homeland, Tanagra in Boeotia, offers the most compelling evidence. In Stehle's reading, the fragment suggests that Corinna addresses two audiences for whom different songs are performed: first the collective audience made up of the women of Tanagra, and then the parthenoi with whom the stories "from our fathers' time" seem to be connected. 
As Campbell's note points out, the catalogue would have ended with Tanagra, whom Hermes stole. Fresh enumerative design follows when the singers remark at $12-18$ of the next column:

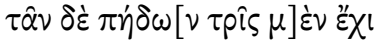

$$
\begin{aligned}
& \Delta \varepsilon \dot{\varsigma} \pi \alpha \tau \varepsilon i[\rho \pi \dot{\alpha} \nu \tau \omega] \nu \beta \alpha \sigma i \lambda \varepsilon \dot{\zeta} \varsigma \text {, }
\end{aligned}
$$

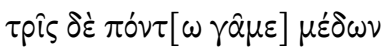

$$
\begin{aligned}
& 15 \Pi[0 \tau 1 \delta \dot{\alpha} \omega \nu, \tau] \alpha \hat{\alpha} \nu \delta \dot{\varepsilon} \delta 0 \nu \hat{\imath} \nu
\end{aligned}
$$

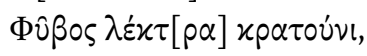

$$
\begin{aligned}
& \tau \hat{\alpha} \nu \delta^{\prime} \text { 'lav Mń }[\alpha \varsigma] \dot{\alpha} \gamma \alpha \theta \dot{\partial} \varsigma \\
& \pi \hat{\jmath} \varsigma^{\prime} \mathrm{E} p \mu \hat{\alpha} \varsigma^{\circ}
\end{aligned}
$$

And of your daughters father Zeus, king of all, has three; and Poseidon, ruler of the sea, married three; and Phoebus is master of the beds of two of them, of one Hermes, good son of Maia.

A marked degree of the repetition characteristic of lists structures this account, with $\tau \hat{\alpha} \nu$ $\delta \dot{\varepsilon}$ standing at the start at each entry naming a god and the number of his conquests, almost like an inscribed victory list. In counterpoint to this homogeneity, but very much in keeping with catalogue design, the numbers diminish, three apiece for the two "top" deities, two for Apollo, one for Hermes. The close of the list is, typically again, resumptive, reassembling the sisters into their collective nine.

As already noted, it has been commonplace to remark on the broader overlap between the subject matter, theme, and arrangement of Corinna's extant poetry and that of the Pseudo-Hesiodic Catalogue, and nowhere more than in fragment 654, a composition whose themes are very much in sync with those of its hexameter precedent. The later poet's concern with genealogy and ancestry through maternity emphatically here recalls the Ehoiai, and Jennifer Larson notes that line 9 "hints at familiarity with the Catalogue"; as she further remarks, "both the Catalogue and Asopid daughters provide a marked, hierarchical catalogue of progenitor gods who beget a race of semidivine heroes." ${ }^{37}$ The enumeration of the Asopids also points back to the Odyssean catalogue of heroines at 11.225-332, and not least for the Boeotian focus prominent in both; among those whom Odysseus encounters is Antiope, another daughter of Asopos in the Pseudo-Hesiodic Catalogue (frs. $38-42$ ), who has strong links to 
Boeotian sites and cults. The sequence of four that follows-Alkmene, Megara, Epikaste, and Chloris-all share connections to the region. ${ }^{38}$

But as I argued for Bacchylides' composition for Automedes, Corinna's song simultaneously taps into the chorality associated with the Asopids in the lyric and visual traditions. With Tanagra concluding the enumeration, the initial list seems designed as a sequence culminating in a final city, singled out by the performers for the closing and privileged position. Since Tanagra was the site of choral performances of Corinna's poetry by parthenoi in fragment 655 (see n. 36), the passage offers a fresh instance of choral projection, with the role of the Asopids reenacted by the latter-day ensemble of maidens in Tanagra also on the threshold of marriage and whose choregos, perhaps decked out in extra finery or with an added accessory, takes on the leading role afforded the local and hence preeminent daughter. ${ }^{39}$

Putting all these pieces together, the Asopids seem firmly grounded in two generic traditions, both visible in the songs of Bacchylides and Corinna. First, that of the genealogical poetry - the sources' chief interest in the maidens seems to be their role as the mothers of the heroes whose lineage reaches down to historical times - that so readily lends itself to catalogue form. The tendency to figure the river's many daughters in the linear structure characteristic of these poetic (and inscribed) lists extends to visual representations: Asopos and his daughters appeared in the now lost bronze statue group that Pausanias saw at Olympia, which depicted Aegina being abducted from the company of her sisters; Pausanias names Nemea, Harpina, Corcyra, and Thebe, with Asopos seemingly positioned last in the line. The language of the passage, complete with the term $\delta\llcorner\alpha \varkappa \sigma \mu \varepsilon \dot{\varepsilon} \omega$ used in other sources for the marshaling-cum-arraying of choral processions, leaves no doubt as to the group's linear presentation while, perhaps, also reflecting the choral formation that the images' deployment brought to the visitor's mind (5.22.6.1-10):

The Philesians also dedicated a Zeus and the daughters of Asopos and

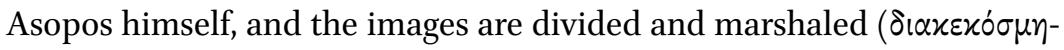
$\tau \alpha l)$ thus: Nemea is the first of the sisters and after her comes Zeus seizing Aegina; next to Aegina stands Harpina ... after her is Corcyra with Thebe next; last of all comes Asopos.

38 See Larson 2000: 198-200.

39 Beyond that fragment, we have no references to choral activity in Tanagra, whether by parthenoi or other groups; note, however, Calame 1997a: 135 n. 131, citing Schachter 19811994: 1.179-180 and 185-186. 
Presumably reading off each name as inscribed beneath the successive images, Pausanias effectively performs a mini-catalogue, complete with internal repetition and a superlative name cap for the last item listed, even as his enumeration might call a choral collective and its performance to mind. ${ }^{40}$

As for the second generic tradition in which Asopos' daughters are embedded, that of choral songs, some in the form of the partheneia performed by maidens in the regions with which the mythical sisters were most closely associated, others by youths equating themselves with those standing choruses, this can be explained on several grounds. First, most simply, because the Asopids form an epichoric company, as do the participants in the corresponding realworld ensembles. And second, because the heroines' "histories" offer a prime instance of the types of myths, themes, and concerns regularly articulated in partheneia, whose composers typically select topics and motifs calibrated to their singer-dancers' gender and time of life. Wayne Ingalls details the contents of such works - those of Alcman, Sappho, Tlesilla, and Corinna among them-and argues that the issue of female sexuality, its positive and negative consequences and the need for its containment, are writ large in these pieces that served a paideutic function for their performers and audiences. ${ }^{41}$ Suggestive of a song designed for a chorus of partheno $i$ is not only the subject matter of Corinna's fragment, a group of maidens destined for marriage and abstracted one by one from their sorority, but also its resolution. In the conversation between Asopos and a local seer in which the list just cited appears, the father learns that the gods will ultimately give him the compensation that recasts these abductions as sanctioned unions. ${ }^{42}$

It is here that the two poetic genres coalesce. It needs no demonstration that unions between maidens, gods, and heroes, some legitimate and orderly, others marked by violence or the transgression of regular matrimonial practices, are the central concerns of the Pseudo-Hesiodic Catalogue. Courtship protocols both observed and violated (so the tale of Mestre) and marriage contests (that of Helen most obviously) also occupy a major place in the work, ${ }^{43}$ as they do in the extant poetry composed on behalf of maiden choruses. In light of their suit-

40 Cf. the Geneleos group from the Heraion at Samos depicting the dedicator's three daughters who are, in the view of Karakasi 2003: 28-29 and Day 2010: 193, depicted as dancers in the choruses that celebrated the goddess; here too a viewer, moving from one figure to the next as he/she reproduced the dancers' processional motions, would read off the identifying inscriptions on the images' bodies (see $I G$ 12.6.2.559 for these), effectively enunciating a genealogical catalogue.

41 Ingalls 2000.

42 See Lardinois 2011: 166.

43 As closely argued and detailed by Ormand 2014. 
ability to parthenaic choral performances, it does not seem wholly implausible that the Pseudo-Hesiodic Catalogue's presentation of the Asopids, along with other maidenly sororities, draws on the lyric repertoire and may have incorporated the choral compositions' diction, imagery, and themes into the hexameter account.

\section{Choral and Catalogue Morphologies}

If, as argued above, archaic and early classical sources demonstrate intimate connections between the "set-piece" catalogue and its choral performance, toggling together generic elements from each tradition within their songs in ways that amplify and extend the scope of their accounts of individuals and events, then how might we explain that affinity? Moving beyond the intuitive notion that a multiplicity of items requires plural performers, do deeper relations exist between catalogue poetry and choruses and are these discernible in the textual and visual evidence? ${ }^{44}$ In attempting some answers, I focus on the "morphology" (to borrow the term of Claude Calame) ${ }^{45}$ of the chorus-its make-up, the interactions between its different members, organization, formations, and movements through space-and suggest that catalogues in archaic sources possess closely corresponding features.

In Benjamin Sammons' definition, a catalogue, whether made up of two or multiple members, is "a list of items which are specified in discrete entries ... no explicit relation is made except for the shared suitability to the catalogue's specified rubric." ${ }^{\text {"6 }} \mathrm{He}$ further defines a rubric as "a stated category or class which legitimates the involvement or exclusion of potential items."47 This "rubric" squares with Calame's delineation of the three most broad-based features that determine membership of a chorus: ties of kinship, locality, and age, ${ }^{48}$ each of which maps still more narrowly onto common criteria for inclusion in a catalogue. Just as so many real and mythical choruses form sororities with a parent or other relation by way of a lead member (in addition to the Muses and Graces,

44 Here I try to build on the insights of Carruesco 2010 and his more generalized and textbased explanation; the overlap is based on "la similitud morfólogica de una unidad articulada a partir de una pluralidad de miembros, como en el más profunda de la función, que es precisamente la capacidad activa de generar esa articulación" (2010: 386).

45 Calame 1997a.

46 Sammons 2010: 9 (emphasis in original).

47 Sammons 2010: 9 .

48 Calame 1997a: 26-34. 
we encounter the Pleiades, Nereids, Asopids, and Hyades), so kinship ties unite the members of the extended family groupings that structure the Catalogue of Women, or the list of ancestors in Glaucus' genealogical recitation at Iliad 6.145211. There are any number of examples of "epichoric" choruses, among them the Deliades, Caryatides, and the maidens on Aegina in Bacchylides 13, who celebrate a local $\left(\tau^{\prime} \dot{\varepsilon}\left[\pi \imath \chi \omega p^{\prime} \alpha \nu, 92\right)\right.$ festival in song and dance and style themselves neighbors (89). Analogous to these are the entries in some catalogues, or parts thereof, whose presence is determined by geographical proximity: the suitors enumerated by Telemachus at Odyssey $16.247^{-253}$ all come from nearby islands (they belong to the same age class too) while the several women clustered at the start of Odysseus' heroine list (Od.11.225-332) share a Boeotian origin.

Beyond membership of an overarching "rubric," studies of the catalogue in early poetry have isolated a variety of syntactic structuring principles. Most simply, parataxis, sustained by bare connectives, these often repeated in a rhythmic sequence marked by the occurrence of the expression in the same position in the hexameter line. While Dolon's list of the Trojan allies in Iliad 10.428-434 uses the conjunctions $x \alpha$ í and $\pi$ pós to link the different contingents introduced sequentially, $\tau \varepsilon$ and $x \alpha$ í, sometimes combined, coordinate the list of Nereid names at Iliad 18.38-49. Ticking off his liaisons in Iliad 14.317-327, Zeus introduces each conquest with ovंठ́, anticipating the structure of the second catalogue in Alcman's first Partheneion (64-77). Representations of choruses on Geometric and early classical vases exhibit a corresponding parataxis through visual means: using repeated elements to link the totality of choreuts into an ensemble, they simultaneously distinguish one performer from the next by giving each some particularized and on occasion unique feature, much as epithets singularize each individual or item in a poetic catalogue. The chorus of the "twice-seven" occupying the top band of the familiar François Vase of ca. 570 (fig. 5.1), ${ }^{49}$ and whose storied bands stacked one onto the other recall the catalogue of scenes on the Iliadic shield of Achilles, ${ }^{50}$ offers a prime example of this simple arrangement. Each chorister wears a different dress and bears a different name, while interlinked hands connect each discrete member to the adjacent individual. Much like the epithets given each Hippocoontid in the first of the two catalogues in Alcman's first maiden song (1-12) are the different shield devices distinguishing each dolphin rider in the chorus on a red-figure psykter by Oltos of ca. $5^{20-} 510$ (fig. 5.2 ); ${ }^{21}$ in this instance too, indi-

49 Florence, Museo Archeologico 4209.

50 Notopoulos 1949: 22 styles the work the "locus classicus for parataxis in vase painting."

$5^{1} \quad$ New York, Metropolitan Museum 1989.281.69. 


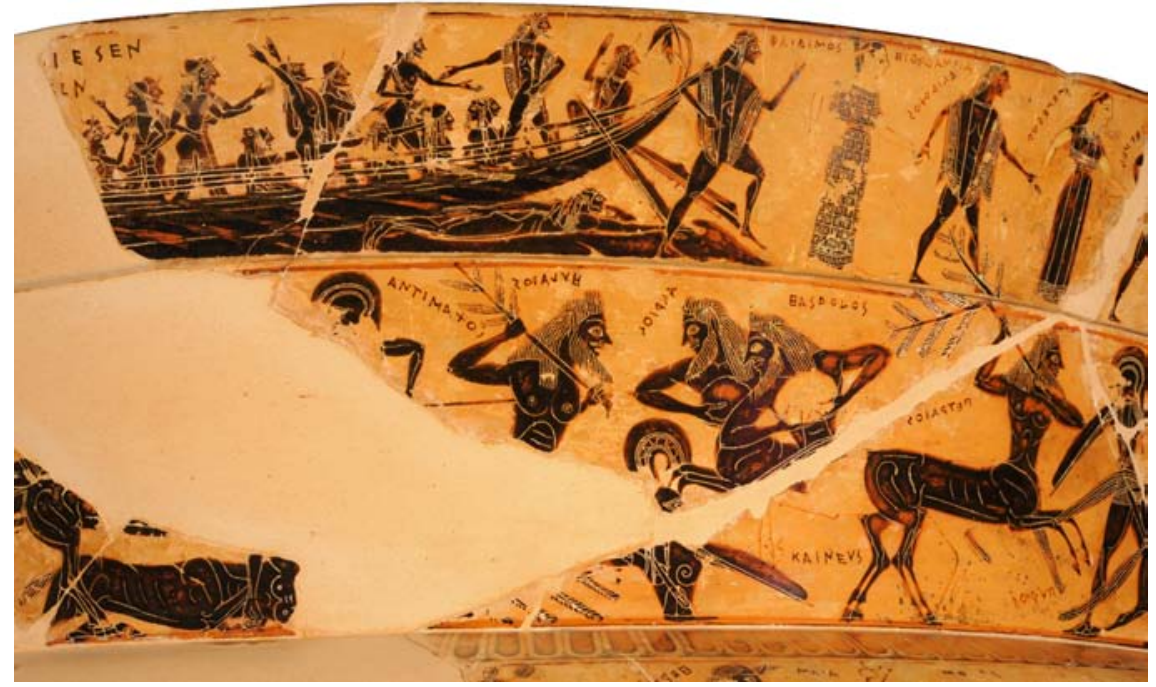

FIGURE 5.1 Attic black-figure volute krater (François Vase), ca. 570 BCE. Florence, Museo Archeologico 4209

PHOTO COURTESY OF SOPRINTENDENZA PER I BENI ARCHEOLOGICI DELLA TOSCANA

viduation coexists with the homogeneity established by the riders' identical poses, mounts, and costumes, and the refrain inscribed in the same position above each rider, which functions like the repeated elements observed in the shaping of poetic catalogues. Enunciation of the inscriptions would reinforce the collective quality of the chorus, the blending of all voices into one and their rhythmic unity: each dipinto reads "on the dolphin."

A second simple organizational device within lists is a "first to last" structure,

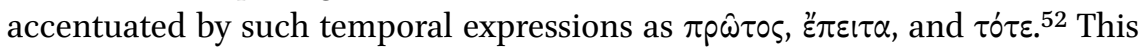
may also coincide with another frequent feature of Homeric catalogues, the suggestion that the speaker visually scans the scene, whether in the mind's eye and/or while performing the list. Both focalization and linearity are emphatic in Odysseus' enumeration of heroines before the Phaeacians ( $\mathrm{Od}$. 11.225-332). Not only does the speaker introduce each of the women by remarking that he "saw" her, but the preliminaries to the successive encounters alert us to the interlocutors' organization into a line. Initially appearing in a disorderly mass and in great numbers ( ${ }^{\circ} \sigma \sigma \alpha l, O d$. 11.227, this a standard term for introducing a catalogue), the shades circle around the pit (so ' $\alpha \mu \varphi^{\prime}$ at 228), and assemble 


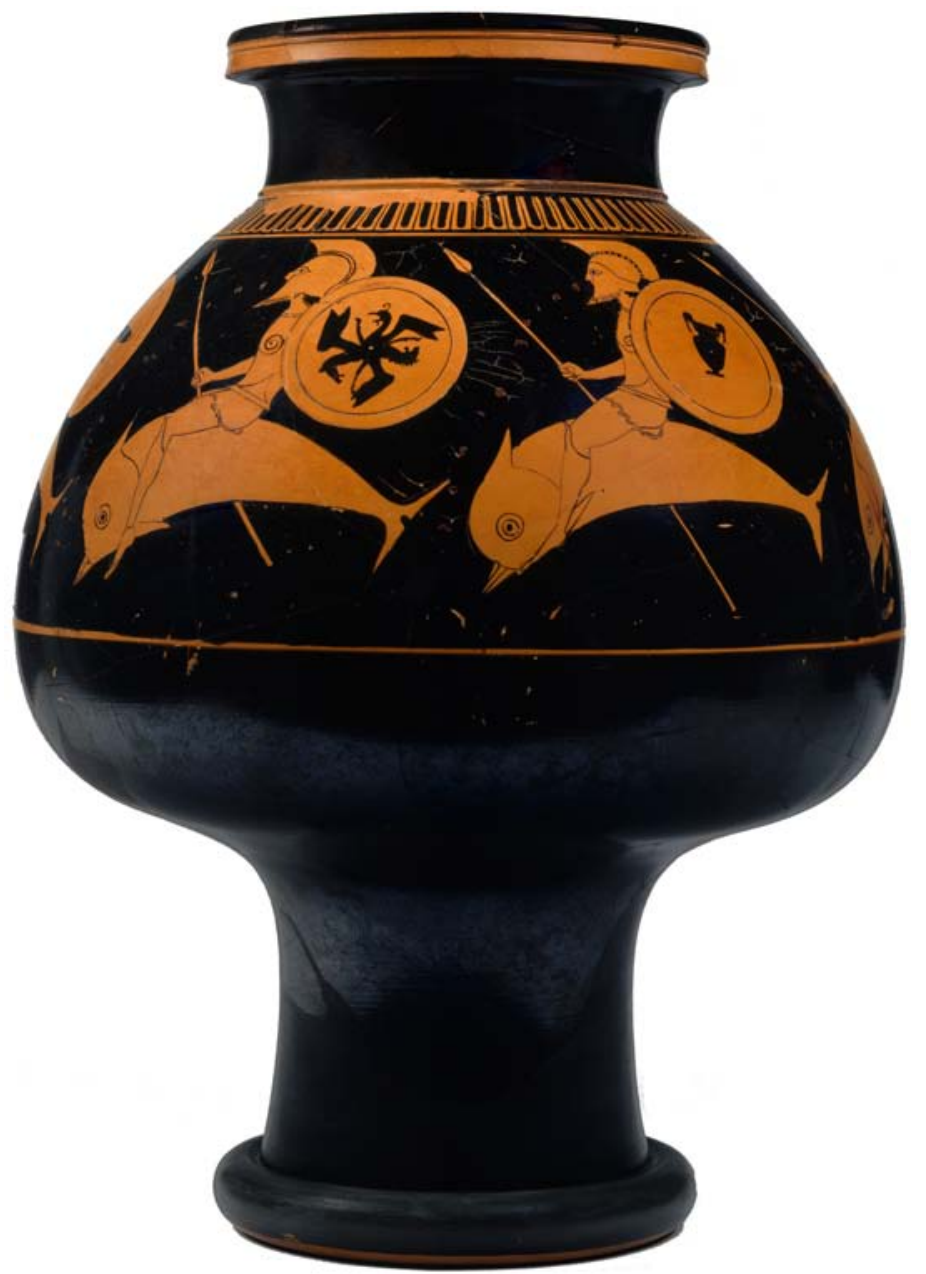

FIGURE 5.2 Attic red-figure psykter attributed to Oltos, ca. 520-510 BСE. New York, The Metropolitan Museum of Art 1989.281.69 PHOTO COURTESY OF THE METROPOLITAN MUSEUM OF ART / ART RESOURCE, NY

in crowds ( $\left.\dot{\alpha} 0 \lambda \lambda \varepsilon \dot{\varepsilon} \varepsilon \eta_{\gamma} \gamma \varepsilon p \varepsilon \dot{\varepsilon} \theta 0 v \tau 0,228\right)$, remaining undifferentiated until Odysseus positions them in linear order, "one by one" ( tioning each shade in turn.

Again choral morphology — each chorister positioned one after the nextoffers a close analogue. In the case of Alcman's parthenaic ensemble, its second catalogue may reflect the performers' current formation; quite plausibly, the singers list their members' accessories and names in accordance with their position within the chorus line, much as with the ordering of the inscribed 


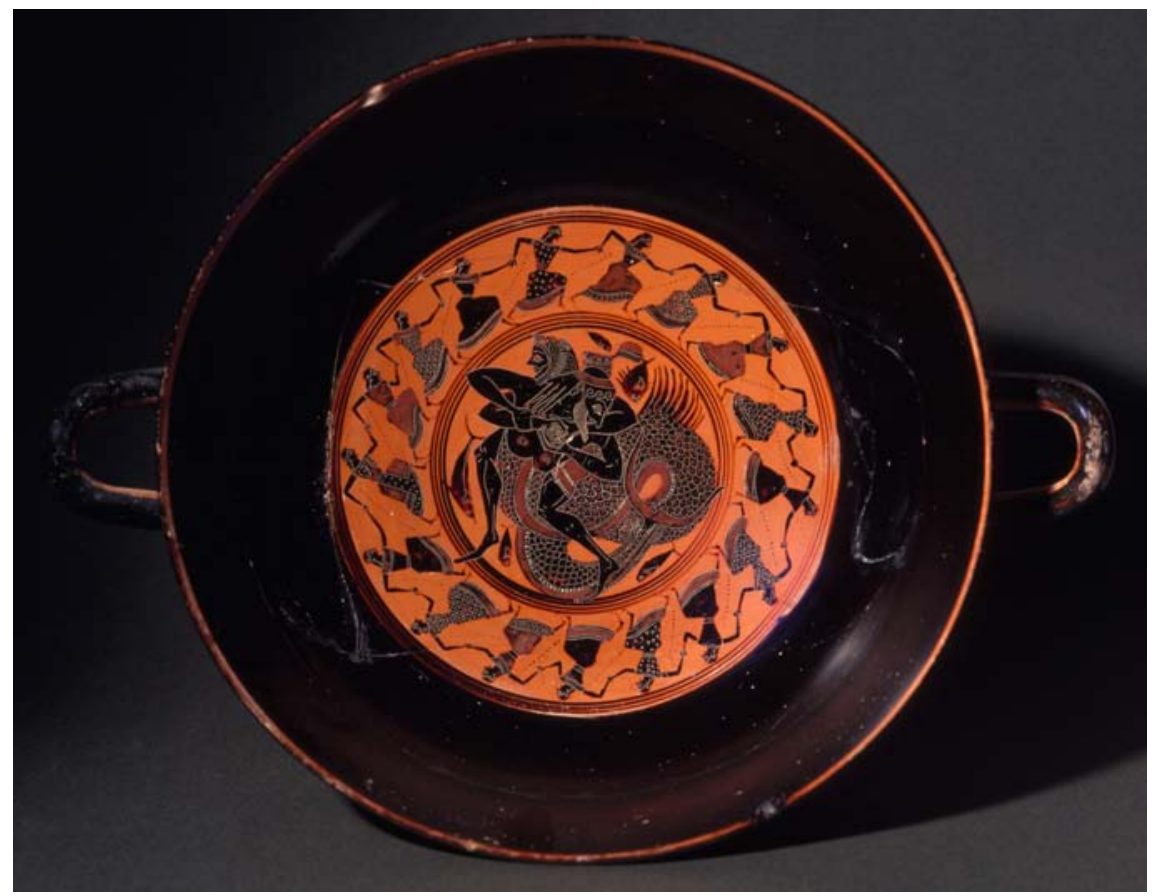

FIGURE 5.3 Attic black-figure Little Master lip kylix, ca. 55 BCE. Tarquinia, Museo Nazionale Tarquinese RC 4194

PHOTO COURTESY OF NimATALlah / ART RESOURCE, NY

names on the François Vase. ${ }^{53} \mathrm{~A}$ mid-sixth-century cup from Tarquinia rings a change on the iconographic design (fig. 5.3). ${ }^{54}$ In his depiction of a chorus of Nereids circle-dancing around the vessel's rim while Heracles wrestles with Triton in the tondo, the artist visually echoes the crook of the nymphs' arms by placing what look like sequences of letters in identical position between each pair and that seem to name, just as Hesiod does in the Theogony (see below), each of the Nereid dancers. On closer inspection, the notations turn out to be no more than nonsense inscriptions that reinforce the performers' homogeneity. But individuation also enters into the design: each of the nymphs wears a differently patterned gown.

Beyond these straightforward devices, many lists display a more refined and complex artistry. Poets may introduce hierarchy and a progressive diminishment or elaboration through the addition or subtraction of epithets and/or by

53 For the intensely "spectacularized" nature of a chorus whose members are both viewers and more frequently viewed, see Swift 2016b. Note too Peponi 2004.

54 Museo Nazionale Tarquiniese RC 4194. 
including additional information concerning more privileged member(s). In the terms Christopher Faraone uses of this gradual auxesis, and the correspondingly expanded space allotted an item standing solo in a line or extending over more than one, such lists culminate in a "superlative name cap" flagged by $\pi \lambda \varepsilon \hat{-}$ $\sigma \tau \sigma \nu, \mu \alpha \dot{\lambda} \mid \sigma \tau \alpha$, or other superlatives. ${ }^{55}$ There is ranking here, a move from less significant objects, places, or individuals to those whose distinction depends, among other properties, on their value, superior craftsmanship, social status, and prior or subsequent importance in the narrative. Often the individual singled out occupies the first or last place in the birth order, a placement that coincides with his or her position in the list; so Cronus is both last born of the offspring of Oceanus and Gaia and the closing entry in that catalogue. Indeed, the passage well illustrates the ordering devices that Faraone identifies: a simple connective joins the first eight names, distributed four per line, while only two names, complete with epithets marking their greater importance, appear in the third line; granted two lines and two superlatives is the final child, who will succeed his father (Hes. Theog. 133-138).

Artists deploy analogous devices to indicate hierarchies in choral collectives, similarly alerting viewers to divisions between one or several members and the rest. Painters distinguish the choregos most simply by assigning him or her the lead or last position in the line, a primacy sometimes underscored by the addition of an accessory, more elaborate clothing, or augmented stature. Preeminence within an overall unity appears on a black-figure kylix from Argos, dated to ca. $600-55$ o (fig. 5.4), ${ }^{56}$ where a single mantle covers nine female choristers with identically styled hair; at the line's head stands a maiden who, uniquely, carries a garland. The "specialness" accorded the third dancer on a late eighthcentury Geometric hydria from Aegina, ${ }^{57}$ whose skirt is chequered differently from those worn by the rest, might be a visual device for establishing leadership when the dancers form a ring, as they frequently do as they circle around the neck or shoulder of a vase. Faraone well explains the privileging of Calliope, introduced last and given an entire line with a superlative in Hesiod's list of the nine Muses at Theogony $76-79$, noting that it suits the thematics of the passage in which she appears. ${ }^{58}$ Kleitias, the painter of the François Vase, may be responding to the Hesiodic account (or to a work drawn from the same source as the Theogony) in similarly according front rank status to Calliope, while

Faraone 2013: 294, 295-298. Here I summarize Faraone's argument and draw on some of his examples.

56 Berlin, Antikensammlung F 3993.

57 Berlin, Antikensammlung F 31312.

$5^{8}$ Faraone 2013: 300-301. 


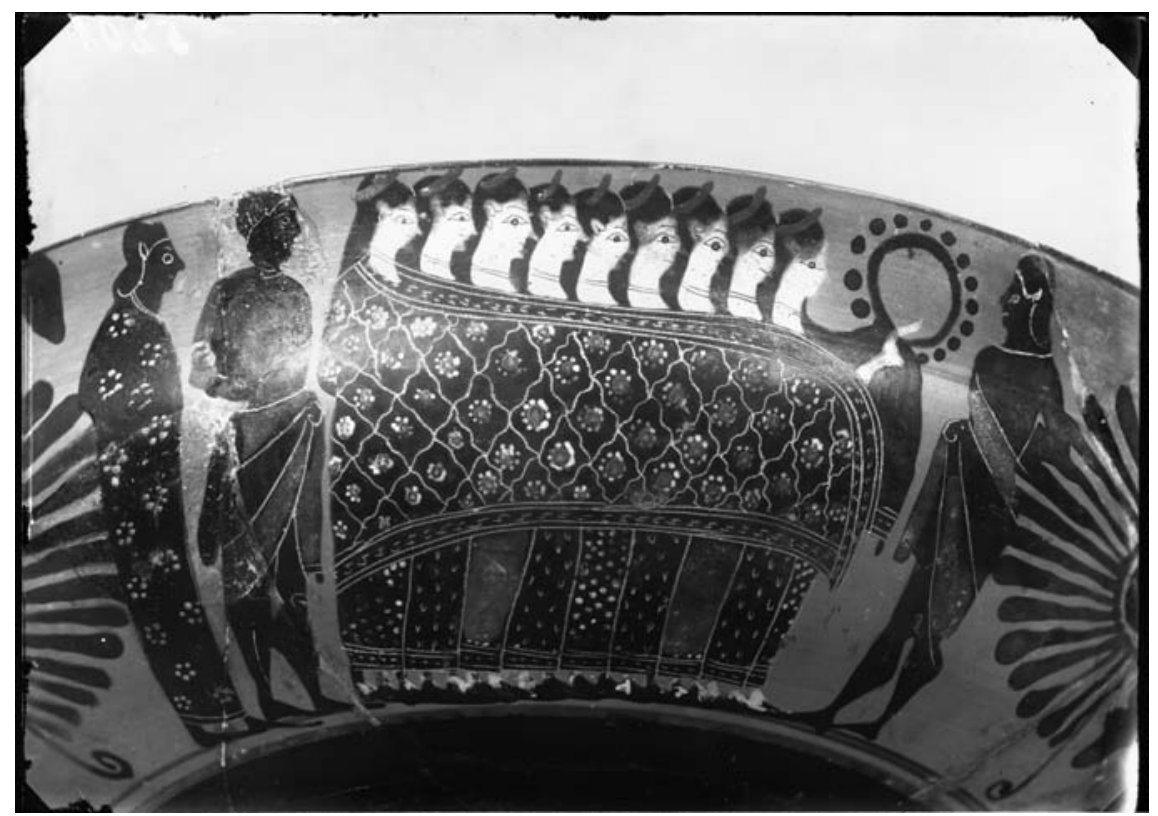

FIGURE 5.4 Attic black-figure kylix from Argos, ca. 6о0-550 BCE. Berlin, Antikensammlung Staatliche Museum F 3993

PHOTO COURTESY OF BPK BILDAGENTUR / ANTIKENSAMMLUNG STAATLICHE MUSEUM / ART RESOURCE, NY

also reworking the poetic template. Where Hesiod positions the preeminent goddess in the final marked position in the catalogue, the visual conventions informing the representation of choruses determine the placement of the figure labeled $\mathrm{Kal}(\mathrm{l})$ iope at the front of the troupe of Muses attending the wedding of Peleus and Thetis on the vase; so located, she occupies the spot reserved for the chorus-leader. Scanning the vase from left to right in accordance with the arrangement of the procession, the viewer would encounter this Muse as the terminus and culminating figure in the ensemble. ${ }^{59}$ Several further devices distinguish this goddess: standing separate from her sisters, she alone faces outwards and plays the syrinx.

The topmost band of the François Vase anticipates the arrangement in the wedding scene below, again signaling the primacy afforded the choregos, the correlate to the singling out of the catalogue's first or last entry. Whereas the other youths wear cloaks and himatia, processing empty-handed, Theseus, positioned at the head of the line, stands out by virtue of his full-length robe 
and the lyre that he carries. And while all the other names appear above the choreuts, similarly positioned, his alone occurs beneath, written retrograde. This visual particularizing of Theseus' identity concludes the written catalogue displayed within the scene: a viewer reading off the list of names, even reciting these in rhythmic fashion so that the sounds coincide with the chorus' processional step, performs a catalogue reminiscent of the enumerations in Alcman's first Partheneion. ${ }^{60}$ On a Corinthian aryballos dated to the early sixth century (fig. 5.5), ${ }^{61}$ image and text freshly declare the star role of the lead dancer/choregos; he too occupies the start of the chorus line, where, viewing from left to right, the audience sees him before the rest of the ensemble. Alone among his otherwise indistinguishable and still static followers lined up in pairs behind their leader, "Pyrrhias" is named in the accompanying inscription that accentuates the height of his leap, the tricky bibasis, and contrasts with the lettering that keeps the other dancers on the ground.

Ring composition and internal patterning act as other structural devices in poetic catalogues. The first occurs several times in the Theogony, as exemplified by the list of Nereids enclosed by the double mention of Nereus, "who bore them," at lines 240 and $263 .{ }^{62}$ The name of the last listed daughter, Nemertes, prepares the way in sound and sense for the second mention of her also "infallible" father by introducing the quality of "unerringness" that he possesses. Two rings, a larger one surrounding a smaller, structure the itemization of Oceanus' progeny, daughters and sons; lines 337 and $367-368$ frame the larger circle, while 346 and $362-363$ bookend the internal ring. A similar arrangement is visible in Alcman's first Partheneion, where chorus line and catalogue design coincide. Prior to its self-introduction, the chorus draws attention to its choregoi, first Hagesichora, then Agido; following the closure of the list of the individual choristers' adornments and names, the singers return to the point of departure, naming Hagesichora first and Agido second. An early seventh-century oinochoe from Pithekoussai (fig. 5.6$)^{63}$ supplies a visual parallel. Here two all

6o In several respects my reading complements that of Olsen 2015. As she argues, the scene carefully differentiates between the orderly chorus under Theseus' leadership and the more haphazardly arranged crew members still on the boat, who do not form part of the "twice seven" elite Athenians. Reinforcing the distinction, I would add, is the absence of the inscriptions identifying the crew members; perusing the vase, a viewer would be unable to "catalogue" these heterogeneous individuals.

61 Corinth, Archaeological Museum C 54-1.

62 See Faraone 2013: 308-309 for close analysis.

63 London, British Museum 1849,0518.18. The "archaizing" Minoan dress of the two female dancers suggests a Cretan scene, as does the gesture of the central figure, presumably Theseus, who places one of his hands on the breast of the figure to his left. 


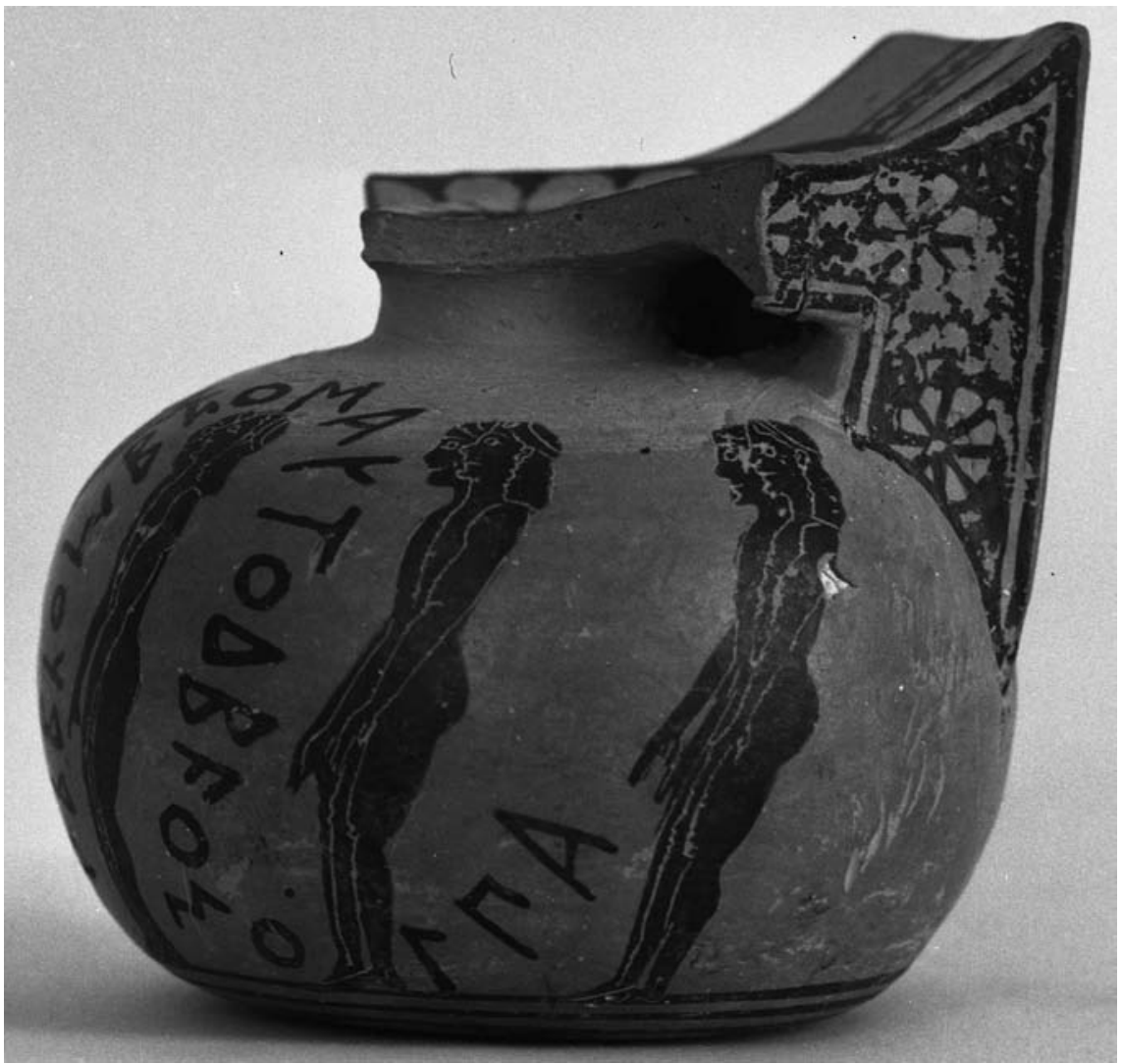

FIGURE 5.5 Middle Corinthian black-figure aryballos, ca. 56o BCE. Corinth, Archaeological Museum, C-1954-1 PHOTO COURTESY OF AMERICAN SCHOOL OF CLASSICAL STUDIES AT ATHENS, CORINTH EXCAVATION

but identical male figures, both executing the same step, frame what may be a representation of the geranos; reinforcing the symmetrical design are the oars each youth holds, which form the boundaries to the scene.

Additional patterns in poetic catalogues depend on verbal, acoustic, and rhythmic relations between the different parts. Anadiplosis, homeoteleuton, and isocolon are common stylistic features that create affinities between two or more items sometimes separated by other elements in the sequence. For all the apparent parataxis in the catalogue of Nereids at Iliad 18.38-49, the poet introduces internal combinations, repetitions, variations, and progressions through the placement of the names and their assonance and alliteration: so Kuposóxn $\tau \varepsilon$ appears at the end of 39 while Ku$\mu 0 \theta$ ó $\tau \varepsilon$ begins 41. Picking up on the suffix of her sister's name, but introducing a new prefix, 'A $\mu \varphi \mid \theta$ ón enters at 42 followed 


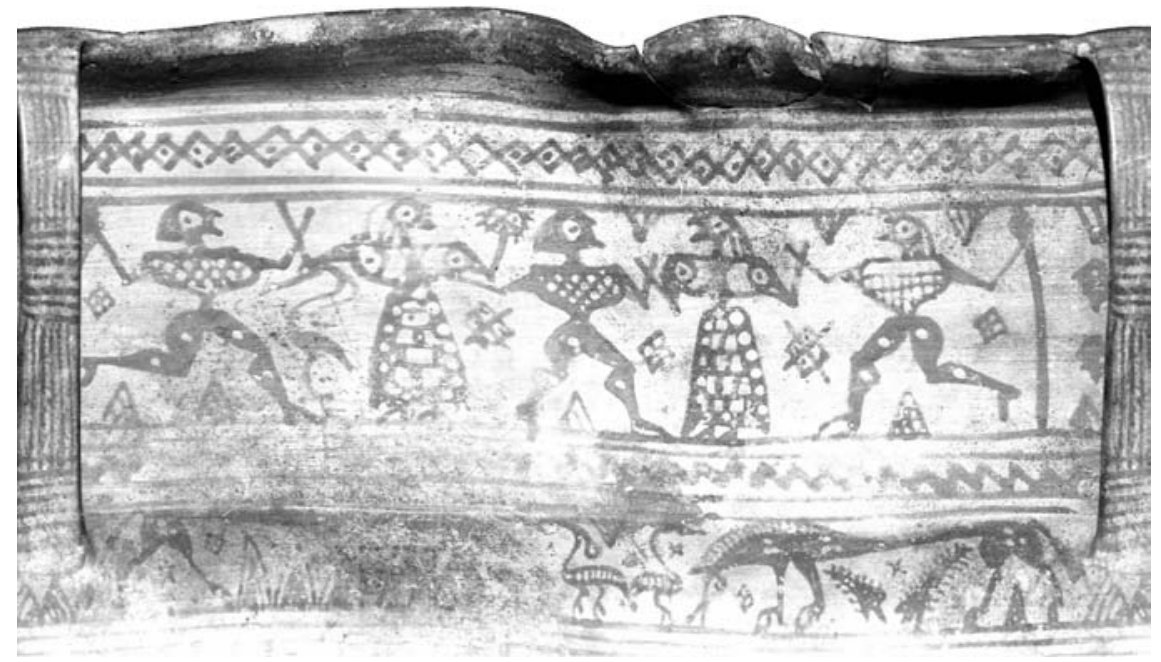

FIGURE 5.6 Late Geometric oinochoe (probably Etrurian), ca. 700-680 BCE. London, British Museum 1849,0518.18

PHOTO COURTESY OF TRUSTEES OF THE BRITISH MUSEUM

by the phrase $x \alpha i$ K $\alpha \lambda i \alpha \dot{\alpha} v \varepsilon \rho \alpha$ at 44; this nymph is then audibly paired with $\mathrm{K} \alpha \lambda$ $\lambda \iota^{\prime} \alpha \alpha \sigma \sigma \sigma \alpha$, also preceded by $x \alpha i$ and standing in verse-final position in 46 .

Such internal forms of iteration and alternation characterize visual representations of choral collectives, prompting viewers to perceive relations between discrete choreuts sometimes adjacent, sometimes positioned at different points in the file. A Polledrara hydria from the Grotta of Isis at Vulci, dated to ca. $575^{-} 55^{\circ},{ }^{64}$ shows on its lower register the dance executed by the Athenian maidens (probably, once again, the geranos with its twists, turns, and combination of linear and circular dancing) rescued by Theseus from the Cretan maze. Here the painter devises an interlinking arrangement evocative of the performance's intricacy: each chorister places one hand on the wrist of the next figure in the line while reaching with the other past her immediate neighbor so as to grasp the back-stretched arm of the next-but-one member of the troupe.

As the examples from the poetic sources already cited demonstrate, two chief structural principles are visible in catalogues from the hexameter repertoire: one linear or paratactic, which may additionally involve the progressive amplification or diminishment of the members in a ranked arrangement, the other determined by the creation of units of repetition and patterning that turn linearity into several circles or one grand ring. These overarching structures not

64 London, British Museum 1859,0227.50. 
only neatly dovetail with the two principal choral formations, processional and circular, but their frequent copresence within a single catalogue parallels the ways in which choral dancing commonly involves switchings-off between the performance modes. The Hesiodic presentation of the Muses' circular dance followed by a processional descent cited at this chapter's start corresponds to the motions of the chorus on the shield of Achilles in Iliad 18; here the youths and maidens sometimes turn in circles, as the simile of the spinning potter's wheel clearly indicates, and then regroup into lines or stichoi (5996o2):

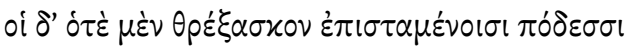 \\ 600

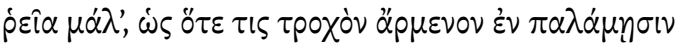

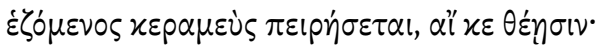

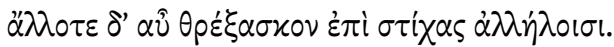

And at times they were running on well-skilled feet, very smoothly, as when a potter who is seated tests the wheel fitted to his hands, to see if it runs; and at others they were running in rows up to one another.

Nor do lines and circles exhaust the structural options available to archaic poets and artists in presenting catalogues and choruses. In one early instance, two groups of choral dancers, one female, the other male, circle around the neck of a loutrophoros of ca. 700 by the Analatos Painter (fig. 5.7$)^{65}$ while a phorminx player appears at the juncture between the two. So too on a diminutive lekythos by the Amasis Painter (fig. 5.8$)^{66}$ four youths and eight dancing maidens are shown around the shoulder of the vase; in this instance, a bride seated on a throne supplies the point at which the two groups converge. We might compare catalogues with gender divisions, such as that of the sons and daughters of Oceanus at Hesiod Theogony 337-370, where Tethys' role in giving birth to them (346) serves as the "meeting point" between the two sets of progeny. A second lekythos, also by Amasis and again with a nuptial theme, ${ }^{67}$ shows only women dancers; nine choristers grouped in two companies of three and six perform a ring dance, their subdivision indicated by the seated auletes and lyre-player bracketing each ensemble. As in the hexameter descriptions of choral dancing, linear and circular motion here coexist: the interlinked hands of the six,

65 Paris, Louvre CA 2985.

66 New York, Metropolitan Museum 31.11.10.

67 New York, Metropolitan Museum 56.11.1. 


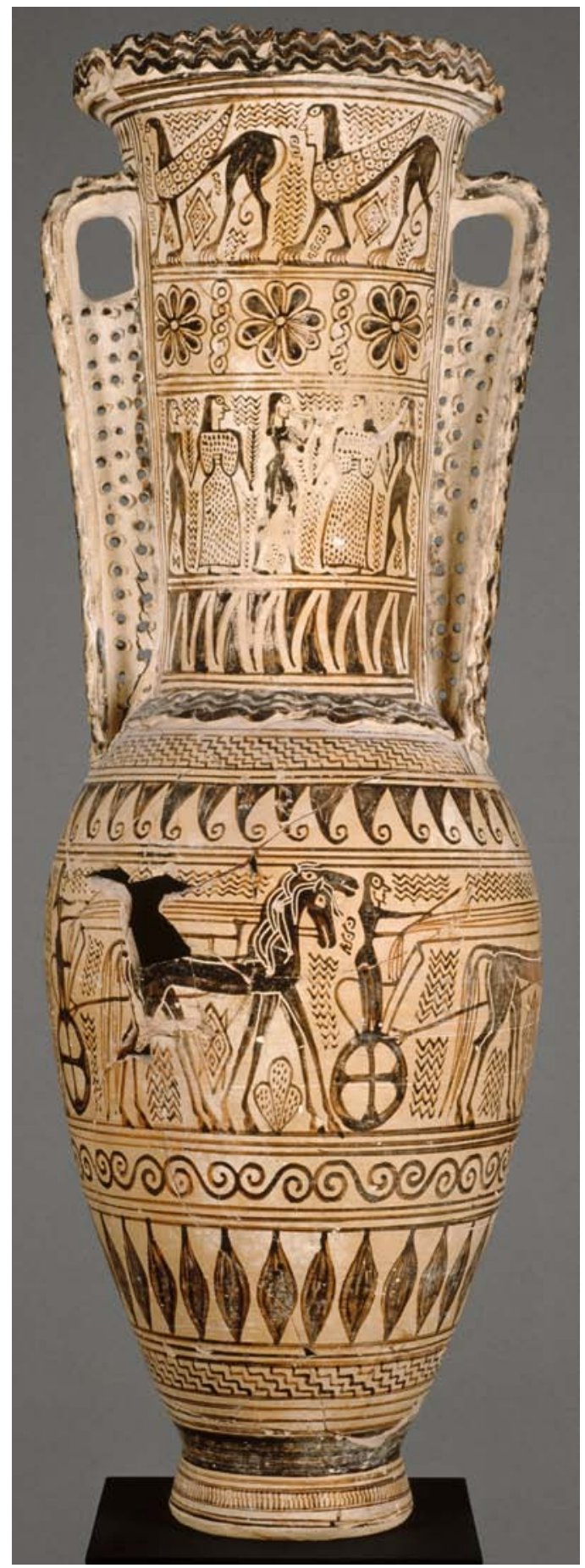

FIGURE 5.7

Protoattic black-figure loutrophoros attributed to the Analatos Painter, ca. 700 BCE. Paris, Musée du Louvre CA 2985 PHOTO COURTESY OF RMNGRAND PALAIS / ART RESOURCE, NY 


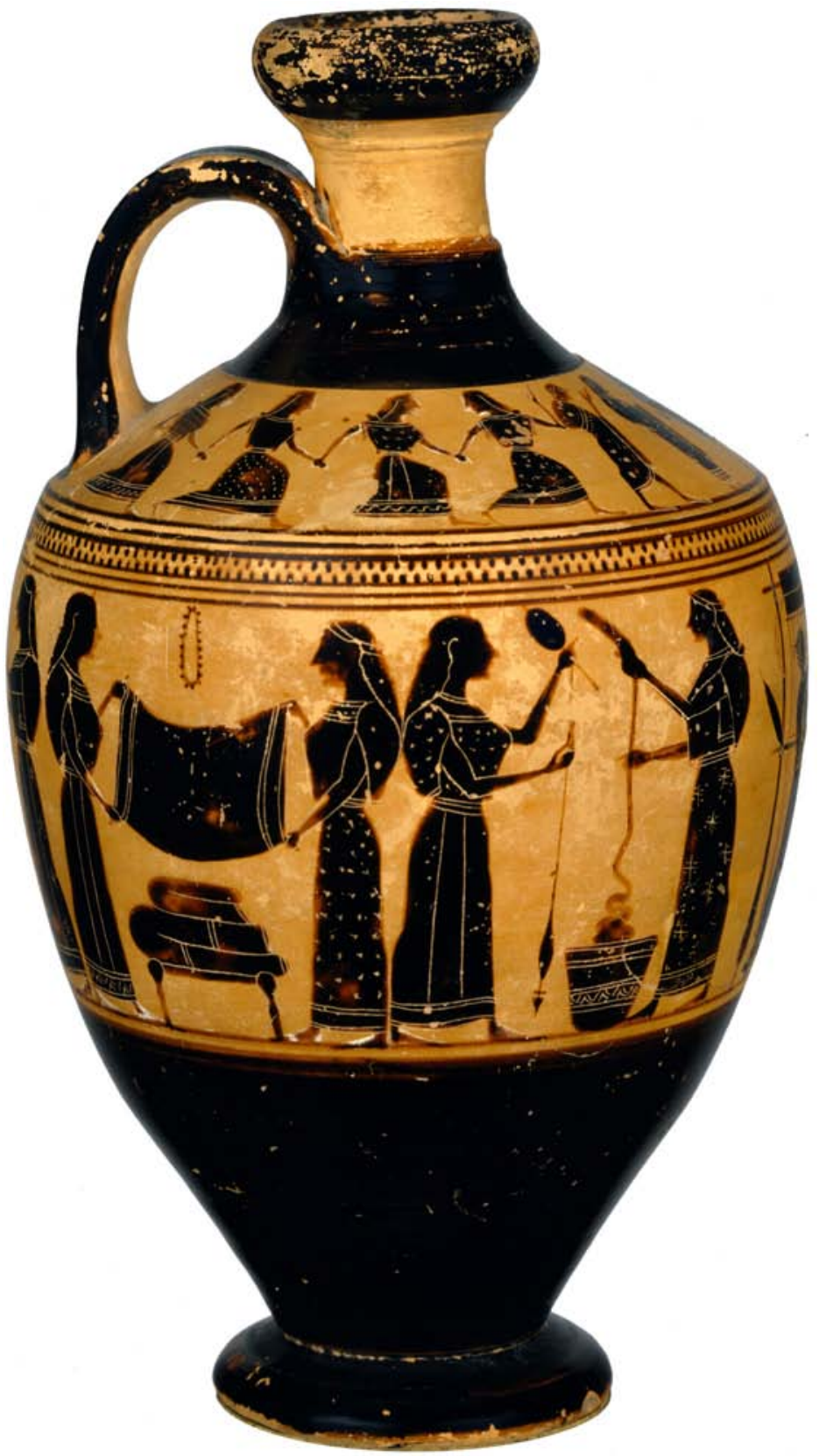

FIGURE 5.8 Attic black-figure lekythos attributed to Amasis, ca. 550-530 BCE. New York, The Metropolitan Museum of Art 31.11.10 IMAGE COURTESY OF THE METROPOLITAN MUSEUM OF ART / ART RESOURCE, NY 
together with the more vigorous step three of their number perform, suggest a ring dance while the smaller, measured motions of the trio evoke a processional formation. The musicians are the place at which the lines converge. These visual representations may propose a different choral formation: the convergence of two discrete choral lines so as to fashion a "v."68 Echoing this deployment is a passage from Euripides' Helen, where the chorus projects its identity onto a flock of cranes that adopts the same distinctive delta-shape in its migratory flights (1479-1484).

Granted, the reciprocal relations between choral compositions and catalogues identified through this chapter's course form part of a well-documented and much more widespread phenomenon, whereby different genres, some contemporary, some chronologically distinct, draw on, incorporate, and rework the diction, subject matter, conceits, performers, and performative contexts native to other generic traditions. But where, I have suggested, this particular instance of "generic contamination" and interchange stands distinct is in the deeper structural similarities that exist between the two modes explored here and that result from affinities discernible in the membership, organization, hierarchy, and the visual deployments common to both sets of collectives; this in turn scrambles straightforward notions of appropriation and borrowing and the agonism that so frequently characterizes relations between poetic traditions in antiquity.

The overlaps illustrated here open up a further possibility only touched on in passing and that would direct us towards the Nachleben of the intersections my argument has proposed. Subsequently preserved in the form of written lists, publicly displayed and inscribed in marble, bronze, or on some other durable matter, might a catalogue both visually and audibly (whether simply glanced at or enunciated à haute voix) have offered a synoptic, miniaturized, and metonymic reenactment of a choral performance? Well beyond this chapter's scope are the Hellenistic inscriptions that minutely record and inventory the choruses that took part in civic and Panhellenic festivals and sacred embassies, detailing the types of songs they sang, their accessories, the groups' positioning within a larger procession, the names of their leaders, provenance, and the rest. A consideration of the visual dimensions of these lists, their layout, the design of the lettering and placement of particular words, and an exploration of the units of rhythmic repetition they frequently include, might reveal additional areas where choruses and catalogues quite literally share a common

68 For discussion of this somewhat debated formation, see Crowhurst 1963: 293-298 and Calame 1997a: 37 . 
space. Through this assemblage of alphabetic notations, typically erected at the sites where the choruses would have performed and might still perform, both individuals and communities could maintain in "lithic" form the sounds and motions executed by a choral troupe and thereby acquire "scripts" for the reenactment of the event. 


\title{
Generic Hybridity in Athenian Tragedy
}

\author{
Naomi Weiss*
}

Though we often view tragedy primarily in terms of the character and actions of its protagonists, it was, first and foremost, a choral genre. Even Aristotle, who in the Poetics largely avoids discussion of the chorus altogether, tells us that

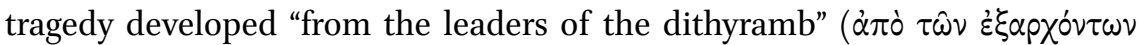

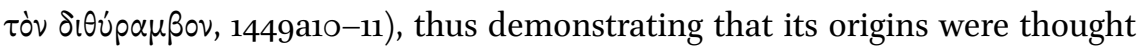
to be choral. In his Laws Plato, who, unlike Aristotle, had grown up in Athens, presumably regularly attending the theater and even participating in various choruses himself, clearly views tragedy in terms of choral song and dance-a combination called choreia, which the Athenian Stranger presents as vital to the city's social, ethical, and physical fabric. The choral nature of this genre also becomes evident when we consider how many tragedies (especially those of Aeschylus) are named after their choruses, and how much of a tragedy could consist in choreia: in Aeschylus' Supplices, for example, the chorus sings for more than half the play; in Agamemnon and Choephoroi for just under half. Though later tragedy tends to include less choral song, on average it still occupies at least 15 percent of Sophoclean and Euripidean drama. ${ }^{1}$

The predominance of choreia in Aeschylus' surviving plays suggests not only that it played a big part in early tragedy, but that early tragedy was by its very nature an amalgamation of different types of choral song, interspersed with actors' dialogue (and occasionally actors' song). Supplices, with its high proportion of choreia, demonstrates this mix well. Initially lament seems to dominate the play, as the maidens mourn their plight and seek protection in Argosindeed, in their parodos they characterize themselves as continuously lament-

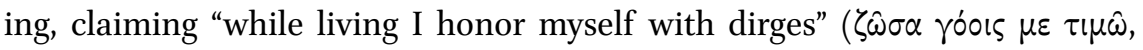

* Many thanks to the participants of the conference on lyric genres at Berkeley for their stimulating comments on the initial version of this paper, and to my coeditors for the astute and helpful feedback that led to its final form.

1 These figures include recitative within the category of choral song. For percentages of song (choral and solo) in the surviving plays of Sophocles and Euripides, see Csapo 1999-200o: 410-411. On tragedy as a choral event see Bacon 1994-1995; Gagné and Hopman 2013a: 1922. Kowalzig 2007a (esp. 225-226) emphasizes that the Athenians thought of their dramatic contests as the "choroi of Dionysus." 
116). As Laura Swift has recently shown, however, the chorus' songs also evoke parthenaic and hymeneal performances, especially in the exodos, which, like some marriage songs, is split between two choruses, the Danaid maidens and most likely the male attendants, and is full of references to both marriage and virginity. ${ }^{2}$ They can resemble hymns too, such as when the maidens sing to Zeus in the second stasimon, addressing him as "King of kings, most blessed of the

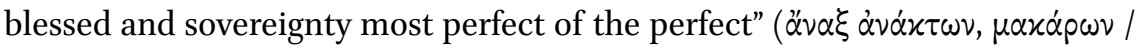

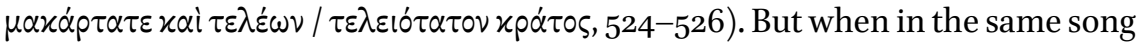
they describe the maddened wanderings of Io through Asia and her arrival in Egypt, where she bore to Zeus their ancestor, Epaphus, they evoke a narrative style more akin to the dithyramb; indeed, Bacchylides makes this very story the subject of his fifth dithyramb. ${ }^{3}$ However, even while we should recognize that these different sorts of choral performance are present in the tragedy, any attempt to label each one according to the particular "nondramatic" lyric genre that it evokes is ultimately unsatisfying, for it is the complex mix of choral styles that makes up the one tragic play. If we separate out and try to categorize the generic strands of a drama we run the risk of missing the all-encompassing capacity of tragedy - its ability to embrace, combine, and transform multiple lyric genres. ${ }^{4}$

Tragedy, then, is a hybrid genre. We might, to borrow Richard Martin's influential term for epic, even call it a "super-genre," one which includes and appropriates a wide variety of lyric subgenres (and nonlyric too, such as oratory), integrating them within the dramatic narrative of a play. ${ }^{5}$ These lyric subgenres are "nondramatic" in the sense that they concern discrete performances of choreia that do not form part of larger dramatic narratives featuring a group of actors assuming a variety of roles. Even the dithyramb, which was performed in the same theatrical space as "dramatic" genres, is still in this way distinct from tragedy, comedy, and satyr play. One way to explore the hybridity of tragedy would be to track allusions to nondramatic lyric through linguistic markers and particular types of imagery in a systematic way, separating out one genre

2 Swift 2010: 280-29o. She argues convincingly against the traditional reading of this song, which assigns the second chorus to the group of female attendants named at Supp. 977-979; cf. McCall 1976.

3 Bacch. 19 (Io, for the Athenians). On this dithyramb's relationship to tragedy, specifically Supplices, see esp. Maehler 2004: 206-209; Battezzato 2013: 96. In addition, the story of Io somewhat resembles that of Dionysus' birth to Semele (also impregnated by Zeus), which seems to have been a frequent subject within the dithyrambic genre, as Timotheus' Birthpangs of Semele in particular attests (fr. 792; see too Pind. fr. 7ob. 29-32; Eur. Bacch. 88-106).

4 My approach here therefore contrasts with that of Swift 2010.

5 Martin 2005: 17. 
from another: parthenaic from hymenaeal, dithyrambic from paeanic, epinician from lament, and so on. ${ }^{6}$ Instead, however, I want to focus here on the malleability of lyric genres within the context of the theater, and on the ways in which generic allusion and interaction might work in performance. My aim is in part to come to a better understanding of what tragedy itself is as a genre, and of how ancient practitioners and theorists of tragedy promoted and played with ideas of what sort of genre it was and how as a genre it developed. But I am primarily concerned with the question of how useful the notion of distinct lyric genres ultimately is for our appreciation of what tragedy can achieve in performance. I suggest that it is useful, perhaps even vital, since the evocation of nondramatic lyric genres within tragic choreia can guide the audience's reception of the dramatic action, and so help to shape the entire plot of a play. But at the same time we must be conscious of how these evocations of genre interact with others, creating a musical narrative in tandem with the dramatic one through the combination of different types of song.

\section{Turning to Lament: Euripides' Heracles and Sophocles' Trachiniae}

Most extant fifth-century tragedies exhibit a conflation or juxtaposition of different choral genres, and often a transition from one to another can complement or even anticipate the direction of the dramatic narrative. This transition is typically to or from lament: from more joyful forms of song (or combinations of song) to lament or vice-versa, depending on the outcome of the plot. Two powerful examples of the former type of musical structure are Euripides' Heracles and Sophocles' Trachiniae, both of which mark the reversal of Heracles' fortunes through a shift from the jubilant conflation of celebratory forms of mousike (music, song, dance) to lament and then, ultimately, to choral silence. In the second stasimon of Euripides' play, after lamenting old age and praising youth, the chorus explicitly points to its own generic mixing as it celebrates Heracles' achievements:

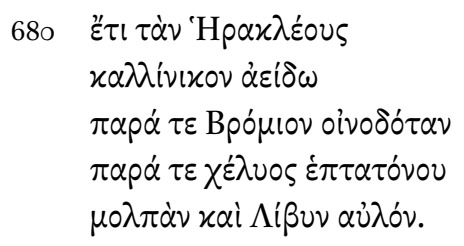

6 As in Swift 2010. 


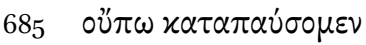

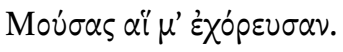

$\pi \alpha \iota \hat{\alpha} \nu \alpha \mu \dot{\varepsilon} \nu \Delta \eta \lambda ı \dot{\alpha} \delta \varepsilon \varsigma$

$\langle\nu \alpha \hat{\omega} v\rangle \dot{v} \mu \nu 0 \hat{\sigma} \sigma^{\prime} \dot{\alpha} \mu \varphi i \pi \dot{u} \lambda \alpha \varsigma$

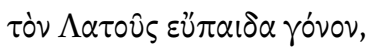

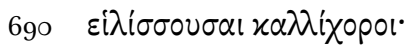

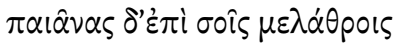

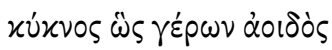

$\pi \circ \lambda ı \hat{\alpha} \nu \dot{\varepsilon} x \gamma \varepsilon v \dot{v} \omega \nu$

$x \varepsilon \lambda \alpha \delta \dot{\eta} \sigma \omega$.

Still I sing the kallinikos 〈song of Heracles, both in the company of Bromios the wine-giver and in the company of the music of the sevenstringed tortoise-shell and the Libyan aulos. Not yet will we put an end to the Muses, who set us dancing.

The Delian Maidens sing a paean around the gates 〈of the temples〉 for the noble child of Leto, whirling, beautiful choruses; so paeans upon your halls I shall cry out like a swan, aged singer, from my grey cheeks.

EUR. $H F$ 68o-694

This polyphonic image is an incongruous one. Here we have old men claiming to sing both an epinician song of victory (kallinikos) and Dionysiac mousike ("in the company of Bromios"), and to combine two instruments, the kithara and aulos, in "a very rare tragic image of harmonious union."7 They encourage the audience to see and hear them as a maiden chorus, like the Muses or the Delian Maidens, yet outside tragedy the paean, the song that they then claim to sing, would typically be performed by men. ${ }^{8}$ Although there are examples within Athenian tragedy of female choruses performing paeans, the muddling of genders here seems to be deliberately marked, pointing to the unlikelihood of this group of old Thebans being able to sing and dance as it claims to.

7 Wilson 1999-200o: 435. On the generic hybridity here, see also Carey 2012: 29-30. Other scholars have tended to focus almost exclusively on the epinician character of this ode: see Parry 1965; Rehm 1996-1997: 53; Swift 2010: 129-131.

8 On this contradictory image, see Henrichs 1996a: 59-6o. On the gender of paeanic performers, see Calame 1997a: 76-79; Rutherford 2001: 58-59; Swift 2010: 64-65. For examples of female choruses performing paeans in tragedy, see Aesch. Cho. 149-151; Soph. Trach. 205-224; Eur. Hel. 174-178, IA 1475-1531. On this phenomenon see Rutherford 1994-1995: 120, 2001:113; Weiss 2014: 125-126. 
This unlikelihood becomes even clearer when the chorus then depicts itself as a swan, singing from grey cheeks: not only does this image underscore the men's age, it also introduces a note of lament, since the swan typically mourns its own impending death. ${ }^{9}$ The extreme mixing of genres here undercuts the chorus' celebratory festivity, as the overload of different forms of choral performance — or at least verbal allusions to these different forms—ends with a reference to lament.

Though it appears celebratory, then, the ode foreshadows with this note of unease the interruption of the chorus' next, even more exuberant song by the appearance of Iris and Lyssa, who herald the bloody reversal in Heracles' fortune. This reversal is marked, as PeterWilson has shown, by an emphasis on the madness brought on by Dionysiac mousike, of which the aulos, the very instrument being played in the theater, is the main agent: Lyssa even declares to the

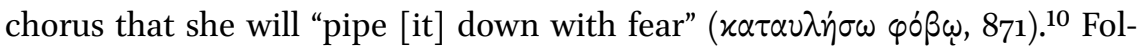
lowing the messenger's account of Heracles' murder of his wife and children, lament then takes over, though the chorus questions even this as an appropriate form of song given the enormity of the hero's suffering:

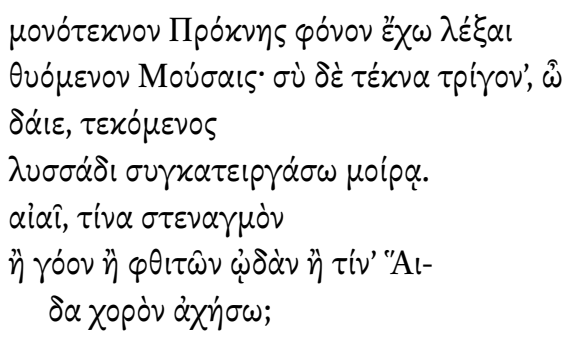

I can tell of Procne's murder of her only child, sacrificed for the Muses. But you, wretched man, sired three children and killed them all together by your raging mad fate. Aiai, what groan or wail or song for the dead or what chorus of Hades shall I cry out?

EUR. $H F$ 1021-1027

After an antiphonal exchange of mourning with Amphitryon, the chorus is then virtually silent for the last third of the play, as the focus turns instead to the exchange between the old man, Heracles, and Theseus.

9 Cf. Aesch. Ag. 1444-1446; Pl. Phd. 84e-85a; Arist. Hist. an. 615b2-6. At Eur. El. 151-156 Electra compares herself to a swan in mourning her father's death, which she seems to equate with her own. On the bird's association with self-lament see Arnott 2007: 123.

Wilson 1999-200o: 435-439. 
The musical structure of Sophocles' Trachiniae is very similar to that of Euripides' play: multiple lyric genres are embedded within the chorus' expressions of premature jubilation, and these transition into markedly different forms after Deianeira unwittingly poisons Heracles. In the first stasimon, following the news of the hero's imminent arrival, the chorus excitedly combines different types of song, and in doing so refers directly to its own performance:11

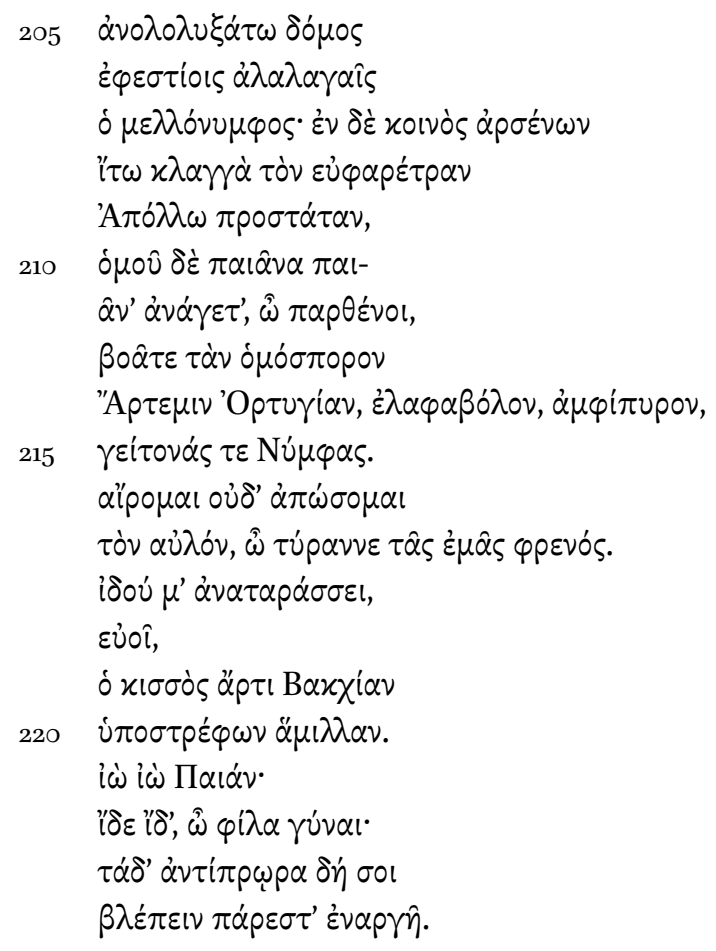

Let the house raise a shout of ololuge, with shouts of alalai by the hearth, [the house] that is to be united in marriage. And let the collective cry of men go up to the one of the fair quiver, Apollo the protector, and you, O maidens, together raise up the paean, the paean, call upon his sister Artemis the Ortygian, deer-shooter, bearer of the double torch, and the neighboring nymphs. I'm lifted up and will not reject the aulos, O tyrant of my mind. Look, the ivy shakes me up, euoi, turning me round just now in the Bacchic contest. Io io Paian! Look, look, O dear lady: You can see these things clearly, right in front of you. (Soph. Trach. 205-224)

\footnotetext{
11 On the generic "fusion" at work in this ode, see also Foster's paper in this volume.
} 
We cannot generically classify this ode, or at least not simply. As both Albert Henrichs and Timothy Power have shown, it includes elements of hymenaeal, parthenaic, paeanic, and dithyrambic song, and shifts from one to the other

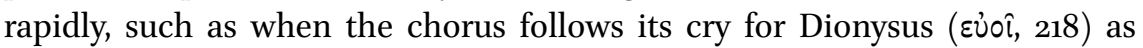

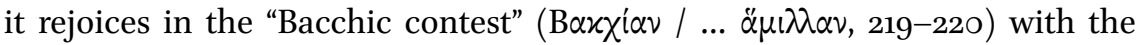

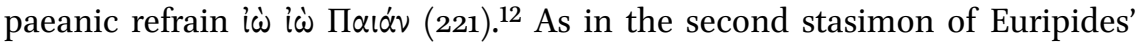
Heracles, there is a confusion of gender as well as genre here, since these maidens sing a paean, emphasizing this particular type of song above all; they mark this mix by beginning with the ritual cry of $\partial \lambda \circ \lambda \nu \gamma \dot{\eta}$, which is typically a female utterance, and ending with $i \omega i \dot{\omega} \Pi \alpha \alpha^{\alpha} \nu .^{13}$ In its ecstatic anticipation of Heracles' arrival the chorus thus transforms itself into multiple performers of multiple songs. Also as in Euripides' ode, however, the extreme nature of its genre (and gender) mixing here adds an unsettling note to their performance, so that, while the audience is encouraged to feel similar excitement through such mousike, it may also have a premonition of the inevitable reversal that is soon to come. Thus it is not simply the prematurely exuberant tone of the song that heralds a tragic reversal, causing it to be a so-called "joy-beforedisaster ode," but the vertiginous overload of different song types combined within it. ${ }^{14}$

The mix of genres in this performance allows the chorus to call on multiple divine participants to join its choreia in celebration of Heracles' returnApollo, Artemis, the nymphs, and Dionysus, who becomes synonymous with

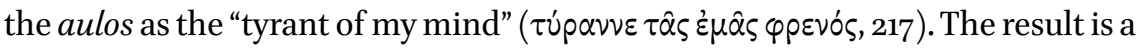
sense of multiple epiphanies, culminating in the chorus' direction to Deianeira to "look, look" (" $\delta \varepsilon \varepsilon$ " $\delta$ ', 222) and see "these things" ( $\tau \dot{\alpha} \delta$ ', 223) before her, so that the divine epiphanies generated through its choreia culminate in what we expect to be Heracles' own long-awaited appearance. Instead, however, a procession of captives enters, and the hero's own triumphant epiphany can only be imagined musically by the chorus, as it is again four hundred lines later:

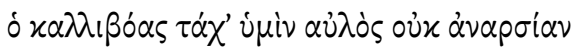

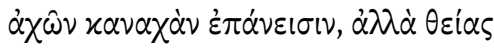

$\alpha \nu \tau i \lambda u p o v \mu \circ v^{\prime} \sigma \alpha \varsigma$.

12 Henrichs 1994-1995: 79-84; Power 2012: 293-295. Cf. Rutherford 1994-1995: 120; Battezzato 2005a: 163 .

13 On these gender divisions, see Henrichs 1994-1995: 104-105, n. 99.

14 On the device of "premature choral jubilation" here, see esp. Henrichs 1994-1995: 7984 . 
Soon the beautiful shout of the aulos will rise up for you again, not sounding out an unharmonious clamor, but [the sound of] divine music, responding to the lyre.

sорн. Trach. 640-642

When Heracles does finally come on stage, however, the chorus' mousike is markedly different. In contrast to its earlier jubilant and multi-genre, multigod performance, now, as the dying hero is carried in, the chorus sings a lament, marking it as such by comparing its song to the "shrill-voiced nightingale" ( $\partial \xi \dot{v}$ $\varphi \omega \nu \circ \varsigma \dot{\omega} \varsigma \dot{\alpha} \dot{\delta} \dot{\omega} v, 963)$, the archetypal figure of mourning. Soon, however, as in Euripides' tragedy, the chorus ceases singing altogether. First it breaks off its lament as it turns to look at the long-awaited Heracles, and focuses on the silence of his entrance instead: the steps of those carrying him are "noiseless"

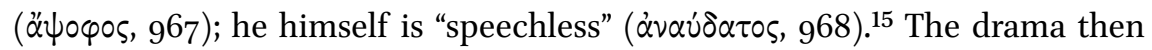
centers on Heracles' own painful singing, followed by the intimate exchange between him and his son. This shift away from the chorus' song and dance, with its inclusion of multiple forms of choreia, stresses the poignant contrast between the public, divine celebration that it previously envisaged and the reality of Heracles' fate.

\section{Moving on from Lament: Euripides' Helen and Iphigenia in Tauris}

In Heracles and Trachiniae, then, we see the dramatic effects of multiple lyric forms giving way first to lament and then to choral silence. Two tragedies by Euripides, Helen and Iphigenia in Tauris, demonstrate the opposite choral structure, whereby an important turning point in the dramatic narrative is marked by a shift from lament into other musical forms. These tragedies have remarkably similar plot structures: both begin with the plight of the central heroine in a barbarian land (Egypt, Tauris), then look toward a more positive outcome once she is reunited with a newly arrived Greek hero (Menelaus, Orestes), with whom she finally travels back to Greece. ${ }^{16}$ They also have very

\footnotetext{
15 Cf. Scott 1996: 15; Henrichs 1994-1995: 85 .

16 On the structural similarities between Helen and IT, see esp. Platnauer 1938: xv-vi; Matthiessen 1964; Mastronarde 2010: 73-74; Marshall 2014: 45-49. Based on these similarities, as well as what remains of Andromeda, Wright (2005: 43-55) has argued that they were all performed together as an "escape trilogy." This argument has rightly been met with some skepticism: Foley 2006; Gregory 2006; Kyriakou 2006; Marshall 2009, 2014: 12.
} 
similar musical narratives, beginning with an antiphonal lament sung by the heroine and her chorus, then transitioning to other types of song as she prepares for her escape.

This is not to say that the laments performed early on in Helen are themselves a "pure" generic form. On the contrary, the parodos that Helen sings with the chorus, though she frames it as one of mourning, asking "what sort of lament should I strive for or what music should I follow, with tears or dirges

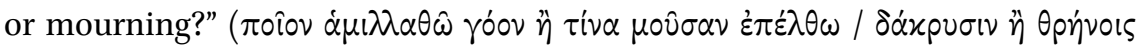
ทे $\pi \varepsilon \dot{\varepsilon} \theta \varepsilon \sigma v$; Hel. 165-166), incorporates parthenaic and paeanic elements as well: she addresses the chorus as Sirens, archetypal parthenaic singers (and ones with strong funereal associations), calling them "winged maidens, virgin

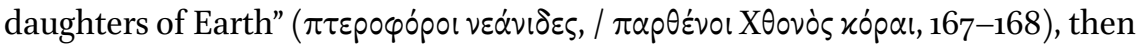

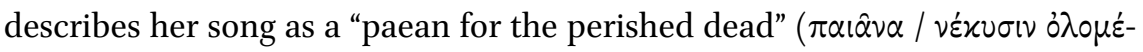
vol5, 177-178). ${ }^{17}$ The chorus in turn portrays Helen as a parthenos or new bride (nymphe) by describing her cry as that of a Naiad nymph (184-190). ${ }^{18}$ Nevertheless, lament remains the dominant genre at play not just in this song, but also in Helen's next lyric exchange with the chorus $\left(33^{0}-385\right)$ and in the long-delayed first stasimon (1106-1164).

The transition from lament to other song types in Helen begins with the socalled "Great Mother Ode," in which the chorus describes the frantic search of Cybele for her daughter, Kore. In the second strophe of this ode it sings of how Zeus finally consoled the goddess by means of a musical performance that is very different from those previously evoked in the play:

$$
\begin{aligned}
& \text { हं } \pi \varepsilon i \delta^{\prime} \text { ' है } \pi \alpha \nu \sigma^{\prime} \varepsilon i \lambda \alpha \pi i \nu \alpha \varsigma
\end{aligned}
$$

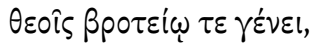

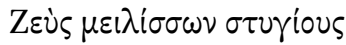

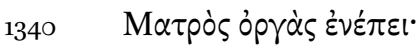

17 On paeans in chthonic contexts, see Rutherford 1994-1995: 119-124, 2001: 118-120; also Swift 2010: 71-72. Rutherford stresses, contra Kannicht 1969: 2. 70, that the chthonic $\pi \alpha \hat{\alpha} v \alpha$ in Hel. 177 is not simply an oxymoron, but that the song itself is a "generic hybrid" (19941995: 124). Ford (2010: 290-294) suggests that, like the description of the nightingale's song in Ar. $A v \cdot 209-222$, the transformation of Helen's song from a solo cry into a choral paean to the dead shows "a solitary outpouring of sorrow being sublimated into a fundamentally different kind of song” (293), marking Helen's own transformation from individual mourner into chorus leader.

18 As many have noted, the chorus' description of their clothes-washing also recalls the account of the companions of Nausicaa, a maiden on the point of marriage, in the Odyssey (6.85-109): see Foley 2001: 306 n. 10; Burian 2007: 10-11; Ford 2010: 294; Murnaghan 2013: 174. On the parthenaic motifs in this song, see also Swift 2010: 225-226. 


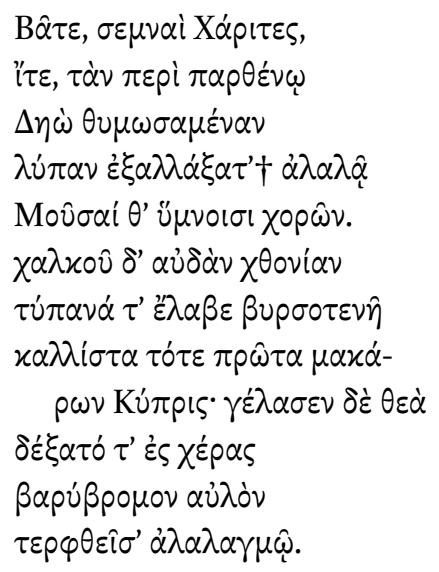

But when she stopped feasts for gods and the mortal race, Zeus, trying to soothe the grim wrath of the Mother, says, "Step forth, holy Graces, go, and take Deo, who is angered for her daughter, away from her griefs with the cry of alala, and you, Muses, with the songs of choruses." And the earthy voice of bronze and the drums of stretched hide then for the first time Cypris, loveliest of the blessed ones, took up; and the goddess laughed and took into her hands the deep-roaring aulos, delighting in the alala cry.

EUR. Hel. $1337-135^{2}$

This story of how song, dance, and instrumental music achieved the appeasement of the Great Mother provides an aetiology for the instruments and choral performances associated with her cult, which is syncretized with the rites of both Demeter and Dionysus: ${ }^{19}$ here the choruses cry alala, Aphrodite takes up the cymbals ("the earthy voice of bronze") and drum (tympanon), and the Great Mother delights in the aulos; earlier in the ode, as the goddess searches for her daughter, the chorus sings of the "roaring castanets (krotala), sending forth

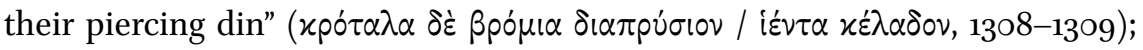
in the final antistrophe it refers to the "whirling, circular shaking of the rhom-

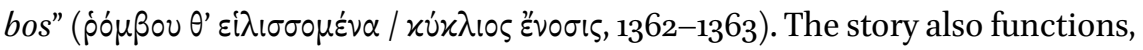
however, as a sort of aition for the Dionysiac performance of Athenian citizens in the orchestra, singing and dancing to the tune of the aulos that causes the goddess so much delight. The ode thus tracks—even enacts—-the transition

19 On the syncretism of the Great Mother, Demeter, and Dionysus, see Parker 1996: 188-189, 2005: 344-345; Roller 1996: 312-313, 1999: 174-176; Allan 2004: 143-146, 2008: 29; Currie 2005: 394-396; D’Alessio 2013: 130-131; Battezzato 2013: 106; Prauscello 2013: 78. 
from lament to the beginnings of Dionysiac mousike, including the mousike of the theater itself. ${ }^{20}$ This generic shift simultaneously mirrors the movement of the plot: now, as Helen and Menelaus put into action their plan to escape from Egypt back to Greece, the chorus abandons its mourning songs and looks forward to Helen's resumption of cultic mousike in Sparta, which it describes and performs itself in the following stasimon. ${ }^{21}$

In Iphigenia in Tauris the initial dominance of responsive lament contrasts sharply with the chorus' third and final stasimon, a hymn to Apollo (12341282). We are primed early on in the play to notice the difference, when, singing the parodos responsively with Iphigenia, the chorus highlights the contrast between laments and paeans:

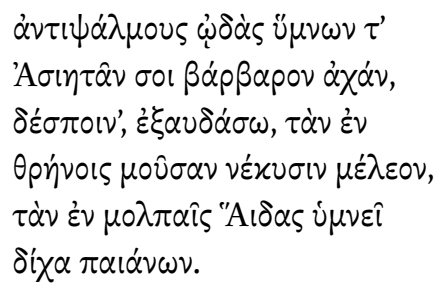

Antiphonal songs and barbarian cry of Asian songs I shall shout out to you, mistress, the music in dirges for the dead, wretched, which Hades hymns in songs, remote from paeans.

EUR. IT 179-185

Lament in tragedy is typically characterized by what it is not: Iphigenia has just

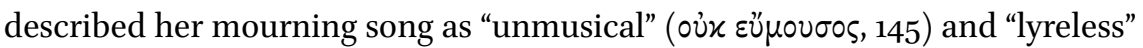
( $\alpha^{2} \lambda$ upos, 146). ${ }^{22}$ Here the chorus again highlights the apparent absence of musicality in its performance as well as its sombre tone by calling it "remote from paeans" ( $\delta \dot{\chi} \chi \alpha \alpha \alpha i \alpha \dot{v} \omega \nu, 185)$. But its final ode, though often labeled "dithyrambic" on account of its mythical narrative, is more (or also) reminiscent of a paean: ${ }^{23}$

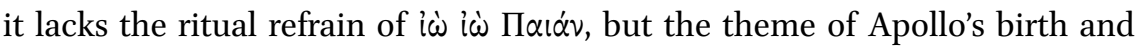
aetiology of his seat at Delphi is a common paeanic one. ${ }^{24}$ This musical shift

$20 \quad$ Ford 2010 argues that the play enacts a "genealogy of song," tracing it back to "the inarticulate grieving of abandoned women" (285). Cf. Murnaghan 2013; Steiner 2013: 177-181.

21 For a fuller discussion of the musical structure of Helen, see Weiss 2018: 140-19o.

22 On the characterization of lament as "unmusical" in tragedy, see Segal 1993: 16-20; Wilson 1999-200o: 433-439; Loraux 2002: 54-65; Weiss 2017.

23 On this ode as "dithyrambic," see esp. Panagl 1971: 119-132; Cropp 20oo: 247; Kyriakou 20o6: 391.

The dactylo-epitrite rhythm is also common to several extant paeans, though in general 
marks the dramatic one, as Iphigenia, having successfully tricked Thoas into letting her carry out a purification ceremony in the sea, has gone with Orestes and Pylades to their ship. Yet the change in music, suggesting a quick, positive resolution to the plot, also somewhat misleads us, so that the messenger's report that follows comes as more of a surprise: even the singing of paeans (1403-1404) failed to prevent the ship from being driven back to land. Iphigenia, Orestes, and Pylades do eventually escape, but only thanks to Athena's intervention.

Between the lament at the start of Iphigenia in Tauris and the paean at its end comes a variety of different song types, as we would expect, and such mixing of lyric genres relates directly to the themes and action of the play. In the second stasimon, for example, the chorus begins with a lament for its own abandonment, likening its singing to that of the mourning halcyon bird: "I compare

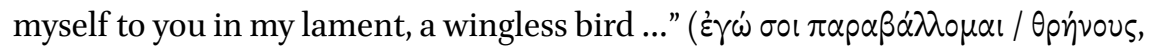

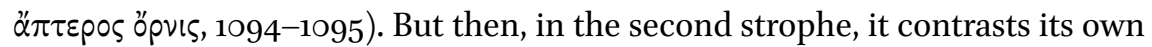
journey to Tauris on a slave ship with a vivid description of Iphigenia's escape back to Greece on a fifty-oared ship, accompanied by Pan with his syrinx and Apollo with his lyre:

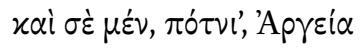 \\ $\pi \varepsilon v \tau \eta x o ́ v \tau \varepsilon p o s$ oix

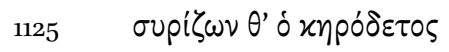 \\ Паvòs oủpzíov xá̀ $\alpha \mu \circ$ \\ $\chi \omega^{\prime} \pi \alpha \iota \varsigma \dot{\varepsilon} \pi \imath \omega \dot{u}^{\prime} \xi \varepsilon$,

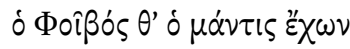

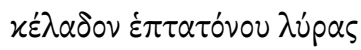 \\ ${ }_{1130} \dot{\alpha} \varepsilon \dot{\delta} \delta \omega \nu \grave{\alpha} \xi \varepsilon 1 \lambda \iota \pi \alpha \rho \dot{\alpha} \nu$

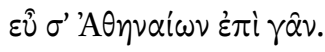 \\ $\dagger \hat{\varepsilon} \mu \dot{\varepsilon} \delta^{\prime} \alpha \dot{\tau} \tau 0 \hat{\nu} \lambda เ \pi \circ \hat{\sigma} \sigma \alpha$

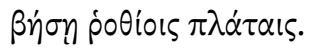

And you, lady, an Argive ship with fifty rowers shall bring home, and the wax-bound reed of Pan, the mountain god, will blow and shout out to the oars, while Phoebus the prophet, holding the noisy seven-stringed lyre, will sing and lead you safely to the gleaming land of Athens. $†$ But me you shall leave here and make your way with splashing oars ...

Eur. IT 1123-1133

surviving songs of this type display a wide range of meters: see Rutherford 2001: 78-79. On the narrative of Apollo's birth and establishment of the oracle at Delphi as a paeanic theme, see ibid: $74-75$. 
Previously in the first stasimon the chorus mentioned "choruses of fifty

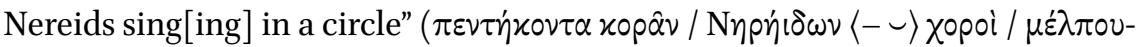
$\sigma \downarrow v \dot{\varepsilon} \gamma x \dot{u} x \lambda 101,427-429)$. In doing so, it evoked the dithyramb, which was danced by fifty choreuts in a circular formation to the accompaniment of the aulos, and with which Nereids are often associated in Greek literature and art. ${ }^{25}$ The dramatic chorus' own dancing (perhaps also circular) to the aulos in the orchestra, combined with its verbal description of the Nereids, would strengthen the suggestion of such a performance. ${ }^{26}$ Now it picks up on this generic allusion again with the image of the fifty-oared ship, which encourages the audience to link oars with dithyrambic dancers, though here dancing to the musical accompaniment of Pan with his syrinx and Apollo with his lyre rather than the aulos. As Barbara Kowalzig has demonstrated, the emphasis on musical, maritime travel is also characteristic of the dithyramb. ${ }^{27}$ The musical journey to Athens that the chorus envisages here looks forward to and proleptically enacts the voyage of Iphigenia, Orestes, and Pylades soon to occur offstage, even as, like the third stasimon, it elides the difficulties of their first attempt.

In the final antistrophe of the second stasimon the women evoke another lyric genre, this time partheneion. First they express the wish to fly like a bird (1138-1142), evoking the sort of avian imagery that we commonly find in parthenaic song, such as Alcman's first Partheneion. ${ }^{28}$ Then they explicitly confirm this generic echo when they imagine returning to the parthenaic choruses in which they once took part:

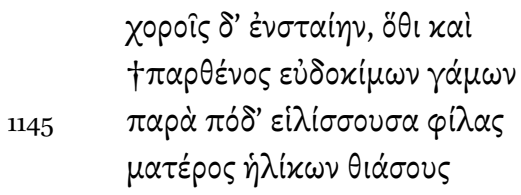

If only I could take my stand in choruses, where also †as a maiden at glorious weddings, whirling my foot alongside the bands of my dear mother's companions ...

EUR. IT $1143^{-1146}$

\footnotetext{
25 On the circular formation of the dithyramb, see D'Angour 1997. On the association of (fifty) Nereids with the dithyramb, see Csapo 2003.

26 On the overlap between such descriptions of mousike and the chorus' own performance, see Weiss 2018.

$27 \quad$ Kowalzig 2013.

28 Alcm. fr. $1 P M G$ 6o, 86. On avian imagery in partheneia, see Steiner forthcoming: ch. 3; Weiss 2018: 29-30.
} 
Though this wish expresses the loss of their former status as marriageable young girls in Greece, the chorus also briefly (re)enacts such choreia through its own song and dance, combined with its vivid description of its former movement. The parthenaic theme and performance here are thus folded into the maidens' lament for their current situation in Tauris. At the same time, however, this evocation of partheneia also encourages the audience to look forward to the chorus' own departure, separate from Iphigenia's, which Athena orders at the end of the tragedy.

\section{Genre and Audience Response}

The combinations and interactions of different genres in a tragedy therefore affect the audience's reception not just of an individual song, but of the dramatic narrative as a whole. Generic allusions are not-or at least need not be-merely discrete and temporary, confined to the one lyric performance without any bearing on the rest of the drama. ${ }^{29}$ On the contrary, as the above analysis of Sophocles' Trachiniae and Euripides' Heracles, Helen, and Iphigenia in Tauris has suggested, they can be intricately connected to the plot and be part of a larger musical pattern at play through the course of a tragedy. It is therefore worth pausing here to consider the process by which evocations of genre in choral lyric - verbal, musical, and/or choreographic — encourage the audience to anticipate an event or movement in the drama as a whole. Genre and audience response are closely tied together. If we apply Jauss' influential terms concerning the response of a reader to that of an audience in the theater, we might think of lyric genres, especially as they are deployed in tragedy, as "horizons of expectation," familiar to the audience from other performances, which are then "varied, corrected, altered, or even just reproduced" within a play. ${ }^{30}$ The ways in which these can guide a specific response from the audience can be similar, then, to how a text "awakens memories of that which was already read, brings the reader to a specific emotional attitude, and with its beginning arouses expectations for the 'middle and end,' which can then be maintained

29 Contra Swift 2010: 72 on the paean: "[ $\mathrm{t}]$ he genre is evoked in order to create a moment of tension or irony; once over, the allusion is no longer relevant, and we are not meant to keep it in mind later during the play."

30 Jauss 1982: 23. On genre as a set or system of expectations, dependent on the reader's (and author's) own generic repertoire, see also esp. Culler 1975: 113-130; Dubrow 1982; Fowler 1982; Todorov 1990. 
intact or altered, reoriented, or even fulfilled ironically in the course of the reading according to specific rules of the genre or type of text."31

The original audiences of classical tragedy would, we can imagine, be especially receptive to evocations of particular types of song, given their own experience of and participation in the "generic system" of song culture both within Attica and, in the case of visitors and metics, elsewhere in Greece. ${ }^{32}$ Many Athenian spectators would at some point have been musical performers themselves, both in and outside the theater, of at least some of the song types represented and included within any given tragedy: ${ }^{33}$ they may have sung and danced, for example, in one of the twenty dithyrambic choruses that performed yearly in Athens (involving a total of one thousand choreuts each year). Some genres might have been known to certain audience members from their experience of being spectators of choreia more than performers, and through their familiarity with allusions to particular forms of song not just in previous plays (tragic, satyric, and comic) but in other media as well, such as inscribed paeans or vase paintings depicting parthenaic or Dionysiac mousike.

The nature of the audience's previous engagement with various lyric genres within and outside the theater suggests that the performance of choreia in tragedy could go beyond Jauss' textual model in its ability to direct an audience's response. As Sarah Olsen demonstrates in this volume, choreia could work on the audience physically, activating its somatic memory (or "embodied cultural knowledge") of a song type as a past performer and/or spectator. ${ }^{34}$ This is memory of particular emotions combined with bodily and sensorial participation - the ecstasy of Dionysiac ritual, for example, or the grief and pity of lament. ${ }^{35}$ When the audience of a tragedy would hear (and see) a turn toward a Dionysiac or paeanic song instead of a lament, or, conversely, the hint of a lament amid more celebratory mousike, it would therefore not only be primed to notice that turn but to feel and participate in it. The audience's response would include adjusting its expectations for the ensuing action within the drama: so when it experiences the new form of choreia in Helen, for instance, it can begin to look toward the plot's happy resolution. Often, of course, the per-

\footnotetext{
31 Jauss 1982: 23 .

32 On ancient Greek "song culture" and its connection to Athenian audiences' experiences of tragedy, see Herington 1985: 3-5; Bacon 1994-1995; Revermann 2006. Cf. Revermann 2006 on the "competence" of audiences of tragedy in fifth-century Athens; also Gagné and Hopman 2013a: 26; Peponi 2013a: 212-213.

34 Olsen takes the term "embodied cultural knowledge" from Sklar 2008. Cf. Olsen 2017 on kinesthetic empathy in choreia; also Weiss 2018: 235-241. Cf. Estrin (this volume) on genre as a "structure of feeling."
} 
formance of a particular song type in a tragedy cannot be taken entirely at such face value, as we saw in the case of the evocations of the dithyramb and paean in Iphigenia in Tauris. A more extreme example is the jubilant first stasimon of Sophocles' Trachiniae that I discussed above: the audience knows of Heracles' imminent fate but must to some degree be carried along with and brought into the performance of ecstatic choreia, which prompts it to hope for an outcome (and a form of epiphany) that it realizes will be impossible.

\title{
The Hybridity of Tragic Song: Euripides' Troades
}

The combination of multiple genres within one song, like the first stasimon of Trachiniae, can also shape the audience's expectations for what tragedy itself is and can be. As we have seen in this tragedy and also in Heracles and Iphigenia in Tauris, different lyric genres can be so intertwined with or embedded within one another that it is often hard to distinguish them. Even in a play where one genre does seem to dominate - and in tragedy, that genre is often lament - we can find a complex generic hybridity within a single song.

Such a mix of generic consistency and hybridity is especially pronounced in Euripides' Troades. Lament pervades this tragedy: it opens and closes with the antiphonal mourning of Hecuba and the chorus, and sung lament repeatedly interrupts spoken dialogue throughout. ${ }^{36}$ But the first stasimon, in which the chorus sings of the night the Trojans brought the horse within their walls, is rather different, combining an extraordinary array of musical genres. It begins with an evocation of epic:

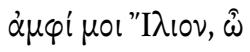

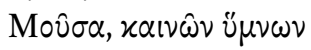

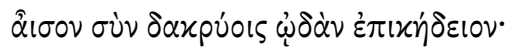

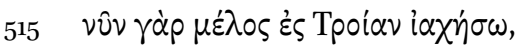

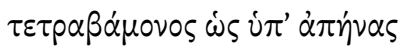

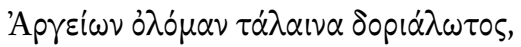

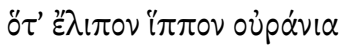

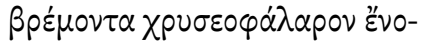

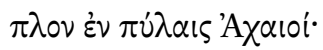 \\ $\dot{\alpha} \nu \dot{\alpha} \delta^{\prime} \dot{\varepsilon} \beta \dot{\alpha} \alpha \sigma \varepsilon \nu \lambda \varepsilon \dot{\omega} \varsigma$

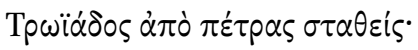

36 On lament in Troades, see Suter 2003; Weiss 2018: 100-139. 
"I $\tau^{\prime}, \hat{\omega} \pi \varepsilon \pi \alpha \nu \mu \varepsilon \varepsilon^{\prime} \circ \mathrm{l} \pi \sigma^{\prime} \nu \omega \nu$,

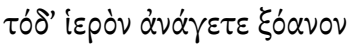

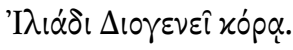

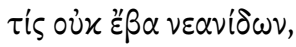

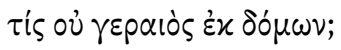

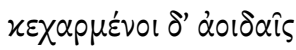

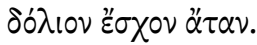

About Troy, O Muse, sing for me a funeral ode of new songs, with tears: for now I will cry out a song to Troy, telling how as a result of a four-footed vehicle I was ruined, [becoming] the Argives' wretched captive, when the Achaeans left at our gates the horse, making a rumbling noise up to the sky, with its trappings of gold and armed [within]; and the people shouted out from the Trojan rock, standing there, "Go, you who have ceased from toils, bring this holy image to [the shrine of] the Zeus-born maiden of Troy!" Who of the young women didn't come, what old man didn't [come] from his house? Rejoicing with songs they received treacherous ruin. EUR. Tro. ${ }^{11-530}$

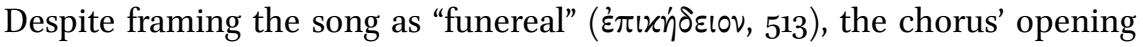
address to the Muse is instead typical of epic and the Homeric hymns. ${ }^{37}$ Within the first three lines some dactylic rhythms also creep in, creating a sense of the tragic appropriation of epic and hymnic style. Yet this evocation of epic is by no means uniform or fixed, as the chorus' proclamation of "new songs" ( $x \alpha \downarrow \omega \omega \nu$ $u \mu \nu \omega \nu, 512$ ) suggests: we have here not only a surprising mix of epic and lament, but also a song delivered from a first-person, female perspective, thus further deviating from traditional epic treatments of Troy's fall. Other lyric genres are present too: Wilamowitz suggested that the ode's opening phrase ( $\alpha \mu \varphi^{\prime}\left(\mu \circ, 5^{11}\right)$ evokes a kitharodic proimion; several scholars have argued that the rare com-

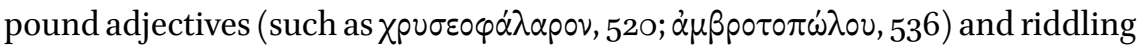

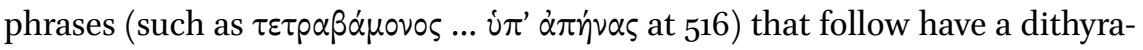
mbic flavor. ${ }^{38}$

37 Cf. esp. Hom. Hymn 19.1, 20.1, 33.1; this use of $\alpha \mu \varphi$ i with the accusative of a song's subject also occurs at Hom. Hymn 7.1, 22.1. On the novelty of this epic address within tragic lyric, see Neitzel 1967: 44; Lee 1976: 164; Hose 1991: 303; Quijada 2006: 844; D’Angour 2011: 194. On further parallels between the Troades first stasimon and the Iliad, see Sansone 2009 . Torrance (2013: 219-228) argues that the "new songs" denote a new version of Demodocus' song about the wooden horse and destruction of Troy (Od. 8.426-534).

38 On the ode's "dithyrambic" language, see Wilamowitz 1921: 174; Neitzel 1967: 45; Battezzato 2005b: 17. Cf. Kranz 1933: 243. 
Such rich mixing of genres continues through the rest of the ode. In the final lines we can detect a trace of epinician, when, in a horrible distortion of a victory song, the women claim that the bloodshed at Troy has produced a child-bearing garland $(\sigma \tau \varepsilon \dot{\varepsilon} \varphi \alpha \nu \vee v, 565)$ for Greece. At the ode's center we find partheneia, this time in the chorus' description of its own choreia on the night of Troy's destruction:

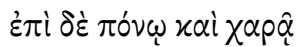

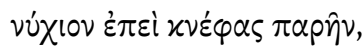

$$
\begin{aligned}
& \Lambda i ß u \varsigma \tau \varepsilon \lambda \omega \tau \dot{\jmath} \varsigma \dot{\varepsilon} \varkappa \tau \dot{\tau} \pi \varepsilon l \\
& 545 \Phi \rho u ́ \gamma \mid \alpha ́ \alpha \varepsilon \mu \dot{\varepsilon} \lambda \varepsilon \alpha, \pi \alpha \rho \theta \varepsilon \varepsilon^{\prime} 01 \delta^{\prime}
\end{aligned}
$$

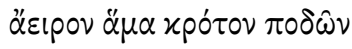

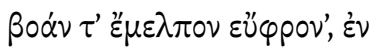

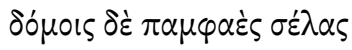

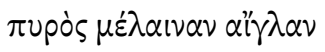

$$
\begin{aligned}
& 550 \dagger \varepsilon ้ \delta \omega x \varepsilon v \ddot{v} \pi \nu \omega \dagger \dagger \text {. } \\
& \varepsilon \dot{\varepsilon} \gamma \dot{\omega} \delta \dot{\varepsilon} \tau \dot{\alpha} \nu \text { ỏp } \sigma \tau \tau \varepsilon \dot{\varepsilon} \rho \alpha \nu
\end{aligned}
$$

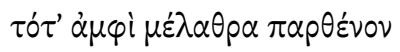

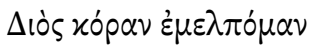

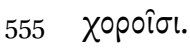

And nighttime darkness came upon their toil and joy, and when the Libyan lotos pipe was sounding as well as Phrygian songs, and maidens raised together the beat of their feet and sang and danced a cheerful cry, and in the halls an all-blazing gleam of fire †shed a dark glow on sleep. $\dagger$

And I to the mountain maiden, the daughter of Zeus, around the halls I was singing and dancing then in choruses.

EUR. Tro. $544-547$

This is more than a verbal signpost toward the parthenaic genre: the chorus

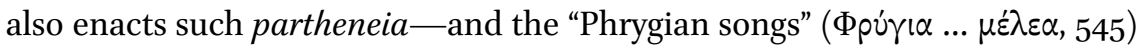
more broadly — through its own song and dance to the accompaniment of the aulos, to which the "Libyan lotos pipe" ( $\Lambda$ iß $\cup$... $\lambda \omega \tau$ ós, 544) refers.

The question of what exactly are the "new songs" that the chorus announces at the start of the first stasimon has been much debated. Luigi Battezzato, in his nuanced reading of this ode, has argued that it enacts the Greeks' victory over the Trojans by replacing the women's Phrygian mousike with distinctively 
Greek forms. ${ }^{39}$ Given the chorus' return (with Hecuba) to lament later in the play, and given the extreme mixing of genres throughout the ode, I do not think that such a replacement of one form of mousike for another is quite as evident as he suggests. Nevertheless, the combination of epic, hymnic, kitharodic, dithyrambic, epinician, and parthenaic elements here does point to the beginnings of these "new" song types in the wake of Troy's fall. Indeed, the idea that such songs have their roots here recurs later in the tragedy, when Hecuba remarks that the Trojan women's sufferings will provide "songs for the music of

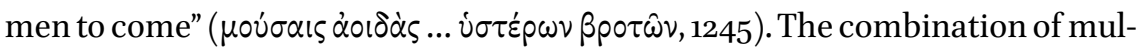
tiple genres in the first stasimon also points to the hybridity of tragedy itself, creating a musical aetiology for the very performance being produced there in the Theater of Dionysus out of Troy's destruction. As in Helen, then, the mousike of the theater is here fashioned out of lament. The "new songs" heralded by the chorus refer to the total amalgam of different lyric forms presented within this ode-an especially pronounced version of a typical tragic trait.

\section{Musical Innovation and the Myth of Generic Purity}

It is tempting to view songs like this one in Euripides' Troades in the light of a famous passage in Plato's Laws, in which the confusion of musical genres appears to be linked to the "New Music" - that is, to the period of musical innovation in the fifth and early fourth centuries BCE that has come to dominate many modern discussions of Greek mousike. ${ }^{40}$ In Book 2 the Athenian

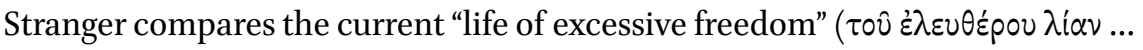

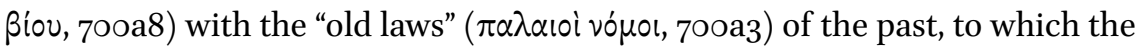
demos strictly adhered:

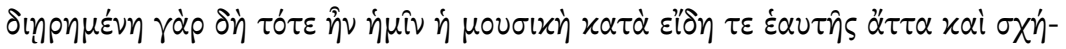

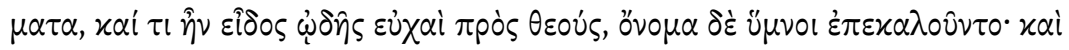

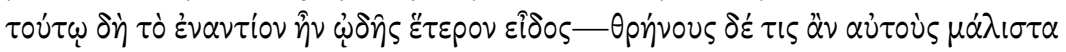

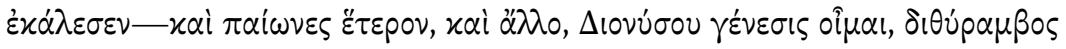

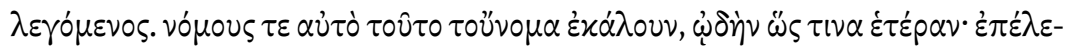

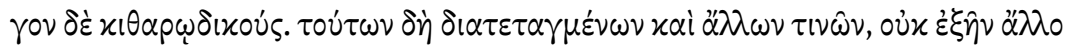

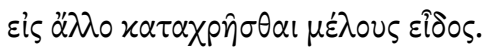

39 Battezzato 2005b.

40 See e.g. Csapo 1999-200o, 2004; D’Angour 2006, 2007. 
For at that time among us mousike was divided according to its various forms and styles, and one form of song was prayers to gods, and they were called "hymns"; and, in contrast to this, there was another form of songone would have best called them "dirges" — and another [called] "paeans," and another, I think originating from Dionysus, called "dithyramb." They used to call one particular one "nomes," as another [type of] song; and they called them in addition "kitharodic." Since these and other types were categorized, it was not possible to misapply one form of song to another.

PL. Leg. 700a9-c1

According to this narrative, the strict separation of different lyric genres later gave way to a licentious blurring of categories that is, the Athenian claims,

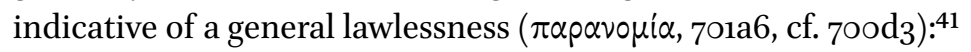

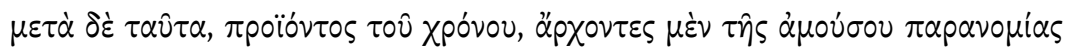

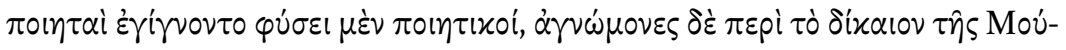

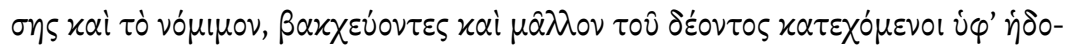

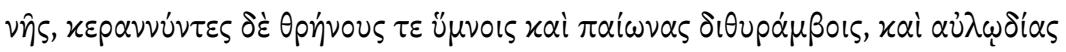

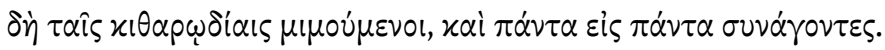

But afterwards, as time went on, there arose leaders of unmusical lawlessness, poets who, though by nature poetical, were ignorant about what is just and lawful in music, being full of Bacchic frenzy and possessed by pleasure more than is fitting, and they mixed both dirges with hymns and paeans with dithyrambs, and represented aulos songs with kithara songs, and brought together everything with everything.

PL. Leg. $700 \mathrm{~d} 2-\mathrm{e} 1$

Might we view Euripides, then, as one of these "leaders of unmusical lawless-

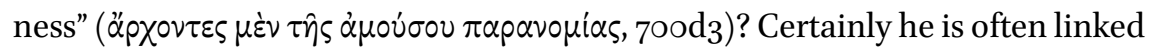
in modern scholarship to the "New Music," and one characteristic of this period of musical innovation may have been experimentation with the mixing of genres, as the Athenian Stranger here claims. And yet, as we have seen in the cases of Supplices and Trachiniae (both tragedies for which the date of production is much debated), Aeschylus and Sophocles also play with combining different lyric genres in their work. ${ }^{42}$

41 On this narrative and the myth of generic purity, see also the Introduction to this volume. 
Indeed, as Battezzato has noted, the parodos of Aeschylus' Agamemnon exhibits an especially complex degree of generic play, combining epic, kitharodic, paeanic, and epinician elements within one song. ${ }^{43}$ At one point, for example, the chorus seems to perform a paean, singing "I call on the healer Paean" (iท่ $\circ \nu \delta \dot{\varepsilon} \chi \alpha \lambda \dot{\varepsilon} \omega \omega \alpha \iota \hat{\alpha} \nu \alpha, 146)$. A few lines later it gives itself the performative direction "utter ailinon ailinon, but let the good win out" ( $\alpha^{\prime} \lambda$ ilvov $\alpha^{\prime} \lambda$ ilvov $\varepsilon i \pi \dot{\varepsilon}, \tau \dot{\partial} \delta$ ' $\varepsilon \hat{\jmath} \nu(x \alpha \dot{\alpha} \tau \omega, 159)$; the combination of this ritual cry of lament following the chorus' account of Calchas' prophecy with the hopeful wish for better things to come demonstrates how closely the mix of song types here (lament and paean) is tied to the song's content and emotional impact. Later in the parodos the chorus evokes the paean again by remembering how Iphigenia used lovingly to sing such a song for her father in his banqueting halls (240-247). In doing so, it, like the chorus of Troades, enacts this paean through its own performance, so that this scene of the past, which contrasts so painfully with the present of the dramatic narrative, comes to life. Genres and genders are not just combined but subverted here, since, as I have already mentioned, performances of paeans outside tragedy were both choral and exclusively male. The embeddedness of this solo paean, sung by Iphigenia in her father's honor, within a choral ode performed by Argive men, is suggestive of how with her singular sacrifice she acts on behalf of the entire community, displacing the army as Greece's savior. At the same time, the men's voices envelop Iphigenia's,

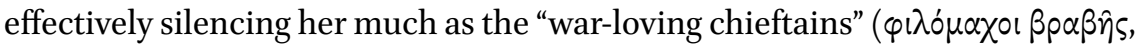
230) did when they disregarded her "pleas and cries of "Father" ( $\lambda ı \dot{\alpha} \varsigma$... xai $x \lambda \eta \delta$ óvas $\pi \alpha \tau p \dot{\omega}$ lous, 228) at the moment of her sacrifice. ${ }^{44}$

In his later plays Euripides may especially revel in mixing up genres, but we can see that this was not just a late fifth-century phenomenon, and indeed there is no suggestion in Plato's Laws that it was one. The Athenian Stranger does not give any precise indication of chronology when he complains about the gradual degeneracy in morals and music: he simply claims that the blurring of categories happened "afterwards, as time went on" ( $\mu \varepsilon \tau \dot{\alpha} \delta \dot{\varepsilon} \tau \alpha \hat{v} \tau \alpha, \pi \rho 0 i ̈ o ́ v \tau o \varsigma$

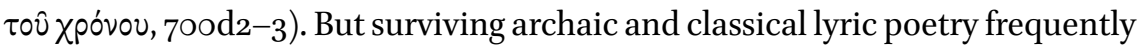
demonstrates how porous the distinction between different song types could

generally thought to be a late play, dated perhaps to the 46оs BCE: see esp. Garvie 1969 . On the date of Trachiniae, see esp. Easterling 1982: 19-23, with further bibliography (she concludes that any date between 457 and 430 is possible).

44 For a similar reading of the Agamemnon parodos, see Weiss 2018: 39-40. Euripides develops the motif of Iphigenia's paean at the end of Iphigenia in Aulis: see Weiss 2014 on Eur. IA 1475-1531; also Weiss 2018: 224-231. Wohl (1998: 77-78) interprets the silencing of Iphigenia in this scene as a violent enforcement of her virginity. 
be, thus undermining this diachronic narrative of generic purity giving way to laxity, as well as demonstrating that such experimentation was not necessarily recent. Bacchylides 17, for example, was marked as a dithyramb within the Alexandrian edition of his songs, but contains an invocation of Apollo at the end (130-132) that seems strongly paeanic, and many scholars have debated to which genre(s) it therefore belongs. ${ }^{45}$ The generic reach of lyric poetry stretched beyond songs typically classified as "lyric" as well, as Sappho's appropriation of Homeric epic clearly demonstrates. Another later and especially hybrid example is Timotheus' Persians (fr. 791), a kitharodic nomos that also combines elements of paean, lament and dithyramb. Timotheus' display here may, like the declaration of "new songs" in Euripides' Troades, be an especially

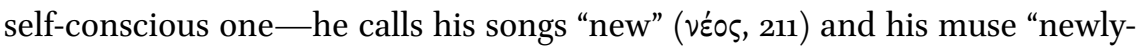

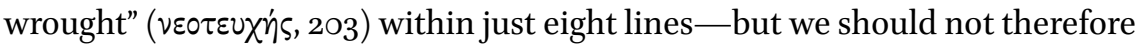
assume that the older lyric poets were any less self-aware in their use of multiple, overlapping genres. ${ }^{46}$

These examples also demonstrate that generic hybridity was by no means confined to the theater in archaic and classical Greece. The Athenian Stranger does seem to have theater especially in mind as the site for generic hybridityit led, he claims, to a "theatrocracy" ( $\theta \varepsilon \alpha \tau p o x p \alpha \tau i \alpha, 701 a 3)$ of noisy theatergoers. Yet he also describes this phenomenon as something which happened within each nondramatic song type: in contrast to their previously strict separation, now dirges, hymns, paeans, dithyrambs, aulos songs, and kithara songs were all mixed up with each other. Since the lyric genres from which the tragedians fashioned their own choreia were seldom themselves fixed, it is then no surprise that Aeschylus, Sophocles, and Euripides all experimented with the effects of combining different types of song.

Nevertheless, the idea that tragedy, in addition to nondramatic song types, was once generically "purer" is evident not just in Plato's Laws but also in the remark by Aristotle in his Poetics with which I began, when he refers to its dithyrambic origins. At work here seems to be the notion that tragedy came from one sort of choral song. We see this also in Euripides' Bacchae, a play

45 On the question of the genre of Bacchylides 17, see esp. Schmidt 199o; Zimmermann 1992: 91-93; Calame 2009a; Tsagalis 2009; D’Alessio 2013: 119-122. Cf. Foster in this volume on the "sequence of generically distinct songs" in Bacchylides 16.

46 On the dynamic play with genre already evident in archaic elegaic, iambic, and melic poetry, see esp. the Introduction to this volume and also the paper by Ford, both of which focus on Pind. fr. 128c SM. Cf. Farrell 2003: 389: "denying these poets an awareness about the instability of generic categories stems from nothing more than a misguided desire to believe that the practice of ancient poets was perfectly congruent with the (after all, rather primitive and simplistic) theories of ancient literary critics." 
which, for all its apparently "new musical" display, is in many respects most innovative in the archaizing nature of its mousike: not only does the chorus sing and dance for almost a quarter of the play-an amount of choreia unmatched by any other surviving Euripidean or Sophoclean tragedy—but its performance retains a strong Dionysiac flavor, and indeed at many points resembles a dithyramb. ${ }^{47}$ The chorus makes the connection between this particular type of choral song and its own performance especially clear when it

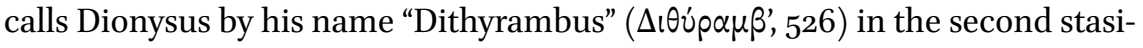
mon. Here, then, Euripides provides a sense of tragedy's aetiology not in terms of generic hybridity but by creating a play that consistently feels like a cult song for Dionysus-perhaps the sort of song from which tragedy as a whole was imagined to have developed.

The extraordinary (and surely deliberate) impression of generic consistency in the Bacchae, in contrast with the majority of our surviving tragedies, confirms that by the time of its production in $405 \mathrm{BCE}$ tragedy had for a long time been a hybrid genre. Using Bakhtin's terminology, we might then view tragedy itself as a "secondary genre," formed through the combination, assimilation, and transformation of various nondramatic genres of choral lyric. ${ }^{48}$ But given the capacious and flexible nature of the generic character of different forms of nondramatic choral lyric, it is problematic to view these in turn as "primary" or "simple," so in the end it is perhaps more helpful still to think of tragedy as a "super-genre" instead. There seem to have been few (if any) limits set on the range of choral lyric that tragedy could include within a performance, and indeed in a song like the first stasimon of Troades Euripides gives the impression of drawing on almost every sort of lyric category of which we, as a modern audience, are aware. Certainly for its original Athenian audience allusions to other types of song would have been apparent as well-after all, this is the poet who, according to the character of Aeschylus in Aristophanes' Frogs, "takes material from everything: from whore songs, drinking songs by Meletus, Car-

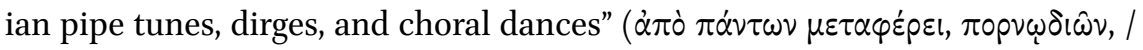

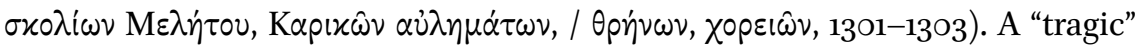
song can, it seems, be almost anything in terms of the forms and styles it includes, evokes, appropriates, and combines. In the end, what makes it "tragic" is its incorporation within a tragedy. If we believe Aristotle in the Poetics, the

47 On the Bacchae as dithyrambic and "new musical," see esp. Zimmermann 1992: 134; Csapo 1999-200o: 426. Battezzato (2005a: 163-164) also notes the remarkable generic consistency of Bacchae, especially in the parodos. On the mix of traditional and innovative mousike at work in the play, see Weiss 2018: 241-245. 
choral songs in tragedy became increasingly irrelevant to the plot, "thrown in" as embolima regardless of their context (1456a27-31) —in which case, at least in those plays surviving from the late 40os, we might expect to be able simply to remove such songs as distinct and generically classifiable without affecting the surrounding drama. But the extant fifth-century tragedies, even Euripides' latest plays, suggest that what also makes a song "tragic" is its deep connection to the dramatic narrative, in large part as a result of the different generic strands at work, their complex interactions with each other, and their resonances for the audience. 


\title{
Athens and Apolline Polyphony in Bacchylides' Ode 16
}

\author{
Margaret Foster*
}

"Despite the address to Pythian Apollo and the reference to paeans and choirs of Delphians, this ode is certainly not a paean since its main part (13-35) has nothing to do with Apollo."1 So begins Herwig Maehler's commentary on Bacchylides' Ode 16 (= Dithyramb 2). Ode 16 comprises a single triad:

[HPAK $\Lambda \mathrm{H} \Sigma($ VEL $\triangle$ HIANEIPA?)

$\mathrm{EI} \Sigma \Delta \mathrm{E} \Lambda \Phi O Y \Sigma]$

... .]!० . . . . . .

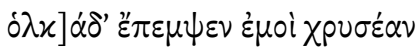

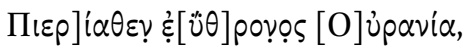

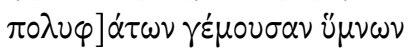

5

.....] ]

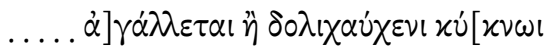

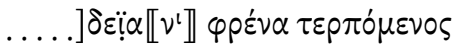

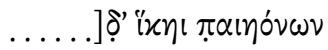

$\ddot{\alpha} \nu \theta \varepsilon \alpha \pi \varepsilon \delta 0 \circ \chi \nu \varepsilon i v$,

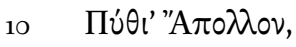

$\tau o ́ \sigma \alpha \chi \varnothing \rho \circ i \Delta \varepsilon \lambda \varphi \omega \hat{\nu}$

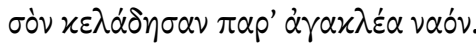

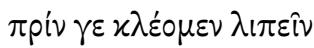

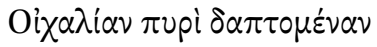

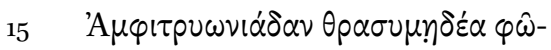

* I am grateful to audiences at UC Berkeley, Indiana University, University of Michigan, and the Society for Classical Studies for their comments on previous versions of this paper. I wish to thank especially Leslie Kurke and Naomi Weiss for their careful readings of earlier drafts of the paper. Their perceptive and generous suggestions have made it better.

1 Maehler 2004: 164. 


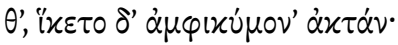

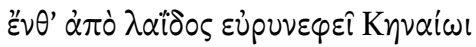

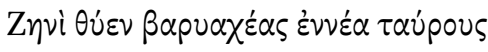

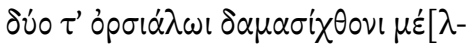

20

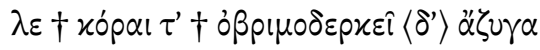

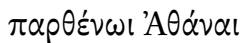

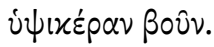

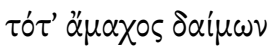

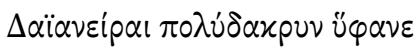

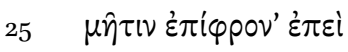

$\pi \dot{u}^{\prime} \theta \varepsilon \tau^{\prime} \alpha \gamma \varepsilon \lambda \lambda^{\prime} \alpha \nu \tau \alpha \lambda \alpha \pi \varepsilon \nu \theta \varepsilon \dot{\varepsilon} \alpha$,

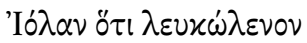

$\Delta$ iòs viòs $\alpha \dot{\tau} \tau \alpha \beta \beta \mu \mu \alpha \alpha \alpha \varsigma$

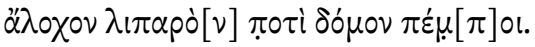

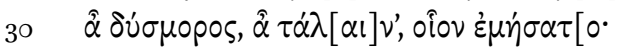

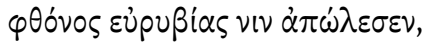

$\delta v o ́ \varphi \varepsilon \delta ́ v \tau \varepsilon x \alpha ́ \lambda \nu \mu \mu \alpha \tau \omega \hat{\omega}$

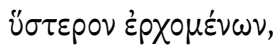

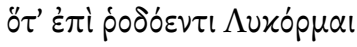

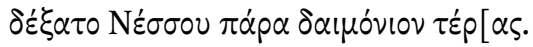

\section{[HERACLES (or DEIANEIRA?); FOR DELPHI]}

... since fine-throned Ourania has sent me from Pieria a golden cargo ship loaded with renowned songs ... upon the banks of the flowery Hebrus

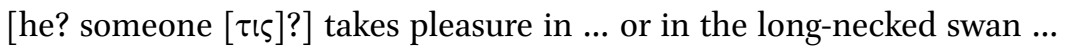
delighting his heart ... you come to pursue flowers of paeans, Pythian Apollo, as many as the choruses of Delphians are accustomed to sing beside your far-famed temple. But, first, we sing how the son of Amphitryon, the bold-planning mortal, left Oechalia devoured by fire and arrived at the promontory washed by waves; there from his spoils he was about to sacrifice nine deep-bellowing bulls to Zeus of Cenaeum, lord of spreading clouds, and two to the sea-rouser and earth-shaker, and a high-horned cow, unyoked, to the maiden Athena with the mighty glance. At that moment an irresistible daimon wove for Deianeira a sorrowful shrewd plan when she heard the distressing news that the intrepid son of Zeus was sending to his gleaming home white-armed Iole to be his wife. Ah, ill-fated, wretched woman, what a plan she devised!Widely powerful jealousy destroyed her and the murky veil covering what was to 
come when by the banks of rosy Lycormas she received from Nessus the fateful marvel. ${ }^{2}$

Ode 16's fragmentary strophe ranges over several figures and locations, including the Muse Ourania and Pieria and a swan at the Hebrus River, before coming to rest on an appeal to Pythian Apollo to pursue "flowers of paeans" (8-9) and a closing image of Delphian choruses singing around the god's temple. The poem then abruptly switches gears: with the onset of the antistrophe, it launches into a mythic narrative from which it never returns. The antistrophe and epode narrate the myth of Heracles and Deianeira or, more precisely, the events leading up to the hero's death at his wife's unwitting hands. The antistrophe centers on Heracles as he prepares to sacrifice to the gods at Cenaeum just before he is poisoned by Deianeira's gift of the deadly robe. The epode turns to Deianeira, her new awareness of Iole and resulting jealousy, and her ignorance of the future and true nature of the gift she once accepted from the centaur Nessus at the Lycormas River.

Maehler's paradoxical statement ("Despite the address to Pythian Apollo and the reference to paeans ... this ode is certainly not a paean") captures well Ode 16's resistance to generic classification along clear-cut taxonomic lines. Nevertheless, a broad scholarly consensus prevails concerning a number of the poem's features. First, since the poem's discovery in the late nineteenth century, scholars have almost unanimously agreed that the absent Apollo invoked in the strophe is returning to Delphi from his winter residence among the mythical, northern Hyperboreans. Second, based on the assumption that the ode's internal chorus is awaiting Apollo's return from the Hyperboreans to Delphi, most scholars also understand Delphi as the site of the ode's present performance. ${ }^{3}$ Third, since Dionysus is said to preside over Delphi in Apollo's absence, scholars argue that Dionysus must be the god whom Ode 16 ultimately celebrates. $^{4}$

This reconstructed scenario for Ode 16 - that a chorus, after signaling Apollo's imminent arrival, sings in the meantime for Dionysus - seems to hold up from the perspective of genre. Plutarch records that while Apollo is absent from Delphi during the three winter months, the Delphians leave off performing

2 The Greek text is from Maehler 2003, although at the end of line 10 I replace Maehler's period with a comma. The translation, discussed in detail below, is my own.

3 On Delphi as the site of Ode 16's performance, see, e.g., Burnett 1985: 125; Platter 1994: 337; Rutherford 1994-1995: 117; Maehler 1997: 150-151 and 2004: 165-166; Pfeijffer 1999a: 55; Wilson 2000: 322 n. 115; Fearn 2007: 237.

4 See, e.g., Fearn 2007: 237. 
paeans with their sacrifices and instead sing dithyrambs in honor of Dionysus (Mor. 389c). Accordingly, scholars will point to the strophe's "paeanic-like elements," including its reference to "flowers of paeans" (8-9), before assigning the extended mythic narrative of the antistrophe and epode to Dionysus' genre of dithyramb. ${ }^{5}$ Ian Rutherford captures well this understanding of the underlying myth and ritual context of Ode 16 and its implications for the poem's genre(s) when he designates Ode 16 as "a vital piece of evidence for a general contrast between paeans and dithyrambs in the fifth century." 6

Alongside discussions of Apollo and Dionysus' Delphic time-share and their respective genres, a debate has raged over the intertextual relationship between Ode 16 and Sophocles' Trachiniae. ${ }^{7}$ For the mythic narrative of Bacchylides' poem not only closely coincides with the plot of the tragedy but also exhibits thematic and dictional parallels strongly suggesting that one text sought to evoke the other. The most convincing arguments have demonstrated that Trachiniae is the earlier text and that Bacchylides presents a version of the myth of Heracles and Deianeira that meticulously corresponds to, even requires knowledge of, the idiosyncratic version of the myth found in the Sophoclean tragedy. ${ }^{8}$ And yet while many scholars agree on Trachiniae's chronological priority, far less attention has been devoted to considering the function of such a farreaching intertextual allusion to a tragedy within a nondramatic lyric poem. ${ }^{9}$

Further, Ode 16's extensive appropriation of Trachiniae has never been convincingly related to the belief that the ode was performed at Delphi. Scholars will point to a loose association between the poem's tragic material and Dionysus' presence at Delphi, but this vague Dionysiac connection does not satisfactorily explain why Bacchylides should wish for his lyric poem to interact so precisely with Trachiniae in particular. The result is that, in the secondary literature, Ode 16 is devoid of any compelling ritual occasion for its performance. What is more, from a formal perspective, Ode 16 also remains a severely

5 Quotation from Rutherford (1994-1995: 116). Maehler (1997:160) suggests that lines 1-10 could either be a cletic hymn or a paean. By contrast, Burnett (1985: 123) seems to view the entire poem as a paean. For the connection between mythic narratives and the genre of dithyramb, see especially D'Alessio 2013.

6 Rutherford 1994-1995: 117. For similar sentiments, see Campbell 1992: 213 and Maehler 2004: 165 .

7 Kenyon 1897: 148; Stoessl 1945: 58-63; Kamerbeek 1959: 5-7; Schwinge 1962: 130-132; Hoey 1979; Burnett 1985: 194-195 n. 27; March 1987: 62-66; Davies 1991: xxxii-xxxiii; Maehler 1997: 151-156 and 2004: 166-167; Pfeijffer 1999a: 51-55; Carawan 200o; Riemer 200o; Kyriakou 2011: 535-538.

8 See especially March 1987: 62-66; Pfeijffer 1999a: 52; Maehler 2004: 167. For the various ways in which Ode 16 alludes to Trachiniae, see Part II below.

9 Pfeijffer 1999a presents an exception to this tendency. 
disjointed poem: its strophe recalling Apollo from the Hyperboreans seems irreconcilably at odds with the "dithyrambic" antistrophe and epode that is both in honor of Dionysus and somehow connected to Sophocles' Trachiniae. These interconnected problems merit a careful reexamination of Ode 16, especially its fragmentary strophe, and merit as well a concerted effort to situate the poem within the evolving and dynamic generic economy of fifth-century choral song.

This paper offers a new reading of Ode 16 and argues that the poem does not await Apollo's Delphic homecoming and is not a dithyrambic poem in honor of Dionysus. The paper falls into two parts. Part I begins with a formal analysis of the fragmentary strophe followed by a consideration of its relationship to the antistrophe and epode. Just as the poem itself is divided into three stanzas, so too the opening strophe consists of three scenes or vignettes. These vignettes map onto three distinct sites, Pieria (1-4), the Hebrus River (5-7), and Delphi (8-12). Taking each of these vignettes in turn, I will argue through a series of close readings that, contrary to the established view, the strophe does not relate an episode from the myth of Apollo's return from the Hyperboreans nor does it indicate that the poem's present performance takes place at Delphi. Rather than tracking Apollo's own movements, the strophe showcases the movement of music by presenting a sequence of generically distinct songs, all tied to discrete geographical locations and all sung in honor of Apollo. When we turn to the opening of the antistrophe, we find that this sequence of songs continues here as Bacchylides shifts from simply listing different song types to presenting an entire song itself, that is, the song comprising the mythic narrative of the antistrophe and epode. Viewed from this angle, Ode 16 can be seen as a polyphony of independent songs, all, including the mythic narrative, sung in honor of Apollo, and yet all presented as in some sense autonomous and separate from one another. ${ }^{10}$

Part II contextualizes this sequence of autonomous songs by suggesting a new ritual occasion for Ode 16, an occasion that places the poem's performance in Athens, not Delphi. Other scholars have mentioned Athens in passing as the possible site of Ode 16's performance, but I offer a more specific context, the Athenian Thargelia. This proposal brings with it a new way of understanding

10 My use of the term polyphony derives from its technical sense: Merriam-Webster defines polyphony as "a musical composition employing two or more simultaneous but relatively independent melodic lines." I modify this definition slightly in reference to Ode 16: its "independent melodic lines" are the autonomous songs (note the $\pi 0 \lambda \nu \varphi] \alpha \dot{\tau} \omega \nu . . . \ddot{\nu} \mu \nu \omega \nu$ at line 4) within it that, although they do not occur simultaneously, all share the space of a single poem. 
Ode 16's explicit allusions to Sophocles' Trachiniae and, more generally, to the genre of tragedy. After reviewing Ode 16's connection to Trachiniae, I will conclude by suggesting that the new formal and historicizing interpretations of Ode 16 explored here allow us to glimpse a larger cultural phenomenon at work: they allow us to understand the poem as a conscious response to tragedy as the "super-genre" of the Athenian empire and to view the poem itself as a vehicle for moving this distinctively Athenian generic form beyond the borders of Attica. ${ }^{11}$

\section{Part I: A Cargo Ship of Songs}

\section{Vignette 1: Pieria}

The ode's own point of departure coincides with the departure of a cargo ship, dispatched from Pieria and brimming with songs (1-4):

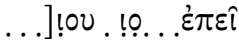

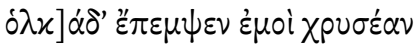

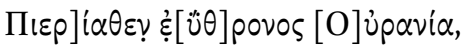

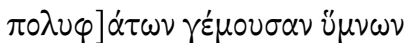

since fine-throned Ourania has sent me from Pieria a golden cargo ship loaded with renowned songs

Boris Maslov's work on Pindar's epinicia allows us to make two crucial observations about the metapoetic function of these opening lines. First, in contrast to Pindar, Bacchylides always explicitly names the Muse he calls upon to sanction his poetry, and the name he most often bestows upon her is Ourania. ${ }^{12}$ As Maslov asserts, this tactic operates as a metapoetic way for Bacchylides to signal, and so authorize, his individual poetic "brand."13 By announcing that it is his personal Muse Ourania who has sent "hymns to me," Bacchylides announces his singular poetic authority. ${ }^{14}$

Second, Maslov's insights into the semantics of $u_{\mu \nu}{ }^{\circ}$ s illuminate the nature of the songs $(\ddot{u} \mu \nu \circ, 4)$ stowed aboard this cargo ship. Even as $\ddot{u} \mu \nu \circ$ comes

\footnotetext{
11 I borrow the term "super-genre" in reference to tragedy from Weiss (this volume).

12 Maslov 2015: 99-100.

13 Quotation from Maslov 2015: 100.

14 The announcement of a Greek lyric poet's "brand" is, as Maslov (2015: 99-100) notes, a sphragis-like moment. Since Bacchylides is showcasing in this way his individual poetic authority, દ̇uoi (2) must refer to the poet and not to the chorus (contra Maehler 2004: 168).
} 
to refer generally to songs of praise in the fifth century, it never fully loses its associations with choral lyric and cult. ${ }^{15}$ These associations suggest that we are meant in Ode 16 to imagine the Muse's freight as songs that are tied to a cult location and that anticipate performances by choruses, associations that the unmarked $\alpha$ oı $\delta$ ', for instance, would not necessarily convey. Yet more pertinent

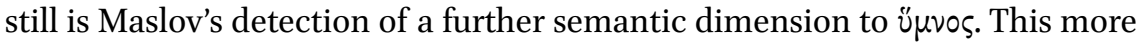
enigmatic nuance is activated when the word appears within a particular cluster of textual elements found in several Pindaric epinicia. In Olympian 1 and Nemean 1, $\ddot{u} \mu \nu 0 \varsigma$ occurs at the beginning of the poem and as part of a construction that includes $-\theta \varepsilon \nu$ (whence) + epithet + $\ddot{\mu} \mu \nu \circ(O .1 .8-10$ and $N .1 .4-6) .{ }^{16}$

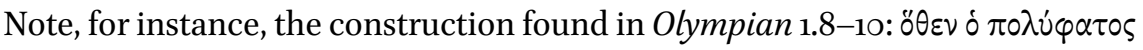

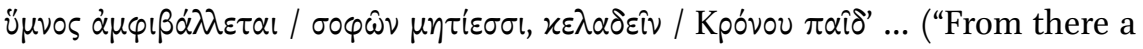
renowned $\ddot{u} \mu \nu \circ$ s enfolds the thoughts of wise men so that they sing the child of Cronus ..."). Similarly, at the opening of Nemean 3, a ü $\mu \nu 0 \varsigma$ (again with an epi-

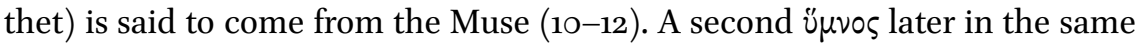
poem travels out from Zeus' cult to its human chorus $\left(65^{-66)} \cdot{ }^{17}\right.$ In these examples, the word's general cultic associations are more explicitly defined: $u \mu \nu \circ \varsigma$ is not just connected to cult but is shown to derive from cult.

This observation has significant implications, as Maslov recognizes. For it exposes how a ü $\mu \nu \circ \varsigma$ can perform an agent-like function as it mediates between its divine cultic origin and the world of its poet and chorus. Moreover, it reveals how, in its role as mediator, a ü $\mu \nu \circ$ is conceived of as something initially independent of and prior to the poet's own creation. That is, in these epinician contexts, ن̌ $\mu \nu \circ \varsigma$ possesses a striking degree of autonomy. ${ }^{18}$ Such a semantic force produces a paradox insofar as Pindar can foreground a ü $\mu \nu \circ \varsigma^{\prime}$ autonomy and agency within an epinician at the same time as he asserts his own active role as poet in the epinician's creation..$^{19}$ Maslov accounts for this paradox by positing a twofold signification of the meaning of ü $\mu \nu \circ$ s: the word seems simultaneously to denote the "text that evokes, and instantiates, goodwill/graciousness/praise"

15 Maslov 2015: 292-293, 302.

16 The two Pindaric examples also both exhibit a present-tense finite verb + purpose infinitive.

17 For these lines, see Maslov 2015: 304.

18 Thus Maslov (2015: 305) calls the poet both an "epiphenomenon" and a "passive conduit" of the üpvos. See too Maslov 2015: 303: "hymnos belongs to the divine sphere; it is then appropriated by the poet who, finally, adapts it to real-life performance. Notably, even at this last stage of materialization hymnos retains an autonomy and agent-like quality: it possesses the chorus" (emphasis in original). 
as well as "goodwill, disposition to praise itself." 20 That is, because ü $\mu \nu \circ \varsigma$ signifies the verbal act of divinely generated praise, and not just the text that is the product of that act, the word can point to or embody a stage in its own evolution that predates the eventual poetic composition of the $\tilde{u} \mu \nu \circ \varsigma$ by the poet.

To return to Ode 16 , I draw attention to how the ü $\mu v 0$ เ of line 4 share a number of formal features with these epinician instances of the word. Ode 16's ü $\mu$ vor also appear at the opening of the poem and also arise from a specific cultic loca-

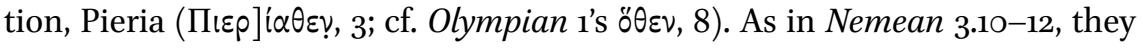
announce that they come from a Muse and, as in Olympian 1.8, they seem to be called $\pi \circ \lambda$ í $\varphi$ $\tau 0$. Given these formal similarities, I suggest that Bacchylides' u $\mu \nu$ o express a comparable semantic nuance to the Pindaric examples. For Ode 16 's $u$ u $\nu$ เ also perform a mediating, agent-like function, as the image of the ship of songs sailing out from Ourania to the poet captures so well. Moreover, as in Pindar's epinicia, these ü $\mu \nu$ o are initially independent of the poet, since they are sent to him by Ourania. As such, they can be seen to possess a degree of autonomy. In fact, I would extend Maslov's argument further here and argue that in the case of Ode 16, which presents a plurality of ü $\mu \nu$ ol, we should understand these songs not merely as autonomous in relation to the poet but also as autonomous in relation to one another.

It is perhaps because of this shared semantic nuance with Pindar's epinicia that the opening of Ode 16 achieves its epinician resonance. In addition to sharing the cluster of formal features that also attend the $\ddot{\mu} \mu \nu$ of olympian 1 and Nemeans 1 and 3, Bacchylides' choice of the word $\dot{\partial} \lambda x \alpha$ s (cargo ship, 2) may also trigger Ode 16's initial epinician sound. The word is extremely rare in poetry but does occur prominently in the opening lines of Nemean 5 where Pindar connects it to his own song. In short, by linking o $\lambda x \alpha \dot{\alpha} \varsigma$ so closely with

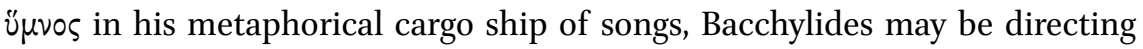
us to apply to these particular ü $\mu \nu$ o the associations of autonomy and agency found in epinician. ${ }^{21}$ Maslov posits the antiquity, even the pre-Greek nature, of this semantic dimension of ü $\mu$ vos, but it may well be that this nuance comes to be associated with the genre of epinician. ${ }^{22}$ If this is the case, then Bacchylides

20 Quotation from Maslov 2015: 303.

21 In Nemean 5, Pindar enjoins his song to "go forth from Aegina on every cargo ship and

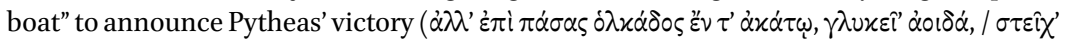
$\dot{\alpha} \pi^{\prime}$ Airivas, 2-3). Nemean 5 is an early epinician (ca. 483 BCE) and must predate Ode 16. If Bacchylides is indeed responding to this particular Pindaric image, he simultaneously inverts it: rather than a single song traveling on every ship, in Ode 16 a single cargo ship contains a multiplicity of songs. This inversion may help to signal that Bacchylides' poem is ultimately up to something different than its epinician predecessor. 
conjures this genre as a way to assert the agent-like and autonomous properties of his cargo ship of ü $\mu$ vo. ${ }^{23}$

Bacchylides thus contructs the opening of Ode 16 as a metapoetic frame in which he asserts his own literary authority. At the same time, through a cluster of dictional cues, he directs us to apply to his $u_{\mu \nu} \mathrm{r}$ a function and meaning of the word found in epinician. In so doing, Bacchylides activates $\ddot{u} \mu \nu \circ \varsigma^{\prime}$ capacity for autonomy. Yet, in so far as these $u_{\mu \nu}$ o are stored together aboard a single cargo ship, he also reveals their potential for collaboration. In this way, Ode 16's metapoetic opening establishes one of the poem's central themes: the polyphony of autonomous songs. I turn now to trace this theme in the rest of the poem.

\section{Vignette 2: The Hebrus River}

Following this metapoetic opening, the fragmentary lines of Ode 16 resurface next at the banks of the northern Hebrus River $\left(5^{-7}\right)$ :

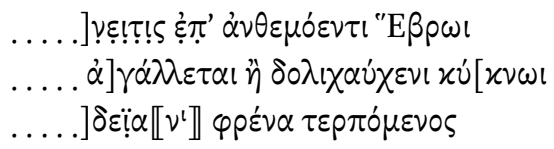

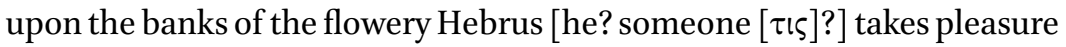
in ... or in the long-necked swan ... delighting his heart ...

For Maehler and others, these lines explicitly call to mind Alcaeus fr. $307 \mathrm{c}$. Alcaeus fr. 307c comes to us in the form of a prose summary by the fourthcentury CE rhetorician Himerius. Because this fragment has traditionally played a leading role in the interpretation of Ode 16, I quote it here in full (Alcaeus fr. 307c = Himerius Orations 48.10-11 [pp. 200-201 Colonna]):

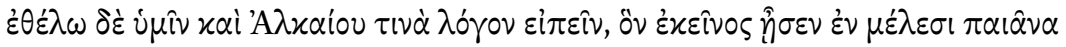

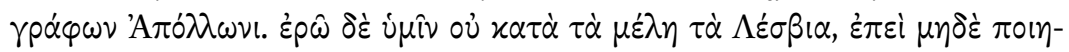

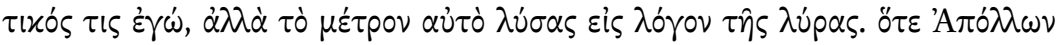

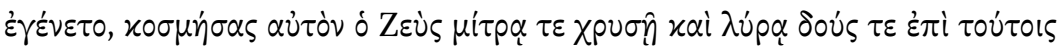

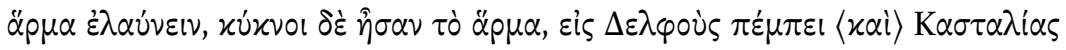

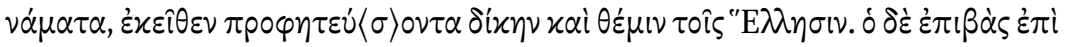

23 At another level, this epinician resonance may anticipate the poem's own encapsulation of Trachiniae and that poem's leveraging and subsequent complication of Heracles' status as an epinician hero. See Swift 2011 for how Trachiniae makes uses of epinician language as well as Heracles' traditional characterization in epinician for its own tragic ends. 


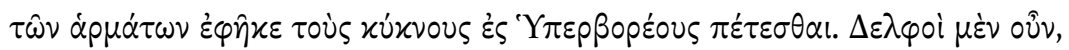

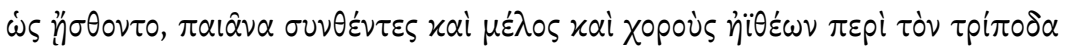

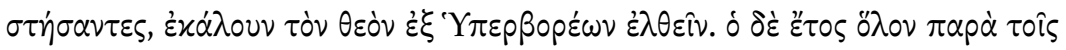

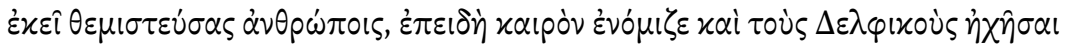

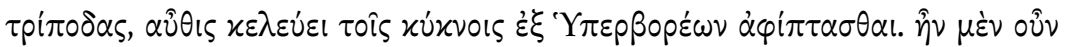

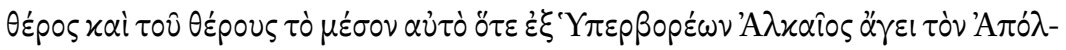

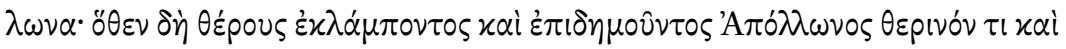

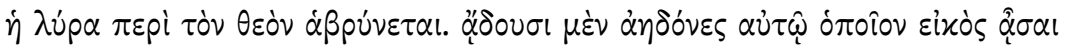

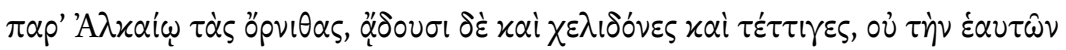

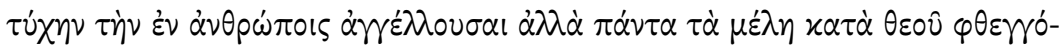

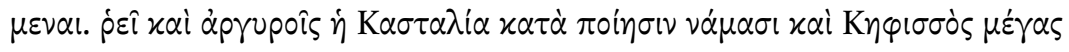

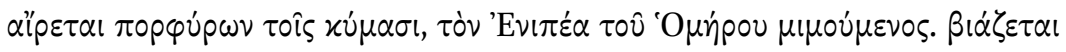

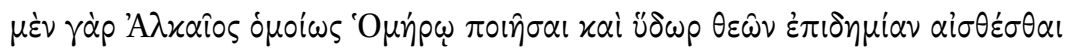

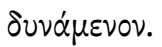

I wish to tell you a tale of Alcaeus, which he sang in lyric verse when he wrote a paean to Apollo; and I shall tell it not in the Lesbian verses, since I have nothing of the poet in me, but changing the actual metre of the lyre into prose. When Apollo was born, Zeus equipped him with golden headband and lyre and gave him also a chariot of swans to drive, and sent him to Delphi and the spring of Castalia, thence to declare justice and right for the Greeks; but when Apollo mounted the chariot he directed the swans to fly to the land of the Hyperboreans. Now when the Delphians learned this, they composed a paean and a tune and arranged dancing choirs of youths around the tripod and called on the god to come from the Hyperboreans. Apollo, however, delivered law among the men of that region for a full year; but when he thought it was time that the tripods of Delphi should ring out too, he ordered his swans to fly back again from the Hyperboreans. Now it was summer and indeed the very middle of summer when Alcaeus brings Apollo back from the Hyperboreans: so what with the blaze of summer and the presence of Apollo the poet's lyre also adopts a summer wantonness in the account of the god: nightingales sing for him the kind of song that one might expect birds to sing in Alcaeus, swallows too and cicadas, not proclaiming their own fortunes in the world but telling of the god in all their songs. Castalia flows in poetic fashion with waters of silver, and great Cephisus rises in flood, surging with his waves, in imitation of Homer's Enipeus: for Alcaeus is compelled just like Homer to give even water the power to sense the presence of gods.

Trans. D.A. CAMPBELL 
Alcaeus' account, as paraphrased by Himerius, encourages Maehler to reconstruct Ode 16's scene at the Hebrus River as a stopover for Apollo as the god travels south on his swan chariot from the Hyperboreans to Delphi. ${ }^{24}$ Even a cursory reading of Himerius' text, however, reveals several discrepancies between it and Ode 16. Himerius' paraphrase does not mention the Hebrus or, more generally, a sojourn of Apollo en route to Delphi. Ode 16, in turn, refers neither to the Hyperboreans nor to a swan chariot.

I note as well a more substantial issue. The long-accepted view that Apollo breaks his southward journey on the banks of the Hebrus in Ode 16 relies on taking the god as the subject of this vignette's main verb, $\dot{\alpha}] \gamma \dot{\alpha} \lambda \lambda \varepsilon \tau \alpha \mathrm{l}$ (6). Yet this reading is not secure. The first visible traces of the fragmentary line 5 seem to be

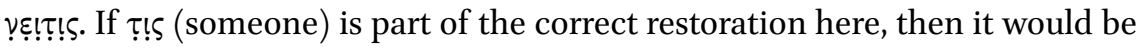
the subject of $\dot{\alpha}] \gamma \dot{\alpha} \lambda \lambda \varepsilon \tau \alpha$. This restoration causes problems for Maehler's image of Apollo at the Hebrus even as he takes $\tau \iota \zeta$ seriously as a possible option. As he

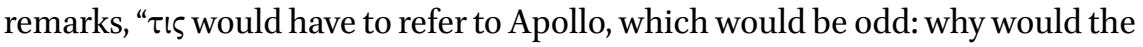
god not be named?"25 Rather than attempt to reconcile Apollo with $\tau \iota \varsigma$, however, we should instead consider the possibility that this "someone" refers to someone other than the god. In so doing, we might compare this $\tau i \varsigma$ to its other, frequent occurrences within the Bacchylidean corpus, including in Odes 3.21-

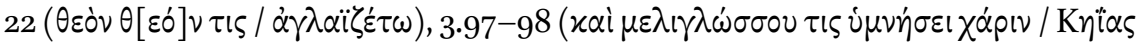

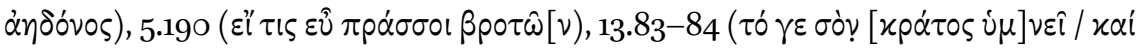

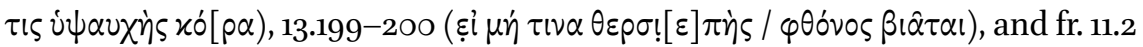

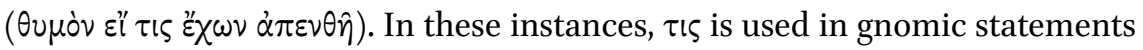
(as in Ode 5.19o and fr. 11.2, where the $\tau \iota \zeta$ is also preceded by $\varepsilon l$, as it seems to be in Ode 16) and is also found in contexts of celebratory singing (for example, Odes 3.97-98 and 13.83-84). It is conceivable that a generic "someone," and not Apollo, is the subject in these lines in Ode 16 and that the scene depicts a customary or habitual event. Although the $\tau \iota \varsigma$ does not seem to be singing himself in this passage, as he/she is in Odes 3 and 13, he is delighting in music: as we will soon see, this vignette's collocation of the swan and the Hebrus is evocative of song and is an image linked specifically to Apolline music.

For now, we cannot determine with any certainty the subject of this vignette.

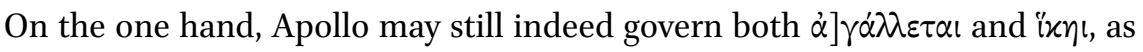
most editors assume. On the other, as the parallels discussed below demonstrate, swans and rivers do not require Apollo's physical presence in order to be paired together, and the subject who enjoys the swan's music may well be

24 Maehler 2004: 165-166. See also Calame 2013: 344 on these lines: "The god clearly breaks his journey [from the Hyperboreans to Delphi] to enjoy the melodious song of a swan."

25 Maehler 2004: 168. 
an unnamed $\tau \iota$ instead. ${ }^{26}$ We should, therefore, not assume that Apollo himself is at the Hebrus and accordingly use that assumption as a way of reconstructing the strophe's larger scenario of the god's return from the Hyperboreans.

I turn instead to two other possible parallels for this vignette. First, the undateable, brief Homeric Hymn to Apollo (21) offers a swan at another northern river, the Peneus $(21.1-5)$ :

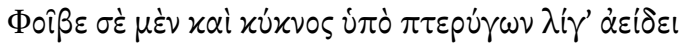

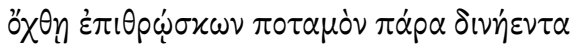

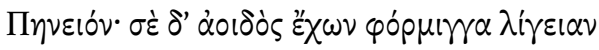

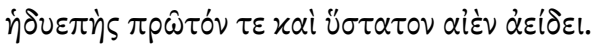

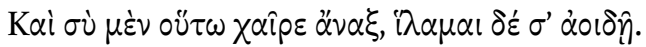

Phoebus, even the swan sings of you in a clear tone to the beating of its wings as he alights upon the bank beside the eddying Peneus River; and the sweet-speaking bard, holding his clear-toned lyre, always sings of you both first and last. So too, greetings, lord; I seek your blessing with my song.

Second, a choral ode in Aristophanes' Birds places swans on the banks of the Hebrus, the same river found in Ode 16 (769-784):

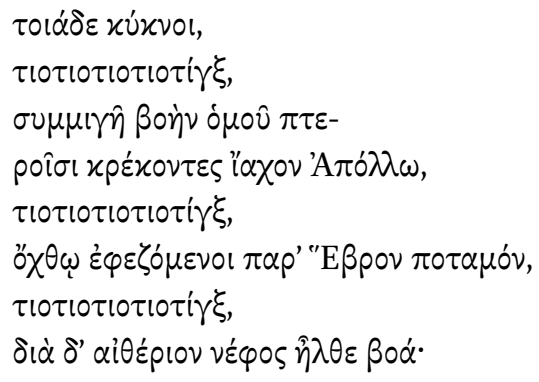

$26 \quad$ Understanding $\tau \iota \varsigma$ as the subject of $\dot{\alpha}] \gamma \dot{\alpha} \lambda \lambda \varepsilon \tau \alpha$ l also eliminates the need to explain why Apollo is first referred to here in the third person and then, only two lines later, in the second person with 'ínı (8). A survey of Bacchylides' extant epinicia and dithyrambs suggests that such a shift from the third to second person is unparalleled, although editors pass over this discrepancy and thus must not view it as particularly abrupt. Ode 19.8-14 may be a rough analogue. Morphologically, ǐ $₹$ ı could also be a third person singular (present subjunctive, from i $i \omega$ ), although I find it more likely that this verb (with its attendant image of pursuing flowers of paeans) belongs with the vocative address to Pythian Apollo in the following line. 


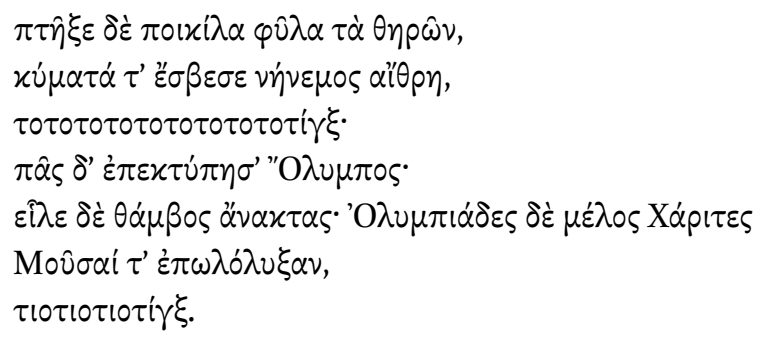

Just so did swanstio tio tio tio tinx!beating wings in unison raise a harmonious whoop for Apollotio tio tio tio tinx!gathered on the bank by Hebrus Rivertio tio tio tio tinx! their whooping pierced the cloud of heaven; the manifold tribes of beasts were cowed, and the cloudless clear air quenched the wavesto to to to to to to to to tinx!All Olympus reverberated, amazement seized its lords, and the Olympian Graces and Muses replied in cheerful songtio tio tio tio tinx!

Trans. J. HENDERSON

In both passages, we encounter swan(s) honoring Apollo through the sound created by their wings alighting on a river bank. The quality of these sounds is characterized in both passages as musical: in the Homeric hymn, the swan's wings are linked to its ability to sing ( $\dot{\alpha} \varepsilon \dot{\delta} \delta \varepsilon ı)$ while, with greater detail, Aristo-

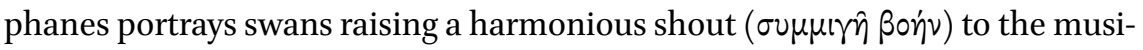

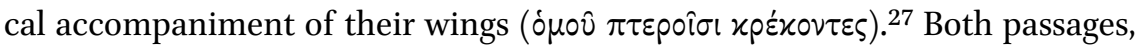
then, foreground the river bank not because it is a resting place for a southbound Apollo but because it is a place that generates a particular kind of music for the god through the sound of swans alighting upon it. It is also worth noting that these passages both juxtapose swan music to another form of singing

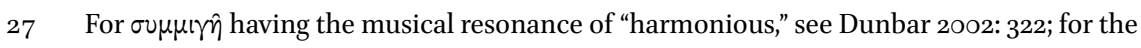

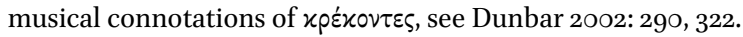


performed by another kind of singer. Thus, in the Homeric hymn's paratactic sequence, we are told that the swan sings for Apollo ( $\dot{\alpha} \varepsilon \dot{\delta} \delta 1,1)$, and the bard sings for him as well ( $\dot{\alpha} \varepsilon \dot{\delta} \delta \varepsilon l, 4)$. In Birds, the Muses and Graces on Olympus

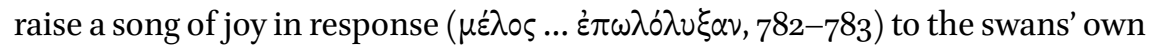
musical outburst for Apollo.

In light of these juxtapositions, I note that Alcaeus fr. 307c itself presents a similar string of discrete but comparable forms of singing. This feature of the fragment is typically overlooked in favor of tracking the course of Apollo's own travels within the passage. Yet, in Himerius' paraphrase, Alcaeus' closing image includes assorted creatures performing in honor of the god's return from the Hyperboreans: "Nightingales sing for him the kind of song that one might expect birds to sing in Alcaeus, swallows too and cicadas, not proclaiming their own fortunes in the world but telling of the gods in all their songs." ${ }^{28}$

A passage from Plutarch conforms to this pattern as well. In connecting swans to Apollo, Plutarch lists their singing as one of the various types of musi-

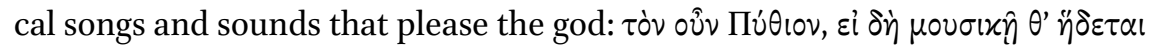

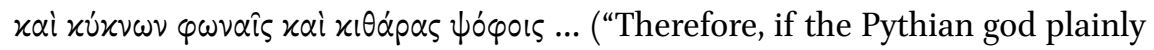
finds pleasure in music and the songs of swans and the sound of lyres ...," Mor. $387 \mathrm{c}$ ). These instances, then, all suggest that the music made by swans can occur as part of a larger motif that presents a pairing or sequence of different Apolline forms of music-making.

To return to Ode 16, it is not likely that the poem's reference to the swan and the Hebrus depict a resting place at the river as Apollo returns from the Hyperboreans, a reconstructed mythic scenario lacking extant parallels. ${ }^{29}$ Rather, the swan and the river seem to signal the poem's interest in the kind of music swans are known to make upon river banks in Apollo's honor, a connection for which parallels do exist. We are further encouraged to understand the swan in Ode 16 as a reference to swan music if we accept Maehler's restorations for the beginning of line 7. On the papyrus, the last letter of the first visible word in the line, $v$, was crossed out and replaced by a superscript iota $\left.(\ldots ..] \delta \varepsilon i ̣ \llbracket \llbracket v^{\imath} \rrbracket\right)$. Maehler suggests that the letters $\ddot{i} \alpha$ of this cluster thus represent $i \hat{\alpha} \iota$ (voice) and connects the word to the swan in the line above. In addition, he proposes $\mu \varepsilon \lambda(\alpha] \delta \varepsilon\langle\hat{\imath}\rangle$ (honey-sweet) for the preceding lacuna, citing a number of other

28 See also Pl. Phd. $84 \mathrm{e}-85$ b, in which the singing of swans is mentioned in relation to a series of other birds' singing (that of the nightingale, swallow, and hoopoe) and swan song is again connected to Apollo.

29 Alcaeus fr. 43 does mention the Hebrus River but in a completely different context and one that does not mention Apollo: it relates instead the course of the river and describes it as a place where young women bathe. 
parallels for the mellifluous singing of swans. ${ }^{30}$ If Maehler is correct, such a restoration would form another connection with both the Homeric hymn and the Birds passages. In both of these passages, the sound of swan wings on the river bank form the accompaniment to the swans' own cries or singing. In Ode 16 , we might have a similar collocation of the swan's voice ( $(\hat{\alpha} \hat{\imath})$ and the music of their alighting upon the Hebrus.

Second, I would suggest that the motif of presenting pairs or larger sequences of songs for Apollo found in the examples above seems to occur in Ode 16 as well. For Bacchylides clearly contrasts the swan in line 6 to another

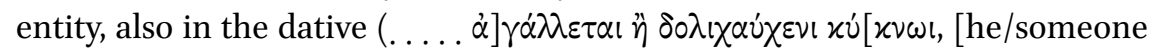
delights in ... or in the long-necked swan ..., 6]). To fill the lacuna, Maehler offers $\mu \circ \sigma_{\sigma \alpha l}$ (muse) and $\mu \circ \lambda \pi \hat{\alpha} \mathrm{l}$ (song) as possible restorations. ${ }^{31}$ These suggestions are intriguing because either possibility would bolster what appears to be the overarching import of these lines, namely, their concern with music or, more specifically, with the juxtaposition of different types of music.

I have proposed in this section that the vignette comprising lines $5^{-7}$ does not in fact depict a scene from the myth of Apollo and the Hyperboreans or model itself on the version of the myth found in Alcaeus fr. 307c. Rather, I would argue that these lines, however fragmentary, reveal themselves to be one instantiation of a widespread motif that links swan music to other forms of singing in honor of Apollo by other discrete types of singers. Put another way, Ode 16 partakes in a larger cultural tendency to present Apollo as a god who inspires instances of polyphony by rousing a veritable cosmos of diverse singers (insects, swans, bards, the Muses themselves) to delight him with their own distinctive music.

\section{Vignette 3: Delphi}

With this conclusion in mind, let us turn to the final vignette of the strophe as well as to the opening line of the antistrophe that moves the poem into its mythic narrative. Before considering the interpretation of these lines, it is worth reviewing Maehler's analyses of this portion of the poem since they best represent a generally accepted approach to this problematic and lacunose passage. As we will see, the established approach to the strophe's ending and the beginning of the antistrophe has far-reaching implications for our sense of Ode 16 as a whole and, more broadly still, for our understanding of the relationship between ancient categories of genre.

$30 \quad$ According to Maehler (2004: 168), since diaeresis frequently occurs over intial iota in this papyrus, the $\ddot{i}$ (in ..... $\left.] \delta \varepsilon \ddot{\alpha} \alpha \llbracket \nu^{\imath} \rrbracket\right)$ could well be the beginning of a new word.

31 On the lacuna of line 6, Maehler (2004: 168) notes, "a dative seems likely in the gap." 
The two primary issues within this portion are the opening lacuna of line 8 and the meaning of $\tau \dot{\sigma} \sigma \alpha$ in line $11(8-13)$ :

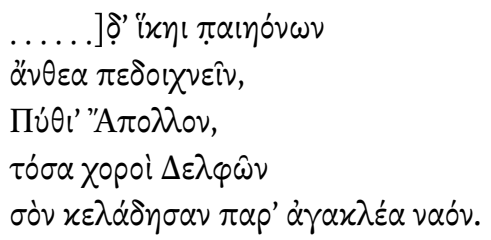

$\pi p^{\prime} \nu \gamma \varepsilon x \lambda \varepsilon \dot{\sigma} \mu \mu \varepsilon \nu \lambda เ \pi \varepsilon i \nu$

... you come to pursue flowers of paeans, Pythian Apollo, as many as the choruses of Delphians are accustomed to sing beside your far-famed temple. But, first, we sing [how the son of Amphitryon] left [Oechalia] ...

Maehler's own translation of this stretch of lines is again linked to his view of the strophe's close kinship with Alcaeus fr. 307c. First, following Paul Maas, Maehler argues that only two syllables are required in the lacuna of line 8 and

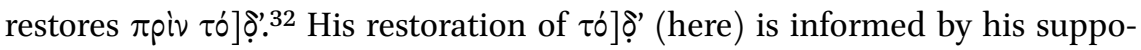
sition that the present poem was performed at Delphi as the Delphians await Apollo's return from the Hyperboreans. Maehler's translation of lines 8-10 thus reads "until you come here, Pythian Apollo, to go after flowers of paeans." 33

Second, Maehler takes $\tau \dot{\sigma} \sigma \alpha$ as a demonstrative pronoun and accordingly translates the subordinate clause as "these things (or 'this much') ( $\tau \dot{\sigma} \sigma \alpha)$ the

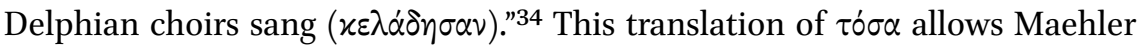
to interpret the preceding lines of the strophe as a quotation of what was sung and, drawing on the paradigmatic Alcaeus fragment, to suggest that the entire strophe can be characterized as a kind of cletic hymn performed by the Delphians to recall Apollo from the Hyperboreans. ${ }^{35}$ The Alcaeus passage does mention that the Delphians composed a paean and a song and set up choruses for the absent Apollo. Yet it is unclear from Himerius' summary whether

32 Maas 1921: 23 n. 2. As Maehler (2004: 168) notes, this use of $\pi$ piv paired with ixn would be in keeping with other uses of $\pi$ pi $v$ with the subjunctive (without $\alpha \nu$ ) that denote an anticipated or recurring event.

33 Maehler 2004: 168.

34 Maehler 2004: 169. He cites several parallels in which this demonstrative pronoun follows a direct speech. See also Uhlig 2017, who discusses this passage as an example of oratio recta and connects this feature to the poem's own conceptualization of reperformance.

35 As Maehler (2004: 169) concludes, the strophe is "rather similar to Alcaeus' hymn." See also Maehler 2004: 164-165. Cf. the similar assessment by Burnett 1985: 193 n. 14. 
the Alcaeus fragment was itself considered a cletic hymn, as Maehler seems to assume. If it were a cletic hymn, it would present itself as a strangely ineffective version of one, since part of the point of mentioning the Delphians' singing in the passage seems to be to highlight its inadequacy at attracting the god's attention: in the summary, Apollo appears to ignore the Delphians when, following the Delphians' choral solicitations, he decides to remain among the Hyperboreans for an entire year instead of heading straightaway to Delphi. That is to say, the Alcaeus fragment once again seems not to correspond with what is taking place in Ode 16.

We are on firmer ground, at least in terms of the state of the papyrus, when we move from the strophe to the antistrophe. The end of the strophe is followed by a strong break, marked by the antistrophe's opening $\pi p^{\prime} \nu \gamma \varepsilon x \lambda \varepsilon \dot{\varepsilon} \mu \varepsilon \varepsilon v$. This use of $\pi$ i iv seems best taken as an adverb and Maehler translates the phrase as "beforehand, we tell ..." ${ }^{36}$ This phrase initiates the extended mythic narrative of the antistrophe and epode.

Maehler's analysis of the transition between the strophe and antistrophe again exemplifies the traditional line of interpretation. His analysis relies on connecting the mythic scenario of Alcaeus fr. 307c to a passage from Plutarch referred to briefly above (Mor. 389c). In Plutarch's passage, the Delphians cease from singing paeans during the three winter months when Apollo is absent and instead sing dithyrambs for Dionysus. According to Maehler's argument, since the strophe, like the Alcaeus fragment, envisions Apollo returning from the Hyperboreans, the antistrophe and epode consequently cast themselves as a performance taking place in the interim at Delphi. Enlisting Plutarch's assertion that the Delphians honor Dionysus with dithyrambs while Apollo is away, Maehler concludes, "If, as seems likely, this statement reflects fifthcentury practice, $\mathrm{B}$ [acchylides'] ode could well be such a dithyramb, performed at Delphi during the winter months before Apollo's return."37 While Maehler goes further than most scholars in his careful efforts to excavate Ode 16's ritual occasion, I emphasize again that there is seemingly universal acceptance that

36 See Maehler 1997: 16o-161 and 2004:169, where he presents his justification for taking $\pi$ piv as an adverb instead of a conjunction and also makes the case for understanding $x \lambda \varepsilon \dot{\varepsilon} \propto \mu \varepsilon \nu$ as a present indictive instead of an imperfect (i.e., $\left.\pi \rho^{\prime} \nu \gamma^{\prime} \varepsilon^{\prime} \chi \lambda \varepsilon \dot{\varepsilon} \rho \mu \varepsilon \nu\right)$.

37 Maehler 2004: 165. In light of this conclusion, Maehler (1997: 150) proposes a possible ritual occasion: he tentatively suggests the performance context of the Delphic Theoxeny, which celebrated Apollo, Leto, and Dionysus together, as the original occasion for Ode 16. If, as he speculates, the Theoxeny began before Apollo's return and culminated in his epiphany (although there is no evidence for this scenario), Ode 16 could have been performed at the beginning of the Theoxeny before the god's return. This scenario is picked up and more forcefully asserted by Calame 2013: 344 . 
the poem was performed at Delphi. ${ }^{38}$ This acceptance extends to the restoration of the poem's title as EI $\Sigma \mathrm{E} \Lambda \Phi O Y \Sigma$ (For Delphi), albeit in brackets, in the major editions of Bacchylides, including the Budé, Loeb, and Teubner.

In short, the traditional interpretation, exemplified by Maehler but articulated by numerous scholars, can be summarized as follows: Ode 16 was performed at Delphi by a chorus awaiting Apollo's return from the Hyperboreans, a return solicited by the strophe's invocation. This reconstruction, in turn, elicits a particular understanding of the poem's genre(s): following the strophe's explicit reference to Apollo's genre of the paean, the poem then shifts generically to the dithyrambic mythic narrative of the antistrophe and epode and, in so doing, implicitly honors Dionysus, the god in residence at Delphi during the present performance.

Before offering an alternative reading, I would like to identify several interrelated problems with this reconstruction. First, this argument relies heavily on both the Alcaeus and Plutarch passages to reconstruct the original performance context of Ode 16 and, in so doing, necessarily views them as complementary texts. We have already found that the Alcaeus fragment in and of itself poses problems as a paradigm for Ode 16. But I note here a further issue, namely, that Alcaeus and Plutarch are not telling quite the same myth. Alcaeus' myth emphasizes Apollo's initial avoidance of Delphi in favor of the Hyperboreans and asserts that, after a year among the Hyperboreans, his eventual arrival to Delphi took place in mid-summer. By contrast, Plutarch's anecdote concerns Apollo's annual return from the Hyperboreans and places this yearly event at the end of winter. Alcaeus and Plutarch deploy Apollo's connection to the Hyperboreans for different aetiological ends. Accordingly, their joint explanatory power for illuminating Ode 16 should be questioned.

Second, this reconstructed context produces an internal temporal disjunction or incoherence between the strophe's $\tau \dot{\sigma} \sigma \alpha . . . \kappa \varepsilon \lambda \alpha^{\prime} \delta \eta \sigma \alpha \nu$ (these things ... they sang, 11-12) and the antistrophe's opening $\pi \rho i \nu \gamma \varepsilon x \lambda \varepsilon$ \&́ $\mu \varepsilon \nu$ (beforehand, we tell, 13). For it is not clear how something taking place in present time ("beforehand, we (now) tell") could occur before something that has happened in the past ("these things the Delphians sang"). The phrase "beforehand, we tell" does make logical sense in relation to the invocation to Apollo, and a paraphrase of that progression would be "until Apollo comes, we (now) tell (this mythic narrative)." But to privilege this progression is to ignore the intervening $\tau$ ó $\sigma \alpha$ clause

38 Pfeijffer's (1999a: 55) comment is representative: "The fact that this ode was performed at Delphi with all probability ..." See also Burnett (1985: 193 n. 14): "The place [of the performance] must be Delphi ...”; Fearn (2007: 237): “In the case of Bacchylides 16, the poem's opening points us to a Dionysiac festival context at Delphi ...” 
that, following Maehler's translation, places the cletic address to Apollo in past time. Maehler's proposed sequence strains or obscures the temporal relationship between the strophe and the antistrophe-epode. ${ }^{39}$

Third and more importantly, this reconstruction rests on an understanding of generic categories as clear-cut and mutually exclusive, with genres neatly mapped onto their respective gods. Because the strophe mentions paeans and Apollo and because, it is argued, Apollo is absent from Delphi for the present performance, the antistrophe and epode must necessarily be a dithyramb in honor of Dionysus. ${ }^{40}$

Finally, and in conjunction with this third concern, it is not evident how the antistrophe and epode's mythic narrative relates to a Delphic context. As we will see in Part II, scholars have demonstrated that this portion of the poem presents a version of the myth of Heracles and Deianeira that closely corresponds to, even depends upon, Sophocles' Trachiniae. The standard interpretation of Ode 16, which places the poem at Delphi, cannot account for this relationship between Ode 16 and Trachiniae beyond pointing to a loose association between the poem's tragic material and Dionysus' purported presence at Delphi during the poem's original performance. ${ }^{41}$ Yet, this vague Dionysiac connection does not satisfactorily address Bacchylides' citation of Sophocles' idiosyncratic tragic version of a myth or, more generally, why he would wish for this particular lyric poem to interact so closely with the genre of tragedy.

How else, then, can we view the relationship between the strophe and antistrophe-epode in a way that attends to these related concerns, especially those of genre and performance context? I suggest that the conclusions reached in the previous section offer a means of addressing them. For it is possible to extend the vision of Apolline polyphony encountered there to the remainder of the poem as well. Ode 16 as a whole appears to be structured as a sequence of different musical performances in honor of Apollo. In order to track this sequence within Ode 16 , however, it is necessary to modify slightly Maehler's translation of lines $8-13$ by recuperating two observations made long ago by Richard Jebb. First, Jebb takes $\tau o ́ \sigma \alpha$ not as a demonstrative pronoun but instead

39 Maehler (1997: 16o-161) himself considers the various possibilities for the temporal rela-

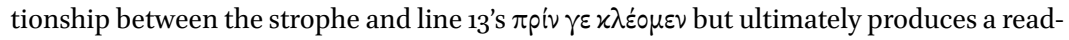
ing that focuses on the relationship between Apollo's arrival and what the chorus is now singing and, in so doing, seems to ignore the intervening $\tau$ có $\alpha$ clause. contrast between paeans and dithyrambs in the fifth century."

41 Thus Rutherford (1994-1995: 118) points to this poem as an example of how the "implied Dionysiac context of the genre [of dithyramb] accommodates the uses of the 'themes of transgression and disaster." 


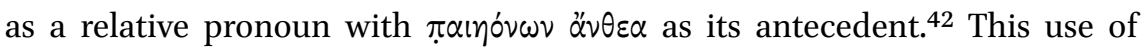
the relative without a correlating demonstrative pronoun is rare, but, as Jebb observes, Bacchylides uses the same construction in Ode $1\left(1.145^{-148}\right):^{43}$

$$
\begin{aligned}
& \ldots \pi] \alpha \tau \rho i \omega \nu \\
& \left.\tau^{\prime} \text { oง่x [.].].[-- }-x\right] \alpha \lambda \omega \hat{\omega} \nu \text {, }
\end{aligned}
$$

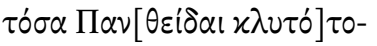

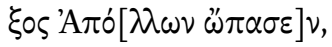

$$
\begin{aligned}
& \text {... his father's fine achievements, all those which the famous archer Apollo } \\
& \text { granted to Pantheides ... }
\end{aligned}
$$

Second, Jebb maintains that $\chi \varepsilon \lambda \alpha \dot{\delta} \eta \sigma \alpha \nu$ (12), the verb within the relative clause, must be a gnomic aorist. ${ }^{44}$ I note that the force of the gnomic aorist, which emphasizes the customary nature of $x \varepsilon \lambda \alpha \dot{\delta} \eta \sigma \alpha \nu$, would correspond well to Maehler's restoration of $\pi$ pí $v$ with the subjunctive to denote a habitual occurrence in the opening lacuna of line $8 .{ }^{45}$

Incorporating Jebb's interpretations, then, I translate lines 8-13 as follows: ${ }^{46}$ "[before] (as you habitually do) you come to pursue flowers of paeans, Pythian Apollo, as many paeans as the choruses of Delphians are accustomed to sing around your famous temple, before (you do that), we now tell how ..." Taking $\chi \varepsilon \lambda \alpha \dot{\delta} \eta \sigma \alpha \nu$ as a gnomic aorist relieves the temporal discordance between

\footnotetext{
42 Jebb 1905: 371.

43 See Jebb 1905: 246-247 (N.B., in Jebb's edition of Ode 1, line 147 = line 37). See also Maehler 1982: 19 on Ode 1.147. Maehler (1997: 159-16o) also considers the possibility that $\tau$ ó $\sigma \alpha$ is a relative pronoun but, in the end, favors taking it as a demonstrative.

44 Maehler raises this possibility in his 1997 commentary but the translation in his 2004 edition suggests that he does not ultimately interpret it as such.

45 See above n. 32 . This use of the subjective $+\pi$ piv occurs without $\alpha$ $v$. Further, as noted above, if we read $\tau$ ı at line 5 in the second vignette and take it to refer to a general, customary action, then the second vignette corresponds to the third in presenting another habitual action related to Apolline music.

46 Jebb (1905: 371) like Maehler takes $\pi$ piv in line 13 as adverbial. In the opening lacuna of

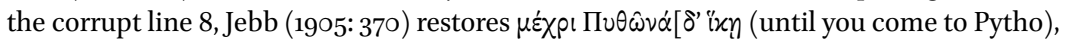
with the supposition that five syllables should fit the textual gap. I remain agnostic about the number of syllables that belong in this lacuna, although for my own interpretation

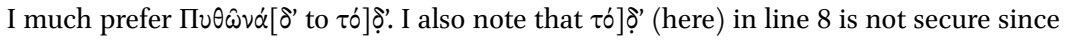
Maehler places a dot under the delta, the one letter of this word that he does not restore. Nevertheless, I would emphasize that Maehler and Jebb, despite their differences over the length of the lacuna, both agree that a temporal conjunction belongs in the gap.
} 
the end of the strophe and the beginning of the antistrophe that was observed above for Maehler's scenario. Moreover, this translation emphasizes the inseparable link between the singing of paeans by choruses and the site of Delphi. ${ }^{47}$ Because of the lacuna, we cannot be certain of the location to which Apollo is being called in the invocation at line 8 ("before you come ..."). What is apparent, however, is the form of music Apollo can expect to find in his honor at Delphi. As the subordinate clause declares, the paean is the song for Apollo there, a category of song whose habitual, predictable performance around Apollo's Delphic temple the gnomic aorist underscores.

With the aid of Jebb's interpretation, the final image in the strophe can be read against the preceding cluster of song type-singer-locations in lines $5^{-7}$. A sequence now materializes in the poem's movement from the music made by swans at the Hebrus River to paeans sung by choruses at Delphi. In other words, in this progression, the strophe offers another instance of the motif of juxtaposing different forms of singing in honor of Apollo. Crucially, in Ode 16's own permutation of this pattern, each shift in song type and singer is accompanied by a corresponding shift in geographical location.

With this permutation in mind, I suggest that Ode 16 then continues this Apolline motif with the opening of the antistrophe, where the poem undergoes yet another shift on all three fronts. As the antistrophe begins, the poem restarts not only by introducing another kind of song performed by other singers but also by conjuring a new physical space. Thus we move from a reference to paeans to a mythic narrative of Heracles and Deianeira, from a reference to a chorus of Delphians to the first-person plural $\chi \lambda \varepsilon^{\prime} \circ \mu \varepsilon v$. And, at the same time, we move, in an attendant shift in location, from a reference to Delphi to the site of the present performance. For here I would revive an old conjecture that the performance of Ode 16 originally took place not at Delphi but at Athens. ${ }^{48}$

In Part II, I will address in greater detail the evidence for Athens as the site of the poem's performance and propose a specific Athenian ritual occasion. But, for now, taking Athens as the location of the chorus presently singing ( $\chi \lambda \varepsilon_{\varepsilon}$ $\mu \varepsilon v)$, we might note that the motif of sequencing songs for Apollo in Ode 16 assumes the shape of an ascending tricolon: first, the music of swans at the Hebrus; second, paeans by choruses at Delphi; finally and most elaborately, a mythic narrative comprising the antistrophe and epode by a chorus at Athens. Accordingly, an expanded translation of lines 8-13 might read: "[before] (as you habitually do) you come to pursue flowers of paeans, Pythian Apollo, as

47 It is worth noting that this argument still holds even if $\tau \dot{\sigma} \sigma \alpha$ is taken as a demonstrative.

48 The possibility of Athens as the site of Ode 16's performance was first suggested by Kamerbeek 1959: 6. See also March 1987: 63 n. 65; Maehler 2004: 165, 17 . 
many paeans as the choruses of Delphians are accustomed to sing around your famous temple, before (you do that), we (here in Athens) now sing (for you) how ..." As this translation underscores, viewing the entirety of Ode 16 as a song in honor of Apollo frees us from trying to excavate a discernible connection between the antistrophe-epode and Dionysus.

These observations yield several related ones in turn. In the case of the culminating element of the tricolon, the poem ceases simply to identify or name different types of Apolline song as it does in the strophe and instead becomes a type of song, as it opens up into the mythic narrative for the remainder of the poem. Put another way, the strophe functions as a kind of priamel to the antistrophe-epode, presenting a list of different song types as the lead-up to the actual song the chorus will now sing. ${ }^{49}$ Further, following their shared cultic origin on Pieria, Ode 16's sequence of individual songs moves from the Hebrus in Thrace, to Delphi, to Athens. This geographical progression implies that place is profoundly connected to, even the determining factor for, the type of song performed at each of the locations in the poem. Since the different songs presented within Ode 16 are all in honor of Apollo, the poem seems to imply that the god himself does not entirely govern the type of music that will be sung for him as much as the physical environment and its inhabitants do. The importance accorded to physical space and community has implications for Ode 16's conceptualization of genre, as we will see in Part I's discussion of Athens as the site of the poem's performance. Before turning to Part II, it is worth observing how this sequence of songs relates both to the antistrophe and epode's mythic narrative and to the poem's opening metapoetic frame.

The autonomy of song as an operating principle within Ode 16 appears to inform the correlation between the antistrophe and epode. For, despite jointly comprising a unified mythic narrative, the two stanzas nevertheless operate independently of one another in at least one important respect, namely, their focalization. At first glance, it is curious that in a mythic narrative of such "extreme brevity" and with so much mythic ground to cover (Heracles's preparations for a sacrifice at Cenaeum, Deianeira's learning of Iole, and the centaur Nessus' fateful gift) Bacchylides devotes the antistrophe to cataloguing preparations for a sacrifice that will never occur. The antistrophe enters its myth at the point at which Heracles is apportioning sacrificial victims to Zeus, Poseidon, and Athena, unaware of his own impending immolation (13-22):50

49 See the discussion in this volume's introduction of Pindar fr. 128c SM as another priamel that presents a series of distinct kinds of song.

50

Quotation from Platter 1994: 338. 


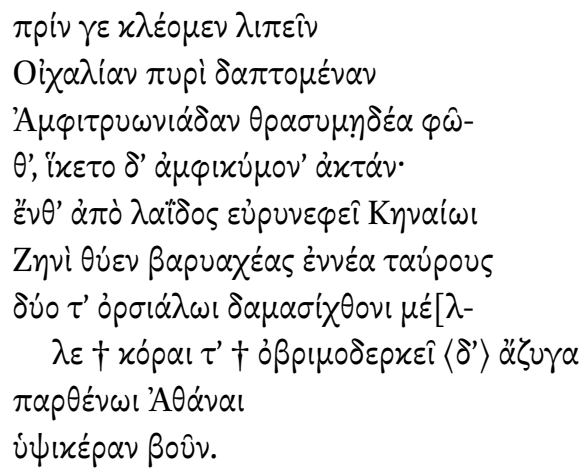

But, first, we sing how the son of Amphitryon, the bold-planning mortal, left Oechalia devoured by fire and arrived at the promontory washed by waves; there from his spoils he was about to sacrifice nine deep-bellowing bulls to Zeus of Cenaeum, lord of spreading clouds, and two to the searouser and earth-shaker, and a high-horned cow, unyoked, to the maiden Athena with the mighty glance.

With these ornate enumerations of animals and gods, the antistrophe is seemingly unaware that this sacrifice will never occur and that its relevance will soon be superseded by the revelation of Heracles as the actual sacrifice. But if we understand the antistrophe as focalized through Heracles, then the care allotted to these futile preparations makes greater sense. As the passage's focalizer, Heracles is, as it were, flaunting or parading these sacrificial victims from his own private store $(\dot{\alpha} \pi \dot{\partial} \lambda \alpha i \ddot{\delta} \circ \varsigma, 17) .{ }^{51}$

In the shift from antistrophe to epode, however, we move from Heracles' "external action" to Deianeira's "internal realm of intellect and emotion," as Anne Pippin Burnett has observed. ${ }^{52}$ Accompanying this shift is a commensurate shift in focalization: the epode does not simply narrate Deianeira's emotional and intellectual experience as she learns that her husband is sending home a new wife but is also focalized through her experience. The transition between the antistrophe and epode crystalizes this shift in focalization

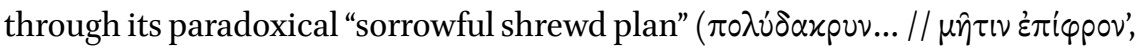

$5^{1}$ And we might note the trick of the grammar with $\theta$ vi (18): we initially assume that Heracles is actually making all of these sacrifices (taking $\theta \dot{v} \varepsilon v$ as an unaugmented imperfect indicative ["he was sacrificing"]) until, upon reaching the delayed $\mu \varepsilon \hat{\varepsilon}[\lambda] \lambda \varepsilon$ in the following line, we double back and reinterpret it as a Doric infinitive. Heracles is only "about to sacrifice" all of these victims. I owe this observation to Leslie Kurke. 
$24-25){ }^{53}$ The phrase bridges the two stanzas with the first adjective $\pi 0 \lambda$ v'$\delta \alpha x p u v$ left dangling in the antistrophe until its noun, $\mu \hat{\eta} \tau \imath$, appears in the epode. Following the appearance of $\mu \hat{\tau} \tau \imath$, however, we encounter the plan's second defining term, $\dot{\varepsilon} \pi i \varphi \rho o v$ '. The resulting phrase, straddling the strophe break, begins as "sorrowful" in Heracles' antistrophe before transforming into something "shrewd" in Deianeira's epode. That is, while his wife's plan will be sorrowful for Heracles at Cenaeum, in her own epode, Deianeira, still ignorant of her plan's fatal consequences, perceives it as a resourceful response to the news of Iole. What is more, this news of Iole, as it is summarized in the epode $\left(25^{-29}\right)$, also seems filtered through Deianeira's perspective since it is characterized as "distressing" ( $\tau \alpha \lambda \alpha \pi \varepsilon v \theta \varepsilon \dot{\varepsilon} \alpha, 26) .{ }^{54}$

Thus, just as the strophe offers vignettes of discrete songs by discrete singers, the antistrophe and epode, though comprising a shared song, simultaneously display a degree of cognitive dissonance between their respective protagonists. ${ }^{55}$ Further, like the strophe's vignettes, Heracles in his antistrophe and Deianeira in her epode occupy separate geographical spaces, with Heracles at Cenaeum and Deianeira, it can be assumed, at Trachis. A temporal disjunction also obtains between them, with Heracles' antistrophe focused on the future ( $\mu \varepsilon \dot{\varepsilon}[\lambda] \lambda \varepsilon, 19-20)$ and Deianeira's epode moving backwards in time from present to past events. ${ }^{56}$ The antistrophe and epode may share a mythic narrative, the

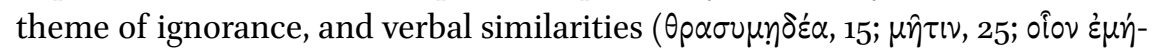
$\sigma \alpha \tau[0,30)$, and yet each stanza also maintains in part its own integrity and autonomy. Ode 16 is a poem in which not only its individual songs (those at the Hebrus, Delphi, and Athens) but also its structural parts (strophe, antistrophe, and epode) are entangled with but also somehow impermeable to one another.

To return to the image with which this section began, we are now in a posi-

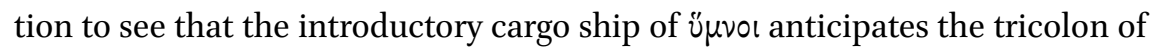
songs that emerges as the poem subsequently moves to the Hebrus, then to Delphi, and on to Athens. For, like these opening autonomous ü $\mu$ vol, the songs within the poem's sequence of physical settings are cast as distinct from one another, even as they share a divine point of departure on Pieria, the impulse to honor Apollo, and the space of Ode $16 .{ }^{57}$ We might even think of the poem

\footnotetext{
53 My thanks to Leslie Kurke for this point.

54 See also Pfeijffer (1999a: 54 ).

55 Platter (1994: 339) refers to Heracles and Deianeira in this poem as "independent actors."

56 I owe these last two points to Naomi Weiss.

57 The discrete parts of the poem are connected in other ways as well, including through recurring imagery: note that the banks of the flowery Hebrus (5) and the banks of the rosy Lycormas (34) bookend the poem.
} 
itself as a kind of metaphorical cargo ship freighted with $\check{\mu} \mu \nu$ o, each one bound for its proper geographical destination. In this way, the metapoetic frame anticipates well the model of song at work in the rest of the poem.

\section{Part II: Athens}

In the previous section, I proposed that we resuscitate an older argument that Ode 16 was first performed in Athens. I will lay out the case for this option in greater detail now. A performance context in Athens will clarify the poem's own capacity for generic flexibility as well as its relationship to the genre of tragedy.

Scholars often note that Bacchylides seems to have enjoyed a greater rapport with Athens than Pindar, especially in the case of his Dithyrambs..$^{58}$ Ode 16 itself exhibits an extensive connection to Sophocles' Trachiniae. And yet, Ode 16 has always been treated as an outlier to Bacchylides' Athenian Dithyrambs because of a pervasive scholarly conviction that it was performed at Delphi. This is not to suggest that a Delphic audience could not be familiar with a Sophoclean tragedy. Nevertheless, Bacchylides' and Ode 16's own close association with Athens encourages us to look for a suitable ritual occasion there for the poem's original performance.

\section{The Thargelia at Athens}

I will pursue the possibility that Ode 16 was performed in Athens by suggesting a specific Athenian ritual occasion that would accommodate such a performance: the Thargelia. The Athenian Thargelia was an annual spring festival that took place over two days during the month of Thargelion. ${ }^{59}$ The first day included a scapegoat ritual involving the expulsion of pharmakoi. On the second day, a procession carried a stew of first fruits in a vessel called the thargelos through the purified city. ${ }^{60}$ The destination of this procession was the sanctuary of Apollo Pythios, located to the southeast of the Acropolis, beyond the city walls, on the banks of the Ilissos River. Following the procession, the Athenians held choral performances, the festival's main attraction and sole competitive event. During the classical period, these contests featured five choruses of boys and five of men, a smaller-scale counterpart to the choral competitions of the

$5^{8}$ See, e.g., Fearn 2007: 234-241 and Calame 2013: $35^{\circ}$.

59 For discussions of the Thargelia, see especially Wilson 2000: 32-34 and 2007.

6o For the "ritual logic" underpinning these two distinct days of the festival, see Wilson 2007: 152, following Parker 1983: 25 . 
Great Dionysia held two months before. ${ }^{61}$ Epigraphic and literary evidence

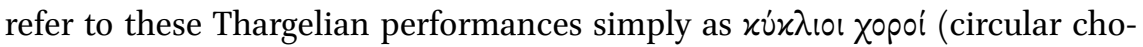
ruses). ${ }^{62}$ I will return to this designation while considering questions of genre below.

Both the cult of Apollo Pythios and its festival were of great antiquity in Athens and appear to date back as far as the eighth century. ${ }^{63}$ In the sixth century, the elder Peisistratus erected the first temple in the sanctuary known as the Pythion, while his grandson, the younger Peisistratus, dedicated an altar, described by Thucydides, whose find-spot has helped to identify the approximate location of the sanctuary. ${ }^{64} \mathrm{~A}$ choregic dedication reveals that the choral contests were well underway by the mid-fifth century, and Peter Wilson notes a general increase in activity for the cult at this time. ${ }^{65}$ I propose that this festival of the Athenian Thargelia occasioned the first performance of Ode 16, not long before the mid-fifth century, when both the cult and its annual festival were in full swing. This proposal frees us from trying to excavate a meaningful connection between the poem and Delphi: we are no longer tied to Delphi, for instance, in order to make sense of the invocation to Pythian Apollo at line 10, since this address is equally at home at the Thargelia with its cult of Apollo Pythios. In this context, it is also tempting to relate the prominence of river banks in Ode 16 ("upon the flowery Hebrus" [5] and "upon the rosy Lycormas" [34]) to the Pythion's setting on the banks of the Ilissos. ${ }^{66}$

We cannot ascribe any extant song with certainty to the Thargelia, but scholars have long contended that Bacchylides' Ode 18 was originally performed

61 Wilson 2007: 151. Although the scapegoat ritual has monopolized modern scholarship on the Thargelia, Parker (1996: 95), followed by Wilson (2000: 32-33), asserts that it was the choral competitions that would have been a fifth-century Athenian's primary association with the Thargelia.

62 Wilson 2000: 33; Fearn 2007: 235 .

63 Wilson 2007: 153 .

64 Thuc. 6.54.6 and Wilson 2007:153-154. The Peisistratids' interest in establishing a cult of Apollo Pythios at Athens may have been due to their fraught relationship with Delphi (Wilson 2007: 153). The prize for the choral competitions was a tripod, and Wilson (2000: 16) makes the intriguing suggestion that the Thargelia, given its link to Delphi through the cult of Pythian Apollo, was the first choral competition in which tripods were awarded, a prize that later also migrated to the Great Dionysia.

$65 I G \mathrm{I}^{3} 963$ with Wilson 2007: 154-155.

66 Himerius tantalizingly connects many of the elements explored here for Ode 16 and the Thargelia (springtime, swans, the Hebrus, and the Ilissos) in his Orations 47.3-4 (pp. 19o191 Colonna): "Now, boys, it is truly spring ... And if swans ever made a song with the Zephyr by the banks of the Ilissos, as they do on the Cayster and the Hebrus, now more than before they will fill the banks with music." 
there. ${ }^{67}$ Building on a supposition that goes back to Jebb, Wilson compellingly argues for Ode 18's performance by a boys' chorus at the Thargelia on both aetiological and formal grounds. ${ }^{68}$ It is also worth noting that, in addition to Ode 18, three of the other five extant poems from the Alexandrian edition of Bacchylides' Dithyrambs, Odes 15, 17, and 19, are connected in some way to Athens. As David Fearn and others have argued, the imagery and characters of Ode 15 call to mind the Panathenaea, while many view Ode 17 as a celebration of Athenian maritime hegemony. ${ }^{69}$ Ode 19 explicitly enjoins the poet to "weave something new in much-loved blessed Athens" (8-10). If we understand Ode 16 as composed for an Athenian chorus in an Athenian cultic context, then Odes $15^{-19}$, that is, all of the surviving poems collected under the rubric of Bacchylides' Dithyrambs, save the Spartan Ode 20, concern Athens.

As Giambattista D'Alessio shows, the Athenians themselves most likely

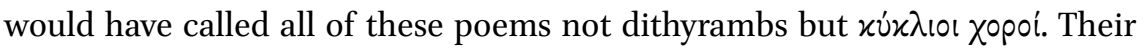
later classification by the Alexandrians as dithyrambs did not have to do with any connection to Dionysiac cult but rather with the poems' extended mythic narratives and a later association that developed between the term dithyramb and the presence of these mythic narratives within certain poems. ${ }^{70}$ Given Ode 16's likely original designation as a $x \dot{x} x \lambda 10 \varsigma \chi 0$ pó and, as I have proposed, its original performance context at the Thargelia, I consider below the implications of these conclusions for our understanding of the poem's genre(s).

\section{Ode 16 and Sophocles' Trachiniae}

Before turning to questions of genre, I must first address the intertextual relationship between Ode 16 and Trachiniae. It is well known that the mythic narrative of Ode 16 coincides with the plot of Sophocles' Trachiniae. Yet, as Jennifer March perceives, the correspondence runs deeper than simply a shared storyline, since the two texts exhibit "distinct similarities of vocabulary, content and

67 Wilson 2007: 174 .

68 Wilson 2007: 173-174 and below.

69 On the performance context of Ode 15 as the Panathenaea, see Maehler 2004: 157-158; Fearn 2007: 257-337. See Fearn 2007: 242, with earlier bibliography, for this interpretation of Ode 17.

70 D'Alessio 2013: 120-122. Thus also Wilson 2007: 174-175 on Bacchylides' Dithyrambs: "Many of these ['dithyrambs'] are in all probability what (at least in an Athenian context) would be termed kyklioi khoroi, for they demonstrate characteristics which prompted the employment of the broader and less explicit category of kyklios khoros, in particular the inclusion of extensive heroic narrative which might have little or nothing to do with Dionysos." See also Fearn 2007: 237-238. 
treatment."71 Numerous scholars and those who, to my mind, have also presented the most compelling arguments, agree on the direction that this intertextual dynamic takes and consider Trachiniae as the source text evoked by the later Ode $16 .{ }^{72}$ The relative priority of Trachiniae holds up from a chronological standpoint. Trachiniae is considered one of Sophocles' earlier plays while Ode 16 , for stylistic and metrical reasons, is thought to have been composed late in Bacchylides' career. The two poets' careers coincided for at least two decades in the 46 os and 45 os, allowing for the two texts to have been composed around the same time, with the lyric poem post-dating the tragedy. ${ }^{73}$

I review here the more salient intersections between the two texts as well as some of the arguments for Trachiniae as the source text for Ode 16. The lyric poem and the tragedy exhibit a remarkable degree of shared vocabulary, a comparable overarching arrangement, and a similarly distinctive treatment of Deianeira.

First, Jennifer March detects the following dictional parallels: Ode 16.16

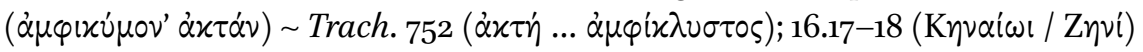

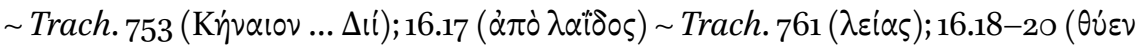

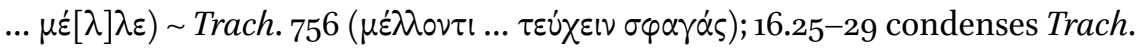
351-368, 380-382; 16.32-33 reworks Trach. 592-593. In addition, as Peter Riemer

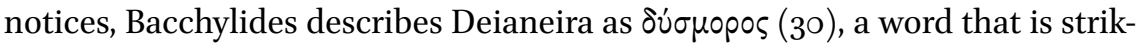
ingly Sophoclean: $\delta \dot{\sigma} \sigma \rho \rho \circ$ s is frequently used by Sophocles, including three times in Trachiniae alone, but is rare in the extant works of other tragedians. ${ }^{74}$

Second, in terms of their similar arrangement, the diptych structure of Ode 16's antistrophe, devoted to Heracles, and epode, devoted to Deianeira, mirrors in reverse order Trachiniae's own configuration, with half of the play devoted to Deianeira and half to Heracles. ${ }^{75}$ Third, a number of scholars also observe that Bacchylides portrays Deianeira in a distinctly tragic, or more precisely, Sopho-

71 March 1987: 62.

72 In addition to March 1987, see Pfeijffer 1999a: 52, Riemer 200o, and Maehler 2004: 167. Contra Kyriakou 2011 and Carawan 200o. As Pfeijffer (1999a: $5^{2}$ ) rightly asserts, the dictional parallels between the two texts are too close for the theory of a common source for both texts to be plausible (cf. Davies 1991: xxxii; Zimmermann 1992: 74-76; Kyriakou 2011: $538)$.

73 On the issue of the relative dating of the two texts, see Pfeijffer 1999a: $5^{2}$ and Riemer 20oo: 170-173, both with earlier bibliography.

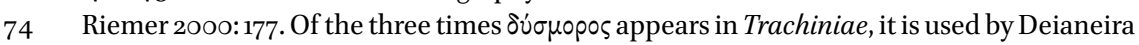
herself to describe Iole (466), by Hyllus in describing Lichas in his speech to Heracles (775, notably the very speech which Ode 16 encapsulates; see below), and by Heracles in describing himself (1005).

Riemer 2000: 173; Kyriakou 2011: 537. 
clean manner. ${ }^{76}$ In Trachiniae, Deianeira is characterized as a passive, fearful woman who, deluded by the belief that Nessus has entrusted her with a lovecharm, unwittingly kills Heracles. This Deianeira stands in stark contrast to pre-Sophoclean versions of the mythic character, including that of Bacchylides' own earlier Ode 5, as a woman who actively desires to kill her husband and whose self-conscious murderous tendencies cast her as another Clytemnestra. ${ }^{77}$

These observations make the tragedy's relative priority probable, but, as Ilja Leonard Pfeijffer rightly argues, Ode 16's evocation of Trachiniae is not only possible but also "highly functional." ${ }^{8}$ For Bacchylides' treatment of the myth of Heracles and Deianeira is so allusive that, without prior knowledge of Sophocles' idiosyncratic tragedy, the precise meaning of several of Ode 16's references would be difficult or even impossible to discern. Thus Bacchylides' audience would have no way of knowing to what Deianeira's $\mu \hat{\tau} \tau \imath \nu(25)$ and Nessus' $\delta \alpha t-$

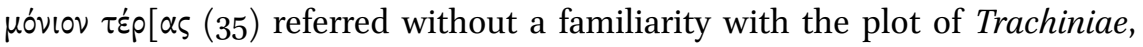
since Deianeira's plan of using Nessus' poisoned blood as a love charm seems to have been Sophocles' innovation. ${ }^{79}$ Moreover, as Pfeijffer observes, Ode 16's dictional similarities with the tragedy conjure, above all, one crucial scene, the beginning of Hyllus' speech to Deianeira (Trach. $75^{\circ}-762$ ). The opening of this speech, just like Ode 16's antistrophe, narrates Heracles' preparations for sacrifice at Cenaeum. As Pfeijffer emphasizes, what Hyllus's speech and Ode 16 both capture in these lines are Heracles and Deianeira in their "final moment[s] of ignorance" before they learn of the deadly properties of Deianeira's gift. ${ }^{80}$

76 See Kamerbeek 1959: 6; Schwinge 1962: 132; Hoey 1979: 215; Easterling 1982: 16; March 1987: 63; Pfeijffer 1999a: 52; Maehler 2004: 166-167.

77 See especially March 1987: 62-71 and Carawan 2000: 191-195. We might note here that Deianeira's very name ("Man-slayer") suggests a more ruthless, pre-Sophoclean past.

78 See Pfeijffer 1999a: 51-55, with quotation from p. 55 .

79 Maehler 1997: 155-156 and 2004: 167.

8o Pfeijffer 1999a: 53. Pfeijffer (1999a: 53-55) argues that the function of Bacchylides' allusions is to thematize the ignorance experienced by Heracles and Deianeira in this scene. Without recourse to Trachiniae, these allusions make the audience of Ode 16 themselves ignorant of exactly what the antistrophe and epode are narrating. In this way, by placing the precise meaning of these allusions "outside the text," Bacchylides effects the audience's empathy for Heracles' and Deianeira's own ignorance. Yet, by triggering their knowledge of Trachiniae as the source text, Bacchylides' audience also experiences dramatic irony. That is, through Trachiniae, the audience is also able to make sense of Ode 16's narrative so that they anticipate the looming events that the characters, without knowledge of the future, cannot (i.e., Heracles' death by the poisoned robe, Deianeira's awareness of her actions). 
In short, Ode 16, beyond merely evoking Trachiniae through its intertextual allusions, depends on Trachiniae in order to be understood fully. Further, what Pfeijffer's study especially highlights is the way in which Ode 16's mythic narrative does not just relay a portion of Trachiniae but encapsulates, in a highly compressed fashion, the tragedy in its entirety. As Pfeijffer perceives, Hyllus' speech, on which Ode 16's narrative is based, forms the "dramatic centre" of the play. ${ }^{81}$ What is more, Ode 16 's concluding sentence calls to mind the entire narrative arc of Trachiniae by alluding both to its end (Deianeira's death) and its inception (the moment she accepts the fateful gift from the centaur Nessus) ${ }^{82}$ We might even compare the disjunction in the focalization between Heracles in the antistrophe and Deianeira in the epode to the fact that in Trachiniae the husband and wife never meet on stage. Finally, Deianeira's own qualities in Ode 16, equal parts ignorance and jealousy, embody the Sophoclean characterization of her "in a nutshell." ${ }^{83}$ Bacchylides does not merely allude to Trachiniae but captures it in its totality so that Ode 16's antistrophe and epode become, as it were, a Trachiniae in miniature.

How can we account for Ode 16's prominent embedding of Trachiniae? We can approach an answer from two different angles, one that attends to Ode 16's specific ritual occasion and, at a more general or abstract level, one that considers questions of genre. For the purposes of this paper, I will focus on some questions of genre but before doing so I would like to offer briefly a way of accounting for this feature that engages with its ritual occasion.

I return again to the observation that Ode 16's antistrophe and epode appropriate, above all, language from the beginning of Hyllus' speech to Deianeira (Trach. 750-762). Accordingly, we can say that Trachiniae's Hyllus himself is evoked at this moment in the lyric poem. As other scholars have noted, in Trachiniae, Hyllus is an ephebic character whose successful transition to adult male status crucially requires Heracles' recognition of him as his son and heir. ${ }^{84}$ As Victoria Wohl asserts, "legitimacy is identity for Hyllus-hence the urgency of the repeated exhortations for him to be "a true son" (1064, 1129, 1157-1158,

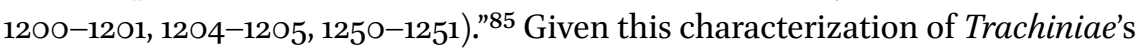
Hyllus, the Thargelia possesses tantalizing explanatory power for the promi-

\footnotetext{
81 Pfeijffer 1999a: 53 .

82 Pfeijffer 1999a: 54 .

83 Hoey 1979: 215, quoted by Pfeijffer 1999a: 54 .

84 See especially Wohl 1998: 11-16.

85 Wohl 1998: 12. Trachiniae's obsessive concern with the bond between father and son is even registered at the dictional level: by Wohl's (1998: 14) count, the word "father" and its cognates occur twenty-three times in the last 307 lines of the play. In this context, I also note that, in Ode 16, Heracles' own patrilineage is doubly determined. Even in the compressed
} 
nence of Hyllus' speech in Ode 16. For the occasion of the Thargelia seems to have been the context in which at least one Atttic phratry gathered to receive new constituents by publicly acknowledging legitimate and adopted sons presented by their fathers. ${ }^{86}$ Wilson in fact applies a comparable logic to bolster an older suggestion that Bacchylides' Ode 18 was performed at the Thargelia. That ode portrays Theseus as a "boy on the cusp of manhood" ( $\pi \alpha \hat{\imath} \delta \alpha \ldots \pi \rho \omega$ $\theta \eta \beta 0 v, 5^{6-57)}$ and showcases explicitly a father's (Aegeus') recognition of his legitimate son (Theseus). ${ }^{87}$

Bacchylides' choice of Trachiniae as the specific tragedy to embed in his lyric poem may thus be informed by Hyllus' ephebic characterization in the tragedy as well as the significance it places on the father-son relationship, both of which suggest fitting mythical counterparts to an important ritual component of the Thargelia. Now, however, I would like to spend the remainder of the paper thinking about Ode 16's inclusion of Trachiniae in terms of genre. In the next section, I will propose that Bacchylides uses the play as a representative of the genre of tragedy in order to respond to tragedy's status as a "super-genre."

\section{Genre at Athens}

If Ode 16 was indeed performed at the Thargelia, fifth-century Athenians would

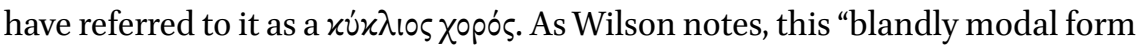
of expression" places emphasis on the configuration of the chorus itself and, in so doing, avoids specific associations with a particular genre or cult, a point to which I will return below. ${ }^{88}$ The phenomenon of designating certain songs simply as $x u ́ x \lambda 10$ ¿ $\chi 0$ poi also provides further evidence for the complex and shifting nature of Greek lyric genres and their frequent tendency to resist assignment to unambiguous generic categories. ${ }^{89}$

Given the challenge of determining the genre of a poem designated as a

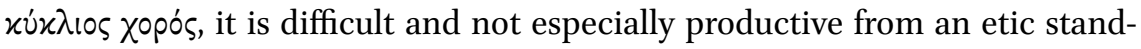
point to attempt to assign Ode 16 a generic label. What we can do instead is consider whether Ode 16 itself tells us anything about genre. As we have already seen, Ode 16 presents us with a vision of Apolline polyphony, a vision

narrative of the ode's antistrophe, Bacchylides makes room to mention Heracles' own two fathers: Heracles is identified as the "son of Amphitryon" (15) and is about to sacrifice to his immortal father, Zeus (18).

86 See Wilson 2007: 174, citing Lambert 1993: 216-217 and Parker 1996: 104-109.

87 Wilson 2007: 172-174.

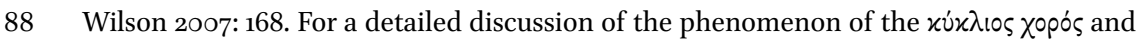
its relationship to dithyramb, see Fearn 2007: 163-225; D'Alessio 2013.

89 See also the Introduction and Weiss in this volume. 
in which the poem's polyphony comprises the sum total of interconnected but autonomous songs. At the level of genre, we might also think of this same vision as one of generic hybridity. The only explicit reference within the poem to genre is the reference to paeans at line 8. But, as Bacchylides stages it, this form of singing for Apollo is marked off, and so implicitly set up as distinct, from both the preceding description of swan song and the song that erupts at line 13, the mythic narrative of Heracles and Deianeria. That is to say, Ode 16's sequence of autonomous songs seems also to be a sequence of generically differentiated songs..$^{90}$

In Part I we found that this sequence of songs was inextricably bound to a sequence of separate geographical spaces, as the poem moved from the Hebrus to Delphi and, finally, to Athens. I would refine that description here and suggest that in Ode 16 geographical location also appears inextricably bound to, perhaps even a generative force behind, individual genres. In other words, generic hybridity is achieved in the poem precisely by moving between physical spaces. One effect of this movement, I suggest, is to drive home the differences between songs.

If Ode 16 indeed conceives of the relationship between genre and location in this way, then the poem simultaneously positions itself in sharp contrast to the form of generic hybridity found in Attic tragedy, including Trachiniae. As Naomi Weiss demonstrates, tragedy can be thought of as a hybrid genre or, more aptly still, as a "super-genre" that commandeers and incorporates an array of different lyric genres by putting them to work in the service of a given play's own narrative. ${ }^{91}$ Weiss' insight can be connected to Barbara Kowalzig's observation that a number of tragic choral odes of Sophocles and Euripides initially give the impression of honoring the cult of a particular god before transforming into a song for Dionysus, the god in whose honor the tragedy itself is being performed. ${ }^{92} \mathrm{~A}$ choral ode from Trachiniae displays both of these qualities $\left(205^{-224)}\right.$ :

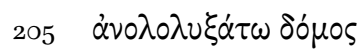

$\dot{\varepsilon} \varphi \varepsilon \sigma \tau i 0 ı \varsigma \alpha \lambda \alpha \lambda \alpha \gamma \alpha \hat{i} \varsigma$

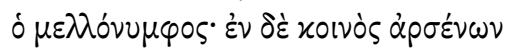

9o Recall here as well the epinician resonance of the strophe's metapoetic opening which evokes yet another genre in this poem and is also tied to a distinct location (Pieria).

91 Weiss (this volume). See too her helpful characterization of early tragedy as an "amalgamation of different types of choral song, interspersed with actors' dialogue (and occasionally actors' song)" (Weiss [this volume] p. 167).

92 Kowalzig 2007a. Other examples of such songs noted by Kowalzig are Soph. OT 151-215 and Ajax 693-718. 


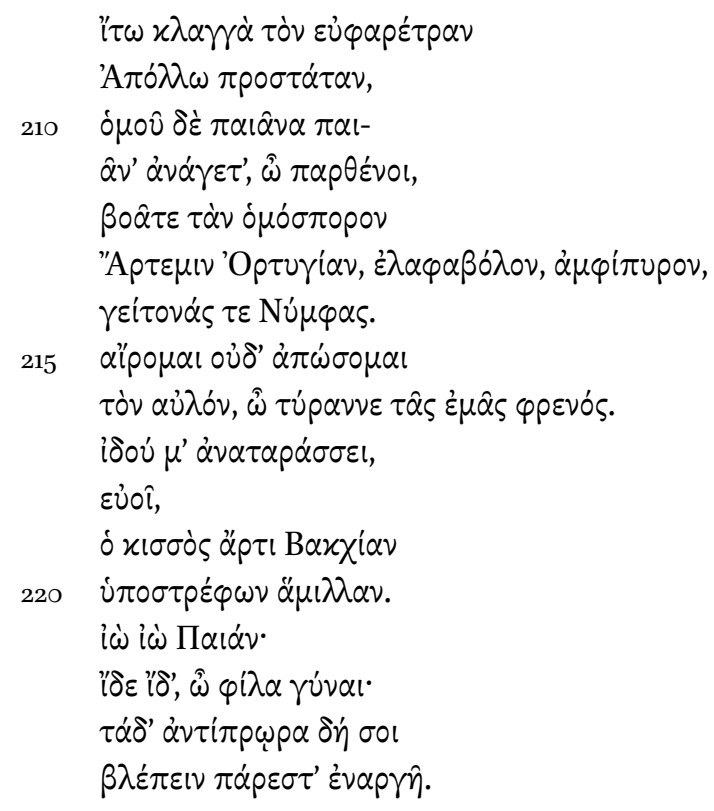

Let the house that is about to be ready for marriage utter a shout of ololuge, with shouts of alalai at the hearth! And let a shared song from the men go up for Apollo of the beautiful quiver, the guardian, and you, maidens, lift up together a paean, a paean, call upon his sister Artemis of Ortygia, shooter of deer, bearer of twin torches, and her neighbors the Nymphs. I am raised up and I will not spurn the aulos, tyrant of my mind. See, it rouses me to frenzy - euoi! — the ivy whirling me around just now in the Bacchic competition. Io, io, Paian! See, see, dear woman: you can behold these things face to face with clarity.

The choral ode's opening invocations to Apollo and Artemis and the appeals for paeans yield to Dionysus' aulos and ivy, the movements of Bacchic dance, and the god's ritual cry of euoi. The passage thus showcases well Dionysus' intrusive tendencies in certain tragic choral odes. And yet, in this instance, it is also worth noting that the choral ode's paeanic element is not lost, since the chorus returns to Apollo with a final outburst of io, io, Paian. The final product is a fusion of paeanic and dithyrambic markers, a kind of generic synthesis or, to use Weiss' term, amalgamation. ${ }^{93}$ This oscillation, in other words, differs sig-

93 See Weiss (this volume) for further discussion of the significance of this ode's generic hybridity. 
nificantly from the interest in maintaining boundaries between autonomous songs that I have suggested for Ode 16.

Tragedy's capacity for generic fusion can also be related to Kowalzig's and Leslie Kurke's work on exposing the ways in which tragedy boldly alters myths and rewrites cultic aetiologies of gods and heroes more readily associated with other Greek communities. ${ }^{94}$ That is, Attic tragedy routinely extracts and combines material from other locations. For example, Kowalzig reveals how Ajax undergoes a process of "Athenianization" in Sophocles' play while Euripides's Hippolytus takes a Troezenian myth and turns it into an explicitly Athenian one. ${ }^{95}$

Tragedy does not necessarily observe the local nature of myth and cult. ${ }^{96}$ We can view tragedy, then, as a genre that both freely mixes lyric genres and freely usurps non-Athenian mythic and cultic traditions that belong to other places. By contrast, in its sequence of songs, Ode 16 maintains, even valorizes, the integrity of what tragedy collapses, namely, the autonomy of generically different songs and the inviolable relationships between these songs and the individual communities to which they belong. ${ }^{97}$ From this perspective, Ode 16 's extended evocation of Trachiniae amplifies its own divergence from tragedy's construction as a super-genre.

The distinction between Ode 16's and tragedy's approaches to genre is thrown into still greater relief if we incorporate Wilson's proposal for the performance venue of the Thargelia's choral contests. Following Claudine Leduc, Wilson questions whether the sanctuary of the Pythion and the neighboring banks of the Ilissos would have provided sufficient space for choruses of fifty men and boys and a large gathering of spectators. ${ }^{98}$ As Wilson notes, "The alternative would be to imagine that the performances were held in the theatre of Dionysos, at least from a date when that had become 'the' place for large-scale choral contest in Athens." ${ }^{\text {99 }}$ This possibility is supported by evidence suggesting that the Athenian assembly met at the theater of Dionysus following the Thargelia to review conduct at the festival, especially any charges

\footnotetext{
94 See Kowalzig 2004 and 20o6; Kurke 2013b.

95 Kowalzig 2006. See also Anderson 2015, who argues that Aeschylus in his Eleusinians shifts the burial place of the Seven against Thebes from Thebes to Eleusis.

96 See especially Kurke 2013b and her discussion of Pindar's Pythian 11 as a response to "tragedy's tendency to displace and deracinate for its own purposes cults that properly belong to other communities" (132).

97 See Weiss (this volume), however, for the ways in which tragedy also leverages the distinctions between different lyric genres in order to shape its dramatic narratives.

98 Wilson 2007: 163, following Leduc 2001: 24-25.

99 Wilson 2007: 163.
} 
of misconduct. ${ }^{100}$ This choice of location for the assembly could imply that the Thargelia's choral performances had also taken place there. It is also worth recalling that the Thargelia took place only two months after the Great Dionysia and thus followed closely on its heels in the calendar of major Athenian religious festivals. From the perspective of fifth-century Athenians, this (possible) spatial and (definite) temporal correspondence would have intensified the potency of Ode 16 as a deliberate response to tragedy in general and Trachiniae in particular. ${ }^{101}$

At the same time, I would contend that Ode 16 does not ultimately position itself as hostile to tragedy's agenda of genre mixing and appropriation. In this respect, Ode 16 differs from several of Pindar's epinicia that do engage in what we might call a polemics of genre with Attic tragedy. ${ }^{102}$ In these epinician examples, Pindar overhauls and rehabilitates imagery and themes from tragedy and then reincorporates them into an epinician ideology. By contrast, Bacchylides does not reject Trachiniae but rather captures it in its entirety, rendering its central dramatic features and characterizations in miniature. Ode 16 seems to set itself up not as a denunciation of but as a counterbalance to tragedy's own generic hybridity. In order to clarify this distinction, I turn finally to a crucial paradox within the poem.

As I argued above, with the onset of the antistrophe, Ode 16 not only shifts to a new type of song and a new group of singers but also shifts to a new location-Athens. Yet Athens, unlike the two other locations of performances in the poem, the banks of the Hebrus and Delphi, is not identified by name. Instead, the antistrophe switches locations, not by explicitly naming Athens but by opening up into the type of choral performance that is performed in and distinctive to Athens, namely, Attic tragedy. At the level of genre, we can view

100 Wilson 2007: 163, citing Dem. 21.10 (the law of Evagoras) with MacDowell 1990 and Scafuro 2004. As noted above, epigraphic evidence seems to indicate that the choral contests of the Thargelia were in full-swing by the mid-fifth century and thus would have counted as a "large-scale choral contest" necessitating the larger space of the theater of Dionysus.

101 Although, as I understand it, the whole of Ode 16 is in honor of Apollo, Dionysus does seem to lurk beneath the surface of the poem in several important ways. With its evocation of Trachiniae, Dionysus is implicitly present as the god whom that tragedy honored. We might also think of Dionysus as present if the choral contests of the Thargelia, even as they honored Apollo Pythios, were performed at the theater of Dionysus. Finally, as scholars have noted, the Thargelia itself appears to have contained a number of Dionysiac components, including an association between the god and the Thargelia's scapegoat ritual (see Wilson 2007).

102 See especially Kurke 2013b for Pindar's ideological response to tragedy's strategies, including its dissolution of traditional ties between cults and communities in Pythian 11. See also Foster 2017 on Pythian 8. 
Ode 16's antistrophe and epode as a highly compressed distillation or snapshot of a tragedy, a distinctly Athenian form of song. ${ }^{103}$ I would like to connect this

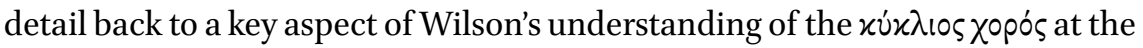
Thargelia. Wilson contends that in fifth-century Athens the use of this modal term and thus the avoidance of classification by genre for certain choral lyric songs allowed these songs to be exported to other performance settings within the Athenian empire:

The effect (and probably the aim) was to make the extremely malleable circular chorus available at the heart of the league and empire to forge and validate in performed myth the city's hegemonic cultural and political identity — and, moreover, to involve the allied states themselves in the performance. ${ }^{104}$

Building on this point, I suggest that by excluding the name of Athens from the poem, Bacchylides makes the tragedy embedded in Ode 16 accessible to non-Athenian audiences and opens it up for export to other communities. This move, however, creates a paradox: on the one hand, as we have seen, Ode 16 establishes and privileges the autonomy of independent locations and their attendant, distinctive songs. In so doing, it positions itself in contrast to tragedy's strategy of collapsing these very distinctions and of upending the relationship between individual places and song. On the other hand, by not explicitly identifying Athens, the poem allows for the location of the present performance in the hic et nunc to be anywhere. What this means is that the poem's chorus, wherever it may be, sings in the antistrophe and epode a miniature tragedy, a uniquely Athenian song. Thus, while the poem promotes the integrity of distinct locations, it simultaneously allows for places beyond Athens to partake in, even to appear willing to produce, a genre distinctive to Athens. We might think of Ode 16's strategy as the inverse of tragedy's own tendencies. Just as tragedy as a super-genre appropriates and folds into itself other songs with mythic and cultic material more readily tied to other communities, Ode 16 finds a means for tragedy to enter these other communities, to be exported beyond the theater of Dionysus. ${ }^{105}$ This final suggestion complicates Ode 16's

103 One can see now why scholars have traditionally considered this portion of Ode 16 a dithyramb. But I would emphasize that Bacchylides is not enlisting the genre of dithyramb here but that of tragedy itself. This evocation of tragedy is in play even as the poem itself is ultimately in honor of Apollo, not Dionysus.

104 Wilson 2007: 175-182, quotation from 175 .

105 In this context, it is worth mentioning an Athenian administrative account that lists 
vision of Apolline polyphony as some number of autonomous songs. For even as the poem valorizes individual songs and their rootedness in particular physical spaces, it simultaneously leaves us with the impression that the cosmos these songs inhabit ultimately skews Athenian, that Athenian songs get to be sung everywhere.

I hope to have shown how an overreliance on Alcaeus fr. 307c as a paradigm for Ode 16's strophe has led to the entrenched assumption that the poem was performed for Dionysus at Delphi by a Delphian chorus awaiting Apollo's return from the Hyperboreans. By attending closely to the strophe and drawing on new parallels, I have painted a different picture, namely that the poem presents a sequence of generically distinct songs, all tied to discrete locations and all sung in honor of Apollo. As such, the poem as a whole amounts to what we might think of as an instance of Apolline polyphony and deploys a motif of singers performing their own distinctive songs for the god. Once we set aside the myth of the Hyperboreans, it also becomes easier to see that there is no indication of the poem's performance at Delphi. Instead, I proposed Athens as the site of the poem's performance and the Thargelia, the annual festival of the Athenian cult of Apollo Pythios, as its specific ritual occasion. Continuing with the poem's connection to Athens, I argued that Bacchylides' intertextual reliance on Sophocles' Trachiniae allows us to see the poem as a conscious response to tragedy's conflations. Ode 16 insists on a polyphony of autonomous songs in opposition to tragedy's amalgamations and appropriations. Yet, in the end, it does not oppose that genre's strategies. Rather, Ode 16's encapsulation of the genre of tragedy within itself offers a way of transmitting, of exporting tragedy beyond the borders of Athens while, or perhaps even because, it simultaneously promotes the importance of the autonomy of song and its attachment to particular places.

A final, fitting detail concerning the Thargelia must be mentioned. The Thargelia's choral contests for Apollo Pythios consisted of five choruses of men and five of boys. As such, they seem to have imitated on a smaller scale the ten choruses each of men and boys at the Great Dionysia. ${ }^{106}$ A remarkable and unparalleled feature accounts for the difference between the five choruses at the Thargelia and the ten choruses at the Great Dionysia in each age category.

expenses for exporting from Athens tripods as prizes, sacrificial bulls, and choruses on a cargo ship to the Delian festival ( $I G \mathrm{II}^{2} 1635 \mathrm{a}$, especially $33^{-}-39$ with Wilson 2007: 175). We might see Ode 16 as another piece of cargo to be exported abroad, an image that recalls and gives a new dimension to the poem's own opening image of a cargo ship of songs.

Wilson 2007: 156 . 
In contrast to the Great Dionysia, where each of the ten Cleisthenic tribes provided a chorus of men and a chorus of boys, at the Thargelia, the ten tribes were paired off in order to make a total of five choruses for each age group. This pairing was random and accomplished by lot until roughly the $370 \mathrm{Os} .{ }^{107}$ Consequently, each Thargelian chorus comprised a tribal pair who performed as a "team." 108 This unique feature of the Thargelia perfectly captures the relationship between autonomy and polyphony that I have explored in Ode 16. For each Cleisthenic tribe within the pair surely viewed itself as autonomous, its membership in a particular tribe an irreducible aspect of its identity. And yet, for the sake of the competition, each tribe worked together to sing and dance as a single chorus with its tribal partner. That is, even at the level of its performers, Ode 16 offers a vision of synchronized autonomous parts singing and dancing in polyphonous collaboration in honor of Apollo.

107 Wilson 2007: 156.
108 Wilson 2007: 156. 


\section{PART 4}

\section{Affect, Materiality, and \\ the Body: The Somatics of Genre}


978-90-04-41259- $\odot$

Downloaded from Brill.come4/26/2023 $09: 51: 26 \mathrm{AM}$ via free access 


\title{
Is Korybantic Performance a (Lyric) Genre?
}

\author{
Mark Griffith*
}

\section{Introduction}

Korybantic rites and other celebrations of similar type, involving loud and exciting music and strong emotional affect, were widely practiced throughout the Greek world, but they are not normally discussed as examples of "Greek lyric," either by ancient or by modern critics. In this chapter, I want to explore not just the reasons for this omission but also some key characteristics of Korybantic performance ${ }^{1}$ that serve to illustrate the extent to which the study and interpretation of Greek "song culture," by focusing - for obvious reasonsso intensively on the verbal aspects of that culture's high-end achievements (i.e., the surviving poetry of Sappho, Pindar, Anacreon, et al.), has tended to underestimate the abundance and significance of some of the popular song and dance forms that do not survive as written texts. Elite biases, ancient and modern, have thus, I suggest, rather distorted our picture of the archaic and classical music scene overall, and have unduly marginalized certain types of lyric performance that deserve to be included more squarely within our critical assessments and definitions. My discussion will also, I hope, contribute another relevant dimension to this volume's range of approaches to the question of what constitutes a "lyric genre," and what poetic, social, and performative criteria should be invoked in answering such a question.

\section{Some Working Definitions of "Genre," "Lyric," and "Song”}

Defining what we might mean by a "genre" of "lyric poetry" in the context of ancient Greek song culture is open to many different approaches and biases. This whole volume is testimony to that range of difference. Whether we prefer

* I am very grateful to the three Editors, especially Naomi Weiss, for constructive criticism and advice at various stages of the writing and revising of this chapter.

1 As will become clear during the course of this chapter, I will be lumping together under the term "Korybantic" a fairly wide range of related performance-types, almost all of them involving vocalizing and dancing accompanied by double-pipes (auloi) and/or percussion instruments as components of an exciting and mood-altering ceremony. 
to emphasize occasion, content, purpose and social function, formal structure, rhetorical strategies, verbal registers and metrical distinctions, persona of the author/singer, or any other set of conventions and poetic/performative "rules," may be largely a matter of taste and critical allegiance. ${ }^{2}$ By any definition, however, specific conventions and distinguishing marks, or actual rules, were always involved in the performance of any particular type of "song" created, performed, and reperformed in archaic and classical Greece, even whilenotoriously—there will always remain a number of poems and song-types that resist easy classification into any one generic category.

"Song" involves a combination of words and music. Greek "song-culture" can and should therefore be discussed in terms both of its verbal content and of its melodic, rhythmic, and textural elements. ${ }^{3}$ Unfortunately, however, almost all of the musical components of our surviving lyric poems are lost to us, except for their metrical structures and a few verbal self-references. ${ }^{4}$ Consequently we are in the habit of discussing them almost exclusively in terms of their verbal elements, i.e., treating them simply as "poems" and works of literature, even though it will often have been the musical (and visual) elements that made the strongest impact on the ears, eyes, and minds of their original audiences. ${ }^{5}$

Sidestepping questions (explored by several other chapters in this volume) about the validity or stability of "generic" categories of lyric poetry within the song-culture of the archaic and classical periods, as defined by themselves or by Hellenistic and later critics, I want in this chapter to focus instead on some of the musical differences that might sometimes serve to categorize particular

2 My own critical debts and allegiances with regard to genre theory are mostly to the following: Färber 1932; Frye 1957; Olson 1969, 1976 (i.e., the school of "Chicago Critics," who, following Aristotle, treated lyric poetry for the most part as a branch of rhetoric); likewise Cairns 2007 (first ed. 1972); also Rotstein 2010, 2012. For further discussion see too Herington 1985; Conte 1992; Nagy 1994-1995, 2016; Calame 1998a; Ford (this volume).

3 In the Greek context, one might say also that song usually involved bodily movement, often in the form(s) of "dance," as well as some kind of audience response. These corporeal aspects of song-performance will accordingly be considered (intermittently) in what follows.

4 See Prauscello 2012 for Pindaric self-references to "Dorian," "Aeolian," "Lydian," and other melodies. Within the lyrics of Greek tragedy, such self-reference is not uncommon: see esp. Weiss 2018. No actual melodies survive for any non-dramatic Greek songs composed earlier than the Hellenistic period. For full discussion of ancient Greek melodies and instruments, see Barker 1984, 1989 passim; West 1992; Matthieson 1999; Pöhlmann and West 20o1; Hagel 2010.

5 So e.g. Hes. Theog. 1-115; cf. Naerebout 1997; Peponi 2012; Butler and Purves 2013; also Martinelli 20ogb; Schironi (this volume) for discussion of ancient scholarly comments about the musical and choreographic elements of archaic lyric, showing that their comments, limited as they are, are almost entirely derived from the words of the written texts themselves. 
types of vocal performance within this or that clearly identifiable type, and on audience affect (the aesthetic/emotional impact on the listeners) as a measure of these differences.

However we choose to define "genre," we can generally expect to understand any particular song better and enjoy it more if we recognize what kind of poem/utterance/performance it is, and this usually entails being somewhat familiar with the musical as well as verbal idiom(s) within which it is composed. In the ancient Greek world, musical categories (i.e., differentiation in terms of tonos, harmonia, rhythm; formal compositional structures; solo voice vs. chorus; also choice of accompanying instruments) were normally established by quite objective criteria and were somewhat consistently recognized. ${ }^{6}$ In particular, musical genres were publicly registered and announced

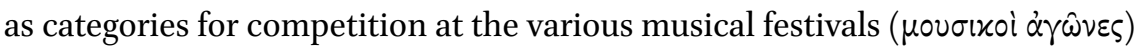
observed all over the Greek world. ${ }^{7}$

Ancient discussions of poetry and literary form, and ancient categories for musical competition, did not apparently recognize "Korybantic," or other kinds of Bacchic/ecstatic performance, as a "genre." But in discussions of music and its effects this kind of subliterary performance sometimes loomed quite large. My chapter is intended as an ethnomusicological inquiry into this discrepancy, focusing on this one particular genre, or type, of Greek musico-religious performance, with a view to clarifying some questions about the nature, purpose(s), and critical reception of a widespread and culturally important phenomenon that has tended to fly somewhat under the radar of modern scholars writing about ancient Greek song culture. I will suggest that whereas Korybantic and other such performance was regarded by most elite writers in antiquity (if it was mentioned at all) as merely a kind of crude psychotherapy and/or vulgar religious extravaganza, of negligible social or artistic worth, the evidence (especially that provided by Plato and by Aristotle in the Politics) suggests that it was in fact widely experienced and enjoyed by all levels of society, and might properly be classified (by us moderns) as a distinct and socially important lyric genre.

Ancient Greek "song culture" has been much discussed and analyzed, since at least the 1970s, in reaction against a previous—and long-standing —overemphasis on the "literary" qualities of the surviving texts. As is by now widely recognized, the texts that we refer to generally as "archaic/classical Greek lyric poetry" were not composed originally nor primarily to be read on the page,

6 See esp. Arist. Pol. bk. 8; [Arist.] Pr. chs. 11, 19, De Audib., P. Hibeh 1.13; further West 1992; Rotstein 2012.

7 Kotsidu 1991; Manieri 2009; Power 2010; Rotstein 2012; etc. 
but to be performed — sung, and often danced as well, i.e., to be heard and seen. ${ }^{8}$ The range of different types of musical performance, even of vocal performance, was broad, and the processes whereby some (relatively few) of these songs ever came to be written down and preserved were many and various. Most musical-poetic performances surely never existed as reading-texts, and the literary texts that we happen to possess will have tended to be, on the whole, the cream of the crop, selected by contemporaries and by later critics/scholars/educators precisely because of their superior verbal quality and prestige. ${ }^{9}$ But in the case of many, perhaps most, of the public and private performances that comprised "Greek song culture," the chief point and impact of the performances, I would suggest, resided less in the details of the words that were sung - the verbal text - than in other aspects, such as the melody, rhythms, choreography, instrumental and vocal timbres, the physical attributes (including costumes as well as gestures) of the performers, and the collective energy of the whole group.

As we all know, a song with only minimal words-and these quite predictable, repetitive, and often banal, perhaps improvised and variable - can still be a powerful and engaging form of cultural expression, celebration, and communication. Some popular songs are poetic (verbal) masterpieces; but in many other cases, it is the quality of the voice(s) and instrumental accompaniment, the affective interplay between sounds (music) and sights (bodily movement, whether as formal "dance" or in other kinds of corporeal expression) that make a "song" into a classic, a hit, a cultural statement. ${ }^{10}$ In a record store, the $45 \mathrm{~s}$ or LPs or CD s containing these various different kinds of songs have always been placed in separate "bins" - they belong to different genres; and Grammies are likewise awarded to singers and groups according to various categories that usually have more to do with musical idiom and style than the actual verbal content. ${ }^{11}$

Poems that were inscribed on stone or bronze-i.e., for reading-were generally composed in non-lyric meters, usually hexameters or elegiac couplets.

9 See esp. Pfeiffer 1968; Reynolds and Wilson 1991; Rutherford 2001: 137-158; Acosta-Hughes 2010 for the ancient reception and textual transmission of the Greek "lyric" corpus.

10 If we look back, e.g., to the era of the 1960s and 1970s, Bob Dylan and Leonard Cohen can be seen occupying one end of this spectrum - these are "wordsmiths, poets" whose actual singing voices are quite limited. On the other end, e.g. the Isley Brothers' "Twist and Shout" (subsequently taken over by the Beatles), or James Brown's "Cold Sweat" spoke to their audiences largely by other means than words. In all four of these cases, their songs quickly became and have remained classics.

11 See, e.g., the scores of separate categories listed in the article "Popular Music Genre" on Wikipedia, accessed June 23, 2016: https://en.wikipedia.org/wiki/List_of_popular_music genres. 
For ancient musical festivals and contests we are fairly well informed as to the different categories of performance, both instrumental and vocal: prizes were normally awarded for kitharoidia, kitharistike, auloidia, auletike, and rhapsoidia, sometimes for dithyrambos, for tragoidia and/or satyr-play and/or komoidia, and even for sophistike. ${ }^{2}$ Virtually none of the texts (words) for any of those thousands of aulodic or kitharodic songs (and very few indeed even of the large-scale choral dithyrambs) have survived; but it is clear that the solo musical events were very popular in their day, and the names of many of the victorious singers and instrumentalists are recorded on stone and, in the case of the most distinguished, in anecdotes and "histories" of Greek musical culture (as we learn from such late sources as Athenaeus and pseudo-Plutarch's On Music). ${ }^{13}$

We are entitled, then, to regard kitharody or aulody not only as musical genres but perhaps as lyric genres as well (since they involved songs). The generic conventions for kitharodic performance were apparently somewhat standardized: a kitharoidikos nomos was a suite of movements, often similar to the musical structure of a purely instrumental competition piece for kithara or auloi. ${ }^{14}$ The surviving fragments of Timotheus and other fifth- and fourth-century performers give us further clues about the language, typical themes, and idioms of such poems. ${ }^{15}$ But these authors too represent the literary high-flyers, and we get a strong impression from descriptions of musical performances of that era that for the most part the audience and judges were more interested in the quality of voice, melody, and delivery, and in instrumental virtuosity, than in subtleties of linguistic structure, imagery, and argument. ${ }^{16}$

12 Kotsidu 1991; Csapo and Slater 1995; Wilson 200o; Le Guen 2001; Manieri 2009; Power 2010; Rotstein 2012; Kowalzig and Wilson 2013; LeVen 2014. Most of our direct epigraphic evidence about festival competitions comes from the third century вСЕ or later, but the basic categories were mostly in place already by the sixth century. For choral contests, see Wilson 2000 (tragedy, comedy and dithyramb); Kowalzig and Wilson 2013 (dithyramb); for Paean, see Rutherford 2001; also in general Kowalzig 2007b.

13 For kitharoidia in particular, see Power 2010. In general, for a prosopography of Dionysian Artists, see Stefanis 1988; Le Guen 2001. For Athenaeus, pseudo-Plutarch et al. on ancient Greek musicians, see esp. Barker 1984: 205-303; West 1992; Olson 2012; and the papers in Gentili 2012.

14 Power 2010: $185^{-234}$.

15 See Campbell 1993 vol. 5; LeVen 2014.

16 Even in the Theater of Dionysus at Athens, the musical (i.e. auditory and choreographic) effects often dominated the audience's experience, from the time of Phrynichus, Pratinas, and Aeschylus through into later centuries. Cf. e.g., Pratinas $(\operatorname{Tr} G F$ 1) 4 fr. 3 , "Aeschylus"

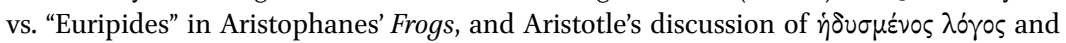
$\mu \varepsilon \lambda \circ \pi \circ i^{\alpha} \alpha$ (Poet. 6.1449b25-34), with e.g. Sifakis 2001. 
These examples should suffice to remind us that ancient Greek "song culture" operated along a spectrum, just as, for example, contemporary rock, pop, folk, soul, hip-hop, and techno music does, with some kinds of songs (song-genres) relying more on their words, others more on their rhythms, melodies, harmonies or vocal-instrumental timbres (and/or the performers' physical appearance), while several occupy a middle ground in which words and music are evenly balanced. In this chapter I will be focusing on some of the Greek song-types that existed on the less verbal and more rhythmic-textural (and corporeal) end of that spectrum, in particular "Korybantic" and other "enthusiastic/orgiastic" performances, and exploring the question whether or not such performances should be regarded as constituting a recognizable and distinctive "lyric genre" - and, if so, what further implications this might have for our overall understanding of the different possible statuses and functions of "lyric genres" within Greek song culture at large.

One way of thinking about the spectrum of song-types that I have outlined here, and the place of korybantic-type performance within it, is in terms of a "grid" of performance practices, on which we can plot the various different forms, instruments, and concepts of ancient Greek musical culture. In Table 8.1, I have organized and presented such a grid so as to illustrate at a glance how the forms of music-making that were most socially respectable, morally approved, and aesthetically admired (at least among our elite literary sources) tend to coalesce around particular instruments, particular divinities, particular types of melody, and a restricted and distinct range of uses of the human voice, while other instruments, divinities, tunings, and modes of vocalizing are associated more or less definitely with non-elite, and in several cases non-Greek, musical performance. ${ }^{17}$

The instruments, vocal sounds, and tunings/styles that are located towards the left-hand side of the grid are generally described by our elite sources as being more appropriate to "high" musical art and to male citizen performance and listening, while those on the right-hand side are generally regarded as more feminine and/or exotic and foreign, more déclassé or morally suspect, and hence to be either ignored completely in the educationalists' and moralists' accounts or to be classified as unsuitable for male citizen performance. In parallel with these tendencies, and providing a vital form of cultural justification for them, we may align the religious elements, with Apollo (and his

17 This grid, or spectrum (which obviously owes much to Bourdieu 1987 and 1990), is largely synchronic and is intended more as a heuristic than as a rigorously analytic device. 


\section{Male}

Greek (esp. “Dorian”) strong, free, direct, dominant regular/regulated, measured rational, civilized normal—tight, tense, straight simple, plain orthos, ithus, gumnos, haplous

\section{IMAGINED CHARACTERISTICS}

\section{Female}

foreign/barbaros/Asian (or "Ionian")

weak, delicate, slavish

irregular, wild/uncontrolled, promiscuous emotional, irrational ("natural"?)

bent, slack, deviant, "queer" adorned, intricate, cosmetically enhanced poikilos, polychordos

\section{INSTRUMENTS USED: STRINGS vS. PIPES and PERCUSSION}

lyres (lura, kithara) ${ }^{\text {a }}$

pipes (auloi)

percussion (tumpanon, seistron, etc.)

TYPES of TUNINGS/SCALES (harmoniai, tonoi)
Dorian
Phrygian
Ionian/Iasti
Lydian, etc.

\section{MUSICAL DIVINITIES}

Apollo, Hermes

Dionysus, Aphrodite

(Zeus, Athena ...)

Rhea, Cybele, Sabazius, Bendis, et al.

Kouretes, Korybantes

\section{USES of VOICE and LANGUAGE}

$\begin{array}{ll}\text { logos (words, language, ratio) aude (human voice) } & \text { phōne (animal/human/ } \\ \text { instrumental "voice") }\end{array}$

\section{DANCE and/or OTHER CORPOREAL ACTIVITY}

symmetrical, disciplined, restricted, restrained unpredictable, free-form,

unrestricted, abandoned

\section{TYPICAL SONG-TYPE/LYRIC GENRE}

$\begin{array}{lll}\text { paean } & \text { threnos } & \text { dithyramb }\end{array}$

a Several (important) differences can be mapped within the broad range of stringed instruments: but these differences are not significant for the purposes of my chapter. See further Maas and Snyder 1989; West 1992: 49-6o, 70-8o; Bundrick 2005: 13-34, 103-131; Griffith 2017. 
parents $)^{18}$ at the left end, and more exotic divinities such as Cybele, Sabazius, Dionysus, and the Korybants at the right: ${ }^{19}$ for different religious ceremonies and rituals might employ distinctly different instruments and different kinds of human vocalizing.

So, for example, a paean to Apollo, composed in Dorian mode, sung in regular strophic stanzas by a stationary soloist or by a chorus dancing in formation to the accompaniment of kithara or lyre, would be located securely at the left end of the grid, while an aulos- and percussion-fueled song in astrophic metrical units (perhaps even improvised) addressed to Cybele or Dionysus, with frequent non- or semi-verbal vocalizings and ululations, would sit at the opposite (right) end. Not quite so far to the right we might locate e.g. a "Carian lament" 20 or a Euripidean monody in the theater-though the fact that the latter is performed by a male actor who is only artfully pretending to be a lamenting woman or foreigner might modify an audience's assessment.

Several of the key oppositions in this schema correspond closely to oppositions outlined in Book 3 of Plato's Republic, where Socrates explains why in the ideal city of Kallipolis the young future guardians and philosopher-kings should not play or listen to any instrument except for the seven-string lyre or kithara, should not sing or hear songs in which the melodic or rhythmic elements dominate over the verbal ones, and should only be exposed to Dorian or Phrygian tunings (no Lydian, Ionian, etc.). ${ }^{21}$ Multi-stringed instruments are explicitly banned, as are the pipes (auloi); ${ }^{22}$ and percussion instruments are

18 In the Homeric Hymn to Apollo, Zeus and Leto do not join the other (young) Olympian divinities in dancing, singing, and "sporting" ( $\pi \alpha i \zeta 0 v \sigma \iota)$ together when their son performs on the kithara (182-206): Apollo's parents prefer to sit, listen, and watch, rejoicing in the whole auditory/visual/social experience (204-206). Aristotle likewise observes (Pol. 8.5.1339b6-10) that Zeus himself does not ever play an instrument (similarly, Aristotle's

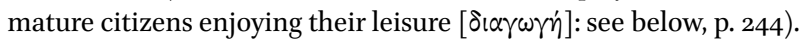

19 The Greeks regarded several of their divinities as being highly musical, but not all in the same ways. As Nietzsche and many others have noted, Apollinian music tended to be different in flavor, instrumentation, and effects from Dionysian music, and as we shall see, "Korybantic" performance belongs quite far to the right side of our spectrum, overlapping with the music of Dionysus and Cybele. On the complex issue of the gendering of Greek music in general, see Griffith 2017 and forthcoming.

20 Pl. Leg. 7.80oe, Ar. Ran. 1296, etc.; cf. Prauscello 2014: 183-191.

21 Pl. Rep. 3.397-402a; see further e.g. Anderson 1966; Barker 1984: 124-136; Wallace 2005; Pelosi 2010: 36-48. On the unexpected favor shown here to Phrygian (as well as to the anticipated Dorian) mode, see e.g. Gostoli 1995 .

22 All of these banned instruments were apparently common in the music-making of Assyria, Phrygia, and elsewhere in the Near East during the ninth to seventh centuries BCE, i.e., the prime sources of early Greek music (Franklin 2002). In Athenian vase paintings of the classical period, multi-stringed instruments are always played by women (Bundrick 
not even mentioned. ${ }^{23}$ The musical regulations for the citizens of Magnesia in Plato's Laws seem to follow similar restrictions, ${ }^{24}$ though there the main focus is on dance and choral performance and less attention is paid to the citizens' actual playing of musical instruments.

The guidelines proposed by Aristotle in the Politics for the musical education of young (male) citizens in school are likewise strictly in favor of lyre and kithara over pipes, and of Dorian melodies over any other. ${ }^{25}$ But Aristotle, as we shall see, has a much broader interest in the overall music scene of a typicalor ideal—community, and of the different possible — and desirable-functions for various kinds of music than we find anywhere in Plato. Aristotle consequently will serve as one of our chief guides in locating and interpreting the nature of "sacred, orgiastic" (including "Korybantic") music and of the psychosocial function(s) of such performances in classical Greece.

In the rest of this chapter, therefore, I will first sketch the place occupied by Korybantic and other "enthusiastic" kinds of music within Aristotle's culturalpolitical universe. Then, after surveying briefly the nature of "trance" musical performances as a world-wide phenomenon, I will discuss the particular forms that such performances (including Korybantic ceremonies) seem to have taken in the ancient Greek world, noting the common elements of intense audience affect, widespread corporeal and kinetic engagement, and predominance of female and non-elite participation, all of which doubtless contributed to the relatively déclassé and/or neglected status of such musical activity among the writings of most ancient critics. I will conclude with some remarks about the place of these performances - and other performances that belong on the farright-hand side of our "grid" - within our broader understanding of ancient concepts of genre.

2005: 30-33). For discussion of the growing disapproval of the auloi among elite Athenian intellectuals from the mid-5th century onwards, see Wilson 1999; Martin 2003; Bundrick 2005 .

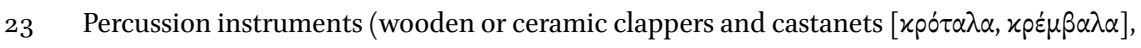

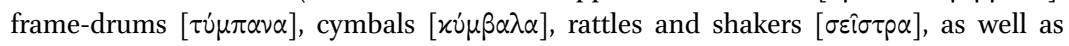
wooden or bronze bull-roarers [ $\hat{\rho} o ́ \mu \beta o l])$ were all quite extensively used in Greek and other Near Eastern musics: West 1992: 122-128; Mathiesen 1999: 162-177; Bundrick 2005: 46-48; Kolotourou 2011. But for the most part Greek educationalists and music theorists disregard them, and when these instruments are mentioned in high literature they are usually treated as belonging to women or foreigners (or both). See further below, p. 258 .

24 Pl. Leg. 653c-66oc, 664b-671a, 70oa-701b, 798d-8o2e, 812b-e; see Barker 1984: 140-168; Peponi 2013b; Prauscello 2014.

25 Arist. Pol. 1341a1o-41b8; 1342a29-42b17; see Newman 1902; Dreizehnter 1970; Lord 1982; Kraut 1997 ad loc.; also Barker 1984: 172-182. 


\section{Aristotle and the Genre of "Enthusiastic" (including Korybantic) Music}

Aristotle is generally our most helpful source of information and ideas about social aspects of ancient Greek musical performance and listening. ${ }^{26}$ In Book 8 of the Politics, Aristotle seeks to describe and explain the different psychological and cultural functions that various kinds of music can serve, and in the course of his discussion he provides interesting perspectives on the effects and value of Korybantic and other kinds of what he terms "enthusiastic" and "sacred" music-making. Aristotle is also valuable to us, of course, as the first author whose work survives to have undertaken a somewhat systematic analysis of artistic and poetic "genres," i.e., the Poetics. Unlike Plato, Aristotle can generally be trusted to report fairly straightforwardly what he takes to be the commonly held opinions of his contemporaries ( $\left.\varepsilon^{2} v \delta \circ \xi \alpha\right)$ and to take these seriously as deserving discussion. His own tastes and opinions also seem to be in many respects normal and typically Greek (in contrast, again, to Plato's): sexist, racist, elitist though Aristotle may be, he nonetheless belongs among the Greek mainstream in most of his basic assumptions about the nature and purpose of human existence. In particular, he recognizes the positive value of pleasure, bodily as well as spiritual/mental, and of material processes and goods as well as intellectual ones; and he is especially interested in the pleasures provided by music.

Aristotle emphasizes the importance and pervasiveness of music in human communities, and devotes considerable attention to the question of how it ought to be deployed in his model polis: indeed the Politics ends with his discussion of music. ${ }^{27} \mathrm{He}$ recognizes that music in general is enjoyable (for everyone, of all ages and character-types: $1340 \mathrm{Oa}-5 ; 1342 \mathrm{~b} 17-32$ ) in acoustic/sensory terms (i.e., the sounds of music are pleasant to our ears), and that it contributes to the well-being of the various (disparate) members of any given society-even while he also argues, like Plato, that certain kinds of music, listened to in the correct manner, may provide a superior benefit to those who are discriminating enough to appreciate them. In his (rather rambling, and in places disjointed)

26 In addition to his remarks in Politics Book 8 about the educational and political functions of music (discussed in what follows), Aristotle is also valuable to us as a theorist of acoustics, aesthetics, and psychology. See esp. Ar. Poet., De an. 2.8; also ps.-Arist. De audib. and $\operatorname{Pr}$. (mainly chs. 11 and 19), both clearly Peripatetic but not authentically Aristotelian.

27 This discussion occurs in the course of Aristotle's larger discussion of citizen education, which has led some commentators-mistakenly—-to try to limit Aristotle's comments to their potential educational implications. 
analysis, Aristotle ends up laying out a basic framework in which musics of various kinds, performed by different practitioners and for different audiences, are to be classified in five basic categories, each of which serves a somewhat different social function - though it seems that in some cases the same musical performance might fall into more than one category, depending on its audience. $^{28}$

Aristotle's categories of musical types, or functions, are not as neatly laid out for us as we might wish. In fact, he deploys two different systems for categorizing music: one in terms of types of melodies ( $\mu \dot{\varepsilon} \lambda \eta$, $\dot{\alpha} p \mu o v i \alpha l)$, according to the way that "some philosophers distinguish/define things" (1341b32-34: $\dot{\omega} s$

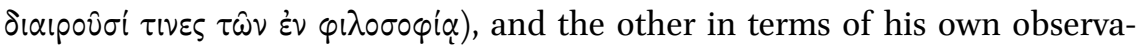
tion of music's psycho-social effects. According to the first system, there are three basic types (we might say, "genres") of melody: "ethical," "practical," and "enthusiastic."29 According to the second system, which forms the organizing principle for most of Aristotle's discussion in Politics Book 8, there are four main functions for music in society: (1) relaxation, release of stress, fun ( $\dot{\alpha} \dot{\alpha} \pi \alpha \nu-$ $\sigma ı \zeta, \ddot{\alpha} v \varepsilon \sigma \iota \varsigma, \pi \alpha ı \delta$ ' $)$; (2) ethical improvement, especially for the young ( $\pi \alpha ı \delta \varepsilon i \alpha)$; (3) development and refinement of good taste in leisured/aesthetic critique and appreciation ( $\delta(\alpha \gamma \omega \gamma)$ ); and (4) arousal of strong emotion and affective

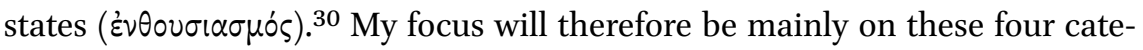
gories that Aristotle discusses in detail—especially the category of "enthusiastic" music.

28 This whole lengthy passage (1339a11-1342b32) presents several minor detours and also a number of textual difficulties and uncertainties, even while the main threads of Aristotle's argument remain fairly clear and self-consistent. Scholars disagree as to how relevant

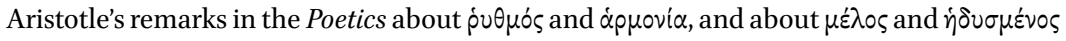
$\lambda$ 'ós, or his and his students' discussions of the effects of sound on the body and soul in any of his more technical works (De an. esp. 2.8, De audib., Pr., esp. chs 11 and 19), are for the interpretation of the Politics. My own opinion is that there is no good reason not to read these works and these passages in light of one another. In general, for commentary and interpretation of the musical content of Politics 8, see esp. Newman 1902; Lord 1982; Barker 1984: 170-182; Kraut 1997; Sifakis 2001; Halliwell 2011: 236-249.

29 Of these three categories, "ethical" and "enthusiastic" are discussed in detail by Aristotle,

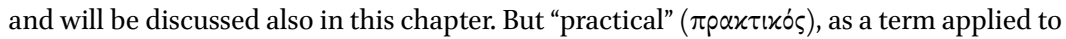
harmoniai, is never explained by Aristotle in the Politics (see n. 30). It presumably refers to non-"enthusiastic" (i.e., non-Phrygian) music that is played in contexts of everyday life and work (rather than for relaxation and entertainment), e.g., in factories, for healing, on ships (to help rowers keep time), for gymnastic and athletic training sessions, etc. Barker

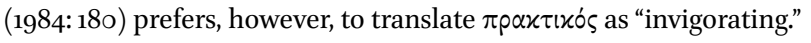

30 In two-or possibly three-places (1341b34; 42a4; 42a15?), Aristotle does use the term "practical" as a possible fifth category, but without any explanation: see n. 29; also n. 39

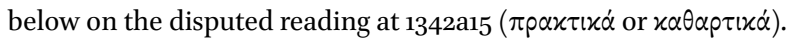


But before we examine in more detail these four categories, we need to pause to clarify an important question concerning the short-term vs. long-term "ethical" impact of music on the soul, according to Aristotle. As he launches himself into his discussion of the role of music in the education of young future citizens, he characteristically pauses to raise some fundamental questions:

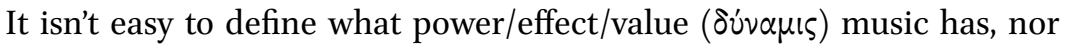

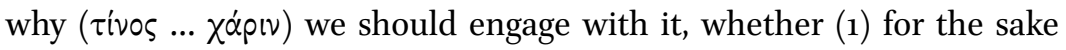

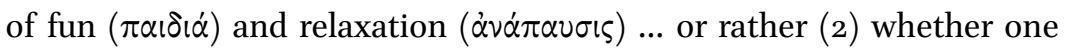

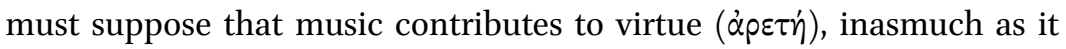

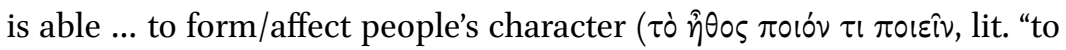
render [someone's] character of such-and-such a kind") by accustoming

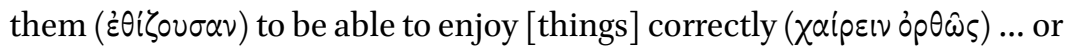
whether (3) it contributes to leisure activity ( $\delta(\alpha \gamma \omega \gamma \eta)$ and to intelligent

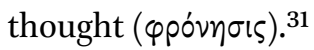

ARIST. Pol. 1339a14-26

A little later (1340a14-28) Aristotle observes as a basic fact that "music is something enjoyable" ( $\tau \hat{\omega} \nu \dot{\eta} \delta \dot{\varepsilon} \omega \nu$, lit. "[one] of the pleasant [things]"), while also suggesting that acoustic/musical stimuli make an unusually strong affective impact on the soul; and he goes on to claim (following the strong critical currents of his day stemming from Damon of Oea and Plato) that the moods or emotions present in and conveyed by melodies and rhythms are "similar to" (o $\left.\mu \circ i^{\prime} \mu \alpha \tau \alpha\right)$ or "expressive/imitative of" ( $\left.\mu \mu \eta \dot{\eta} \mu \alpha \tau \alpha\right)$ actual moods and emotions that are produced by events in the real world. ${ }^{32}$ Then he adds: "For we change [in] our soul when we listen to such [affective rhythms and melodies]" ( $\mu \varepsilon \tau \alpha-$

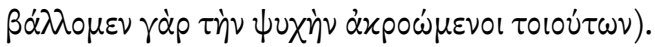

31 It is noticeable that here Aristotle omits "enthusiastic" music from his list and proposes only three functions, one of several indications that his discussion in Book 8 of the Politics exists in a somewhat preliminary, unrevised, and even muddled state. But as I will attempt to demonstrate in what follows, not only does he credit "the philosophers" with including enthusiastic music as one of the three basic types (above, n. 29) but he also himself devotes considerable attention to this a little later on (below, pp. 245-248).

32 Aristotle suggests that when music is/sounds "angry" or "mild," "courageous" or "restrained," these affective qualities in the music constitute "likenesses of the actual natures"

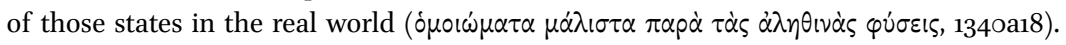
This question, how and in what sense music can be or can sound (i.e., strike listeners as being) "emotional," and how music is able to trigger the strong affective states that it demonstrably does, continues to be hotly debated by musicologists, neuroscientists, and philosophers: see e.g. Meyer 1956; Kivy 1989, 199o; Patel 2008; Juslin and Sloboda 20o1; Bicknell 2009. 
Does Aristotle think that every moment spent listening to an affecting, emotionally arousing piece of music (or watching an affecting tragedy, for that matter), produces a lasting effect (a "change") in the "character" of a person's soul? (This appears to be e.g. Plato's view, and is one of Socrates' chief reasons for banning most tragic performances from Kallipolis.) Or does Aristotle make a distinction between habitual listening to certain types of character-building music (especially for the young), on the one hand, and occasional listening to various kinds of more or less affecting music (or watching pity- and fearinducing tragedies in the theater) by adults, on the other? I believe that the latter is Aristotle's position (though he may indeed vacillate a bit, during the course of his discussion in Politics 8). For Aristotle, listening to emotionally arousing music of a "non-ethical" kind can be both enjoyable and worthwhile for all kinds of people, and this is because the affective state that is produced by the music is short-term and transitory. (The same is true for the enjoyment of tragedy.) Aristotle thus recognizes that one major "genre" of music - which must necessarily include songs as well as purely instrumental performancesis designed and experienced primarily for its affective qualities, rather than for its verbal (intellectual) content or ethical impact. We shall return to this issue at the end of this chapter. But first we need to survey in a little more detail Aristotle's account of the four (or five) basic functions for music in society.

The first and most obvious function of music that he outlines is also the most pervasive: (1) Relaxation, release of stress, fun ( $\alpha \dot{\alpha} \alpha \dot{\alpha} \alpha \nu \sigma \iota \varsigma, \alpha^{\prime} \nu \varepsilon \sigma \iota \varsigma, \pi \alpha \iota \delta 1 \alpha$ ). Music is greatly enjoyed by absolutely everyone (1339b2o), young or old, male or female, gentleman, laborer, or slave, and its ability to provide harmless pleasure (like, e.g., sleep, or drinking, or dancing, as Aristotle suggests at 1339a17-21) is recognized as a benefit by all, especially by those whose lives are full of stress

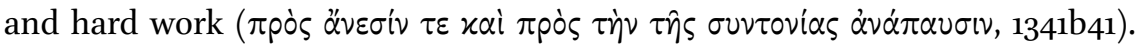
Thus music in general is recreational, relaxing and enjoyable, with no harmful side-effects—-definitely a social good. ${ }^{33}$

(2) Like Plato's Socrates and many other ancient philosophers and educational theorists, Aristotle also is committed to the notion that certain kinds of music can provide ethical improvement, especially for the young (Pol.1339a2o ff.

33 Aristotle does not go into detail in the Politics about the physiological and psychological mechanisms through which such "relaxation" is provided by music, nor why playing and/or listening to music is such "fun" ( $\pi \alpha \iota \delta$ ' $)$ for humans. But he appears to relate these effects to the natural human delight in rhythm, harmony, and mimesis (as in Poet. ch. 4), while recognizing (as in De an. 2.8) that sounds of all kinds cause "movement" (xivnoı) and "change" within the human ear and hence in the soul $\left(\psi v \times \eta^{\prime}\right)$, a process of stimulation that can be inherently — and harmlessly—pleasurable, just like other sensory experiences (taste, smell, touch, and sight). See further Sifakis 2001; Griffith 2018. 
and passim). Specifically, he recommends that musical pieces composed in the Dorian mode and performed on stringed instruments (cf. Pl. Rep. 397a-402a, discussed above) should be taught in school as a component of the characterformation of future citizens (1341a1o-42b17). ${ }^{34}$ Accordingly, he disapproves of aulos-music within an educational program (1341a17-24) because "the aulos is not an 'ethical' instrument but rather an 'orgiastic' one," i.e. it is not good for building a virtuous character but rather for arousing emotional responses. So, he explains (1341a22-24), "the proper occasions (xaıpoús) for using the aulos are those in which the performance $\left(\theta \varepsilon \omega p^{i} \alpha\right)$ is designed to produce emotional stimulation-and-release ( $\left.\alpha^{\prime} \dot{\theta} \alpha \rho \sigma v\right)$ rather than instruction ( $\left.\mu \dot{\alpha} \theta \eta \sigma v\right) . "$

(3) Rather nebulous-but important for Aristotle's elitist aesthetics-is music's function as an object of leisured, aesthetic critique and appreciation,

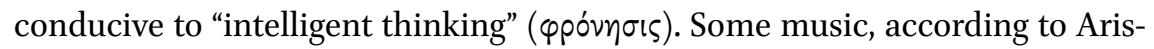
totle, should be designed and played in a refined style so as to be appreciated (though not actually performed) by highly discriminating, leisured listeners, for its own sake. This music will be performed, it appears, by professional musicians who themselves presumably lack the aesthetic discrimination of their elite audience, yet can perform the appropriate pieces with the requisite skill. Aristotle's rather evasive label for this psycho-social function, or activity, is $\delta$ ¿ $\gamma \omega \gamma \eta$ ' (lit. "pastime"), and this kind of "appreciation" of music, he insists, should be quite distinct from-and is superior to-the cruder "relaxation,

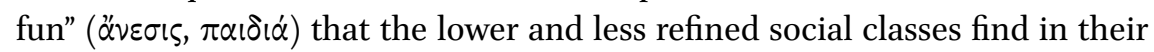
music-listening. The question, whether or not Aristotle succeeds in drawing a valid distinction between these categories (1) and (3), need not concern us here. $^{35}$

34 Belief in the ethical effects of music was widespread in antiquity, but by no means universal. Thus whereas Plato takes it for granted in the Republic and the Laws that Dorian melodies will produce courageous and self-disciplined character in those who perform and listen to them, while Ionian or Lydian will produce more dissolute characters, other authors from around the same date pour scorn on the idea that musical tunings affect character and social behavior (e.g., the author of P.Hibeh 1.13, focusing on alleged differences in character between communities in different regions of Greece who are brought up on enharmonic vs diatonic tunings; see e.g. Barker 1984: 183-185).

35 In the end this distinction may be thought to amount to nothing more than a mystification of certain arbitrarily preferred kinds/modes of "relaxation" and "fun," i.e. a typical upperclass fetishizing of (high) "art" vs. (low, vulgar, cheap) "entertainment." See e.g. Bourdieu 1987; also Ford 2004. Kidd 2016 argues that Aristotle here and elsewhere always distinguishes between "play" ( $\pi \alpha \iota \delta i \alpha)$, as involving purely corporeal effects of $\alpha^{\prime} \nu \varepsilon \sigma \iota \varsigma, \dot{\alpha} \nu \alpha \dot{\pi} \pi \alpha v \sigma \varsigma$, etc., and the higher-grade psychic effects of "leisure" ( $\sigma \chi 0 \lambda \eta^{\prime}, \delta 1 \alpha \gamma \omega \gamma \eta$ ). But given Aristotle's account of sound and hearing (De an. 2.8), it is hard to see how corporeal and psychic responses can be thus kept completely separate. 
(4) Aristotle's most important category for our purposes is music's capacity to be especially affective and emotionally arousing. He frequently employs

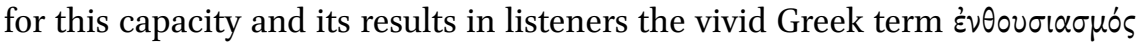
(lit. "the state of being है $20 \varepsilon \circ \varsigma^{\prime}$ " "having god inside one") along with the adjec-

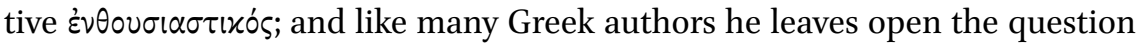
whether the term is to be understood literally or figuratively. ${ }^{36}$ Other, less colorful terms that Aristotle uses in the Politics, apparently interchangeably with

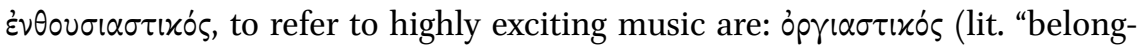

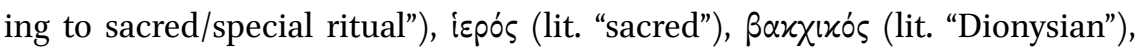
and $\pi \alpha \theta \eta \tau$ ixós (lit. "pathos-inducing," i.e. affective, emotional). ${ }^{37} \mathrm{He}$ repeatedly makes clear that this/these kind(s) of music is/are played (mostly, or always) by the pipes (auloi) and in the Phrygian mode (harmonia or tonos). ${ }^{38}$ It becomes clear as Aristotle's discussion proceeds that he thinks virtually all listeners find music of this kind to be exciting, affective, and mood-altering, even while he notes that certain especially impressionable or unstable people may be stimulated to an exceptional degree and may experience an extreme state of emotional "release" as a result ( $\varkappa \dot{\alpha} \theta \alpha \rho \sigma \iota \varsigma)$. This is the point at which Aristotle mentions what must be Korybantic or Korybantic-type performances:

It is clear, therefore, that all the musical modes (íproviaıs) should be employed [sc. in an ideal city], but not all in the same way. In education

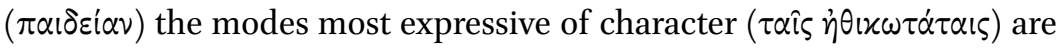
to be preferred, but in listening to the performances of others we may admit the "practical" modes ( $\pi \rho \alpha \kappa \tau i x \alpha i \varsigma)$ and the "affective" modes ( $\sigma(\alpha \sigma \tau i x \alpha i \varsigma)$ also. For any affect/emotional state $(\pi \dot{\theta} \theta 0 \varsigma)$ that exists very

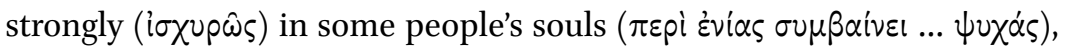

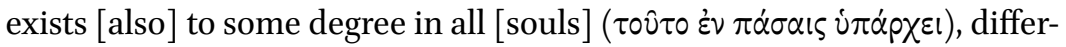
ing only in degree ( $\tau \hat{\omega} \delta \dot{\varepsilon} \hat{\eta} \tau \tau o \nu ~ . . . ~ x \alpha i े ~ \tau \hat{\omega} \mu \hat{\alpha} \lambda$ ov): for example, pity, fear,

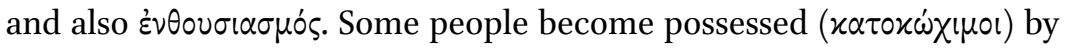

$3^{6}$ Similar ambiguity between literal and figurative reference surrounds other such terms, e.g.

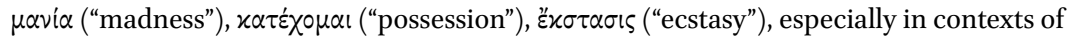
artistic creativity and religious fervor: see further Burkert 1987: 112-113; Halliwell 2011: 166179; Peponi 2012: 20-23.

37 Modern scholars have employed various translations for the kind of altered mental state

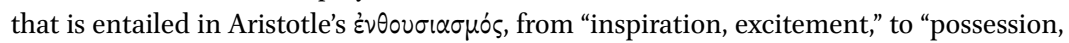
ecstasy," to outright "frenzy."

38 See esp. 1342b1-5: "Among the modes ( $\dot{\alpha} p \mu o v i \omega \hat{v})$ the Phrygian has the same impact/effect/

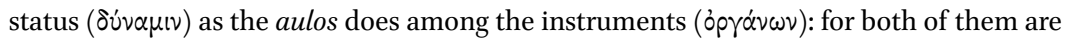
'orgiastic' and 'pathetic' ..." Thereupon Aristotle proceeds to discuss the dithyrambic performances of Philoxenus and others (1342b6 ff.). 
this movement ( $\varkappa(\eta \dot{\gamma} \sigma \varepsilon \omega \varsigma$, sc. of the soul by musical stimuli), and from

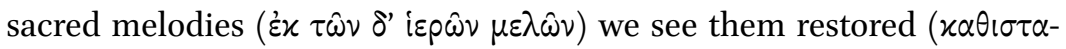
$\mu \varepsilon \dot{\varepsilon}$ ous) when they employ the melodies that especially arouse the soul

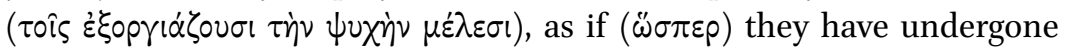
a healing process (i $\alpha \tau \rho \varepsilon i \alpha \varsigma$ ) and a "release" ( $\varkappa \alpha \theta \dot{\alpha} \rho \sigma \varepsilon \omega \varsigma)$. Those who are prone to feelings of pity and fear and those who are in general very emo-

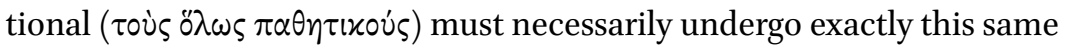
experience ( $\tau \alpha \dot{\jmath} \tau \dot{\delta} \delta \dot{\eta} \tau 0 \hat{\imath} \tau 0 \ldots \pi \dot{\alpha} \sigma \chi \varepsilon v)$ ), and everyone else too according to the degree to which each one possesses such [tendencies]; and to all of them a kind/degree of "stimulation-and-release" occurs ( $\pi \hat{\alpha} \sigma l \gamma$ r $\gamma v \varepsilon \sigma \theta \alpha i$ $\tau \imath \nu \alpha x \dot{\alpha} \theta \alpha \rho \sigma \nu)$ and they experience delight and a feeling of lightness (xov$\varphi\left(\zeta \varepsilon \sigma \theta \alpha \iota \mu \varepsilon \theta^{\prime} \dot{\eta} \delta 0 \nu \hat{\eta} \varsigma\right) .{ }^{39}$

AR. Pol. 1342a1-15

Aristotle does not mention Korybants specifically here, but it seems clear that he has in mind a spectrum of "enthusiastic/orgiastic" musical performances and experiences, ranging from all-out healing rituals in which people are "possessed ... and restored ..., as if undergoing a healing" (which sounds very Korybantic) to somewhat milder and more restrained enjoyment of e.g. "high art" auletic recitals or tragic and dithyrambic songs; and somewhere between these two extremes we might expect to situate a wide variety of other "Bacchic, sacred" musical events. Aristotle appears to consider it normal and natural that one and the same musical performance might elicit differing degrees of arousal within a group of listeners, depending on their individual personalities and dispositions; and even the more restrained listeners might still enjoy some

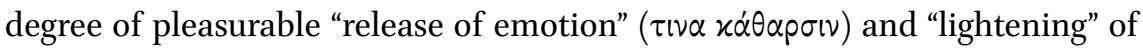
their mood ( $\varkappa \cup \cup \varphi i \zeta \varepsilon \sigma \theta \alpha \mathrm{l})$.

As he continues (1342a16-28), Aristotle explains that musicians competing in the theater and at festivals should be allowed to use the more affective modes and melodies, particularly for the "relaxing entertainment" ( $\dot{\alpha} \alpha \dot{\pi} \pi \alpha v-$ $\sigma(v)$ of the lower-class, less sophisticated elements in the audience ("craftsmen, laborers, and such like"); yet he acknowledges that there is also a more

39 The next sentence presents a problem of reading and interpretation. In the MSS, we have "Similarly, 'kathartic' melodies ( $\tau \dot{\alpha} \mu \dot{\varepsilon} \lambda \eta \tau \dot{\alpha} \varkappa \alpha \theta \alpha \rho \tau \varkappa \alpha \dot{\alpha})$ provide harmless pleasure to peo-

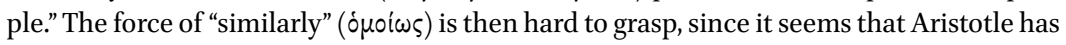
already been discussing "kathartic" melodies in the preceding sentence. So several editors and translators (including Ross in his 1957 OCT) follow Sauppe in reading $\pi p \alpha x \tau i x \alpha$ for $x \alpha \theta \alpha p \tau i x \alpha$ (picking up on 1342a4, just above). The main thrust of Aristotle's argument is not affected by our choice of reading. 


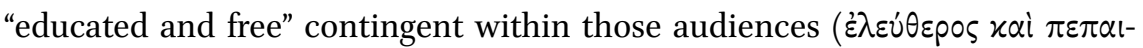
$\delta \varepsilon \cup \mu \varepsilon^{\prime} v \circ \varsigma$ ), even while he implies that these discriminating listeners will be less affected than the vulgar lower classes by the "extremely strained and colorful" melodies ( $\sigma \dot{v} v \tau o v \alpha$ xai $\pi \alpha \rho \alpha \kappa \varepsilon \chi \rho \omega \sigma \mu \varepsilon \dot{v} \alpha)$. He sums up: "What belongs naturally

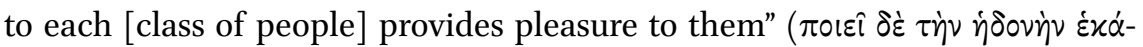

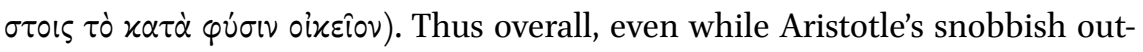
look leads him to insist that the more emotionally affective types of music appeal more to the lower classes, it is quite clear that (unlike Plato) he does not consider the more extreme forms of emotional arousal and relief to be appropriate only for defective human beings. One does not have to be a baby, or demented and pathologically fearful (as e.g. at Leg. 79oc-791b), to enjoyand benefit from-listening to (and perhaps even participating in? ${ }^{40}$ these exciting, "enthusiastic" music-forms and songs, even though they surely would not be so suitable for the leisured discussion-sessions and critical appreciation $(\delta 1 \alpha \gamma \omega \gamma \eta$ ') of Aristotle's citizens, nor obviously for the teaching of children in school. ${ }^{41}$ And from the Poetics we learn that Aristotle thinks that attending the theater to watch and listen to tragedies being performed can be both highly pleasurable and quite "philosophical," even while he is fully aware that all the music played there is accompanied by the auloi and much of it is in Phrygian harmonia.

It is remarkable-but should not be surprising to us-that Aristotle is so comfortable in acknowledging that enthusiastic/orgiastic/sacred/Bacchic/ pathos-inducing music is going to be widely available and highly valued in his (and any) polis. He seems to take this for granted as a normal social fact. This does not mean that he thinks most of his population will need or will want to engage in full-scale Korybantic therapy (a process which we will discuss below). Rather, he stipulates that, even while most people will not actually fall into ecstatic trance states in listening to Phrygian music played on the auloi

40 At 1342a3-4 Aristotle stipulates that in the context of education, students should only be exposed to "ethical" harmoniai, but that adults should be allowed to listen to all kinds. (He has also previously proposed that boys should only learn to play instruments well enough to be able as adults to appreciate and critique music played by others.) So the actual performing of e.g. Phrygian tunes on the auloi should be left to others ( $(\dot{\tau} \varepsilon \dot{\rho} \rho \nu \chi \varepsilon i p-$

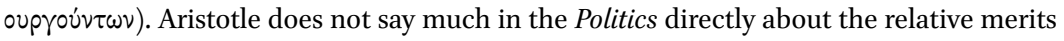
of listening/watching vs. performing, for those who seek only "relaxation, fun" — but his remark about the relaxing effects of dance (1339a17-21) includes the comment "some people think ...," as if he himself is dubious. Aristotle never engages in direct discussion of the social value of dance and choral performance within a community, as Plato does (see esp. Peponi 2013b; Prauscello 2014).

Aulos-music at gentlemen's symposia was of course absolutely normal, almost mandatory. 
(i.e. such states are just for actual "patients" seeking a katharsis-type cure), most people nonetheless do get affected by such music to some (more limited) degree, and they derive harmless pleasure from listening to it. As Aristotle phrases it (1340a8-14), music of the affective genre, such as Olympus' aulosmelodies, "by common agreement makes [people's] souls 'enthusiastic', and enthousiasmos is an affective reaction of the ethos involving the soul" ( $\delta \delta$ ' $\varepsilon v \theta 0 v-$

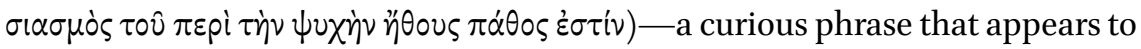
mean by pathos a temporary stimulation and alteration of physiological and mental state. Such "arousal/alteration" occurs for a relatively short period of time, and the whole process of arousal and subsequent calm does not bring about permanent change in the character, disposition $(\hat{\eta} \theta 0 \varsigma)$ of the listener; hence such music does not fall into the "ethical," i.e. character-building, category. ${ }^{42}$ The auditory stimulation of "enthusiastic" music provides for almost everyone harmless excitement and pleasure-in Aristotle's terms, "fun" ( $\pi \alpha \mathrm{l}-$ $\delta(\alpha)$ ) and "release, relaxation" ( $\left.\alpha^{\prime \prime} \varepsilon \sigma \iota \varsigma\right) .{ }^{43}$ In the field of musical performance, then, we can say that "enthusiastic" music comprises a large but distinct genre with a specific function; and within this genre, actual Korybantic-type performances (which obviously entail additional activities beyond simply listening to "musical" sounds) constitute a particular, relatively small, sub-set. We may observe too that Aristotle seems to recognize that the large and capacious genre of "enthusiastic" music overlaps to some degree with the genre of competitive "theater music" and thus also with the ("literary") genres of dithyramb, tragedy, and comedy, i.e., genres which include high-art, virtuoso specimens of enthusiastic, aulos-accompanied song-types.

42 Aristotle seems to hold the same opinion about going to the theater: watching (and listening to) a good tragedy arouses quite strong emotions $(\pi \dot{\alpha} \theta \eta)$ — especially pity and fear-in the audience members; but the resultant "katharsis of such emotions" does not alter their character permanently in the way that Plato's Socrates asserts in the Republic. For further discussion of this (controversial) issue, see esp. Halliwell 1998; Sifakis 20o1; also Bernays $1857 / 2015$.

43 For a full and fascinating exploration of Aristotle's katharsis, see esp. the long discussion of Bernays 1857/2015 (which has often been consulted by subsequent scholars only in abbreviated form, and consequently misrepresented and misinterpreted: cf. Porter 2015). Bernays argues convincingly that the katharsis provided by music or drama according to Aristotle entails a process of stimulus-and-release/relief of emotions/affect that is relatively brief, short-term, and self-contained; the process is in itself exciting, pleasurable, experience-enhancing, and repeatable. Thus his position is not so far from that of Halliwell 2011: $236-265$ as the latter suggests. 


\section{Musical Genres and Emotional Arousal (Possession/Trance/Ecstasy): Comparative Evidence}

The Greeks were not unusual in their appetite for musically induced possession or trance, nor in their recognition that such kinds of musical experience fall into a distinct category. Rituals designed to elicit or facilitate altered states of consciousness through music are widespread and well-documented, from many different regions of the world. The most wide-ranging investigation of this phenomenon remains that of Gilbert Rouget (1980/1985), though several important studies since then have shed further light on particular contexts and on some of the neurological, physiological and psychological processes that are involved. ${ }^{44}$ This is not the place to try to discuss in detail all the various aspects of this rich and complex topic; but a brief summary of the current state of anthropological and neuroscientific knowledge concerning strong emotional arousal in response to music should help us see the ancient Greek phenomena in appropriate context(s).

Listening to and enjoying music in general for humans-and apparently the same is true of several animal species as well-depends on fairly elaborate neurological processes of expectation-arousal and satisfaction. A series of acoustic stimuli provokes listeners, on the basis of their previous experience of the conventions of the musical "language" of their particular society, to recognize formal patterns as they develop and are elaborated, modified, and perhaps challenged before finally resolving themselves into a (somewhat intelligible and reassuring) cadence and "sense of an ending." 45 The neurological processes involved in listening to music have much in common with listening to and interpreting human speech, though of course in the case of music, factors of pitch, regular rhythm (meter, "beat"), and tonal timbre tend to be more finely and precisely calibrated. ${ }^{46}$ Anticipation, tension, build-up of emotion/affect,

44 Rouget's book was first published (in French) in 1980; the second edition (significantly revised, and in English translation) appeared in 1985. Rouget discusses ancient Greek (1985: 187-226) and Arab culture (255-314), as well as many different kinds of possession, trance, shamanism, exorcism, initiation, etc. that involve music in various parts of the world. His book is surprisingly seldom mentioned in Anglophone classicists' discussions of ancient Greek music. Among more recent publications I have found useful especially the following: Becker 2001, 2008; Juslin and Sloboda 2001; Nettl 2005: 244-258; Bicknell 2009. See too Keil and Feld 1994; Sacks 2008.

45 Meyer 1956.

46 Meyer 1956; Kivy 1989, 1990; Davies 2003; Levitin 2006; Patel 2008. For non-human (animal) responses to music, see e.g. Wallin et al. 2000; Marler and Slabbekoorn 2004; Kroodsma 2005 . 
and release - along with inherently pleasurable regularities of rhythm, variations in vocal or instrumental textures, and possible memories or associations imported from previous social contexts-all combine to make the process of responding to music both intensely personal/individual and yet also to a large degree (in most human societies) communal, predictable, and programmable. And among the various different kinds of music that any particular society may have developed, there are usually certain types that lend themselves especially well to a program of lengthy build-up of mood and sustained expectation, and the response to these musical types more often than not involves not only "passive" listening but also active bodily movements of some kind (dancing, swaying, hand-clapping, foot-stomping, etc.) on the part of the listeners/participants. ${ }^{47}$ In these respects such kinds of performance may be said to conform to the parameters of a "genre," with performers and participants/listeners alike all operating within a recognized and adaptable set of expectations and "rules"rules that include a significant—-though variable—component of embodied audience response. ${ }^{48}$

Musically-induced states of altered consciousness that we refer to as "possession," or "trance," or "ecstasy,"49 are an empirically observable and welldocumented phenomenon. Those who enter such a state display an accelerated heart-rate, lighter and more uneven pulse, shallower breathing, increased body temperature, and significantly altered patterns of brain activity. In most cases, those "possessed" respond corporeally to the music by dancing and/or vocalizing or gesturing. ${ }^{50}$ Musical "possession" in many cultures is induced through regular and carefully controlled mechanisms, whether as a religious ceremony, a form of therapy, or simply entertainment, and it is usually a collective event. But at the same time it is a subjective process, in that any individual who enters into the process will only become "possessed" if s/he wants to. Unlike, for example, magic spells or drugs, one cannot through purely musical and performative means make someone succumb to these effects if that person is not already so disposed.

47 Rouget 1985: 114-119, 201-206, and passim; Becker 2001.

48 Compare the chapters by Olsen, Estrin, and Weiss in this volume.

49 The terms "trance," "ecstasy," "possession" are unfortunately not defined or employed consistently by most anthropologists or musicologists. Objectively, there is more than one kind of emotional arousal that can arise from music and that might be classified as "ecstatic." Rouget 1985 makes a strong distinction between the "ecstasy" of a listener who enters an altered state of extreme quietness and contemplation and the state of "trance" in which bodily movement and active participation in the musicking are usual. 
Almost all trance-inducing performances deploy some acoustic effects, and most of them use designated instruments and/or a singing style of some distinctive kind: that is to say, there is usually a recognizable "soundscape" and character to trance music within a given society. But this sound can be very different from one culture to another. Thus, even though some scholars have claimed that particular musical instruments, or particular rhythmic patterns, are the universal key to producing altered mental and physiological states, in fact the processes are quite variable and culturally specific. ${ }^{51}$ Usually a professional group of experts leads and supervises the performance; these may or may not be the musicians themselves. Sometimes the musicians enter a trance state along with the listeners/dancers; but sometimes the musical performers remain in a calmer and more distanced mood while the dancers and/or other listeners become "possessed."

Even while trance music can come in many forms (as can the physical manifestations of a "possession" state), usually such music is designed so as to maintain a steady rhythm and/or repetitive melodic pattern, thus prolonging the in-between stages of "listening," i.e., deferring the "sense of an ending" and resultant release of tension, so that listeners are drawn into participating continuously in these regular and perhaps gradually intensifying patterns. In some trance performance traditions, singing (often more or less improvised) is an important component and the words may be central to the experience; in others, the emotional impact is provided almost entirely by instrumental music instead, even while sometimes the participants may add improvised or repetitive vocalizing of their own. The duration of a single trance performance is usually rather extended (as compared with other types of song or instrumental recitation); and this may allow each of the members of the congregation/group to arrive at her/his state of heightened consciousness or trance at different moments in the ceremony. Thus while the whole performance will usually begin at a relatively low level of volume and intensity, the build-up will be sustained long enough for the whole group to get engaged, though not necessarily

$51 \quad$ So for example the once widely-believed claim that drums are key to trance-inducing has been shown to be unfounded; likewise the claim that $5 / 8$ or $11 / 8$ rhythms invariably have such effects on all listeners: see Rouget 1985: 73-94, 169-176; Becker 20o1; Bicknell 2009: 77-79. In all ancient Greek contexts, as Rouget notes, the almost mandatory acoustic ingredient is the pipes (auloi), while percussion instruments are prominent in some ceremonies but not in all "enthusiastic" music-making: see further below. In general, the musical idiom through which trance is effected may allow for many variations, depending on the specific focus of a performance and its participants: see e.g. Rouget 1985: 100-102 (tarantism) and passim. 
all at the same moment or with the same degree of intensity. ${ }^{52}$ But again one must bear in mind that the overall character of the music and of the associated dance and movements, or even the overall purpose of such "possession," may be different from one culture to another. ${ }^{53}$

The use of music for healing purposes in general is a broader phenomenon than "trance music" and "possession" ritual, since there are countless different processes through which people may find music effective in a process of bodily or mental therapy, in contexts of, for example, trauma, memory loss, depression, and various kinds of social dysfunction. Music therapy of various kinds was known and practiced quite extensively by the Greeks (as by most other societies); but in this chapter I am considering only the types of musical therapy that employed trance/possession. ${ }^{54}$

Finally, a note on demographics and language. Trance/possession performances are most commonly found among socially disadvantaged or marginalized communities, rather than as a component of "high" culture or mainstream religion. ${ }^{55}$ Many of the best known and most socially impactful modern contexts of possession/trance performance (leaving aside Western disco/techno/ house/trance forms of dance music $)^{56}$ are most widely practiced by women and/or the socially disadvantaged: e.g., North African zar (Sudan/Egypt, Morocco, Mali, etc.); Haitian voudun; American Pentecostal ceremonies. In some

$5^{2}$ Becker 2001 discusses several examples, including (at 146) Sufi qawwal performances in Pakistan and North India and (at 149-150) Pentecostal performances in the USA.

53 Becker 2001: 141-143 offers a helpful analysis of the different processes and effects of a silent, physically motionless Western listener responding to and appreciating a piece of classical music - even a highly "emotional" piece—vs. the engagement of a Sufi celebrant during a mevlevi (Dervish) or qawwal performance, or (146-149) the interaction between musicians, masked dancer, and audience in a Balinese bebuten gamelan performance designed to arouse the participants' anger to the point where they can collectively defeat and exorcize the evil witch Rangda who is threatening the whole community. In this latter case the emotional arousal is not inherently pleasant, but the overall social outcome of the performance is one that brings calm and satisfaction to all.

54 On music therapies in the modern world, see Becker 2001; Bunt and Pavlicevic 2001; Sacks 2008; Yinger 2017. For ancient Greece, see Jeanmaire 1949; Barker 1984: index s.v. "healing."

55 See Rouget 1985 passim. Exceptions obviously exist, such as the Ottoman version of the Sufi dancing of the Mevlevi orders (Dervishes). Several Persian and Arabic writings in the Sufi tradition acknowledge the possibilities of attaining closer access to God through such musical processes (e.g. Abu Hamid Al-Ghazali's Alchemy of Happiness [Kimiya-yi Sa'ādat]). By contrast, modern Salafi and Wahabi doctrine presents a very different view of music's value.

$5^{6}$ I leave these aside not because they are irrelevant, but because the sociological, demographic, religious, and aesthetic elements seem to be too complex and shifting to be easily summarized. 
cases, the ceremonies are conducted in a language that is not that of the dominant culture and that may not even be well understood by many of the celebrants: thus the "foreignness" of the divinities who are imagined to control the event is underlined, and the special expertise of the ministrants is duly authorized as well. ${ }^{57}$ The sense of "escape" from normality and of liberation from the pressures of the dominant culture outside the performance event may also temporarily be enhanced. These features seem clearly to have been true of classical Greece, at least for certain forms of ecstatic music-making in Attica, a point to which we will return towards the end of this chapter.

\section{Korybantic and Other "Enthusiastic" Musical Performances in Classical Greece}

Bearing in mind the comparative material that we have surveyed, as well as Aristotle's statements about "enthusiastic" types of music from the previous section, it is time now for us to focus directly on ancient Greek Korybantic-type rituals, to see whether these should qualify as a distinct "genre" of performance, and if so, whether they should count as "lyric." In this section I consider a number of ritualized, mood-altering, and in some cases trance-inducing ancient musical performances, which seem to fall roughly into three separate but overlapping categories.

In the first category we may place initiation ceremonies that were specifically said to be conducted by or for the Korybantes or similar entities (Kouretes, Kabeiroi, Dactyls), with ministrants (i.e., designated officials or priests) presiding over a sequence of organized events, some of them musical. A second category-perhaps not always distinct from the first-comprises therapeutic rituals performed in the name of the Korybantes that employed music and other sounds and sights to induce extreme affective states, including terror, disorientation, and even hallucinations, in one or more participants, resulting in behaviors that might lead observers to conclude that these participants were temporarily "out of their minds." A third, broader category consists of a range of exciting, musically-enhanced performances of the kind that were generally described (for example, by Plato and by Aristotle, as we have seen)

57 Rouget 1985. In the ancient Greek context, cf. Parker 2005 on the Athenians' growing penchant in the fifth and fourth centuries BCE for Bendis-festivals and other Thracianor Phrygian-tinged performances; also Wilson 2009 on the exotic (especially Thracian) associations of Thamyris and Orpheus as imagined "originators" of Greek musicality, and G. Martin 2009 . 
as "orgiastic," "enthusiastic," "sacred," or "Bacchic," and that are usually associated with divinities such as Cybele or Rhea (the Great Mother), Sabazius, or Dionysus - whether or not the Korybantes or similar daimonic entities are explicitly involved as components of the ceremony. ${ }^{58}$

These categories are not hard and fast. The second should perhaps be considered only a sub-division or modified — or intensified — version of the first, while the distinction between the first (specifically "Korybantic/Kouretic" etc.) and the third ("Bacchic/Sabazian/Cybelean/orgiastic/enthusiastic," etc.) is by no means always clear or absolute. As we shall see, there was a strong tendency in antiquity to blur some of these distinctions and indulge in what Bourdieu calls the "fuzzy logic" by which analogous or similar-looking behaviors end up being lumped together in the social imagination as being all the "same"in this case, musical and performative elements that all cluster to the right end of our grid (Table 1) - even when in some cases they may involve some significantly different features and functions. As we shall see, Greek authors, including especially Plato and (less so) Aristotle, often slide rather casually and fuzzily from one set of terms to another in describing "Bacchic" and "Korybantic" performances, without making a clear distinction. For the purposes of our discussion of lyric genres it may not matter much in the end whether a particular (type of) performance was or was not specifically "Korybantic," or should be categorized as more indeterminately "Bacchic." But a brief survey of the different types will help us come to recognize both the broader contours and some of the recurrent and distinctive features of the rather capacious musical genre that Aristotle referred to as "enthusiastic."

The various different groups of minor divinities (daimones) that were named Korybantes (or Kyrbantes), Kouretes, Kabeiroi, or Idaean Daktyloi, must originally have been quite separate cultural entities, celebrated in different places by different people, each with their particular melodies, dances, etc., during the Archaic period and into the early Classical period. ${ }^{59}$ But these distinctions became conflated and confused as time went on, even while separate local cults for one or other group persisted ${ }^{60}$ and aetiological myths continued to circu-

$5^{8}$ The purely figurative use of $x o p v \beta \alpha \nu \tau i \alpha$ ' $\omega$, to denote extreme excitement of any kind, will crop up here and there (esp. in Plato), but does not need a separate category.

59 For full discussion and references, see esp. Poerner 1913; Burkert 1985: 8o, 173, 280-285, 297; Parker 1996, 2005: 120-121, 373-374; Bowden 2010; Bremmer 2014. Ustinova 19921998 attempts to treat Korybantic cult as a more or less self-contained and distinct phenomenon, and focuses largely on Athens.

6o So for example Plato's Socrates remarks (Ion 536c2-4): "The Korybantic devotees have a quick ear for only one tune, the tune of that god by whom they are possessed, whoever

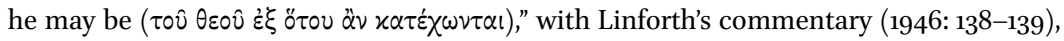


late linking each to different origins and locations. By the late fifth century BCE there was also a habit of referring generically to any kind of psychotherapeutic treatments for mental or spiritual distress that involved music or other loud sounds along with ritualistic/ecstatic movement and dance as "Korybantic." Hence (more broadly) anyone who was behaving in a very eccentric manner might be said figuratively to be "Korybanting" even when no real connection to daimonic (Korybantic or other) musical ritual was present.

Let us begin by quickly surveying the particular names and aetiologies for these various daimones, since these on the face of it do provide some evidence about their musical and performance characteristics. The Korybantes or Kyrbantes seem to have originated in Anatolia, as associates of Cybele the Great Mother. Sometimes described as wearing triple-crested helmets, they are imagined as dancing and making percussive music among her retinue. ${ }^{61}$ Late (perhaps Orphic) sources describe them singing and dancing noisily around the enthroned baby Dionysus, protecting him from the Titans. ${ }^{62}$ The Kouretes were imagined as youthful armed warriors (hence perhaps kouroi), and were primarily associated with Crete and the birth of Zeus, and thus also with Rhea, i.e., another version of the Great Mother. Their noisy clashing of shields and vocalizing are supposed to have drowned out the cries of baby Zeus and/or to have frightened away Kronos when he was seeking to capture and destroy his son. ${ }^{63}$ The Kabeiroi are most fully attested in Lemnos and Samothrace, apparently as metal-working daimones - the number varies, from two, three, or four to a whole band - while another branch of their cult (a sixth-century вСE Kabeirion) was established also at Thebes. ${ }^{64}$ Jan Bremmer and others have

observing that there must have been many different versions of Korybantic performance, each one favoring "one particular tune."

61 Immisch 1897; Poerner 1913; Schwenn 1922; Linforth 1946; Burkert 1985: 80, 173, 280-285; Parker 1996, 2005; Bremmer 2014: 48-53. "Kyrbantes" was said to be the Phrygian form of the name, but the etymology is unknown (see Bremmer 2014: 48-49). We may note that early Iron Age illustrations of Phrygian (or "neo-Hittite") music-makers depict extensive use of cymbals, frame-drums, and double-pipe, and in some cases several of the performers appear to be wearing distinctive head-gear (though not helmets). In the classical period and later, at Erythrae (an Ionian Greek city in western Anatolia) an annual dual priesthood for the Korybantes is recorded, to be held by a man and woman: see Herrmann 2002.

62 Burkert 1984: 297; Edmonds 2006.

63 Harrison 1912; Poerner 1913; Jeanmaire 1939; Burkert 1985: 280. One of the earliest attestations of the Kouretes occurs at Eur. Cretans fr. 472.9-19 TrGF; see also the Palaikastro Hymn (discussed below, n. 73).

64 Poerner 1913; Hemberg 1950; Burkert 1985: 281-285; Daumas 1998; Blakely 2006; Constantakopoulou 2015: 281-284. 
suggested that the Samothracian mystery cults were modeled to some extent on the Eleusinian Mysteries; ${ }^{65}$ but the Kabeiroi themselves, as metal-workers, seem to have no Eleusinian equivalent, and the Theban Kabeirion does not much resemble anything from Eleusis. ${ }^{66}$ As for the Idaean Dactyls-likewise metal-working daimones - these were of course connected to Mount Ida (on Crete) and to the Great Mother, but they otherwise seem to have little by way of a distinctive identity. 67

Some have seen all or most of these cults as being connected with male adolescent rites of passage, but the evidence for this is very thin. Walter Burkert, Sandra Blakely, and others have suggested instead that several of these cults

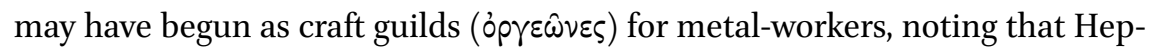
haestus continues to be prominent in the cult of the Kabeiroi. But then the connections with Cybele and Rhea are not easy to explain. Probably there were several different origins and specific ritual functions for these various cults, and only later did homogenizing aetiologies (and names) come to be assigned. ${ }^{68}$ But whatever the precise origins of each particular cult, we can observe that the performative elements (choice of instruments, use of nonverbal vocalizing, unchoreographed dance and movement) and divine sources (Asian, Cretan, Thracian) for all of them belong squarely on the right end of our grid (Table 8.1).

As many scholars, ancient and modern, have pointed out, a blurring of distinctions between these various groups, their names, origins, and characteristics, had begun already by the fifth century $\mathrm{BCE}^{, 69}$ and such blurring was doubtless especially pervasive in a multicultural environment such as classical Athens. Thus in Euripides' Bacchae, the chorus of Asian Bacchantes sing of Crete and the joyous music of the Phrygian mother:

65 Bremmer 2014: 22-36, with further references.

66 The iconography (vase paintings and figurines) from the Theban Kabeirion presents many scenes of drinking and carousing, several of them involving pygmy-like and other grotesque (fat, ithyphallic) human or daimonic figures. Many of the scenes show pipeplayers as well; see Daumas 1998. The singular name Káßıpos is sometimes found, along with $\pi \alpha \hat{i}$ ("child" or "son"), but there is scant evidence for any sort of coming-of-age ritual.

67 Burkert 1985: 173. On the Dactyls as metal-working daimones, see Blakely 2006.

68 For adolescent rites of passages (kouroi Kouretes, etc.), see esp. Harrison 1912; Jeanmaire 1939. On metal-working, see Burkert 1985:281-285; Blakely 20o6. For emphasis on the wide range of different functions served by "mystery cults" in general, see Burkert 1987; Bowden 2010.

69 So already in Pherecydes ( $F G r H 3$ fr. $48=$ fr. 48 Fowler) the Kabeiroi and Korybantes are combined; see further Hemberg 1950: 304; Bremmer 2014. 
O holy places of Crete, the caves of the dancing Kouretes, there where Zeus was born, where helmed in triple tier the Korybantes invented this leather drum; and with their intense god-filled dance ( $\beta \alpha x x \varepsilon i \alpha)$ they mixed the drum-beat with the sweet cry of the Phrygian pipes. Then, from them to Rhea's hands the holy drum was handed down, to give the beat for Bacchantes' dances, and, taking up from the Mother, the raving/inspired ( $\mu$ alvó $\mu \varepsilon v o l)$ Satyrs now accompany the festivals in which every other year Dionysus delights! EUR. Bacch. 120-134, tr. W. ARROWSMITH, adapted

This is quite a delicious jumble: Kouretes and Korybantes and Satyrs all together, or in sequence; Crete and Phrygia, Rhea and Cybele (the Mother) and the Bacchantes, along with Dionysus himself-all one great musical party. This chorus has been performing all over Asia, we are told (Bacch. 13-22, 55-59, etc.), and is now beginning the process of importing their new musical styles into mainland Greece. Presumably the theater audience at this point is hearing and seeing a performance that was designed by Euripides and his musical collaborators to recall to some extent "Korybantic" song, whether or not a full panoply of percussion was employed in the production in addition to the standard theatrical double-pipes (auloi). But the description leaves open the possibility that the musical elements may have been modified during the course of the transmission of these instruments from the Korybantes to the Bacchantes, Satyrs, and Dionysus. Nowhere in this description is there any suggestion of initiation, $\theta$ póv $\omega \sigma \iota \varsigma$, or terror and confusion being aroused among the participants (as, for example, Plato tends to describe Korybantic rituals), nor of healing the mentally ill-instead the celebrations seem not only exuberant but entirely cheerful.

In another choral song from tragedy—but a completely different imagined context - a famously obscure, but highly evocative, passage in Euripides' Helen (1337-1352) narrates the invention (or so it appears) of a new kind of music, long ago, to cheer up the distraught Deo/Demeter when she had lost her daughter Persephone and was bitterly blighting the crops all over the world. ${ }^{70}$ Here there

70 Elements of Rhea, Cybele, and Demeter seem to be combined in this passage, even while the mention in 1342-1343 of "Deo" and "the Girl" ( $\pi \dot{\alpha} \rho \theta \varepsilon v \circ \varsigma)$ makes Demeter obviously the prime referent. See further Allan 2008 ad loc. 
is no mention of Korybantes, nor of any male participants at all in the musicmaking (indeed, the context requires that "Deo" be comforted only by female companions). But the insistence on the "chthonian voice of bronze" (either a rhombos or cymbals, or possibly a gong) and "skin-strung drums" (tumpana), as well as "deep-sounding auloi," suggests a similar soundscape to that described in the Bacchae passage. This scene takes place on Mount Ida (Hel. 1324)—but which one? Is this the Great Mother in Anatolia? Or is Demeter-Rhea imagined here as being in Crete? In either case, she is surrounded by exciting, semiarticulate female vocalizing (1344 $\left.\dot{\alpha} \lambda \alpha \lambda \hat{\alpha}, 135^{2} \dot{\alpha} \lambda \alpha \lambda \alpha \gamma \mu \hat{\omega}\right)$ and double-pipes in combination, and the result is a transformation of her mood and of her relationship to her surroundings. It even appears that the Mother herself begins to play the pipes. ${ }^{71}$ Whether this scene is entirely Euripides' invention, or is based on actual Greek musical practices and/or cult reenactments known to his Athenian audience, it is only intelligible if that audience is already familiar with the idea that such combinations of voices and instruments, producing music that apparently relies much more heavily on rhythms, melodies, and timbres than on words, could conventionally be expected to have strong and positive affective impact, in particular on someone in a deeply depressed state.

In a later period (first century вСE), Strabo observes explicitly (Geography 10.3.7) that those various Kouretes, Korybantes, Kabeiroi, Daktyloi, and even

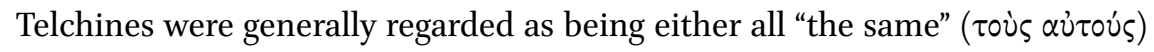

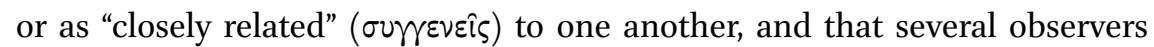
"differentiate only certain small matters in which they differ in respect to one another; roughly speaking and in general ( $\tau \dot{\tau} \pi \omega)$, they represent them, one and all, as a kind of inspired people ( $\dot{\varepsilon} v \theta_{0} v \sigma \alpha \sigma \tau i x \circ v$ s) and as subject to Bacchic

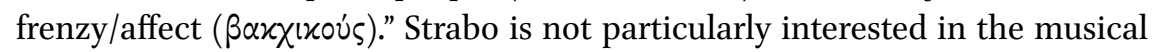
aspects of these cults/performances, but he confirms that the typical instruments employed are cymbals, tumpana, and metal shields, along with auloi; the

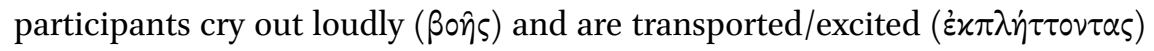
also by the movement/costume $(\sigma \times \eta \dot{\eta} \mu \tau \iota)^{72}$ of the attendants. In what follows (10.4), Strabo expands his account, noting that such rites were "common" to

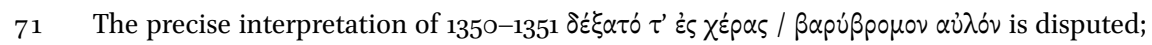
some critics prefer to take this as Deo "welcoming" the sound of the instrument rather than actually playing it. See further on this passage Weiss in this volume.

$72 \Sigma \chi \eta^{\prime} \mu \alpha \tau \iota$ in Strabo's account here is ambiguous, as to whether it means the "costume" of the

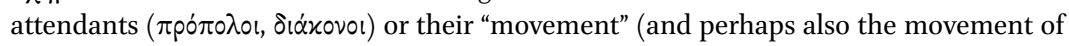
the celebrants themselves?): $\sigma \chi \hat{\eta} \mu \alpha$ can often mean "dance-step, choreography" or "physical arrangement, gesture." In either case, a strong visual and corporeal component of the ceremony seems to be entailed. 
Hellenes and to barbaroi; some were public, others were mystery-cults; some

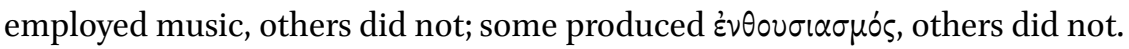

Several Hellenistic and later writers provide quite detailed aetiologies for one or other of these differently-named spirits and their musical activities, but these tell us little about the actual musical and performance characteristics of the rituals as practiced in the classical period. ${ }^{73}$ From that period, we do find Euripides and Aristophanes (both in the 420s) including references to "Korybantic" possession as a form of mental distraction as if this is something already quite familiar to their Athenian audience. But unfortunately these references are brief and not easily interpreted. In Euripides' Hippolytus (141-147) the Chorus speculate about the reasons for Phaedra's distress as she tosses and turns wildly on her bed, and propose the Korybantes as one of several possible causes. ${ }^{74}$ The references in Aristophanes' Wasps (5-10, 118-123) are even more difficult to sort out. At the beginning of the play two bored and sleepy slaves, who have been ordered, with threats from their master, to stay awake all night on guard duty, are comparing notes as to whether their sleepiness is due to a Korybantic state (8-9) or to Sabazius (10). Sabazius was a Thracian and/or Anatolian divinity similar in attributes and characteristics to Dionysus, and his rituals were especially popular with the laboring classes in Athens, including slaves, and with women. ${ }^{75}$ The notion that one might enter a state of pleasant drowsiness and thus "escape anxiety" ( $\dot{\alpha} \pi \mu \varepsilon \rho \mu \eta p i \sigma \alpha l, 5)$ with the help of Korybantic ritual or devotion to Sabazius suits the situation well, though in this case the drowsiness does not seem to have been triggered by any musical or communal performance.

A little later in the play, Xanthias describes how Bdelycleon tried to "cure, purge" ( $(\dot{\alpha} \theta \alpha i \rho$ ', 118) his father of his obsession with jury duty by various therapeutic means:

73 For example: Callim. Hymn 1 (to Zeus) 46-57 (on Kyrbantes, Kouretes, the nurse Amaltheia, and baby Zeus); Aratus, Phaen. 30-35 (Dictaean Kouretes); Nonnus, Dion. 46.1318 (Rhea, Korybantes, and baby/kouros Zeus). At least one account (apparently from a lyric poet, of unknown date) suggests that these entities were not in fact daimones, but were the very first human beings ( $P M G /$ Campbell 985 a and 985 b; paraphrased by Hippol. Haer. 5.17). Another fascinating lyric poem of the Hellenistic era, the so-called Palaikastro Hymn to the Kouretes $\left(I_{3}\right.$.2) refers to Rhea, the birth of Zeus and the "shield-bearing [nurses]," but otherwise contains no "Korybantic" or ecstatic elements (pace Harrison 1912; see Fontenrose 1966 and esp. Alonge 2008).

74 It seems that the implication here is that her condition is involuntary; Pan and Hecate are also mentioned as possible sources of her mental distraction.

75 Parker 1996: 161-162, 191-194, 2005: 325. See below for discussion of the involvement of Aeschines and his mother Glaucothea in running a Sabazius cult in Athens. 
Then he tried a Korybantic treatment ( $(\dot{x} \circ \rho \cup \beta \alpha \dot{v} v \tau \zeta)$ ); but his father rushed into the Common Court, tumpanon and all, and resumed his jury activity! AR. Vesp. $119-120$

In this (ludicrous and exaggerated) scenario, old Philocleon was apparently quite willing to join a Korybantic group, but the strength of the possession that he underwent there was not sufficient to overpower his maniacal desire to keep judging cases and he simply channeled the ritual energy into continued activity in the lawcourts. Although the two slaves' enjoyment of Sabazian and/or Korybantic release in the earlier scene seems to entail a very different process from the "rituals" ( $\tau \varepsilon \lambda \varepsilon \tau \alpha \hat{\imath} \zeta, 121)$ that the old man has experienced, in both cases the affected person has clearly entered an altered state and hence for some hours responded to his situation very differently from those who were not thus "possessed," though in the one case the result was frenetic activity, in the other sleepiness - presumably successive phases of the Korybantic/Sabazian ritual process.

Of all classical Greek authors the one who most frequently and prominently mentions "Korybantic" things is Plato, as Ivan Linforth observed in his careful and much-cited 1946 article. Plato's dialogues include seven passages where the term crops up, whether in a shorter or longer discussion: Crito $54 \mathrm{~d}$; Euthydemus $277 \mathrm{~d}-\mathrm{e}$; Phaedrus 228b-d; Ion $533 \mathrm{~d}-536 \mathrm{~d}$ (twice); Symposium 215c-e; Laws $790 c-791 b$. Unfortunately for our purposes, the discussions are mostly facetious, so that it is difficult to determine how much is metaphorical, how much literal in these Korybantic references, and how seriously to take what is said by Socrates or by the Athenian Visitor in the Laws, or by their various interlocutors. Linforth is certainly right, however, in observing that Plato (like Euripides and Aristophanes) takes for granted that his Athenian and wider Greek reading public is pretty familiar with Korybantic activity, and his descriptions are vivid and often amusing.

There is no need to go through all these passages in detail here. ${ }^{76}$ For the most part, Plato refers to "Korybantic" behavior as a humorous foil for more creditable, rational activities of the kind recommended by Socrates or the Athenian Visitor. That is to say, people who indulge in Korybantism, whether literally or metaphorically, are over-excitable, and are engaging with the world in a quaint and intellectually defective way, one that is characteristic of children or

76 The most thorough, nuanced, and judicious—and best known—discussion remains that of Linforth 1946, though he has small interest in the musical aspects of any of the passages and perhaps also understates the degree of Plato's purposeful unreliability. See also Dodds 1951: 77-79; Rouget 1985: 187-22o; Ustinova 1992-1998; Parker 1996, 2005; Edmonds 2006. 
over-impressionable and neurotic adults. Thus in Phaedrus (228b-d), the terms "Korybantic" and "Bacchic" appear to be used interchangeably (and metaphorically) to describe reactions of extreme delight at listening to a speech composed by Lysias. Similarly, in Ion (533e-534a) Socrates describes the sources and effects of artistic creativity with an amusing comparison to both Korybantic and Dionysian ecstasy, as he claims that lyric poets, like participants in Korybantic rites, are "possessed" ( $\propto \tau \tau \varepsilon \chi o ́ \mu \varepsilon v o l)$ and "not in their right minds"

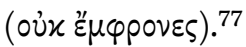

A passage from Plato's Euthydemus $(277 \mathrm{~d}-\mathrm{e})$ provides a rather detailedand again humorous - description of a Korybantic initiation process. Socrates suggests that, just as in the preliminary stages of Korybantic ritual a person is surrounded by swirling motion and confusing sounds, as s/he is carried around and "enthroned" in preparation for his (or her) culminating initiation, so has his young Athenian gentleman-friend Clinias been subjected by the two unscrupulous sophists, Euthydemus and Dionysodorus, to a purposely confusing hubbub of clever arguments as a warm-up for their big, revelatory performance of sophistry to follow. ${ }^{78}$ The actual process whereby the enthroned person is gradually rendered more and more excited in anticipation, before attaining the final state of initiated bliss, is not explained here. Some other accounts describe the initiand's state as one of terror (recalling the rituals of the Eleusinian Mysteries), but most trance rituals, especially if conducted with music and dancing, involve a more positive anticipatory mood, as well as movement (rather than inert sitting) on the part of the main participants. If the "enthronement" ( $\theta$ póvw$\sigma(\varsigma)$ is meant to recall that of baby Zeus or Dionysus, it is not clear whether the "baby/initiand" is supposed to be more terrified or comforted by the musicafter all, it should, in mythical terms, be the (absent) father Kronos or the murderous Titans, not the musical Korybantes, that are to be feared.

An even more extended-and whimsical - account of Korybantic procedure is provided by a well-known passage in the Laws (79oc-791b) which refers to the healing power of such ritual. Here the Athenian Visitor explains how the expert ministrants and musician(s) of the Korybantic and/or Bacchic ritu-

77 For discussion of Plato's notions of creative "madness" and "possession" in Ion and Phaedrus see e.g. Dodds 1951: 64-101; Rouget 1985: 188-201; Halliwell 2011; cf. too [Longinus] Subl.39.2.

78 Socrates includes a phrase "[as you know], if in fact you've actually been initiated [your-

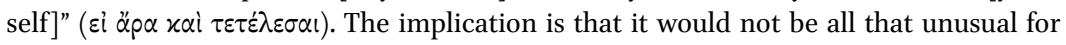
a well-brought-up young gentleman such as Clinias to have experienced this ceremony

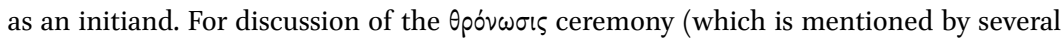
other authors as well, some of them probably influenced by Plato), see further Ustinova 1992-1998; Edmonds 2006. 
als, ${ }^{79}$ just like mothers and nurses of new-born babies, calm the agitated celebrants by means of incessant "shaking" and "movement": this, he suggests, is also the explanation for adult pleasure and satisfaction in choral dancing to music. Plato puns here on the words for "nursing" ( $\tau \theta \theta \dot{\eta} \nu \eta \sigma v)$ and "moving" ( xiv $^{\prime} \sigma v$ ), suggesting that dance-movements and the power of the double-pipes to "induce trance-states" ( $\dot{\alpha} \tau \varepsilon \chi \nu \omega \hat{\omega}$ o oiov $\varkappa \alpha \tau \alpha \nu \lambda \circ \hat{\sigma} \sigma \mathrm{l}, 790 \mathrm{e})^{80}$ provide effective treatment for people who suffer from acute mental-spiritual instability (i.e., are like babies), with the implication that normal, healthy adults would find no occasion for such treatment. Clearly we should not swallow too much of Plato's tongue-in-cheek analogy here. ${ }^{81}$ Nonetheless, its observations about the effectiveness of trance music and dance (especially the reference to auloi and $\varkappa \alpha \tau \alpha \nu \varepsilon^{\prime}(\omega)$ in drastically altering the physiological and mental state of participants, bringing them to a pitch of excitement and exhilaration, and finally leaving them exhausted and pleasantly calm, squares well with other references to this kind of performance, including Aristotle's account from the Politics.

The Symposium presents another vivid and famous simile, as Alcibiades compares the effect of listening to Socrates' voice to being possessed by Korybantic music (215e). Strikingly, as Linforth observes, this explicitly "Korybantic" reference follows more or less continuously upon an extended reference (215d) to the aulos-compositions of Marsyas and Olympus, which generally

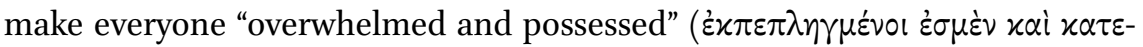
$\chi^{\prime} \mu \varepsilon \theta \alpha$ ). Marsyas the satyr and his (human) student Olympus have nothing really to do with Korybants (and Alcibiades makes no mention of percus-

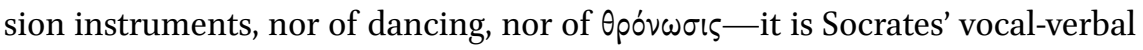
impact that Plato wishes to highlight). Thus once again we seem to be dealing with a spectrum of musical-ritual responses, causing varying degrees of affective arousal that range from the almost universal experience of listening to pipe-music in Phrygian mode ${ }^{82}$ to the more extreme and particular experi-

79 The Visitor specifies "the women who officiate in the healing rituals of the Korybants" ( $\alpha i$

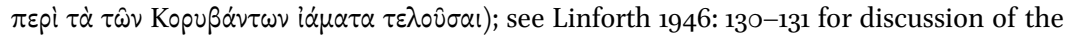
interpretation and translation of this phrase. Elsewhere in the same passage the Visitor describes the participants in these rituals as being "in the grip of Bacchic frenzy" ( $\tau \hat{\omega} \nu$

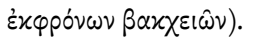

8o The term $\varkappa \alpha \tau \alpha u \lambda \varepsilon \dot{\varepsilon} \omega$ means specifically to "play the auloi to get someone to enter a trance state," i.e., "to entrance them with the pipes"; cf. Eur. HF 867-879, 892-899; Pl. Rep. 411a. See further Rouget 1985: 201-202.

81 The Visitor concludes by underscoring his frivolity with a mock-solemn claim: “... this

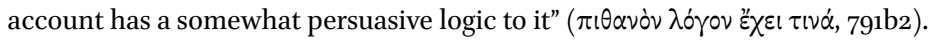

82 The semi-mythical Phrygian piper Olympus was widely regarded as the source of the basic 
ences specific to Korybantic ritual. ${ }^{83}$ Within everyday fifth- and fourth-century BCE Athenian discourse, the terms "Korybantic" and "Bacchic"—or in some cases "Sabazian" - or even "aulos-musically-affective" and "enthusiastic" can all apparently be employed almost interchangeably.

A particularly vivid sidelight on Sabazius-cult in Athens, and on the larger phenomenon of "enthusiastic" performances in general, is provided by the remarks of Demosthenes in the course of his notorious character-assassination of his rival Aeschines, in his speech On the Crown. Here he harps on the abject poverty of Aeschines' whole family and the demeaning occupations that they took up in order to earn a living. Aeschines' father had been a school teacher, and his mother, assisted by Aeschines himself as a young man, was leader of a Sabazius cult:

You assisted your mother in her rituals ( $\tau \varepsilon \lambda \circ \sigma^{\circ} \eta$ ) and at night you would read out loud the [sacred] books and helped prepare all the paraphernalia - the fawn-skins, the mixing bowl ... washing and purifying the participants ..., and you were especially proud of the fact that nobody ever

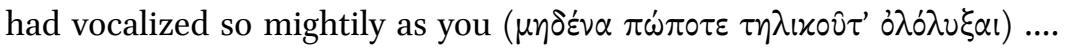

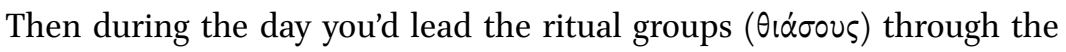
streets ... squeezing the snakes and raising them above your head, crying

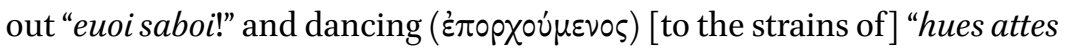

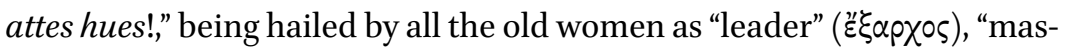
ter of ceremonies" ( $\left.\pi \rho \circ \eta \gamma \varepsilon \mu \omega^{\prime} \nu\right)$...

DEM. $18.259-26$ o

The performances clearly had much in common with Dionysian celebrations (mixing bowl, fawn-skins, snakes, etc.), while the ululations and foreign-sounding ritual incantations seem to provide a rather "Thracian" flavor, even while Aeschines' family were themselves completely Athenian. ${ }^{84}$ Demosthenes tells

Greek aulos-repertoire, much as Terpander was credited with having founded the kithararepertoire. The tunes attributed to Olympus were not all in Phrygian harmonia: some were e.g. in Dorian (Barker 2012). See further Barker 1984, 2012; West 1992: 105, 163-164, 181.

83 The disturbing impact of the pipes is also mentioned by Socrates in a Korybantic context near the end of Crito (54d), though the reference is rather obscure; cf. (contra Harte 1999) Griffith 2017 n. 13.

84 G. Martin 2009: 106-117 argues that the foreign-sounding ingredients in this description are largely an artificial invention, either by the Athenians in general (who generally liked to mix all kinds of "exotic" features into their Dionysus-celebrations) or by Demosthenes for rhetorical effect, and that there is little or nothing specific to Sabazius in this description, except possibly the snakes. He suggests that Demosthenes' account is a "hotchpotch 
us nothing about the musical aspects of these celebrations (e.g., what instruments were used to accompany the chanting and dancing), and he is more concerned to highlight the incongruity of an adult Athenian man participating in such activities - and even taking a leading role in them - than to discuss their effect on the (mainly female?) celebrants who paid (apparently with cakes rather than cash) to participate in the thiasos.

Altogether, the evidence concerning specific Korybantic rituals is thus quite various and some of it is confusingly inconsistent, even while the "fuzzy logic" of cultural analogy can be observed in the various more or less casual references of our classical sources, jumbling together the multifarious phenomena in rather consistent and predictable ways. We see that both male and female musicians and conductors/ministers/leaders of the ceremonies are attested, but we do not know quite how they were supposed to relate to the mythical daimones whose cult they were promoting. ${ }^{85}$ The original Korybantes (and Kouretes, Kabeiroi, etc.) themselves are male, while the nurturing goat Amaltheia is female and the whole idea of "nurses" for baby Zeus or Dionysus implies some female presence (such as the Meliae nymphs; cf. Plato's remarks in the Laws passage). Similarly many of the more plainly Dionysian groups of celebrants in myth include both satyrs and nymphs (or maenads), whether or not the god himself, or a male priest, personally presides over the drinking and dancing. ${ }^{86}$

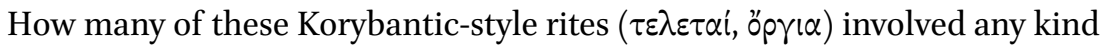
of "initiation" and/or "enthronement"? How similar or different was an initiation-type Korybantic ritual from a healing-type ritual? (Might they be two stages of the same ceremony?) In the case of healing ceremonies, we can assume that if an individual was selected to be thus healed s/he must usually have been recognized as being in a particularly troubled mental/spiritual state,

of various rites," with intentional exaggeration and absurd details included for humorous effect. On Greek incantations ( $\dot{\varepsilon} \pi \omega \delta \alpha i)$ in general, see Furley 1993.

85 In Hellenistic and later times, we find inscriptions recording e.g. that citizens $\mathrm{X}$ and $\mathrm{Y}$ served $a s$ the Kabeiroi in a given year, i.e., that this was an annual office; see Herrmann 2002. But this is presumably not the original pattern: human priests and ministers cannot normally become the actual gods or daimones being invoked, even if they may mimetically represent them in some respects.

86 See e.g. Parker 2005: 306-312, Scullion n.d. for discussion as to whether, and if so in what capacity, men could and did participate along with female celebrants in Dionysiac rituals at Athens. In the case of the Eleusinian Mysteries, the chief ministers of the cult were male (from the aristocratic Eumolpid clan), but the initiates were both male and female (including slaves), all apparently celebrating together. For discussion of the musical components of the Eleusinian (and other) Mysteries, see esp. Hardie 2004. 
whereas if a largish group met up for a celebration not all of the participants would be in the same state of spiritual need, though it is possible that different individuals would find themselves engaged and excited to different degrees during the course of a performance (as often happens in such trance contexts). In the case of initiation ceremonies, we might also conjecture that the initiand (e.g., someone like Socrates' young friend Clinias) may not always have been selected because of their state of mental disturbance, i.e., was not always seeking the same kind or degree of therapeutic treatment and cure. Many may have attended such ceremonies in a spirit more of "play" than of initiation, and those who enjoyed Dionysian celebrations were certainly not confined to women and those at the margins of society.

Further questions present themselves: were these ceremonies usually public or private? Were they conducted indoors or outdoors, at night or by day? Were they usually domestic and focused primarily on one person's cure or initiation? Or were they group sessions, in which many might join in as the mood took them, like other kinds of Dionysian thiasoi? ${ }^{87}$ Did the participants recognize a significant difference in function and performance character between specifically "Korybantic" rituals (and their equivalents: Kabeiroi, Kouretes, Dactyls), and other orgiastic and "enthusiastic" celebrations involving such individual gods as Sabazius and Bendis, Cybele, and even Adonis? As we have seen, casual parlance could apparently refer to almost any such cult performances as "Bacchic." 88

Even if we cannot answer all these questions in the present state of the evidence, enough common features and procedures are identifiable amidst this multifarious range of names and cults for us to regard them collectively as a single broad "type" of religious and musical event-a genre, analogous, for example, to our contemporary genre of "Electronic" popular music, with its many sub-categories and multiple additional sub-divisions. ${ }^{89}$ Even while the particular divinities might vary, and only a rather small proportion of these

87 Rouget 1985: 103 asserts "Every, or almost every possession cult has two aspects, that of its private rituals, reserved for the initiates or those being initiated, and that of its public rites, in which both adepts and followers of the cult take part and which more or less always take the form of a performance in which possession dances constitute the main element." This seems to square well with our evidence for ancient Korybantic and generally Dionysian rituals.

88 I will leave out of consideration here so-called "Orphic" documents, since whatever musical elements may or may not have been involved, these do not seem to have had much in common with Korybantic-style ritual. See further Edmonds 2008, 2013.

89 Within the "Electronic" category, "House," for example, includes "Acid," "Rave," "Tribal," etc. 
Dionysian/Cybelean-type performances might be classified as strictly "Korybantic," the common elements of the genre can be fairly definitely specified: loud music (almost always involving auloi, and often also animal-skin-drums and metal percussion instruments), vigorous movement (whether dance or other gestures), and an unusual degree of emotional arousal and altered men-

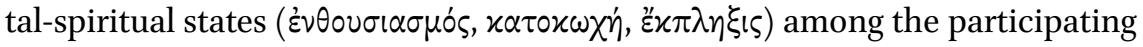
group, culminating in a "release" and a pleasant, prolonged mood of exhausted calm or sleep. Vocalizing of one kind or another was often included, but not always: in any case the music that was being performed did not depend on words for much - if any — of its effect. Women comprised a high proportion of the participants and performers, and elements that were regarded by elites as "non-Greek" and/or "banausic" (low-class, vulgar) were prominent. With regard to "Greek song culture" as a whole, this range of performances thus consistently occupies a far-right position on our grid, even while it appears already by the fifth century вСЕ, and probably earlier, to be quite deeply embedded within the social fabric-i.e., not a new foreign import nor a marginal activity confined to social misfits.

\section{Conclusions: Enthusiastic Performance as a Lyric Genre}

Greek song-culture offered multiple venues and occasions for musical performances, often of a non- or subliterary kind and supported by aulos-playing, that could be enjoyed by people from all social classes, in small or larger groups. These events - which in many cases might be regarded as "religious" celebrations (hence Aristotle's use of the term "sacred" [iєpós] and "Bacchic" interchangeably with "enthusiastic") — provided entertaining and stimulating auditory experiences that in their intensity often went beyond the casual "fun, play" of more neutral listening, and thus beyond the milder forms of relaxation outlined by Aristotle under the category of $\pi \alpha \iota \delta$ ' $\alpha$ and $\alpha \dot{v} \varepsilon \sigma ı \zeta$. These occasions provided escape from the drudgery of work and the stresses of everyday reality, and in some cases also served as an opportunity for some kind of healing of spiritual

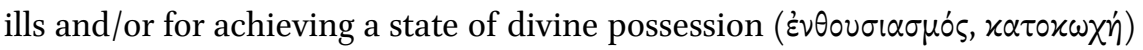
in the company of a group of like-minded companions. The words of the songs that were performed at these events were, for the most part, relatively unimportant: the emphasis was more on the melodies, rhythms, vocal and instrumental timbres, i.e., the overall auditory stimulation and the strong — and pleasantemotional affect (pathos) that these could induce-and sometimes also on the opportunities for dancing. Spontaneous, improvised participation in the music-making by the celebrants themselves might often constitute a feature 
of some of these performances, which consequently might or might not be counted as "choral," depending on one's definition. ${ }^{90}$

Some of the occasions at which Aristotle's most "enthusiastic" and emotionally affective kinds of music were performed involved ritual celebrations explicitly linked to the Korybants, Kouretes, Kabeiroi, or other local daimones of this kind. Others were less specific, more vaguely/generically "Bacchic," including several in honor of Cybele, Sabazius, etc. For most of these "enthusiastic" and "sacred" performances, the polis (or deme) as such usually had little to do with the organization and design of the events: they were organized instead by

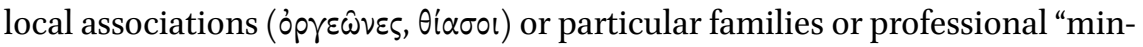

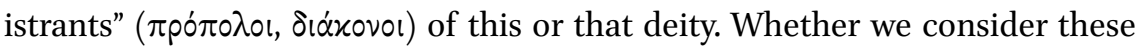
performances to be private or public, they seem to have been available to virtually every member of any Greek community, male and female, including metics and slaves, and to have been ubiquitous. I suggest that we should expand our idea of Greek "lyric genres" so as to include these somewhat déclassé/subliterary and even nonverbal types of performance, and that we should recognize, as Aristotle seems to have done, that it was specifically their emotional/affective impact on listeners (and on performers) that justified their being considered a distinctive genre of their own.

Modern scholars tend to treat these various "Bacchic" and orgiastic ceremonies as aspects of "Greek religion," and to discuss them in terms of the belief-systems and ethnic/gender/social identities that they might have represented and fostered. Their subliterary (and in some cases completely nonverbal) nature has meant that they have not generally been included in ancient or modern discussions of Greek song-culture (let alone lyric poetry), or only as a marginal postscript to it. Yet the evidence suggests that these "Bacchic"including more specifically Korybantic-type-occasions constituted a significant fraction of the "songs" and performances that would have been heard and seen from month to month in any given community. We should acknowledge the distinctive artistic, performative, and affective dimensions of such celebrations, and regard them as constituting a vibrant genre within Greek song culture, running in parallel to the more mainstream and socially elevated cultural forms that we find most prominently discussed and defined in our surviving literary sources.

$90 \quad$ See e.g. Budelmann and Power 2015, for discussion of various forms of women's "choral performance" in Athens that have mostly passed below the historians' and cultural critics' radar, including semi-formal "Bacchic" events. 
Most of our ancient sources that discuss the history of Greek poetry or music focus on high-end productions and performances, just as American and European music historians and critics tended until quite recently to focus only on the Western European art music tradition ("Classical" music). Discussions of the Greek symposium have tended likewise to focus more on the verbal exchanges and poetic sophistication of the male symposiasts than on the musical contributions of the professional and/or slave musicians, who in most cases were presumably rather more accomplished on their instruments than the actual guests. ${ }^{91}$ The fact that "Bacchic" musical events in general, outside the theater and other competitive festival contexts, were so readily available to such a wide range of people, in terms of gender, ethnicity, and social class, together with the high degree of emotional (and often corporeal) engagement that many of these performances entailed, meant that our elite sources consistently relegate them to the margins of their discussions and/or write as if they catered only to the vulgar or the demented. But on closer inspection it looks as if all kinds of people enjoyed such performances, in one context or another, and they deserve a more prominent position among our standard lists of Greek "lyric genres."

The Athenian theater-and in due course, theaters all over the Greek world-made the most of this type of music and performance too, incorporating it readily into dithyrambs and (especially) dramas, in which highly emotional rituals and songs could be mimetically reproduced in more or less authentic styles. The aulos-fueled music of the Athenian theater ${ }^{92}$ depended on a well-trained cluster of experts who between them could provide virtuoso pipe-playing, elaborate choreography, and an extensive range of melodies for the delight of thousands of audience-members. How closely these theater performances resembled the less culturally exalted and less heavily (finan-

91 Many scholars write as if the $\alpha \dot{\lambda} \lambda \eta \tau p i \delta \varepsilon \varsigma$ who played at these symposia were little more than cheap prostitutes, whose musical skills were secondary or negligible; but see e.g. Goldman 2015.

92 The dithyrambs and dramas performed in the Theater of Dionysus seem mostly to have employed Phrygian and Lydian harmoniai, though other modes could be used as well. The same is probably true of the music performed at symposia. But it is obvious that not all Phrygian melodies on the auloi were thought to have an "enthusiastic" effect, and we do not hear of people becoming possessed and going into a quasi-Korybantic trance at the theater or at a symposium. So it was only certain particular types of pipe-melody that were especially suited for producing this kind of pathos (affect, effect), and-crucially, as we noted above-it was only those who were positively seeking the trance effect who would find themselves so transported by music. 
cially) subsidized genre of actual (non-mimetic) orgiastic/enthusiastic ritual performance, we cannot tell. In those real-life cases, the degree of vocal and choreographic training, coordination, and uniformity shared by the performers would usually, one may conjecture, have been much smaller than in the case of dithyramb or tragedy - though the participation of women must have added a significantly fuller and richer dimension to the soundscape than the all-male performers in the theater could ever have attained. As we noted above, some Korybantic/orgiastic performances may have dispensed with verbal song completely, confining the vocalizations to shouts, ululations, and other more or less inarticulate cries, and inviting the celebrants (unlike the theater audiences) to enter or exit the music-making as the mood struck them. In the case of the two Euripidean examples that I discussed above, i.e., the mixed-status celebrants of Cybele/Rhea/Dionysus in Bacchae and the female friends who come to console Deo/Cybele/Rhea with their music in Helen, it is the nonverbal textures of the music that seem most prominent and salient, and it is these (above all, the auloi) that are cited as being most characteristic of this genre of mood-altering performance.

The fact that many of these kinds of performances were conducted by non-citizens-often by non-Greeks (or by Greeks pretending to be nonGreeks) ${ }^{93}$ —adds another dimension to this genre, and will have added to its déclassé status. And, to return to my grid (Table 8.1), this fact must have significantly affected the ways in which language was and was not employed in the different types of Korybantic and Bacchic musical performance. Clearly the melody, the timbre of the auloi and percussion, and the rhythm of the music and corporeality of the dance, were largely what induced in a listener the exhilaration and ascension to a state of altered consciousness and perhaps trance/ healing, while the actual words uttered by the ministrants or by the participants themselves do not seem generally to have been very important, or even always to have been coherent Greek. Foreigners and slaves - those with limited capabilities as users of the Greek language-would thus be just as capable of accessing these trance states as anyone else. The Korybantes (whatever/whoever they are supposed originally to have been) were not Greek. The Kouretes and Dactyls were Cretan (i.e., only borderline-Greek). The Kabeiroi seem not even to have been entirely anthropoid. The exotic character of these daimones was essential to the imagined origin and effect of their music, whether or not

93 This should be the topic for a separate paper; but meanwhile see Parker 1996: 170-175 (young men dressing up as Thracians to celebrate the goddess Bendis) and Power 2010: 47-48, 257 (a fashion for "Thracian chic" among kitharodes in Athens). 
Cybele or Rhea or Dionysus or Sabazius was directly invoked as well. The music over which all of these daimonic entities presided was appreciated particularly because it was different from that of the Olympian hierarchy, and the $\dot{\varepsilon} v \theta 0 v \sigma-$ $\alpha \sigma \mu o ́ s$ that it could instil was a precious cultural asset. Even Greek gentlemen might engage in a little "enthusiasm" from time to time. They recognized that this might be good for them, and as Aristotle noted, this musical genre constituted a vital component of their "song culture." 


\title{
Iambic Horror: Shivers and Brokenness in Archilochus and Hipponax
}

\author{
Mario Telò
}

Now, the letter rho, as I was saying, seemed to the name giver a good instrument for the representation of motion.... Through this letter, he imitates motion first of all in the words pॄîे ("to flow") and pon̂ ("flow"), then

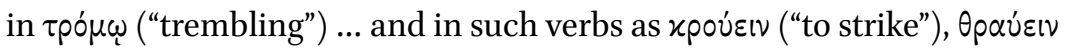
("to crush") ... Өpú $\pi \tau \varepsilon \imath \nu$ ("to break").... He saw, I think, that the tongue in

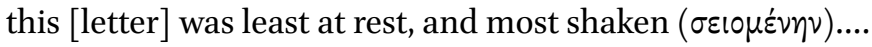

Do you think we were right to say that the rho resembles motion, movement, and harshness $(\sigma x \lambda \eta p o ́ \tau \eta \tau \iota)$ ?

PLAT. Crat. $426 \mathrm{~d}-\mathrm{e}, 434 \mathrm{C}$

The Romantic fetishization of feeling, as Gérard Genette has told us, was decisive in shaping the modern notion of lyric as a coherent and inclusive genre. While the obvious mimetic quality of epic and drama made them easy for Plato and Aristotle to categorize, the illusion of non-representational spontaneity created by the speaking "I," The Architext suggests, prevented lyric from attaining autonomous, all-encompassing generic dignity in antiquity. ${ }^{1}$ In order to claim a belated place beside epic and drama, ancient lyric, in the hands of the Romantics, had to be granted full mimetic status; it had to be conceptualized as

* I am very grateful to Meg Foster, Leslie Kurke, and Naomi Weiss for improving this chapter with their suggestions. Special thanks are owed to Leslie for encouraging me to participate in the conference on which this volume is based. Thanks also to all the participants for their illuminating comments, and to Emily Gowers, Mark Griffith, and Alex Press.

1 Genette 1992: 6o-67. 
a "representation of feeling rather than as feeling itself" - to quote the editors of the recent Lyric Theory Reader. ${ }^{2}$

Although this schema and especially the notion of lyric as a unified category, in ancient as well as modern literature, are controversial, Genette's narrative invites us to test how a renewed emphasis on feeling and its transmissionwhat social scientists and increasingly literary scholars call "affect" — may help us reconsider our understanding of Greek lyric forms in terms of genre. Sharing ancient literary criticism's preoccupation with the affective power of literary mimesis, we can try to locate a sense of genre in the ways lyric's representations of feeling achieve sensory immediacy, becoming embodiments and projections of "feeling itself." We can heuristically identify genre with the distinctive energies that a lyric form arguably diffuses to its audiences through the materiality of language - the affective force of recurring imagery or sounds. ${ }^{3}$ Affect theory views emotion as a boundless exchange of feeling, circulating beyond bodily boundaries, blurring the distinction between subject and object, the source or producer and the target or receiver. Feeling, in this perspective, becomes a dispossessed, impersonal, contagious force. ${ }^{4}$ The "sensuous dimension of literary experience," ${ }^{25}$ which the idea of affect helps us conceptualize, can contribute to a lyric text's construction of the frame of reference that governs its reception - precisely what we call genre. ${ }^{6}$ While scholarship on archaic Greek lyric has usually emphasized the pragmatics of genre-how a poetic form communicates, socially and culturally, with an audience through its performative occasion-my emphasis is rather on physiology and psychology. Not just fixing the horizon of expectations through social context, ideology, themes, and style, genre can be viewed as a genuinely aesthetic category, a notional, if problematic, demarcation of the quality of intensities that pass between text and recipients, turning form into bodily and psychic engagement. ${ }^{7}$ Genre can also

2 Jackson and Prins 2014: 12. For the link between genre and mimesis in archaic Greek lyric, see esp. Nagy 1994-1995.

3 On poetic sound as feeling, see, among others, Stewart 2002: 100-101 and Gumbrecht 2012: 4, 13 .

4 Deleuze and Guattari 1987: 257 have observed that "we know nothing about a body until we know what it can do ... what its affects are, how they can or cannot enter into composition with other affects." Seigworth and Gregg 2010: 1 remark that affect "is found in those intensities that pass body to body ..., in those resonances that circulate about [and] between ... bodies" and "sometimes stick to [them]."

5 In the phrase of Altieri 2007.

6 For this definition of genre, see, e.g., Depew and Obbink 20ooa: 6.

7 On embodiment, see Olsen and Estrin (this volume). 
be seen as the material environment created by the unlimited circulation of lyric affect, inside and outside the poetic frame. ${ }^{8}$

Applying this interpretive framework to the case study of one particular Greek lyric genre (or subgenre), iambos, I will explore unfamiliar connections in the extant corpora of Archilochus and Hipponax and in selected expressions of their ancient reception, tying together topographical and bodily images that set up what I call the generic texture of iambos - the tactile experience that this lyric form appears to channel to its audience. The generic affect of Archilochus' and Hipponax's iambos amounts to hairy, bristly, prickly roughness-horror in the Latin sense of the word, with a sensual charge. In their treatment of the "affective fallacy," Wimsatt and Beardsley famously stigmatized aesthetic responses such as the "shiver down the spine" and "tears, prickles, or other physiological symptoms." I will be concerned precisely with how shivers and prickles shape iambos' generic affect in the physical perceptions that its archaic practitioners and their later followers have of it. Iambos' powers of horror emerge from the unexpected textural continuity of disparate objects and sensations - rocky landscapes, shaggy skin, spiny plants, teeth-chattering coldness - as well as from recurring sounds, such as rho, which, in line with the trembling and breaking ascribed to it in Plato's Cratylus, almost functions as a generic phonestheme. ${ }^{10} R h o$ and other broken sounds convert language into sensation, invective discourse into emotional, fleshy investment. Iambic horror, in fact, can produce an edgy feeling of pushing the boundaries of pain and pleasure in an audience that, while touching the iambic texture, identifies with the target of aggression and with the poet himself, whose relationship to his own abjection may be marked by queasy enjoyment as much as aversion." A function of an ever-present and intrinsically ambiguous "you" (both target and audience), this mimetic dynamic realizes the lyric dimension of iambos and enables us to materialize its projected generic identity, to perceive such

8 Affect is what brings out, in Deleuze's words, "the atmospheric quality" of discourse (1994: 24). While affect has been identified with form itself (see Brinkema 2014), in my analysis I maintain a notional distinction between affect as emotional, psychosomatic content and lyric form as the conveyor of such content.

$9 \quad$ Wimsatt and Beardsley 1949: 43, 47.

10 Julia Kristeva's examples of texts with the "powers of horror" include Celine's London Bridge, with its descriptions of "piercing," “quaking," and "shaking”: see Kristeva 1982: 148. By phonestheme, Firth 1964 meant a pairing of phoneme and meaning such as, in English, the consonant cluster $g l-$, which tends to appear in words relating to light and vision.

11 On the reflexivity between the iambic poet and his target, see, among others, Miralles and Pòrtulas 1983, but this reflexivity involves the audience as well. 
an identity as a manifestation of "feeling itself."12 Linda Williams has assimilated the experience of horror films - a "body genre" par excellence- to "a roller-coaster ride of sadomasochistic thrills." ${ }^{13}$ Figuring an audience's material experience of the genre, not just its roughness against satirical targets, the surfaces that we will touch upon here reveal the masochistic side of iambic thrills, teasing us with frissons, jolts, and spasms, titillating sensations of aestheticized abjection that disrupt corporeality yet expand its limits. Iambos' distinctive projection toward a "you," in its double valence of target and audience, produces a poetic frame predicated on a programmatic transgression of that frame (in the etymological sense of "stepping out or beyond" it). ${ }^{14}$ In its formal inclination to step outside of its own discursive frame, iambos is emblematic of lyric affect. As an impulse to push past the frame of the body, the masochistic thrills promised by iambos affectively realize the stepping beyond that is intrinsic to its discursive form.

A journey through the textures of iambos might begin with Archilochus' programmatic description of Thasos, in which topographical and animal imagery figure the generic feel of iambos (fr. 21):

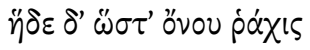

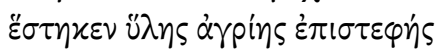

This [island] stands like the spine of a donkey, garlanded with a wild forest

Noting that Archilochus seems to efface Thasos' abundance of fruit trees and

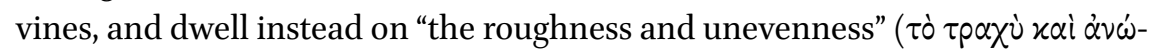
$\mu \alpha \lambda \circ v)$ of the landscape, Plutarch, the fragment's source (De exil. 6o4c), sees this emphasis as satiric "slander" ( $\delta เ \varepsilon \hat{\beta} \beta \lambda \varepsilon)$. The victim of Archilochean aggression, in Plutarch's view, Thasos is itself cast as an aggressor, its Thracian wildness matching the iambographer's verbal roughness, as showcased by the verbal res-

12 According to Culler 1977, 2015: 186-243, the apostrophe (the inscription of a "you" within a poem's discursive framework) is an essential device for creating the impression of temporal presentness, a fundamental dimension of the "lyric event." Waters 2003 has seen the apostrophe as tactile, a marker of lyric's aspiration to direct feeling beyond the closed space of the poem, to establish an affective relation with its audience. Regarding the sensual implications of the overlap between satiric addressee and audience, I have found the analysis of the Priapea offered by Young 2015a particularly illuminating.

13 Williams 1991: 7.

14 As Leslie Kurke points out to me, this iambic "stepping out or beyond" previews, in a sense, the parabasis of Old Comedy. 
onance of Archilochus' simile ( $\dot{\rho} \alpha \dot{\chi} \backslash \varsigma)$, Plutarch's metadescription ( $\tau p \alpha \chi \dot{\jmath} \varsigma$ ), and the place name $(\Theta p \dot{\alpha} x \eta) .{ }^{15}$ Whatever Archilochus might have thought of his second home - the place where his Parian father allegedly founded a colonythe exiled poet found in the island a reflection of iambic $\tau p \alpha \chi \dot{v} \tau \eta \varsigma .{ }^{16}$ Hipponax's birthplace, Ephesus, performs the same self-reflexive function. Its urban topography, as we see in fragment 50.2, includes a place situated "between Rough and

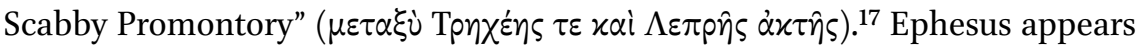
to be an obstacle course through pointed surfaces like the rocks and forests of Thasos, as well as iambos' harmful sounds. In the Archilochean fragment, $\dot{\alpha} \alpha \mathbf{x}$ 's, which causes savage terrain to slip into animal physicality, contains a substantial phonemic portion of $\tau p \alpha \chi \dot{v} s$, an aural reflection of the unity of Thasos' sharp edges and a donkey's bristly hide. ${ }^{18}$ Through this insistent combination of aspirated rho and velar consonants corresponding to Archilochus' and Hipponax's

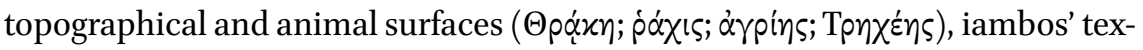
ture, its affect of harshness, thus emerges. In a fragment of Aristophanes, the "hardness" ( $\sigma x \lambda \eta$ pótn $)$ of Aeschylean tragedy is compared to the tough skin of pigs and cows. ${ }^{19}$ Almost a crypt word for $\tau p \alpha \chi ن$ 's, the spine of the Archilochean donkey, isolated at the end of the line, similarly embodies a generic sensation, enabling us to experience, almost physically, the edgy quality of iambos, its character as a locus horridus, its Thracian position—on the fringes of literary pleasure.

The convergence of asinine body, locus horridus, and novelistic texture in Apuleius' Metamorphoses can help us understand how, in the Archilochean fragment, the donkey's skin materializes the iambic persona's double role as an agent of abuse and an abject victim. Some of Apuleius' descriptions of

15 On $\tau p \alpha \chi ن \dot{\varsigma} \varsigma$ as a designation of an angry voice, see, e.g., [Aesch.] $P V$ 311, 1048.

16 On the relation between the persona loquens and Archilochus' autobiography in this fragment, see Bowie 2009: 108-109; for a more skeptical approach, see Owen 2003. The reception of Archilochus takes his association with Thasos as a generic marker, as shown by

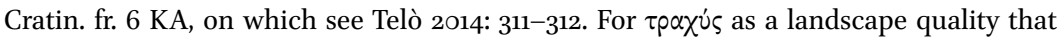
transfers virility to inhabitants in Hdt. 1.71.2, see Purves 2013b: 31-32. On landscape as a reflection of literary-critical categories, see esp. Worman 2015a, 2015b; on "generic topography" in Pindar, see Kurke 2013b: 120.

17 The Ephesian topography alluded to here is discussed by Strab. 14.1.4, the source of the fragment.

18 ' $\mathrm{\alpha} \chi \chi \measuredangle \varsigma$ is almost an anagram of the Latin acris, feminine of acer, a common onomatopoetic designation of satiric roughness: see esp. Gowers 1993: 131-132. In discussing the aesthetics of $\pi \cup x v o ́ t \eta \varsigma$ in Homeric narrative, Purves 2013a: 58 connects the thick bristliness of the boar's back in $\mathrm{Od}$. 19.446 with "the thickly-charged environment" of the scene.

Ar. fr. 663 KA. 
loci horridi-mountains, rocks, torrents, and thickets—are entangled with language used for the donkey's body. ${ }^{20}$ In particular, Lucius' metamorphosis takes place through a thickening of hair, marked by the verb horripilo, into a virtual thicket, and a hardening of skin — both folding the human-turned-animal into the frightful landscape. ${ }^{21}$ Lucius' transformation equips him with the power to kick, but also makes him a slave, by definition subject to beating and flogging. ${ }^{22}$ The donkey's horrid landscape - the spiky rocks and craggy mountain pathscomplements his abusers' sticks and whips. ${ }^{23}$ As Jason König has observed, Apuleius' novel presents "an obsessive and gruesome fascination with the extreme vulnerability of human and asinine bodies to the physicality of landscape." ${ }^{24}$ The landscape, which victimizes the protagonist even after co-opting him, reifies not just the notorious asperity of Apuleius' style, but also his text's narrative texture. ${ }^{25}$ Before the final redemption, the novel's ceaseless obstacles and travails are like rough edges whose abrasions accrue on the bristly skin of the novel's animal protagonist and victim. The horrid terrain of Archilochus' Thasos empathically connects his audience with the target of iambic invective, who is forced to pass through the cutting crags and prickly vegetation of his satire. However, Thasos' donkey-like bristliness also mimetically channels to the audience the downtrodden affect of the satirist, who, besides kicking, is himself a victim of blows, like the Apuleian Lucius.

This iambic abjection concentrated in Thasos also takes a human shape, a grotesque female figure emanating a prickly sensuality. Fragment 22 continues the portrait of Thasos by contrasting the island with the region of Siris-an icon of southern Italian abundance and fertility named after the first wife of King Metapontus: ${ }^{26}$

$20 \quad$ On the locus horridus in Apuleius, see esp. Schiesaro 1993; König 2013.

21 Cf. 3.24, where duratur, which designates the hardening of Lucius' skin, echoes the description of petrified humans in 2.1.

22 For the connection between Lucius' donkey skin and slavery, see Fitzgerald 2000: 100.

23 See 7.17.4.

24 König 2013: 231.

25 Selden 2014: 239-245 has recognized distinctive Afro-Asiatic elements in Apuleius' style, whose harsh twists and turns could be viewed as a reflection of the rugged Libyan landscape. The horrid nature of Apuleius' loci horridi is enhanced by the concentration of moody sound effects, noted by De Biasi 1990: 14-15, including a prevalence of $r$.

26 This is the identification proposed by Athenaeus (12.523d), who cites the fragment. Against the tenuous hypothesis that Archilochus may refer instead to a river in the Propontis called Syros or Sirios, see Moscati Castelnuovo 1989: 43-47. According to $\Sigma$ Dion. Perieg. 461, when Metapontus replaced Siris with another woman, he sent her off into the eponymous region. 


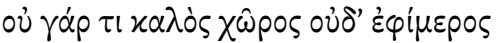

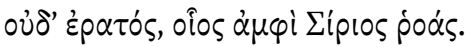

For it is not at all a beautiful, desirable, or lovely land, like the one around Siris' stream.

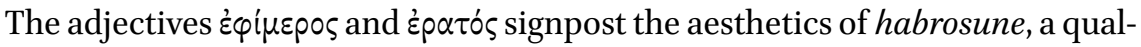
ity proper to erotically charged bodies and loci amoeni but also to the soft poetic texture that several lyric voices, privileging these imagistically interchangeable subjects, claim for themselves. ${ }^{27}$ In Sappho fragment $16 \mathrm{~V}$, Anactoria's "lovely stride" (हैp $\alpha \tau o v ~ . . . \beta \hat{\alpha} \mu \alpha$ ) points to the poem's own soft, rhythmic pace, as Yopie Prins has suggested. ${ }^{28} \mathrm{Alcman}$ indirectly maps the alluring topography of

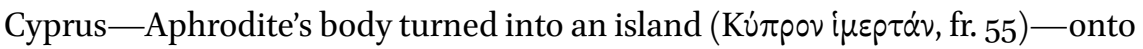

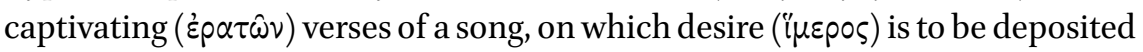
as a quasi-tactile layer (fr. 27). ${ }^{29}$ Archilochus irreverently purports to enter this generic landscape in the last section of the Cologne Epode, where the account of the sexual encounter proceeds through references to a locus amoenus, soft surfaces (of a female body and a cloak), and gentle touching - possibly deceptive flirtations with other lyric genres' sensoria, which are then overturned by the iambic coarseness of the final act. ${ }^{30}$ Against this background, the comparison of Thasos with Siris, a counterpart of Alcman's Cyprus, invites us to view the

27 On the complex materiality of lyric habrosune, see Kurke 1992, 2007: 147-152; on the aesthetics of softness in Sappho and Alcman, expressed by the recurring adjectives $\mu \alpha \lambda \theta \alpha$ xós and $\dot{\alpha} \pi \alpha \lambda$ ós, see also Burnett 1983: 299 and MacLachlan 1993: 63 n. 17. In Sappho, softness is one of the sensory domains where, as Prins 1999: 98 observes, "the language of place shades into the language of the body."

28 See Prins 1999: 128, who presents Anactoria as "a figure fleshed out by the rhythms of Sappho and bodied forth as rhythm itself."

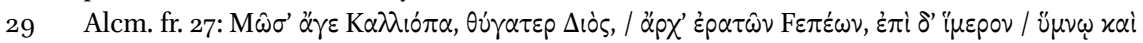

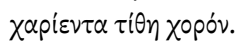

30 Cf. 196a.42-43 $\varepsilon^{\prime} \nu \ddot{\alpha} \nu \theta \varepsilon[\sigma / \nu / \tau \eta \lambda] \varepsilon \theta \dot{\alpha} \varepsilon \sigma \sigma l$ (a phrase that is resonant with Sapph. fr. 2.9-10

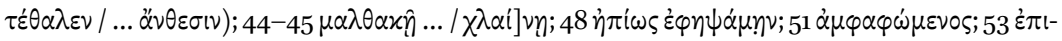

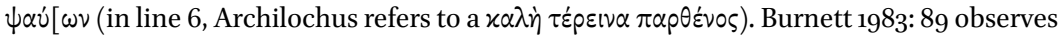
in the poem "an astonishing confluence of abuse with ... sensual detail" - an aspect of its self-consciously "insidious" nature, in the words of Kurke 2000: 71. Even when infiltrating other lyric territories, the iambicist cannot entirely leave aside his innate roughness; conversely, ostensibly soft lyricists represent the violence, the "roughness" of love (see for example, Sappho fr. $3^{1} \mathrm{~V}$ ) and occasionally seem even to be able to assume an iambic guise (see Brown 1984 on Anacreon, and Rosenmeyer 2006 and Martin 2016 on Sappho). Besides the Archilochean poem's well-known engagement with epic seduction scenes (on which see Swift 2015), there is, thus, an intralyric dimension, a self-positioning that tries to negotiate the complex play of difference and similarity at the root of the notion of genre itself. 
former as a female surface - a reading also suggested by the following passage from Semonides' misogynistic tirade (fr. 7.50-54):

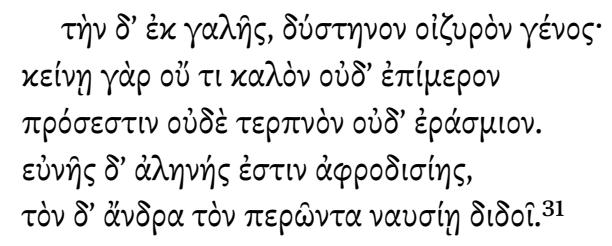

Another woman is from the weasel, a wretched and woeful creature; she has nothing that is beautiful or desirable or pleasant or lovely. But she is mad for the sexual bed, and gives the man who penetrates her to nausea.

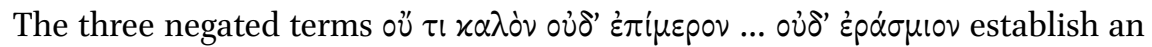
unexpected link between this presumably bristly weasel-woman and Archilochus' donkey-like Thasos, as does the onomatopoetic adjective oi̧upóv, derived from the exclamation of grief ol. Archilochus calls Thasos a "three times

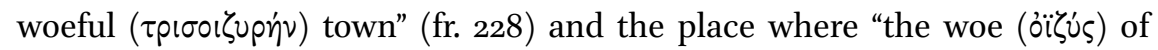
all Greeks has run together" (fr. 102). The textural kinship of the weasel with the Thasian donkey, in turn, alerts us to a possible identification between the Semonidean abuser and his target. In general, the iambicist shares with the weasel a trickster mind and sexual voraciousness; more importantly, in the passage above, Semonides makes his audience experience, even vocalize the sensation he attributes to the female/animal target's lover. ${ }^{32}$ The line that speaks

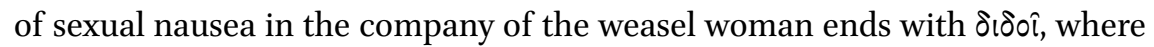
the stress, grammatical and metrical, on the last syllable enacts the affective dynamic, exposing the listener/reader to the sound of the pain (oil) conveyed by oǐupós. It is as though listening or reading allowed one to feel the disagreeable conclusion of an intimate encounter that resembles a ramble through Thasos' craggy landscape. The grammatical structure of the last sentence, with the dative $v \alpha v \sigma i n$ governed by $\delta i \delta \circ \hat{l}$, suggests that this sensory experience is tantamount to intercourse with nausea itself, personified and domineering.

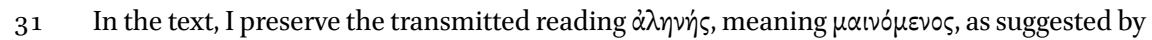

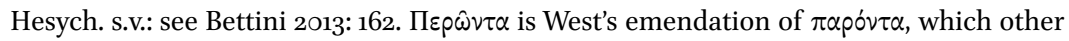
editors retain in the appropriate dialectal form $\pi \alpha p \varepsilon o ́ v \tau \alpha$. Regardless of the text, the line clearly describes sexual intimacy between the weasel-woman and $\tau \dot{\nu} v \alpha \dot{\alpha} \nu \rho \alpha$.

32 On the weasel as a sexually voracious trickster, see Bettini 2013: 162-163, who also points out the animal's foul smell. On "the iambic poet as a trickster," see Miralles and Pòrtulas 1983: 11-5o. 
Conversely, in light of Semonides, Thasos' savage vegetation starts to resemble, as the adjective $\dot{\varepsilon} \pi\left\llcorner\tau \varepsilon \varphi \eta \dot{\zeta}\right.$ suggests, the rough garland specifically of a woman. ${ }^{33}$ The iambicist presents a hairy, uneven, masculine surface as female in lieu of conventional lyric softness-not unlike $\dot{\eta}$ $\nu \bar{\eta} \sigma 0 \varsigma$ itself, which bears the duality of feminine gender in a male form. ${ }^{34}$ Although the iambicist often fantasizes about tender, fragrant female bodies or lovely tresses and may even seem to valorize Siris in comparison with the donkey-(or weasel-)like Thasos, he ends up aestheticizing sensual edginess as generic difference, titillating his audience with coarse textures, perhaps even stimulating a queasy delight. ${ }^{35}$

Bristly Thasos may lurk behind Archilochus' famous contrast of generals, suggesting another connection between iambic landscape and human surfaces. In his First Tarsian Speech, Dio Chrysostom (33.17) cites these lines, which have traditionally been read as an Archilochean intervention on the theme of epic heroism (fr. 114): ${ }^{36}$

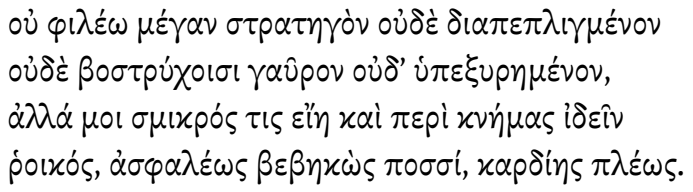

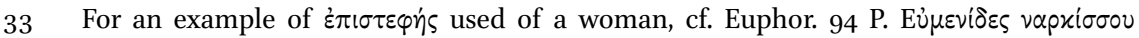

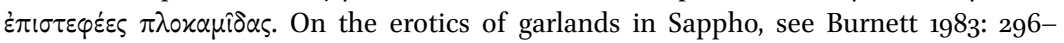
297 .

34 On the transgender dimension of the iambic persona in Horace, see most recently Gowers 2016, who mentions Lamia, a female figure with male genitals, among iambos' mythological ancestors.

35 In fr. 119 Hipponax expresses a desire for a "tender" $\pi \alpha p \theta \varepsilon$ vo Cologne Epode (see n. 30). In frs. 30-31, Archilochus provides other snapshots of fantasized female habrosune, probably looking ahead to a scenario of iambic coarseness (see

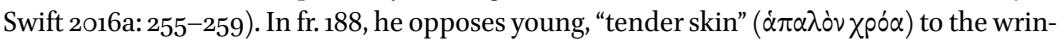
kles of old age, which are imputed to wintry winds. The bodily and natural roughness apparently deplored here is precisely the generic feel of iambos that we are reconstructing (on coldness and shivers, see below). Horace's widely recognized appropriation of the Archilochean wrinkles in Epod. 8.3-4 belongs to a similar stew of miasmic misogyny. Yet, as Richlin 1992: 113 observes, "Horace clearly enjoys ... a thorough stare at ugliness, wallowing in the foulness he creates and rejects." Moreover, the decrepit female bodies so vividly detailed here are "uncomfortably" similar to that of the invective poet himself, as Oliensis 1998: 75 has noted. A generalized preference for the rough, uneven surface and sensation may well transcend gender divisions, as we will see in Archilochus' preference-sexual or otherwise-for the "bent" general over the smooth, shaved one, with his legs apart. Greek archaic iambos offers itself to its audience precisely as an ugly body pushing sensory experience to the edge.

36 See, for example, Toohey 1988. 
I do not love a big general, with legs apart, proud of his curls, and partly shaved. Let me have one who is small, looks bent around the shins, stands firmly on his feet, and is full of heart.

Critics have noted the lack of parallelism in the portraits of the two strategoi-

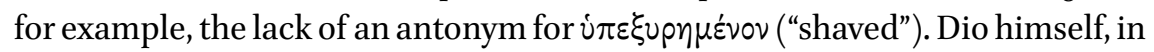
his paraphrase, presents Archilochus' preferred general, "mulish" or "perhaps even donkeylike," in Mark Griffith's words, as "hairy" ( $\delta \alpha \sigma$ $\varsigma)$ on his shins. ${ }^{37}$ Certainly, as Tom Hawkins observes, this added detail, playing on the classic opposition of effeminate smoothness and virile hairiness, fits the moralistic agenda shaping Dio's reperformance of Archilochean iambos in Roman Cilicia. ${ }^{38}$ Going a step further, we might detect in Dio's invocation of Archilochus' preferred general, wrapped in a critique of the unmanliness of the Tarsians, a residue of the original Thasian texture of iambos, which is similarly cast

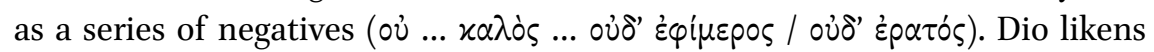
the two generals, one slick and the other hairy, to urban landscapes: the former to an imperial, sumptuous locus amoenus - rivers, baths, fountains, porticoes, and fancy houses; the latter to a small town built "on a rock" ( $\dot{\pi} \pi \mathrm{i}$ $\pi \dot{\varepsilon} \tau p \alpha \varsigma)$. This alignment of hairiness with a rugged landscape recreates Thasos' iambic topography, the "unevenness" that Plutarch had criticized Archilochus for emphasizing - also expressed in the bent, though firmly planted, legs of the preferred general. The Archilochean phrase $\dot{\alpha} \sigma \varphi \alpha \lambda \varepsilon^{\prime} \omega \varsigma \beta \varepsilon \beta \eta x \dot{\omega} \varsigma \pi 0 \sigma \sigma i$ would be apt for the stabilization of the originally floating Delos, for example, which both Pindar and Callimachus anthropomorphize, respectively assigning it "steely

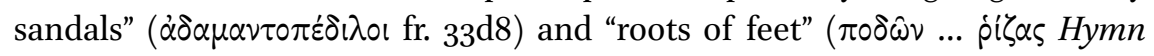
$4 \cdot 54) \cdot{ }^{39}$ The unshakability goes along with the island's rough, rocky geology, unsuitable for cultivation, like Thasos. 40

Discovering reflections of Thasos' rockiness in the asperity of Archilochus' description, we may supplement Dio's moralistic take on the general's shaggy body with an appreciation of its "powers of horror," its scratchy (dis)pleasures. The smoothness of the freshly shaved general is matched by the glossy verbal and rhythmic surface of the first two lines, organized into symmetrical units of syntax and meter joined by polysyndeton and internal echo ( $\sigma \tau \alpha \tau \eta-$

37 Griffith 2006: 314. Some modern critics have tried to insert Dio's $\delta \alpha \sigma \dot{\sigma} \varsigma$ in Archilochus' text: see Pisani 1938.

38 See Hawkins 2014: 206-214.

39 On these two passages, see Nishimura-Jensen 200o: 289-292.

$40 \quad$ As emerges from $\Sigma$ Call. Hymn 4.11a, b, which gloss $\ddot{\alpha} \tau p \circ \pi \circ \varsigma$, said of Delos, as $\dot{\alpha} x i v \eta \tau \circ \varsigma$ xai

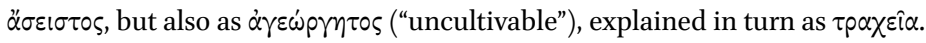




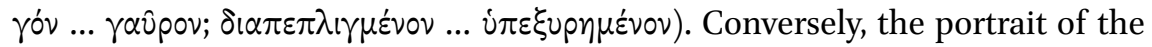
hairy one is a Thasian thicket of qualifiers, unevenly linked (first by $x \alpha i$ and then with asyndeton), disrupting the previous lines' seamless continuity with a sharp enjambment. Closely resembling póxı , the marker of the asinine feel of Archilochus' home, pooxós captures Thasian $\delta \alpha \sigma u ́ t \eta \varsigma$. As an aspirated consonant, rho is, according to ancient grammarians, a quintessentially hairy sound, $\delta \alpha \sigma \dot{v}$ or hispidum. It is the so-called canine letter, which Genette included in his Voyage en Cratylie, following the lead of this passage of Persius (1.107-110):41

\section{Sed quid opus teneras mordaci radere vero auriculas? Vide sis ne maiorum tibi forte limina frigescant: sonat hic de nare canina littera.}

But what is the need of scraping tender little ears with biting truth? See to it that the thresholds of your betters do not, by chance, become cold for you: here the snarl of a doggy rrrr sounds from the nose.

Bundles of rhotic energy, radere and frigescant render satiric invective's scratchiness and the shivers of the abject satirist. ${ }^{42}$ The initial rho of porxo's and $\dot{\rho} \alpha \chi \zeta$ in Archilochus affects both the iambicist and his targets, victims of

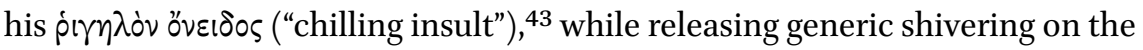
audience. The sequence of aspiration in ṕx $\chi 15$, besides reproducing the feel of asinine skin, may suggest the goosebumps caused by Thracian rigors, while pixvós, an alternative form of poxxós, can, in fact, mean $\pi \varepsilon \varphi p(x \omega \dot{\omega} \varsigma$ ("shriveled with cold"). ${ }^{44}$ Archilochus' celebration of his general's courage and "unshaken" temper is central to Dio's moralistic reading. Still, the texture of poixós, which $\sigma \mu \iota x p o ́ s$ anticipates, hints at a not-so-firm figure who perhaps, like the iambi-

41 Cf. Genette 1995: 37-38. On rho as hispidum, cf. Terent. Maur. GL vi 333, 262 K. In De comp. verb. 14, p. 54. 13 U.-R., Dionysus of Halicarnassus defines rho as the liquid sound that "roughens ( $\tau p \alpha \chi ن \dot{v \varepsilon \varepsilon l) ~ t h e ~ e a r . " ~ T h e ~ c a n i n e ~} r$ is also discussed in Lucil. 377 M., to which Persius alludes. Dionysius' treatment of "rough" sounds has been widely discussed; most recently, Purves forthcoming has called attention to the temporal dimension of such sounds, their effect of slowing down a text. Porter 2010: 371-397 offers an extensive discussion of the aesthetics of another notoriously "harsh" consonant, sigma.

On this passage, see Bramble 1974: 151-152 and esp. Keane 2006: 93. On the shivering Hipponax, see below.

43 This is the characterization of Archilochean iambos that we find in an epigram by Dioscorides $(A P$ 7.351.5-6), spoken in the voice of Lycambes' daughters.

44 Cf. Soph. fr. $1091 \mathrm{R}^{2}$. 
cist, trembles while attacking. The iambic phonestheme rho, which growlingly initiates poixós and $\dot{p} \alpha \dot{\chi} \backslash \varsigma$, feels like an encounter with hispid body parts that slides into shudders, the generic sensation of horror.

Turning our attention to one of Archilochus' widely recognized animal alter egos, we can appreciate other ways in which iambic affect emerges from the friction of scratchy surfaces-a stick, a trap spring, or a fox's tail. Fragments 185-187 relate to the Aesopic tale of the fox who brings down a pompous monkey elected king of the animals. ${ }^{45}$ The fable, deployed to attack a "herald's son" ( $\hat{\omega}$ Knpuxio $\eta$ ), is presented, in fragment 185 , as the message on a leather strip wrapped around a herald's stick-a $\sigma \varkappa v \tau \alpha \dot{\lambda} \eta \eta$ that, like the iambicist, shouts in distress $\left(\dot{\alpha} \chi v \nu \mu \varepsilon^{\prime} \nu \eta\right) .{ }^{46}$ After luring his target into a trap, the fox scornfully points out his fall, from top to bottom (fr. 187):

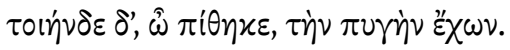

monkey, with a tush like that

As has been observed, $\pi \cup \gamma \eta \dot{v}$ reconfigures $\pi \cup x v o ́ v$, employed in fr. 185 to express the fox's (and satirist's) intellectual primacy ( $\pi \cup x v o v v$ É $\chi 0 v \sigma \alpha$ vóov) ${ }^{47}$ But aside from signaling a mind-body opposition, the intratextual pun may point to a physical contrast-between the monkey's smooth $\pi \cup \gamma \dot{y}$ and the fox's own

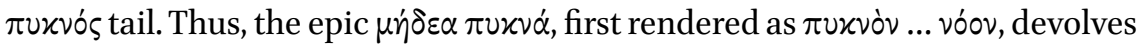
into a bodily extremity, coarse in both its register and materiality. The fox's tail is not just shaggy, but pointed, a stand-in for other sharp vulpine edges-tongue, teeth, claws, ears, snout, and, figuratively, mind. His base self-aggrandizement, then, helps us see the fox, whom Theocritus calls $\delta \alpha \sigma u x \varepsilon p$ xos ("bushy-tailed"), as another bristly animal analogue for Thasos-like the shaggy general, who is similarly positioned against a shamefully smooth adversary. ${ }^{48}$ We can tease out further implications by considering the trap that defeats the monkey (186):

45 On the place of this fable in the Aesopic tradition, see van Dijk 1997: 144-147; on Archilochus' treatment of this fable in relation to his satiric agenda, see esp. Rosen 1988: 17-18; Bowie 2008: 133-136; Steiner 2010: 99-100, 2012b: 19-29, 2014b, and 2016; Pappas 2014.

46 I take $\alpha \chi \chi v \mu \varepsilon \dot{\varepsilon} \eta \eta \sigma x v \tau \dot{\alpha} \lambda \eta$ as a nominative. The classic discussion of the Archilochean $\sigma \times v-$ $\tau \dot{\alpha} \lambda \eta$ is West 1988. On the interpretation of $\alpha \chi \chi v \mu \varepsilon \dot{\varepsilon} \eta \eta$, see Pappas 2014. On the rich imagery of the $\sigma \varkappa v \tau \dot{\alpha} \lambda \eta$ in Pindar's Olympian 6, see Neer and Kurke 2019, ch. 8.

47 See Pappas 2014: 28.

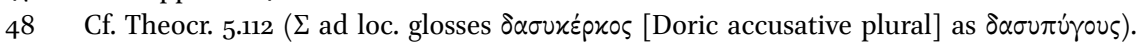
The connection of the monkey with the "shaved" (i $\pi \varepsilon \xi \cup p \eta \mu \varepsilon v o v)$ general is perhaps reinforced by Aristophanes' appropriation of the Archilochean line in Ach. 119-120, in which an ambassador is addressed as "smooth-assed," a "monkey, with a beard like that": $\pi \rho \omega x \tau$ òv 


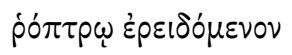

pressing on the trap spring

A piece of bent wood that sets a trap in motion when touched, the pó $\pi \tau p o v$ brings to mind the crooked legs ascribed to the poxxós Archilochean general. ${ }^{49}$ The semantic connection corresponds with the textural consistency of the two words, which both incorporate the letter rho ( $\dot{\rho} \circ$ ) itself, making palpable the contact of some body-monkey, satiric target, or listener/reader-with the rough and curved surface of iambos. In this moment of contact, triggering iambic horror, the ṕó $\tau$ pov, in a way, realizes the generic affect of the similarly curved fox's tail and the $\sigma x v \tau \alpha \dot{\lambda} \lambda \eta$, the doleful stick that resembles the shaggy general's firmly planted legs.

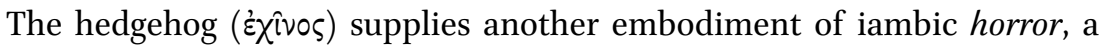
further example of how this generic feel arises from animals' bodies and a corresponding rough sound. The apparent confrontation of fox and hedgehog in fragment 201 has caused much disagreement over which of the two has a stronger claim as an authorial alter ego. ${ }^{50}$ Like the fox, the "rough hedgehog"

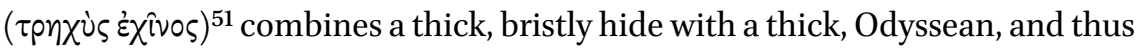
Archilochean, mind; ${ }^{2}$ its spiky surface provides another bodily surrogate of Thasos' topography. ${ }^{53}$ What modern interpreters see as a problem - the apt-

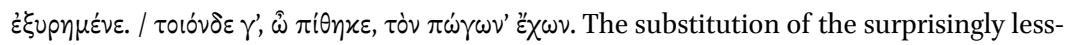
vulgar $\pi \dot{\omega} \gamma \omega \nu^{\prime}$ for $\pi \cup \gamma \eta \dot{v}$, referring here precisely to the lack of a beard, may be informed by the earlier contrast between the monkey's smoothness and the beard-like shagginess of the fox's tail. A self-aggrandizing allusion to vulpine bristliness may also be the point of one of the fragments that map the fable of the vixen and the eagle onto Archilochus' dispute with Lycambes. In fr. 178, the vixen is probably warning the hubristic eagle, whiterumped according to ancient interpreters, that punishment awaits him: $\mu \eta \dot{\gamma} \tau \varepsilon v \mu \varepsilon \lambda \alpha \mu \pi \dot{\gamma} \gamma o v$

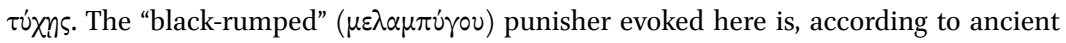
and modern critics, a different type of eagle, proverbially braver than the vixen's enemy and an agent of Zeus himself. If we consider that Luc. Pseudol. 32 connects $\mu \varepsilon \lambda \alpha \dot{\alpha} \mu \tau \gamma \circ \varsigma$ with $\delta \alpha \sigma \dot{\varsigma}$, thus interpreting the epithet as "hairy-tailed," it becomes attractive to think that the "black-rumped" punisher may well be the "hairy-tailed" vixen herself.

49 The source of the fragment (Et. Mag. 715.44) glosses pó $\tau$ tpov as "the bent piece of wood in a trap."

50 For an account of the various positions, see Corrêa 2001: $85^{-89}$, who reacts against the prevailing identification of the Archilochean persona with the hedgehog; see also Bowra 1940 and, most recently, Swift 2019: 386.

51 Opp. Hal. 2.36o.

52 On the Odyssean Archilochus, see esp. Seidensticker 1978. As Meg Foster points out to me, in $O d .13 .242$ Ithaca is described as $\tau p \eta \chi \varepsilon i \alpha$.

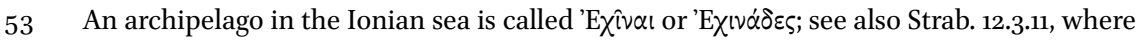


ness of both animals as iambic stand-ins - may be precisely the point of the poem, which could be considered a varied display of generic $\tau p \alpha \chi v^{\prime} \tau \varsigma$ or a dramatization of iambos' boundary-crossing between aggressor and target. ${ }^{54}$

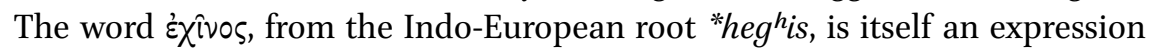
of $\delta \alpha \sigma i \tau \eta$ in the sense of "aspiration," the letter $\chi$ capturing the sensation of the animal's spines-but there is an additional relation with the idea of aspiration as iambic. In the fragment mentioned above, the hedgehog is said to know "one big thing" ( $\varepsilon \nu \mu \varepsilon \gamma \gamma \alpha$ ) while the fox knows many $(\pi \circ \lambda \lambda \dot{\alpha})$, an echo of fragment 126, where the poet, too, professes to know "one big thing" ( $\tilde{\varepsilon} \nu \delta$ ' $\dot{\varepsilon} \pi i \sigma \tau \alpha \mu \alpha \iota \mu \varepsilon^{\prime} \gamma \alpha$ ), how to repay attackers with harm. Whenever the hedgehog feels under attack, it rolls itself up into a ball—in Pliny's description, folding together multiple bodily parts into one. ${ }^{55}$ With the posture that enables the hedgehog's spiky (passive) aggression, it not only knows one thing but becomes one thing ( $\tilde{\varepsilon} v)$, and thus a prickly reflection of the sound of the word, which, like the rolling rho, sends forth an iambic intensity that threatens to scratch and tear the iambicist's enemies but is inevitably felt also on his audience's skin. ${ }^{56}$

This double directionality of iambic feeling has implications for some of Hipponax's poems and their ancient reception. The powers of horror ostensibly mobilized against targets or the self-abusing iambicist appear to impinge on the readers of the Hipponactean corpus. We will see how iambos' sadomasochistic power, its ability to stimulate an audience's desire to push roughly against the human body's limits, contributes to creating a persistent sense of itself as a genre.

The pharmakos fragments, with their imagistic and phonic display of beating and flogging, seem to have shaped ancient readers' perception of the feel of Hipponactean iambos, of its affective legacy. Tzetzes, the main source of

Sinope is said to be inaccessible "because of the prickly ( $\left.\chi^{\prime} \chi v \omega \dot{\delta} \eta\right)$ surface of the rock." In Archil. fr. 190 we find the adjective $\delta v \sigma \pi \alpha i \pi \alpha \lambda \circ \varsigma$, a synonym of $\tau \rho \alpha \chi \dot{\nu}^{\prime} \varsigma$ and $\alpha \nu \omega \dot{\omega} \mu \alpha \lambda \circ \varsigma$,

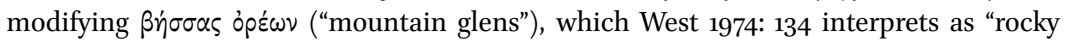
glens ... of the woman's body." This adjective refers to the hedgehog's skin in Opp. Hal. 2.369.

54 Payne 2010: $3^{0-31}$ is an exception, regarding the alleged problem as an expression of the shifting complexity of Archilochus' animal alignments.

55 Plin. NH 8.133 ubi vero sensere venantem, contracto ore pedibusque ac parti omne inferiore ... convolvuntur in formam pilae, ne quid comprehendi possit praeter aculeos.

56 In Hor. Ep. 5.27-28 the bristly hair of an iambic witch, Sagana, is compared to the hedgehog's spiny skin: horret capillis ut marinus asperis / echinus aut currens aper. In these lines, the echinus, probably appropriated from the Archilochean fable, becomes an objective correlative of sonic roughness amid a host of $r$ 's, including the geminated $r$ 's of horret and currens. 
the pharmakos cycle, informs us that the ritual included the use of squills, wild fig branches, and "other wild plants" ( $\ddot{\alpha} \lambda$ oเ $\tau \hat{\omega} \nu \dot{\alpha} \gamma p i \omega \nu$ ) against the scapegoat (Chil. 5.736). We find a glimpse of this practice and its effects in two short fragments, where an iambic victim or the iambographer himself may lie behind the beaten pharmakos - the uncertainty reflects iambos' distinctively mimetic violence (frs. 6,10$): 57$

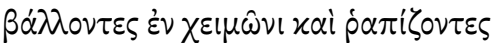

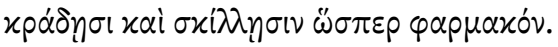

In the winter, hitting and flogging [him] with fig branches and onions like a scapegoat.

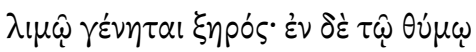

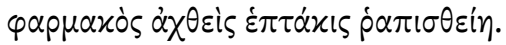

In order for him to become withered with starvation; and having been led off, a scapegoat, may he be flogged seven times on his penis.

With its rhotic force, the verb $\rho \alpha \pi i \zeta \omega$ materializes flogging as an aspirated vibration, which, in the first fragment, is prolonged and intensified through the initial sounds of the word for fig branches, $x p \alpha ́ \delta \eta \sigma$. Here the programmatic force of this painful vibration is underscored by the word's occurrence at the end of the line - the point where a rupture occurs, which is suggestive of the bodily laceration caused by flogging: the marked breaking of the rhythmic flow caused by the choliambic meter. ${ }^{58}$ In the second fragment, $\rho \alpha \pi i \sigma \theta \varepsilon i \eta$ — the culmination of a sequence of aspirated sounds ( $\theta \dot{v} \mu \omega, \varphi \alpha p \mu \alpha x o ́ s, \alpha \dot{\alpha} \theta \varepsilon i \varsigma)$-intimates

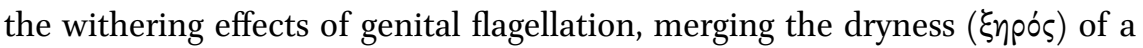
starving mouth with the dryness of impotence, a typical iambic punishment. ${ }^{59}$

57 See Miralles and Pòrtulas 1988: 136.

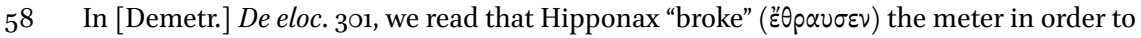
slander his enemies ( $\theta p \alpha v$ w is another onomatopoetic verb cited by Plato in Cratylus: see the epigraph of this chapter). West 1974: 30 refers to the choliamb as "a deliberate crashing incorrectness": see also Boedeker 2016a: 58 . A more extreme form of the meter, with a concentration of long syllables before the final spondee, was referred to in antiquity as

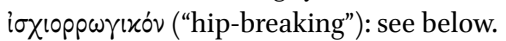

59 In fr. 84.21, $\rho$ '] ب̣ఠóv ("wrinkled"), describing a flaccid penis during intercourse, looks back

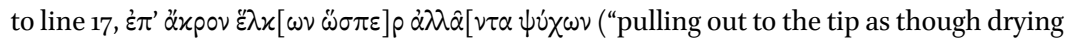

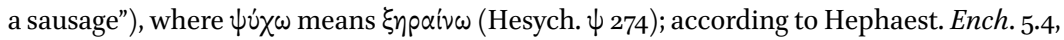
as a result of the spondaic foot that precedes $\psi \dot{v} \chi \omega \nu$, the line becomes "rougher" ( $\tau \rho \alpha \chi v^{\prime}-$ 
This iambic violence is in the background of a Hellenistic epigram by Alcaeus of Messene $\left(A P 7.536=H E 7_{7} 6-81\right)$, where Hipponax's tomb site, covered with brambles and prickly pears, resembles Thasos, Archilochus' locus horridus: 60

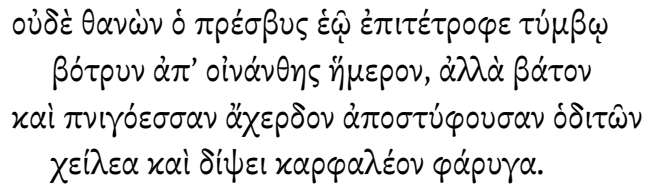

And not even in death does the old man rear upon his tomb a cultivated grape cluster from a tender vine, but a bramble bush and a choking wild pear that constricts travelers' lips and throats, withered with thirst.

The passers-by - images of future readers of Hipponax - are in the same physical condition as the scapegoat, as they approach the iambic thicket with throats

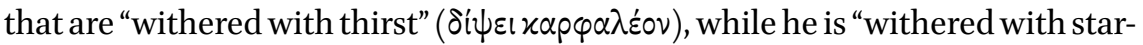

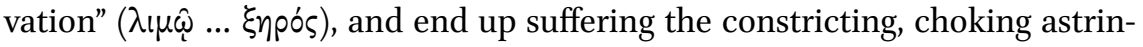
gency of the prickly pear ( $\alpha \chi \chi \varepsilon p \delta \circ \varsigma$ ) — not just a variant of the plants employed in the ritual, but also a "transgender" female like Thasos ( $\pi v v \gamma o ́ \varepsilon \sigma \sigma \alpha \nu$ a $\chi \varepsilon \rho \delta \circ \nu)$

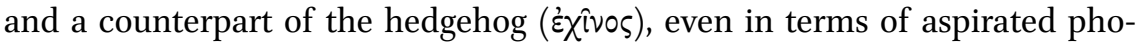
netics. ${ }^{61}$ The verb used to describe the effect of the wild pear, $\dot{\alpha} \pi \circ \sigma \tau \dot{v} \varphi \omega$, strikingly resembles the rare Archilochean verb $\dot{\alpha} \pi \circ \sigma \tau u \pi \dot{\alpha} \zeta \omega$, "to drive away with a stick"62 — as though the blows of a wooden stick, as on the scapegoat's genitals, related in some way to a rough oral sensation, the same constriction of the lips that would be caused by the shift in pronunciation from $\pi$ to $\varphi \cdot{ }^{63}$ The

$\tau \varepsilon p \circ v)$, an effect enhanced by the sequence of $p s i$ and $c h i$. The representation of a genital

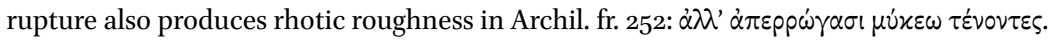

6o For a general discussion of the Hellenistic epigrams on Archilochus and Hipponax, see Rosen 2007.

61 In Hor. Epod. 14.4, we find the phrase arente fauce in a context that emphasizes sexual and poetic impotence (see Oliensis 1998: 89-91), perhaps refashioning the Hipponactean nexus of dryness in the genitals and throat. The hissing viper that we see in Hippon. fr. 79.11

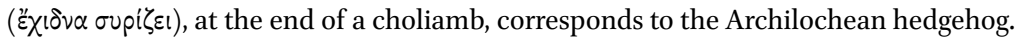

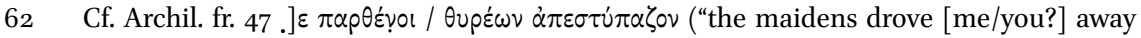
from the doors with cudgels"). The source of the fragment glosses $\dot{\alpha} \pi \circ \sigma \tau \cup \pi \dot{\alpha} \zeta \varepsilon \varepsilon \nu$ as $\sigma \tau \dot{\tau} \pi \varepsilon$ । $\pi \alpha i \varepsilon i \nu$ and $\xi \cup \lambda \circ$ x० $\pi \varepsilon i v$.

63 The epigram's correlative oن่ $\delta \dot{\varepsilon}$... $\dot{\alpha} \lambda \lambda \dot{\alpha}$ recalls the priamels of Archilochus' island and general fragments, the resemblance to the latter reinforced by ßótpus (line 2), which is cognate

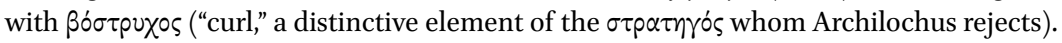
In Callimachus' Iamb. 4, based on a botanical fable, Hipponax is allegorized as thorny flora

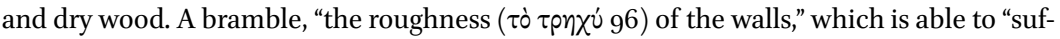


articulatory strain imposed on the reader mimics the violence of the text, as in Hipponax fragment 22, where a representation of torture entails the jugular spasm of a tight, virtually unpronounceable sequence of $x i$ 's: $\tau \dot{\eta} v$ piv $2 \alpha$ xai $\tau \dot{\eta} \nu \mu \dot{v} \xi \alpha \nu \dot{\xi} \xi \alpha \rho \dot{\alpha} \xi \alpha \sigma \alpha$ ("shattering the nose and the mucus"). ${ }^{64}$ The travails of the pharmakos are deeply implicated in Hipponactean readers' iambic experience, modeling the material feel of the genre's contact with its audiences across space and time. The verb $\rho \alpha \pi i \zeta \omega$ appears again at the end of a choliambic line in a rather obscure fragment (fr. 40), in which a mysterious speaker begs Athena to stop his master from flogging him: $x \alpha i$ $\mu \varepsilon \delta \varepsilon \sigma \pi \dot{\sigma} \tau \varepsilon \omega \beta \varepsilon \beta \beta \rho \hat{v} / \lambda \alpha \chi \delta^{\prime} v \tau \alpha \lambda i \sigma \sigma o \mu \alpha i \sigma \varepsilon$ $\mu \eta \dot{\eta} \rho \alpha \pi i \zeta \varepsilon \sigma \theta \alpha \mathrm{l}$ ("since I have been allotted a crazy master, I beg you that I not be flogged"). Through the rhotic force of the verb $\rho \alpha \pi i \zeta \omega$, the prayer actualizes the flagellation it seeks to avert, displacing it phonically onto readers, pharmakoslike victims of iambos' powers of horror.

The mismatch between the iambicist's request for mercy and its effects within and outside the lyric frame is evident in Hipponax's self-presentation as a shivering beggar, which as we will see, looms large in iambos' generic legacy as an affective experience. Hipponax's shivering image emerges in the following addresses to Hermes - first a prayer for help and then a reproach (32 and 34):

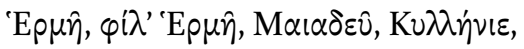

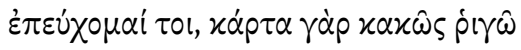
xai $\beta \alpha \mu \beta \alpha \lambda \dot{\zeta} \zeta \omega$...

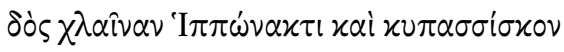

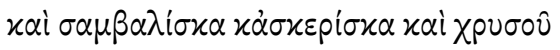

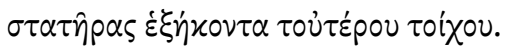

Hermes, dear Hermes, son of Maia, Cyllenian, I entreat you, for I am shivering fiercely, badly, and my teeth are chattering ... give Hipponax a cloak

focate," is one of two alter egos of the Hipponactean persona: see D'Alessio 1996: 17-18. From the Diegesis we know that the bramble stands for the addressee of the poem, the son of Charitades (X $\alpha \rho \imath \alpha \dot{\delta} \delta \omega)$ from Thrace. This identification with a Thracian, whose name

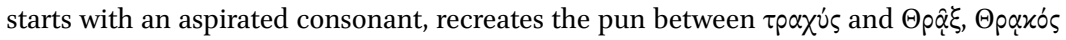
that we found in Archilochus' island fragment. The other iambic alter ego, a "sun-struck" olive tree, which recalls the wooden stick used in the pharmakos ritual and the withered pharmakos himself, declares: "I do not mutter ( $\gamma p u ́ \zeta \omega)$ anything harsh against you" (6o61 - circulating, notwithstanding the negation, the harsh energy of $\gamma p u ́ \zeta \omega$, at the end of the choliamb.

64 West 1974: 143 interprets $\tau \dot{\eta} \nu \hat{p} i v \alpha$ and $\tau \dot{\eta} \nu \mu \dot{\xi} \xi \alpha \nu$ as metaphors for the male sexual organ, but see the reservations of Degani 1983: 43 . 
and a little tunic and little sandals and little felt shoes, and 6o gold staters from the other side of the wall.

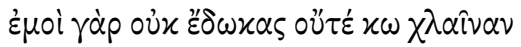

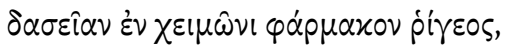

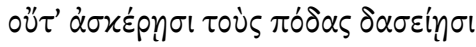 \\ हैx
}

For you haven't given me a shaggy cloak yet as a remedy against cold in winter, nor did you cover my feet in shaggy felt shoes, so that chilblains might not break for me.

Although as a modifier of $\chi \lambda \alpha i v \alpha \nu$ and $\dot{\alpha} \sigma \dot{\varepsilon} p \eta \sigma \mathrm{l}$ in the second fragment, $\delta \alpha \sigma \dot{\nu} \varsigma$ suggests, according to commentators, a protective, healing "thickness" for the shivering speaker, its technical meaning of "aspirated" alerts us to the possibility that Hipponax may, on some level, be looking to augment his shivers and horror - the physiological analogs of phonetic aspiration, as we have seen. ${ }^{65}$ Though the grammatical sense of the adjective postdates Hipponax, $\delta \alpha \sigma u s$ (chosen instead of $\pi \cup x v o ́ s$, the modifier of $\chi \lambda \alpha i v \alpha$ in the Odyssey) indicates a "shaggy" version of a customarily "soft" cloak-something between the conventional urbane garment and an animal skin. ${ }^{66}$ The $\chi \lambda \alpha i v \alpha \delta \alpha \sigma \varepsilon i \alpha$ that the iambicist wishes for might thus be a pharmakon in the full, contradictory sense-a Derridean drug that is not "simply beneficial" but "can worsen the ill instead of remedy[ing] it." ${ }^{\prime 7}$ The prayer and the reproach themselves, while pleading for relief from cold, supply a pharmakon to the audience, engendering shudders through the harsh sibilant and velar sounds of $x v \pi \alpha \sigma \sigma i \sigma x \circ v, \sigma \alpha \mu \beta \alpha \lambda i \sigma x \alpha$, and

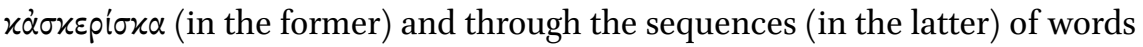

65 On the therapeutic materiality of the $\chi \lambda \alpha \hat{\imath} \nu \alpha$, see Telò 2016 .

66 See Hom. Od. 14.521, 529. The $\chi \lambda \alpha$ iv $\alpha$ requested by Hipponax is usually identified with the typical prize at the Hermaia, the athletic games of Pellene: see Degani 1971: 103. This textile is qualified as soft in Pind. Nem. 10.44-45; see also Archil. fr. 196a.44-45 (see in n. 23). In asking for a "shaggy" $\chi \lambda \alpha i v \alpha$, perhaps Hipponax is playing with his audience's textural expectations and imagining something vaguely similar to the $\chi \imath \tau \dot{\omega} \nu \delta \alpha \sigma u$ s listed as the costume of satyrs in Poll. 4.118-although, as Mark Griffith points out to me, there is countervailing imagery in satyr drama of the creatures' smooth bodies and bald heads that goes along with their tendency to settle back into infantile pleasure taking and comfort seeking.

67 See Derrida 1981: 97, 99, in which he refers to the discussion of relieving an itch in Plato's Philebus as "a painful pleasure, linked as much to the malady as to its treatment" and thus "a pharmakon in itself." See also Peponi 2002: 145-155 and 2012: 116-117. 


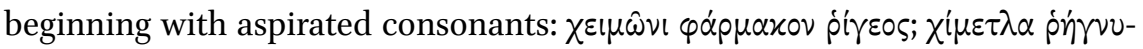
$\tau \alpha$. In particular, píros, which, together with $\dot{p} \gamma \hat{\omega}$ in the prayer, brings us back to frigescunt in Persius' discussion of the canine $r$, has a quasi-programmatic force. We find it, arguably, in encrypted form in fragment 54 as xpir that seems to conflate an owl's shriek with the teeth-chattering chills it pro-

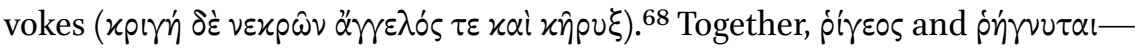
both located where the choliamb breaks - capture the rough iambic energy of Hipponax's poem, a request for a pharmakon that is itself capable of extending the pharmakos-like sensations it apparently seeks to suppress.

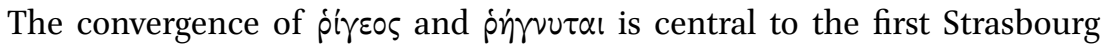
epode (fr. 115), attributed by most scholars to Hipponax. Here all the elements of the generic texture we have sampled so far congeal around the velar and rhotic sounds in $\ddot{x} x$ pos (Latin acer, related to $\alpha x i \varsigma$ "pointed object"), creating a sense of lyric materiality, scratchy and shuddering intensities that cut across thematic and imagistic boundaries:

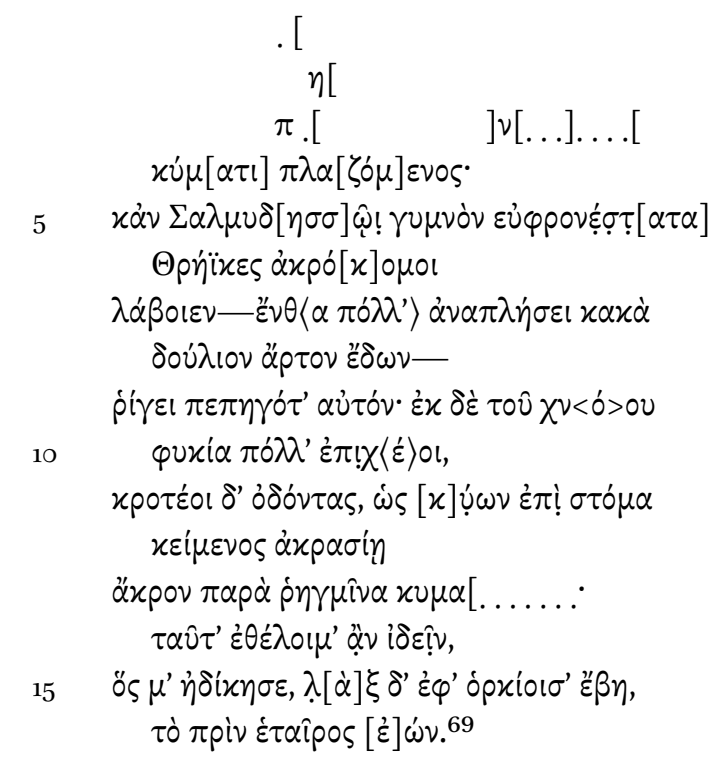

68 See Degani 1982: 257 for the distinction between xpirn, "screech owl" and xply by $\Sigma$ Ar. $A v$. 1521 as "the shrill produced by the teeth of the dead." This dental sound is similar to the chattering teeth described by $\beta \alpha \mu \beta \alpha \lambda \nu^{\prime} \zeta \omega$ in Hipponax's prayer to Hermes. In Hor. Ep. 5 a strix, a screech owl, with a name phonically reminiscent of $x p i \gamma \eta$, appears in a packed catalogue of the iambic images and sounds we have discussed: trementi ... ore (11); Thracum (14); horret capillis ... asperis / echinus (27-28), on which see n. 56 .

69 The text here follows Degani 1983. 


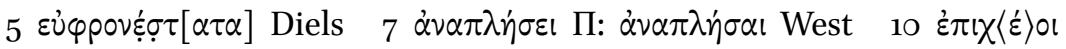
Masson: $\dot{\varepsilon} \pi \dot{\varepsilon} \chi 0 ।$ West

... struck by the waves. And at Salmydessus may Thracians with hair standing up on end most merrily take him while he's naked - there he will have a full share of many evils, eating slavish bread-stiffened from cold. And out of the foam, may he shed much seaweed and may his teeth chatter as he lies face down, dog-like, at the very breaking of the wave, depleted.... I would wish to see these things [happen to the one] who wronged me and trod his oaths underfoot, though formerly a comrade.

Standing on end and making the sea shudder, the waves that will crash on the curse victim express the same material horror as the hair of the $\dot{\alpha} x \rho \dot{0}[\varkappa] \circ \mu \mathrm{ol}$ Thracians - inhabitants of the cold land where Hipponax's enemy will be shipwrecked, near Archilochus' Thasos. ${ }^{70}$ 'Axpóxopor indicates upright hair, similar to bristly, trembling stalks or a lion's shaggy mane-perhaps also sexual arousal, an impression reinforced by the nakedness and proneness of the victim. ${ }^{71}$ The image converges with another hint of iambic texture: the castaway's emergence from the sea, "shedding" ( $\dot{\varepsilon} \pi \backslash \chi\langle\dot{\varepsilon}\rangle / \iota)$ a salty crust of seaweed (9-10), a kind of marine fur comparable to a fox's coat or a $\delta \alpha \sigma \varepsilon \hat{i} \alpha \chi \lambda \alpha i v \alpha .{ }^{72}$ The phrase

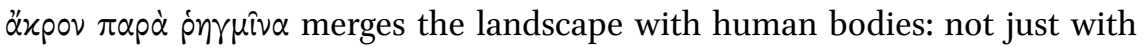

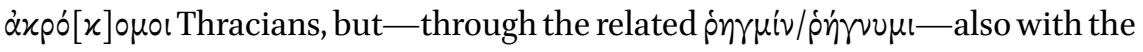
shipwrecked man's skin, beaten, like Odysseus', by waves and "broken," like Hipponax's, by shivers. ${ }^{73}$ Hipponax's own symptoms, epitomized, as we have seen,

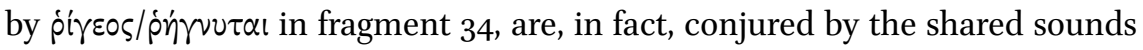

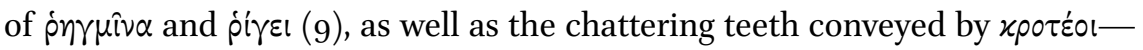
an onomatopoetic verb that incorporates $\ddot{\alpha} x p o s$. The scratchy sounds ( $x$ and $\rho$ )

70 In Il. 4.424-426 a simile presents a wave that "rises to a crest," breaks on the shore ( $\chi \dot{\varepsilon} \rho \sigma \omega$

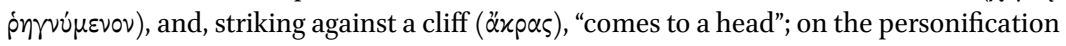
of these waves, which "get their crests up," see Martin 1997:154-156. In Hor. Epod. 10, whose intertextual debt to Hipponax's poem is widely acknowledged, the vehicle of iambic retaliation is "rough waves" (horridis ... fluctibus 3-4); see also Epod. 2.6 and 13.1-3. I owe these references to Emily Gowers.

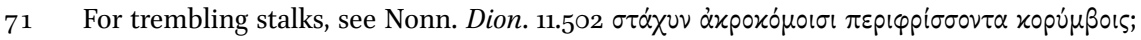

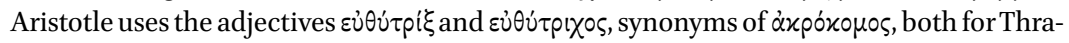
cians and lions: see $G A 782 b_{34}$ and $H A 629 b_{35}$.

72 On the interpretation of $\dot{\varepsilon} \pi \mathrm{\chi} \chi\langle\dot{\varepsilon}\rangle 0 \mathrm{l}$, see Nicolosi 2007: 68-69 and Swift 2019, 427.

73 Odysseus' shipwreck is the main subtext of Hipponax's description. The iambic target's

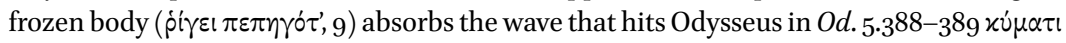

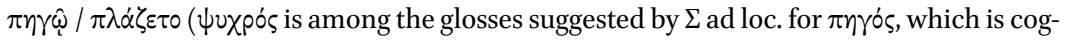
nate with $\pi \dot{\eta} \gamma v u \mu)$. 
of this word, whose Latin counterpart, acer, is used by Horace to describe Hip-

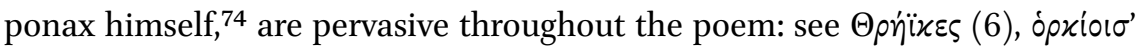
(15), and $\dot{\alpha} x p \alpha \sigma i n$ — which the line break separates from $\ddot{\alpha} x p o v(12-13) .{ }^{75}$ Denoting the weariness of Hipponax's enemy, $\dot{\alpha} x \rho \tilde{\alpha} \sigma i \alpha$ puns on $\dot{\alpha} x p \bar{\alpha} \sigma i \alpha$, a synonym of $\alpha \nu \omega \mu \alpha \lambda i \alpha$, meaning "unevenness," a feature of the iambographer's shaking skin or, as we have previously seen, of Archilochus' Thracian island. ${ }^{76}$ While delivering his curse and vocalizing the sounds that spread its harming power, the poet/performer (re-)experiences his own iambic pathology, eliding again the distance between aggressor and victim. It is as though the somatic horror, the vibrations of Hipponax's body, were directed outward, exposing the listeners/readers to a quasi-physical force similar to the waves' flogging the target $\left(\pi \lambda \alpha\left[\zeta \delta^{\prime} \mu\right] \varepsilon v \circ \varsigma, 4\right)$, to incessant blows of barbed plants on the pharmakos' genitals, or to the prick of pointed objects. ${ }^{77}$

We can see the diachronic reach of Hipponax's shudders in a passage of Plutarch, where a hypocritical Stoic who vaunts his autarkeia is seen at people's doors invoking the iambographer: "Give Hipponax a cloak, for I'm shivering

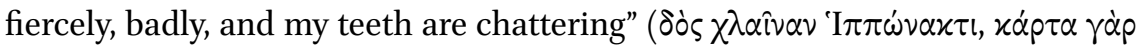

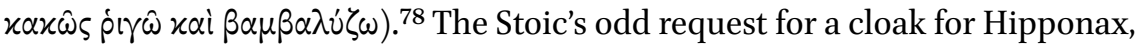
rather than himself, is not simply a matter of theatrical impersonation. ${ }^{79}$ The pompous philosopher's formulation suggests that his hypothermia depends on Hipponax's chills — as though they have been transmitted by contagion. Far from indicating citational "confusion" or an attempt to involve interlocutors and audience in a decoding game, the inversion of the original Hipponactean order- "I'm shivering fiercely, badly, and my teeth are chattering" followed by "give Hipponax a cloak" - may underline this transmissibility: "give Hipponax a cloak because I'm shivering fiercely, badly, and $m y$ teeth are chattering." ${ }^{\prime 80}$ In another Hellenistic epigram warning passersby about the dangers of Hip-

74 Hor. Epod.6.14.

75 On the phonic symbolism of $c r$ as indicating "brokenness" in English, see Genette 1995: 37.

76 Cf. Hesych. $\alpha 2543 \dot{\alpha} x p \alpha \sigma i \alpha \varsigma \cdot \dot{\alpha} \nu \omega \mu \alpha \lambda i \alpha \varsigma . \pi \alpha \rho \dot{\alpha} \tau \dot{o} \mu \dot{\eta} \sigma 0 \gamma x \varepsilon x p \hat{\sigma} \sigma \theta \alpha \mathrm{l}$.

77 On the equivalence between $\pi \lambda \dot{\alpha} \zeta \omega$ and $\pi \lambda \dot{\eta} \tau \tau \omega$, see Nicolosi 2007: 43-44. Commenting on Epod. 10.3-4, which translates the beginning of Hipponax's poem (see n. 70), Oliensis 1998: $92 \mathrm{n}$. 70 suggests that the resemblance between verberes and verba brings together Horace's own "tongue-lashing" and the lashing of wind and waves. On whipping produced by sound in Catullus' iambics, see esp. Young 2015b: 69-7o. For a parallel outside classical literature, cf. Prins 2013: 106-108, where she observes that in A.J. Swinburne's poem On the Flogging Block, "the beating of the body is performed in the beat of the poem."

78 Plut. Stoic. Parad. 6.1058d.

79 Cf. Hawkins 2014: 216-219, who sees in the Stoic's impersonation of Hipponax a dramatization of the iambographer's own programmatic assumption of a mask.

8o In the edition of West the adverb confuse introduces the Plutarch passage as a testimo- 
ponax's final resting place $(A P 7.405=G P 2861-2866)$, including the poet-as-

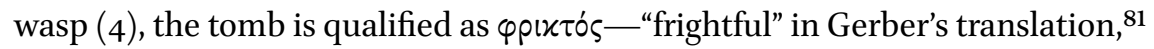
but also, more specifically, "making one's skin shiver." ${ }^{82}$ Like this tomb, Hipponax's poem perpetuates a generic tradition through affect - that is to say, by converting the poet's own staged abjection, his shivers and shudders materialized by formal $\delta \alpha \sigma u$ ins, into a pharmakon for readers-as-targets.

A comparable dynamic of generic affect is observable in one of Catullus' iambic experiments, in which the poet feels on his own skin and spreads Hipponactean shivers, closely aligning them with their pharmakon. In poem 44, written in choliambics, Catullus oddly addresses his own farm (o funde noster, 1), thanking it (as though it were a god) for helping him overcome a recent illness - a cough, whose origins and consequences are detailed in these lines:

nam, Sestianus dum volo esse conviva, orationem in Antium petitorem plenam veneni et pestilentiae legi. hic me gravedo frigida et frequens tussis quassavit usque, dum in tuum sinum fugi, et me recuravi otioque et urtica. quare refectus maximas tibi grates ago, meum quod non es ulta peccatum. nec deprecor iam, si nefaria scripta Sesti recepso, quin gravedinem et tussim non mihi, sed ipsi Sestio ferat frigus, qui tunc vocat me, cum malum librum legi.

For since I wished to be Sestius' dinner guest, I read his oration against the candidate Antius, full of poison and plague. At that point, a chilling head cold and a constant cough shook me, until finally I fled to your bosom, and cured myself with leisure and nettle. Therefore, restored, I thank you enormously because you did not punish my mistake. Now, if I ever shall have accepted again Sestius' foul scripts, I offer no prayer to prevent the

nium. Hawkins 2014: 218 observes that the Stoic's "Hipponactean display throws the onus of connecting the dots onto the audience."

$81 \quad$ Gerber 1999.

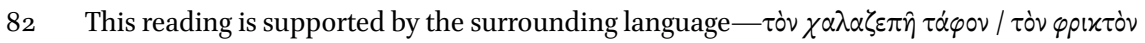
I $\pi \pi \dot{\omega} \nu \alpha \chi \tau \circ \varsigma$, ô $\tau \varepsilon \chi \dot{\alpha} \tau \varepsilon \dot{\varepsilon} \varphi \rho \alpha / i \alpha \mu \beta ı \dot{\alpha} \zeta \varepsilon l(1-3)$-in which the adjective $\chi \alpha \lambda \alpha \zeta \varepsilon \pi \hat{\eta}$ ("hurling abuse as thick as hail" LSJ), together with the proliferation of aspirated sounds, recreates the texture of Hipponactean shivering, casting the tomb, and the iambic tradition, as an archive of shudders. 
chill from bringing a head cold and cough not to me, but to Sestius himself, since he invites me only when I have read a baneful book.

Brent Vine has recognized in ferat frigus at the end of line 20 "a faint but clear lexical and metrical echo of the mot clén 83 of Hipponax's shivering addresses to Hermes, which, as we have seen, present lines closing with ṕr $\gamma \varepsilon \circ \varsigma$ and $\dot{p} 1 \gamma \hat{\omega}$, cognates with frigus. In triggering the rhythmical breach distinctive of the choliamb, frigus like tussis bodies forth the cough that provides the poem's generative conceit. Although cough and chills are said to have been caused by the frigid orator Sestius' speech "full of venenum," this narrative may playfully cover up the real culprit - the venomous Hipponax. The lyric influence of Hipponax, whose beggarly persona is already reflected in Catullus' selfpresentation as a parasite enslaved to his belly (venter, 8 ), may have made Catullus catch a cold, realizing the threat raised by Hipponax's $\varphi p(x \tau$ ós tomb, an archive of shivers. The appropriation of a generic form, then, has physiological consequences. $^{84}$ The feel of iambos is passed on to Catullus' readers through tussis, used three times in a final trochee (the rhythmical cough); 85 the rhotic, fricative, and guttural sounds that rework and extend the Hipponactean tag ferat frigus (gravedo/gravedinem, frigida, frequens); ${ }^{86}$ and quassavit. The last

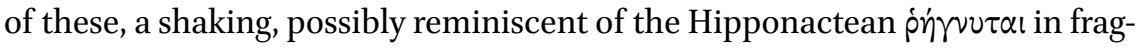
ment 34, translates the shiver roughening Hipponax's skin into fractured syntax, the sharp enjambment that separates the verb in line 14 from the subject tussis (possibly etymologically connected with tundo, "thrust, knock"). ${ }^{87}$ Allied with the salubrious fundus - the poem's Hermes-like addressee - the remedy for Catullus' illness, "nettle" (urtica), equally contributes to this materialization of generic sensation. Like Hipponax's $\delta \alpha \sigma \varepsilon \hat{i} \alpha \lambda \lambda \alpha \hat{\imath} \nu \alpha$, the urtica exemplifies the duplicity of a pápraxov (or, the Latin equivalent, venenum) as both drug and

83 Vine 2009: 215 .

84 Young 2015b: 116-120 has viewed Catullus' translation of Sapph. fr. $3^{1} \mathrm{~V}$ in poem $5^{1}$ as a "virulently contagious" experience whereby the Roman poet "allow[s] the form of erotic selfhood [Sappho] modeled to seep under his skin and into his own poem." In poem 36 Catullus uses the phrase truces vibrare iambos (5), which is usually taken as an allusion to the possible derivation of $i \alpha \mu \beta$ os from $i \alpha \dot{\alpha} \tau \varepsilon i v$. One may also see a subliminal reference to the bodily vibrations, the horrores produced by the genre.

85 In line 7 , as well as lines 13 and 19.

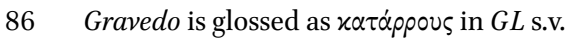

87 In Sen. Ep. 95.17 fevers are described as accompanied "by much shaking (quassatione) of limbs." In English, the phoneme $q u$ - has been judged a phonestheme of the idea of "shaking" (quake, quiver, quaver, quash): see Marchand 1959: 258. The iterative verb quassavit could also render $\beta \alpha \mu \beta \alpha \lambda \dot{\zeta} \zeta \omega$ in fr. 32 , where the reduplication $(\beta \alpha \mu \beta \alpha-)$ onomatopoetically expresses the continuous movement of chattering teeth. 
poison-delivering therapeutically burning stings that, along with the shivers themselves, channel iambic affect. ${ }^{88}$ Sensually akin to the hedgehog, the nettle belongs among Hipponax's prickly flora. Indeed, the appearance of urtica in the same marked metrical position as frigus and tussis underscores this collapsing of remedy and illness, which may potentially turn the wholesome fundus into a Hipponactean thorny garden, if we consider the medicinal plant, as much as the otium, a product of the farm. We can see something similar in the proximity of refectus (preceded by quare) and recuravi $\left(1^{-16}\right)$, which, through the repetition of $r$, emphasize recovery while diffusing a rhotic sensation (cf. frequens tussis 13) that perhaps evocatively reaches back to the Hipponactean ṕr $\gamma v v \tau \alpha$. At the formal level, it is through sound that the vitality of Catullus' ostensibly cured illness lingers and remains transmissible to other victims (Sestius as well as listeners/readers). There is, in a sense, a homology between the sounds and the urtica, which, in its own way, keeps the illness alive, redoubling it by applying an iambic sting to iambic chills. The correspondence between urtica and frigus, burning remedy and chilly illness, in turn, invites us to consider a further aspect of aesthetic duplicity. Not only can the curative pharmakon act as a prickly venom, but shivers, pungent sensations, bodily lacerations, and aspirated intensities can themselves be thought of as healing, a cleansing through and as pain that would cast iambos' feel—its "attractive aversion[s]"89—as a quasi-cathartic force.

Hipponax's shaggy $\chi \lambda \alpha i v \alpha$ and Catullus' urtica, which roughens his villa's comforting (and seductive) bosom (in tuum sinum 14), ${ }^{90}$ are emblematic of iambos' masochistic asperity, the way this genre projects the painful pleasures of edgy experiences. The iambographer's request for bodily protection in the form of an "aspirated" textile reinscribes pain within pleasure. As shown by the outburst of aspirated sounds-materializations of somatic horror on the page-it also feels theatrically insincere, a masochist's disingenuous plea to end the game. If the iambographer's own chilly shudders ceased reverberating on the reader, the poem would be depleted of its generic vitality. Coldness, which, as we have seen, is central to the iambic imaginary (of Hipponax as well as Archilochus) and to the symbolism of $r h o / r$, is the feeling of social exclusion, bringing pockets of death into our bodies. ${ }^{91}$ This impulse may underlie the

88 The presence of recuravi and urtica in the same line (15) makes us see in the former's phonetic configuration the latter's burning force, captured by its etymological link with uro.

89 I borrow this phrase from Korsmeyer 2011.

9o In line 17 es ulta signals a shift of address from the fundus to the villa (see Fordyce 1961: 201), eroticized by in tuum sinum fugi (14).

91 See Clare 2013: 176: "[Coldness] is the bit of death inside of me that I struggle to guard 
pushing of aesthetic boundaries fostered by the imaginary contact with iambic surfaces-brambles and wood, Thasos' craggy landscape, bushy or spiny animals, frigid temperatures. At the same time, since the iambographer is always positioned on the line between attacker and victim, sadistic and masochistic impulses, the audience's absorption of the sensations he generates and ostensibly feels may result in something comparable to the Freudian notion of reflexive masochism. Such a notion is predicated on "two contrary images of self - the image of the one who pleasurably inflicts pain ... and that of the one who pleasurably suffers that pain." ${ }^{\text {92 }}$ Kaja Silverman has seen this dynamic at work in T.E. Lawrence's Seven Pillars of Wisdom, an account of his experience as a member of the British Forces of North Africa during the Arab revolt of 19161918. In this book, physical pain often feels like eroticized pleasure, one that "is compatible with —indeed, perhaps a requisite for—extreme virility" ${ }^{\prime 3} \mathrm{~A}$ sharp crust of snow that gashes wrists and ankles until they bleed, "harsh stalks of wormwood stabbing into wounded" feet, skin torn away in "ragged sheets" by burning rocks, a body kicked by nailed boots, and genitals exposed to "the full length of [the] whip";94 these images, which recall the spiky surfaces of iambos' generic imaginary (brambles and wood, craggy landscapes, frigid temperatures), articulate a corporeal model of subjectivity, whereby sexually charged physical pain, enervating flagellation, paradoxically entails a self-aggrandizing sense of dominance, "the illusion of a contained and autonomous self." ${ }^{\prime 95}$ This notion is captured in the feel of the R.A.F. uniform, described by Lawrence in another novel- "tightly ... [gripping] the flesh," causing a form of sexual pleasure while impounding and constricting. ${ }^{96} \mathrm{~A}$ similar dynamic lurks behind Hipponax's request for a $\chi \lambda \alpha i v \alpha$ whose scratchiness, in this case, subjects the iambicist to a kind of self-inflicted, perhaps self-fortifying, discomfort. ${ }^{97}$

myself from." Deleuze 1991: 52 sees coldness as the programmatic antisensual, frozen condition of the masochist, who, although he feels, is constantly engaged in "the disavowal of sensuality." The characters we see in Leopold Von Sacher-Masoch's Venus in Furs are frequently cold, especially the women, "so chilled that they must be wrapped in furs and set before the fire" (MacKendrick 1999: 59).

92 Silverman 1992: 325. Reflexive masochism is elaborated by Freud 1915, who sees it as a defense against the castrating power of so-called feminine masochism.

93 Silverman 1992: 327. In a fable preserved by Babrius (95.74) but probably containing much older Aesopic material, a fox — an emblem of iambic bristliness, as we have seen — blames a deer for not being able to "endure the scratch" of a lion's paw: see Kurke 2011: 154-155.

94 Lawrence 1962: 509, 454, 487, 308.

95 Silverman 1992: 326.

96 Lawrence 1955: 56 .

97 Iambos' generic imaginary includes other hints of masochism. In Pythian 2, which polemically engages with Archilochus (see esp. Brown 2006), Pindar refers to abusers, probably 
An alternative to this paradigm - equally suitable to iambos' sympotic male homosociality, but conceivable for other readerly contexts across time, space, and gender-is Leo Bersani's idea of "sexuality as productive masochism." 98 Programmatically contesting the ideal of the unified self, the masochistic "selfshattering" that Bersani sees as intrinsic to the experience of sexuality could exemplify an equation between "self-divestiture" and "self-expansiveness, ... something like ego-dissemination rather than ego-annihilation." "Shatter-

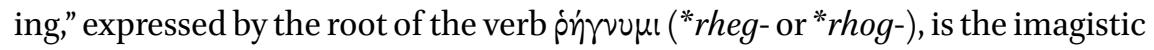
domain that connects iambos' form, its distinctive sounds and rhythm, with its vision of a body exposed to "sadomasochistic thrills" - a vision not altogether different from the representation of love travails in Sappho fragment 31, where the body trembles and the tongue is splintered. ${ }^{100}$ An extreme variant of the

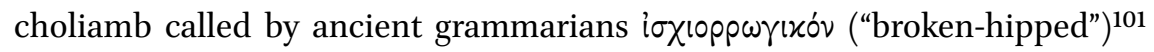
seems a metrical expression of the shivering Hipponax's chillblain-wracked

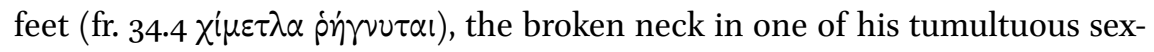

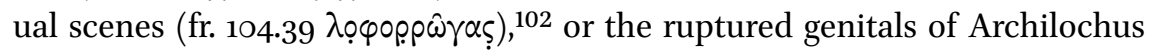
himself or of one of his targets (fr. $252 \dot{\alpha} \lambda \lambda^{\prime} \dot{\alpha} \pi \varepsilon p \rho \omega^{\prime} \gamma \alpha \sigma \iota \mu v^{\prime} x \varepsilon \omega \tau \varepsilon^{\prime} v 0 v \tau \varepsilon \varsigma$ ). In these shattered corporealities we can perceive, as disabilities studies have shown us, the potential for an expansive disruption, that is to say, the possibility of an

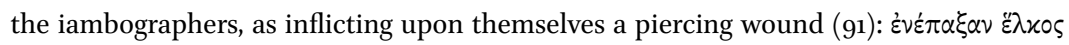

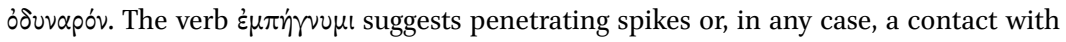
the pointed surfaces we have examined above. In fr. 193, Archilochus presents himself as "pierced $(\pi \varepsilon \pi \alpha \rho \mu \varepsilon$ vo $)$ in his bones" by longing.

98 Bersani 1986: 63 .

99 Bersani and Phillips 2008: 57. The notion of "self-shattering" is discussed in Bersani's famous essay "Is the Rectum a Grave?" (Bersani 20o9: 3-30). For a feminist critique of the notion of "productive masochism," see Booth 2014.

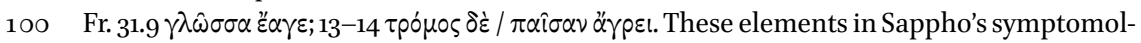
ogy are discussed at length by Bonanno 1993, O'Higgins 199o, and esp. Prins 1999: 27-51. On the poem as a whole, see esp. Carson 1998: 12-17. Cf. also fr. 47 for the image of Eros as a shaking force $(\dot{\varepsilon} \tau i \nu \alpha \xi \xi)$. On iambos and soft lyric genres, see n. 3 .

101 The extant Hipponactean corpus presents thirteen certain examples of this version of the meter, marked by the presence of five long syllables from the fourth foot to the end. If the usual version of the choliamb displays "formlessness and incapacity" (Payne 2010: 38 ), the ischiorrhogic pushes further in the direction of self-imposed disability (and selfovercoming).

102 In the same poem (104W $=107$ Deg.), we find ]pp $\eta^{\circ} \sigma \sigma \omega \nu$ (line 7), most likely a form of $p \dot{\eta} \sigma \sigma \omega$, cognate with $p \dot{\eta} \gamma v v \mu l$; in the following line, we read, in the same metrical position, $\left.\eta_{\rho}\right] \alpha \xi \varepsilon$, probably a form of $\dot{\xi} \xi \alpha \rho \dot{\alpha} \sigma \sigma \omega$, the verb that indicates "shattering" in fragment 22 . We thus find a metrically recursive concentration of $r$ sounds to represent bodily roughness (the

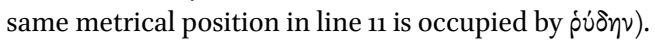


enhanced notion of embodiment, ${ }^{103}$ the idea of "a body ... that opens itself up rather than seals itself"104 or "attempts to escape from itself," in Deleuze's theorization of the spasm. ${ }^{105}$ This self-divestiture is the physical counterpart of the formal trespassing that defines iambos, with its constant projection toward a "you," its inbuilt temptation to break the frame. The rho itself, the sound that,

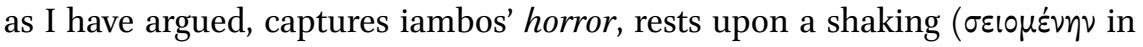
Plato's account), a breaking of vocal bounds, that results in enhancement or, we might say, phonic prosthesis. ${ }^{106}$ Appreciating its programmatic force, heeding its masochistic texture, we can sense iambos' generic affect - a "remapping and reintensifying"107 of feeling itself through the obtrusion of piercing pleasures that break through the fourth wall of the performance and the page of the text.

103 See esp. Braidotti 2013: 146 and Goodley et al. 2014: 348, who observe that "disability crips what it means to be a human being ... [calling] for new ... ways of relating, living, and dying." In this perspective, disability is central to theorizations of human enhancement.

104 The citation is from Grosz 1994: 201.

105 Deleuze 2003: 16, analyzing the spasms represented in Francis Bacon's work as an "approximation of horror or abjection," where "the body exerts itself ... or waits to escape from itself."

106 In Archil. fr. 128 we find the first occurrence in Greek literature of the term $\dot{\rho} v \sigma \dot{\alpha}^{\prime} \varsigma$, referring to the vicissitudes of human life. According to Benveniste 1971: 285-286, the pre-Platonic use of this term exhibits a tension between the etymological meaning- "flowing"-and the idea of a fixed, regular, patterned form, which still permeates contemporary accounts of rhythm (see Ristani 2016). The rho that launches puopós could itself be seen as an image of the body in flux.

107 I borrow this phrase from Sweetman 1999: 179, who considers the expansion of bodily faculties afforded by piercing and tattooing. 


\title{
Experiencing Elegy: Materiality and Visuality in the Ambracian Polyandrion
}

\author{
Seth Estrin*
}

\section{Introduction}

To talk about a poem's genre is not simply to place it in an analytic category or performance context, but to bring to the surface structures that underlie it. The structural nature of genre allows it to intersect with features of a poem's performance that would have been immediately accessible to audiences in antiquity, but that today can only be discursively reconstructed. Our ability to understand how a poem's genre relates to the visual and auditory spectacle of its performance is, in most cases, limited by the nature of the evidence at our disposal, which often comes from secondary accounts or literary reimaginations. ${ }^{1}$ In this respect, poems inscribed on stone monuments offer a unique opportunity to consider how genre relates to the visual and material experience of poetry. $^{2}$

Even within the large corpus of archaic inscriptions, there is no other poem whose visual impact can rival that of the one discovered chiseled into

* Thanks to the organizers of the Berkeley conference and to the participants for their discussion. Nikolaos Papazarkadas and Mario Telò especially offered important feedback. Before the conference, Deborah Steiner kindly shared with me a chapter of her forthcoming monograph that includes a stimulating analysis of the Ambracian monument from a perspective similar to the one presented here (though with different arguments and conclusions). I am grateful to Leslie Kurke for her help with this paper at multiple stages and to Niall Atkinson, Joseph Day, Margaret Foster, Naomi Weiss, and the volume's readers for their comments on earlier versions. Finally, I owe thanks to various people who helped me study and publish the monuments in this paper: Kevin Daly and Ioanna Damanaki at the American School of Classical Studies in Athens, Barbara Papadopoulou of the Ephorate of Antiquities of Arta, the staff at the Archaeological Museum of Arta, and Leonidas Bournias at the Kerameikos Museum in Athens.

1 E.g. Kurke 2012: 220 on choreia: "it is by its very nature evanescent and therefore more or less invisible in the archaeological record."

2 On the materiality of inscription in classical antiquity, see most recently the papers collected in Petrovic, Petrovic, and Thomas 2019. 
the surface of a cenotaph in the modern city of Arta, ancient Ambracia (SEG 41.54OA, 44.463): ${ }^{3}$

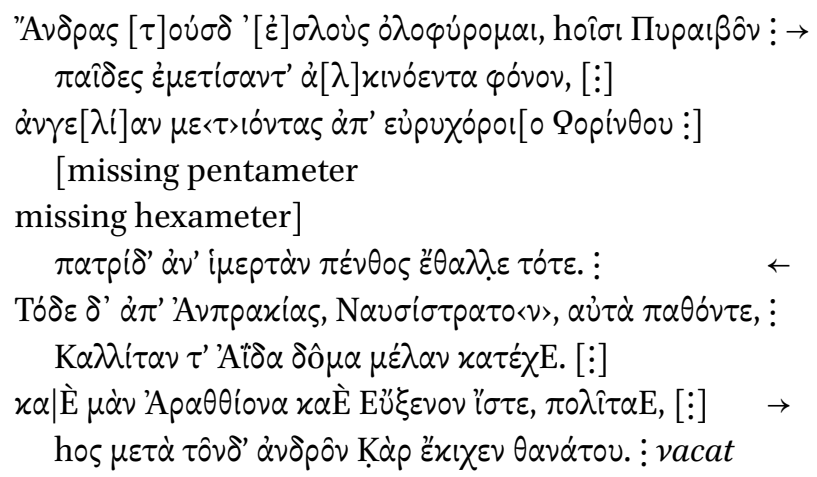

I mourn these good men, for whom the sons of the Pyraiboi devised a painful slaughter,

while they were escorting an embassy from [the Corinthia] with wide dancing places

\section{then in their lovely fatherland grief blossomed.}

And these two from Ambracia, who suffered the same things, Nausistratos and Kallitas the black house of Hades holds back.

And here again, fellow citizens, (you) know Araththion and Euxenos, whom the Ker of death overtook with these men.

The Ambracian monument, usually dated to the second half of the sixth century $\mathrm{BCE}$, is a massive structure, $12.4 \mathrm{O} \mathrm{m}$ long and $2.5 \mathrm{O} \mathrm{m}$ high, built of imposing ashlar masonry made from local limestone (figs. 10.1-2). ${ }^{4}$ It consists of a rectilinear crepidoma, $0.40 \mathrm{~m}$ high, surmounted by five courses of stone, each

3 Ed. princ. Andreou 1986; Bousquet 1992; Cassio 1994; D'Alessio 1995; Day 2007; Randone 2013; Graninger 2014. I follow the text in Cassio 1994: 103, D'Alessio 1995: 26, Day 2007: 30, and Day 2019: 238. While the inscription has received significant scholarly attention, the monument's architecture and the finds within it await full publication. In addition to the preliminary publication of the archaeology of the monument in Andreou 1986, I rely on my own observations of the monument.

4 For the dimensions see Andreou 1986: 425 . 


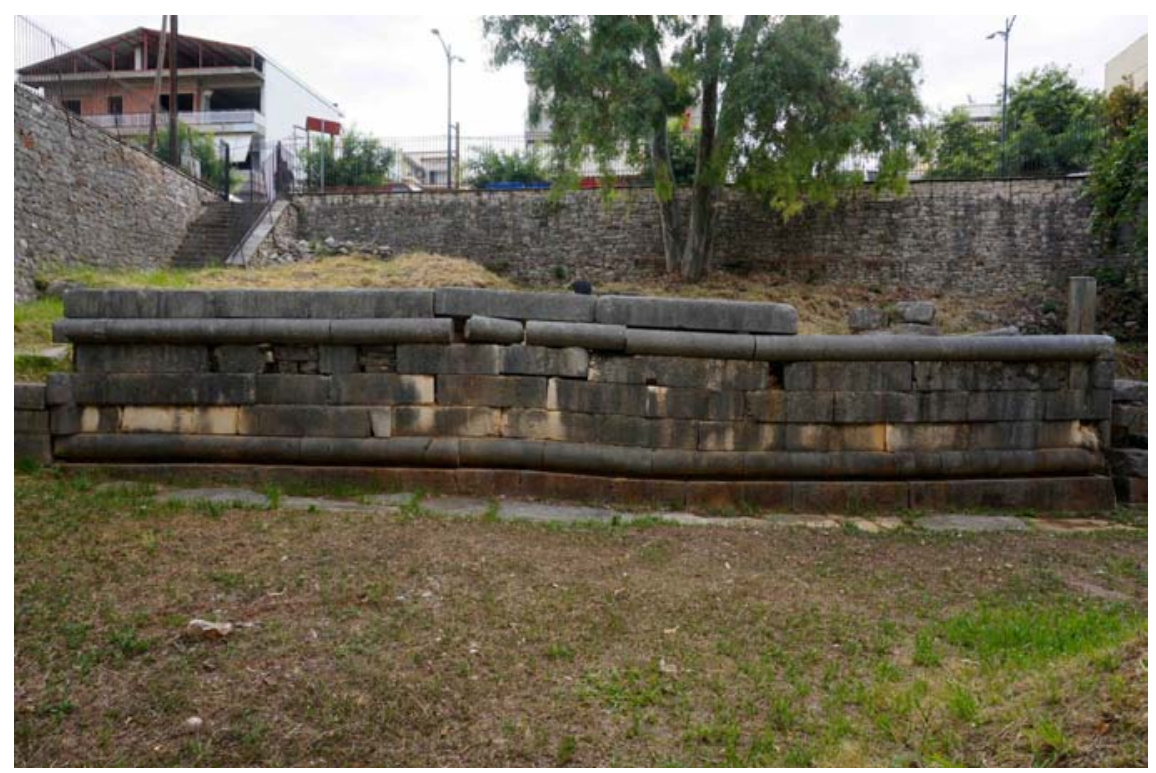

FIGURE 10.1 The Ambracian polyandrion. Second half of sixth century BCE. Ephorate of Antiquities of Arta PHOTO: AUTHOR. COPYRIGHT (C HELLENIC MINISTRY OF CULTURE AND SPORTS

between $0.32 \mathrm{~m}$ and $0.36 \mathrm{~m}$ tall, which are framed by a large rounded torus molding. An additional sixth course of the same height sits on top, more or less at eye level, bearing the three lines of inscription, which, when the monument was complete, ran boustrophedon twice across the length of the façade and once more to its center, just below a cutting on the monument's upper surface for a now-lost stele. ${ }^{5}$

If the monument's size and scale demand to be seen, this is an inscription that demands to be read. The letters are not only unusually large but unusually fine in their carving, generously spaced out and oriented in stoichedon style both horizontally and vertically. The poem itself, originally composed of five elegiac couplets, is the longest surviving example of inscribed funerary epigram of the archaic period, and its language and imagery are among the

5 Andreou 1986: 438. A number of stelai were found during the course of excavation, one of which Andreou (1986: 438-445) associated with this cutting and which is now on display in the Archaeological Museum of Arta. But as Matthaiou (1990-1991) notes, and as my own observations have confirmed, its dimensions are too large. See also Bousquet 1992: 6o5-6o6. The other stelai remain unpublished. 


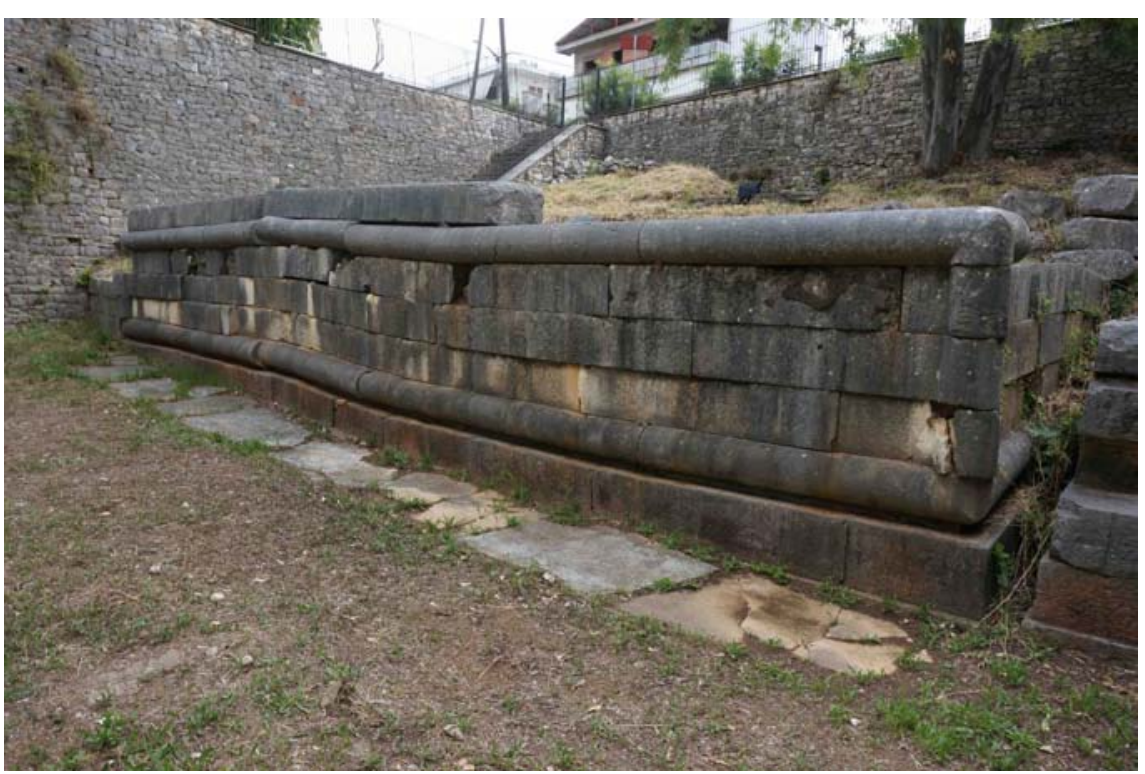

FIGURE 10.2 The Ambracian polyandrion. Second half of sixth century BCE. Ephorate of Antiquities of Arta PHOTO: AUTHOR. COPYRIGHT (C) HELLENIC MINISTRY OF CULTURE AND SPORTS

most sophisticated of poems of this kind. ${ }^{6}$ The combination of monument and poem presents a unique opportunity to experience a relatively complex work of archaic poetry in the same format, in the same location, and as a function of the same monument as it was experienced in antiquity.

Since its discovery, the Ambracian monument has been recognized for its potential to provide insight into how archaic elegy relates to mourning and funerary ritual. ${ }^{7}$ This relationship is usually considered at the level of semantic content, and the Ambracian poem has often been treated as a document of the kind of poetry performed at funerals. In contrast, this paper explores how the monument itself structures a relationship between genre and mourning in order to highlight effects of an elegiac poem that we could not anticipate without access to the monument on which it was inscribed. The monument's elegiac couplets, I will argue, do not record mourning so much as they configure mourning, giving it material shape and form in the here and now. When expe-

6 For more detailed readings of the poem itself, see Bousquet 1992; Cassio 1994; D’Alessio 1995; Day 2007 and 2019; Faraone 2008: 133-136; Randone 2013; Steiner forthcoming.

7 For the debate over the relationship between elegy and mourning or threnody, see Bowie 1986; Aloni 2009. 
rienced as a feature of the monument, elegy - which is to say genre itself - can structure viewers' feelings and emotions, their ability to empathize and mourn, their engagement with their built environment, and, ultimately, their capacity to become citizens.

\section{Elegy and the Structure of Mourning}

The poem opens with a first-person voice-a mourner whose grief tears them apart, casting them between a state of active engagement with the deceased, whom they recognize as still present, and a state of helplessness, of acknowledgment of the absence of the deceased. The dialectic emerges in the very first couplet. The first line states "I mourn these good men," pointing to the deceased as a visible presence within the speaker's time and space. The gesture towards the dead suggests their immediate presence as something visible to the first-person mourner, and so, once we acknowledge this voice, to us as well. And yet, towards what can this deictic actually gesture? Not the bodies of the deceased, since the monument, according to its excavators, is a cenotaph. ${ }^{8}$ And the suggestion that it pointed to the deceased as somehow embodied within the now-lost stele or, even less likely, statues that stood above the monument, is mere speculation. Instead, just as the first-person voice introduces a previously invisible mourner, the deictic at the very beginning of the poem opens up a new form of visual experience, one contingent upon memories and visions of the deceased that continue to haunt the mind of the mourner.

The visual experience so dramatically initiated in the first line is immediately undercut by the second line, in which we learn that "these men" cannot, in fact, be present in any tangible form, because they have been slaughtered while on an embassy from far-away Corinth. Where the deictic in the first line points to the men as persons who are here, present to the extent that they can be mourned, this vivid description of the slaughter emphasizes their inaccessibility, their existence only as corpses, which, as the next line makes clear, are not here in Ambracia, and so cannot, in fact, be pointed towards.

This push and pull between the first and second lines of the couplet is not merely a feature of its semantic content. Instead, it is embedded in the metrical structure of elegy, in which hexameter and pentameter lines are set against one another. In many elegiac poems, form and content are aligned, with the

8 Andreou 1986. This point has been contested by Matthaiou (1990-1991), whose arguments have in turn been rebutted by the excavators (Andreou and Andreou 1988). 
pentameter offering a complement or corrective to the assertion of the hexameter in what Gregory Nagy has called "the supplementary function of elegy." For Nagy, this supplementary function arises from the origins of elegy in the context of lament, where one mourning voice was picked up or supplemented by that of another mourner, leading to a communalizing effect that originated in the very structure of the couplet. Nagy applies this model to the funeral where multiple mourners are present and different laments are heard. Yet the embeddedness of this supplementary function in the generic structure of the couplet itself allows it to generate an experience of grief even outside of the context of a funeral - in the encounter, for instance, between a passerby and a funerary monument that offers mournful poetry governed by the same metrical structure.

In the Ambracian poem, the supplementary nature of the first couplet initiates a pattern that occurs throughout the other remaining lines in which a disjunctive statement pits visible presence of the dead against the poignant reality of their absence. Where the hexameter points to the deceased and so, fittingly, draws on techniques of visualization associated with epic poetry, the pentameter that follows - the overtly nonepic feature of elegy — pulls us back to reality. When we turn to the next complete couplet, in lines 7 and 8 , we see this same structure at work. ${ }^{10}$ The hexameter opens once again with a deictic that gestures towards two more men, Nausistratos and Kallitas, introduced as if present. "Yet the pentameter reminds us that "dark Hades" holds them back, forever out of reach. The use in this context of the verb $x \alpha \tau \dot{\varepsilon} \chi \omega$ ("to hold back," or, in reference to a burial, "to cover") finds a parallel in a fourth-century Attic funerary epigram (CEG 479), inscribed on a stele carved with relief images of a man and a woman: ${ }^{12}$

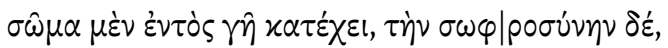

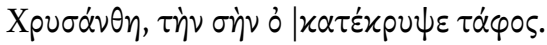

$9 \quad$ Nagy 2010: 20. On the structure of elegy see also Faraone 2008.

10 The second and third couplets are too incomplete to comment on their structure. Nonetheless, the pentameter of the third couplet, with its statement that "sadness blossomed then" ( $\pi \dot{\varepsilon} v \theta \circ \varsigma$ है $\left.\theta \alpha \lambda \lambda_{\varepsilon} \tau \tau^{\prime} \tau \varepsilon\right)$, is entirely consistent with the pattern in its focus on absence, here imagined as not only material but temporal.

11 A different reading of $\tau \delta \delta \delta \varepsilon$, as a genitive singular $\tau 0 \hat{\delta} \varepsilon$, was offered by Matthaiou (19901991: 310). While rejected by most commentators, it has recently been accepted and developed by Graninger (2014: 229-230).

12 Copenhagen, Ny Carlsberg Glyptotek 1595. Clairmont 1993: vol. 2, no. 282b. On epigrams of the fourth century with similar language see Tsagalis 2008: 125 . 
The earth holds back your body within it, but your moderation, Chrusanthe, your tomb has not hidden.

The disjunction the epigram draws between the body that is hidden beneath the earth and the moderation of the deceased that is still visible at her tomb is surely a reference to the relief below-a visual presence that compels us to remember Chrusanthe even as it cannot render her actually present. ${ }^{13}$ Where Chrusanthe's monument is able to compartmentalize what is held back and what is present as if the deceased has been divided up at the moment of her death, the Ambracian poem confuses the two states in a single mourning voice that swings from pointing to fellow Ambraciate citizens as present to announcing that the deceased themselves - not merely their bodies-are held back, out of sight.

The hexameter of the final couplet is even more forceful than the deictics in previous lines, commanding us directly to "know" (or reminding us that we know, if the verb is taken as indicative) the deceased by addressing us as "citizens" and so naming us as participants in the ideological system of the city. ${ }^{14}$ No longer are the deceased visible only to the mourning voice. Instead, we, as citizens affected by their death, are responsible for knowing them, for assuring their continued presence. And yet as we move to the final pentameter, we read that the fate of death has overtaken them, holding them back in the same place as the men named earlier. The object of our cognitive attention and emotional engagement once again slips away.

\section{The Monument's Grief and the Viewer's Pity}

This interpretation of the generic structure of the Ambracian poem as itself articulating grief depends on an interpretive move so far taken for granted: the

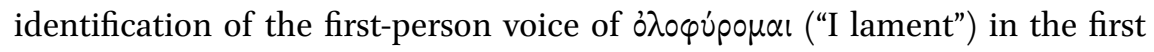
line as that of the monument. ${ }^{15}$ In contrast, most scholars, following Albio Cesare Cassio, have placed this first-person voice in the body of the viewer

\footnotetext{
13 For this formulation on another Classical Attic stele (CEG 534) see Estrin 2018: 116.

14 For the ambiguity of the mood of the verb and its relation to the identity implied by "citizens," see Graninger 2014: 231-236. Randone 2013 argues that this couplet is a later addition.

15 Interestingly, the verb occurs here in Ionic rather than local spelling, suggesting that its function is derived from a previously established tradition. On the spelling see Cassio 1994: 104; Day 2007: 40.
} 
who reads the poem. ${ }^{16}$ The text of the poem, in this interpretation, is similar to-perhaps even identical with-the poem that was performed at the funeral of the men named in it. Whoever happens across the monument could take on the mourning voice by reading the inscription out loud, and so reenact the sort of performance, if not the exact performance, that took place at the funeral. When the monument is treated as a record of a prior performance, the meaning of the poem is located in a time and space outside of our encounter with the monument. The monument itself, in turn, is understood as configured so as to reactivate the aesthetics of this hypothetical original performance. ${ }^{17}$

Cassio supports this hypothesis by pointing to other funerary monuments in which a first-person voice expresses distress in the face of death, such as a late sixth-century epigram for the dead Smikuthos inscribed on a stele base from the Kerameikos in Athens (CEG 51; fig. 10.3): ${ }^{18}$

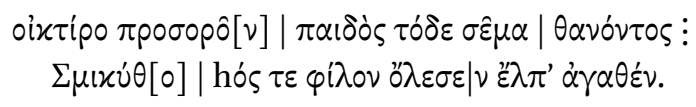

I feel pity as I look at this sema of a son who is dead of Smikuthos who destroyed his loved ones' good hope.

There are important differences—ones that are often overlooked—between the voice of the Ambracian monument and that of epigrams such as Smikuthos'. The Ambracian monument mourns, as we have seen, using the verb

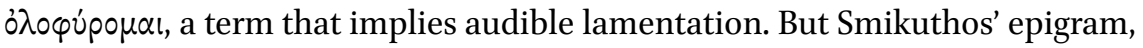
like many others that give voice to the anonymous bystander, expresses a less demonstrative and more distanced emotion: pity (oîx $0 \varsigma) .{ }^{19}$ True mourning, as

16 Cassio 1994; Day 2007: 30-31, 40; Faraone 2008: 133-136; Randone 2013: 34; Steiner forthcoming.

17 Joseph Day has suggested that the reader of the Ambracian poem might "replicate a processional ritual, or perhaps a choral performance" (2007:40). Yet in his overall approach to archaic dedicatory inscriptions, fully developed in his recent monograph (2010), he compellingly argues that the significance of the inscribed monument was only revealed in the dynamics of an encounter with it. Following this account, we can see how the act of reading might have allowed readers to draw on the rhetorical force of an imagined earlier performance, without necessarily replicating one that had actually happened.

18 Kerameikos Museum I 327. See Day 2007: 40-41. For the base, see Kissas 2000: 41-42, cat. A.7.

19 On pity in archaic funerary epigram see Sourvinou-Inwood 1995: 176; Tueller 2010. 


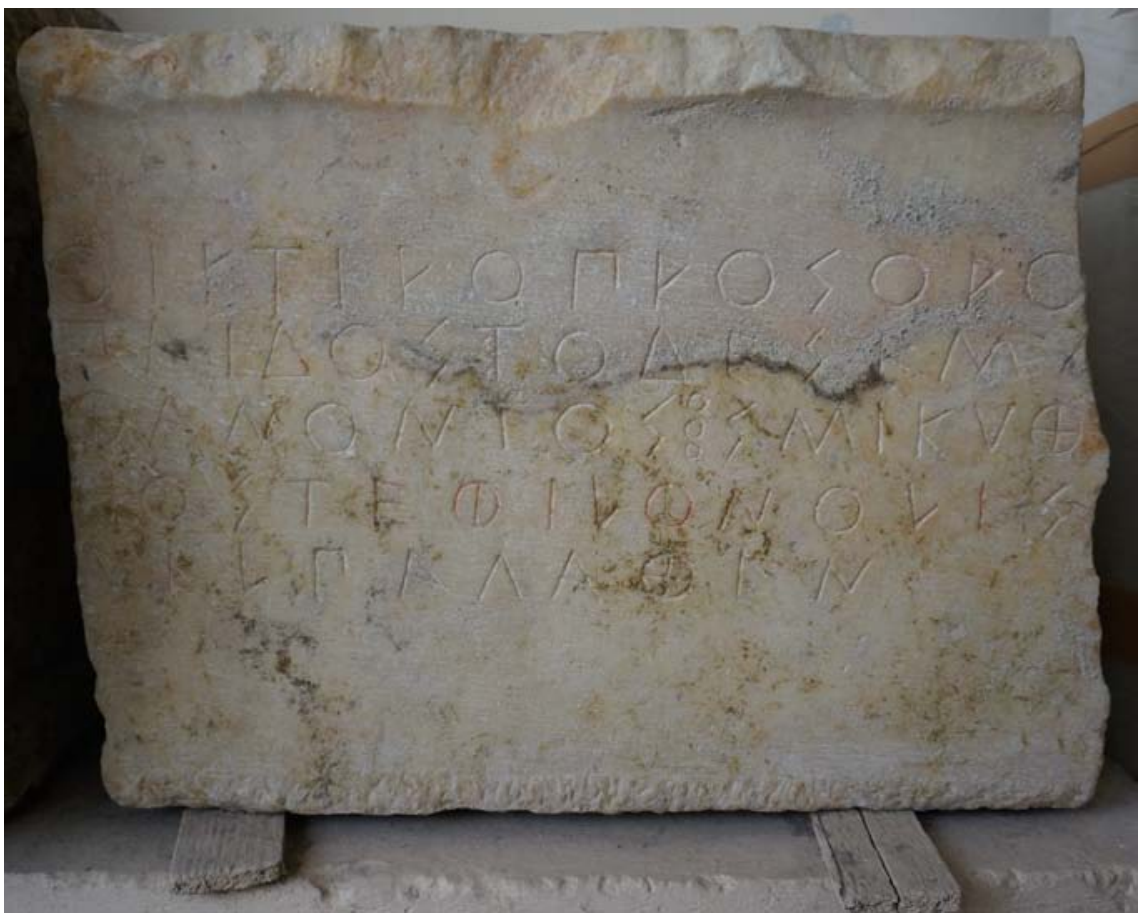

FIGURE 10.3 Inscribed stele base of Smikuthos. Late sixth century BCE. Ephorate of Antiquities of Athens-Kerameikos Museum I 327

PHOTO: E. BARDANI. COPYRIGHT (C) HELLENIC MINISTRY OF CULTURE AND SPORTS

expressed on the Ambracian monument, is reserved in such epigrams for family members - a fact the reader of Smikuthos' epigram seems to acknowledge by pointing to the destruction of their good hopes.

A closer parallel is found on a mid-sixth-century base now in New York but said to be from Athens, whose inscribed epigram for Chairedemos (CEG 14) expresses the grief of a bereaved father using a form of $0 \lambda \circ \varphi v$ po $\mu \alpha:^{20}$

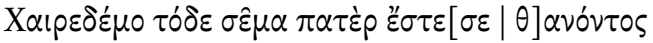

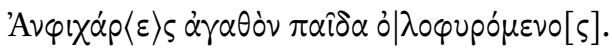

Of Chairedemos, dead, this sema his father

Amphichares set up, mourning a good son.

20 Metropolitan Museum of Art, New York 16.174.6. See Day 1989: 25. For the base, see Kissas 2000: 43, cat. A.9. 
Taken together, inscriptions like those of Smikuthos and Chairedemos make clear a distinction between the trauma experienced by those in mourningfamily directly affected by the death - and the more detached and analytic expressions of pity, reserved for those who empathize with the bereaved but who have not themselves suffered loss. ${ }^{21}$

The distinction between grief and pity affects not only the intensity of the emotional experience but also its object. As an emotion experienced by those who are actually bereaved, grief is directed towards the deceased, as is the case with Chairedemos' father. Pity, in contrast, is generated by and usually oriented towards the monument itself, named as a sema or mnema, as in Smikuthos' epigram, where the speaker is standing before the monument and looking directly at it $(\pi$ poбopó $[v]){ }^{22}$ The connection between our pity and our visual experience of the monument as a material object is similarly made explicit in an epigram for a man named Kleoitos (CEG 68):

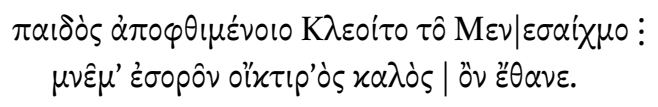

Of a son who died, Kleoitos the son of Menesaichmos, looking on the mnema have pity that he died being so beautiful.

Kleoitos' epigram frames the pity felt by the passerby as a function of looking at the monument (mnema), which, as the cutting in the base indicates, would have consisted of an unusually large stele (fig. 10.4). ${ }^{23}$ The phrase "being so beautiful" indicates that it is the beauty of this stele that provides the measure of Kleoitos' own beauty: he is accessible as an object of pity only insofar as we extrapolate him from the appearance of the monument. And yet the monument's ability to provide access to Kleoitos is undercut by both the content of the epigram and its orthograde configuration on the low and relatively wide base. ${ }^{24}$ The second line break dramatically divides the final phrase of the epigram, ò $x \alpha \lambda$ ò | oै $v$ है $\theta \alpha v \varepsilon$ ("so beautiful | being, he died"), with the first two words at far right and the last two at far left. The physical severing of the phrase

\footnotetext{
21 On this distinction more generally in Greek literature, see Konstan 2001.

22 This is also true of other epigrams cited by Cassio (CEG 470, and Peek 1976: $93 \mathrm{n} .1$ ) as well as $C E G_{27}$ and $C E G_{28}$. An exception is $C E G_{13}$, where the deceased himself is an object of pity. For epigrams that induce the passerby to feel pity, see Tueller 2010.

23 Athens, Epigraphical Museum 10641. For the base and its cuttings see Kissas 2000: 249 cat. C4. Compare the archaic stele of Mnasitheos (SEG 49.5०5, 56.508, 59.466), which speaks in the first person as the "beautiful" ( $\alpha \lambda \lambda_{0}$ ) mnema of the deceased (see Estrin 2016).

The base is $0.735 \mathrm{~m}$ in width (Kissas 2000: 249).
} 


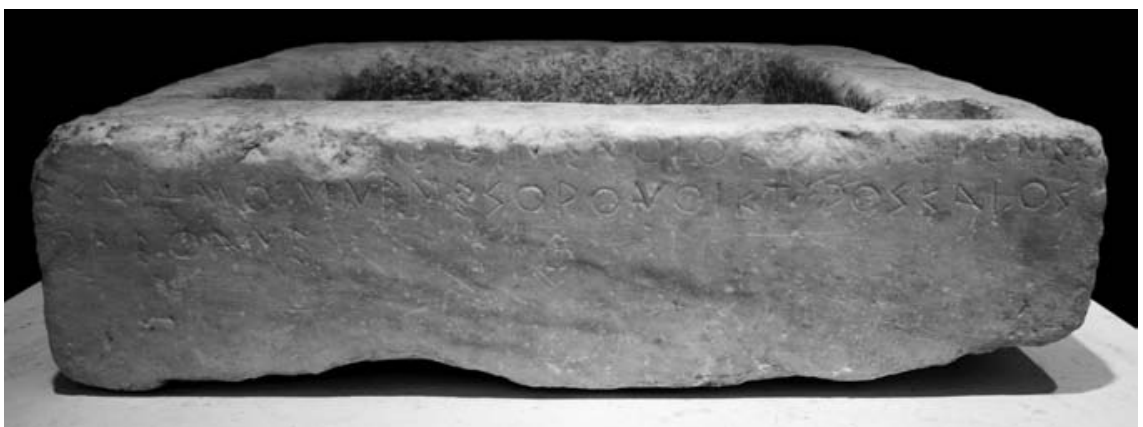

FIGURE 10.4 Inscribed stele base of Kleoitos. Third quarter of the sixth century BCE.

Athens, Epigraphical Museum 10641

PHOTO: AUTHOR/MAGDALENA GLOTZER

materializes the split between the monument's beauty and the man's deatha visual effect that might have, in turn, structured our visual experience of the monument above, including any sculpted or painted image it contained. Yet the epigram suggests that it is not an image of the deceased but the entirety of the monument (mnema) itself that is both the source and the object of our pity.

While pity arises from an experience of the monument itself, the objects of the verbs of mourning - in the Ambracian inscription, the epigram of Chairedemos, and others-are the deceased, unmediated by the monument. If in Smikuthos' epigram "this sema" is the thing that itself triggers pity, in Chairedemos' epigram "this sema" is the material residue, rather than the cause, of mourning. "This sema," in other words, stands between grief and pity, between mourner and passerby: it has been set up by the first in order to affect the second. Understood in these terms, the mourning expressed by the Ambracian monument's voice speaks to a deeply felt personal grief, suggesting that it shares an intimate connection with the deceased that no passerby could establish simply through the act of reading aloud. It is this trauma reserved for the mourner, I argue, that is expressed in the Ambracian poem by the first-person voice that simultaneously points to the deceased and laments their absence.

The monument of Smikuthos and others that articulate pity in similar terms come primarily from Attica, and so pity as an emotion felt by the anonymous viewer has often been seen as a phenomenon particular to that region. ${ }^{25}$ Yet

25 Tueller 2010: 42-46. There are, however, important exceptions, such as an early fifthcentury monument from Sinope (CEG $174 \mathrm{~B})$ and a Hellenistic one from Amphipolis (CEG $724)$, suggesting a wider spread both geographically and chronologically than is generally acknowledged. 
even if the formulaic expression of pity found in archaic funerary epigram originated in Attica, literary evidence from the archaic period upholds a broader cultural distinction between a mourner's grief and a stranger's pity-a distinction between different forms of emotional behavior that extended beyond Attica and of which the language in Attic epigrams is merely an expression. ${ }^{26}$ To return to Smikuthos' epigram, while it contrasts with the Ambracian poem in the identification of the first-person voice, they are linked at a more structural level by their exploration of grief through the supplementary function of the elegiac couplet - through a hexameter that opens up a visual spectacle that is subsequently undermined in the pentameter.

In Smikuthos' epigram, the first line asserts the physical presence of the monument, which is pointed to with a deictic marker, and the emotional presence of the viewer, who offers pity in the first person. The second, in contrast, describes what is absent: the good hopes of Smikuthos' family destroyed by his death. These good hopes were presumably not anticipated by the viewer who never knew Smikuthos, and so reference the family's grief that is distinct from the viewer's pity. The very structure of elegy, in other words, is able to suggest analogies between the different emotions of the bereaved family member and the pitiful passerby by formalizing the conflicting experiences of presence and absence that arise in the face of death.

If the voice of the Ambracian monument that mourns in the first person does not immediately become our own, instead it initiates an encounter with a monument that itself mourns. This capacity for monuments to mourn is clear from other funerary epigrams, such as a six-line inscription on a monument for Anaxilas set up in the Athenian Kerameikos (CEG 58), one of the longest preserved inscribed epigrams from the archaic period after the Ambracian poem: ${ }^{27}$

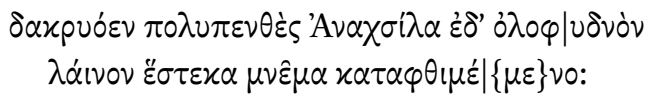

26 There has been unfortunately little overlap between the scholarship on pity in funerary epigram and the numerous studies of pity in Greek literature and culture that have appeared in recent years, such as Kim 2000; Konstan 2001; Sternberg 2005, 2006; Munteanu 2012. An exception is O'Sullivan 2008. At the same time, several recent epigraphic studies address the emotional nature of the experience of reading inscriptions in more general terms: Tsagalis 2008; Day 2010; Chaniotis 2012.

27 Athens, Kerameikos Museum I 388. For the base see Kissas 2000: 62-63 cat. A.29. For the length of these inscriptions see Bowie 2010: $361-363$. More generally on monuments from the archaic period that speak and/or mourn in the first person, see Christian 2015: 28-45, 141-144. 


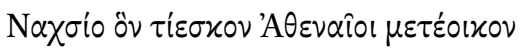

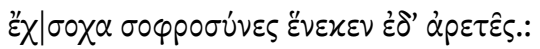

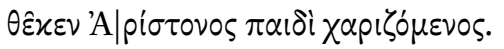

Tearful, exceedingly sorrowful, and mournful

I stand here as a stone mnema of the deceased Anaxilas,

a Naxian whom the Athenians honored as a metic

especially on account of his good character and excellence.

Timomachos set me up over him having performed a reverent funeral honor,

thereby gratifying the son of Ariston, who died.

Using an adjectival form of the same verb of mourning found on the Ambracian

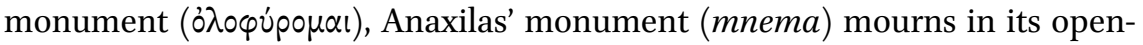
ing hexameter, and even sheds tears. Yet the following pentameter consists of images of static stone and death, and the first-person voice goes on to explain how, as a stone monument, it is something that has been set up as a funeral honor. There is no ambiguity here: this is a mourning block of stone, a fullyformed social agent, occupying the same space as us, but caught in a paralytic state of lamentation. The monument's abrupt transition from describing its

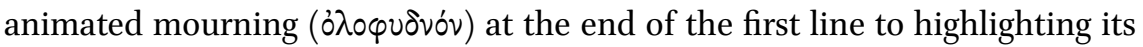
stone materiality ( $\lambda \dot{\alpha}(v \circ v)$ at the beginning of the next once again enables it to embed this disjunctive emotional state in its very generic structure. The tension between the monument's stone materiality and sense of agency would have been simultaneously acted out by the now-lost statue that once stood above it, which was most likely a kouros - a monument that is simultaneously alive and inanimate, mortal and never-aging, and that, as epigrams on bases of other kouroi testify, demands our pity. ${ }^{28}$ Informing both the epigram and the statue, this tension between the monument's materiality and its capacity for animation is at the heart of how it communicates the pain caused by death.

28 The epigram for the kouros monument of Kroisos (CEG 27) famously demands pity. Richard Neer has remarked on the relationship between the formal appearance of a kouros and mourning, arguing that the "pose of a kouros is not a 'mere' formal device, but the means by which the statue expresses its peculiar temporal predicament: that of mourning" (2010: 42). Anaxilas' base is sometimes assumed to have supported a seated statue, but parallels for inscribed blocks of its size and proportions much more frequently belong to the kind of stepped base that supported a kouros; see Kissas 200o: 62-63, cat. A.29. 
We can see the distinction between mourning and pity at the site of the funerary monument at work in a passage from the Iliad where Achilles' horses - the only animals in the Iliad endowed with human qualities such as speech-encounter the corpse of Patroclus and begin to mourn. ${ }^{29}$

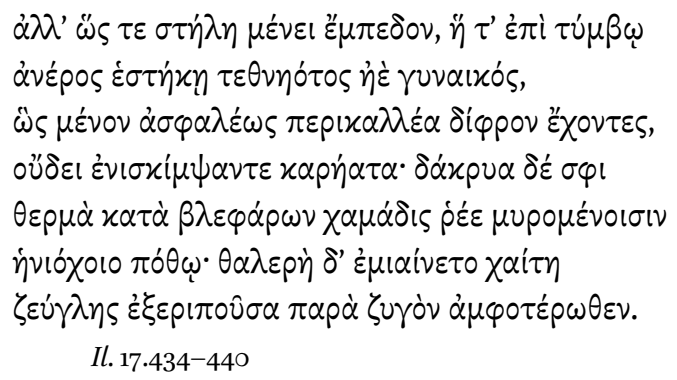

... but still as stands a grave monument which is set over the mounded tomb of a dead man or lady, they stood there holding motionless in its place the fair-wrought chariot, leaning their heads along the ground, and warm tears were running earthward from underneath the lids of the mourning horses who longed for their charioteer, while their bright manes were made dirty as they streamed down either side of the yoke from under the yoke pad.

Trans. R. LATTIMORE

The metaphoric comparison of the horses to a stele underscores not simply their lack of movement, but the channeling of all their emotional and affective engagement towards Patroclus. As in Anaxilas' epigram, the descrip-

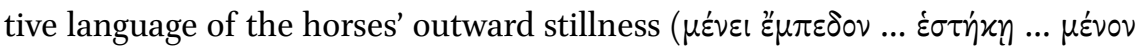
$\left.\dot{\alpha} \sigma \varphi \alpha \lambda \varepsilon^{\prime} \omega \varsigma\right)$ contrasts sharply with their inner emotional turmoil—a turmoil so potent that it overwhelms their solid, unmoving forms, staining their bodies with tears. Like the structure of the elegiac couplet, the paradoxical ontology of the weeping stone monument serves to formalize the traumatic effects of grief. Where grief brings the stone monument of Anaxilas closer to life, it works on the living horses from the opposite direction, bringing out the monument-like qualities of sentient beings. ${ }^{30}$

29 For a comparison between the movements of the viewer of the Ambracian monument and Achilles' horses in this passage, see Steiner forthcoming.

30 For related observations on the blending of animate and inanimate in Homeric poetry, see Purves 2015 . 
Just as Anaxilas' monument calls out in its grief to those who pass by it, so too do the horses attract the attention of a bystander:

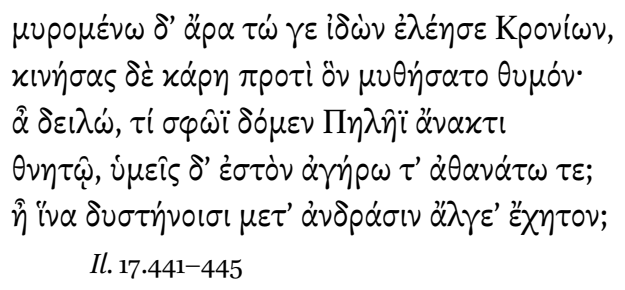

As he watched the mourning horses the son of Kronos pitied them and stirred his head and spoke to his own spirit: "Poor wretches, why then did we ever give you to the lord Peleus, a mortal man, and you yourselves are immortal and ageless? Only so that among unhappy men you also might be grieved?"

Trans. R. LATTIMORE

Where the true mourners are assimilated with the monument itself, Zeus, as an onlooker not directly affected by Patroclus' death, feels pity instead. ${ }^{31}$ The language Zeus uses to describe his pity attends precisely to the tensions we find in inscribed funerary epigram, suggesting that the metaphoric comparison of the horses to a stele focalizes Zeus' own experience as viewer. The epigrams of Smikuthos and Kleoitos generate pity by asking the viewer to attend to the gap between the material presence of the stele above and the absence of the deceased in the lives of those who erected the monument. In the same way, Zeus explains that his pity arises from the tension he observes between the horses' immortality and their experience of grief-an emotional experience normally reserved for mortals. That the horses appear stele-like in this moment suggests that it is precisely this tragic tension between the existence of the stone monument as a permanent, immortal, and unfeeling object, outside of the realm of human experience, and its status as a social agent endowed with human emotion that engenders pity in the viewer. It is this tension that is built into the Ambracian poem at the level of genre.

31 A similar episode occurs at Il. 16.1-5, where the weeping Patroclus is described as looking like water streaming over rock-a sight that inspires pity in Achilles. See Christian 2015: $145^{-146 .}$ 


\section{Movement and Agency}

What is the status of a monument that mourns? It is certainly not identical to that of a human mourner, and my claim is not that the monument has somehow come to life or taken on human agency. Rather, the mourning monument draws us into an intersubjective, empathetic relationship with what makes it nonhuman: its stone materiality, its durability, its monumentality, its embeddedness in its surrounding landscape. In so doing it puts into question a strict binary between human and thing, exposing mourning as a state that affects both. ${ }^{32}$ When after the initial cry grief reappears in the poem, in line 6 , it is as something that "blossoms," overtaking the beautiful fatherland of the men who died as if growing from the earth. Like the description of Achilles' horses as inert yet stained with their own tears, this image of mourning as emerging from the inanimate of its own accord compels us to look for grief not only in the metrical structure of the poem but in the very materiality of the monument. The result is a tension between the monument's materiality and its animation that amplifies the same tension inherent in the structure of elegy through which it expresses its grief.

The strategies a monument could employ to suggest an interplay between its inscribed epigram and its materiality are perhaps more obvious in the case of those that were decorated with figurative elements. The viewer of the monument of Smikuthos, for instance, encounters an epigram inscribed in five lines of clear, carefully carved letters on a base that supported a marble stele (see fig. 10.3). As we read each line downwards, our eyes move from the stele above - now lost but likely painted or carved with a vivid, life-size image of a young man like Smikuthos himself - towards the ground where his dead body lies. In the process, we move from our own emotional reaction to what we see in the first line ("I feel pity as I look at ...") towards the loss that haunts the bereaved family. The very generic structure of the elegiac couplet here helps integrate the work of the epigram into a more holistic visual and emotional experience from which it cannot be separated.

Instead of figurative imagery, the Ambracian monument uses the configuration of its stones and of the poem across its face to activate the structure

32 Compare Jane Bennett's observations that material things are not static and immobile in binary opposition to humans, but rather their "rate of speed and pace of change are slow compared to the duration and velocity of the human bodies participating in and perceiving them. 'Objects' appear as such because their becoming proceeds at a speed or a level below the threshold of human discernment" (Bennett 2010: 58). We might say that genre makes the "becoming" of the monument discernable as such. 
of elegy. The integral role of the monument's material presence is established through its ability to control readers' movements, with the layout of the inscription requiring a reader to walk a distance of almost $30 \mathrm{~m}$, crisscrossing the monument's façade twice. ${ }^{33}$ Those who see the inscription as a record of a performance interpret this choreographed path as recreating, either symbolically or literally, the funeral procession that might have accompanied the poem's original performance, before it was inscribed. Yet rather than remove us to an imagined earlier performance, our encounter with a mourning monument compels us to directly confront the built structure before us, from which the voice emerges. As we finish reading, we are left standing almost directly in the center of the monument, surrounded by it on either side, our bodies aligned with the stele above.

This act of walking makes us acutely aware of its sheer physicality and draws our eyes towards details of its visual configuration. ${ }^{34}$ But it might do much more than that. For in retracing our steps and submitting the animation of our own bodies to the control of the monument, we reciprocate and amplify the animate presence of the first-person voice in a way that coincides with attitudes towards the agency and vitality of nonhuman matter as expressed in early Greek literature, such as the passage of the Iliad discussed above, as well as in pre-Socratic philosophy and scientific writing. ${ }^{35}$ Thales' understanding of magnets, as recorded by Aristotle, provides a way of thinking about this relationship between motion and agency: "Thales, too, seems, from what they record, to have supposed that the soul was something motive, since he said that the stone [i.e., the magnet] has a soul because it moves iron" (trans. Collins). ${ }^{36}$ If a stone appears to have a soul when it causes something else to move, animation is not an inherent property of stone, but a quality that

33 Day 2019: 241-242.

34 This emphasis on the material structure of the monument is made explicit in some inscribed epigrams, such as that of another large-scale archaic funerary monument, the tomb of Menekrates, perhaps dating as early as the late seventh century, on Corfu, another Corinthian colony ( $C E G$ 143). The circular tomb was ringed around its circumference with six lines of hexameter that describe how it was constructed through the grief of the deceased's family and community, linking the materiality of the monument and the grief that occasioned it for the viewer who walked around it to read the poem. See Bousquet 1992: 6o5; Bowie 2010: 310.

35 See, for instance, Alex Purves' account of "the lively and permeable boundary between human and nonhuman in early Greek epic, one that suggests that objects can have their own life form, their own energy, vitality, and even creativity" (Purves 2015: 75).

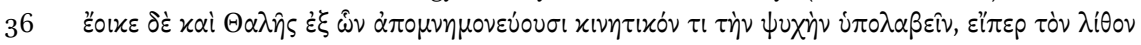

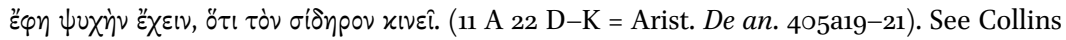
20०3: $37-38$. 
emerges as a function of the presence of the thing moved. By recognizing that a stone monument has caused our bodies to move, we not only recognize its animate potential, but the materiality of our own bodies. Inherent in the fabric of the monument yet only perceived through the embodied act of reading, genre provides a mechanism for awakening what Thales might call the monument's soul. $^{37}$

Acknowledging the authority of the monument encourages us to see the same tension between animation and immobility-itself an elaboration of the disjunction between presence and absence we first saw in the structure of the elegiac couplet-in the configuration of the inscription. The text we read, carved in unusually careful stoichedon, forms a visually consistent pattern aligned with the size and orientation of the horizontal blocks that make up the monument. ${ }^{38}$ As we move across its front, abstract letterforms transform into a unified poem, bringing forth the animate first-person voice.

But just as it gives structure to the content of the poem, genre reconfigures this regulated appearance. Tricola have been carved between the hexameter and pentameter lines, in the gap between the regularly spaced letters. These give visual and material presence to the tension between presence and absence - and the grief caused by that tension - that is embedded in the poem's very genre. ${ }^{39}$ We can see in the break between the third and fourth couplets, for instance, how a tricolon marks a gap between the visually similar words $\tau \dot{o} \tau \varepsilon$, the temporal adverb meaning "then," pointing in the pentameter to mourning in the past at the end of the third couplet, and $\tau \delta \delta \varepsilon$, a deictic adjective meaning "these two" which opens the following couplet by pointing to two deceased men (fig. 10.5). As we read the poem, the tricolon breaks up the text at metrical, semantic, and visual levels, giving material weight to the disjunctive effects of the poem by making them visible on the surface of the stone itself. The mourning voice and its disjunctive effects only emerge by upsetting the regularity and solidity of the poem as a visual feature of the monument.

This tension between the visual unity of the text and its fragmentation through genre is amplified by the configuration of the thick molding carved in a

37 Considering the wall-like qualities of the monument as discussed below, we might compare Thales' account of the stone's soul with the description of Ajax in the D scholion on

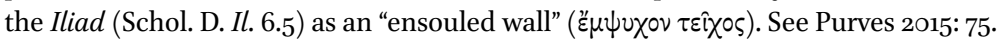

38 On the high quality of the carving see Bousquet 1992: 597-599, 6 o4.

39 Tricola are lacking after lines 8 and 9 -one of the features that has led Randone (2013: 45) to argue that the final couplet is inscribed by a different hand and is possibly a later addition to the monument. 


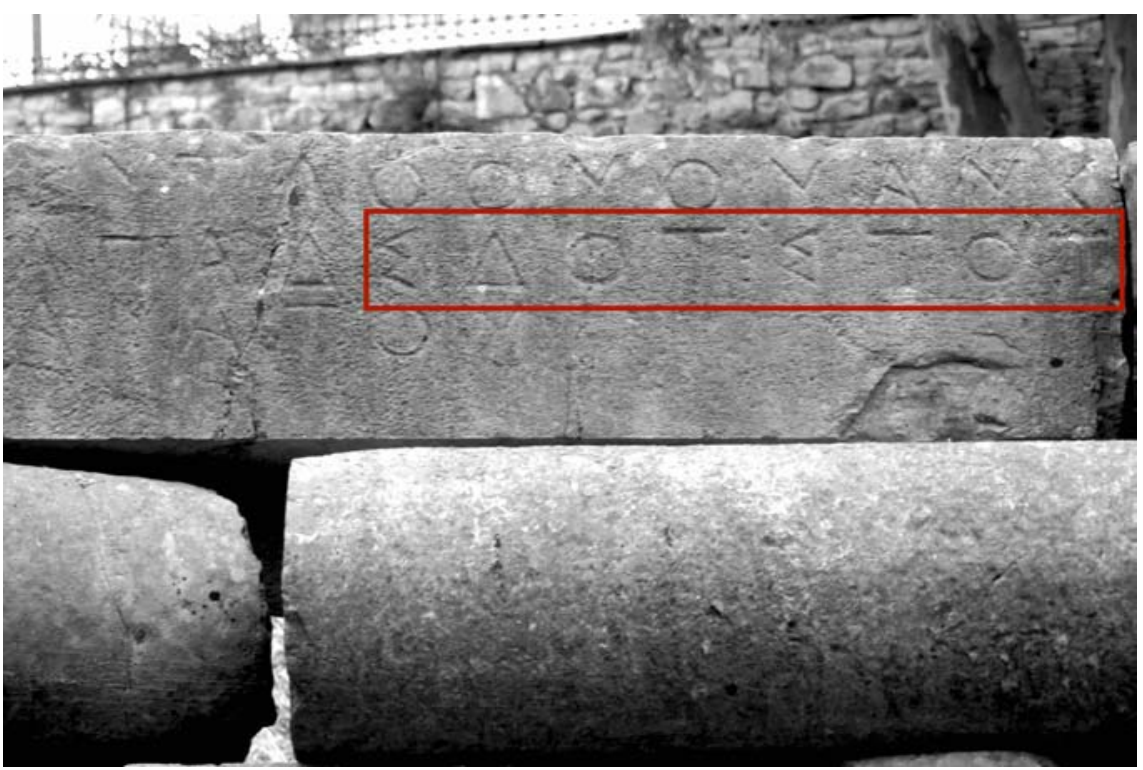

FIGURE 10.5 Detail of inscription of Ambracian polyandrion. Ephorate of Antiquities of Arta

PHOTO: AUTHOR. COPYRIGHT (C HELLENIC MINISTRY OF CULTURE AND SPORTS

deep, convex torus around the edges of the monument. ${ }^{40}$ The gap between the strict right angle of the crepidoma's edge and the rounded curve of the molding running above it creates a line of shadow that makes the bulk of the monument appear to sit on top of - rather than extend out of - its base. It is this structure, encased by the molding, that in turn supports the uppermost course of stones on which the inscription is carved.

Even though the monument follows the cuboid structure of its base, the molding gives it a shape and form of its own. Running both up and down, from both left and right, the molding follows the orientation and regularity of the inscribed letters and the viewer's movement across the façade. Particularly unusual is the upright orientation of the molding at the outer edges, where vertical stretches join the lateral ones to complete a rectangle across the front surface, surrounding the recessed inner face (see fig. 10.2). This formation enables viewers to follow the molding not only horizontally but, at the edges of the monument, vertically as they move their eyes downwards and backwards according to the boustrophedon layout of the inscription.

$40 \quad$ On the molding see Andreou 1986: 426. 
Complex planning was required to give the appearance of a unified rectangle across the monument's face. The horizontal sections at the bottom and top constitute a discrete course of stones, with their outer edges above and below corresponding with the edges of the blocks from which they are formed. In contrast, the vertical sections of the molding emerge from the corners of the blocks at the ends of the second, third, and fourth courses. In this sense, their orientation works against that of the horizontal ashlar blocks of the monument - a virtuoso display of craftsmanship that would have wasted a significant amount of stone. The interplay of the molding with the flat surface it encompasses continues around the sides, so that vertical sections of the molding trace three-quarters of a cylinder that joins two perpendicular faces. The four extremities of the façade mark where not two but three stretches of molding converge from different angles, creating something like an exoskeleton-an autonomous plastic form that contrasts with the flat, horizontal blocks from which it is, in fact, materially formed.

The patterning is deceptively simple, but the effect depends on strategies of negotiating the relationships between parts and the whole that are hallmarks of archaic sculptural practice-what Richard Neer has called "joining." ${ }^{41}$ In archaic sculpture, for Neer, representations of physical bodies and visual images emerge by integrating and synthesizing discrete sculptural flourishes through practices of carving and viewing. So, for instance, a sculpture might be articulated with individual anatomical elements - a pair of eyes, a nose, a chin, and so forth - which come together to form a representation of a human face only through the eyes of a viewer. A viewer who visualizes the molding of the Ambracian monument as a continuous entity, surrounding and moving across the surfaces of the monument, must synthesize distinct stone blocks in a similar fashion. ${ }^{42}$

The viewer's experience of negotiating between how the molding is visualized (as something independent of the interior of the monument) and how it has been constructed (as configured from the monument's blocks) can be understood as operating according to the same disjunctive structure as the poem. Reading the inscription requires us to disrupt the regular stoichedon pat-

\footnotetext{
41 Neer 2010: 40-46.

42 To adopt the theoretical language of Whitney Davis' recent work on visuality (2017), we might say that a viewer will pictorialize the monument- that is, understand its visual coherence as an intended aspect of its configuration —only from particular standpoints in time and space. Because these standpoints constantly shift as the viewer reads the epigram and moves across the monument's façade, any visualization of the monument is inevitably unstable and its appearance is continuously renegotiated.
} 
terning of the text according to the inherent tension of elegy. Simultaneously, following the molding with our eyes compels us to reconfigure the monument itself according to new structures, joining some blocks together to follow its winding form while breaking up others into discrete elements of flat surface and molding. The transformation of distinct blocks into composite forms offers the possibility of opening up new realities, of encountering something that is not actually there, as in the hexameter lines. But seeing only the blocks of stone in themselves means seeing what is here and now, as in the pentameter lines, and so acknowledging the form traced by the molding as marking out an absence as much as a presence. The carving of the monument and the articulation of its molding, in other words, not only provides a visual formalization of our own movements, changing directions with us as we transform stone blocks into a mourning voice, but gives material substance to the mourning voice we encounter in the poem.

\section{A City That Mourns}

The interpretation of the monument so far presented indicates that it was configured in every aspect for a viewer who was not already a mourner-a viewer who perhaps had no prior knowledge of the slaughter commemorated by the monument. As we have seen, the couplets of the poem create a gradual buildup of intensity for the viewer who reads them and moves across the façade, culminating in the strong political overtones in the final couplet, where the viewer is addressed in the plural as "citizens" and asked to know the deceased directly. If the initial lines invite us to confront the disjunctive structure of mourning from an outsider's perspective, by the time we reach this final couplet we are asked to experience them as if we are ourselves, in a sense, bereaved. ${ }^{43} \mathrm{~A}$ private grief, such as the one expressed on the monument of Smikuthos, generates pity. But the Ambracian monument instantiates a public loss, its anonymous first-person voice not that of a bereaved parent suffering an individual tragedy, but that of a monument that forms part of the built landscape of the city we ourselves inhabit. ${ }^{44}$ The passerby who reads the monument moves from an

43 Even if Randone 2013 is right to argue that this couplet is by a different hand than the first four, it is close enough not only in its overall appearance but also in its disjunctive structure that any reader would have experienced it as continuing and amplifying the effects of the first four couplets. For an argument that the five couplets form a unified structure, see Faraone 2008: 133-136.

On public elegiac epigram see Aloni 2009: 181-182. 
encounter with a mourning voice to a submission to that voice's-and so the city's - physical, emotional, and social control. The eventual transformation of our emotional engagement from pity into mourning is the same process as our transformation from stranger into citizen. ${ }^{45}$

In its presentation of an individual mourning voice as assimilating its grief into the broader civic community, the Ambracian poem is similar to other archaic elegiac poems that attempt to reconcile the concerns of the city with the mutability of the fate of the individual. ${ }^{46}$ The speaker of Archilochus fragment 13 , for instance, explains to his fellow symposiasts the difficulty of engaging in civic affairs or festivities when we are afflicted by grief. ${ }^{47}$ The pain of grief is difficult to put aside, as he says:

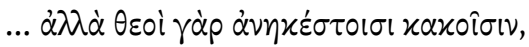

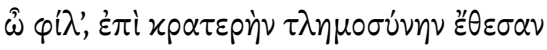

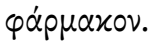

ARCHIL. fr. 13 W, $5^{-7}$

... but the gods, over our incurable misfortunes,

my friend, have set up strong endurance

-a magical antidote.

Grief does not go away—its effects are literally without cure. And yet the gods temporarily mask this sorrow by placing a sort of protective shell over it that works through its strength, its endurance, and its magical properties. ${ }^{48}$ The materiality of the cover is underscored by the use of the verb हं $\pi \iota \tau^{\prime} \theta \eta \mu \iota$ ("to place on top"), a verb commonly used in funerary epigrams - as, for instance, in Anaxilas' epigram discussed earlier-to describe how the visible monument has been placed over the corpse. ${ }^{49}$ Where in the sympotic context Archilochus can use this cover to put aside mourning and take up festivities, the stone monument works from the other end, pockmarking its smooth, solid surface with traces of mourning. Elegiac poetry, in both the sympotic and the cemetery con-

45 We find a similar transformation from pity to mourning in the epigram on the base of an archaic funerary monument from Attica inscribed for Tetichos (CEG 13).

46 For comparison of the language of the poem with elegy from other contexts see Cassio 1994; Faraone 2008: 135; Bowie 2010: 322, 356.

47 See Steiner 2012a.

48 See Steiner 2012a: 34 .

49 For this use of ह̇ $\pi \imath i \theta_{\eta} \mu l$, see also $C E G_{32}, C E G_{35}, C E G_{53}, C E G_{138}$, and $C E G_{169}$. 
text, works to make individual grief resonate more broadly by giving mourning a structure that can unite singer and audience and integrate grief into civic culture as a shared experience.

Only when we consider the Ambracian monument as a function of that civic culture can we evaluate the impact of its politicization of mourning. The monument forms part of the city's largest cemetery, located along the most important road between the port and the city. ${ }^{50}$ This road was monumental in scale, ranging from $10 \mathrm{~m}$ to $12 \mathrm{~m}$ in width and paved in part with large stone slabs. Excavations of sections of this road have revealed three-sided funerary enclosures ranging in date from the archaic to the end of the Roman period, a number of them likewise fronted with impressive built walls marked with stelai and rivaling the polyandrion in size and scale.

Apart from its inscription, what distinguishes the polyandrion from other funerary enclosures is the fact that it is a cenotaph for a group of men not linked by family ties, but by their sacrifice for their city. Where the other funeral plots contain numerous inhumations and vessels for cremated remains, the polyandrion, according to its excavators, contained no burials contemporary with its construction. ${ }^{51}$ The walls, in this sense, are not functional, and do not create an interior space-indeed, in contrast to the smooth outer surface of the stones, on their inside faces they are left roughly carved and unfinished. Instead, they are closer to the defensive walls built around the city of Ambracia itself in the archaic period, constructed from blocks that are likewise commonly dressed on the outside but not on the inside, and filled with rubble-walls made to appear as solid when they are not. ${ }^{52}$ The monument is built, in other words, as an empty shell, something whose meaning is contained neither only in its visible appearance nor in what it contains inside, but instead in the dialectic interactions between finished exterior and empty interior-between what we can point to and what is held back. ${ }^{53}$

At the level of civic performance, close parallels between how the materiality of the monument enacts the rhetorical effects of its inscribed poem can

50 For the location of the monument within the city and cemetery, see Angeli 2013.

$5^{1}$ The excavations have not been fully published and unfortunately it is impossible to know at the moment which, if any, monuments predate or were contemporary with the polyandrion. See Angeli 2013 for an overview.

$5^{2}$ On the fortification walls of Ambracia, see Angeli 2013: 179-180.

53 Compare the role of the Achaean wall in Homer's Iliad which, as James Porter (2011) and Karen Bassi (2016: 40-63) have separately argued, moves between fact and fiction, between the visible and the invisible, to construct a layered epic past through the material present. 
be found in choral poetry. ${ }^{54}$ In a fragment of Pindar (fr. 194.1-3 Maehler), for instance, the chorus describes itself as stamping out a foundation for its songs and exhorting itself to "build a wall ( $\tau \varepsilon \varepsilon \chi \zeta \zeta \omega \mu \varepsilon \nu)$ that serves as an adornment

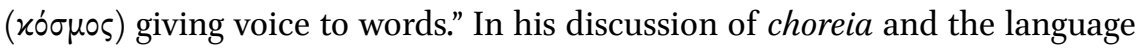
of craft, Timothy Power highlights how in this passage "the chorus is notionally constructing itself through its very performance as an intricately crafted thing of beauty ... that yet has voice. ${ }^{55}$ Like the mourning voice embedded in the Ambracian monument, the chorus conceives of itself as something between human and nonhuman, something that combines the solidity and materiality of a built structure with the animation of a human being. The material foundations of the chorus' performance not only ensure its continued presence, but, as Power argues, articulate the political character of choreia, which emerges as a foundational act that allows the city to take form. Embedding its speaking voice not simply in a crafted chorus but in an actual material construction - an elaborate walled adornment to the city-only enhances the Ambracian poem's ability to unite its citizens in a common emotional experience.

As Power and others have shown in recent years, choreia often draws explicitly on the language of craft to achieve this sense of civic unity. ${ }^{56}$ Such imagery serves to heighten the visual and emotional effects of performance by giving a formalized structure to the relationship between audience members and choreuts. The stone Ambracian monument works in similar terms, drawing us towards it through its ability to speak and make us move. So, for instance, the monument's ability to open up new forms of visual experience through its first-person voice and its use of deictic gestures is analogous to how AnastasiaErasmia Peponi has described Alcman's first Partheneion, where deixis and movement likewise take hold of and extend the audience's gaze from what is materially present into a realm of psychic imagination. ${ }^{57}$ As in the Ambracian poem, where each surviving couplet presents a new pair of men, the Partheneion introduces young girls sequentially, pointing to them with demonstratives and deictics and asking the audience to visualize them through color-

54 Steiner forthcoming likewise explores the relationship between the monument and choral performance.

55 Power 2011: 96.

56 Peponi 20o9; Power 2011; Kurke 2012, 2013a; Neer and Kurke 2014; Steiner 2014a: 31-33, forthcoming; Weiss 2016. In particular, the notion of "joining" outlined above in terms of the monument's construction finds close parallels in Kurke's exploration of the relationship between craft and choreia (Kurke 2012: 230, 2013a: 156-157). More generally on the relationship between aesthetics and the architecture of both built monuments and poetry in ancient Greece, see Porter 2010: 453-523.

Peponi 2004, 2015. 
ful metaphors and imagery. Where these effects serve to transform the visual experience of the dancers who are present into something visionary and dream-like, in the Ambracian monument, as we have seen, such possibilities are undercut almost as soon as they are presented through the structure of elegy. Nonetheless, the comparison highlights the rhetorical effectiveness of the Ambracian monument's voice as constructing the monument itself as a vibrant material presence with which we can empathetically engage.

The Ambracian monument's control of the viewer's body is suggestive of the effects of chorality that make use of physical attraction and kinesthetic movement to create bonds between audience and performers. In a recent discussion of choral mimesis, Leslie Kurke points to a passage in Plato's Ion (533d-536d) where Socrates makes the analogy between the individual involved in a poetic performance and an iron ring in a chain attracted to a magnetic stone. ${ }^{58}$ The magnetic stone in this metaphor is the divine source-the Muse-that does not simply inspire but kinesthetically attracts the poet. This attraction initiates a literal chain reaction of rings physically linked to one another and drawn together through the magnetic force imparted from one to the next. If, following Thales, the physical pull of the stone monument that makes us move is similar to that of a magnetic stone that moves iron, we can see how our movements as we read the inscription draw on the same structures of agency and efficacy as choral performance.

For Kurke, this understanding of choreia as operating according to the logic of magnetic attraction speaks to its ability to generate an "intersubjective fusion and merging of chorus and audience." ${ }^{59}$ In her account, "[i]nsofar as the chorus serves to represent and draw in the whole community, its bodying forth of magical unity animated by a higher power is closely linked to moral effects: the affirmation of proper communal (civic) order as part of a proper, hierarchized cosmic order."60 In the context of choreia, as in the context of inscribed monuments dedicated to deities, such "intersubjective fusion" between the chorus and its material environment serves as a mechanism to connect its members with the divine. ${ }^{61}$ But the goal of the Ambracian monument is to link us with the men whose slaughter it commemorates-a connection that can never be fully achieved. In the Ion, Socrates describes how each element - whether poet, audience member or choreut — is "possessed" or "held" ( $\kappa \alpha \tau \varepsilon \chi \varepsilon \tau \alpha l)$ by the next in the magnetic chain. In the Ambracian poem,

\footnotetext{
$5^{8} \quad$ Kurke 2013a: 151-152.

59 Kurke 2012: 231.

6o Kurke 2012: 231.

61 On the ability of inscribed epigrams to connect a reader with a named deity, see Day 2010.
} 
in contrast, the same verb $(\kappa \alpha \tau \dot{\varepsilon} \chi \mathrm{E})$ is used to describe how the dead, even as they are pointed to, are held back from us in Hades. ${ }^{62}$ Even as it draws on aesthetic devices also found in choral performance, the disjunctive structure at the heart of the Ambracian monument complicates any sense of assimilation.

Thinking through choreia allows us to appreciate how the monument questions a binary between human and nonhuman not just by asserting its own agency, but by compelling the reader to confront their own materiality. In reading the poem we adopt the same disjunctive structure that configures the entire monument, from the shape of its stones to the genre of its inscribed poem. Our mourning makes us stone-like agents whose devotion to the deceased constricts our bodily independence. Yet the more we adopt the structure of the mourning monument, the more deeply we internalize its inherently broken relationship with the deceased. For the mourner-whether made of stone or of flesh and bones - a sense of emotional and even visual proximity never transforms into a true connection, and the sense of fusion is always painfully incomplete.

Such comparisons with choreia do not necessarily suggest that the configuration of the monument mimics the effects of a choral performance that took place at a prior funeral. Instead, I offer them in order to show how the monument's very materiality is able to align the social value of carved and inscribed stone with that of other poetic practices. The aesthetic effects of the monument, in this sense, are like those of a choral performance not because one records or imitates the other, but because both are shaped according to a shared basic structure-a structure rooted in genre as a stable feature of the poem, whether it is experienced as carved or sung. ${ }^{63}$ Yet even if the genre is shared between the different contexts, the monument, as a built material presence, amplifies the structure of elegy on its own terms, giving architectural form to the poetic language of mourning. In so doing, it presents not only Ambracia's citizens - including those of us who read the poem — but the very material fabric of the city as shaped by the structure of elegy.

62 These uses of the verb $\chi \alpha \tau \dot{\varepsilon} \chi \omega$ find close parallels in curse inscriptions of the Classical period, where those writing a curse ask Hermes or Persephone to "hold back" ( $\kappa \alpha \tau \varepsilon \dot{\varepsilon} \chi$ ) the target of their curse (see Eidinow 2007: 147). Although emerging in a very different context, the shared use of the verb is suggestive of the animate potentiality of the material object, whether curse tablet or cenotaph, in generating intersubjective connections between individuals in ways that parallel those achieved in choral performance.

63 See also Sarah Olsen's contribution to this volume, which draws on the concept of genre as a form of embodied cultural knowledge to examine it as a stable feature across different performance contexts. 


\section{Conclusion}

When we examine the poem inscribed on the Ambracian polyandrion in isolation, apart from the medium through which it was experienced, it is easy to understand the relationship between its genre and its content as primarily taxonomic: elegy is the genre of lamentation. In contrast, I hope to have shown that genre only becomes visible - only matters - in the context of an encounter with the inscribed monument as a material object, one that asserts itself as a mourner in the first person. The structure of the elegiac couplet, I have argued, does not communicate lamentation so much as it provides a formalization of mourning that is simultaneously enacted at multiple levels in the configuration of the poem and the monument as a whole.

Understood this way, the choice to inscribe a massive civic cenotaph with a poem in elegiac couplets is significant not because elegy is generically associated with funerary ritual, but because the metrical structure of the couplet-its most basic generic feature-is what enables a community of individuals to experience these deaths on an empathetic level as fellow citizens. It is only as we read the text, as we reorient our movement, as we perceive the tricola that create fissures in the regular pattern of the text, as we mark out the disjunctive structure and content of the couplets on the surface, as we understand that the carefully carved façade we see has no interior, that the dead that we are commanded to know remain forever out of reach-it is only through this process that we come to terms with the monument, and it is only through this encounter that the genre of the poem gains any real meaning. 


\title{
Pindar, Paean 6: Genre as Embodied Cultural Knowledge
}

\author{
Sarah Olsen*
}

By linking genre with occasion, scholars of Greek song invigorated the study of performance, ritual, and society in archaic and classical Greece. Recent attention to the reperformance of choral song has not diminished the importance of original performance context. Rather, studies of reperformance have consistently uncovered additional layers of meaning within individual songs, highlighting how the force of a song, a myth, or an image may shift in relation to different audiences and places of performance. ${ }^{1}$ In this chapter, however, I want to focus on what remains the same. How does an archaic choral song retain its fundamental generic quality across multiple occasions for performance? How might we preserve the insights gained from the "performance context" model of Greek song genre while also acknowledging the richness and complexity of reperformance? I will argue that understanding genre as a form of "embodied cultural knowledge" can explain how an archaic Greek choral song can be both an artifact of a specific performance occasion and a flexible expressive mode, adaptable to multiple situations and singers.

I owe the concept of "embodied cultural knowledge" to dance theorist Deirdre Sklar, whose observations I will discuss at greater length below. In essence, this phrase refers to the somatic and sensory experiences that an individual accrues in the course of living and moving within a particular societythe ways in which one's body both participates in and resists the process of acculturation. ${ }^{2}$ Given that the embodied presence and experience of both performers and audience members are a crucial element of Greek choral song as

* I am grateful to the editors of this volume, Meg Foster, Leslie Kurke, and Naomi Weiss, for their expert guidance and feedback in the preparation of this paper, and to all the participants in the 2015 conference on lyric genre at UC Berkeley, whose lively papers and stimulating questions have informed this work. Special thanks to Erin Lam for her insightful comments on an early draft of the project.

1 On performance context, occasion, and Greek song genre, see Bowie 1986; Nagy 1994-1995. On the reperformance of archaic choral song (especially Pindar) see, e.g., Currie 2004; Hubbard 2004; Kurke 2005; Morrison 2007, 2012; Athanassaki 2012.

2 Sklar 2008. 
an "occasional" phenomenon, I thus propose that genre was a form of embodied cultural knowledge for ancient Greeks. A married woman might remember what it felt like to perform as a young girl in a maiden chorus-nimble, active, perhaps filled with the simultaneous anticipation and anxiety of a particular performance and the major life transition it would facilitate. A frequent festival attendee could access the kinesthetic sensation-wearied limbs, the particular tilt of the climbing body — of approaching the steep shrine at Delphi. Terms like partheneion, prosodion, and paean—or related words and patterns of imagery-translate those visceral experiences into a common descriptive language. By the same token, an audience listening to the reperformance of a specific song-genre, even in a different setting and under different formal conditions, may be prompted to engage in sensorial memory of that genre as it would have originally been performed.

In this paper, I will focus on the paean, a notoriously difficult genre to define. Paeans have confounded categorization within the occasional model because of their apparent diversity and flexibility: while they were often performed by a chorus as part of religious festival, we also find evidence for paeans performed at symposia and in military contexts. ${ }^{3}$ In addition, a choral paean could be reperformed solo at a symposium, accomplishing the kind of shift in context and formal performance conditions that I am interested in exploring here. ${ }^{4}$ I will take Pindar's Paean 6 as my case study, though I intend my observations and claims to extend to Greek choral song in a broader sense as well. For that reason, I will begin by sketching out some salient features of choreia in general and Delphic paean specifically, drawing on the performance paradigm offered by the Homeric Hymn to Apollo. The Hymn offers one mythic account of the original paean performance at Delphi and demonstrates that choreia, as

3 For a thorough overview of the various performance contexts attested for the paean, see Rutherford 2001: $3^{-136 .}$

4 On the reperformance of paeans, see Rutherford 2001: 176, who posits three potential reperformance scenarios for Pindar's paeans: 1. repeated (presumably choral) performance in the same cult context as the original performance; 2. choral reperformance elsewhere; 3. performance at symposia (Rutherford gives as an example the performances of Simonides' mele referenced in Ar. Nub. 1355-1358, on which see also Nagy 1990: 107-108). On paeans at symposia more generally, Rutherford stresses the flexibility of the genre and suggests that a "symposium-paean" should not be considered categorically different from other forms, and that one kind (e.g., an apotropaic paean for Poseidon) could be reperformed at a symposium (2001: $\left.5^{-}-5^{2}\right)$. On the likely absence of dance when a choral paean is reperformed at symposia, see Rutherford 2001: 18. Athenian familiarity with Pindar's paeans is supported by the apparent intertextual relationship between Paean 9 and the parodos to Antigone, as discussed by Rutherford 2001: 199-200 and Budelmann 2013: 84. Sympotic reperformance would be the most likely scenario for preserving and disseminating that knowledge. 
an expressive and embodied ritual mode, creates a delicate balance between divine authority and the flexibility of individual experience. This is consistent with Sklar's conceptualization of embodied cultural knowledge, and at the end of my discussion of the Homeric Hymn, I will reflect further on the ramifications of her model for our understanding of Greek performance in general. I will then turn to Paean 6, first outlining the various possibilities for the performance and reperformance of this song and then zooming in on sympotic performance in particular, in order to illuminate how Paean 6 preserves and engages embodied choral experience even when reperformed in a sympotic setting. I will ultimately argue that Pindar uses the imagery of embodiment to allude to the invention of the paean itself, thereby reinstantiating the genre at each occasion of performance and drawing upon the audience's embodied knowledge in order to create generic continuity across differing performance contexts.

\section{Embodying the Divine: Paeanic Choreia at Delphi in the Homeric Hymn to Apollo}

The dynamics of embodiment at work in paeanic choreia in Paean 6 are largely consistent with the elements of choral performance as depicted elsewhere in early Greek literature, but one parallel is particularly illuminating: the representation of paeanic procession in the Homeric Hymn to Apollo. ${ }^{5}$ The final part of the Hymn to Apollo chronicles the god's arrival at Delphi and installation of a crew of Cretan sailors as his priests. This portion of the hymn also offers one account of the very first performance of paeans at Delphi, and as such, provides an illuminating intertext for Pindar's paean. In particular, the Hymn to Apollo emphasizes the god's power over the bodies of his followers, a potent vision of divine authority. At the same time, the Hymn stresses the preservation of individual autonomy and local ties within the larger confines of the chorus. It thereby sets out a reassuring ritual model for the performance of paeans at Delphi.

On one level, Apollo's treatment of the Cretan sailors in the Homeric Hymn is brutal. By steering them to Krisa, a port town close to Delphi, the god rup-

5 On the conceptualization of choreia in archaic and classical Greece, especially as a ritual and social institution, see Stehle 1997: 17-25; Kowalzig 2007b: 43-55; Kurke 2013a; Peponi 2013a. I understand the Homeric Hymn to Apollo as a paradigm of performance likely to be familiar to a range of audiences in the late archaic and classical periods (on the Hymn as a performance paradigm, see especially Lonsdale 1995). 
tures the men's ties to their homes and families. When the leader of the men addresses Apollo, he stresses their own lack of will. He claims, "we came here,

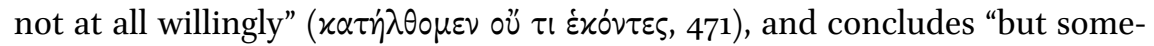
one of the immortals led us here, though we did not will it" ( $\dot{\lambda} \lambda \dot{\alpha} \tau \tau \varsigma \dot{\alpha} \theta \alpha \nu \alpha \dot{\alpha} \tau \nu$

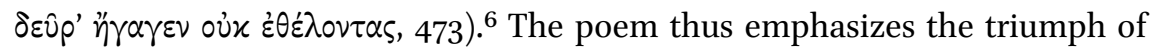
divine will over human intention, reminding its audience that men have no power to alter the plans of the gods. The Cretan leader also mentions his men's original plans, further highlighting Apollo's disruption of their lives. The man says, "for we were sailing the great sea, with another intention in mind, / to [go to] Pylos from Crete, where we claim our family (genos) is from" ( $\alpha \lambda \lambda \eta \eta \dot{\eta} \dot{\alpha}$

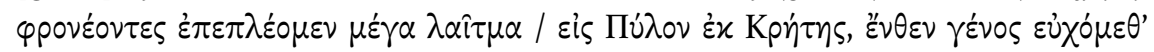
हival, 469-470). Even as he states their intended goal, the leader simultaneously emphasizes his men's origins. He reminds the god and the audience that

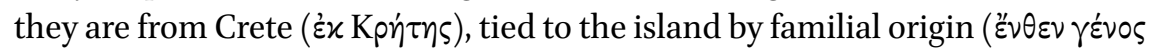

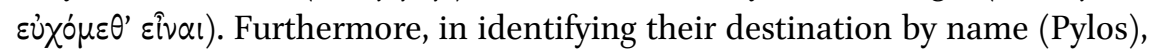
he contrasts it with their actual location (Krisa), a place unknown to them and unnamed. Apollo has interrupted a journey from familiar and familial territory to a known destination. His transportation of the Cretans to a place unknown and insignificant to them represents an ultimately permanent break from their local and personal priorities. It is no surprise, then, that the leader of the men interrogates Apollo, asking, "what people, what land is this? Which

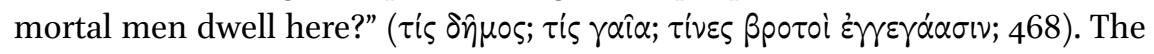
Cretans are disoriented, having arrived in an unfamiliar place. They have lost their bearings and must ask Apollo for even the most basic information about Krisa.

Apollo then informs the men that their affiliation with Knossos has ended, that their homes and wives are now lost to them:

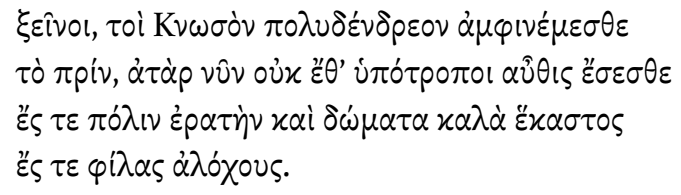

Strangers, you inhabited Knossos, thick with trees, previously, but now you will not return again

6 Translations, where not otherwise indicated, are my own. I have used Allen's (1912) text of the Homeric Hymn to Apollo. 
to the lovely city, and each to your fine halls and dear wives.

$$
475^{-478}
$$

The god acknowledges the men's affection for their homeland, remarking on

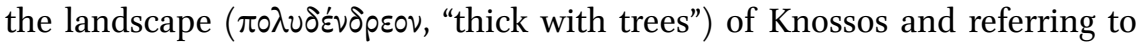

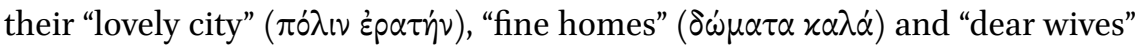
( $\varphi$ i $\lambda \alpha \varsigma \alpha \lambda{ }^{\prime}$ ó ovs). Yet even as he reminds the audience of the Cretans' connection to their homeland, he permanently severs those very ties. He emphasizes that their habitation of Knossos was "previous" ( $\tau \dot{0} \pi \rho i v)$, and that "they will not

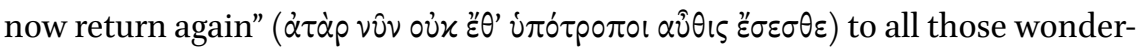
ful things.

If lines 388-485 were all that remained of the Homeric Hymn to Apollo, Delphi might seem a rather forbidding place. In this episode, Apollo presents himself as a god ready to disrupt local and personal ties and prevent his followers from returning home again. The foundation myth itself-Apollo's claim to Delphi and his importation of the Cretan sailors-is relentlessly focused on the needs of the god and his panhellenic shrine. How can such a totalizing account be reconciled with the likely realities of Apolline worship at Delphi? As Paean 6 itself demonstrates, Delphi would have had to accommodate worshippers from a variety of geographic locations and subgroup affiliations, the vast majority of whom would not, like the Cretan sailors in the Homeric Hymn to Apollo, remain permanently at Delphi as Apollo's priests. ${ }^{7}$ Rather, they would hope and plan to return home safely to their own towns or cities.

The representation of ritual procession in the Homeric Hymn ameliorates the complete rupture of the local and the personal accomplished by Apollo's initial relocation of the Cretan sailors. The poem thus offers a model of such ritual that supports and maintains local and personal identity while still emphasizing the ultimate authority of the god.

After informing the men of their permanent resettlement, Apollo gives them a set of specific instructions for prayer, sacrifice, feast, libations, and, finally, a musical procession to Delphi itself (487-501). The Cretans follow Apollo's instructions. Yet, after the procession has taken place, the leader of the Cretans again questions Apollo, emphasizing his local and personal affiliations just as he did in his first address to the god, prior to participation in the ordained ritual

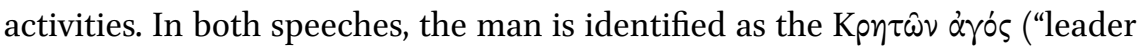

7 On the likely original performance context of Paean 6, see Kurke 2005. On the performance of paeans at Delphi in general, see Rutherford 2001: 24-29. 
of the Cretans," 463 and 525). When the man first speaks, this label seems natural enough - he is the preeminent figure among a group of men originating on the island of Crete. Yet by the time he speaks again, Apollo has informed the men that they will never return to Knossos, effectively stripping them of their local affiliations. The persistence of this marker of personal and local identity

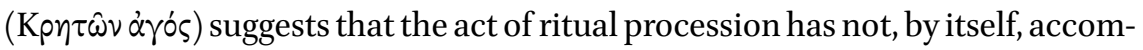
plished Apollo's goals. The man continues to be the leader of the Cretans, not yet a Delphic priest.

The poem also creates distinct spheres of leadership for both the Cretan man and the god himself. The leader of the Cretans is persistently referred to as such

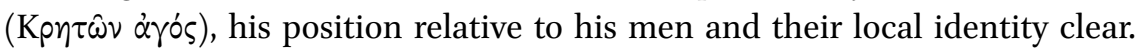
Yet while the noun àós marks the man, Apollo is repeatedly characterized by forms of the verb $\alpha \gamma \omega$. The Cretans acknowledge that the god "had led them

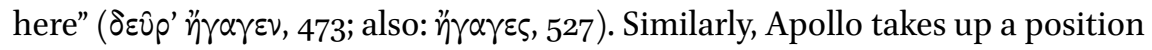
of leadership in the procession:

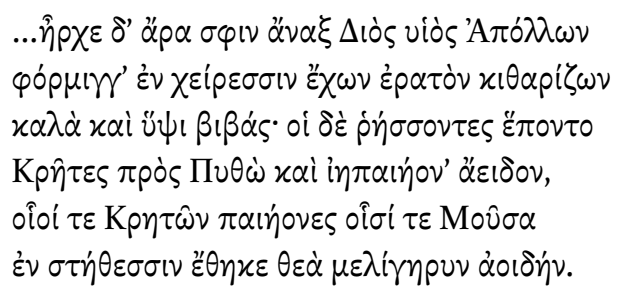

And the lord Apollo, the son of Zeus, began for them, having in his hands a lovely lyre, strumming well and stepping high. And the Cretans followed, stamping their feet, toward Pytho and they were singing a paean, and they were like paeans ${ }^{8}$ of the Cretans, even those for whom the Muse, the goddess, placed sweet song in their breasts. 514-519

While the verb $\ddot{\alpha} \gamma \omega$ does not appear in this description, the word $\hat{\eta} p \chi \varepsilon$ has a similar force, as Apollo "begins," or leads off, the procession. ${ }^{9}$ Apollo's leadership, in this episode, is primarily spatial. In the form of a dolphin, he leads the

8 Or, "like the paean-singers"; see Rutherford 2001: 74; Richardson 2010: 148.

9 For $\dot{\xi} \xi \dot{\alpha} \rho \chi \omega$ and related verbal forms as terms for choral leadership, see Archil. fr. 12oW, [Hes.] Sc. 205-206; Homeric Hymn to Artemis 14-18; Pind. Nem. 2.25. 
men to Krisa. As a god, he leads them in musical procession to the sanctuary itself. The Cretan leader, however, retains a kind of political leadership defined by his relationship to his group.

As the passage above also indicates, the ritual accommodates specifically Cretan modes of expression. The men sing paeans to Apollo in the mode typical of their homeland, expressing themselves as Cretans even as they process to their new and permanent home (517-519). The paean itself thus represents both the authority of the god and the preservation of local modes of expression within a choral context. This is consistent with Catherine Bell's conceptualization of "ritualization," a framework for understanding choreia that has been particularly fruitful in the study of archaic and classical Greek performance. ${ }^{10}$

Bell identifies two major dimensions of ritualization. The first, she argues, is the "projection and embodiment of a structured environment," accomplished by "ritualized agents," i.e., participants. ${ }^{11}$ These ritualized agents, however, "do not see themselves as projecting schemes; they see themselves only as acting in a socially instinctive response to how things are."12 I would argue that the procession to Delphi, both as depicted in the Homeric Hymn to Apollo and in a more general conceptual sense, clearly and visibly embodies a specifically structured worldview. The movement of a procession delineates a relationship between center and periphery, as the processional group moves from the margins to the center, or, occasionally, vice-versa. ${ }^{13}$ The participants use their own bodies and movements to display and enact a specific spatial relationship.

In the Homeric Hymn, the Cretan sailors' organized movement towards Delphi emphasizes the site's position as the omphalos, the center of the Greek world. We will see that this spatial organization is highlighted in Paean 6 as well, for that song opens by mentioning landmarks near the entrance of the shrine

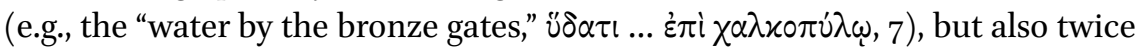

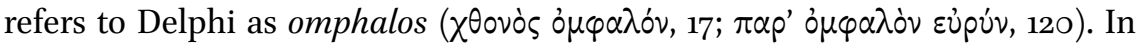
the Hymn, Apollo's position at the head of the procession symbolically asserts his role as the agos, or leader. As Bell suggests, the Cretan men act in basically socially instinctive ways- they obey Apollo's commands, and, in a very prac-

\footnotetext{
10 On the utility of Bell's model for the study of ancient Greek ritual practices, especially choreia, see Kurke 2005; Kowalzig 2007b: 32-43; Mackil 2013: 152-156; Olsen 2015.

11 Bell 1992: 207.

12 Bell 1992: 208.

13 Procession from a polis to a rural shrine is an example of the latter: see de Polignac 1984, esp. 101-108, for conceptual analysis of processional routes generally. For related readings of poetic representations of processions, see Dougherty 1994; Connor 2000.
} 
tical sense, they follow him to Delphi because he is the only one who knows where he is. But their actions project and embody a specific sense of social and cosmic order.

Bell, however, also identifies a second key dimension of ritualization. She contends that "a participant, as a ritualized agent and social body, naturally brings to such activities a self-constituting history that is a patchwork of compliance, resistance, misunderstanding, and redemptive personal appropriation of the hegemonic order."14 She thus asserts that an individual's experience as a participant in a ritual practice is actually far more complicated than the apparent projection of a particular cosmic scheme. Bell makes the related observation that "ritualized practices, of necessity, require the external consent of participants while simultaneously tolerating a fair degree of internal resistance."15 This second aspect of ritualization helps articulate how the model constructed by the Homeric Hymn to Apollo is able to leave space for the personal and the local even within the larger framework of divine, choral worship.

As we have seen, Apollo's transformation of the Cretan sailors into Delphic priests is a powerful act of divine authority. By interrupting the men in the midst of their journey, Apollo displaces their personal agency in favor of a migration accompanied by significant political and religious symbolism. By participating in a ritual that symbolically affirms Apollo's leadership and the centrality of Delphi, the Cretans do exactly what Bell suggests when she says that "specific relations of domination and subordination are generated and orchestrated by the participants themselves simply by participating."16 But Bell also remarks that ritual participants bring their own "self-constituting histories," their own patterns of both "compliance and resistance," to their ritualized practice. ${ }^{17}$ This is what happens when the Cretan sailors incorporate their local

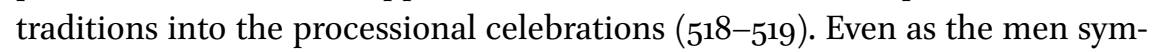
bolically affirm Delphi's centrality and Apollo's authority, they also maintain certain elements of their local affiliations and identities. A striking moment of temporal confusion in the narrative may even be read as part of this strategy. On the one hand, Apollo has just established his shrine at Delphi, and so this procession constitutes the first performance of a paean in honor of Apollo at this site. Yet the Hymn also describes the processional song as "like the paeans

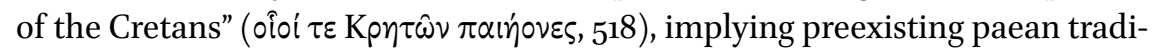
tions on Crete. Paeanic invention and innovation is thus ascribed to both the

\footnotetext{
14 Bell 1992: 208.

15 Bell 1992: 221.

16 Bell 1992: 208.

17 Bell 1992: 208.
} 
Cretans and Apollo, another way in which the Hymn presents choreia as a delicate balancing act, a ritual practice that symbolically affirms certain notions of cosmic and social order while simultaneously maintaining "the autonomy of individuals [and] subgroups."18

Bell's model of ritualization is consistent with Sklar's understanding of kinesthesia as embodied cultural knowledge. Specifically, Sklar explores how embodied sensory perception figures into the experience of memory. ${ }^{19}$ She suggests that our memories of embodied experiences-like dance or performance-are not pure or unmediated. Rather, different people "access memory via different sensory modalities," and one can often access or experience memory via one mode, but represent or describe it in another. ${ }^{20}$ For Sklar, the distinction between an individual's personal experience of embodied remembrance and the often-verbal representation thereof is crucial. The former is generally more visceral and kinesthetic, whereas the latter is heavily conditioned by cultural hierarchies of sense perception-for example, in much of western culture, an emphasis on the primacy of vision and visual metaphor. ${ }^{21}$ Sklar argues that kinesthesia, the sensation of one's own bodily presence, tension, and movement, constitutes an important form of cultural knowledge. ${ }^{22}$ Significantly, she suggests that embodied recollection and perception constitute an intimate and individual kind of knowledge, forming experiences that can both conform to and resist dominant ideological narratives. ${ }^{23}$

Sklar's conception of embodied remembrance may be understood as one form of the "self-constituting" personal history that a participant, in Bell's

18 Bell 1992: 222.

19 E.g., Sklar recounts a teaching anecdote (meditative remembering of an incident related to dance), which concludes with her asking students: "What was your dominant mode of remembering? What sensory modality emerged to trigger memory? Sound, like music or words in your mind's ears? A visual image of a setting or of yourself moving? A kinesthetic sensation of movement or of a particular dynamic of movement? And which sense was easiest to fill out once you tried to retrieve the event in detail?" (2008: 86).

20 "Richard Bandler and John Grinder ... have shown that different people access memory via different sensory modalities. Further, the sensory mode by which an individual accesses a memory is often different from the one in which he or she represents the memory" (Sklar 2008: 86).

21 Sklar specifically suggests kinesthesia "has been entirely omitted from the western sensorium" (2008: 87). For recent approaches to sense perception and hierarchies thereof in the ancient world, see, e.g., Porter 2010; Peponi 2012; Butler and Purves 2013; Bradley 2014; Squire 2015 .

22 Sklar 2008.

23 See especially Sklar 2008: 91. On this point, see also Noland, who characterizes gesture as a vital site for both the "embodiment" and "testing" of "cultural conditioning" (2009:2). 
model, can bring to ritual observance. The Cretan men outwardly embody the divine authority of Apollo, as their procession points toward his shrine and makes visible his performative leadership. Yet they remain linked with their community of origin through the political organization of their group under their established agos and the Cretan quality of their paean. Moreover, the Hymn links the local with the personal. The men's ties to Crete are expressed specifically in terms of their "fine homes" ( $\delta \omega \mu \alpha \tau \alpha \kappa \alpha \lambda \dot{\alpha}, 477)$ and

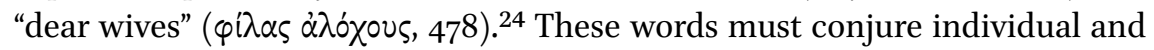
varied memories-each man surely possesses his own home, his own wife. Likewise, we might imagine that each man experiences the paean in his own personal way: just as ritual choreia accommodates both divine panhellenism and local performance idiom, so too may it allow for individual variations within a shared experience. "Paean," like "home" or "wife," is a term that can encompass both common and personal meaning. Moreover, Sklar's analysis suggests that it is a conscious and active engagement with embodied experience that enables the process of "personal appropriation" described by Bell. ${ }^{25}$ The Homeric Hymn to Apollo shows that paeanic choreia has the potential to facilitate that kind of ritual balancing act, but as hexameter solo song, its representation remains paradigmatic rather than actively engaged with immediate experience. In the second part of this paper, I will trace patterns of sensory and kinesthetic engagement in an actual paean, demonstrating how the interplay of personal and communal serves to define generic experience within the parameters of live performance.

\section{Embodying the Paean: The Dynamics of Pindar, Paean 6}

As I demonstrated above, the Homeric Hymn to Apollo offers a paradigm for paeanic choreia as a form of communal, embodied worship that leaves space for personal experience and appropriation. Pindar's sixth paean puts that model into practice in the service of preserving communal chorality and its embodied essence across diverse contexts for performance. To develop this claim, I will first comment briefly on the transmission and performance history of Paean 6, then turn to a close reading of the song that attends specifically to issues of sense perception, somatic experience, and the generic construction of the paean.

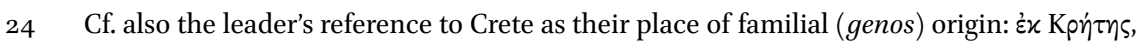

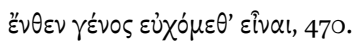

25 Sklar 2008: 91, cf. n. 16; Bell 1992: 208. 


\section{Performance and Reperformance: The Possibilities for Paean 6}

Paean 6 is a particularly good candidate for the analysis of performance dynamics due to the debate surrounding its original conditions of performance and its unusual transmission history. In order to avoid devoting too much time to a survey of these issues, I will begin by noting that I concur with Ian Rutherford's hypothesis, taken up in greater detail by Leslie Kurke, that the original performance of this paean may have been split between a Delphian chorus, performing the first two triads, and an Aeginetan one, performing the final triad. ${ }^{26}$ This scenario resolves several problems pertaining to this song, including the double transmission of the third triad: in the papyri, we find both the "full" paean (three triads) as well as the third triad alone, apparently as a prosodion, or processional song. ${ }^{27}$

There are also multiple possibilities for the reperformance of Paean 6. First, it is likely that the third triad alone was reperformed as a choral song (and perhaps also as sympotic, solo song) on Aegina by Aeginetans. ${ }^{28}$ Second, the entire song could have been reperformed, either by a chorus or at a symposium, in any number of locations. And third, I will suggest here that the first two triads alone could plausibly function as a sympotic paean in their own right. In fact, the omission of the third triad removes the most explicit references to the original Aeginetan theoria, thereby creating a song that evokes paeanic, Apollonian performance in a general sense and enables the singer to sidestep thorny questions of Aeginetan politics and affiliation. To be sure, we do not find

$26 \quad$ Rutherford 2001: 337-338; Kurke 2005.

$27 \quad$ POxy. 841 has all three triads, with the marginal title (discovered and discussed by Rutherford 1997) identifying the third triad as a prosodion -in a sense, therefore, we do not have a version of the paean that actually presents the song as a single cohesive whole. POxy. 1792 has just the third triad, with a different colometry: D'Alessio 1997 argues that this is a volume of prosodia. Recent discussions (with earlier bibliography) include Rutherford 2001: 333-338; Currie 2005: 322-325; Kurke 2005.

28 See Kurke 2005: 119-124 for one scenario, closely connected with the sacred landscape of Aegina. On the ideological force of such reperformance (not necessarily exclusive of Kurke's approach), see Fearn: "yet the separate transmission of the closing section of Paean 6 as an Aeginetan prosodion might also be a sign that original theoric thrust of the paean was capable of redirection for epichoric effect by Aeginetan elite administration, through separate and repeated subsequent performances. The reference to the excellence of righteous networking', $\tau \dot{\alpha} \nu \theta \varepsilon \mu$ ' $\xi \varepsilon v 0 \nu \dot{\alpha} \rho \varepsilon \tau[\dot{\alpha} \nu$, at line 131 in the prosodion section emphasizes the theoric impact of the Delphic paean, but through re-performance, could serve separately, though in a subtle way, to celebrate the current Aeginetan theoric administrators as organizers of the ongoing tradition of ritual pilgrimage" (2011a: 203). 
the first two triads transmitted independently. But the fact that the third was apparently seen as "detachable" suggests that the first two could also comprise a proper song in their own right. I will discuss below how the internal logic of the song supports this hypothesis, and my reading here will be limited to the first two triads as a complete sympotic song. ${ }^{29}$ I will begin, however, with a consideration of the sensory and somatic imagery of the first triad of Paean 6 , exploring how the song works to activate the embodied memories of its listeners.

\section{Song and Sense Perception}

In this section, I will be looking closely at the ways in which Pindar's Paean 6 , as reperformed at a symposium, rekindles somatic memories of choral performance in its audience. First, however, I want to comment briefly on the distinctions I am drawing between the poet, the speaking ego of the song, and the sympotic singer. Kurke has examined the unique qualities of this paean's ego in its choral context, arguing that the first triad in particular serves to establish the speaker as an "authoritative outsider" — distinct from the chorus — who effectively mediates between the various groups involved in the ritual performance of the song. ${ }^{30}$ On one level, even when relocated from Delphi to a symposium elsewhere, the characterization of the speaking voice retains this role. But the distinctiveness of this paean's speaking voice also facilitates the transition from Delphi to such sympotic contexts. As Kurke notes, the speaking ego is positioned outside of the Delphian chorus, as a figure possessed of his own independent mantic authority and "honors" $(\tau \mu[\alpha] \hat{\imath} \varsigma, 11) .{ }^{31}$ Yet his relationship to the Delphian chorus is also positive, consolidated via the imagery of reciprocal kinship ( $\tilde{\varepsilon} \tau \alpha \iota \varsigma, 10)$. A solo singer can thus seamlessly take up this song (at least in its first triad), adopting a fictive position as the singular internal speaker who is nevertheless figured in positive relation to the larger (now also fictive) chorus.

Beginning with the first triad of Paean 6, let us now consider how it operates, not as choral song with a prominent, poetic ego, but as the address of a sympotic singer to his immediate comrades. Since the song does not lose its strong

29 I do not mean to suggest that this is the only configuration of the song available for sympotic reperformance, merely that this is the version I have chosen to focus on as my "case study" for this paper.

3о Kurke 2005, esp. 104-119.

31 Kurke 2005: 104-105. 
sense of place, time, and occasion, I want to suggest that it creates a fictional space wherein the singer presents himself as authoritative speaker, enabling the audience to imagine themselves as choral performers.

It is plausible that sympotic audience members would be inclined to imagine themselves as choreuts, since Greek men of the late archaic and early classical periods had many opportunities to watch and perform choreia. Paeans in particular were performed at major festivals as well as more intimate sympotic settings. ${ }^{32}$ I suggested above that choral performance modes constituted a kind of "embodied cultural knowledge" for ancient Greeks—experiences that could be-and certainly were-spoken about and described at length, but would also have been viscerally, kinesthetically "known." In a sympotic context, the rich sensory imagery of the first triad of Paean 6 serves to cue the audience's embodied remembrance of their own past performance experiences, including but not limited to paeanic ones, thereby drawing them into a particular relationship with the song itself. ${ }^{33}$

The speaking voice of the song first locates his appeal to the gods within "holy time" ( $\left.\dot{\varepsilon} \nu \zeta \alpha \theta \dot{\varepsilon} \omega \ldots \chi \chi \chi^{\prime}{ }^{\prime} \nu \omega, 5\right) .{ }^{34}$ This recalls, for the audience, the special temporality of ritual performance - the time set apart from ordinary life for the express purpose of worship and celebration. ${ }^{35}$ The speaker then remarks that "having heard, by the water from the bronze gates, the murmur of the Kastalian

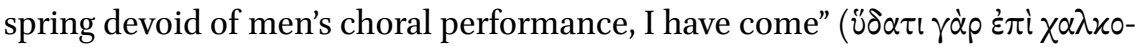

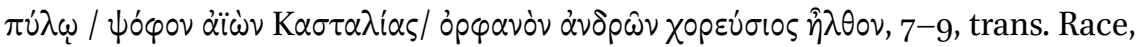
modified). The listening symposiasts are relocated to the entrance of the sanctuary at Delphi, prompted to imagine the specific features of architecture and landscape - bronze gates, murmuring spring of Kastalia — that they have pre-

32 See Rutherford 2001: $23-83$ for an overview of paeanic performance contexts and configurations. I focus here on elite listeners with personal experience of choral paean-the audience most explicitly addressed by this song. But a study of the possible effects of such songs upon other audiences present at a symposium (servants, slaves, hired entertainers) would be another desirable (if largely speculative) project.

33 See Eckerman 2014 for the analysis of a similarly sensory evocation of space and place in Pindar's Pythian 6.

34 I use Rutherford's (2001) text of Paean 6. Longer translations are by Race (1997), occasionally modified.

35 E.g., Kurke suggests that "we can see the elaborate form and production of choral song and dance as precisely a means of 'making special the everyday' - a cultural practice that marks off and differentiates a particular space and time from the ordinary, while it serves to form and reproduce ritualized bodies in action" (2005: 84). Cf. also Kowalzig, who observes that "the ability to transcend time is not only a feature of ritual, but one of its strategies" (2007b: 41). 
sumably seen and heard during their own trips to the shrine. ${ }^{36}$ The song thus engages the listener's visual and aural memory of the approach to the sanctuary.

While Pindar's chosen word for "sound"— - ó $\varphi \circ$, line 8-may be used for a fairly wide range of noises, two distinctive uses are relevant here. On the one hand, it has clear musical connotations. Sappho, for example, describes the psophos of castanets that accompanies the song of maidens in a wedding procession for Hector and Andromache (fr. 44.24-26). Euripides, in Bacchae, refers to the "psophos of the Lydian lotos-pipe," and in Cyclops, mentions the "psophos of the Asian kithara." ${ }^{37}$ At the same time, it is also used pejoratively to refer to weak, ineffective, or "empty" noise. In Euripides' Heracles, for example, Amphitryon laments that he has become "nothing but the psophos of the tongue" (

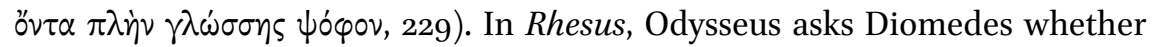

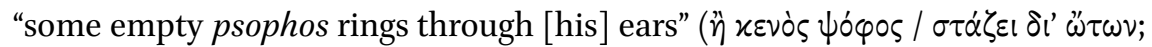
565-566). In Paean 6, the reference to the psophos of the Kastalian spring may thus endow the gurgling water with its own latent musicality. But linked fur-

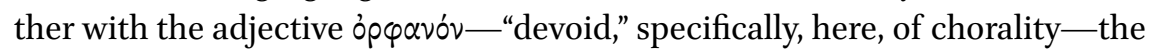
sound of the spring is subordinated to the superior musicality of the coming choreia. The language of the song turns the audience's attention to sound in general while simultaneously reinforcing the preeminence of choral song and dance. The song's first ten lines thus employ visual and aural imagery in order to recreate for the audience the experience of heightened sensation that accrues in the moments of performance.

Paean 6 now pivots to a vivid image of another, projected chorus, as the speaker explains:

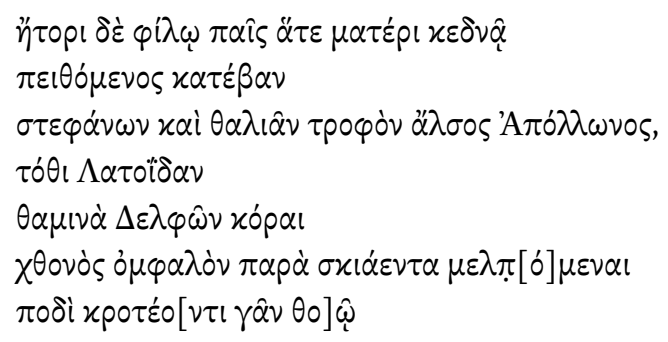

for in heeding my own heart, as a child obeys his dear mother, I have come

$3^{6} \quad$ On this imagery, see also Eckerman 2014: $36-37$.

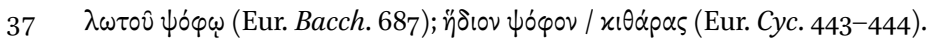


to Apollo's precinct, nurse of crowns and feasts, where the maidens of Delphi often sing to Leto's son at the shady navel of the earth and beat the ground with a rapid foot.

$12-18$, trans. RACE

These lines continue the pattern of attention to sensory perception, prompting their audience to recall their own embodied experiences of Delphic festivitycool shade (17), the combined sonic-and-visual experience of choreia (18). Even if the paean is not specifically invoked, the Delphic setting and references to Apollo gesture toward the genre.

But these lines also feature distinctly feminine focalization, as they thrice appeal to female roles and maternal-feminine descriptive terms. As Eva Stehle has noted, "images of nurture prevail." 38 The speaker first figures himself as a "child" obedient to his "dear mother" (12). He then describes Apollo's sanctuary as the "nurse" (14) of crowns and feasts. And while he initially refers to the god by his own proper name ('A $\pi \dot{0} \lambda \omega \omega \nu \circ \varsigma, 14)$, he follows this with an immediate reference to the god via his matronymic $-\Lambda \alpha \tau \sigma^{i} \delta 0 \alpha v$, "son of Leto" (15). This turn to the feminine strengthens the parallel between the described chorus of maidens ( $x^{\prime}$ pal, 16) and the original chorus of Paean 6 itself, both of whom sing and dance for Apollo at Delphi. By invoking a series of feminine descriptors in the lines preceding the description of the girls' chorus, the singers of Paean 6 are placed in a close, empathetic relationship with these projected female performers-singing, for the space of these few lines, in a notably femaleoriented mode.

The song also encourages its performers and listeners to imagine their viewing of the Delphian korai as a thoroughly embodied experience. The girls are

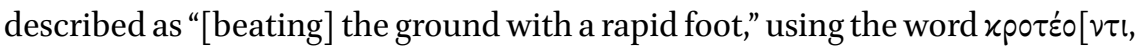

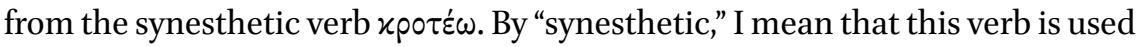
to denote both sound (a rattling or beating noise) and motion (the action of rattling or beating). It thus prompts the listener to imagine, simultaneously, the sound of the dance and the motion of the bodies in performance-again,

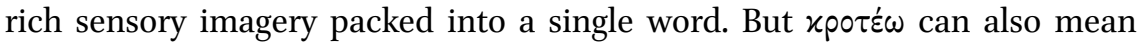
"to applaud."39 It thus effects a kind of collapse between the performers and

38 Stehle 1997: 142.

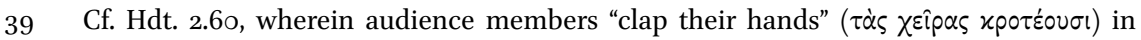
response to a musical performance. 
the audience - casting the motion of the dancing foot ( $\varkappa p \circ \tau \varepsilon \dot{\varepsilon} \omega)$ as analogous to

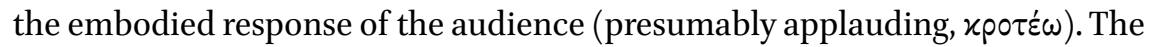
description encourages its performers and listeners to imagine a shared experience of embodied or kinesthetic empathy, whether in the actual moment of performance or in the recollection, prompted perhaps by the reperformance of this song, of prior experiences of spectatorship. ${ }^{40}$

The next thirty lines of the song are missing. But sensory imagery resurfaces in the surviving eleven lines of the triad, wherein the speaker "longs [perhaps to

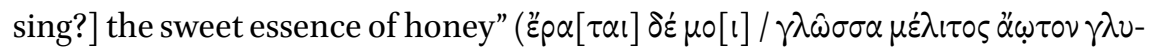
xúv, 58-59) — vividly evoking taste, possibly combined in a synesthetic image of taste, vocalization, and sound. The references to the "virgin Muses" ( $\pi \alpha p-$

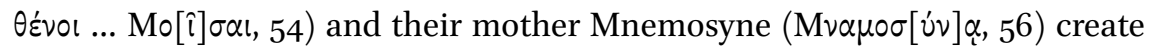
a kind of ring composition when combined with the song's opening invoca-

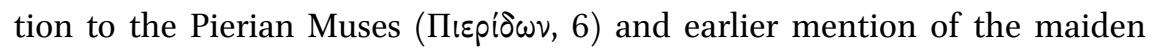
performers of Delphi (16-17). The naming of Mnemosyne, or Memory, may further act as a kind of metacommentary on the work of recollection that the song encourages in its listeners. Given this return to multisensory imagery, we might reasonably posit that the theme persisted throughout this portion of the song.

The first triad of Paean 6 thus engages the embodied memory of the audience on multiple levels, reminding them of what it feels like to watch and perform choreia at Delphi. The abundant references to Apollo and Delphi point to the paean and may well have primed the audience to situate their embodied recollections within the framework of that specific genre. Yet many of the features that I have discussed here are characteristic of Greek choral performance broadly, not the paean in particular. The performers are invited to feel empathy with maiden song (lines 12-18), and at least in the extant text, there is no characteristic paean-cry (ie paian). This song, in a reperformance context, thus relies upon shared cultural knowledge of choreia and its sensory experience, as well as a general knowledge of Delphic topography, but it does not yet insist that the listener focus specifically on the experience of the paean. This changes, however, in the second triad, which chronicles Apollo's conflict with Achilles and Neoptolemus and builds toward the explicit invocation of the paean and its characteristic refrain. 


\section{Divine Action, Mortal Bodies}

The early, fragmentary portion of the second triad addresses events from the Trojan War. While the state of the papyrus prevents us from fully restoring the text, there is a reference to Apollo, "the far-shooter," acting "in the mortal

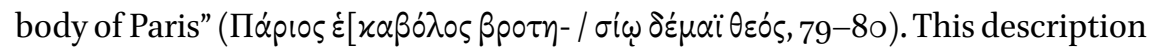
stresses that Paris retains his corporeality ( $\delta \varepsilon \dot{\varepsilon} \mu i i)$, but his agency is transferred to Apollo. This is significant because it is consistent with the somatic experience of choral performance as generally conceptualized in ancient Greecehuman bodies move and dance, but their choreographed action is conceived as intimately linked with divine will. ${ }^{41}$ Likewise, in the final episode of the triad, the song claims that Apollo killed Neoptolemus at Delphi $\left(\varkappa \tau \alpha \dot{\alpha} v \varepsilon \nu /\langle\dot{\varepsilon} \nu\rangle \tau \varepsilon \mu \varepsilon^{\prime}\right] \nu \varepsilon i ̈$ $\varphi(\lambda \omega, 119-120)$, although a version of the same myth in Pindar's Nemean 7 features a mortal man as the killer of Neoptolemus. ${ }^{42}$ As Rutherford observes, the discrepancy is minimized if we understand Apollo as capable of acting via the bodies of his followers. ${ }^{43}$ The song's assumption of continuity between the body of the god and the bodies of mortals has particular relevance for the study of ritual performance.

As we saw in the Homeric Hymn to Apollo, the choral performance of paean may be conceived as a way of granting the god ultimate authority over the bodies of his followers - the ability to direct and organize their movements in order to project a particular image of divine order. At the same time, performers may retain important markers of individual and local identity. Likewise, the imagery of the first triad of Paean 6 encourages the communal appreciation of choreia and embeds its listeners within the performance landscape of Delphi. But its attention to sensory experience (cool shade, the sensation of the foot striking the earth) also prompts listeners to turn inward, toward the recollection of personal kinesthetic experience. The second triad continues in the same vein by highlighting the complex relationship between divine authority and human bodies, as when Apollo acts "in the mortal body" of Paris $(79-80)$. As in the Homeric Hymn to Apollo, the god exercises control over a man's body without entirely usurping his personal identity. The comparison I have drawn with the Homeric Hymn to Apollo was intended to highlight how choreia in general, and the paean in particular, maintain a balance between individual and local iden-

\footnotetext{
41 See especially Kurke 2013 a.

42 On the relationship between Nemean 7 and Paean 6 (both contra the notion that Nemean 7 is an "apology" for Paean 6), see Burnett 1998: 504-514; Currie 2005: 315, 321-331.

43 Rutherford 2001: 314.
} 
tities and the articulation of divine authority through communal action. I have now traced how Paean 6 gestures in a similar direction through the sensory imagery of the first triad and the relationship between the god and the mortal body mentioned at the beginning of the second. I will now contrast those patterns with the negative depiction of Neoptolemus in the later portion of the second triad of Paean 6.

\section{A Transgressive Leap: Neoptolemus and Apollo}

Paean 6 alleges that Apollo denied Neoptolemus a safe homecoming because "he killed aged Priam, who had leapt up on the altar of Zeus Herkeios" ( $\gamma \varepsilon \hat{\varepsilon}[$ pov $] \theta^{\prime}$

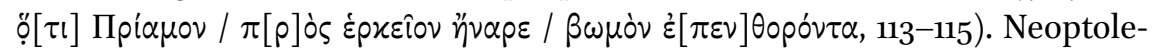
mus' fatal transgression is thus aligned with his active physical pursuit of Priam, who, despite being "aged" ( $\gamma^{\varepsilon}\left[\right.$ pov] $\theta^{\prime}, 113$ ), is described as "having leapt"

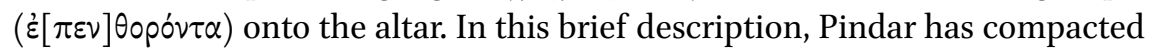
a rich tradition surrounding Neoptolemus' actions at both Troy and Delphi.

The sources I am about to discuss mostly postdate Pindar's sixth paean. But given the commonalities among them, I would posit that they all draw upon an early tradition - likely part of the epic cycle. For example, both Neoptolemus and his father Achilles are frequently associated with leaping and even dancing - in Neoptolemus' case, usually in a negative, destructive, or transgressive way. Archilochus reports that Pyrrhus (an alternate name for Neop-

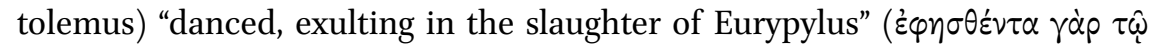

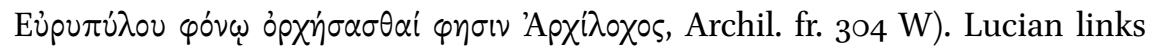
Neoptolemus' skill in armed dance with his prowess in battle, and remarks that "while Troy had been, until that point, impregnable, his dancing destroyed it

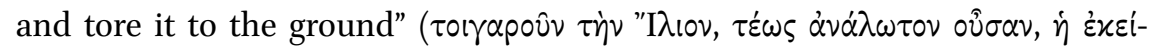

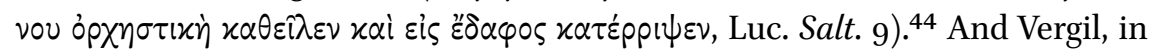
his account of Priam's death, stresses that Neoptolemus deliberately dragged (traxit, 551) Priam to the altar to kill him, a stunning act of violence and transgression of Greek social norms. ${ }^{45}$ Neoptolemus is thus associated with inappropriate kinds of movement: dancing in celebration of slaughter and killing within the sanctuary of a god.

44 See Borthwick 1967 for many other relevant parallels.

45 Verg. Aen. 2.550-551 (hoc dicens altaria ad ipsa trementem / traxit et in multo lapsantem sanguine nati). On the death of Priam in Greek art, see Anderson 1997 passim (with discussion of Homer and the epic cycle as well); Hedreen 2001: 64-9o. On the depiction of Neoptolemus' murder of Priam as an act of sacrilege, see Miller 1993: 452; Rehm 2002: 247-248. 
In Paean 6, Neoptolemus murders Priam on the altar of Zeus at Troy (113115), and Apollo retaliates by slaying Neoptolemus at Delphi (119-120). Given the association of Neoptolemus with jumping, leaping, and dancing, it is tempting to read the unlikely description of the elderly Priam "having leapt" ( $(\dot{\varepsilon}[\pi \varepsilon v]-$

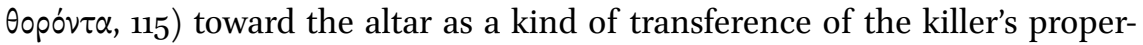
ties onto the victim. The description underscores Neoptolemus' transgressive movement and action, striding into the sacred space of Troy and slaying its king upon the altar. Euripides, in Andromache, describes Neoptolemus similarly leaping and fighting at the altar at Delphi (1135-1140), immediately prior to his death.

By highlighting the inappropriate action of Neoptolemus at the altar of Zeus at Troy, the chorus of Paean 6 calls attention to its own proper movement within the divine space of Apollo at Delphi. A subsequent sympotic audience is thereby encouraged to consider its own corporeal allegiance, and ideally engage in an embodied, kinesthetic remembrance of correct ritual performance. Through their bodies and actions, paean-performers and followers of Apollo manifest the authority of the god while still retaining their individual identities and personal experiences. Neoptolemus, by contrast, is fatally out of sync with the god, engaging in transgressive kinds of motion and action and suffering death as a consequence. ${ }^{46}$

\section{Experiencing the Origins of the Paean}

But in his depiction of Neoptolemus, Pindar does not just draw a contrast between communal choral ritual and an individual act of violent transgression. He also alludes to the origins of the paean, thereby drawing the performing chorus and the listening audience into a closer relationship with the genre itself. As I discussed above, the Homeric Hymn to Apollo offers one account of the first performance of paeans at Delphi, and Paean 6 is similar to the Hymn in its representation of choreia as a form of communal embodiment that reinforces cosmic order while leaving space for individual kinesthetic experience. But Pindar's sixth paean alludes to a different aetiology for paean performance at Delphi-one which serves to cement the links between the performing chorus and the imaginative and empathetic sympotic audience.

46 See Kurke 2005: 100 on Neoptolemus' transgressions at Delphi, as well as Kowalzig 2007b: 192-201 for another angle on Neoptolemus' fraught relationship with Delphi and role as a paradigm figure for failed theoria. 
Rutherford suggests that "the conflict between Apollo and Neoptolemus [in Paean 6] is analogous to the Pythoctonia." 47 That is, Apollo's defeat of the transgressive hero at Delphi reenacts his defeat of the monster Pytho and reinstates the god's authority over the shrine. Moreover, Apollo's defeat of Pytho is specifically relevant to the paean itself: in one version of that myth, Apollo's triumph over the serpent is also the origin of the paean. According to Atheneaus, for example, Leto calls upon her son to "shoot, child!" ("ॄ $\pi \alpha \hat{\imath}$ ) when the monster attacks, referring to Apollo's skill with the bow. Athenaeus then claims that this phrase is modified over time, such that the rough breathing on the initial word ("i $\pi \alpha \hat{\imath})$ becomes smooth (" $\varepsilon \pi \alpha \hat{\imath})$, and is eventually transformed into the characteristic paean cry (ì $\left.\pi \alpha \iota^{\prime} \omega\right)$ ). ${ }^{48}$ I am not concerned here with the plausibility of this transformation on linguistic grounds; rather, I want to suggest that it constitutes one of several origin-myths for the paean likely familiar to an archaic audience. While I have drawn from Athenaeus' explanation here, Rutherford makes a compelling case that this aetiology would have been known to Pindar (and his audiences). ${ }^{49}$

Rutherford further argues that, if Apollo's conflict with Neoptolemus is analogous to the Pythoctonia origin-myth of the paean, then "the present song [that is, Paean 6 itself] is analogous to the original $\pi \alpha i \alpha \nu$... thus Pindar recalls the origins of the genre."50 I would expand this point to say that Paean 6 takes its performers and audiences along on a descriptive journey culminating in the reinvention of the paean. The strong sensory evocation of Delphic festivity and choreia in the opening triad and the assimilation of the follower's body to the body of the god in the second triad work together, such that the listener is encouraged to imagine himself as Apollo's embodied agent. The contrast with the transgressive corporeality of Neoptolemus-who has no divine patron in this song - thus acquires an additional force: Apollo and his followers, through the performance of paean, repeatedly triumph over their enemies.

The final lines of the second triad- "sing now, young men, sing now the mea-

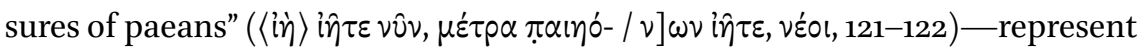
an important climax, dense with meaning: the moment when the song fully comes into being as a paean. ${ }^{51}$ The original choral performers reenact the exhilarating moment of generic innovation, crying out in response to Apollo's defeat of Neoptolemus just as Leto cries out at the moment of her son's triumph over

47 Rutherford 2001: 319. See also Rutherford 1991 for an earlier formulation of this argument.

48 Ath. 15.701c-e.

49 See Rutherford 2001: 35-26, 318-319.

$50 \quad$ Rutherford 2001: 319 .

$5^{1} \quad$ See further Rutherford 2001: $315^{-320}$. 
Pytho. The term $\mu \varepsilon \dot{\varepsilon} \tau \alpha$ highlights the regulated, communal motion of the chorus, revisiting the earlier contrast between the organized movement of ritual and the violent actions of a transgressive individual like Neoptolemus. And the vocative véol, "young men," does double duty: in the original performance context, it functions as choral self-address, shifting attention from mythic narrative back to contemporary ritual context. In a subsequent sympotic context, it opens the song up for further reflection and engagement, addressing the

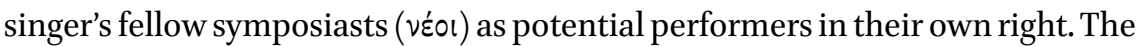
paean-cry at the end of the second triad thus concludes the song with a powerful affirmation of the genre. These two triads stand alone as a complete song, with a length and internal logic appropriate to a symposium.

\section{Conclusion}

Mikhail Bakhtin posits that an utterance's conception of its addressee-its addressivity - is a constitutive marker of speech genre. ${ }^{52}$ On one level, this is consistent with the occasional model of Greek song genre, which maintains that a song's conception and representation of its audience is an important component of the larger framework of "performance context." ${ }^{33}$ In this chapter, I have argued that choral song genre is constituted, not by a merely abstracted sense of the addressed audience, but rather by conscious reference to the audience as an embodied presence. In Paean 6, we can see how visual, sonic, and kinesthetic cues encourage a process of embodied remembrance of Delphic choreia that culminates with the explicit performance of the paean refrain. Throughout the song, the balance between communal and individual experience characteristic of Greek choral performance is rekindled in the body of the listener, even if that listener now reclines at a symposium instead of standing in

$5^{2}$ Bakhtin 1986b: 95-99. We might compare this with Frow's analysis of "generic cues" (2015: 119-124), wherein the author provides a nursery rhyme as an example and observes that its genre "is defined, above all, by its situation of address: it is characteristically spoken or sung, to or by a child, and is usually short, strongly rhythmical, and may involve a play with nonsense words; it may accompany such activities as skipping, slapping, or counting, or being sung to sleep. In a sense it is a conglomerate genre, and may include such kinds as ballads, riddles, proverbs, street cries, skipping songs, lullabies, or counting out rhymes" (2015: 120). Cf. also Jauss 1982 on how the expectations of an audience or reader condition the reception of a literary work (especially as discussed by Weiss in this volume).

53 E.g., the surviving portions of Alcman's partheneia display a keen awareness of their intended audience and its role in constituting the particular identity of the performing parthenoi (see Stehle 1997: 71-93; Peponi 2004). 
the shade at Delphi. Paean 6 thus relies upon the complicity and engagement of the audience in its process of reconstituting and reinstantiating the choral paean within the imaginative space of the symposium. In this sense, the notoriously flexible paean genre displays a crucial continuity in its addressivity. On the one hand, the occasion of Paean 6 may have shifted significantly over the life of the song: from Delphi to a symposium, from performance by a DelphianAeginetan chorus to that of a solo singer from (or in) another place entirely. At the same time, the way in which it conceives of and addresses the embodied, sensory presence of its audience remains remarkably consistent. 


\section{Bibliography}

Ablow, R., ed. 2010. The Feeling of Reading: Affective Experience and Victorian Literature. Ann Arbor.

Abrams, M.H. 1953. The Mirror and the Lamp:Romantic Theory and the Critical Tradition. Oxford.

Acosta-Hughes, B. 2010. Arion's Lyre: Archaic Lyric into Hellenistic Poetry. Princeton.

Adam, J.-M. 1995. “Aspects du récit en anthropologie.” In J.-M. Adam, M.-J. Borel, C. Calame, and M. Kilani, eds., Le discours anthropologique: description, narration, savoir, 227-254. 2nd ed. Lausanne.

Adam, J.-M., and U. Heidmann. 20o6. "Six propositions pour l'étude de la généricité." In Baroni and Macé 2006: 21-34.

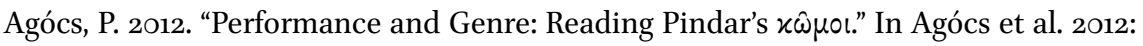
191-223.

Agócs, P., C. Carey, and R. Rawles, eds. 2012. Reading the Victory Ode. Cambridge.

Ahmed, S. 2004. "Affective Economies." Social Text 79: 117-139.

Albert, W. 1988. Das mimetische Gedicht in der Antike: Geschichte und Typologie von den Anfängen bis in die augusteische Zeit. Frankfurt.

Allan, W. 2004. "Religious Syncretism: The New Gods of Greek Tragedy." HSPh 102: 113155 .

Allan, W. 2008. Euripides: Helen. Cambridge.

Alonge, M. 2008. "The Palaikastro Hymn and the Modern Myth of the Cretan Zeus." In

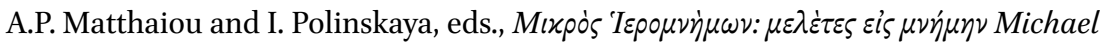
H. Jameson, 229-249. Athens.

Aloni, A. 1997. Saffo: Frammenti. Florence.

Aloni, A. 2001. "What Is That Man Doing in Sappho, fr. 31 v.?" In Cavarzere et al. 20o1: 29-40.

Aloni, A. 2009. “Elegy: Forms, Functions, and Communication." In Budelmann 20o9: 168-188.

Altieri, C. 2007. "The Sensuous Dimension of Literary Experience: An Alternative to Materialist Theory." New Literary History 38.1: 71-98.

Anderson, A.S. 2015. "The Seven against Thebes at Eleusis." ICS 40: 297-318.

Anderson, M.J. 1997. The Fall of Troy in Early Greek Poetry and Art. Oxford.

Anderson, W.B. 1966. Ethos and Education in Greek Music: The Evidence of Poetry and Philosophy. Cambridge MA.

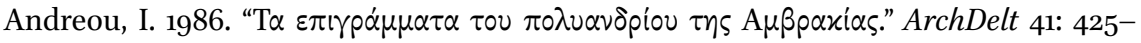
446.

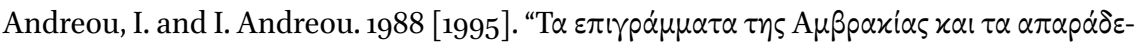

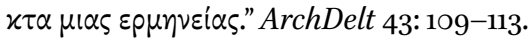


Andrisano, A.M. 2001. “Iambic Motifs in Alcaeus' Lyrics." In Cavarzere et al. 2001: 41-63. Andújar, R., T. Coward, and T. Hadjimichael, eds. 2018. Paths of Song: The Lyric Dimension of Greek Tragedy. Berlin.

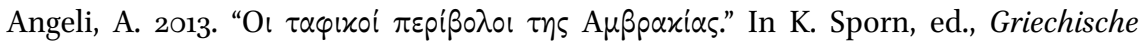
Grabbezirke klassischer Zeit: Normen und Regionalismen, 179-187. Munich.

Arnott, W.G. 2007. Birds in the Ancient World from A to Z. London.

Athanassaki, L. 2004. "Deixis, Performance, and Poetics in Pindar's First Olympian Ode." Arethusa 37.3: 317-341.

Athanassaki, L. 2011. "Giving Wings to Aeginetan Sculptures: The Panhellenic Aspirations of Pindar's Eighth Olympian." In Fearn 2011: 257-293.

Athanassaki, L. 2012. "Performance and Re-performance:The Siphnian Treasury Evoked (Pindar's Pythian 6, Olympian 2 and Isthmian 2)." In Agócs et al. 2012: 134-157.

Athanassaki, L., and E. Bowie, eds. 2011. Archaic and Classical Choral Song:Performance, Politics and Dissemination. Berlin and New York.

Athanassaki, L., R.P. Martin, and J.F. Miller, eds. 2009. Apolline Politics and Poetics. Athens.

Austin, J.L. 1975. How to Do Things with Words. 2nd ed. Cambridge MA.

Azzarello, G. 2008. "Sprecherhinweise in homerischen Papyri." In S. Lippert and M. Schentuleit, eds., Graeco-Roman Fayum: Texts and Archaeology: Proceedings of the Third International Fayum Symposion, Freudenstadt, May 29-June 1, 2007, 27-44. Wiesbaden.

Bacon, H. 1994-1995. "The Chorus in Greek Life and Drama." Arion 3.1: 6-24.

Badiou, A. 2013. Philosophy and the Event. Trans. L. Burchill. Cambridge.

Bakhtin, M. 1984. "Les genres du discours." In Esthétique de la création verbale, 265-308. Paris.

Bakhtin, M. 1986a. "The Problem of Speech Genres." In Speech Genres and Other Late Essays, 6o-102. Trans. V.W. McGee. Ed. C. Emerson and M. Holquist. Austin.

Bakhtin, M.1986b. Speech Genres and OtherLate Essays. Trans. V.W. McGee. Ed. C. Emerson and M. Holquist. Austin.

Bakola, E., L. Prauscello, and M. Telò. 2013. "Introduction: Greek comedy as a fabric of generic discourse." In E. Bakola, L. Prauscello, and M. Telò, eds., Greek Comedy and the Discourse of Genres, 1-12. Cambridge.

Barchiesi, A. 200o. "Rituals in Ink: Horace on the Greek Lyric Tradition." In Depew and Obbink 200o: 167-182.

Barchiesi, A. 2001. "The Crossing." In S.J. Harrison, ed., Texts, Ideas, and the Classics: Scholarship, Theory, and Classical Literature, 142-163. Oxford.

Barker, A. 1984. Greek Musical Writings, Vol. 1: The Musician and His Art. Cambridge.

Barker, A. 1989. Greek Musical Writings, Vol. 2: Harmonic and Acoustic Theory. Cambridge.

Barker, A. 2012. "The Music of Olympus." In Gentili 2012: 43-57. 
Baroni, R., and M. Macé, eds. 2006. Le savoir des genres. Rennes.

Barringer, J. 1995. Divine Escorts: Nereids in Archaic and Classical Greek Art. Ann Arbor.

Barris, J.S. 2016. "No Linos-Song in Achilles' Shield." In L. Bravi, L. Lomiento, A. Meriani, and G. Pace, eds., Tra lyra e aulos: tradizioni musicali e generi poetici, $285^{-296}$. Pisa and Rome.

Barthes, R. 1989. The Rustle of Language. Trans. R. Howard. Oxford.

Bassi, K. 2016. Traces of the Past: Classics Between History and Archaeology. Ann Arbor.

Battezzato, L. 2005a. “Lyric.” In J. Gregory, ed., A Companion to Greek Tragedy, 149-166. Oxford.

Battezzato, L. 2005b. "The New Music of the Trojan Women." Lexis 23: 73-104.

Battezzato, L. 2011. Review of L. Swift, The Hidden Chorus: Echoes of Genre in Tragic Lyric. JHS 131: 180-181.

Battezzato, L. 2013. "Dithyramb and Greek Tragedy." In Kowalzig and Wilson 2013: 93110.

Bauman, R. 2000. "Genre." Journal of Linguistic Anthropology 9.1-2: 84-87.

Bauman, R. 2004. A World of Others' Words: Cross-Cultural Perspectives on Intertextuality. Malden MA.

Baumbach, M., A. Petrovic, and I. Petrovic, eds. 2010. Archaic and Classical Greek Epigram. Cambridge.

Becker, J. 2001. "Anthropological Perspectives on Music and Emotion." In Juslin and Sloboda 2001: 135-160.

Becker, J. 2008. Deep Listeners: Music, Emotion, and Trancing. Bloomington IN.

Bell, C. 1992. Ritual Theory, Ritual Practice. Oxford and New York.

Bennett, J. 2010. Vibrant Matter: A Political Ecology of Things. Durham NC and London.

Benveniste, E. 1966. Problèmes de linguistique générale. Paris.

Benveniste, E. 1971. Problems in General Linguistics. Coral Gables FL.

Bernays, J. 2015 [1857]. “Outlines of Aristotle's Lost Work on the Effects of Tragedy," sect. 4 (trans. J.I. Porter) $=$ Appendix in Billings and Leonard 2015: 317-328.

Bersani, L. 1986. The Freudian Body: Psychoanalysis and Art. New York.

Bersani, L. 2009. Is the Rectum a Grave? And Other Essays. Chicago.

Bersani, L., and A. Phillips. 2008. Intimacies. Chicago.

Best, S. and S. Marcus. 2009. "Surface Reading: An Introduction." Representations 108: $1-21$.

Bettini, M. 2013. Women and Weasels: Mythologies of Birth in Ancient Greece and Rome. Trans. E. Eisenach. Chicago.

Bettini, M., and C. Brillante. 2002. Il mito di Elena: immagini e racconti dalla Grecia a oggi. Turin.

Bicknell, J. 2009. Why Music Moves Us. London.

Bicknell, J. 2011. "Musical Chills and Thrills." Psychology Today. https://www.psychology today.com/blog/why-music-moves-us/201106/musical-thrills-and-chills/. 
Bierl, A. 2003. "'Ich aber (sage), das Schönste ist, was einer liebt!': eine pragmatische Deutung von Sappho Fr. 16 LP/V." QUCC 74: 91-124.

Bierl, A. 2008. "Der neue Sappho-Papyrus aus Köln und Sapphos Erneuerung. Virtuelle Choralität, Eros, Tod, Orpheus und Musik.” Center for Hellenic Studies. http://chs .harvard.edu/CHS/article/display/2122.

Bierl, A. 20o9. Ritual and Performativity: The Chorus in Old Comedy. Trans. A. Hollmann. Washington DC.

Bierl, A. 2011. "Prozessionen auf der griechischen Bühne: Performativität des einziehenden Chors als Manifestation des Dionysos in der Parodos der Euripideischen Bakchen." In K. Gvozdeva and H.R. Velten, eds., Medialität der Prozession:Performanz ritueller Bewegung in Texten und Bildern der Vormoderne: Médialité de la procession: Performance du mouvement rituel en textes et en images à l'époque pré-moderne, 3561. Heidelberg.

Bierl, A. 2016a. “'All You Need is Love:' Some Thoughts on the Structure, Texture, and Meaning of the Brothers Song as well as on Its Relation to the Kypris Song (P. Sapph. Obbink)." In Bierl and Lardinois 2016: 302-336.

Bierl, A. 2016b. "Sappho as Aphrodite's Singer, Poet, and Hero(ine): The Reconstruction of the Context and Sense of the Kypris Song." In Bierl and Lardinois 2016: 339-352.

Bierl, A. 2016c. "Visualizing the Cologne Sappho: Mental Imagery through Chorality, the Sun, and Orpheus." In Cazzato and Lardinois 2016: 307-342.

Bierl, A. and A. Lardinois, eds. 2016. The Newest Sappho: P. Sapph. Obbink and P. GC Inv. 105, Frs. 1-4. Leiden and Boston.

Billings, J., F. Budelmann, and F. Macintosh, eds. 2013. Choruses, Ancient and Modern. Oxford.

Billings, J., and M. Leonard, eds. 2015. Tragedy and the Idea of Modernity. Oxford.

Bing, P., and J.S. Bruss, eds. 2007. Brill's Companion to Hellenistic Epigram. Leiden and Boston.

Blakely, S. 2006. Myth, Ritual, and Metallurgy in Ancient Greece and Recent Africa. Cambridge.

Boedeker, D. 2016a. "Coarse Poetics: Listening to Hipponax." In Swift and Carey 2016: $5^{6-73}$.

Boedeker, D. 2016b. "Hera and the Return of Charaxos." In Bierl and Lardinois 2016:188207.

Boehringer, S. 2013. "Je suis Tithon, je suis Aurore': Performance et érotisme dans le 'nouveau' fr. $5^{8}$ de Sappho." QUCC 133: 23-44.

Boehringer, S., and C. Calame. 2016. "Sappho and Kypris: 'The Vertigo of Love' (P. Sapph. Obbink 21-29; P. Oxy. 1231, fr. 16)." In Bierl and Lardinois 2016: 353-367.

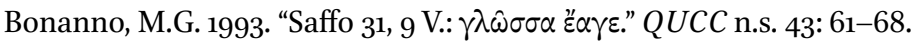

Bond, G.W. 1981. Euripides: Heracles. Oxford.

Bonifazi, A. 2004. "Communication in Pindar's Deictic Acts." Arethusa 37.3: 391-414. 
Booth, N. 2014. "Bathetic Masochism and the Shrinking Woman." New Formations 83: 47-63.

Borthwick, E.K. 1967. "Trojan Leap and Pyrrhic Dance in Euripides' Andromache 11291141." JHS 87: 18-23.

Bourdieu, P. 1975. "Le langage autorisé: note sur les conditions sociales de l' efficacité du discours rituel." Actes de la Recherche en Sciences Sociales 5-6: 183-19o.

Bourdieu, P. 1977. Outline of a Theory of Practice. Trans. R. Nice. Cambridge.

Bourdieu, P. 1987. Distinction: A Social Critique of the Judgement of Taste. Trans. R. Nice. Cambridge MA.

Bourdieu, P. 1990. The Logic of Practice. Trans. R. Nice. Stanford.

Bousquet, J. 1992. "Deux épigrammes grecques (Delphes, Ambracie)." BCH 116: 5856 o6.

Bowden, H. 2010. Mystery Cults of the Ancient World. Princeton.

Bowie, E. 1986. "Early Greek Elegy, Symposium and Public Festival." JHS 106: 13-35.

Bowie, E. 2008. "Sex and Politics in Archilochos' Poetry." In D. Katsonopoulou, I. Petropoulos, and S. Katsarou, eds., Paros II: Archilochos and His Age, 133-143. Athens.

Bowie, E. 2009. "Wandering Poets, Archaic Style." In R. Hunter and I. Rutherford, eds., Wandering Poets in Ancient Greek Culture: Travel, Locality, and Panhellenism, 105-136. Cambridge.

Bowie, E. 2010. "Epigram as Narration." In Baumbach et al. 2010: 313-384.

Bowie, E. 2016. "How Did Sappho's Songs Get into the Male Sympotic Repertoire?" In Bierl and Lardinois 2016: 148-164.

Bowman, L. 2004. “The 'Women's Tradition' in Greek Poetry." Phoenix 58:1-27.

Bowra, C.M. 1940. "The Fox and the Hedgehog." CQ 34: 26-29.

Bradley, M., ed. 2014. Smell and the Ancient Senses. Durham UK.

Braidotti, R. 2013. The Posthuman. London.

Bramble, J.C. 1974. Persius and the Programmatic Satire: A Study in Form and Imagery. Cambridge.

Bremmer, J.N. 2014. Initiation into the Mysteries of the Ancient World. Berlin and Boston.

Briand, M. 2009. "La danse et la philologie: à partir du mouvement strophique dans les scholies anciennes à Pindare." In S. David, C. Daude, E. Geny, and C. MuckensturmPoulle, eds., Traduire les scholies de Pindare ... I. De la traduction au commentaire: problèmes de méthode. Franche-Comté.

Briggs, C.L., and R. Bauman, 1992. "Genre, Intertextuality, and Social Power." Journal of Linguistic Anthropology 2.2: 131-172.

Brinkema, E. 2014. The Forms of the Affects. Durham NC.

Brown, C.G. 1984. "Ruined by Lust: Anacreon, fr. 44 Gentili (432 PMG)." CQ 34: 3742.

Brown, C.G. 2006. "Pindar on Archilochus and the Gluttony of Blame (Pyth. 2.52-56)." JHS 126: 36-46. 
Budelmann, F., ed. 20o9. The Cambridge Companion to Greek Lyric. Cambridge.

Budelmann, F. 2013. "Greek Festival Choruses in and out of Context." In Billings et al. 2013: 81-98.

Budelmann, F. 2017. "Performance, Reperformance, Preperformance: The Paradox of Repeating the Unique in Pindaric Epinician and Beyond." In Hunter and Uhlig 2017: 42-62.

Budelmann, F., and T. Phillips, eds. 2018. Textual Events: Performance and the Lyric in Early Greece. Oxford.

Budelmann, F., and T. Phillips. 2018a. "Introduction: Textual Events: Performance and the Lyric in Early Greece." In Budelmann and Phillips 2018: 1-27.

Budelmann, F., and T. Power. 2015. "Another Look at Female Choruses in Classical Athens." ClAnt 34.2: 252-295.

Bundrick, S. 2005. Music and Image in Classical Athens. Cambridge.

Bundy, E.L. 1986 [1962]. Studia Pindarica. Berkeley and Los Angeles.

Bunt, L., and M. Pavlicevic. 2001. "Music and Emotion: Perspectives from Music Therapy." In Juslin and Sloboda 2001: 181-201.

Burian, P. 2007. Euripides: Helen. Oxford.

Burkert, W. 1985. Greek Religion. Trans. J. Raffan. Cambridge MA.

Burkert, W. 1987. Ancient Mystery Cults. Cambridge MA.

Burnett, A.P. 1983. Three Archaic Poets: Archilochus, Alcaeus, Sappho. Cambridge MA.

Burnett, A.P. 1985. The Art of Bacchylides. Cambridge.

Burnett, A.P. 1998. "Spontaneity, Savaging, and Praise in Pindar's Sixth Paean." AJPh 119.4: 493-520.

Burris, S., J. Fish, and D. Obbink. 2014. "New Fragments of Book 1 of Sappho." ZPE 189: 1-28.

Butler, S., and A. Purves, eds. 2013. Synaesthesia and the Ancient Senses. Durham UK.

Caciagli, S. 2009. "Sapph. fr. 27 V.: l'unità del pubblico saffico." QUCC 120: 63-80.

Caciagli, S. 2010. "Il temenos di Messon: uno stesso contesto per Saffo e Alceo." Lexis 28: $227-256$.

Caciagli, S. 2011. Poeti e società: comunicazione poetica e formazioni sociali nella Lesbo del viI/VI secolo a.C. Amsterdam.

Caciagli, S. 2016. "Sappho Fragment 17: Wishing Charaxos a Safe Trip?" In Bierl and Lardinois 2016: 424-448.

Cairns, D.L. 2010. Bacchylides: Five Epinician Odes (3, 5, 9, 11, 13). Cambridge.

Cairns, F. 2007. Generic Composition in Greek and Latin Poetry. 2nd ed. Ann Arbor.

Calame, C. 1974. "Réflexions sur les genres littéraires en Grèce archaïque." QUCC 17:113128.

Calame, C. 1977. Les choeurs de jeune filles en Grèce archaïque. 2 vols. Rome.

Calame, C. 1983. Alcman: introduction, texte critique, témoignages, traduction et commentaire. Rome. 
Calame, C. 1995. The Craft of Poetic Speech in Ancient Greece. Trans. J. Orion. Ithaca and London.

Calame, C. 1997a. Choruses of Young Women in Ancient Greece: Their Morphology, Religious Role, and Social Functions. Trans. D. Collins and J. Orion. Lanham MD. [Translation of Calame 1977 vol. 1.]

Calame, C. 1997b. "Diction formulaire et fonction pratique dans la poésie mélique archaïque." In F. Létoublon, ed., Hommage à Milman Parry: le style formulaire de l'épopée homérique et la théorie de l'oralité poétique, 215-222. Amsterdam.

Calame, C. 1998a. “La poésie lyrique grecque: un genre inexistant?" Littérature 111: 87110.

Calame, C. 1998b. "Mémoire collective et temporalités en contact: Somare et Hérodote." RHR 215: 341-367.

Calame, C. 200o. Poétique des mythes dans la Grèce antique. Paris.

Calame, C. 2001. Choruses of Young Women in Ancient Greece: Their Morphology, Religious Role, and Social Functions. Trans. D. Collins and J. Orion. New and rev. edition. Lanham MD. [Translation of Calame 1977 vol. 1.]

Calame, C. 2004. "Identités d'auteur à l'exemple de la Grèce classique: signatures, énonciations, citations." In C. Calame and R. Chartier, eds., Identités d'auteur dans l'Antiquité et la tradition européenne, 11-39. Grenoble.

Calame, C. 2005. Masques d'autorité: fiction et pragmatique dans la poétique grecque antique. Paris.

Calame, C. 2006. "Identifications génériques entre marques discursives et pratiques énonciatives: pragmatique des genres 'lyriques.” In Baroni and Macé 2006: 35-55.

Calame, C. 20oga. "Apollo in Delphi and in Delos: Poetic Performances between Paean and Dithyramb." In Athanassaki et al. 2009: 169-197.

Calame, C. 2oogb. L'Éros dans la Grèce antique. 3 rd ed. Paris.

Calame, C. 2009c. "Referential Fiction and Poetic Ritual: Towards a Pragmatics of Myth (Sappho 17 and Bacchylides 13)." Trends in Classics 1:1-17.

Calame, C. 2011. Mythe et histoire dans l'Antiquité grecque: la création symbolique d'une colonie. 2nd ed. Paris.

Calame, C. 2013. "The Dithyramb, a Dionysiac Poetic Form: Genre Rules and Cultic Contexts." In Kowalzig and Wilson 2013: 332-352.

Calame, C. 2015. Qu'est-ce que la mythologie grecque? Paris.

Campbell, D.A., ed. 1982-1993. Greek Lyric. 5 vols. Cambridge MA.

Campbell, D.A. 1992. Greek Lyric IV: Bacchylides, Corinna, and Others. Cambridge MA.

Campbell, D.A. 1993. Greek Lyric V: The New School of Poetry and Anonymous Songs and Hymns. Cambridge MA.

Cannatà Fera, M. 1987. "Schol. Eur. Rh. 895 e Pind. Fr. 128c S.-M." RFIC 115: 12-23.

Cannatà Fera, M. 199o. Pindaro Trenodie: Introduzione, testo critico, traduzione e commento. Rome. 
Carawan, E. 2000. "Deianira's Guilt." TAPhA 130: 189-237.

Carey, C. 1995. "Pindar and the Victory Ode." In L. Ayres, ed., The Passionate Intellect: Essays on the Transformation of Classical Traditions, 85-103. New Brunswick.

Carey, C. 2ooga. "Genre, Occasion, and Performance." In Budelmann 20o9: 21-38.

Carey, C. 2oogb. "Iambos." In Budelmann 20o9: 149-167.

Carey, C. 2012. "The Victory Ode in the Theatre." In P. Agócs, C. Carey, and R. Rawles, eds., Receiving the Komos: Ancient and Modern Receptions of the Victory Ode, 17-36. London.

Carruesco, J. 2010. "Prácticas rituales y modos del discurso: la coralidad como paradigma del catálogo en la poesía arcaica griega.” In J.F.C. Castro, J. Siles Ruiz, and J. de la Villa Polo, eds., Perfiles de Grecia y Roma: Actas del XII Congreso Español de Estudios Clasicós, 2: 271-277. Valencia.

Carruesco, J. 2012. "Helen's Voice and Choral Mimesis from Homer to Stesichorus." In X. Riu and J. Pòrtulas, eds., Approaches to Archaic Greek Poetry, 149-172. Messina.

Carson, A. 1984. “The Burners: A Reading of Bacchylides' Third Epinician Ode." Phoenix 38.2: 111-119.

Carson, A. 1995. Glass, Irony, and God. New York.

Carson, A. 1998. Eros the Bittersweet. Champaign IL.

Cassio, A.C. 1994. “I distici del polyandrion di Ambracia e l' 'io anonimo' nell'epigramma greco." SMEA 33:101-117.

Cavarzere, A., A. Aloni, and A. Barchiesi, eds. 2012. Iambic Ideas: Essays on a Poetic Tradition from Archaic Greece to the Late Roman Empire. Lanham MD.

Cazzato, V., and A. Lardinois, eds. 2016. The Look of Lyric: Greek Song and the Visual. Leiden and Boston.

Chaniotis, A. 2009. "A Few Things Hellenistic Audiences Appreciated in Musical Performances.” In Martinelli 2oogb: 75-97.

Chaniotis, A. 2012. "Moving Stones: The Study of Emotions in Greek Inscriptions." In A. Chaniotis, ed., Unveiling Emotions: Sources and Methods for the Study of Emotions in the Greek World, 91-129. Stuttgart.

Chantraine, P. 2009. Dictionnaire étymologique de la langue grecque: histoire des mots, achevé parJ. Taillardat, O. Masson et J.-L. Perpillou, nouvelle éd. Paris.

Chomsky, N. 1965. Aspects of the Theory of Syntax. Cambridge MA.

Christian, T. 2015. Gebildete Steine: Zur Rezeption literarischer Techniken in den Versinschriften seit dem Hellenismus. Göttingen.

Cingano, E. 2003. 'Entre 'skolion' et 'enkomion:' réflexions sur le 'genre' et la performance de la lyrique chorale grecque.” In J. Jouanna and J. Leclant, eds., Colloque: la poésie grecque antique: actes, 17-45. Paris.

Clairmont, C.W. 1993. Classical Attic Tombstones. Kilchberg.

Clare, S. 2013. "Feeling Cold: Phenomenology, Spatiality, and the Politics of Sensation." Differences 24.1: 169-191. 
Cohen, R., and H. White, eds. 2003. Theorizing Genres I and Theorizing Genres II. New Literary History 34.2 and 34.3.

Cole, A.T. 1988. “Translator's Introduction.” In Gentili 1988: xi-xviii.

Collins, D. 2003. "Nature, Cause, and Agency in Greek Magic." TAPhA 133: 17-49.

Collins, D. 2004. Master of the Game: Competition and Performance in Greek Poetry. Washington DC.

Collins, D. 20o6. “Corinna and Mythological Innovation." CQ 56: 19-32.

Connor, W.R. 200o. "Tribes, Festivals, and Processions: Civic Ceremonial and Political Manipulation in Archaic Greece." In R. Buxton, ed., Oxford Readings in Greek Religion, 56-75. 2nd ed. Oxford.

Constantakopoulou, C. 2015. "Regional Religious Groups, Amphictionies, and Other Leagues." In E. Eidinow and J. Kindt, eds., The Oxford Handbook of Ancient Greek Religion, 273-289. Oxford.

Conte, G.B. 1992. "Empirical and Theoretical Approaches to Literary Genre." In K. Galinsky, ed., The Interpretation of Roman Poetry: Empiricism or Hermeneutics?, 104-123. Frankfurt am Main.

Conte, G.B. 1994. Genres and Readers: Lucretius, Love Elegy, Pliny's Encyclopedia. Trans. G.W. Most. Baltimore.

Corrêa, da Cunha, P. 2001. "The Fox and the Hedgehog." Phaos 1: 81-92.

Cousland, J.R.C., and J. Hume, eds. 20o9. The Play of Texts and Fragments: Papers Presented to Martin Cropp on the Occasion of His Sixty-Fifth Birthday. Leiden.

Croce, B. 1902. Estetica come scienza dell'espressione e linguistica generale. Milan, Palermo, and Naples.

Cropp, M.J. 200o. Euripides: Iphigenia in Tauris. Warminster.

Cropp, M.J., K. Lee, and D. Sansone, eds. 1999-200o. Euripides and Tragic Theatre in the Late Fifth Century. Champaign IL.

Crowhurst, R. 1963. "Representations of Performance of Choral Lyric on the Greek Monuments, 8 oo-350 B.c." Dissertation. University of London.

Crusius, O. 1888. "Stesichoros und die epodische Composition in der griechischen Lyrik." Commentationes philologae quibus Ottoni Ribbeckio etc., 1-22. Leipzig.

Csapo, E. 1999-200o. "Later Euripidean Music." In Cropp et al. 1999-200o: 399-426.

Csapo, E. 2003. "The Dolphins of Dionysus." In E. Csapo and M.C. Miller, eds., Poetry, Theory, Praxis: The Social Life of Myth, Word and Image in Ancient Greece: Essays in Honour of William J. Slater, 69-98. Oxford.

Csapo, E. 2004. "The Politics of the New Music." In Murray and Wilson 2004: 207-248.

Csapo, E. 2008. "Star Choruses: Eleusis, Orphism, and New Musical Imagery and Dance." In M. Revermann and P. Wilson, eds., Performance, Iconography, Reception: Studies in Honour of Oliver Taplin, 262-290. Oxford.

Csapo, E., and W.J. Slater. 1995. The Context of Ancient Drama. Ann Arbor.

Culler, J. 1975. Structuralist Poetics: Structuralism, Linguistics, and the Study of Literature. Ithaca NY. 
Culler, J. 1977. “Apostrophe." Diacritics 7.4: 59-69.

Culler, J. 2015. Theory of the Lyric. Cambridge MA.

Currie, B. 2004. "Reperformance Scenarios for Pindar's Odes." In Mackie 2004: 4969.

Currie, B. 2005. Pindar and the Cult of Heroes. Oxford.

Currie, B. 2013. "The Pindaric First Person in Flux." ClAnt 32: 243-282.

Currie, B. 2017. "Festival, Symposium, and Epinician (Re)performance: The Case of

Nemean 4 and Others." In Hunter and Uhlig 2017: 187-208.

D’Agostino, B. 2016. "Potters and Painters in Archaic Corinth: Schemata and Images." In G. Colesanti and L. Lulli, eds., Submerged Literature in Ancient Greek Culture, Vol. 2: Case Studies, 243-258. Berlin and Boston.

Dale, A. 2011. "Sapphica." HSPh 106: 47-74.

Dale, A. 2015. "The Green Papyrus of Sappho (P.GC inv. 105) and the Order of Poems in the Alexandrian Edition." ZPE 196: 17-30.

D’Alessio, G.B. 1991. "Osservazioni e paralipomeni ad una nuova edizione dei frammenti di Pindaro," RFIC 119: 91-117.

D’Alessio, G.B. 1994. "First-Person Problems in Pindar." BICS 39: 117-139.

D'Alessio, G.B. 1995. “Sull'epigramma dal polyandrion di Ambracia." ZPE 106: 22-26.

D’Alessio, G.B. 1996. Callimaco. Milan.

D'Alessio, G.B. 1997. "Pindar's Prosodia and the Classification of the Pindaric Papyrus Fragments." ZPE 118: 23-6o.

D’Alessio, G.B. 2004. "Past Future and Present Past: Temporal Deixis in Greek Archaic Lyric." Arethusa 37.3: 267-294.

D'Alessio, G.B. 2005. "Ordered from the Catalogue: Pindar, Bacchylides, and Hesiodic Genealogical Poetry." In R. Hunter, ed., The Hesiodic Catalogue of Women: Constructions and Reconstructions, 217-238. Cambridge.

D’Alessio, G.B. 20o9. “Language and Pragmatics.” In Budelmann 2009: 114-129.

D’Alessio, G.B. 2013. "The Name of the Dithyramb: Diachronic and Diatopic Variations." In Kowalzig and Wilson 2013: 113-132.

D’Alessio, G.B. 2018. "Fiction and Pragmatics in Ancient Greek Lyric: The Case of Sappho." In Budelmann and Phillips 2018: 31-62.

D’Angour, A.J. 1997. "How the Dithyramb Got Its Shape." CQ 47: 331-351.

D'Angour, A.J. 1999. "Archinus, Eucleides and the Reform of the Athenian Alphabet," BICS 43: 109-130.

D’Angour, A.J. 20o6. “The New Music—So What's New?” In S. Goldhill and R. Osborne, eds., Rethinking Revolutions through Ancient Greece, 264-283. Cambridge.

D’Angour, A.J. 2007. "The Sound of Mousikē: Reflections on Aural Change in Ancient Greece." In R. Osborne, ed., Debating the Athenian Cultural Revolution: Art, Literature, Philosophy, and Politics 430-380 BC, 288-300. Cambridge.

D'Angour, A.J. 2011. The Greeks and the New: Novelty in Ancient Greek Imagination and Experience. Cambridge. 
Daumas, M. 1998. Cabiriaca: recherches sur l'iconographie du culte des Cabires. Paris.

Davies, M. 1988. "Monody, Choral Lyric and the Tyranny of the Handbook." CQ $38: 5^{2-}$ 64.

Davies, M. 1991. Sophocles: Trachiniae. Oxford.

Davies, S. 2003. "Music." In J. Levinson, ed., Oxford Handbook of Aesthetics, 489-515. Oxford.

Davis, W. 2017. Visuality and Virtuality: Images and Pictures from Prehistory to Perspective. Princeton.

Day, J.W. 2007. “Poems on Stone: The Inscribed Antecedents of Hellenistic Epigram.” In Bing and Bruss 2007: 29-47.

Day, J.W. 2010. Archaic Greek Epigram and Dedication: Representation and Performance. Cambridge.

Day, J.W. 2019. "The Origins of Greek Epigram: The Unity of Inscription and Object." In Christer Henriksén, ed., A Companion to Ancient Epigram, 231-247. Hoboken NJ.

De Biasi, L. 199o. "Le descrizioni del paesaggio naturale nelle opere di Apuleio. Aspetti letterari." MAT 14: 3-72.

Degani, E. 1971. "Metafore ipponattee." In Studi filologici e storici in onore di Vittorio De Falco, 87-103. Naples.

Degani, E. 1982. Studi su Ipponatte. Bari.

Degani, E. 1983. Hipponactis Testimonia et Fragmenta. Leipzig.

Deleuze, G. 1991. Masochism: Coldness and Cruelty. Trans. J. McNeil. New York.

Deleuze, G. 1994. "He Stuttered." In C.V. Boundas and D. Olkowski, eds., Gilles Deleuze and the Theater of Philosophy, 23-29. London.

Deleuze, G. 2003. Francis Bacon: The Logic of Sensation. Trans. D.W. Smith. Minneapolis.

Deleuze, G., and F. Guattari. 1987. A Thousand Plateaus: Capitalism and Schizophrenia. Trans. B. Massumi. Minneapolis.

de Man, P. 1983. Blindness and Insight: Essays in the Rhetoric of Contemporary Criticism. 2nd ed. Minneapolis.

Depew, M., and D. Obbink. 20ooa. "Introduction." In Depew and Obbink 20oo: 1-14.

Depew, M., and D. Obbink, eds. 20oob. Matrices of Genres:Authors, Canons, and Society. Cambridge MA.

Derrida, J. 1980. “The Law of Genre.” Trans. A. Ronell. Critical Inquiry 7.1: 55-81.

Derrida, J. 1981. Dissemination. Trans. B. Johnson. Chicago.

Destrée, P., and P. Murray, eds. 2015. A Companion to Ancient Aesthetics. Malden MA.

Diehl, E. 1940. "Fuerunt ante Homerum poetae." RhM 89: 81-114.

Dodds, E.R. 1951. The Greeks and the Irrational. Berkeley and Los Angeles.

Dougherty, C. 1994. "Pindar's Second Paean: Civic Identity on Parade." CPh 89.3: 205218.

Dover, K.J. 1964. “The Poetry of Archilochus." In Archiloque. Entretiens sur L'Antiquité Classique. Tomé X, 181-212. Geneva. 
Drachmann, A.B. 1903-1927. Scholia vetera in Pindari carmina. 3 vols. Leipzig.

Dreizehnter, A. 1970. Aristoteles Politik. Munich.

Dubrow, H. 1982. Genre. London.

Duchemin, J. 1970. "Essai sur le symbolisme Pindarique: or, lumière, et couleurs." In W.M. Calder and J. Stern, eds., Pindaros und Bakchylides, 278-289. Darmstadt.

Duff, D. 20o9. Romanticism and the Uses of Genre. Oxford

Dunbar, N. 2002. Aristophanes: Birds. Oxford.

Easterling, P.E. 1982. Sophocles: Trachiniae. Cambridge.

Eckerman, C. 2014. "Pindar's Delphi." In C. Gilhuly and N. Worman, eds., Space, Place, and Landscape in Ancient Greek Literature and Culture, 21-62. Cambridge.

Edmonds, R.G., III. 2006. "To Sit in Solemn Silence? Thronosis in Ritual, Myth, and Iconography." AJPh 127: 347-366.

Edmonds, R.G., III. 2008. "Extra-ordinary People: Mystai and Magoi, Magicians and Orphics in the Derveni Papyrus." CPh 103: 16-39.

Edmonds, R.G., III. 2013. Redefining Ancient Orphism: A Study in Greek Religions. Cambridge.

Edmunds, L. 2008. "Deixis in Ancient Greek and Latin Literature: Historical Introduction and State of the Question." Philologia Antiqua 1: 67-98.

Edmunds, L. 2012. "Deixis and Everyday Expressions in Alcaeus frs. 129 V and 13ob V." In V. Bers, D. Elmer, D. Frame, and L. Muellner, eds., Donum natalicium digitaliter confectum Gregorio Nagy septuagenario a discipulis collegis familiaribus oblatum: A Virtual Birthday Gift Presented to Gregory Nagy on Turning Seventy by His Students, Colleagues and Friends. http://chs.harvard.edu/CHS/article/display/4353.

Edwards, M.W. 1991. The Iliad: A Commentary. Vol. 5: Books 17-20. Cambridge.

Eidinow, E. 2007. Oracles, Curses, and Risk among the Ancient Greeks. Oxford.

Estrin, S. 2016. "Cold Comfort: Empathy and Memory in an Archaic Funerary Monument from Akraphia." ClAnt 35.2: 189-214.

Estrin, S. 2018. "Memory Incarnate: Material Objects and Private Visions in Classical Athens, from Euripides' Ion to the Gravesite." In M. Telò and M. Mueller, eds., The Materialities of Greek Tragedy: Objects and Affect in Aeschylus, Sophocles and Euripides, 111-132. London.

Evans, D. 1982. Big Road Blues: Tradition and Creativity in the Folk Blues. Berkeley and Los Angeles.

Faraone, C. 2008. The Stanzaic Architecture of Early Greek Elegy. Oxford.

Faraone, C. 2013. "The Poetics of the Catalogue in the Hesiodic Theogony." TAPhA 143: 293-323.

Färber, H. 1932. Zur dichterischen Kunst in Apollonios Rhodios' Argonautica. Dissertation. Berlin.

Färber, H. 1936. Die Lyrik in der Kunsttheorie der Antike. Munich.

Farrell, J. 2003. "Classical Genre in Theory in Practice." New Literary History 34.3: 383408. 
Fearn, D. 2003. "Mapping Phleious: Politics and Myth-Making in Bacchylides 9." CQ 53: $347-367$.

Fearn, D. 2007. Bacchylides: Politics, Performance, Poetic Tradition. Oxford.

Fearn, D., ed. 2011. Aegina: Contexts for Choral Lyric Poetry: Myth, History, and Identity in the Fifth Century вс. Oxford.

Fearn, D. 2011a. “Aeginetan Epinician Culture: Naming, Ritual, and Politics." In Fearn 2011: $175^{-226 .}$

Felski, R. 2015. The Limits of Critique. Chicago.

Felson, N. 1999. “Vicarious Transport: Fictive Deixis in Pindar's Pythian Four." HSPh 99: $1-31$.

Felson, N., ed. 2004. The Poetics of Deixis in Alcman, Pindar, and Other Lyric. Arethusa Special Issue, Vol. 37 , No. 3 .

Felson, N. 2004a. "Introduction." Arethusa 37.3: 253-266.

Felson, N. 2004b. “The Poetic Effects of Deixis in Pindar's Ninth Pythian Ode." Arethusa 37.3: 365-389.

Ferrari, F. 2010. Sappho's Gift: The Poet and Her Community. Trans. B. Acosta-Hughes and L. Prauscello. Ann Arbor.

Ferrari, F. 2012. "Representations of Cult in Epinician Poetry." In Agócs et al. 2012: 158172.

Ferrari, F. 2014. "Saffo e i suoi fratelli e altri brani del primo libro." ZPE 192: 1-19.

Ferrari, G. 2008. Alkman and the Cosmos of Sparta. Chicago.

Firth, J.R. 1964. The Tongues of Men, and Speech. Ed. P.D. Strevens. Oxford.

Fitzgerald, W. 200o. Slavery and the Roman Literary Imagination. Cambridge.

Floyd, E.D. 1965. "The Performance of Pindar, Pythian 8.55-70." GRBS 6:187-200.

Folch, M. 2015. The City and the Stage: Performance, Genre, and Gender in Plato's Laws. Oxford.

Foley, H.P., ed. 1981. Reflections of Women in Antiquity. Philadelphia.

Foley, H.P. 2001. Female Acts in Greek Tragedy. Princeton.

Foley, H.P. 20o6. Review of M. Wright, Euripides' Escape-Tragedies: A Study of Helen, Andromeda, and Iphigenia Among the Taurians. AJPh 127-3:465-469.

Fontenrose, J. 1966. The Ritual Theory of Myth. Berkeley and Los Angeles.

Ford, A. 2002. The Origins of Criticism: Literary Culture and Poetic Theory in Classical Greece. Princeton.

Ford, A. 2004. "Catharsis: The Power of Music in Aristotle's Politics." In Murray and Wilson 2004: 309-336.

Ford, A. 20o6. "The Genre of Genres: Paeans and Paian in Early Greek Poetry." Poetica 38: $277-296$.

Ford, A. 2010. “'A Song to Match My Song:' Lyric Doubling in Euripides' Helen.” In P. Mitsis and C. Tsagalis, eds., Allusion, Authority, and Truth: Critical Perspectives on Greek Poetic and Rhetorical Praxis, 283-302. Berlin. 
Fordyce, C.J. 1961. Catullus: A Commentary. Oxford.

Foster, M. 2017. "Fathers and Sons in War: Seven Against Thebes, Pythian 8, and the Polemics of Genre." In I. Torrance, ed. Aeschylus and War: Comparative Perspectives on Seven Against Thebes, 150-172. London.

Foucault, M. 1969. "Qu' est-ce qu'un auteur?” Bulletin de la Société française de Philosophie 63: 73-104.

Fowler, A. 1982. Kinds of Literature: An Introduction to the Theory of Genres and Modes. Cambridge MA.

Fraenkel, E. 1950. Aeschylus: Agamemnon. 3 vols. Oxford.

Fraenkel, E. 1957. Horace. Oxford.

Fränkel, H. 1975. Early Greek Poetry and Philosophy. New York.

Franklin, J.C. 2002. "Musical Syncretism and the Greek Orientalizing Period." In E. Hickmann and R. Eichmann eds., Archäologie früher Klangerzeugung und Tonorinungen: Studien zur Musikarchäologie 3, Orient-Archäologie 10: 441-451.

Franklin, J.C. 2003. “The Language of Musical Technique in Greek Epic Diction.” Gaia: Revue interdisciplinaire sur la Grèce archä̈que 7: 295-307.

Freud, S. 1915. "Instincts and their Vicissitudes." In Standard Edition 14: 117-140.

Frow, J. 2015. Genre. New York.

Frye, N. 1956. "Introduction: Lexis and Melos." In N. Frye, ed., Sound and Poetry: English Institute Essays, $\mathrm{ix}-\mathrm{xxvii}$. New York.

Frye, N. 1957. Anatomy of Criticism. Princeton.

Führer, R. 1967. Formproblem-Untersuchungen zu den Reden in der frühgriechischen Lyrik. Munich.

Furley, W.D. 1993. "Besprechung und Behandlung: Zur Form und Funktion von ЕП $\Omega$ I$\triangle \mathrm{AI}$ in der griechischen Zaubermedizin." In G.W. Most, H. Petersmann, and A.M. Ritter, eds. Philanthropia kai Eusebeia: Festschrift für A. Dihle zum 70. Geburtstag, 8o104. Göttingen.

Furley, W.D., and J.M. Bremer. 20o1a. Greek Hymns, Vol. I: The Texts in Translation. Tübingen.

Furley, W.D., and J.M. Bremer. 20o1b. Greek Hymns, Vol. II: Greek Texts and Commentary. Tübingen.

Gadamer, H.-G. 1975. Truth and Method. New York.

Gagné, R. 2013. Ancestral Fault in Ancient Greece. Cambridge.

Gagné, R., and M.G. Hopman. 2013a. "Introduction:The Chorus in the Middle." In Gagné and Hopman 2013b: 1-34. Cambridge.

Gagné, R., and M.G. Hopman. 2013b. Choral Mediations in Greek Tragedy. Cambridge.

Gaisford, T. 1823. Poetae minores Graeci II: Scholia ad Hesiodum. Oxford.

Gammacurta, T. 2006. Papyrologica scaenica: $i$ copioni teatrali nella tradizione papiracea. Alessandria.

Garvie, A.F. 1969. Aeschylus' Supplices: Play and Trilogy. Cambridge. 
Gell, A. 1998. Art and Agency: An Anthropological Theory. Oxford.

Genette, G. 1986. "Introduction à l' architexte." In G. Genette and T. Todorov, eds., Théorie des genres, $89-160$. Paris.

Genette, G. 1992. The Architext: An Introduction. Trans. J.E. Lewin. Berkeley and Los Angeles. [Translation of Genette 1986.]

Genette, G. 1995. Mimologics. Trans. T.E. Morgan. Lincoln NE.

Gentili, B. 1984. Poesia e pubblico nella Grecia antica, da Omero al v secolo. Rome and Bari.

Gentili, B. 1988. Poetry and Its Public in Ancient Greece from Homer to the Fifth Century. Trans. A.T. Cole. Baltimore. [Translation of Gentili 1984.]

Gentili, B., ed. 2012. Atti del Seminario Internazionale di Studio Poesia, canto, accompagnamento strumentale nel De musica attribuito a Plutarco. Pisa and Rome.

Gerber, D.E. 1999. Greek Iambic Poetry: From the Seventh to the Fifth Centuries BC. Cambridge MA and London.

Giuliani, L. 2013. Image and Myth: A History of Pictorial Narration in Greek Art. Trans. J. O’Donnell. Chicago and London.

Goldhill, S. 2013. "The Greek Chorus: Our German Eyes." In Budelmann et al. 2013: 35$5^{2 .}$

Goldman, M.L. 2015. "Associating the Aulētris: Flute Girls and Prostitutes in the Classical Greek Symposium." Helios 42: 29-6o.

Goodley, D., R. Lawthorn, and K. Runswick Cole. 2014. "Posthuman Disability Studies." Subjectivity $7: 342-361$.

Goody, J., and I. Watt. 1968. “The Consequences of Literacy." In J. Goody, ed., Literacy in Traditional Societies, 27-68. Cambridge.

Gostoli, A. 1995. "L'armonia frigia nei progetti politico-pedagogici di Platone e Aristotele." In B. Gentili and F. Perusino, eds., Mousikē: metrica, ritmica e musica greca in memoria di G. Comotti, 133-144. Pisa and Rome.

Gowers, E. 1993. The Loaded Table: Representations of Food in Roman Literature. Oxford.

Gowers, E. 2016. "Girls Will Be Boys and Boys Will Be Girls, Or, What is the Gender of Horace's Epodes." In P. Bather and C. Stocks, eds., Horace's Epodes: Context, Intertexts, and Reception, 103-130. Oxford.

Grandolini, S. 1999. "Didimo e la classificazione della poesia lirica." GIF 51: 1-22.

Graninger, D. 2014. "Ambracian Cruces (SEG 41.540A)." RhM, Neue Folge, 157: 225238.

Greene, R. 1991. Post-Petrarchism: Origins and Innovations of the Western Lyric Sequence. Princeton.

Gregory, J. 20o6. Review of M. Wright, Euripides' Escape-Tragedies: A Study of Helen, Andromeda, and Iphigenia Among the Taurians. Hermathena 181: 230-233.

Greimas, A.J., and J. Courtes. 1979. Sémiotique: dictionnaire raisonné de la théorie du langage. Paris. 
Griffith, M. 2006. "Horsepower and Donkeywork: Equids and the Ancient Greek Imagination. Part Two." CPh 101.4: 307-358.

Griffith, M. 2017. "The Voices of the Bass." In S. Beta, ed. Scritti in onore di Maurizio Bettini, 171-176. Milan.

Griffith, M. 2018. "Music and Dance." In V. Liapis and A. Petrides, eds. Greek Tragedy after the Fifth Century, 204-242. Cambridge.

Griffith, M. Forthcoming. Music and Difference in Ancient Greece.

Gronewald, M. and R.W. Daniel, eds. 2007. "Griechische literarische Texte: 429." Kölner Papyri 11: 1-11.

Grosz, E. 1994. Volatile Bodies: Toward a Corporeal Feminism. Bloomington IN.

Guillén, C. 1971. Literature as System: Essays Toward the Theory of Literary History. Princeton.

Gumbrecht, H.U. 2012. Atmosphere, Mood, Stimmung: On a Hidden Potential of Literature. Trans. E. Butler. Stanford.

Güthenke, C. 2013. "The Middle Voice: German Classical Scholarship and the Greek Tragic Chorus." In Budelman et al. 2013: 53-66.

Hagel, S. 2010. Ancient Greek Music: A New Technical History. Cambridge.

Hallett, J.P. 1979. "Sappho and Her Social Context: Sense and Sensuality." Signs 4: 447464.

Halliwell, S. 1986. Aristotle's Poetics. London.

Halliwell, S. 1998. Aristotle's Poetics. 2nd ed. Chicago.

Halliwell, S. 2002. The Aesthetics of Mimesis: Ancient Texts and Modern Problems. Princeton.

Halliwell, S. 2011. Between Ecstasy and Truth:Interpretations of Greek Poetics from Homer to Longinus. Oxford.

Hallward. 20o6. "Staging Equality: On Rancière's Theatrocracy." New Left Review 37:109129 .

Halpern, R. 2011. “Theater and Democratic Thought: Arendt to Ranciere." Critical Inquiry 37-3: 545-572.

Hardie, A. 2004. "Music and Mysteries." In Murray and Wilson 2004: 11-37.

Harris, W.V. 1989. Ancient Literacy. Cambridge MA.

Harrison, J.E. 1912. Themis: A Study of the Social Origins of Greek Religion. Cambridge.

Harte, V. 1999. "Conflicting Values in Plato's Crito." Archiv für Geschichte der Philosophie 81: $117-147$.

Harvey, A.E. 1955. "The Classification of Greek Lyric Poetry." CQ 5:157-175.

Haslam, M.W. 1972. "Plato, Sophron, and the Dramatic Dialogue." BICS 19: 17-38.

Häussler, R. 1974. "Linos ante linon?" RhM 117: 1-14.

Havelock, E.A. 1963. Preface to Plato. Cambridge MA.

Havelock, E.A. 1982. The Literate Revolution in Greece and its Cultural Consequences. Princeton. 
Hawkins, T. 2014. Iambic Poetics in the Roman Empire. Cambridge.

Hedreen, G. 2001. Capturing Troy: The Narrative Functions of Landscape in Archaic and Early Classical Greek Art. Ann Arbor.

Heiden, B. 2008. "Common People and Leaders in Iliad 2: The Invocation of the Muses and the Catalogue of Ships." TAPhA 138: 127-154.

Hemberg, B. 1950. Die Kabiren. Uppsala.

Henrichs, A. 1994-1995. “'Why Should I Dance?' Choral Self-Referentiality in Greek Tragedy." Arion 3.1: 56-111.

Henrichs, A. 1996a. "Dancing in Athens, Dancing on Delos: Some Patterns of Choral Projection in Euripides." Philologus 140: 48-62.

Henrichs, A. 1996b. “Warum soll ich denn tanzen?” Dionysisches im Chor der griechischen Tragödie. Stuttgart and Leipzig.

Henry, W.B. 1999. "Pindar, Fragments 128c (Thren. 3) and 26o." ZPE 128: 14.

Herington, J. 1985. Poetry into Drama: Early Tragedy and the Greek Poetic Tradition. Berkeley and Los Angeles.

Herrmann, P. 2002. “Eine 'pierre errante' in Samos: Kultgesetz der Korybanten." Chiron 32: 157-171.

Hoey, T.F. 1979. "The Date of the Trachiniae." Phoenix 33: 210-232.

Horn, E. 1883. De Aristarchi studiis Pindaricis. Dissertation. Greifswald.

Hose, M. 1991. Studien zum Chor bei Euripides. Vol. 2. Stuttgart.

Hubbard, T.K. 1993. "The Theban Amphiaraion and Pindar's Vision on the Road to Delphi." Museum Helveticum 50: 193-203.

Hubbard, T.K. 2004. "The Dissemination of Epinician Lyric: Pan-Hellenism, Reperformance, Written Texts." In Mackie 2004: 71-94.

Hunter, R., and A. Uhlig, eds. 2017. Imagining Reperformance in Ancient Culture: Studies in the Traditions of Drama and Lyric. Cambridge.

Hutchinson, G.O. 2001. Greek Lyric Poetry: A Commentary on Selected Larger Pieces. Oxford.

Hutton, J., trans. 1982. Aristotle's Poetics. New York.

Hymes, D. 1977. Foundations in Sociolinguistics: An Ethnographic Approach. London.

Immisch, O. 1897. "Kureten und Korybanten." In W.H. Roscher, ed., Ausfürhliches Lexikon der griechischen und römischen Mythologie II.1, 1587-1628. Leipzig.

Ingalls, W.B. 200o. "Ritual Performance as Training for Daughters in Archaic Greece." Phoenix 54: 1-20.

Irigoin, J. 1952. Histoire du texte de Pindare. Paris.

Jackson, V. 2005. Dickinson's Misery: A Theory of Lyric Reading. Princeton.

Jackson, V., and Y. Prins, eds. 2014. The Lyric Theory Reader: A Critical Anthology. Baltimore.

Jameson, F. 1981. The Political Unconscious: Narrative as a Socially Symbolic Act. Ithaca NY. 
Jauss, H.R. 1982. Aesthetic Experience and Literary Hermeneutics. Trans. M. Shaw. Minneapolis.

Jeanmaire, H. 1939. Couroi et Courètes: essai sur l'éducation spartiate et sur les rites d'adolescence dans l'antiquité hellénique. Lille.

Jeanmaire, H. 1949. "Le traitement de la mania dans les 'Mystères' de Dionysos et des Corybantes." Journal de Psychologie 46: 64-82.

Jebb, R.C. 1905. Bacchylides: The Poems and Fragments. Cambridge.

Johnson, W.R. 1982. The Idea of Lyric: Lyric Modes in Ancient and Modern Poetry. Berkeley and Los Angeles.

Jones, J. 1962. On Aristotle and Greek Tragedy. Stanford.

Juslin, P.N., and J.A. Sloboda, eds. 2001. Music and Emotion: Theory and Research. Oxford.

Kamerbeek, J.C. 1959. The Plays of Sophocles. Vol. 2. Leiden.

Kannicht, R. 1969. Euripides: Helena. 2 vols. Heidelberg.

Käppel, L. 200o. "Bakchylides und das System der chorlyrischen Gattungen im 5. Jh. v. Chr." In A. Bagordo and B. Zimmermann, eds., Bakchylides: 100 Jahre nach seiner Wiederentdeckung, 11-27. Munich.

Karakasi, K. 2003. Archaic Korai. Los Angeles.

Kavoulaki, A. 2011. "Choral Self-Awareness: On the Introductory Anapests of Aeschylus' Supplices." In Athanassaki and Bowie 2011: 365-39o. Berlin.

Keane, C. 2006. "Life in the Text: The Corpus of Persius's Satires." In S. Braund and J. Osgood, eds., A Companion to Persius and Juvenal, 79-96. Malden MA.

Keil, C., and S. Feld. 1994. Music Grooves. Chicago.

Kenyon, F.G. 1897. The Poems of Bacchylides. London.

Kidd, S.E. 2016. "Play in Aristotle." CPh 111.4: 353-371.

Kim, J. 200o. The Pity of Achilles: Oral Style and the Unity of the Iliad. Lanham MD.

Kirk, A.E. Forthcoming. The Tally of Text: Catalogues and Inventories Across Greek Literature and Epigraphy. Cambridge.

Kissas, K. 200o. Die attischen Statuen- und Stelenbasen archaischer Zeit. Bonn.

Kivy, P. 1989. Sound Sentiment: An Essay on the Musical Emotions. Philadelphia.

Kivy, P. 199o. Music Alone: Philosophical Reflections on the Purely Musical Experience. Ithaca NY.

Kolotourou, K. 2011. "Musical Rhythms from the Cradle to the Grave." In M. Haystom and J. Wallensten, eds., Current Approaches to Religion in Ancient Greece, 169-188. Stockholm.

König, J. 2013. "Landscape and Reality in Apuleius's Metamorphoses.” In M. Paschalis and S. Panayotakis, eds., The Construction of the Real and the Ideal in the Ancient Novel, 219-241. Groningen.

Konstan, D. 2001. Pity Transformed. London.

Korsmeyer, C. 2011. Savoring Disgust: The Foul and the Fair in Aesthetics. Oxford. 
Kotsidu, H. 1991. Die musischen Agone der Panathenäen in archaischer und klassischer Zeit. Munich.

Kowalzig, B. 2004. "Changing Choral Worlds: Song-Dance and Society in Athens and Beyond." In P. Murray and P. Wilson, eds., Music and the Muses: The Culture of Mousike in the Classical Athenian City, 39-65. Oxford.

Kowalzig, B. 2006. "The Aetiology of Empire? Hero-Cult and Athenian Tragedy." In J. Davidson, F. Muecke, and P. Wilson, eds., Greek Drama III: Essays in Honour of Kevin Lee. BICS Supplement 87, 79-98. London.

Kowalzig, B. 2007a. “'And Now All the World Shall Dance!' (Eur. Bacch. 114): Dionysus' Choroi Between Drama and Ritual." In E. Csapo and M. Miller, eds., The Origins of Theater in Ancient Greece and Beyond: From Ritual to Drama, 221-251. Cambridge.

Kowalzig, B. 2007b. Singing for the Gods: Performances of Myth and Ritual in Archaic and Classical Greece. Oxford.

Kowalzig, B. 2013. "Dancing Dolphins on the Wine-Dark Sea: Dithyramb and Social Change in the Archaic Mediterranean." In Kowalzig and Wilson 2013: 31-58.

Kowalzig, B., and P. Wilson, eds. 2013. Dithyramb in Context. Oxford.

Kranz, W. 1933. Stasimon: Untersuchungen zu Form und Gehalt der griechischen Tragödie. Berlin.

Kraut, R. 1997. Aristotle: Politics, Books VII and VIII. Oxford.

Krieger, I. and B. Maslov, eds. 2016. Persistent Forms: Explorations in Historical Poetics. New York.

Kristeva, J. 1982. Powers of Horror: An Essay on Abjection. Trans. L.S. Roudiez. New York. Kroll, W. 1924. “Die Kreuzung der Gattungen." In Studien zum Verständnis der Römischen Literatur, 202-224. Stuttgart.

Kroodsma, D. 2005. The Singing Life of Birds: The Art and Science of Listening to Birdsong . New York.

Kurke, L. 1988. "The Poet's Pentathlon: Genre in Pindar's First Isthmian." GRBS 29: 97113 .

Kurke, L. 199o. "Pindar's Sixth Pythian and the Tradition of Advice Poetry." TAPhA 120: 85-107.

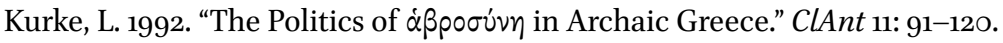

Kurke, L. 1996. "Pindar and the Prostitutes, or Reading Ancient 'Pornography', Arion 4.2: 49-75.

Kurke, L. 1997. "Inventing the Hetaira: Sex, Politics, and Discursive Conflict in Archaic Greece." ClAnt 16: 106-15o.

Kurke, L. 200o. “The Strangeness of 'Song Culture:' Archaic Greek Poetry.” In O. Taplin, ed., Literature in the Greek and Roman Worlds: A New Perspective, 58-87. Oxford.

Kurke, L. 2005. “Choral Lyric as 'Ritualization:' Poetic Sacrifice and Poetic Ego in Pindar's Sixth Paian." ClAnt 24.1: 81-130. 
Kurke, L. 2007. “Archaic Greek Poetry." In H.A. Shapiro, ed., The Cambridge Companion to Archaic Greece, 141-168. Cambridge.

Kurke, L. 2011. Aesopic Conversations: Popular Tradition, Cultural Dialogue, and the Invention of Prose. Princeton.

Kurke, L. 2012. "The Value of Chorality in Ancient Greece." In J.K. Papadopoulos and G. Urton, eds., The Construction of Value in the Ancient World, 218-235. Los Angeles.

Kurke, L. 2013a. “Imagining Chorality: Wonder, Plato's Puppets, and Moving Statues." In Peponi 2013b: 123-170.

Kurke, L. 2013b. "Pindar's Pythian 11 and the Oresteia: Contestatory Ritual Poetics in the 5th c. BCE." ClAnt 32.1: 101-175.

Kurke, L. 2016. “Gendered Spheres and Mythic Models in Sappho's Brothers Poem.” In Bierl and Lardinois 2016: 238-265.

Kyriakou, P. 2006. A Commentary on Euripides' Iphigenia in Tauris. Berlin.

Kyriakou, P. The Past in Aeschylus and Sophocles. Berlin.

Ladianou, K. 2016. "Female Choruses and Gardens of Nymphs: Visualizing Chorality in Sappho." In Cazzato and Lardinois 2016: 307-342.

Lambert, S.D. 1993. The Phratries of Attica. Ann Arbor.

Lardinois, A. 1994. "Subject and Circumstance in Sappho's Poetry." TAPhA 124: 57-84.

Lardinois, A. 1996. “Who Sang Sappho's Songs?” In E. Greene, ed., Reading Sappho: Contemporary Approaches, 150-172. Berkeley and Los Angeles.

Lardinois, A. 2001. “Keening Sappho: Female Speech Genres in Sappho's Poetry." In Lardinois and McClure 2001: 75-92.

Lardinois, A. 2011. "The Parrhesia of Young Female Choruses in Ancient Greece." In Athanassaki and Bowie 2011: 161-172.

Lardinois, A. 2014. "Sappho en haar broers: een nieuw lied van Sappho." Lampas 47.3: 179-201.

Lardinois, A. 2016. "Sappho's Brothers Song and the Fictionality of Early Greek Lyric Poetry." In Bierl and Lardinois 2016: 167-187.

Lardinois, A., and L. McClure, eds. 2001. Making Silence Speak: Women's Voices in Greek Literature and Society, Princeton.

Larson, J. 200o. "Boiotia, Athens, the Peisistratids, and the Odyssey's Catalogue of Heroines." GRBS 41: 193-222.

Larson, J. 2002. "Corinna and the Daughters of Asopos." SyllClass 13: 47-62.

Lasserre, F. 1989. Sappho: Une autre lecture. Padua.

Latour, B. 2005. Reassembling the Social: An Introduction to Actor-Network-Theory. Oxford.

Latte, K. 1953. Review of H. Fränkel, Dichtung und Philosophie des frühen Griechentums. Göttingische Gelehrte Anzeigen 207: 30-42.

Lawrence, T.E. 1955. Seven Pillars of Wisdom: A Triumph. New York.

Lawrence, T.E. 1962. The Mint. New York. 
Leaf, W. 1900-1902. The Iliad. 2nd ed. 2 vols. London.

Leduc, C. 2001. "En quoi cela concerne-t-il l' archonte? (A.P., LVI, 2-5)." Pallas 56:15-44. Lee, K.H. 1976. Euripides: Troades. London.

Lefkowitz, M.R. 1973. "Critical Stereotypes and the Poetry of Sappho." GRBS 14: 113-123. Lefkowitz, M.R. 1975. "The Influential Fictions in the Scholia to Pindar's Pythian 8." CPh 70: $173-185$.

Lefkowitz, M.R. 1991. First-Person Fictions: Pindar's Poetic 'T'. Oxford.

Lefkowitz, M.R. 2012. The Lives of the Greek Poets. 2nd ed. Baltimore.

Le Guen, B. 2001. Les associations de Technites dionysiaques à l'époque hellénistique. 2 vols. Nancy and Paris.

Lesky, A. 1966. A History of Greek Literature. Trans. J. Willis and C. de Heer. London.

LeVen, P. 2014. The Many-Headed Muse: Tradition and Innovation in Late Classical Greek Lyric Poetry. Cambridge.

Levine, C. 2015. Forms: Whole, Rhythm, Hierarchy, Network. Princeton.

Levitin, D.J. 20o6. This is Your Brain on Music: The Science of a Human Obsession. New York.

Liberman, G., ed. 1999. Alcée: Fragments. 2 vols. Paris.

Lidov, J.B. 2002. "Sappho, Herodotus, and the Hetaira." CPh 97: 203-237.

Lidov, J.B. 2016. "Songs for Sailors and Lovers." In Bierl and Lardinois 2016: 55-109.

Linforth, I.M. 1946. The Corybantic Rites in Plato. Berkeley and Los Angeles.

Lobel, E., and D. Page, eds. 1955. Poetarum Lesbiorum Fragmenta. Oxford.

Lonsdale, S.H. 1993. Dance and Ritual Play in Greek Religion. Baltimore.

Lonsdale, S.H. 1994-1995. "Homeric Hymn to Apollo: Prototype and Paradigm of Choral Performance." Arion 3.1: 25-40.

Loraux, N. 2002. The Mourning Voice: An Essay on Greek Tragedy. Trans. E.T. Rawlings. Ithaca NY.

Lord, A.B. 196o. The Singer of Tales. Cambridge MA.

Lord, A.B. 200o. The Singer of Tales. 2nd ed., ed. S. Mitchell and G. Nagy. Cambridge MA.

Lowe, N. 2007. "Epinikian Eidography." In S. Hornblower and C. Morgan, eds., Pindar's Poetry, Patrons, and Festivals From Archaic Greece to the Roman Empire, 167-176. Oxford.

Maas, P. 1921. Die neuen Responsionsfreiheiten bei Bakchylides und Pindar. Vol. 2. Berlin. Maas, M., and J.M. Snyder. 1989. Stringed Instruments of Ancient Greece. New Haven.

MacDowell, D. 1990. Demosthenes 21: Against Meidias. Oxford.

Mace, S.T. 1993. "Amour, Encore! The Development of $\delta \eta \vartheta ิ \tau \varepsilon$ in Archaic Lyric." GRBS 34: $335^{-364}$.

MacKendrick, K. 1999. Counterpleasures. New York.

Mackie, C.J., ed. 2004. Oral Performance and Its Context. Leiden and Boston.

Mackil, E. 2013. Creating a Common Polity: Religion, Economy, and Politics in the Making of the Greek Koinon. Berkeley and Los Angeles. 
MacLachlan, B. 1993. The Age of Grace: Charis in Early Greek Poetry. Princeton. Maehler, H. 1982. Die Lieder des Bakchylides. 2 vols. Leiden.

Maehler, H., ed. 2001. Pindarus. Pars II: Fragmenta, Indices. Munich and Leipzig.

Maehler, H. 2003. Bacchylides: Carmina cum Fragmentis. Munich and Leipzig.

Maehler, H. 2004. Bacchylides: A Selection. Cambridge.

Malinowski, B. 1974. Les Jardins de corail. Paris.

Manieri, A. 20o9. Agoni poetico-musicali nella Grecia antica, vol. 1: Beozia. Pisa and Rome.

March, J.R. 1987. The Creative Poet. London.

Marchand, H. 1959. "Phonetic Symbolism in English Word-Formation." Indogermanische Forschungen 64: 146-168, 256-277.

Marler, P. and H. Slabbekoorn, eds. 2004. Nature's Music: The Science of Birdsong. London.

Marshall, C.W. 2009. "Sophocles' Chryses and the Date of Iphigenia in Tauris." In Cousland and Hume 2009: 141-156.

Marshall, C.W. 2014. The Structure and Performance of Euripides' Helen. Cambridge.

Martin, G. 20og. Divine Talk: Religious Argumentation in Demosthenes. Oxford.

Martin, R.P. 1989. The Language of Heroes: Speech and Performance in the Iliad. Ithaca NY.

Martin, R.P. 1997. "Similes and Performance." In E. Bakker and A. Kahane, eds., Written Voices, Spoken Signs: Tradition, Performance, and the Epic Text, 138-166. Cambridge MA.

Martin, R.P. 2001: "Just Like a Woman: Enigmas of the Lyric Voice." In Lardinois and McClure 2001: $55^{-74}$.

Martin, R.P. 2003. "The Pipes are Brawling: Conceptualizing Musical Performance in Classical Athens." In C. Dougherty and L. Kurke, eds., The Cultures within Ancient Greek Culture, 153-180. Cambridge.

Martin, R.P. 2005. “Epic as Genre." In J.M. Foley, ed., A Companion to Ancient Epic, 9-19. Malden MA.

Martin, R.P. 2008. "Keens from the Absent Chorus: Troy to Ulster." In A. Suter, ed., Lament: Studies in the Ancient Mediterranean and Beyond, 118-138. Oxford.

Martin, R.P. 2016. "Sappho, Iambist: Abusing the Brother." In Bierl and Lardinois 2016: 110-126.

Martinelli, M.C. 2ooga. "Testi musicati, testi per la musica: ipotesi su alcuni papiri lirici." In Martinelli 2oogb: $75^{-97}$.

Martinelli, M.C., ed. 200gb. La musa dimenticata: aspetti dell'esperienza musicale greca in età ellenistica. Pisa.

Maslov, B. 2015. Pindar and the Emergence of Literature. Cambridge.

Mastronarde, D.J. 2010. The Art of Euripides: Dramatic Technique and Social Context. Cambridge. 
Mathiesen, T.J. 1999. Apollo's Lyre: Greek Music and Music Theory in Antiquity and the Middle Ages. Lincoln NE and London.

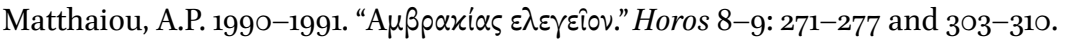

Matthiessen, K. 1964. Elektra, Taurische Iphigenie und Helena: Untersuchungen zur Chronologie und zur dramatischen Form im Spätwerk des Euripides. Göttingen.

McCall, M. 1976. "The Secondary Choruses in Aeschylus' Supplices." California Studies in Classical Antiquity 9: 117-131.

McNamee, K. 2007. Annotations in Greek and Latin Texts from Egypt. New Haven CT.

Meijering, R. 1987. Literary and Rhetorical Theories in Greek Scholia. Groningen.

Menn, S. n.d. "The Problem of the Poetics, or Why Aristotle Has No Theory of Lyric Poetry." Unpublished manuscript.

Meyer, L.B. 1956. Emotion and Meaning in Music. Chicago.

Meyerhoff, D. 1964. Traditioneller Stoff und individuelle Gestaltung: Untersuchungen zu Alkaios und Sappho. Hildesheim, Zürich, and New York.

Miller, M.C. 1993. "Priam, King of Troy." In J. Carter and S. Morris, eds., The Ages of Homer, 449-465. Austin.

Miller, P.A. 1994. Lyric Texts and Lyric Consciousness: The Birth of a Genre from archaic Greece to Augustan Rome. London and New York.

Minchin, E. 1996. "The Performance of Lists and Catalogues in the Homeric Epics." In I. Worthington, ed., Voice into Text: Orality and Literacy in Ancient Greece, 3-20. Leiden.

Miner, E. 200o. “Why Lyric?” In E. Miner and A. Dev, eds., The Renewal of Song: Renovation in Lyric Conception and Practice, 1-21. Calcutta.

Minton, W.W. 1962. "Invocation and Catalogue in Hesiod and Homer." TAPhA 93: 188212.

Miralles, C., and J. Pòrtulas. 1983. Archilochus and the Iambic Poetry. Rome.

Miralles, C., and J. Pòrtulas. 1988. The Poetry of Hipponax. Rome.

Montanari, F. 1988. I frammenti dei grammatici Agathokles, Hellanikos, Ptolemaios Epithetes: in appendice i grammatici Theophilos, Anaxagoras, Xenon, 1-128. Berlin and New York.

Morgan, K.A. 1993. "Pindar the Professional and the Rhetoric of the $x \hat{\omega} \mu \circ \varsigma^{. "}$ CPh 88: 115.

Morgan, K.A. 2015. Pindar and the Construction of Syracusan Monarchy in the Fifth Century B.c. Oxford.

Morris, I. 1996. "The Strong Principle of Equality and the Archaic Origins of Greek Democracy." In J. Ober and C. Hedrick, eds., Dēmokratia: A Conversation on Democracies, Ancient and Modern, 19-48. Princeton.

Morris, I. 20oo. Archaeology as Cultural History. Malden MA and Oxford.

Morrison, A.D. 2007. Performances and Audiences in Pindar's Sicilian Victory Odes. London. 
Morrison, A.D. 2012. "Performance, Re-performance, and Pindar's Audiences." In Agócs et al. 2012: 111-133.

Moscati Castelnuovo, L. 1989. Siris: tradizione storiografica e momenti della storia di una città della Magna Grecia. Brussels.

Most, G. and G.-B. Conte. 2012. “Genre.” In S. Hornblower et al., eds., The Oxford Classical Dictionary. 4th ed. Oxford.

Muellner, L. 1990. "The Simile of the Cranes and Pygmies: A Study of Homeric Metaphor." HSPh 93: 59-101.

Müller, K.O. 1840. A History of the Literature of Ancient Greece. London.

Munteanu, D. 2012. Tragic Pathos: Pity and Fear in Greek Philosophy and Tragedy. Cambridge.

Murnaghan, S. 2013. “The Choral Plot of Euripides' Helen." In Gagné and Hopman 2013b: $155^{-177 .}$

Murray, O., ed. 199o. Sympotica: A Symposium on the Symposion. Oxford.

Murray, O. 20o9. "The Culture of the Symposion.” In K.A. Raaflaub and H. van Wees, eds., A Companion to Archaic Greece, 508-523. Malden MA and Oxford.

Murray, P., and P. Wilson, eds. 2004. Music and the Muses: The Culture of Mousikē in the Classical Athenian City. Oxford.

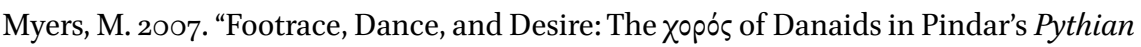
9." SIFC 5: 230-247.

Naerebout, F.G. 1997. Attractive Performances: Ancient Greek Dance: Three Preliminary Studies. Amsterdam.

Nagy, G. 1974. Comparative Studies in Greek and Indic Meter. Cambridge MA.

Nagy, G. 1976. "Iambos: Typologies of Invective and Praise." Arethusa 9:191-205.

Nagy, G. 1979. The Best of the Achaeans: Concepts of the Hero in Archaic Greek Poetry. Baltimore.

Nagy, G. 1982. “Hesiod." In T.J. Luce, ed., Ancient Writers: Greece and Rome, vol. 1, 43-73. New York.

Nagy, G. 1985. "Theognis and Megara: A Poet's Vision of His City." In T. Figueira and G. Nagy, eds., Theognis of Megara: Poetry and the Polis, 22-81. Baltimore and London.

Nagy, G. 199o. Pindar's Homer: The Lyric Possession of an Epic Past. Baltimore and London.

Nagy, G. 1993. “Alcaeus in Sacred Space.” In R. Pretagostini, ed., Tradizione e innovazione nella cultura greca da Omero all' età ellenistica: Scritti in onore di Bruno Gentili.1:221225. Rome.

Nagy, G. 1994-1995. "Genre and Occasion." Mètis 9-10: 11-25.

Nagy, G. 1996. Poetry as Performance: Homer and Beyond. Cambridge.

Nagy, G. 2004. "Transmission of Archaic Greek Sympotic Songs: From Lesbos to Alexandria." Critical Inquiry 31: 26-48. 
Nagy, G. 2007. "Did Sappho and Alcaeus Ever Meet? Symmetries of Myth and Ritual in Performing the Songs of Ancient Lesbos." In A. Bierl, R. Lämmle, and K. Wesselmann, eds., Literatur und Religion 2: Wege zu einer mythisch-rituellen Poetik bei den Griechen, 211-269. Berlin and New York.

Nagy, G. 20o8. Greek:An Updating of a Survey of Recent Work. Cambridge MA and Washington DC.

Nagy, G. 2010. “Ancient Greek Elegy." In K. Weisman, ed., The Oxford Handbook of the Elegy, 13-45. Oxford.

Nagy, G. 2011a. "Asopos and His Multiple Daughters: Traces of Preclassical Epic in the Aeginetan Odes of Pindar." In Fearn 2011: 41-78.

Nagy, G. 2011b. "Diachrony and the Case of Aesop." Classics@ 9: Defense Mechanisms in Interdisciplinary Approaches to Classical Studies and Beyond. https://chs.harvard .edu/CHS/article/display/4O24.

Nagy, G. 2011c. "The Aeolic Component of Homeric Diction." In S.W. Jamison, H.C. Melchert, and B. Vine, eds., Proceedings of the 22nd Annual UCLA Indo-European Conference, $133^{-179 . ~ B r e m e n . ~}$

Nagy, G. 2013a. The Ancient Greek Hero in 24 Hours. Cambridge MA.

Nagy, G. 2013b. "The Delian Maidens and Their Relevance to Choral Mimesis in Classical Drama." In Gagné and Hopman 2013b: 227-256. Cambridge.

Nagy, G. 2015. Masterpieces of Metonymy: From Ancient Greek Times to Now. Cambridge MA and Washington DC.

Nagy, G. 2016. "A Poetics of Sisterly Affect in the Brothers Song and in Other Songs of Sappho." In Bierl and Lardinois 2016: 449-492.

Neer, R.T. 2002. Style and Politics in Athenian Vase Painting: The Craft of Democracy, ca. 530-46о всE. Cambridge.

Neer, R.T. 2010. The Emergence of the Classical Style in Greek Sculpture. Chicago.

Neer, R.T., and L. Kurke. 2014. "Pindar Fr. 75 SM and the Politics of Athenian Space." GRBS 54.4: 527-579.

Neer, R.T., and L. Kurke. 2019. Pindar, Song, and Space: Towards a Lyric Archaeology. Baltimore.

Negri, M. 2001. "Ptolemaios: chi era costui? Sulla paternità e i contenuti del Peri statikes poieseos (Ptol. Epith. fr. 6* Montanari)." Paideia 56: 123-155.

Negri, M. 2004. Pindaro ad Alessandria: le edizioni e gli editori. Brescia.

Nehamas, A. 1982. "Plato on Imitation and Poetry in Republic 10." In J. Moravcsik and P. Temko, eds., Plato on Beauty, Wisdom, and the Arts, 47-78. Totowa NJ.

Neitzel, H. 1967. Die dramatische Funktion der Chorlieder in den Tragodien des Euripides. Dissertation. University of Hamburg.

Neri, C. 2014. "Una festa auspicata? (Sapph. Fr. 17 V e p. gc. inv. 105 fr. 2 c. ii rr. 9-28).” Eikasmos 25: 11-23.

Neri, C. 2015. "Il Brothers Poem e l'edizione alessandrina (in margine a P. Sapph. Obbink)." Eikasmos 26: 53-76. 
Nettl, B. 2005. The Study of Ethnomusicology: Thirty-one Issues and Concepts. 2nd ed. Urbana.

Newman, W.L. 1902. The Politics of Aristotle. Vol. 3. Oxford.

Nicolosi, A. 2007. Ipponatte, "Epodi di Strasburgo"-Archiloco, "Epodi di Colonia" (con un'appendice su P. Oxy. LXIX 4708). Bologna.

Nishimura-Jensen, J. 20oo. "Unstable Geographies: The Moving Landscape in Apollonius's Argonautica and Callimachus's Hymn to Delos." TAPhA 130: 287-317.

Noland, C. 2009. Agency and Embodiment: Performing Gestures/Producing Culture. Cambridge MA.

Notopoulos, J.A. 1949. "Parataxis in Homer: A New Approach to Homeric Literary Criticism." TAPhA 80: 1-23.

Nünlist, R. 2009. The Ancient Critic at Work: Terms and Concepts of Literary Criticism in Greek Scholia. Cambridge.

Obbink, D. 2014. "Two New Poems by Sappho." ZPE 189: 32-49.

Obbink, D. 2016a. "The Newest Sappho: Text, Apparatus Criticus, and Translation." In Bierl and Lardinois 2016: 13-33.

Obbink, D. 2016b. "Ten Poems of Sappho: Provenance, Authenticity, and Text of the New Sappho Papyri." In Bierl and Lardinois 2016:34-54.

Obbink, D. 2016c. "Goodbye Family Gloom! The Coming of Charaxos in the Brothers Song." In Bierl and Lardinois 2016: 208-224.

O’Higgins, D.M. 1990. “Sappho's Splintered Tongue: Silence in Sappho 31 and Catullus 51." AJPh 111: 156-167.

O'Higgins, D.M. 2001. "Women's Cultic Joking and Mockery: Some Perspectives." In Lardinois and McClure 2001: 137-160.

O'Higgins, D.M. 2003. Women and Humor in Classical Greece. New York and Cambridge.

Oliensis, E. 1998. Horace and the Rhetoric of Authority. Cambridge.

Olsen, S. 2015. "Conceptualizing Choreia on the François Vase: Theseus and the Athenian Youths." Mètis 13: 107-121.

Olsen, S. 2017. "Kinesthetic Choreia: Empathy, Memory, and Dance in Ancient Greece.” CPh 112: 153-174.

Olson, E. 1969. “The Lyric." Papers of the Midwest Modern Language Association 1: 5966.

Olson, E. 1976. On Value Judgments in the Arts, and Other Essays. Chicago.

Olson, S.D., ed. 2006-2012. Athenaeus: The Learned Banqueters. 8 vols. Cambridge MA and London.

Ong, W.J. 1982. Orality and Literacy. London.

Ormand, K. 2014. The Hesiodic Catalogue of Women and Archaic Greece. Cambridge.

O'Sullivan, N. 1992. Alcidamas, Aristophanes, and the Beginnings of Greek Stylistic Theory. Stuttgart. 
O'Sullivan, P. 2008. "Aeschylus, Euripides, and Tragic Painting: Two Scenes from Agamemnon and Hecuba." AJPh 129.2: 173-198.

Owen, S. 2003. "Of Dogs and Men: Archilochos, Archaeology, and the Greek Settlement of Thasos." PCPhS 49: 1-18.

Page, D. 1955. Sappho and Alcaeus: An Introduction to the Study of Ancient Lesbian Poetry. Oxford.

Panagl, O. 1971. Die 'dithyrambischen Stasima' des Euripides: Untersuchungen zur Komposition und Erzähltechnik. Vienna.

Pangle, T.L., trans. 1980. The Laws of Plato, Translated, with Notes and an Interpretive Essay. New York.

Pappas, A. 2014. "An Iambic Scepter? The Akhnymenē Skytalē of Archilochus." Arethusa 47.1: $19-38$.

Parker, H.N. 1993. "Sappho Schoolmistress." TAPhA 123: 309-351.

Parker, H.N. 2005. “Sappho's Public World.” In E. Greene, ed., Women Poets in Ancient Greece and Rome, 3-24. Norman.

Parker, R. 1983. Miasma: Pollution and Purification in Early Greek Religion. Oxford.

Parker, R. 1996. Athenian Religion: A History. Oxford.

Parker, R. 2005. Polytheism and Society at Athens. Oxford.

Parry, H. 1965. "The Second Stasimon of Euripides' Heracles (637-700)." AJPh 86: 363374.

Parry, M. 1971. The Making of Homeric Verse: The Collected Papers of Milman Parry, ed. A. Parry. Oxford.

Patel, A.D. 2008. Music, Language and the Brain. Oxford.

Patey, D.L. 1993. "'Aesthetics' and the Rise of Lyric in the Eighteenth Century." Studies in English Literature 33.3: 587-6o8.

Payne, M. 2010. The Animal Part: Human and Other Animals in the Poetic Imagination. Chicago.

Payne, M. 2018. "Fidelity and Farewell: Pindar's Ethics as Textual Events." In Budelmann and Phillips 2018: 257-274.

Peek, W. 1976. "Grabepigramm aus Selinus." ZPE 23: 93-94.

Pelosi, F. 2010. Plato on Music, Soul and Body. Trans. S. Henderson. Cambridge.

Peponi, A.-E. 2002. "Mixed Pleasures, Blended Discourses: Poetry, Medicine, and the Body in Plato's Philebus 46-47c." ClAnt 21: 135-16o.

Peponi, A.-E. 2004. "Initiating the Viewer: Deixis and Visual Perception in Alcman's Lyric Drama." Arethusa 37: 295-316.

Peponi, A.-E. 20o9. "Choreia and Aesthetics in the Homeric Hymn to Apollo: The Performance of the Delian Maidens (Lines 156-164)." ClAnt 28: 39-70.

Peponi, A.-E. 2012. Frontiers of Pleasure: Models of Aesthetic Response in Archaic and Classical Greek Thought. Oxford.

Peponi, A.-E. 2013a. “Choral Anti-Aesthetics." In Peponi 2013b: 212-239. 
Peponi, A.-E. ed. 2013b. Performance and Culture in Plato's Laws. Cambridge.

Peponi, A.-E. 2013c. “Theorizing the Chorus in Greece." In Billings et al. 2013: 1534 .

Peponi, A.-E. 2015. “Dance and Aesthetic Perception.” In Destrée and Murray 2015: 204217.

Peponi, A.-E. 2016. "Sappho and the Mythopoetics of the Domestic." In Bierl and Lardinois 2016: $225^{-237 .}$

Perceau, S. 2002. La parole vive: communiquer en catalogue dans l'épopée homérique. Louvain and Paris.

Petrovic, A., I. Petrovic, and E. Thomas, eds. 2019. The Materiality of Text-Placement, Perception, and Presence of Inscribed Texts in Classical Antiquity. Leiden and Boston.

Pfeiffer, R. 1968. History of Classical Scholarship: From the Beginnings to the End of the Hellenistic Age. Oxford.

Pfeijffer, I.L. 1999a. “Bacchylides' Homer, His Tragedy, and His Pindar.” In I.J. Pfeijffer and S.R. Slings, eds., One Hundred Years of Bacchylides, 43-6o. Amsterdam.

Pfeijffer, I.L. 1999b. Three Aeginetan Odes of Pindar: A Commentary on Nemean V, Nemean III, and Pythian VIII. Leiden.

Phillips, T. 2018. "Polyphony, Event, Context: Pindar, Paean 9." In Budelmann and Phillips 2018: 189-209.

Pironti, G. 2007. Entre ciel et guerre: figures d'Aphrodite en Grèce ancienne. Liège.

Pisani, V. 1938. "Sulla radice П $\Lambda \mathrm{I \Xi -”} \mathrm{AIPhO} \mathrm{6:181-192.}$

Platnauer, M. 1938. Euripides: Iphigenia in Tauris. Oxford.

Platter, C. 1994. "Heracles, Deianeira, and Nessus: Reverse Chronology and Human Knowledge in Bacchylides 16." AJPh 115: 337-349.

Poerner, J. 1913. De Curetibus et Corybantibus. Dissertation. Halle.

Pöhlmann, E., and M.L. West. 2001. Documents of Ancient Greek Music: The Extant Melodies and Fragments. Oxford.

de Polignac, F. 1984. La naissance de la cité grecque: cultes, espace et société VIIIe-VIIe siècles avant J.-C. Paris.

Porter, J.I. 1992. "Hermeneutic Lines and Circles: Aristarchus and Crates on the Exegesis of Homer." In R. Lamberton and J.J. Keaney, eds., Homer's Ancient Readers: The Hermeneutics of Greek Epic's Earliest Exegetes, 67-114. Princeton.

Porter, J.I. 2010. The Origins of Aesthetic Thought in Ancient Greece: Matter, Sensation, and Experience. Cambridge.

Porter, J.I. 2011. "Making and Unmaking: The Achaean Wall and the Limits of Fictionality in Homeric Criticism." TAPhA 141.1: 1-36.

Porter, J.I. 2015. "Jacob Bernays and the Katharsis of Modernity." In Billings and Leonard 2015: 15-41.

Power, T. 2000. "The Parthenoi of Bacchylides 13." HSPh 100: 67-81.

Power, T. 2010. The Culture of Kitharöidia. Washington DC. 


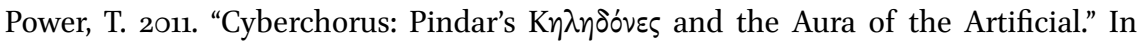
Athanassaki and Bowie 2011: 67-113.

Power, T. 2012. "Sophocles and Music." In A. Markantonatos, ed., Brill's Companion to Sophocles, 283-304. Leiden and Boston.

Power, T. 2018. "The Sound of the Sacred." In S. Butler and S. Nooter, eds., Sound and the Ancient Senses, 15-30. London and New York.

Prauscello, L. 2006. Singing Alexandria: Music Between Practice and Textual Transmission. Leiden and Boston.

Prauscello, L. 2012. “Epinician Sounds: Pindar and Musical Innovation.” In Agócs et al. 2012: 58-82.

Prauscello, L. 2013. "Demeter and Dionysos in the Sixth-Century Argolid: Lasos of Hermione, the Cult of Demeter Chthonia, and the Origins of Dithyramb." In Kowalzig and Wilson 2013: 76-92.

Prauscello, L. 2014. Performing Citizenship in Plato's Laws. Cambridge.

Pretagostini, R. 2009. "Occasioni di performances musicali in Callimaco e in Teocrito." In Martinelli 2oogb: 3-3o.

Prins, Y. 1999. Victorian Sappho. Princeton.

Prins, Y. 2013. "Metrical Discipline: Algernon Swinburne on 'The Flogging Block.'” In C. Maxwell and S. Evangelista, eds., Algernon Charles Swinburne: Unofficial Laureate, 95-124. Manchester.

Privitera, G.A. 1988. "Pindaro, Nem. III 1-5, e l'acqua di Egina." QUCC 58 (n.s. 29): 63-70.

Purves, A. 2013a. "Thick Description: From Auerbach to the Boar's Lair (Od. 19.388475)." In M. Skempis and I. Ziogas, eds., Geography, Topography, Landscape: Configurations of Space in Greek and Roman Epic, 37-62. Berlin.

Purves, A. 2013b. "Haptic Herodotus." In Butler and Purves 2013: 27-42.

Purves, A. 2014. "Who, Sappho?” In R. Scodel and D. Cairns, eds., Defining Greek Narrative. Edinburgh Leventis Studies, vol. 7. 175-196. Edinburgh.

Purves, A. 2015. "Ajax and Other Objects: Homer's Vibrant Materialism." Ramus 44: 7594.

Purves, A. Forthcoming. "Rough Reading: Tangible Language in Dionysius's Criticism of Homer." In J. Grethlein, L. Huitlink, A. Tagliabue, eds., Experience, Narrative, and Criticism.

Quijada, M. 2006. “'Por Ilión, ¡Oh Musa!, cántame entre lágrimas un canto de duelo, un himno Nuevo' (Eurípides, Troyanas 511 ss.)." In E. Calderón, A. Morales, and M. Valverde, eds., Koinòs Lógos: Homenaje al Profesor José García López, 841-853. Murcia.

Race, W.H., trans. 1997. Pindar. 2 vols. Cambridge MA.

Rancière, J. 2004. The Politics of Aesthetics: The Distribution of the Sensible, trans. G. Rockhill. London and New York.

Randone, G.F. 2013. "I distici del polyandrion dei Ambracia: un dibattito interrorro." Acme 66: 33-52. 
Rehm, R. 1996-1997. "Performing the Chorus: Choral Action, Interaction, and Absence in Euripides." Arion 4: 45-6o.

Rehm, R. 2002. The Play of Space: Spatial Transformation in Greek Tragedy. Princeton. Riemer, P. 2000. "Die 'ewige Deianeira." In A. Bagordo and B. Zimmermann, eds., Bakchylides: 100 Jahre nach seiner Wiederentdeckung, 169-182. Munich.

Revermann, M. 2006. "The Competence of Theatre Audiences in Fifth- and FourthCentury Athens." JHS 126: 99-124.

Reynolds, L.D., and N.G. Wilson. 1991. Scribes and Scholars: A Guide to the Transmission of Greek and Latin Literature. 3 rd ed. Oxford.

Richardson, N. 2010. Three Homeric Hymns: To Apollo, Hermes, and Aphrodite. Cambridge.

Richer, N. 2012. La religion des Spartiates: croyances et cultes dans l'Antiquité. Paris.

Richlin, A. 1992. The Garden of Priapus: Sexuality and Aggression in Roman Humor. Rev. ed. Oxford.

Rissman, L. 1983. Love as War: Homeric Allusion in the Poetry of Sappho. Königstein.

Ristani, M. 2016. "Articulated Arrhythmia: Samuel Beckett's Shorter Plays." In S.J. Bailes and N. Till, eds., Beckett and Musicality, 119-135. London and New York.

Robbins, E. 1994. "Alkman's Partheneion: Legend and Choral Ceremony." CQ 44: 7-16.

Robert, L. 196o. "Recherches épigraphiques: v. Inscriptions de Lesbos." REA 62: 285-315.

Roller, L.E. 1996. "Reflections of the Mother of the Gods in Attic Tragedy." In E.N. Lane, ed., Cybele, Attis and Related Cults: Essays in Memory of M.J. Vermaseren, 305-321. Leiden.

Roller, L.E. 1999. In Search of God the Mother: The Cult of Anatolian Cybele. Berkeley and Los Angeles.

Römer, C. 2013. "Alcman.” In G. Bastianini, M. Haslam, H. Maehler, F. Montanari, and C. Römer, eds., Commentaria et lexica Graeca in papyris reperta, I.2.1. 2nd ed. BerlinBoston.

Rosen, R. 1988. Old Comedy and the Iambographic Tradition. Atlanta.

Rosen, R. 2007. "The Hellenistic Epigrams on Archilochus and Hipponax." In Bing and Bruss 2007: 459-476.

Rosenmeyer, P.A. 2006. “Sappho's Iambics." Letras Clássicas 10: 11-36.

Rösler, W. 1980. Dichter und Gruppe: eine Untersuchung zu den Bedingungen und zur historischen Funktion früher griechischer Lyrik am Beispiel Alkaios. Munich.

Rösler, W. 1985. "Persona reale o persona poetica? L'interpretazione dell'io nella lirica greca arcaica." QUCC 48: 131-144.

Ross, W.D. 1957. Aristotelis Politica. Oxford.

Rossi, L.E. 1971. "I generi letterari e le loro leggi scritte e non scritte nelle lettere classiche." BICS 18: 69-94.

Rossi, L.E. 1988. "La dottrina dell' 'ethos' musicale e il simposio." In B. Gentili and R. Pretagostini, eds., La musica in Grecia, 238-245. Rome and Bari. 
Rotstein, A. 2010. The Idea of Iambos. Oxford.

Rotstein, A. 2012. "Mousikoi Agones and the Conceptualization of Genre in Ancient Greece." ClAnt 31.1: 92-127.

Rouget, G. 1985. Music and Trance: A Theory of the Relations between Music and Possession. 2nd. ed. Chicago.

Rutherford, I. 1991. "Neoptolemus and the Paean-Cry: An Echo of a Sacred Aetiology in Pindar." ZPE 88: 1-10.

Rutherford, I. 1994-1995. “Apollo in Ivy: The Tragic Paean.” Arion 3.1: 112-135.

Rutherford, I. 1997. “'For the Aeginetans to Aiakos a Prosodion:' An Unnoticed Title at Pindar, Paean 6, 123, and Its Significance for the Poem." ZPE 118: 1-21.

Rutherford, I. 2001. Pindar's Paeans: A Reading of the Fragments with a Survey of the Genre. Oxford and New York.

Rutherford, I. 2013. "Chorus, Song, and Anthropology." In Billings, Budelmann, and Macintosh 2013: 67-77.

Sacks, O. 2008. Musicophilia: Tales of Music and the Brain. Rev. ed. New York.

Sammons, B. 2010. The Art and Rhetoric of the Homeric Catalogue. Oxford.

Sansone, D. 2009. "Euripides' New Song: The First Stasimon of the Trojan Women." In Cousland and Hume 2009: 193-203.

Saussure, F. de. 1972. Cours de linguistique générale. Ed. T. de Mauro. Paris.

Scafuro, A. 2004. "The role of the prosecutor and Athenian legal procedure (Dem. 21.10)." Dike 7: 113-133.

Schachter, A. 1981-1994. Cults of Boeotia. 4 vols. London.

Schechner, R. 2006. Performance Studies: An Introduction. 2nd ed. New York and London.

Schein, S.L. 1987. "Unity and Meaning in Pindar's Sixth Pythian Ode." Mètis 2: 235-247.

Schiesaro, A. 1993. "Il locus horridus nelle Metamorfosi di Apuleio." Maia 37: 211-223.

Schironi, F. 2016. "Alcman's Semi-Choruses—in the Text ... and Beyond It." MD 76: 33$5^{2 .}$

Schironi, F. 2018. The Best of the Grammarians: Aristarchus of Samothrace on the Iliad. Ann Arbor.

Schlesier, R. 2013. "Atthis, Gyrinno, and Other Hetairai: Female Personal Names in Sappho's Poetry." Philologus 157: 199-222.

Schlesier, R. 2016. "Loving, but not Loved: The New Kypris Song in the Context of Sappho's Poetry." In Bierl and Lardinois 2016: 368-395.

Schmidt, D.A. 1990. "Bacchylides 17-Paean or Dithyramb?" Hermes 118: 18-31.

Schwartz, J. 1954. "Papyrus homériques (II)." BIAO 54: 45-71.

Schwenn, F. 1922. "Korybanten." In A. Pauly, G. Wissowa, and W. Kroll, eds., RealEncyclopädie der klassischen Altertumswissenschaft, 11: 1441-1446. Stuttgart.

Schwinge, E.-R. 1962. Die Stellung der Trachinierinnen im Werke des Sophokles. Göttingen. 
Scott, W.C. 1996. Musical Design in Sophoclean Theater. Hanover NH and London.

Scullion, S. n.d. "Maenads and Men." http://www.classics.ox.ac.uk/tl_files/Downloads/ Maenads-and-Men.pdf/. URL last retrieved July 5, 2017.

Searle, J.R. 1969. Speech Acts: An Essay in the Philosophy of Language. Cambridge.

Sedgwick, E.K. 2003. "Around the Performative: Periperformative Vicinities in Nineteenth-Century Narrative." In Touching Feeling: Affect, Pedagogy, Performativity, 6791. Durham NC and London.

Sedgwick, E.K. 2011. “Cavafy, Proust, and the Queer Little Gods.” In J. Goldberg, ed., The Weather in Proust, 42-68. Durham NC and London.

Segal, C. 1993. Euripides and the Poetics of Sorrow: Art, Gender, and Commemoration in Alcestis, Hippolytus, and Hecuba. Durham NC.

Seidensticker, B. 1978. "Archilochus and Odysseus." GRBS 19: 5-22.

Seigworth, G.J., and M. Gregg. 2010. "An Inventory of Shimmers.” In M. Gregg and G.J. Seigworth, eds., The Affect Theory Reader, 1-25. Durham NC.

Selden, D.L. 2014. "Apuleius and Afroasiatic Poetics." In B.T. Lee, E. Finkelpearl, and L. Graverini, eds., Apuleius and Africa, 205-270. New York and London.

Severyns, A. 1938. Recherches sur la Chrestomathie de Proclos. Vol. 2. Paris.

Shaw, B.D. 2013. Bringing in the Sheaves: Economy and Metaphor in the Roman World. Toronto.

Sifakis, G.M. 2001. Aristotle on the Function of Tragic Poetry. Herakleion.

Silverman, K. 1992. Male Subjectivity at the Margins. New York.

Silverstein, M. 1993. "Metapragmatic Discourse and Metapragmatic Function." In J.A. Lucy, ed., Reflexive Language:Reported Speech and Metapragmatics, 33-58. Cambridge.

Sklar, D. 2008. "Remembering Kinesthesia: An Inquiry into Embodied Cultural Knowledge." In C. Noland and S.A. Ness, eds., Migrations of Gesture, $85^{-111}$. Minneapolis.

Slings, S.R. 199o. “The I in Personal Archaic Lyric: An Introduction.” In S.R. Slings, ed., The Poet's I in Archaic Greek Lyric: Proceedings of a Symposium Held at the Vrije Universiteit Amsterdam, 1-30. Amsterdam.

Smith, B.H. 1978. On the Margins of Discourse: The Relation of Literature to Language. Chicago.

Snell, B. 1946. Die Entdeckung des Geistes: Studien zur Entstehung des europäischen Denkens bei den Griechen. Hamburg.

Snell, B. 1953. "Der Anfang eines äolischen Gedichts." Hermes 81: 118-119.

Snell, B. and H. Maehler, eds. 1987. Pindarus. Pars I: Epinicia. Stuttgart and Leipzig.

Sourvinou-Inwood, C. 1995. "Reading" Greek Death: To the End of the Classical Period. Oxford.

Spelman, H. 2018. Pindar and the Poetics of Permanence. Oxford.

Squire, M., ed. 2015. Sight and the Ancient Senses. Durham UK. 


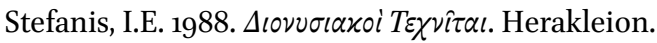

Stehle [Stigers], E. 1981. "Sappho's Private World." In Foley 1981: 45-61.

Stehle [Stigers], E. 1997. Performance and Gender in Ancient Greece: Nondramatic Poetry in Its Setting. Princeton.

Stehle [Stigers], E. 2009. "Greek Lyric and Gender." In Budelmann 2009: 58-71.

Stehle [Stigers], E. 2016. "Larichos in the Brothers Poem: Sappho Speaks Truth to the Wine-Pourer." In Bierl and Lardinois 2016: 266-292.

Steiner, D.T. 2010. "Framing the Fox: Callimachus's Second Iamb and Its Predecessors." JHS 130: 97-107.

Steiner, D.T. 2012a. "Drowning Sorrows: Archilochus fr. 13 W. in Its Performance Context." GRBS 52: 21-56.

Steiner, D.T. 2012b. "Fables and Frames: The Poetics and Politics of Animal Fables in Hesiod, Archilochus, and the Aesopica." Arethusa 45:1-41.

Steiner, D.T. 2013. "The Gorgons' Lament: Auletics, Poetics, and Chorality in Pindar's Pythian 12." AJPh 134.2: 173-208.

Steiner, D.T. 2014a. "Greek and Roman Theories of Art." In C. Marconi, ed., The Oxford Handbook of Greek and Roman Art and Archaeology, 21-40. Oxford.

Steiner, D.T. 2014b. "Solon fr. 1-3 W: The Poetics and Politics of a Gesture." Cahiers "Mondes Anciens" 5: 1-17.

Steiner, D.T. 2016. "Making Monkeys: Archilochus frr. 185-187 W." In Cazzato and Lardinois 2016: 108-145.

Steiner, D.T. 2018. "Lists in Performance: Maritime Catalogues, Naval Inventories and Choral Song and Dance in the Archaic and Classical Period." Mètis 16: 139-165.

Steiner, D.T. Forthcoming. Choral Constructions: The Idea of the Chorus in Archaic and Early Classical Greece. Cambridge.

Stephens, S.A. 2002-2003. "Linus Song." Hermathena 173-174: 13-28.

Sternberg, R.H., ed. 2005. Pity and Power in Ancient Athens. Cambridge.

Sternberg, R.H. 20o6. Tragedy Offstage: Suffering and Sympathy in Ancient Athens. Austin.

Stewart, S. 2002. Poetry and the Fate of the Senses. Chicago.

Stoessl, F. 1945. Der Tod des Herakles. Zurich.

Suter, A. 2003. "Lament in Euripides' Trojan Women." Mnemosyne 56.1: 1-28.

Sweetman, P. 1999. "Only Skin Deep? Tattooing, Piercing and the Transgressive Body." In M. Aaron, ed., The Body's Perilous Pleasures: Dangerous Desires and Contemporary Culture, $165^{-187}$. Edinburgh.

Swift, L. 2010. The Hidden Chorus: Echoes of Genre in Tragic Lyric. Oxford.

Swift, L. 2011. "Epinician and Tragic Worlds: The Case of Sophocles' Trachiniae." In Athanassaki and Bowie 2011: 391-413.

Swift, L. 2015. "Negotiating Seduction: Archilochus' Cologne Epode and the Transformation of Epic." Philologus 159.1: 2-28. 
Swift, L. 2016a. "Poetics and Precedents in Archilochus's Erotic Imagery." In Swift and Carey 2016: 253-270.

Swift, L. 2016b. "Visual Imagery in Parthenaic Song." In Cazzato and Lardinois 2016: 255287.

Swift, L., and C. Carey, eds. 2016. Iambus and Elegy: New Approaches. Oxford.

Swift, L., ed. 2019. Archilochus: The Poems. Oxford.

Telò, M. 2014. "On the Sauce: Cratinus, Cyclopean Poetics, and the Roiling Sea of Epic." Arethusa 47.3: 303-320.

Telò, M. 2016. Aristophanes and the Cloak of Comedy: Affect, Aesthetics, and the Canon. Chicago.

Thévenaz, O. Forthcoming. "Sappho's Soft Heart and Kypris' Light Wounds: The Restoration of the Helen Poem (esp. Sa. 16.13-14) and Ovid's Sappho Epistle."

Thomas, O. 2018. "Hermetically Unsealed: Lyric Genres in the Homeric Hymn to Hermes." In Budelmann and Phillips 2018: 173-188.

Thomas, R. 1989. Oral Tradition and Written Record in Classical Athens. Cambridge.

Thomas, R. 1992. Literacy and Orality in Ancient Greece. Cambrige.

Todorov, T. 1990. Genres in Discourse. Cambridge.

Tognazzi, G. 2009. "Il fr. 27 V. di Saffo." QUCC 91: 51-62.

Toohey, P. 1988. “Archilochus's General (fr. 114 W): Where Did He Come From?” Eranos 86: $1-14$.

Torrance, I. 2013. Metapoetry in Euripides. Oxford.

Tsagalis, C. 2008. Inscribing Sorrow: Fourth-Century Attic Funerary Epigrams. Berlin and New York.

Tsagalis, C. 2009. "Blurring the Boundaries: Dionysus, Apollo and Bacchylides 17." In Athanassaki et al. 2009: 199-215.

Tsomis, G. 2001. Zusammenschau der frühgriechischen monodischen Melik. Stuttgart.

Tueller, M. 2010. "The Passer-by in Archaic and Classical Epigram." In Baumbach et al. 2010: 42-6o.

Turner, V. 1982. From Ritual to Theatre: The Human Seriousness of the Play. New York.

Uhlig, A. 2017. "Models of Reperformance in Bacchylides." In Hunter and Uhlig 2017: $111-137$.

Ustinova, Y. 1992-1998. "Corybantism: The Nature and Role of an Ecstatic Cult in the Greek Polis." Horos 10-12: 503-520.

van der Valk, M. 1963. Researches on the Text and Scholia of the Iliad. Leiden.

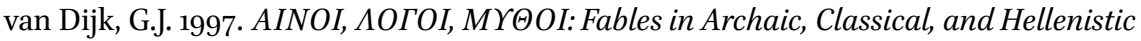
Greek Literature. Leiden.

Van Oeveren, C.D.P. 1999. "Bacchylides Ode 17: Theseus and the Delian League." In I.L. Pfeijffer and S.R. Slings, eds., One Hundred Years of Bacchylides, 31-42. Amsterdam.

Vernant, J.-P. 1991. Mortals and Immortals: Collected Essays, ed. F.I. Zeitlin. Princeton. 
Vetta, M. 1981. "Poesia e simposio (A proposito di un libro recente sui carmi di Alceo)." RFIC 109: 483-495.

Vetta, M. 1992. "Il simposio: la monodia e il giambo." In G. Cambiano, L. Canfora, and D. Lanza, eds., Lo spazio letterario della Grecia antica, vol. 1: La produzione e la circolazione del testo, 1: La polis, 177-218. Rome.

Vine, B. 2009. "A Hipponactean Echo in Catullus (Frigus, 44.20)." CPh 104: 213-216.

Voigt, E.-M., ed. 1971. Sappho et Alcaeus: Fragmenta. Amsterdam.

Wallace, R.W. 2005. "Performing Damon's Harmoniai." In S. Hagel and C. Harrauer, eds., Ancient Greek Music in Performance, 147-157. Vienna.

Wallin, N.L., B. Merker, and S. Brown, eds. 200o. The Origins of Music. Cambridge MA.

Waters, W. 2003. Poetry's Touch: On Lyric Address. Ithaca NY.

Wecowski, M. 2014. The Rise of the Greek Aristocratic Banquet. Oxford and New York.

Weiss, N. 2014. "The Antiphonal Ending of Euripides' Iphigenia in Aulis (1475-1532)." CPh 109.2: 119-129.

Weiss, N. 2016. “The Choral Architecture of Pindar's Eighth Paean.” TAPhA 146.2: 237255 .

Weiss, N. 2017. "Noise, Music, Speech:The Representation of Lament in Greek Tragedy." AJPh 138: 243-266.

Weiss, N. 2018. The Music of Tragedy: Performance and Imagination in Euripidean Theater. Oakland.

Wellek, R. 1967. "Genre Theory, Lyric and the Erlebnis." In H. Singer and B. von Wiese, eds., Festschrift für Richard Alewyn, 392-412. Cologne.

West, M.L. 1970. "Burning Sappho." Maia 22: 307-33o.

West, M.L. 1971. "Stesichorus." CQ 21: 302-314.

West, M.L. 1974. Studies in Greek Elegy and Iambus. Berlin and New York.

West, M.L. 1983. The Orphic Poems. Oxford.

West, M.L. 1985. The Hesiodic Catalogue of Women. Oxford.

West, M.L., ed. 1989-1992. Iambi et Elegi Graeci. 2 vols. 2nd Edition. Oxford.

West, M.L. 1992. Ancient Greek Music. Oxford.

West, M.L. 2013. The Epic Cycle. Oxford.

West, M.L. 2014. "Nine Poems of Sappho." ZPE 191: 1-12.

West, M.L. 2015. “Epic, Lyric, and Lyric Epic.” In P.J. Finglass and A. Kelly, eds., Stesichorus in Context, 63-80. Cambridge.

West, S. 1988. “Archilochus' Message-Stick." CQ 38.1: 42-48.

Whitman, C. 1958. Homer and the Homeric Tradition. Cambridge MA.

Wilamowitz-Moellendorff, U. von. 1913. Sappho und Simonides: Untersuchungen über griechische Lyriker. Berlin.

Wilamowitz-Moellendorff, U. 1921. Griechische Verskunst. Berlin.

Willi, A. 2008. Sikelismos: Sprache, Literaturund Gesellschaft im griechischen Sizilien(8.5.Jh. v. Chr.). Basel. 
Williams, G. 1968. Tradition and Originality in Roman Poetry. Oxford.

Williams, L. 1991. "Film Bodies: Gender, Genre, and Excess." Film Quarterly 44.4: 213 .

Williamson, M. 1995. Sappho's Immortal Daughters. Cambridge MA.

Williamson, M. 1998. "Eros the Blacksmith: Performing Masculinity in Anakreon's Love Lyrics." In L. Foxhall and J. Salmon, eds., Thinking Men: Masculinity and Its SelfRepresentation in the Classical Tradition, 71-82. London and New York.

Wilson, P. 1999. "The Aulos in Athens." In S. Goldhill and R. Osborne, eds., Performance Culture and Athenian Democracy, 58-95. Cambridge.

Wilson, P. 1999-200o. “Euripides' Tragic Muse." In Cropp et al. 1999-200o: 427-499.

Wilson, P. 200o. The Athenian Institution of the Khoregia: The Chorus, the City, and the Stage. Cambridge.

Wilson, P. 2007. "Performance at the Pythion: The Athenian Thargelia." In P.Wilson, ed., The Greek Theatre and Festivals: Documentary Studies, 150-182. Oxford.

Wilson, P. 20og. “Thamyris the Thracian: The Archetypal Wandering Poet?” In R. Hunter and I. Rutherford, eds., Wandering Poets in Ancient Greek Culture, 46-79. Cambridge.

Wimsatt, W.K., and M.C. Beardsley. 1949. "The Affective Fallacy." Sewanee Review 57.1: $31-55$.

Winkler, J.J. 1981. “Gardens of Nymphs: Public and Private in Sappho's Lyrics." In Foley 1981: 63-89.

Winkler, J.J. 199o. “Double Consciousness in Sappho's Lyrics." In J.J. Winkler, The Constraints of Desire: The Anthropology of Sex and Gender in Ancient Greece, 162-187. New York and London.

Wohl, V. 1998. Intimate Commerce: Exchange, Gender, and Subjectivity in Greek Tragedy. Austin.

Worman, N. 2015a. Landsape and the Spaces of Metaphor in Ancient Literary Theory and Criticism. Cambridge.

Worman, N. 2015b. "Stylistic Landscapes." In Destrée and Murray 2015: 291-306.

Wright, M. 2005. Euripides' Escape Tragedies: A Study of Helen, Andromeda, and Iphigenia Among the Taurians. Oxford.

Yatromanolakis, D. 1999. "Alexandrian Sappho Revisited." HSPh 99: 179-195.

Yatromanolakis, D. 2004. "Ritual Poetics in Archaic Lesbos: Contextualizing Genre in Sappho." In D. Yatromanolakis and P. Roilos, eds., Greek Ritual Poetics, 56-70. Washington DC.

Yatromanolakis, D. 2007. Sappho in the Making: The Early Reception. Cambridge MA. Yatromanolakis, D. 20o9a. "Alcaeus and Sappho." In Budelmann 20og: 204-226.

Yatromanolakis, D. 20ogb. "Ancient Greek Popular Song." In Budelmann 20o9: 263276.

Yeager, P., ed. 2008. “The New Lyric Studies." PMLA 123.1: 181-234.

Yinger, O.S. 2017. Music Therapy: Research and Evidence-Based Practice. London. 
Young, E.M. 2015a. "The Touch of the Cinaedus: Unmanly Sensations in the Carmina Priapea." ClAnt 34.1: 183-208.

Young, E.M. 2015b. Translation as Muse: Poetic Translation in Catullus's Rome. Chicago. Zetzel, J.E.G. 1983. "Re-Creating the Canon:Augustan Poetry and the Alexandrian Past." Critical Inquiry 10.1: 83-105.

Zimmermann, B. 1992. Dithyrambos: Geschichte einer Gattung. Göttingen. 


\title{
Index Locorum
}

1

\author{
Literary Sources
}

Aeschylus

Agamemnon

$\begin{array}{ll}121 & 8 \text { on } 48 \\ 146 & 187 \\ 159 & 187 \\ 228-230 & 187 \\ 240-247 & 187 \\ 1072-1079 & 16 \text { n62 } \\ 1444-1446 & 171 n 9\end{array}$

\section{Choephoroi}

$$
\text { 149-151 }
$$

Supplices

$$
\begin{array}{r}
116 \\
5^{24-526} \\
977-979 \\
\text { fr. } 161 \operatorname{Tr} G F
\end{array}
$$

\section{[Aeschylus]}

Prometheus Bound

$$
311
$$

1048

\section{Alcaeus}

fr. 6

fr. 10

fr. 34

fr. 43

fr. 129

fr. $130 \mathrm{a}$

fr. $13 \mathrm{ob}$

fr. 249.2

fr. 307

fr. $307 \mathrm{c}$

fr. 308

\section{Alcman}

fr. 1

fr. 3

fr. $14 \mathrm{a}$

fr. 26

\section{6n62, 17on8}

167-168

168

168n2

16n62

$275 \mathrm{n} 15$

$275 \mathrm{n} 15$

104

86n14, 97n48

98

204n29

99, 101-105, 108

$105 \mathrm{n} 74$

24, 96n43, 103n67,

104-107, 108

104

98

199-201, 204, 206-

208, 227

98

119, 132, 139-140, 146,

$153,155,159,179,321-$

322

$135 \mathrm{nl}, 136 \mathrm{n} 3$

83

93n35 fr. 27

277

fr. 55

277

\section{Anacreon}

fr. $35^{8}$

$84 \mathrm{n} 7$

fr. 385

fr. 432

86n14, 97n48

$86 \mathrm{n} 14$

$\begin{array}{cl}\text { Anthologia Palatina } & \\ 7 \cdot 351 \cdot 5^{-6} & 281 \\ 7 \cdot 405 & 291-292 \\ 7.536 & 286-287 \\ 9.189 & 84\end{array}$

Apuleius

Metamorphoses

$\begin{array}{ll}2.1 & 276 \mathrm{n} 21 \\ 3.24 & 276 \\ 7.17 \cdot 4 & 276 \mathrm{n} 23\end{array}$

\section{Aratus}

Phaenomena

$$
\text { 30-35 }
$$

259n73

\section{Archilochus}

Cologne Epode (fr. 196a)

11-12, 86n14, 277, 279n35, 288n66

fr. $13 \cdot 5^{-7}$

319-320

fr. 21

$274-276$

fr. 22

276-277

frr. $3^{0}-31$

fr. 47

fr. 102

$279 n 35$

286n62

fr. 114

278

fr. 120

279-282

fr. 122

33ong

fr. 126

$86 \mathrm{n} 14$

284

fr. 128.7

fr. 178

frr. $185^{-187}$

297n106

$283 n 48$

fr. 188

282-283

fr. 190

279n35

284n 53

fr. 193

296n97 

fr. 201
fr. 228
fr. 252
fr. 304

\section{Aristophanes}

Acharnians

\begin{tabular}{|c|c|}
\hline $119-120$ & $282 n 48$ \\
\hline \multicolumn{2}{|l|}{ Birds } \\
\hline $209-222$ & $175 \mathrm{n} 17$ \\
\hline $769-784$ & $202-204$ \\
\hline \multicolumn{2}{|l|}{ Clouds } \\
\hline 153 & $78 \mathrm{n} 46$ \\
\hline 320 & $78 \mathrm{n} 46$ \\
\hline $1355^{-135^{8}}$ & $3^{26 n_{4}}$ \\
\hline 1496 & $78 \mathrm{n} 46$ \\
\hline \multicolumn{2}{|l|}{ Frogs } \\
\hline 828 & $78 \mathrm{n} 46$ \\
\hline 876 & $78 \mathrm{n} 46$ \\
\hline 956 & $78 \mathrm{n} 46$ \\
\hline 1296 & $238 \mathrm{n} 20$ \\
\hline 13O1-1303 & 189 \\
\hline \multicolumn{2}{|c|}{ Thesmophoriazusae } \\
\hline $101-129$ & 98 \\
\hline $953^{-958}$ & 89 \\
\hline \multicolumn{2}{|l|}{ Wasps } \\
\hline $5^{-10}$ & 259 \\
\hline 118-123 & $259^{-26 o}$ \\
\hline fr. $663 \mathrm{KA}$ & 275 \\
\hline
\end{tabular}

\section{Aristophanes of Byzantium}

fr. 340 A-E Slater $\quad 77$

\section{Aristotle \\ De anima \\ 405a19-21 (= Thales 11 A 22 D-K) \\ 314-315 \\ 419b5-421a7 (2.8) 24on26, 241n28, \\ 243n33, 244n35}

De generatione animalium

\begin{tabular}{|c|c|}
\hline \multicolumn{2}{|c|}{$782 b_{33}$} \\
\hline Iistoria ani & \\
\hline $615 \mathrm{~b} 2-6$ & $171 n 9$ \\
\hline 62gb35 & $290 \mathrm{n}$ \\
\hline
\end{tabular}

Poetics

$\begin{array}{ll}1447 \mathrm{~b} & 69 \\ 1448 \mathrm{a} & 69,110 \\ 1448 \mathrm{~b} & 47 \\ 1449 \mathrm{a} & 167\end{array}$

$$
\begin{array}{ll}
1449 \mathrm{~b} & 235^{\mathrm{n} 16} \\
145^{\circ} \mathrm{b} & 13 \mathrm{O}-13 \mathrm{1} \\
145^{2} \mathrm{~b} & 129 \\
1453 \mathrm{~b} & 13 \mathrm{O}-131 \\
145^{6} \mathrm{a} & 189-19 \mathrm{O}
\end{array}
$$

Politics

1339a-1342b 240-248

1339b 238n18, 243

1340a 240, 242-243, 248

1341a-1342b 239, 244

$1341 \mathrm{~b} \quad 241,243$

1342a 241n3o, $245^{-248}$

$1342 \mathrm{~b} \quad 240,245 \mathrm{n} 38$

Rhetoric

$1371 \mathrm{~b} \quad 47-48$

Sophistical Refutations

$177 \mathrm{~b} \quad 129 \mathrm{n} 6 \mathrm{o}$

fr. 519 Rose $\quad 124^{-125}$

\section{Athenaeus}

$10.425 \mathrm{a} \quad 5^{1}$

12.523d 276n26

13.596c (= Posidippus 122 Austin-

Bastianini) $\quad 51054$

13.599c (= Chamaeleon fr. 10 Koepke) $84 \mathrm{n} 7$

14.619b (= Ar. Byz. fr. 340 A-E Slater)

$77 \mathrm{n} 41$

15.678b-c (= Sosibius, $F G r H 595$ fr. 5)

123

$15.701 \mathrm{C}-\mathrm{e}$

344

Aulus Gellius

Noctes Atticae

19.9.4 82n2

\section{Bacchylides}

$\begin{array}{ll}1.145^{-148} & 210 \\ 3.21-22 & 201 \\ 3 \cdot 97-98 & 201 \\ 5 \cdot 19 \circ & 201 \\ 9 \cdot 23 & 145 \\ 9.27-36 & 144,145^{-147} \\ 9 \cdot 39 & 144-145,146 \\ 9 \cdot 40-52 & 142 \\ 9 \cdot 47-65 & 142-145 \\ 9.68 & 144-145 \\ 13 \cdot 77^{-95} & 142 \mathrm{n} 16 \\ 13.83^{-84} & 201\end{array}$




\begin{tabular}{|c|c|}
\hline \\
\hline \multicolumn{2}{|c|}{$\begin{array}{l}\text { Bacchylides (cont.) } \\
13.89\end{array}$} \\
\hline \multicolumn{2}{|l|}{$13 \cdot 92-93$} \\
\hline \multicolumn{2}{|l|}{$13.199-200$} \\
\hline \multicolumn{2}{|r|}{$196-199,214-215$} \\
\hline 16.4 & 195 nio \\
\hline 16.5 & $214 n_{57}, 216$ \\
\hline $199-205,211$ & $199-205,211$ \\
\hline \multicolumn{2}{|l|}{16.8} \\
\hline \multicolumn{2}{|r|}{$193-194$} \\
\hline \multicolumn{2}{|l|}{$16.8-13$} \\
\hline \multirow[t]{2}{*}{$16.13-35$} & $212-215,218-221$, \\
\hline & $225^{-227}$ \\
\hline \multicolumn{2}{|r|}{$214 n_{57}, 216$} \\
\hline \multicolumn{2}{|l|}{$17.117-139$} \\
\hline \multicolumn{2}{|l|}{$17.130-13^{2}$} \\
\hline \multicolumn{2}{|l|}{$18.5^{6}-57$} \\
\hline \multicolumn{2}{|l|}{$19.8-10$} \\
\hline \multicolumn{2}{|r|}{$202 n 26$} \\
\hline \multicolumn{2}{|l|}{$20.1-6$} \\
\hline \multicolumn{2}{|l|}{ fr. 11.2} \\
\hline
\end{tabular}

\section{Babrius}

$95 \cdot 74$

\section{Callimachus}

\section{Hymns}

$$
\begin{aligned}
& 1.46-57 \\
& 4.54
\end{aligned}
$$

Iambs

$$
\begin{aligned}
& 4.60-61 \\
& 4.96
\end{aligned}
$$

\section{Carmina Popularia}

fr. 880

\section{Catullus}

36.5
44
$5^{1}$

\section{Chamaeleon}

fr. 10 Koepke

\section{Corinna \\ fr. 654 \\ col. 2, 33-40 \\ col. $3,12-18$ \\ fr. 655}

295n93

$259 n 73$

28 o

287n63

286n63

$17 \mathrm{n} 67$

$293 n 84$

292-294

$293 n 84$

$84 n_{7}$

$148-15^{1}$
$148-149$
149
$148 n_{3} 6,15^{\circ}$

\section{Cratinus}

fr. $6 \mathrm{KA}$

$275 \mathrm{n} 16$

[Demetrius]

De elocutione $301 \quad 285 n_{5} 8$

Demosthenes

$$
\begin{array}{ll}
18.259-26 \text { o } & 263-264 \\
21.10 & 225 \text { n1oo }
\end{array}
$$

Didymus

On Lyric Poets ap. EM 690.33-36 126-127

\section{Dio Chrysostom}

33.17

279-28o

Dionysius of Halicarnassus

De compositione verborum

$$
\text { 14.80 281n41 }
$$

\section{Epicharmus}

fr. 75 Kaibel = fr. $92 \mathrm{KA}$

$$
\text { 124-125 }
$$

\section{Etymologicum Magnum}

$\begin{array}{ll}690.33-36 & 126-127 \\ 715.44 & 283 n 49 \\ 777.8-10 & 127 n 54 \\ & \\ \text { uphorion } & \\ \text { fr. } 94 \text { Powell } & 279 n 33\end{array}$

\section{Euripides}

Andromache

$$
\text { 1135-1140 }
$$

\section{Bacchae}

$\begin{array}{ll}13^{-22} & 257 \\ 55^{-59} & 257 \\ 88^{-106} & 168 \mathrm{n} 3 \\ 120-134 & 25^{6-257} \\ 526 & 189 \\ 687 & 33^{-2} \\ 693 & 139 \\ \text { retans } & \\ \text { fr. } 47^{2.9-19} \operatorname{Tr} G F & 255^{\mathrm{n} 63} \\ \text { clops } & \\ 443^{-444} & 33^{2}\end{array}$


Electra

$$
\begin{aligned}
& 15^{1-156} \\
& 167-174 \\
& 43^{2}-434 \\
& 464-469 \\
& 910
\end{aligned}
$$

Helen

165-168

174-178

177-178

184-19o

$330-385$

1106-1164

1308-1309

1337-1352

$1362-1363$

1479-1484

Heracles

229

348

348-358

68o-694

$781-789$

867-879

871

892-899

1021-1027

Hippolytus

$$
\text { 141-147 }
$$

Iphigenia at Aulis

1475-1531

Iphigenia in Tauris

$$
\text { 145-146 }
$$

179-185

427-429

1094-1095

1123-1133

$1138-1142$

$1143-1146$

1234-1282

1403-1404

Rhesus

$$
5^{6} 5^{-5} 66
$$

Troades

$511-530$
536
$542-555$
565
1245

$$
171 n 9
$$$$
41
$$

100

$128 n_{5} 6$

$5^{1}$

175

16n62, $170 n 8$

175

175

175

175

176

$175^{-177}, 257^{-25} 8$

176

165

338

77

79-8o

169-171

142

262n8o

171

262n8o

171

259

16n62, 17on8, 187n44

177

177

179

178

178-179

179

179-18o

177

178

$33^{8}$

182-183

183

184

184

185

\section{Glossaria Latina}

s.v. gravedo

293n86

\section{Hephaestion}

Enchiridion

$5.4 \quad 285 n^{n} 59$

Heraclides of Pontus

fr. 16o Wehrli 77

$\begin{array}{ll}\text { Herodotus } & \\ 1.71 .2 & 275^{\mathrm{n} 16} \\ 2.6 \mathrm{o} .1 & 339 \mathrm{n} 39 \\ 2.79 & 74 \\ 7.199-2 \mathrm{Oo} & 142 \mathrm{n} 21\end{array}$

Hesiod

Theogony

$1-11 \quad 135^{-136}$

1-115 232n5

76-79 157

100-101 66n19

$133-138$

240-264 159

337-370 159, 162

fr. $305 \mathrm{M}-\mathrm{W} \quad 74,76,8$ o

[Hesiod]

Catalogue of Women frr. 38-42

$149-15^{\circ}$

Shield

205-206 33ong

Hesychius

Lexicon

$\begin{array}{ll}\alpha 2543 & 29 \circ \text { n }_{76} \\ \alpha 2938 & 278 \text { n }_{31} \\ \psi 274 & 285 n 59\end{array}$

\section{Himerius}

47.3-4 216n66

48.10-11 (= Alcaeus fr. 307c)

199-201, 204, 206208, 227

\section{Hippolytus}

Refutatio omnium haeresium

$$
5.17 \text { (= PMG 985) 259n73 }
$$




$\begin{array}{ll}\begin{array}{l}\text { Hipponax } \\ \text { fr. } 6\end{array} & \\ \text { fr. } 10 & 285 \\ \text { fr. } 22 & 285 \\ \text { fr. } 32 & 287 \\ \text { fr. } 34 & 287-289,293 n 87 \\ & 24 n 95,287-289, \\ \text { fr. } 35 & 290-296 \\ \text { fr. } 36 & 24 n 95 \\ \text { fr. } 38 & 24 n 95 \\ \text { fr. } 40 & 24 n 95 \\ \text { fr. } 50.2 & 287 \\ \text { fr. } 54 & 275 \\ \text { fr. } 84 & 289 \\ \text { fr. } 79.11 & 285 \text { n59 } \\ \text { fr. } 104 & 286 \text { n61 } \\ \text { fr. } 115 & 296 \\ \text { fr. } 119 & 289-291 \\ & 279 n 35\end{array}$

\section{Homer}

Iliad

$\begin{array}{ll}1.1 & 75 \\ 1.317-337 & 119-122 \\ 1.469-474 & 63^{-64} \\ 1.174 & 75 \\ 2.362 & 138 \\ 2.446 & 138 \\ 2.474-481 & 138-140 \\ 2.489 & 141 \\ 2.525 & 140 \\ 2.554-555 & 140-141 \\ 2.558 & 140 \\ 4.424-426 & 290 \mathrm{O} 70 \\ 5.204-290 & 122 \\ 6.145^{-211} & 153 \\ 6.152 & 116 \\ 9.308 & 119 \\ 9.661 & 78 \\ 10.428-434 & 153 \\ 14.313-328 & 153 \\ 16.1-5 & 312 \mathrm{n} 31 \\ 17.434-445 & 311-312 \\ 18.38-49 & 153,16 \mathrm{o}-161 \\ 18.490-561 & 136 \mathrm{n} 3 \\ 18.491-497 & 74 \\ 18.561 & 103 \\ 18.565-572 & 74-79 \\ 18.600 & 146 \\ 20.497 & 77 \\ & \end{array}$

$\begin{array}{ll}\begin{array}{l}24.616 \\ \text { Odyssey }\end{array} & 136 \mathrm{n} 2 \\ 2.350 & \\ 5 \cdot 388-389 & 290 \mathrm{on} 73 \\ 6.85^{-109} & 175 \mathrm{n} 18 \\ 6.109 & 139 \\ 8.265 & 147 \\ 8.370-38 \mathrm{o} & 146 \\ 8.426-534 & 183 \mathrm{n} 37 \\ 10.412 & 76 \\ 11.225^{-} 33^{2} & 149,153,154- \\ & 155 \\ 13.242 & 283 \mathrm{n} 5^{2} \\ 14.521 & 288 \mathrm{n} 66 \\ 14.529 & 288 \mathrm{n} 66 \\ 16.247-253 & 153 \\ 19.446 & 275 \mathrm{n} 18 \\ 21.411 & 76 \\ 24.6 \mathrm{o}-61 & 141\end{array}$

\section{Homeric Hymns}

3 (Hymn to Apollo)

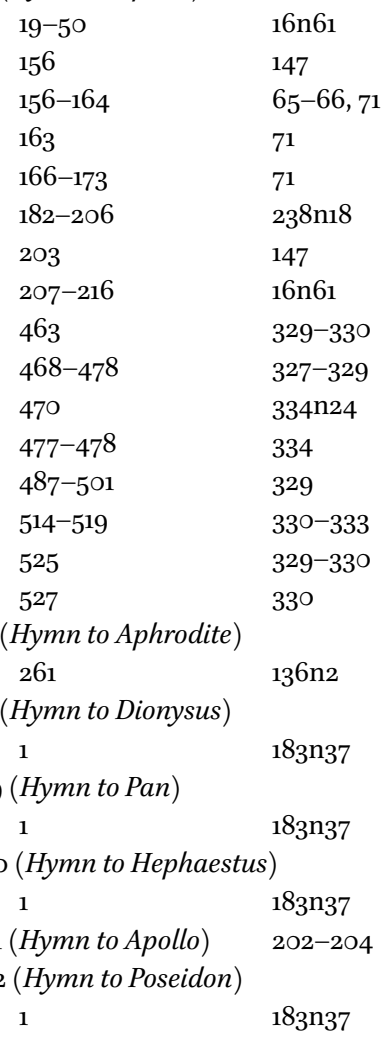




$$
\begin{array}{lr}
27 \text { (Hymn to Artemis) } \\
14-18 & 330 n 9 \\
33 & \text { (Hymn to the Dioskouroi) } \\
1 & 183^{n} 37
\end{array}
$$

$\begin{array}{cl}\begin{array}{c}\text { Horace } \\ \text { Epodes }\end{array} & \\ 2 & 290 \mathrm{n} 7 \mathrm{O} \\ 5 & 284 \mathrm{n} 56,289 \mathrm{n} 68 \\ 6 & 291 \\ 8 & 279 \mathrm{n} 35 \\ 10 & 290 \mathrm{n} 7 \mathrm{O}, 29 \mathrm{n} 77 \\ 13 & 290 \mathrm{n} 7 \mathrm{O} \\ 14 & 286 \mathrm{n} 61\end{array}$

Lucian

De saltatione 9

Pseudologista $3^{2}$

\section{Lucilius}

377 Marx

\section{Nonnus}

Dionysiaca

$\begin{array}{ll}11.5 \mathrm{O} 2 & 29 \circ \mathrm{On} \\ 46.13^{-18} & 259 \mathrm{n} 73\end{array}$

\section{Oppian}

Halieutica

$\begin{array}{ll}2.36 \text { o } & 283 \\ 2.369 & 284 n_{53}\end{array}$

\section{Papyri}

P.Berol. inv. 7807

P.Berol. inv. 13876

P.Berol. inv. 21119

P.Hibeh 1.13

P.Hibeh 2.180

P.Lit.Lond. 28

P.Lit.Lond. 97

P.Louvre E332O

P.Mich. inv. 2810

POxy. 2.223

POxy. 3.413

POxy. 5.841

POxy. $6.85^{2}$

POxy. 15.1792
342

$283 n 48$

$281 n 41$

$284 n 53$

119
$118 n 37$
$118 n 37$
$233 n 6,244 n 34$
$118 n 37$
122
118 n 37
$119,123,13^{2}$
$119-120$
122
118 n 37
112 n16, 335n27
118
335 n27
POxy. 18.2165
$105 \mathrm{n} 74$
POxy. 26.2447, fr. 4b $15 \mathrm{n} 58$
POxy. $26.2449 \quad 126 \mathrm{n}_{51}$
POxy. 27.2458 $\quad 118$
POxy. 37.2811, fr. 5.3-6
$\begin{array}{ll}\text { P.Ryl. } 3.484 & 286 \mathrm{n} 62 \\ \text { PSI 10.1176 } & 118 \mathrm{n} 37 \\ & 118 \mathrm{n} 37\end{array}$
P.Strasb. gr. inv. 31-32 verso

$\begin{array}{ll} & 119-122 \\ \text { P.Varsov. } 2 & 118 \mathrm{n} 37\end{array}$
Pausanias
5.22.6.1-10 150-151
$\begin{array}{ll}9.29 .6 & 17 \mathrm{n} 67\end{array}$

\section{Persius}

$\begin{array}{ll}1.107-110 & 281\end{array}$

Pherecydes

$\mathrm{FGrH}_{3}$ fr. $48 \quad 256 \mathrm{n} 69$

Philochorus

FGrH 328 fr. $207 \quad 17 n 67,76$

\section{Photius}

Bibliotheca

$$
\begin{array}{ll}
319 b 32-35 \text { Bekker } & 5^{8} \\
320 a 20-24 \text { Bekker } & 64
\end{array}
$$

Lexicon

s.v. גívov (= Heraclid. Pont. fr. 16o Wehrli)

77 n 40

\section{Pindar}

Isthmian Odes

$\begin{array}{ll}7.1-15 & 16 \mathrm{n} 61 \\ 7 \cdot 39-42 & 117 \\ \text { Nemean Odes } & \\ 1.4-6 & 197 \\ 2.25 & 33 \text { ong } \\ 3 \cdot 10-12 & 197-198 \\ 3.65-66 & 197 \\ 5 \cdot 2-3 & 198 \\ 5 \cdot 36 & 17 n 65 \\ 6.36 & 17 n 65 \\ 7.84-85 & 115 \\ 10.1-18 & 16 \mathrm{n} 61 \\ 10.44 & 288 \mathrm{n} 66\end{array}$




\begin{tabular}{|c|c|c|c|}
\hline Olympian Odes & & fr. $128 \mathrm{c}$ & $1-3,13,14-18$ \\
\hline $1.1-4$ & $16 n 6 o$ & & $66-67,188 \mathrm{n} 46$ \\
\hline $1.8-10$ & $197-198$ & & $212 n 49$ \\
\hline $6.82-88$ & 113 & $6-8$ & $78 \mathrm{n} 45$ \\
\hline $6.92-93$ & $113 \mathrm{n} 22$ & 8 & 18 \\
\hline 6.104 & $17 n 65$ & 12 & 18 \\
\hline $9.1-4$ & 125 & fr. $194.1-3$ & $3^{21}$ \\
\hline 9.6 & 112 & & \\
\hline 9.11 & 112 & Plato & \\
\hline 9.109 & 112 & Cratylus & \\
\hline $11.1-4$ & $16 \mathrm{n} 6 \mathrm{o}$ & $426 \mathrm{~d}-\mathrm{e}$ & $271,285 n_{5} 8,297$ \\
\hline $13.11-23$ & $16 \mathrm{n} 61$ & $434 \mathrm{c}$ & 271 \\
\hline Pythian Odes & & Crito & \\
\hline $2.55^{-5} 6$ & 14 & $54 \mathrm{~d}$ & 26 o, $263 n 83$ \\
\hline 2.69 & 124 & Euthydemus & \\
\hline 2.91 & $295^{\mathrm{n} 97}$ & $277 \mathrm{~d}-\mathrm{e}$ & $26 o-261$ \\
\hline 5.104 & $18 \mathrm{n} 71$ & Ion & \\
\hline 8.31 & 114 & $533^{d-536 d}$ & $260-261,322$ \\
\hline 8.34 & 114 & $536 c 2-4$ & $254 \mathrm{n} 6 \mathrm{o}$ \\
\hline $8.57-58$ & 114 & Laws & \\
\hline 8.68 & 114 & $653 c-66 o c$ & 239 \\
\hline 8.70 & 114 & $654 a$ & 136 \\
\hline 8.98 & 114 & $664 b-671 a$ & 239 \\
\hline $9.88-89$ & 113 & $700 a-701 b$ & 239 \\
\hline 9.118 & $14 \mathrm{On} 12$ & $700 a$ & 185 \\
\hline fr. 29.1 & $17 \mathrm{n} 65$ & $700 a-e$ & $1-4,14-15,18,66$ \\
\hline fr. 33d. 8 & 280 & & $185^{-188}$ \\
\hline fr. $5^{2 b}(=$ Paean 2$)$ & & $701 a 3$ & 188 \\
\hline 99 & $140 n 11$ & $701 a 6$ & 186 \\
\hline fr. $5^{2 f}(=$ Paean 6$)$ & & $79 \circ c-791 b$ & $247,26 o-262$ \\
\hline 5 & 337 & $798 \mathrm{~d}-8 \mathrm{o} 2 \mathrm{e}$ & 239 \\
\hline 6 & 340 & 8 ooe & $238 \mathrm{n} 20$ \\
\hline 7 & 331 & $812 b-e$ & 239 \\
\hline $7-9$ & $337-33^{8}$ & Phaedo & \\
\hline $10-11$ & 336 & $84 \mathrm{e}-85 \mathrm{a}$ & $171 n 9$ \\
\hline $12-18$ & $338-340$ & $84 \mathrm{e}-85 \mathrm{~b}$ & $204 \mathrm{n} 28$ \\
\hline 17 & 331 & Phaedrus & \\
\hline 54 & 340 & $228 \mathrm{~b}-\mathrm{d}$ & $26 o-261$ \\
\hline $5^{6}$ & 340 & Republic & \\
\hline $5^{8-59}$ & 340 & $392 c-394 c$ & $68-69,110$ \\
\hline $79-80$ & 341 & $397 a-402 a$ & 238,244 \\
\hline $113-115$ & $342-343$ & $411 \mathrm{a}$ & $262 n 80$ \\
\hline $119-120$ & 341,343 & Symposium & \\
\hline 120 & $33^{1}$ & $215 \mathrm{c}-\mathrm{e}$ & $26 \circ, 262-263$ \\
\hline $121-122$ & $344-345$ & & \\
\hline 131 & $335 \mathrm{n} 28$ & Pliny the Elder & \\
\hline fr. 7 ob & $103,168 n_{3}$ & Natural History & \\
\hline fr. $105 \mathrm{a}$ & $124-125$ & 8.133 & 284 \\
\hline
\end{tabular}




\begin{tabular}{|c|c|c|c|}
\hline \multirow{2}{*}{\multicolumn{2}{|c|}{$\begin{array}{l}\text { Plutarch } \\
\text { De E apud Delphos }\end{array}$}} & \multicolumn{2}{|l|}{ Kypris Song } \\
\hline & & $1-6$ & 46 \\
\hline $387 \mathrm{c}$ & 204 & fr. 1 & $23,83-84,86,87$ \\
\hline $389 \mathrm{c}$ & $193^{-194,207-208}$ & $3-4$ & $45^{-46}$ \\
\hline De exilio & & $18-24$ & $89 n 25$ \\
\hline $604 c$ & $274-275$ & fr. 2 & 103 \\
\hline \multicolumn{2}{|c|}{ Quaestiones convivales } & $9-10$ & $277 \mathrm{n} 30$ \\
\hline $615 b$ & $105 \mathrm{n} 72$ & fr. 5 & \\
\hline \multicolumn{2}{|c|}{ Stoicos absurdiora poetis dicere } & $1-2$ & 99 \\
\hline \multirow{2}{*}{$1058 \mathrm{~d} 9-\mathrm{e} 1$} & 291 & $1-11$ & $44-45$ \\
\hline & & 6 & $5^{1}$ \\
\hline \multicolumn{2}{|l|}{ Pollux } & 18 & 45 \\
\hline \multicolumn{2}{|l|}{ Onomasticon } & fr. 9 & $39,41,43,49,51,99$ \\
\hline \multicolumn{2}{|c|}{4.107 (p. 233.4-9 Bethe) } & fr. 15 & 99 \\
\hline & 123 & fr. 16 & \\
\hline \multirow[t]{2}{*}{4.118 (p. 236.1 Bethe) } & $288 n 66$ & 17 & 277 \\
\hline & & $17-18$ & 93,147 \\
\hline \multicolumn{2}{|l|}{ Porphyry } & fr. 17 & $24,84,93-101,104$ \\
\hline \multicolumn{3}{|l|}{ Homeric Questions } & 106,108 \\
\hline \multirow{3}{*}{\multicolumn{2}{|c|}{$\begin{aligned} \text { Il. } 297.16-17 \text { Scharder } & =\mathrm{I}, 56.3-6 \text { Sodano } \\
& 131 n 64\end{aligned}$}} & $1-16$ & $42-44$ \\
\hline & & 2 & 49 \\
\hline & & fr. 22 & $24 n 96$ \\
\hline \multicolumn{2}{|l|}{ Posidippus } & fr. $26.11-12$ & 46 \\
\hline \multicolumn{2}{|l|}{ 122.3 Austin-Bastianini } & fr. 27 & $24 \mathrm{ng} 6,87-91,93,98$ \\
\hline \multirow{2}{*}{\multicolumn{2}{|c|}{$5^{1}$}} & & $100 n 62$ \\
\hline & & fr. 30 & $87-91,98$ \\
\hline \multicolumn{2}{|l|}{ Pratinas } & fr. 31 & $277 n 30,293 n 84$ \\
\hline \multirow[t]{2}{*}{$\operatorname{Tr} G F \mathrm{I}, 4$ fr. 3} & $235 \mathrm{n} 16$ & 9 & 296 \\
\hline & & $13-14$ & 296 \\
\hline \multicolumn{2}{|l|}{ Proclus } & fr. 44 & $86,87,96,106,338$ \\
\hline \multicolumn{2}{|l|}{ Chrestomathia } & fr. 47 & 296 nioo \\
\hline \multicolumn{2}{|c|}{ ap. Phot. Bibl. 319b32-35 Bekker } & fr. $5^{8}$ & 93 \\
\hline & $5^{8}$ & fr. 65 & 86 \\
\hline \multicolumn{2}{|c|}{ ap. Phot. Bibl. 320a2o-24 Bekker } & fr. 70 & $93 n_{34}, 96 \mathrm{n} 41$ \\
\hline & 64 & fr. $71.5^{-6}$ & $93 n 34$ \\
\hline \multicolumn{2}{|l|}{ Prolegomena to Hesiod } & fr. 94 & 86,93 \\
\hline \multirow[t]{2}{*}{ 5.8-15 Gaisford } & $109-110$ & fr. 95 & 86 \\
\hline & & fr. 96 & 93,146 \\
\hline Ptolemy Epithetes & & fr. 114 & $87,89 n 25$ \\
\hline On Stationary Poetry & & fr. 137 & $86,89 n 25$ \\
\hline ap. Capitula ad praef & at. sch. Pind.f & fr. 140 & $85^{-87}, 89 n 25,98$ \\
\hline & $127-128$ & fr. 214 & $76 \mathrm{n} 37$ \\
\hline Sappho & & scholia & \\
\hline Brothers Song & 23n93, 24ng6, 31-32, & Aristophanes & \\
\hline & $39-41,49-52,91 n 29$ & Birds $15^{21}$ & $289 n 68$ \\
\hline 5 & $5^{1}$ & Frogs $1281 \mathrm{a}$ & 128 \\
\hline $5^{-6}$ & 44 & Callimachus & \\
\hline $9-11$ & $99-101$ & Hymns 4.11a, b & 28on4o \\
\hline
\end{tabular}


Dionysius Periegetes 461

$$
276 \mathrm{n} 26
$$

Scholia Londinensia in Dionysii Thracis Artem Grammaticam

\begin{tabular}{|c|c|}
\hline \multicolumn{2}{|c|}{ 3.450.10-451.27 Hilgard } \\
\hline & $58 \mathrm{n} 4$ \\
\hline \multicolumn{2}{|l|}{ Euripides } \\
\hline \multicolumn{2}{|l|}{ Orestes } \\
\hline 1390 & $77 \mathrm{n} 41$ \\
\hline 1396 & $77 \mathrm{n} 41$ \\
\hline \multicolumn{2}{|c|}{ Rhesus 895 (= Pind. fr. 128c) } \\
\hline & 1n1, $18 \mathrm{n} 7 \mathrm{O}$ \\
\hline Phoenissae 202 & 128 \\
\hline \multicolumn{2}{|l|}{ Homer } \\
\hline \multicolumn{2}{|l|}{ Iliad } \\
\hline $2.57 \mathrm{Oa}^{1}$ & 116 \\
\hline $4 \cdot 3 \circ 3^{a}$ & $123 n 45$ \\
\hline $6.15^{2 b}$ & $116 n 33$ \\
\hline $12.29 \mathrm{~d}^{1}$ & $315^{\text {n37 }}$ \\
\hline $13 \cdot 301 b$ & 116n33 \\
\hline $15.256 \mathrm{a}^{1}$ & $18 \mathrm{n} 70$ \\
\hline 16.2о3а & $123 n 45$ \\
\hline $18.57 \mathrm{Oa}$ & 76 \\
\hline $18.57 \mathrm{Oc}^{1}$ & $17 \mathrm{n} 67,76-77$ \\
\hline $20.234 \mathrm{~d}$ & $5^{1}$ \\
\hline $21.388 a^{3}$ & 116 \\
\hline $23.855^{a}$ & $123 n 45$ \\
\hline \multicolumn{2}{|c|}{ D scholia to the Iliad } \\
\hline 18.571 & 78 \\
\hline Odyssey $5 \cdot 388$ & $29 \circ 73$ \\
\hline
\end{tabular}

Pindar

Capitula ad praefationem scholiorum ad Pindari carmina $\mathrm{f}$

(3.311.3-14 Drachmann)

$\begin{array}{cl}\text { Isthmian Odes } & 127-128 \\ 1.6 \mathrm{~d} & \\ 7 \cdot 51 \mathrm{a} & 124 \mathrm{n} 47 \\ 7 \cdot 53^{\mathrm{a}} & 112 \mathrm{n} 14 \\ 7 \cdot 55^{\mathrm{a}}, \mathrm{b} & 117 \\ & 117\end{array}$

Nemean Odes

$\begin{array}{ll}1.29 \mathrm{a} & 124 \mathrm{n} 47 \\ 3.1 \mathrm{c} & 126 \mathrm{n} 49 \\ 3.6 \mathrm{a} & 112 \mathrm{n} 13 \\ 3.136 \mathrm{a} & 126 \mathrm{n} 51 \\ 4.71 & 126 \mathrm{n}_{51} \\ 5.7 \mathrm{Oa} & 126 \mathrm{n} 49 \\ 7.123 \mathrm{a} & 115^{-116} \\ 8.24 \mathrm{a}, \mathrm{b} & 126 \mathrm{n}_{51}\end{array}$

\begin{tabular}{|c|c|}
\hline $9.1 \mathrm{a}$ & 112 \\
\hline $9.1 \mathrm{~b}$ & $112 n 13$ \\
\hline $10.73 \mathrm{~b}$ & $117 n_{34}$ \\
\hline \multicolumn{2}{|l|}{ Olympian Odes } \\
\hline $1.26 \mathrm{a}, \mathrm{c}, \mathrm{g}$ & $126 n_{51}$ \\
\hline $1.164 \mathrm{~b}$ & $126 n_{51}$ \\
\hline $3.9 \mathrm{a}, \mathrm{c}, \mathrm{d}$ & $126 n_{51}$ \\
\hline $4.7 \mathrm{~h}$ & $112 n 15$ \\
\hline $5.44 a, c, g, i$ & ${ }_{126} n_{51}$ \\
\hline $6.88 \mathrm{c}$ & $118 n 35$ \\
\hline $6.148 \mathrm{a}$ & 113 \\
\hline $6.149 \mathrm{a}$ & $113 n 22$ \\
\hline $6.158 b$ & $113 n 22$ \\
\hline 8.66 & $112 n 15$ \\
\hline $9.1 \mathrm{a}-\mathrm{k}$ & 125 \\
\hline $9 \cdot 3 \mathrm{a}-\mathrm{l}$ & 125 \\
\hline 9.11a, c, d & 112 \\
\hline $9 \cdot 17 \mathrm{~b}$ & 112 \\
\hline $9 \cdot 94 b$ & 118 \\
\hline $9.163 b$ & 112 \\
\hline 10.1a, d, h, i & $113 n 21$ \\
\hline $10.17 \mathrm{k}$ & $126 n_{51}$ \\
\hline $10.18 b$ & $126 n_{51}$ \\
\hline $13.100 \mathrm{c}$ & 118 n35 \\
\hline $14.21 d$ & $112 n 13$ \\
\hline $14.23 \mathrm{C}$ & ${ }_{126} n_{51}$ \\
\hline $14.27 \mathrm{C}$ & $112-113$ \\
\hline Paean $8(=P C$ & 41) \\
\hline
\end{tabular}

Pythian Odes

$\begin{array}{ll}2.6 \mathrm{~b} & 124 \mathrm{n} 47 \\ 2.125 \mathrm{c} & 126 \mathrm{n}_{51} \\ 2.128 \mathrm{a} & 126 \mathrm{n}_{51} \\ 4.67 \mathrm{~b} & 118 \mathrm{n} 35 \\ 5.96 \mathrm{a} & 112 \mathrm{n} 16 \\ 6.1 \mathrm{a}, \mathrm{e} & 112 \mathrm{n} 16 \\ 8.1 \mathrm{~b} & 114 \\ 8.10 \mathrm{a} & 114 \\ 8.40 \mathrm{a}, \mathrm{b} & 114 \\ 8.43 \mathrm{a} & 114 \\ 8.46 \mathrm{~b} & 114 \\ 8.78 \mathrm{a} & 114,117 \mathrm{n} 34 \\ 8.78 \mathrm{~b} & 114 \mathrm{n} 27 \\ 8.83^{\mathrm{a}} & 114 \\ 8.95 \mathrm{a} & 114 \\ 8.99 \mathrm{a} & 114 \\ 8.140 \mathrm{Oc} & 112 \mathrm{n} 15,114 \\ 9.156 \mathrm{~b} & 113 \\ 9.172 & 112 \mathrm{n} 14\end{array}$


Theocritus

5.112

Semonides

fr. $7 \cdot 5^{\circ}-54$

Seneca the Younger

Epistles

95.17

Solon

fr. 1.1-2

Sophocles

Ajax

693-718

Antigone

1146-1152

Oedipus Tyrannus

151-215

Trachiniae

205-224

$35^{1-368}$

$380-382$

466

592-593

640-642

$75^{\circ}-762$

775

963

967-968

1005

fr. $1091 \operatorname{Tr} G F$

Sosibius

$\begin{array}{ll}\text { FGrH } 595 \text { fr. } 5 & 123 \\ \text { FGrH } 595 \text { fr. } 23 & 124-125\end{array}$

Strabo

$\begin{array}{ll}10.3 \cdot 7-9 & 25^{8-259} \\ 12.3 .11 & 283 \mathrm{n} 53 \\ 14.1 .4 & 275^{\mathrm{n} 17}\end{array}$

${ }_{128 n} 6$
Thales

$$
11 \text { A } 22 \text { D-K 314-315 }
$$

\section{Theocritus}

$5.112 \quad 282$

\section{Theognis}

$\begin{array}{ll}257-26 \text { o } & 97 \mathrm{n} 48 \\ 579-582 & 97 \mathrm{n} 48 \\ 861-864 & 97 \mathrm{n} 48\end{array}$

Thucydides

$\begin{array}{ll}2.15 .2 & 43 \\ 6.30-32 & 141 \\ 6.54 .6 & 216 \\ 6.57 .1 & 139\end{array}$

Timotheus

fr. 791

$\begin{array}{rl}203 & 188 \\ 211 & 188 \\ \text { fr. } 792 & 168 \mathrm{n} 3\end{array}$

Tzetzes

Historiarum variarum Chiliades 5.736 285

Vergil

Aeneid

$$
2.55^{\mathrm{O}-55^{1}} 34^{2}
$$

\section{Xenophon}

Cyropaedia

$\begin{array}{ll}1.6 .18 & 140 \\ 3.3 .70 & 140\end{array}$

Memorabilia

$3 \cdot 3.12 \quad 100$

$3.4 .4 \quad 140$

Oeconomicus
8.19-20
139

Xenophon of Ephesus

1.2 .4

139

\section{Terentianus Maurus}

GL 6.333, line 262 Keil

281n41 
Epigraphical Sources

\begin{tabular}{|c|c|c|c|}
\hline CEG 13 & $307 n 22,319 n 45$ & CEG $174 \mathrm{~B}$ & $308 n 25$ \\
\hline CEG 14 & $306-307$ & $C E G 470$ & 307 n22 \\
\hline CEG 27 & 3o7n22, 310n28 & CEG 479 & $303-304$ \\
\hline$C E G 28$ & $307 \mathrm{n} 22$ & $C E G_{534}$ & $304 n 13$ \\
\hline$C E G_{32}$ & $319 n 49$ & $C E G 724$ & 308 n25 \\
\hline$C E G_{35}$ & $319 n 49$ & \multicolumn{2}{|c|}{$I_{3.2}$ (Palaikastro Hymn) } \\
\hline \multirow[t]{2}{*}{$C E G_{51}$} & $305-306,307,308-$ & & $255^{\mathrm{n} 63}, 259 \mathrm{n} 73$ \\
\hline & 309,313 & $I G \mathrm{I}^{3} 963$ & $216 n 65$ \\
\hline$C E G_{53}$ & $319 n 49$ & $I G \mathrm{II}^{2} 1635^{\mathrm{a}}$ & 226 n105 \\
\hline$C E G_{5}^{8}$ & $309-312$ & $I G$ XII.6.2 559 & $15^{1 n} 40$ \\
\hline$C E G 68$ & $307-308$ & $S E G 41.540 \mathrm{~A}, 44.463$ & $298-324$ \\
\hline$C E G 138$ & $319 n 49$ & SEG $49.5 \circ 5,56.5 \circ 8,5$ & \\
\hline CEG 143 & 314n34 & & 307 n23 \\
\hline$C E G{ }_{169}$ & $319 n 49$ & & \\
\hline
\end{tabular}




\section{General Index}

Achilles 75, 119, 121, 125, 311, 340

shield of $74,78,103,136,146,153,162$ addressee 73,345

Aegina 114-115, 142-143, 147-148, 150, 153, 157,335

Aeschylus 167, 186-189, 275

aesthetics

in Aristotle 244

and genre $\quad 272-273,277$

of leptotes $\quad 78$

aetiology 15, 208, 224

of Korybantic daimones $\quad 246-256$, 259

of Linus-song $\quad 76,78$

of paean $\quad 343-344$

of ritual $\quad 95,176$

of threnos $\quad 67$

of tragedy 185,189

affect $\quad 181,187$

as an approach to genre $9-10,24-28$,

233-234

in Aristotelian music theory $\quad 242-249$

and enthusiastic music $\quad 258,266$

and funerary elegy/monuments $302-$

320

and iambic horror $\quad 26,273-297$

and the periperformative 20,24

See also embodied cultural knowledge; emotion

affective fallacy $\quad 273$

agency

and funerary monuments $\quad 313-323$

in ritual practice $\quad 327-333,341$

See also autonomy

agon. See festivals, music

ailinon. See Linus/Linus-song

Alcaeus 39, 72, 83, 98, 227, 286

and Bacchylides $16 \quad$ 199-201, 204, 207208

Hellenistic edition of $\quad 23,105 \mathrm{n} 74$

parachorality in $\quad 24,101-108$

Alcman $7,64,83,93,130,132,139-140,146$, $153,277,321$

choral morphology in $\quad 155,159$

female voices in $86 \mathrm{n} 14,97 \mathrm{n} 48$

Louvre papyrus of 119,123
Alexandrian scholarship. See Hellenistic scholarship

allusion, generic $\quad 169,179-181$

See also intertextuality

Amasis Painter 162

Ambracian polyandrion

298-309, 312-324,

Fig. 10.1, 10.2, 10.5

Anacreon 83, 231

Anactoria 147, 277

Analatos Painter 162

anthropological approaches

to genre $\quad 7-10,35,73$

to music $\quad 249-253$

Aphrodite 23, 45, 46, 53, 86, 176, 237, 277

Apollo $15-17,63-65,67,76,79,80,148-149$, 170, 172-173, 177, 179, 188, 191-195, 200215, 221-223, 227, 236-238, 327-334, 339-344

temples of $177,215^{-216}, 331,337,339$

Apuleius $\quad 275^{-276}$

Archilochus 11-12, 14, 23, 91229, 319

and iambic horror $\quad 273-284,286,294$, 296

Aristarchus $\quad 76-78,112,116,125^{-126,128,131-}$ 132

Aristophanes of Byzantium $\quad 77,79$

Aristophanes (playwright) $\quad 98,189,202-$ 205, 259, 275

Aristotle 125, 233, 253-254, 314 devaluation of spectacle in tragedy by 130-131

on mimesis $\quad 3,47-48,60,67-71,271$

on musical education 239

on musical theory $\quad 27-28,240-248$

on tragedy and choral song $167,189-190$

arrangement

of catalogues and choruses $\quad 138-166$

musical 64

Alexandrian, of Sappho's poems $\quad$ 91, 99

Artemis 15, 17, 64, 65, 67, 172, 173, 223

Asopos/Asopids 142-153

Athena 43, 125, 192, 212-213, 237

Athenaeus 51, 235, 344

Athens $37,66,84,167,179$

as setting of Bacchylides $16 \quad 211-217,221-$ 222, 225-227 
attribution, of choral utterances $\quad 112-123$

audience $5,19,26-27,97,100,101,180-182$, 219n8o, 273, 317-328, 336-346

identification of, with performers 26

involvement of, in generification 57,59 , 65

and choral (re)performance $\quad 325^{-327}$, 336-346

of funerary elegy/monument $317-$ 324

relationship with iambicist $\quad 273^{-294}$

of tragedy, as responsive to genres $27-$ $28,180-182$

See also horizon of expectations; reader; reception; viewer

aulos. See under instruments, musical

authority

appeal to 70

divine, in ritual performance $\quad 327-334$, $337,341-344$

of epinician, establishment of 22,196 , 198-199

of genre $\quad 57-58$

of lyric forms $\quad 73,81$

of monument 315

autonomy

artistic 61

generic, of song 19, 196-199, 212-214, 222-228

of individual in ritual practice $327,331^{-}$ 334

of self 295

See also agency

Bacchylides 3, 142-147, 153

mixing of genres in $11,19,188,191-$ 228

Bakhtin, M. 12, 189, 345

Battezzato, L. 184, 187

Beardsley, M.C. 273

Bell, C. $\quad 25,27,331-334$

Bersani, L. 296

Bierl, A. 41

biography, and Sapphic personae $\quad 5^{2}$

Blakely, S. $\quad 256$

Bourdieu, P. 25-27, 254

Bowie, E. 37

Bremmer, J. 255

Briand, M. 142
Brothers Song $31,39-40,44,5$ o, 99-100

addressee of $31,39-40$

occasion for $5^{\circ}$

Budelmann, F. $\quad 8-9$

Bundy, E. 6

Burkert, W. $\quad 256$

Burnett, A.P. $\quad 24,213$

Burris, S. 97

Byzantine Capitula $\quad$ 127-128

Calame, C. $\quad 5-6,8-10,21,25,59,83,15^{2}$

Callimachus 78,280

Calliope $\quad 2,15,17,66-67,157$

canon, of lyric poets 58

Carson, A. 24, 106

Cassio, A.C. $\quad 304-305$

Castoreion 124-125

catalogues

in connection with choruses $19,27,135^{-}$ 166

definition of $15^{2}$

morphology of $\quad 15^{2-155}$

structuring principles of $\quad 153^{-166}$

Catalogue of Ships $\quad 136-142$

catharsis $\quad 245^{-246}$

Catullus 292-294

character/ethos

affected by music $\quad 242-244,248$

and attribution of choral lines $\quad 123$

and genre 13

Charaxos 40, 44, 49-51, 96, 99-100, 104, 108

choir. See chorus

choral act 44

choral poetry/song $\quad 22-23,59$

civic unity promoted by $\quad 320-321$

fictionality in $\quad 99^{-100}$

and generic taxonomy 110

evocation of hexametric catalogues in $137-15^{2}$

as a flexible expressive mode $\quad 327,334-$ 346

materality of $\quad 321-324$

in relation to monody $18,22-23,82-108$

projection in: See choral projection

and tragedy $\quad 167-168,173^{-174}, 180,187-$

189

See also chorus; parachorality

choral leader

Agathon as $\quad 98$ 
and choral mapping $\quad$ 139-141, 145-147, 150, 157-159

and communal functions of poetry 7

addressed by Pindar 113

Sappho as 44, 84, 93

choral projection $22 \mathrm{n} 85,72,96,142,15$ O, 165

choral value $24,99,107$

choregos. See choral leader

choreia. See dance/dancing; singing

chorus

evoked by catalogues $\quad$ 19, 27, 135-166

evoked in Alcaeus 104-108, 200, 206207

and Bacchylides 193, 208, 211

circular, at festivals $\quad 215^{-217}, 221-227$

epichoric 147, 151, 153

in Euripides 80

fusion of, with audience and environment

$$
3^{22-}-323
$$

in Homer and Hesiod $\quad 74^{-75}, 135^{-136}$

and mimesis $33,49^{-} 5^{2}, 71^{-} 73$

morphology of $\quad 152-165$

movement of $123-129,136$

and paeanic (re)performance $\quad 326-346$

in Pindar, as speaking persona $\quad 112-123$,

132

and Sappho, performance context of

$$
\text { 32-33, 38-44, 82-100 }
$$

in tragedy, switching between lyric forms

169-180, 182-19o

visual representations of $\quad 153^{-165}$

See also choral poetry/song; dance/danc-

ing; semi-chorus

citizenship

and funerary epigrams 302,304

and Greek song-culture $\quad 236,247,269$

civic community. See social community

Cohen, R. 61

comedy $78,110,123,168,235,248$

See also drama

composition $4,12,21,34,48,82,84,198$, 233

oral $4-7,12-13$

Conte, G.-B. $\quad 57,62$

content, and generic difference $\quad 65,83,109$, 231-232

context, performance $\quad 33,59,62,68,72,84-$

$85,92,103-108,165,298,325-327,345$

of Bacchylides $16 \quad$ 208-217 of Corinna $\quad 148$

of Sappho 33, 103-108

in connection with reperformance $325^{-}$ 327,345

See also performance

context, reperformance $\quad 334-340,345$

See also reperformance

Corinna 142, 148-151

criticism, ancient

of genre $1-4,13-18,57-60,63-70$, 8o, 109-111, 185-19o, 271

of music $\quad 27-28,240-248$

See also Aristotle; Hellenistic scholarship; Plato; Proclus; scholia

criticism, modern, of genre $\quad 5^{-19}, 57^{-63}$, $70-72,84-85,231-233,271-272,326$

Culler, J. $\quad 8,62$

Cybele $175,237-238,254^{-257}, 265^{-267}$, 269-270

Dactyls $\quad 253,256,265,269$

D'Alessio, G.B. 143, 217

dance/dancing

ancient commentary on $27,124-130$

and Bacchylides 223, 228

Castoreian 124-125

depicted on vases $157,159-165$

and enthusiastic music $\quad 25^{\mathrm{O}-252,255^{-}}$

257, 261-266, 269

evoked in epic catalogues $\quad 136-147,153$

and choral (re)performance $32,36,38-$

$39,44,49-5$ O, 52-53, 124-130, 322

and embodied knowledge $\quad 25,333,338-$ 343

in the Hellenistic period $\quad 111$

in Pindar 103

in Sappho 9o, 92-93

and taxonomy of Greek song-culture

$237-238$

and tragedy $167,169-170,174,176,179-$

181,184

Davies, M. $\quad 82-85$

Day, J. 141

Deianeira 172-173, 192-194, 209, 211-214,

218-220, 222

deictics 21

in Anacreon 101-105

in funerary epigrams $302-304,309,315$, 321 
over-determination in 103

in Sappho 96

Delphi 177

and paeanic choreia $\quad 326-327,329,331$,

$336,339-340,343-344,346$

and the setting of Bacchylides 16 192-

195, 200-201, 206-216, 222, 227

temple of Apollo at 177

Deleuze, G. 297

Demosthenes 263

diachronic view of performance $37,71-72$

dialect, and genre difference 83

Didymus 58, 126-129

diegesis. See narration

diminutives $5^{0-51}$

Dio Chrysostom 279-281

Dionysia. See festivals

Dionysus $1-2,43,66,102,173,176,186,255$,

257, 259, 261, 264

and Bacchylides $16 \quad 193-195,208,212$, 222-223, 227

cult of 217

and dithyramb $15,17,67,173,189,207$, 209

mousike of $170,177,181,237-238,254$

sanctuary of 95

See also festivals, Dionysia; Theater of

Dionysus

dirge. See threnos

dithyramb

and Bacchylides $\quad 68,194-195,207-209$,

215, 217, 223, 226n1o3

associated with Dionysus $1,15^{-17}, 67$,

$186,189,194,207$

performed at Athens $\quad 181$

and Athenian drama $\quad 268-269$

of Pindar 69, 215

and taxonomy of lyric genres $1,4,11,15$,

66 , 110, 168-169, 186, 217, 235, 237, 246, 248

as origin of tragedy $\quad 167,188$

evoked in tragedy $173,177,179,182-186$, 188-189

drama

attribution of speakers in scholia on 10 , 118-119, 123, 13o-131

and audience reception $\quad$ 18o-182

choral song in 167-168

enthusiastic music in $\quad 246-248,268$ genre mixing in $\quad 168-180,182-190$,

248

and lyric $\quad 22,61,86$

and mimesis $\quad 47,6 \circ, 69-70,73,271$

solo singer voicing chorus in 98

and threefold division of mimetic poetry $3,60,68,109-110,132,271$

See also comedy; tragedy

ecphrasis 78,103

See also Achilles, shield of

Edmunds, L. 107

education, and music $\quad 234,236,239-247$

Edwards, M. $\quad 75^{-77}$

ego. See first person; persona; poetic "I";

speaker

elegy

historical context of 7

genre mixing in 11

funeral 26-27, 299-324

reconciliation of civic and individual concerns in 319-324

Salamis Elegy of Solon 97

supplementary function of 303

and taxonomy of Greek genres $58,6 \circ$,

64

embodied cultural knowledge

as an approach to genre $\quad 25^{-27}, 25^{\circ}, 3^{26}$

definition of 325

in paean $\quad 26-27,325-327,333^{-340,343-}$ 346

in tragedy $\quad 27-28,181$

See also memory; ritual

emotion

in affect theory $\quad 25^{-26,272}$

and choral mimesis $\quad 42-53$

of Deianeira, evoked in Bacchylides 213

and embodied cultural knowledge $\quad 181$

evoked by enthuasiastic music 181 , 231-233, 237, 241, 245, 249-253, 266268

of grief and pity, in elegy and lament $181,302-324$

of pity and fear, in tragedy $\quad 28,131,243$, $245^{-246}$

of love, longing, and grief, in Sappho 35 , $42-47,49,52-53$

in musical theory of Aristotle 131, 242248 
in dramatic audiences $\quad 28,180-181,187$, 268

See also affect

epic

as "super-genre" $\quad 11,168$

and choruses $\quad$ 135-137

epic cycle 342

generic mixing in 13

evoked in lyric $\quad 23,85,279,282$

evoked in tragedy $\quad 182-188$

Linus-song in 78

and taxonomy of Greek poetry $\quad 3,6-7$,

$34,58,60-61,64,68-70,110,271$

See also Homer

epigram

of Alcaeus $\quad 286$

funerary $298-324$

Hellenistic 291-292

epinician

not an ancient generic category 3

evoked in tragedy $80,169,170,184-187$

the fictional in 22

genre mixing in 11,225

humnos in 196-199

occasionality of $48,59,72$

performance cues in $21,88 \mathrm{n} 21$

praise in 6

and scholia 117

and taxonomy of Greek poetry 110, 132, 169

epiphany $23,86,173^{-174}, 182$

epitaph 141

See also epigram, inscribed funerary; inscriptions

epithalamium $82,86-87,108$

See also hymeneal; weddings

epithets, in catalogues $144,153,156-157$

epos, vs. melos $\quad 64-65,68$

Erlebnis 61

eros/erotic desire $\quad 45-46,83,277$

erotic verse 12,35

Estrin, S. 10, 26-27

Euripides $\quad 41,51,338,343$

chorus and generic hybridity in $\quad 139^{-142}$, 165-19o, 222, 224

enthusiastic music in $\quad 257-259,260,269$

and evolution of genre $62,67,79-80$, 167-19o

generic mixing in 80 and "new music" $\quad 185^{-187}$

scholia on 118

exile $105^{-106,275}$

Faraone, C. 157

Farrell, J. $\quad$ 13-15

Fearn, D. 144, 147, 217

Fera, M.C. $\quad$ 16-17

festivals

Dionysia 72, 216, 225, 227-228

Kallisteia 97, 106

Panathenaia 139, 217

Thargelia $\quad 215^{-217}, 220-221,224-228$

and Alcaeus 106-107

in Bacchylides 153

in Sappho 41-44, 94-96

as performance context for Sappho $36-$ $39,49-52,54,94-99,108$

choruses in 165

music festivals $36-39,49-52,54,233$,

235,246

paeans at 337

See also ritual

fiction(ality)

in iambos $\quad 22-23$

in lyric performance settings 10, 99-100, 103, 108

in Pindaric paean $\quad 336-337$

retrospective 70

vs. ritual(ity), as an approach to poetry

$8,19-25,73$

in Sappho's poems $\quad 32,52,99-100$

first person 183, 211

and assignation of speaking personae $112,115,117$

as distinguishing lyric from epic 6

in funerary epigrams $302,304,308,314$, 318-319

and the performative 20

and (re)performance $\quad 49,87-90,95,104$

in Sappho $\quad 87-90,104$

Fish, J. 97

Floyd, E. $\quad 114$

focalization 154, 212-213, 220, 312, 339

Ford, A. $\quad 8,10,13^{-15}, 18$

formalism $\quad 6-9,61$

form, as criterion of genre $\quad 64-65,83,231-$ 232

Foster, M. 10-11, 19 
frame/framing $4,24,27,35,57,71,97,128$, 131, 142

See also metapoetics

Fraenkel, E. 80

Fränkel, H. $\quad 6-7$

garlands 2, 64, 145

gender

and focalization $\quad 339$

in performance $32,36,49,64,75,82,84$, $96,151,170,187,264-269$

confusion/inversion of $24,170,173,187$

and taxonomy of Greek song $\quad 236-239$

genealogy, in catalogues $\quad$ 149-153

See also kinship

generification $10,13,57-67,77,80-81$

Genette, G. $\quad 68,70,73,271-272,281$

genre

affect, as circulation of $\quad 27,272-273$

approaches to, modern $\quad 5^{-19}, 57-63,70-$

$72,84-85,231-233,271-272,326$

and audience response $\quad 18 \mathrm{o}-182$

contamination of 19,137

as embodied cultural knowledge 27 ,

$326-327,343-346$

location and 222

musical 27, 233-238, 241-243, 248, 250,

253-283

new formalist model of $\quad 8-9,61-62$

mixture/hybridization of $10-19,80,137-$

$152,165,167-19$ o, 220-227

performance/occasion model of $5^{-12}$,

$33-35,48-49,59,70-72,84-85,109$,

231-232, 326

process of production of $10,73-81$

primary and secondary $12,19,189$

as a structural system $\quad 14-16,298$

subdivided into epic, drama, and lyric 3 ,

6o, 68, 109-110, 132, 271

taxonomies and concepts of, ancient $\quad 1-$

4, 13-15, 58-6o, 63-70, 75-81, 109-111,

$126,131-132,186,271$

and visual/material experience $\quad 298,315$, 323-324

See also generification; criticism, ancient;

criticism, modern; "super-genre";

transgenericity; and names of indi-

vidual genres

Gentili, B. $\quad 4-7,9,59$
Gore, L. $\quad$ 52-53

Greene, R. 19-22

Griffith, M. $10,27,28$ o

habrosune 277

hapaxlegomenon 77, 145

harmonia. See modes, musical

Harvey, A.E. $\quad 3-4,63$

Havelock, E. 4, 12

Hawkins, T. 280

Heiden, B. $\quad$ 137-138, 140-141

Henrichs, A. $\quad 72,173$

Hellenistic poetry 13

Hellenistic scholarship

on choral performance 110-111, 131

edition of Alcaeus $\quad 23,105 \mathrm{n} 74$

edition of Sappho $\quad 86-87,91,99$

and genre $\quad 58,62-63$

and organization of Greek lyric 3

See also Aristarchus; Didymus; scholia

Henrichs, A. 72

Hera $40-44,53,98-102,113$

etymology of 43

festival of 97,106

sanctuary of $24,84,95^{-96,100,108}$

Heracles 79, 113

in Bacchylides 192-194, 211-214, 220, 222

in Euripides $\quad 169-171$

in Sophocles $173-174,182,209,218-219$

on vases $\quad 156$

Heraclides of Pontus $\quad 76$

Herodotus 67,74

Hesiod 74, 75, 78, 109-110, 135-137, 156-159, 162

hetaireia, of Alcaeus 105

hexameter, structural principles in 136-162 See also epic; meter/metrics

hierarchy

in catalogues and choruses 137,149 , $156-157,165$

of genres 13

Himerius 199-201, 204, 206

Hipponax 23, 273, 275, 284-296

Homer

in lyric 188,200

catalogues and choruses in $\quad 137-141,146-$ 147, 153-155

emotion in $311-312$

genre mixing in $11,63-64,137-141$ 
generic self-consciousness of 13

and Linus-song $\quad 74-79$

and oral formulaic theory 4,7

speaking personae in $10,115^{-122,132}$

and taxonomy of Greek genre $\quad 58,68,110$

See also epic; scholia, on Homer

horizon of expectations $\quad 5,180-182,272$

See also audience; reader; viewer

Hutchinson, G.O. 106-107

hymeneal/humenaios $\quad 63,77-78,87-93,108$

evoked in tragedy 168,173

See also epithalamium; weddings

hymn/humnos

in lyric $196-198,206-207,214$

and generic mixing $16,23,66,104,138$, $185^{-186}$

meaning of 198

and taxonomy of Greek genre $\quad 1-3,66$,

127,186

in tragedy $177,185^{-186}$

iambos

affective horror in $18,26,273-297$

elision of aggressor and victim in 291, 295

fictionalization in $\quad 22-23$

and taxonomy of Greek genre $\quad 58,64$

violence in $\quad 284-287$

Ibycus 83

identity

and choral mimesis $\quad 5^{\circ}$

fostered by music $\quad 267$

and ritual practice $\quad 327-334,341-346$

idyll 12,6 o

imagination $\quad 98,339$

imitation. See mimesis

impersonation $86,89,97-98,114,291$

and mimesis $\quad 47,68-71$

See also mimesis; persona

inscriptions

as evidence for choral performance 111

epitaphic $\quad 26,141,298-324$

victory lists 149,235

on vases $\quad 154-159,165$

See also Ambracian polyandrion

instruments, musical $\quad 233^{-239}, 244,247-$ 248, 251, 257-258, 264-269

aulos/pipe 1, 125, 127, 171-174, 176, 179,

184, 186, 223, 231-269 passim kithara/lyre $\quad 1,74-79,85,127,159,170,174$, 178-179, 200, 204, 237-239

percussion $176,238-239,255,257,262$, 266, 269

intersubjectivity 313,322

intertextuality $96 \mathrm{n} 43,146-15 \mathrm{O}, 194,217-221$, 327

intimacy, and choral performance $\quad 51,83$

invocation $16,64,74,95,135,141-143$

of Apollo, in Bacchylides $16 \quad$ 188, 193, 208, 211, 216, 223

irony, dramatic $219 n 80$

Jackson, V. $\quad 8,61-62$

Jameson, F. $\quad 57,61$

Jauss, H.R. $\quad$ 5, 180-181

Jebb, R. 209-210, 217

Johnson, W.R. 63

joining, in archaic sculpture 317

Kabeiroi $\quad 253-256,258,264-265,267,269$

kinesthesia $\quad 333-334,337,340,343$

kinship $\quad 63,152-153,336$

See also genealogy

kithara. See under instruments, musical

kitharodic nome $\quad 66,69,235$

evoked in tragedy $183,185^{-188}$

Kleitias $\quad 157$

komos 21, 36, 114

König, J. $\quad 276$

Korybantic rites/performance $236-240$, 245-248, 253-269

in relation to Greek song-culture 27, 231-233, 267

Kouretes 237, 253-255, 257-258, 264-265, 267,269

Kowalzig, B. 73, 179, 222, 224

Kreuzung. See genre, mixing/hybridization of

Kurke, L. $\quad 31-32,39-41,44,99,224,322,335^{-}$ 336

Lacy, R. 54

lament. See threnos

Lardinois, A. $\quad 31,51,83-87,92$

Larichos $41,44,49-51$

Larson, J. 149

laudandus

in Bacchylides $\quad 144,147$ n33

in Pindar 113, 117-118, 123 
Leduc, C. $\quad 224$

leptos/leptotes $\quad 77-78$

Lesbos $\quad 7,31-32,36-37,39,83-84,93,96,99$, 100,146

Linforth, I. 26o, 262

linguistics $7,14,37$

Linus/Linus-song $\quad 2,11,13,15^{-18}, 60,63^{-69}$, $73-81$

locus amoenus $\quad 277,28$ o

Lord, A. 4-5

love song $5^{\circ}$

See also erotic verse

lyre. See under instruments, musical lyric

and affect 27

definition(s) of $\quad 62-64,69,231-232$

affective/material quality of $\quad 271-285$

approaches to, modern $\quad 5^{-9}, 19^{-23}, 59^{-}$

$63,70-73,109,271-273$

broader than "genre" 34

catalogues and choruses in $137,142-152$

in epic $\quad 63-66,74-77$

ecstatic music, as a genre of 27,233 ,

$235^{-237}, 253^{-268}$

fictionality and rituality in $\quad 19-23$

and generification $\quad 59-6 \circ, 63,65^{-67}, 78$, $80-81$

and genre mixing $\quad 11,18,137-15^{2}, 168-$

169, 172-189, 209, 217-224

performance contexts of $\quad 35^{-} 39,59,7^{-}$

72, 83-109, 111, 233

scholia on $111-117,119,123,126-132$

and subjectivity/self-expression $\quad 6-7,61$,

71

and taxonomy of genre $2-4,15,58-61$,

64-70, 77, 186, 231-232, 271-272

lyric "I". See poetic "I"

Maas, P. 206

Maehler, H. 191, 193, 199, 201, 204-211

maiden song. See partheneion

March, J. 217-218

Martin, R. 11, 50, 168

Maslov, B. $12,14,196-198$

materiality

and approaches to Greek poetry $\quad 25^{-27}$

of funerary epigrams/monument 26 , 298-324

of iambos 26, 271-297 melody $69,234,235,236,239,241,242,258$, 266

melos/melic poetry $\quad 58,72,82,84$

vs. epos $\quad 64-65,68-69$

See also lyric

memory

embodied $\quad 25,181,326,333-338,340$

and (re)performance of poetry 5,93 , 326,340

Messon (Mesa) 39, 41, 50, 95, 97, 99-105, 107-108

meta-performative aspect 107

metapoetics

in Bacchylides $16 \quad$ 196, 199, 212, 215

in Pindar's Paean 6340

See also frame/framing

meter/metrics

and ancient commentary $\quad 111,129$

referenced in Sappho 96n41

and taxonomy of genre $2,4,64-65,83$, $87,109,232$

elegiac couplet, in funerary epigrams 30o-304, 307-310, 313, 315, 317-318, 323-324

Sapphic stanzas 87

stichic verse 64

strophic stanzas 127,238

mimesis

as imitation and/or reenactment $3,5^{-}$ 6, 9-10, 22, 31-33, 39, 47-53, 6o-61, $67-73,8$ o

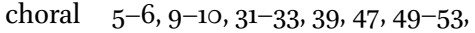
86,322

in drama 268, 271

Plato and Aristotle on $\quad 6,47-48,60,67-$ 71, 8o, 243n33, 271

See also imitation; reperformance; representation

Miner, E. 70

models $38,47,72$

modes, musical

in Aristotelian music theory $\quad 244-247$, 268ng2

inferred by scholia $\quad 126,129-130$

modes, of apprehension $\quad 19-20$

modes, of performance $\quad 92,162$

modes, of representation $\quad 69$

monody

in Alcaeus $\quad 104-108$ 
vs. chorality, in Sappho $18,24,36,49$, 82-101, 108 and choral lyric $\quad 137$

dramatic 238

fictionalization in $\quad 22-24$

monuments, funerary $\quad 298-324$

and affect $\quad 301-324$

morphology. See under catalogues; chorus

Most, G. $\quad 57,62$

mousike. See music

movement

and agency $\quad 313-318$

of chorus: See under chorus

Müller, K.O. 83

Muse(s) 1, 66-67, 152, 203-204, 322

in Bacchylides $\quad 192-193,196-198,205$

in Euripides $\quad 170-171,183,188$

in Hesiod $\quad 135^{-136}, 157^{-1} 5^{8}$

in Homer $\quad 138,140-141$

and Linus $\quad 73^{-74}$

See also Calliope; Ourania

music/mousike

anthropological perspectives on 249253

Aristotelian theory of $\quad 27,240-248$

in Bacchylides $16 \quad$ 195, 201-205, 209, 211

of choruses $111,127-131,165$

effects of, on listeners $\quad 233-270$

enthusiastic/orgiastic $\quad 233,236-270$

ethical impact of $\quad 242-244,248$

and genre $64,66,70$

"new music" 185-187

performative practice of, as grid 236238

Platonic theory of $\quad 238-239$

in tragedy $\quad 169-187$

See also Korybantic rites/performance; modes, musical; rhythm myth

ancient commentators on 111,125

of generic purity $\quad 185^{-188}$

and ritual performance $\quad 5-6,35,47-48$, 71-73, 95, 104, 147

in Pindar 67

See also narrative, mythic

Nagy, G. $\quad 5^{-12,}$ 21-22, 71-73, 77, 80, 100, 303

narrative, in taxonomy of genre $\quad 68,109-111$ narrative, mythic $\quad 86,177,195,209,211-214$, 217-221, 345

narratology: See Genette, G.; narrator

narrator

omniscient external $\quad 118,122-123$

solo singer as $\quad 89$

Neer, R. 317

Negri, M. 128

Nereids 44, 153, 156, 159-16o, 179

New Criticism 6,61

See also formalism

New Materialisms 25

See also materiality

"new music": See under music

Nünlist, R. 130

Obbink, D. 94, 97

occasion $\quad 266-267$

absolutization of $\quad 48-49$

and Alcaeus' poems 101-108

of Bacchylides $16 \quad$ 194-195, 207, 211, 215221, 227

in Homer $\quad 63-64,75-79,136-137,141$

as an approach to genre $\quad 2-12,19-21,25$, $33-36,63-65,68,71,73,81,109,231-$

$232,272,325^{-}-327$

concept and definition of $\quad 33^{-35}$

cues for 21

festival as $32,36-39,44,49-52,93-94$, 97, 99

loss of $5,34-36,71$

and mimesis $\quad 47-48,71$

as performative frame 48

and Sappho's poems $\quad 36-39,44,49-53$,

82-99, 108

symposium as 37

thematized in Pindar $\quad 15^{-16,72}$

See also performance; reperformance

Odysseus $23,63,76,147,149,154-155,29$ o, 338

ololuga. See ululation

Olsen, S. $\quad 10,25^{-27,181}$

Ong, W.J. 13

onomatopoeia $75,278,290$

orality

as an approach to Greek poetry $\quad 4-7$, $12-13$

and literacy $\quad 12-13,33$

orchestra 176,179 
$\begin{array}{lc}\text { Orpheus } & 2,15^{-16}, 18,67 \\ \text { Ourania } & 192-193,196,198\end{array}$

paean

in Alcaeus 200

audience response to 181

in Bacchylides 16 191-194, 206-212, 222223

at Delphi $\quad 327-334$

difficulty of defining $\quad 326$

evoked in tragedy $170,172-173,175,177-$ $178,181-182,186-188$

in Homer $\quad 63-64,75^{-76}, 106$

Pindaric, and embodied knowledge 326-346

(re)performance of $\quad 25^{-27}, 335^{-346}$

and taxonomy of Greek genre $1-2,4,11$, $15^{-17}, 66-67,169,186,194,237-238$

Page, D.L. $\quad 64,85^{-86}, 91,98$

papyri Fig. 4.1, 4.2

of Bacchylides $16 \quad$ 201, 204, 207

change of speakers signaled in 111nı, $118-123,132$

Hellenistic editing of 3

of Pindar 15, 335

of Sappho $\quad 23,39,45,94$

parachorality 10, 24

in Alcaeus $\quad 101-108$

in Sappho $\quad$ 91-101

paragraphoi 118-119

parataxis, in catalogues $153,160-161$

paroidia 97

Parry, M. 4

partheneion/maiden song $\quad$ 151-153

in Alcman 119, 130, 132, 146, 155, 159, 321

in Sappho 88-91, 93

and embodied knowledge $\quad 326,338-340$

evoked in tragedy $168-170,175,179-18$ o,

$$
\text { 184-185 }
$$

patrons

divine $23,65,344$

human $\quad 74-75,78$

Pausanias $\quad 150-151$

Peisistratids 216

Peponi, A.-E. $\quad$ 99, 321

performance

ancient commentators on 109-132

as an approach to genre $\quad 5^{-13}, 33^{-35}, 49$,

$59,62,64-65,70-73,109,231-232,325$ choral $32-39,49-52,82-94,97,103-108$,

$111,136-138,141,144,147,15^{0-152, ~} 155$,

$168,322-323,337,341$

cues of 21

depicted on vases $\quad 153^{-15} 8$

ecstatic musical $\quad 27,231-239,244-269$

embodiment/affect and $\quad 26-27,314$, 320-321, 331, 337-340, 343-346

and funerary epigram $\quad 298,305,314$,

$320-322$

in epic choruses/catalogues $\quad 134^{-152}$, 161-165

inscriptions about 111

and mimesis $33^{-} 34,72$

of paean $\quad 325,327,331,334-335,337-345$

ritual/myth and $\quad 5^{-6}, 35,33^{-3} 33$

solo $83-85,107$

as speech act $34 \mathrm{nnniO}-11$

sympotic $\quad 37,97-98,104-105,268$

in tragedy $\quad 168-182,187,189$

See also context, performative; frame/

framing; occasion; performative;

periperformative; reperformance

performative $\quad 5,20-24,34-35,95$

Peripatetics 58

periperformative $\quad 20-24$

person. See first person; persona; poetic "I";

second person; third person

persona

and fictionalization 23,61

in Platonic theory 68

of Sappho $\quad 9,3^{2-33}, 37-38,41-46,49-52$, 72,147

speaking, inferred by ancient commenta-

tors 10, 109-123, 132

and taxonomy of genre $\quad 232$

See also impersonation; poetic "I";

speaker; voice

Pfeijffer, I.L. $\quad 219-220$

Phillips, T. $\quad 8-9$

Philochorus $\quad 76$

Pindar

and Athens 215

choreia in $321,326-327,334^{-} 33^{6}$

dithyrambs of 69

epinicia of, formalist analysis of 6

epinicia of, generic complexity in 11

on Greek genre, in threnos fragment $\quad 1-$ $3,13-18,66-67,71$ 
humnos in $\quad 196-198$

and Linus-song $\quad 74,77$

occasionality and performance cues in

$27,48-49,59,72,88 \mathrm{n} 21,334-336$

speaking personae in, according to scho-

lia $10,27,110-118,122-126,131-13^{2}$

incorporation of tragedy in $\quad 225$

"Pindaric" 6o

pipe. See under instruments, musical

Plato

on choreia $\quad 136,167$

as evidence for Greek song-culture 233,

240, 253-254, 257, 26o-262

mimetic theory of $\quad 3,60,68-72$

musical theory of $\quad 238-239,242-243$,

$247,260-262$

and "new music" 184-187

on poetic performance $\quad 322$

on taxonomy and mixing of genres $1-4$,

$14-16,18,66-67,110,132,185^{-188,271}$

on tragedy $\quad 167$

Plutarch 193, 204, 207-208, 274-275, 28o, 291

poet, as speaking persona $\quad 114-123,132$

poetic "I" $7,12,14,21,61,83,86 \mathrm{n} 14,115,271$, 336

See also first person; persona; speaker;

voice

poetry

ancient classification of 3

anthropological/linguistic approach to

73

equation of, with lyric 62

as mimesis: see mimesis

Platonic theory of $\quad 68-69$

politics, in relation to $5,7,73,107,226$, $318-321$

social/pragmatic character of 98

as subcategory of song 33

politics, in relation to poetry. See under poetry

polyphony, in Bacchylides 11, 195, 199, 205, 209, 221-222, 227-228

Posidippus 51

Power, T. 10, 24, 37, 173, 321

Prauscello, L. 126

prayer/supplication $\quad 3,43,45,68,104,329$

See also hymn/humnos

precinct. See sanctuary presence and absence, in funerary epigram

302-304, 309, 312-315, 318, 321-323

priamel $15^{-18,212}$

Prins, Y. 8, 277

procession/pompe

choral 41, 9o, 96, 100, 136, 139, 150, 159, 162,165

funeral 314

paeanic $\quad 327-332$

Panathenaic 139

Thargelian 215

wedding $88 \mathrm{n} 20,338$

Proclus $58,64,66-67,77,80,109$

prosodion $96,127,326,335$

prostitutes 37n21, 50, 268ng1

Ptolemy Epithetes $\quad 128-129$

reader

of funerary epigram $\quad 302-309,312-324$

lyric discourse and $\quad 19-20$

involved in generification $\quad 57-59,81$

relationship with iambicist $\quad 273^{-294}$

response of, to genre mixing in tragedy $180-182$

visualizing dramatic plot $\quad 129-130$

See also audience; horizon of expectations; reader response; viewer

reader response $18 \mathrm{o}-182,219 n 80$

reality effect 103

reception

of drama $\quad 27-28,169,180-182$

and genre $13,57-59,81,272$

overlooked by ancient commentators $57-58$

of Sappho 84

See also audience; reader; reperformance; viewer

reenactment. See reperformance refrain

on François vase 154

in Linus-song $\quad 73^{-75}$

in paean 4

reperformance $82 \mathrm{n} 2,88 \mathrm{n} 21,166$

deictic signals of 21

and embodied cultural knowledge $\quad 325-$ 327, 333-340, 343-346

funeral epigram and 305

ritual, and occasion $\quad 5,9-10,21,32-33$,

$47-49,54,71-73$ 
at symposium $\quad 326-327,335-337,343$,

$$
\text { 345-346 }
$$

See also performance

representation, mimesis as $3,32-33,47,6$ o,

$$
\text { 69-71, } 108
$$

See also mimesis; parachorality

reversal, tragic 173

rhythm

ancient commentators on 125,127

and choral arrangement 139,153

in Greek music $\quad 232-234,236,238,242$, 243n33, 249-251, 258, 266, 269

as medium of representation $\quad 69$

Riemer, P. $\quad 218$

ritual

compliance and resistance in $\quad 327-334$

definition of 35

and fictional(ity), in Greek poetry $\quad$ 19-26

funerary, and archaic elegy $\quad 301-302$,

324

and the occasion of Bachylides $16 \quad 215$,

220-224, 227

and Pindaric paean $\quad 327-334,341$

reenactment, mimesis as $5,9-10,34-35$,

$43,47,71-73$

temporality of 337

See also embodied cultural knowledge;

festivals; performance; reperformance

ritualization 331-333

Romanticism $59,61,63,80,271$

Rösler, W. 59

Rouget, G. 249

rubric 152-153

Rutherford, I. $\quad$ 194, 335, 341

Sammons, B. $\quad 152$

sanctuary

of Hera, at Messon $\quad 24,3^{8-} 39,41,44,5^{\circ}$, 95-108

of Apollo, at Athens $\quad 215^{-216}$

of Apollo, at Delphi $\quad 177,331,337-339$

Sapphic stanzas. See meter/metrics

Sappho

Alexandrian edition of $\quad 86-87,91,99$

allusion to, in Alcman 277

allusions to, in Bacchylides 146-147

epic in 188

choral and monodic readings of 10,18 , $24,39,49-52,82-92,108$ fictionalization in $\quad 23,103$

as mimetic persona $7,9,32-33,37-38$,

$43-46,52-53,72$

occasions for poems of $\quad 36-53$

parachoral reading of $\quad$ 91-101, 103-108

psophos in 338

See also Brothers Song

satire 60,276

satyr play $168,181,235$

Schironi, F. 10, 27

scholia 119-132

on Homer $51,76,78,110,119-123$,

132

on Pindar $10,27,110-118,123^{-126,131-~}$ 132

See also Aristarchus; criticism, ancient schoolroom, and Sappho 108

sculpture, archaic $\quad 317$

See also statues

second person 49, $202 \mathrm{n} 26$

Sedgwick, E. 20-24

selectiveness, of ancient sources 234

self-awareness, of Sappho 46

self-consciousness, poetic $\quad 11,13-15,188$

self-expression, in lyric $35,70-71$

self-representation, of Alcaeus 107

semi-chorus $119,123,130$

Semonides 278-279

Silverman, K. 295

similes

in epic $\quad 115^{-116}, 13^{-139,162}$

in lyric $\quad 146$

in tragedy $\quad 170-171,174$

in Plato $\quad 262$

in iambos $\quad 274-275,277-278,290$

singing $90,145^{-146}, 170-171,174,176-18$ o, 203-207, 210-212, 225-228

and audience $\quad 336-340,344-346$

choral, at festivals $\quad 32-33,35-37,49,53$, 73-74

scholia on 127-128

at symposia 37,336

in trance performance $\quad 251,255$

Sklar, D. $325,327,333$

Snell, B. 6-7

social community

and lyric $\quad 7,24,105^{-108,226}$

and funerary epigram $3 \circ 3,318-322$

Solon, and Salamis Elegy $\quad$ 97-98 
song culture, Greek $\quad 231-238,246-248,253^{-}$ 270

as a spectrum $\quad 236-238$

sonnet 60

Sophocles $167,169,172-174,180,186-189$, 215-227 passim

Sosibius $123,125,130$

speaker

in Archilochus 275n16, 319

change of, analyzed by scholia $\quad 118-$ 122

fictionalization of, in lyric $\quad$ 19-21

as persona: See persona

in lyric and epic, analyzed by scholia

109-123, 132

in Pindaric paean 336

See also first person; poetic "I"; voice spectacle

Aristotle on $\quad 130-131$

chorus as 139

spectator. See viewer

stage action, discussed in scholia $\quad 118,130$

stasimon, scholia on $\quad 128-130$

statues 302,310

of Asopids, at Olympia 150

Geneleos group $15 \mathrm{in} 40$

status, social

and catalogue structure 138,157

of performers 63,65

of poets, and hierarchy of genres 13

and possession/trance performance $25^{2}, 265^{-267}$

and the spectrum of Greek song-culture 236-239, 246-247, 265-268

Stehle, E. 339

Steiner, D. 10, 19, 27

Stesichorus 83,85

stichic poetry. See meter/metrics

strophic stanzas. See meter/metrics

structuralism $\quad 5-7,12-14,16,37-38$

stylistic devices, in catalogues $\quad 153^{-155}, 160-$ 161

subjectivity $\quad 6,20,61,295$

See also intersubjectivity

"super-genre"

epic as 11, 168

tragedy as $18-19,168,189,196,221-224$, 226

Swift, L. $\quad 168$ symposium

aulos-music at $247 \mathrm{n} 41$

paeans and $64,326-327,335^{-} 337,343^{-}$ 346

performance, as context for $37,97-98$, 104-105, 268

as private sphere $\quad 22$

reperformance, as context for $37,49,84$, 326-327, 335-337, 343-346

syntax. See linguistics; parataxis

Tanagra 148-150

Telò, M. 10, 18, 26-27

temenos. See precinct

temple. See sanctuary

testimonia, as evidence for performance 85

Thargelia. See festivals

Thasos, in iambos $\quad 274-282,286,290-291$, 295

Theater of Dionysus $185,224,225$ nnioo101, 226, 235n16, 268ng2

Theognis $7,97 \mathrm{n} 48$

Theseus 43, 158-159, 161, 171, 221

third person $\quad 6,49,89,112 \mathrm{n} 14,2 \mathrm{O} 2 \mathrm{n} 26$

threnos/lament

in epic 11, 138, 141

and Linus-song $\quad 74-76,79$

and occasion 34,63

Pindaric fragment of $15^{-16}, 66-67$, 71

in Sappho 86

and taxonomy of Greek song $\quad$ 1, 237

in tragedy $\quad 167-188$

Thucydides 43, 139, 216

Timotheus 188, 235

tonos. See modes, musical

tragedy

attribution of lines in 123

audience response to $27-28,180-182$, 243, 247-248

and Bacchylides $16 \quad$ 194, 196, 209, 215, 218-227

a choral genre originally $167,188-$ 189

choral movements in $\quad 128$

generic hybridity of $11,27-28,59,167-$ 19o, 222-227

and Greek mousike $\quad 235,269$

and mimesis $\quad 6,110$ 
as a "secondary genre" 189 spectacle excluded from, by Aristotle

130-131

as "super-genre" 11, 18-19, 168, 189, 196, 221-224, 226

and taxonomy of Greek genre $\quad 110$

See also drama

transgenericity $11 n 39,142$

ululation/ololuga $\quad 43,95^{-96}, 106-107,172-$ $173,223,238,263,269$

vases

choruses represented on $\quad 153^{-159}$,

Fig. 5.1-5.8

François Vase $\quad$ 156-159, Fig. 5.1

mousike depicted on $\quad 181$

victory lists 149, 235

victory odes. See epinician

viewer

of choral performance $129,140,154$,

339-340, 343-346

of funerary monument $\quad 305^{-324}$

of tragedy, as responsive to genres $180-$ 182

of tragedy, and emotional response

247-248

See also audience

Vine, B. 293

visual arts

and Asopids $142,15^{\circ}$

and choruses at weddings 86

and Kabeiroi $\quad 256 \mathrm{n} 66$

and Nereids 179

and Sappho 84

See also Ambracian polyandrion; sculp-

ture; statues; vases visual effects, in funerary monuments $307-$ $308,314-318$

voice

female $86 n 14,97 n 48$

in lyric and epic, analyzed by scholia 109-123, 132

in funerary epigrams $302,308,314,318-$ 321

and persona $\quad 72,86 \mathrm{n} 14,89$

and the performative 20

in Sappho and Alcaeus 104-105

and subjectivity 6

See also first person; persona; second person; speaker; third person

weddings $50,63,74,77-78,86-91,96,108$, $158,179,338$

See also epithalamium; hymeneal

Weiss, N. 10-11, 18, 25, 27, 222

Wellek, R. 61-62

West, M. 39, 142

Whitman, C. $\quad 138$

Wilamowitz, U. 183

Wilson, P. 171, 216-217, 221, 224-226

Wimsatt, W.K. 273

Xenophon of Athens 139-140

Xenophon of Ephesus 139

Zenodotus, text of Homer of 76

Zeus 4O, 43, 79, 95, 102, 118, 121, 135, 136, 139, $143,148-15$ o, 153, 168, 175-176, 192, 200, $212-213,237,255,257,261,264,312$, $342-343$ 